\title{
Earthquake Engineering Site Characterization - Proceedings of Research Needs Workshop
}

by Joseph P. Koester, Tina L. Holmes

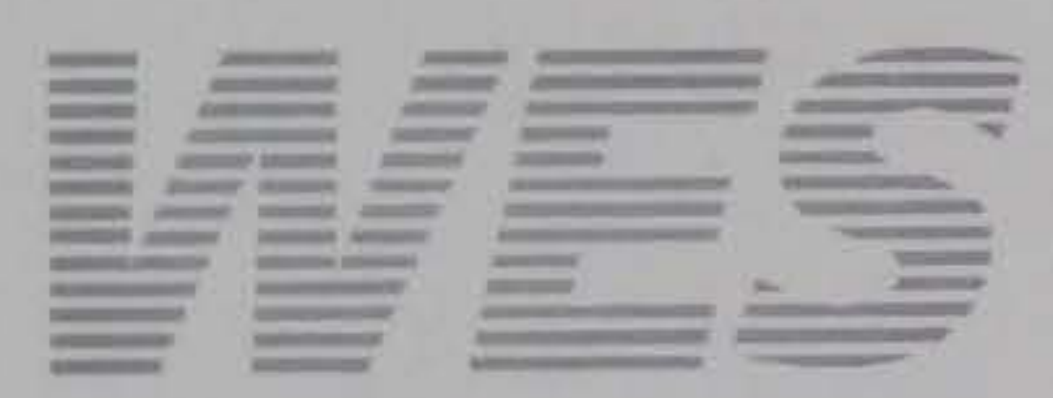

Approved For Public Release; Distribution Is Unlimited

Research Library

US Army F Anoger Waterways

- un Station

Wississippi 


\section{Earthquake Engineering Site Characterization - Proceedings of Research Needs Workshop}

by Joseph P. Koester, Tina L. Holmes

U.S. Army Corps of Engineers

Waterways Experiment Station

3909 Halls Ferry Road

Vicksburg, MS 39180-6199

Final report

Approved for public release; distribution is unlimited

Cruectud

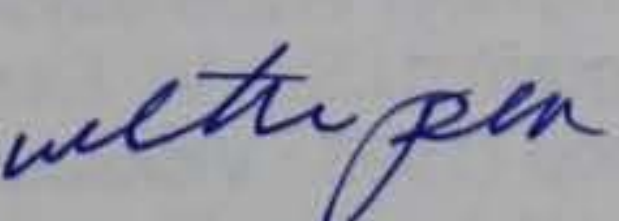




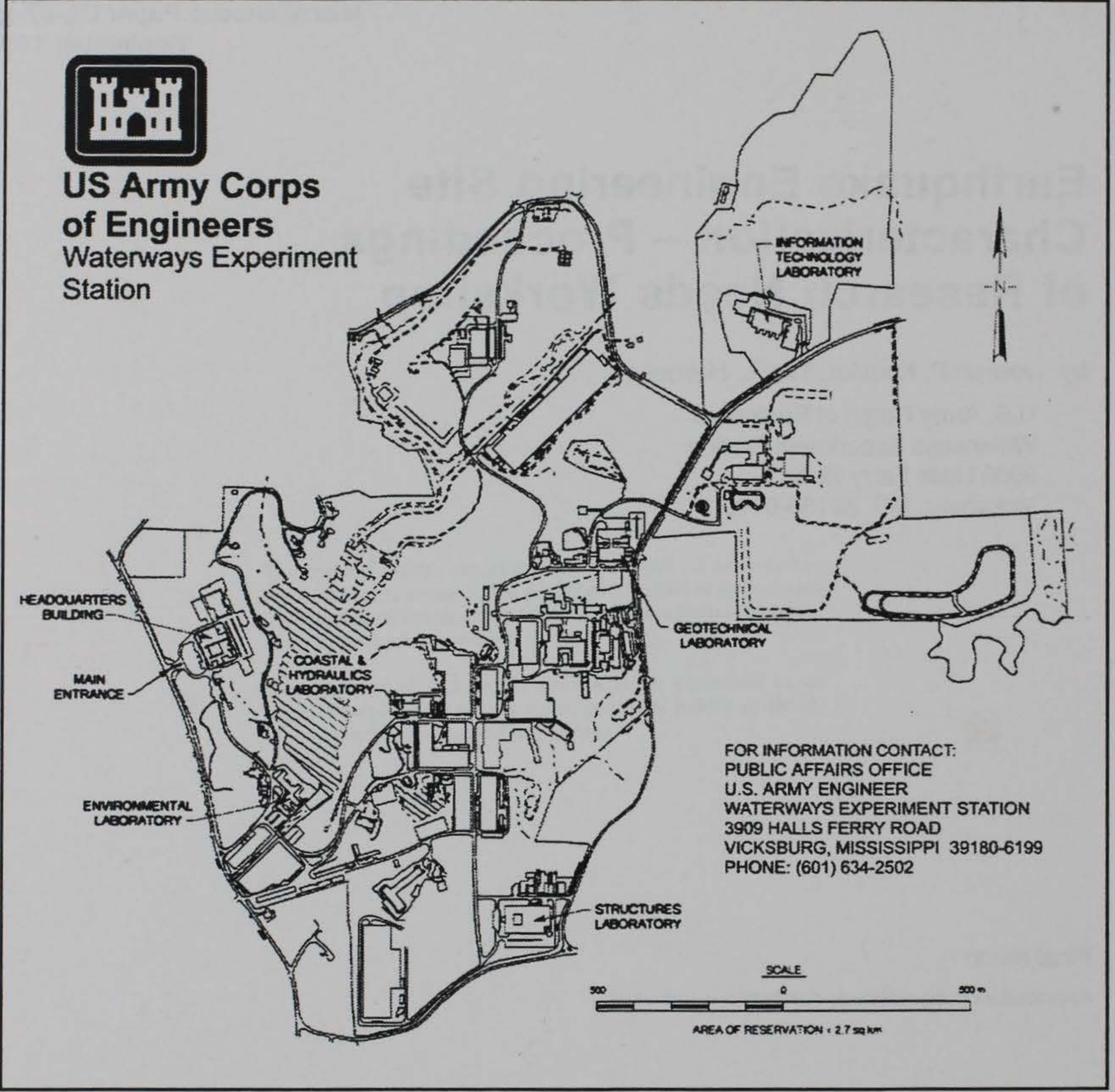

\section{Waterways Experiment Station Cataloging-in-Publication Data}

Koester, Joseph P.

Earthquake engineering site characterization : proceedings of research needs workshop / by Joseph P. Koester, Tina L. Holmes ; prepared for U.S. Army Corps of Engineers

Earthquake Engineering Research Program.

320 p. : ill. ; $28 \mathrm{~cm}$. - (Miscellaneous paper ; GL-97- 18 )

Includes bibliographic references.

1. Earthquake engineering - Congresses. 2. Engineering geology - Congresses.

3. Earthquake hazard analysis - Congresses. I. Holmes, Tina L. II. United States. Army.

Corps of Engineers. III. U.S. Army Engineer Waterways Experiment Station.

IV. Geotechnical Laboratory (U.S. Army Engineer Waterways Experiment Station)

V. Earthquake Engineering Research Program (U.S.) VI. Earthquake Engineering Site

Characterization-Research Needs Workshop (1995 : Vicksburg, Miss.) VII. Title. VIII. Series:

Miscellaneous paper (U.S. Army Engineer Waterways Experiment Station) ; GL-97-

TA7 W34m no.GL-97- 


\section{Contents}

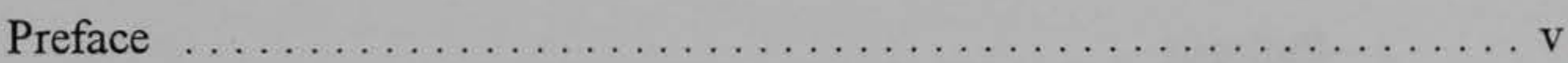

Conversion Factors, Non-SI to SI Units of Measurement . ........... vi

1 -Introduction $\ldots \ldots \ldots \ldots \ldots \ldots \ldots \ldots \ldots \ldots \ldots \ldots \ldots \ldots \ldots$

Purpose ................................ 1

Problem Definition $\ldots \ldots \ldots \ldots \ldots \ldots \ldots \ldots \ldots \ldots \ldots$

Approach ............................... 1

Results (Anticipated) ....................... 1

Format of Proceedings Report . . . . . . . . . . . . . . . 2

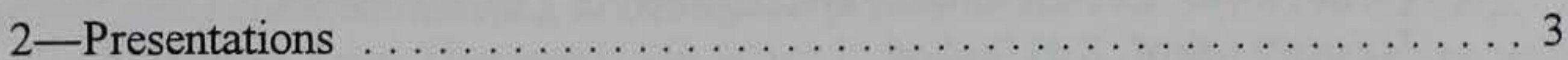

Topic I: Geotechnical Indicators of Liquefaction Potential of In Situ Materials - W. D. Liam Finn $\ldots \ldots \ldots \ldots \ldots \ldots \ldots \ldots \ldots$

Topic II: Geophysical Indicators of Liquefaction Potential $\ldots \ldots \ldots 5$

Investigation of Liquefiable Soils Using Shear Wave Velocity Ken Stokoe . . . . . . . . . . . . . . . . . . . . . 5

Seismic Velocity, Attenuation and Liquefaction -

Philip Sirles . . . . . . . . . . . . . . . . . . . 6

A Non-Destructive Method of Estimating Properties of Soil

Subjected to Earthquake Strong Motion - Steven Glaser . . . . 6

Surface Wave Method - A Tool for Lifeline Earthquake

Engineering - Ronald Andrus . . . . . . . . . . . . 6

The Biot Model and Waveform Tomography -

Richard Rechtien . . . . . . . . . . . . . . . . . . . 7

Summary of Topics I and II - Dwain Butler .............. 7

Topic III: Field Test Sites . . . . . . . . . . . . . . . . . . 9 
Organization and Operation of National Geotechnical Test Sites

- Richard Woods . . . . . . . . . . . . . . . . . . . 9

Effect of Stress State and Soil Fabric on Seismic Wave Velocities Measured by Borehole Methods - Ken Stokoe . . . . . . . 10

Success Dam - John Nickell ... . . . . . . . . . . . . 10

Test Sites Discussion - Robert F. Ballard, Jr. . . . . . . 10

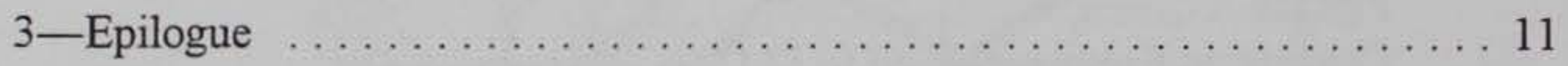

Table 1: Potential field test sites $\ldots \ldots \ldots \ldots \ldots \ldots \ldots \ldots \ldots \ldots \ldots \ldots \ldots$

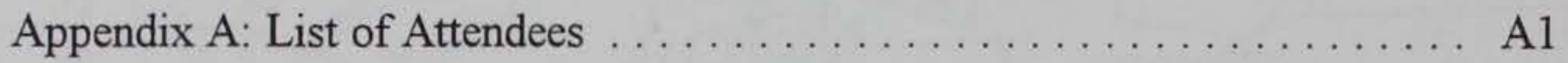

Appendix B: Agenda $\ldots \ldots \ldots \ldots \ldots \ldots \ldots \ldots \ldots \ldots \ldots \ldots \ldots \ldots \ldots \ldots$

Appendix C: Proceedings Submissions by Prof. W. D. Liam Finn . . . . . . C1

Appendix D: Lecture Slides: Investigation of Liquefiable Soils Using Shear Wave Velocity - Prof. Ken Stokoe . . . . . . . . . . . . . . . . . . . . D1

Appendix E: Lecture Slides and Article Submitted by Mr. Philip Sirles . . . . E E1

Appendix F: Proceedings Submissions by Prof. Steven Glaser $\ldots . \ldots \ldots \ldots$ F1

Appendix G: Surface Wave Method - A Tool for Lifeline Earthquake

Engineering, Submitted by Dr. Ronald Andrus ............. G1

Appendix H: Organization and Operation of National Geotechnical Test Sites,

Submitted by Prof. Richard Woods . . . . . . . . . . . . . . . . H1

Appendix I: Lecture Slides: Effect of Stress State and Soil Fabric on Seismic Wave Velocities Measured by Borehole Methods - Prof. Ken Stokoe . . . . . . Il

SF 298 


\section{Preface}

The Earthquake Engineering and Geosciences Division (GG), Geotechnical Laboratory (GL), U.S. Army Engineer Waterways Experiment Station (WES), conducted the workshop described in this report during the period 27-28 June 1995. Funding for the workshop was provided by the Earthquake Engineering Research Program (EQEN), Work Unit No. 33014, "Geophysical Methods for Site Characterization."

Mr. Robert F. Ballard, Jr., is the Principal Investigator for EQEN Work Unit No. 33014. Dr. Joseph P. Koester, Earthquake Engineering and Seismology Branch (GG-H), and Ms. Tina L. Holmes, Soil Mechanics Branch, Soil and Rock Mechanics Division (GS-S), compiled the proceedings of the subject workshop. The EQEN Program Manager is Dr. Mary E. Hynes, GG-H. EQEN research was conducted under the general supervision of Dr. Arley G. Franklin, Chief, GG, and Dr. William F. Marcuson III, Director, GL.

This report is a summary of presentations and discussions that took place during the subject workshop, as transcribed by Dr. Koester and Ms. Holmes. Not all presenters submitted proceedings papers; hard copies of presentation materials and available papers are provided in appendices for those materials that were available.

Director of WES during the conduct of this study and preparation of the report was Dr. Robert W. Whalin. Commander was COL Bruce K. Howard, EN.

The contents of this report are not to be used for advertising, publication, or promotional purposes. Citation of trade names does not constitute an official endorsement or approval of the use of such commercial products. 


\section{Conversion Factors, Non-SI to SI Units of Measurement}

\begin{tabular}{||l|l|l||}
\hline \hline Multiply & By & To Obtain \\
\hline \hline bars & 100,000 & pascals \\
\hline feet & 0.3048 & meters \\
\hline inches & 2.54 & centimeters \\
\hline $\begin{array}{l}\text { kilograms force per square centimeter } \\
\text { (ksc) }\end{array}$ & $98,066.5$ & pascals \\
\hline kilopounds per square foot (kips) & $47,880.26$ & pascals \\
\hline tons per square foot (tsf) & $95,760.52$ & pascals \\
\hline
\end{tabular}




\section{Introduction}

\section{Purpose}

The Earthquake Engineering Site Characterization - Research Needs Workshop was held at the U.S. Army Engineer Waterways Experiment Station (WES) on 27-28 June 1995. The purpose of the workshop was to bring together technical specialists from WES, Corps of Engineers Districts, the US Bureau of Reclamation (USBR) and academia to solicit input for initial planning of a multiyear project intended to develop improved geophysical techniques for earthquake engineering site characterization.

\section{Problem Definition}

The ultimate goal of the sponsoring Earthquake Engineering Research Program (EQEN) work unit is to develop tools to assist Corps of Engineers agencies responsible for safe, cost-effective design of reservoir dams and other critical water resource and navigation facilities in their determination of accurate engineering site condition parameters. The focus of the work unit is on in situ technologies.

\section{Approach}

The subject workshop was convened at an early stage in the investigation, to identify candidate techniques for detailed evaluation and to facilitate informed planning of project direction. Primary activities to follow included selection of a field test site and performance of field experiments in FY 1996. Future project activities were to be planned based on results from the initial experimentation program.

\section{Results (Anticipated)}

In the near term, the objectives to be realized from the workshop and subsequent research in the sponsoring work unit included: 
(1) consensus of attendees on the definition and causes of liquefaction during earthquakes;

(2) selection of desirable characteristics of a test site for evaluation of geophysical techniques; and

(3) determination of criteria for test site credibility.

Ultimately, the work unit's goals include, but are not limited to:

(1) reliable determination of indicators that liquefaction has occurred or will occur in the future;

(2) determination of any correlations between geophysical and geotechnical parameters;

(3) definition of seismic methods for site characterization using energy loss and other parameters, and, generally;

(4) improvement of geophysical site characterization procedures.

\section{Format of Proceedings Report}

This report summarizes issues raised by each presenter during the lecture sessions of the workshop, in order of presentation. The primary technical content of each lecture is, of course, found in papers submitted by the presenters at or following the workshop; all papers submitted are provided in appendices to this proceedings report; a transcript of notes taken by the authors of this report during the workshop is also provided in the beginning text. It was also the intent of the proceedings authors to reconstruct audience discussion as faithfully as possible. Electronic media versions were not available for all papers; in these instances, copies of documents provided by presenters were scanned and adapted into a consistent format for publication. Photographic images and graphic illustrations were not scanned; these were photocopied and placed at the end of each paper. A list of attendees and their addresses at the time of the workshop is provided in Appendix A. A transcript of the meeting agenda, developed from a handout made available to attendees at the workshop, is provided in Appendix B. 


\section{Presentations}

The workshop was opened with a welcoming statement by Dr. William F. Marcuson III, Director of the Geotechnical Laboratory, followed by a summary briefing by Dr. A. G. Franklin, Chief, Earthquake Engineering and Geosciences Division, on the Earthquake Engineering Research Program (EQEN), which provided funding support for the workshop. The EQEN is itself funded by direct allotment from Headquarters, US Army Corps of Engineers, through the Civil Works Research and Development Program. Dr. Dwain K. Butler and Mr. Robert F. Ballard, Jr., introduced the workshop participants and described the intended purposes and agenda. Individual invited technical presentations are discussed below.

\section{Topic I: Geotechnical Indicators of Liquefaction Potential of In Situ Materials}

Professor W. D. Liam Finn, University of British Columbia, presented the opening lecture of the workshop, describing the fundamental issues of liquefaction that are of most concern to engineers. In addition to his presentations at the workshop, Professor Finn submitted two technical papers, which are included in Appendix $\mathrm{C}$ to these proceedings. The following several paragraphs are a transcript of notes taken during Professor Finn's lecture.

Professor Finn prefaced his presentation by posing the following three questions and one task of geotechnical engineering concern, namely:

-What is the potential for pore water pressure buildup?

-What is the response of the structure?

-How has and how much has the structure moved, deformed, ...etc?

Look for indicators of movement and overall response during and after the earthquake.

The troublesome areas, as Prof. Finn saw them, were (a) measures to deal economically with the occurrence and consequences of liquefaction, and (b) the cost of remediation. 
The conventional view of liquefaction, according to Prof. Finn, involves a three step concept:

(1) Before the earthquake; sand may be loose, and sand grains are interconnected with each other;

(2) During the earthquake; sand grains float in groundwater, and the water and sand are forced to the surface, where sand and water are observed to boil from the ground;

(3) After the earthquake; sand is more compacted, the ground has subsided, and water has been removed from within the sand structure.

Relating to the use of geotechnical/geophysical techniques to indicate potential for liquefaction occurrence, Prof. Finn observed that liquefaction is accompanied by notable modifications in frequency and signature in the ground motion record; he suggests that $\mathrm{p}$-wave velocity may be a stable indicator. He noted that blastinduced liquefaction induces surface settlements on the order of 10 percent, whereas earthquake-induced liquefaction generally causes settlements nearer to about 2 percent. Blasting appears to break down contacts between particles, allowing the soil to achieve a denser state.

At shallow depths (less than about $30 \mathrm{~m}$ ), characterization of the effects of (previous) earthquakes on a site may be a good measure of liquefaction potential. These effects may be characterized by visual observation of surface manifestations, or by use of in situ investigation tools, such as Standard or Cone Penetration Tests (SPT's or CPT's, respectively). These tests are strongly affected by density, and Prof. Finn maintained that liquefaction does not depend solely on density; stress-versus-strain behavior, as tracked by shear modulus, may be a prime indicator of liquefaction (at least in theory). Prof. Finn emphasized that surface manifestations of liquefaction, though most obvious, are not always of engineering significance; rather, high excess pore pressures and concomitant shear strength reduction may be more important. He cautioned attendees against restricting their concern only to $100 \%$ pore pressure response, as damage may result from pore pressure development at lower levels. His concluding question to the audience was "What is the pore water pressure doing if we have saturated material, where boundary conditions and permeability are conducive to sustaining excess pore water pressures caused by earthquake shaking?"

Prof. Finn challenged the attendees to consider changing contemporary defensive design of dams to restrict deformations at key points, rather than by limiting allowable global deformation involving the footprint of the embankment. $\mathrm{He}$ contended that a factor of safety (against liquefaction) equal to unity does not necessarily denote complete loss. He recommends designing the structure to limit damage to reparable levels. Prof. Finn also stated that geologists and geologic mapping information (e.g., percent fines, how much sedimentation, etc.) should be brought into an investigation to aid understanding of a site prior to detailed field visits and exploration. 
Finally, Prof. Finn discussed the use of blast-induced liquefaction to judge whether a site would likely liquefy during earthquake shaking. He agrees that blasting may indeed cause liquefaction of susceptible deposits, depending on geologic structure and layering, but he maintains that much of the response is dependent on the blasting pattern, which could induce an artificially damaging set of conditions. He advised the group to be careful in the use of data on reliquefaction.

As mentioned earlier, Professor Finn submitted two companion technical papers for publication in these workshop proceedings, titled, respectively: "A Basis for Selecting Indicators of Liquefaction Potential," and "Evaluation of Liquefaction Potential by In Situ Methods." Both papers are provided in Appendix C, adapted to the format of choice for the proceedings.

\section{Topic II: Geophysical Indicators of Liquefaction Potential}

\section{Investigation of Liquefiable Soils Using Shear Wave Velocity - Ken Stokoe}

Professor Ken Stokoe II, University of Texas, and Dr. Ronald Andrus, National Institute of Standards and Technology, co-presented a lecture on "Investigations of Liquefiable Soils Using Shear Wave Velocity and Associated Correlations," for which lecture graphics were reproduced for inclusion in these proceedings. The lecture developed the topic of seismic velocity surveying, by both borehole and surface means, and its specific application to evaluate liquefaction potential of various soils. Prof. Stokoe observed during his presentation that currently applied procedures cannot determine whether a soil is as much as $90 \%$ saturated, and that perhaps the ratio of compression wave velocity, $\mathrm{V}_{\mathrm{p}}$, to shear wave velocity, $\mathrm{V}_{\mathrm{s}}$, offers a reliable correlation. He pointed out that $\mathrm{V}_{\mathrm{s}}$ is directly relatable to shear modulus and has been correlated to SPT blowcounts, thus it follows that liquefaction potential may be inferred from the parameter, as well.

Prof. Stokoe listed a series of engineering parameters and behavior indices that may be directly or indirectly evaluated in terms of seismic velocity, and presented field occurrence data on liquefaction to prove his point. Shear wave velocity is gaining acceptance rapidly in the geotechnical earthquake engineering field, based on successful application to observed soil response at well-studied sites.

Professor Stokoe and Dr. Andrus presented the theory and application of the Spectral Analysis of Surface Waves (SASW) technique (developed by Prof. Stokoe and his colleagues at the University of Texas), and described recent adaptation of the technique to liquefaction potential evaluation. Copies of lecture graphics are provided in Appendix D for detailed examination of these data by the reader. 


\section{Seismic Velocity, Attenuation and Liquefaction - Philip Sirles}

Mr. Philip Sirles, US Bureau of Reclamation, gave a background discussion of the purposes and techniques for geophysical investigations applied to evaluate engineering sites for liquefaction potential. He did not submit a formal technical paper to the workshop; hard copies of his lecture graphics and a copy of an article Mr. Sirles published in a newsletter for the US Committee on Large Dams titled "Geophysics for Soil Characterization at New and Existing Dams" are included in the text of the proceedings, immediately following this synopsis.

Mr. Sirles' presentation emphasized safety evaluation of reservoir dams, in keeping with the focus of the sponsoring EQEN research program. He discussed the entire range of field investigation techniques available to engineers, including those employed at the ground surface, such as seismic refraction and reflection surveys, SASW methods, electrical property measurement and electromagnetic survey approaches. Mr. Sirles also presented the principles and practices associated with borehole-based techniques. His presentation was organized to then integrate the suite of available tools into a method for liquefaction potential investigation, culminating in case studies of two existing dams where the process has been employed. His presentation graphics are provided in Appendix E and contain substantial detail to convey the salient features of his lecture.

\section{A Non-Destructive Method of Estimating Properties of Soil Subjected to Earthquake Strong Motion - Steven Glaser}

Prof. Steven Glaser, Colorado School of Mines, Golden, Colorado, presented the subject lecture and submitted a companion technical paper with the same title. His topic addressed the concept and application of system identification, based on recorded site response during earthquakes, to evaluate dynamic properties. Prof. Glaser presented the scheme used to acquire and analyze data at the instrumented Wildlife Liquefaction Site in southern California during two recent earthquake events. Prof. Glaser discussed the interpretation of motion records between in situ accelerometers, leading to parametric modeling of time-varying soil properties. Complete pore pressure histories were also obtained by transducers implanted at the site. The system identification process allows the use of a real geologic site for experimentation, whereas boundary conditions and loads in existence are not well simulated in an elemental representation of the actual site by means of laboratory tests. Prof. Glaser's presentation graphics and technical paper are provided in Appendix $\mathrm{F}$ and provide additional detail on the concept and the case studies just described.

\section{Surface Wave Method - A Tool for Lifeline Earthquake Engineering - Ronald Andrus}

Dr. Ronald Andrus, National Institute of Standards and Technology, presented and submitted a technical paper titled as above, to describe application of the 
SASW technique to liquefaction potential evaluation in general, and assessment of the effects of liquefaction on lifelines specifically. The SASW technique is attractive in this application due to its ability to assess, non-intrusively, large areas quickly and economically without requiring boreholes. Dr. Andrus described the use of the SASW procedure to discriminate liquefied and nonliquefied soils in the areas affected by the 1983 Borah Peak, Idaho earthquake. Few discussion comments were made by attendees during the workshop; the brief technical paper is provided in Appendix $G$ and provides some details for the reader to understand the concepts and case studies presented.

\section{The Biot Model and Waveform Tomography - Richard Rechtien}

Prof. Rechtien, University of Missouri - Rolla, presented a background lecture on the Biot Model applied to soil-water continua and the hydrodynamic interactions between the soil solid and liquid phases, for the interpretation of seismic waveforms transmitted through geologic media between source and receiver boreholes. Waveform tomography provides multidimensional interrogation and modeling of the ground, and involves collection and processing of a very large quantity of high-resolution motion data. The result of seismic surveys conducted in this manner may be thought of as a computer-aided tomographic, or CAT scan, of the subsurface. The parameters of the particular scan may vary, to the point that dynamic soil properties may be mapped and perhaps liquefaction potential may be inferred in a two-dimensional fashion. It may also be possible to extract permeability data, through adaptation of the Biot Model. In any case, two- or three-dimensional measurement of shear wave velocities is possible applying the tomography procedure, and shear wave velocity, as has already been discussed, is well correlated to liquefaction potential.

Prof. Rechtien submitted no presentation visuals or technical papers to the workshop for inclusion in these proceedings. Prof. Rechtien published a WES technical report: Contract Report No. GL-96-1, "In Situ Seismic Investigation of Liquefaction Potential of Soils," after the workshop, which provides excellent descriptions of theory, field data acquisition, and the state of the art for application of the waveform tomography method to the interpretation of liquefaction potential.

\section{Summary of Topics I and II - Dwain Butler}

Dr. Dwain Butler, Geotechnical Laboratory presented a summary of the key issues discussed in the previous portions of the workshop, beginning by echoing back to attendees what he understood from earlier presentations. Dr. Butler outlined the liquefaction concept for a simple, level-ground, three-layer deposit using the following illustration: 


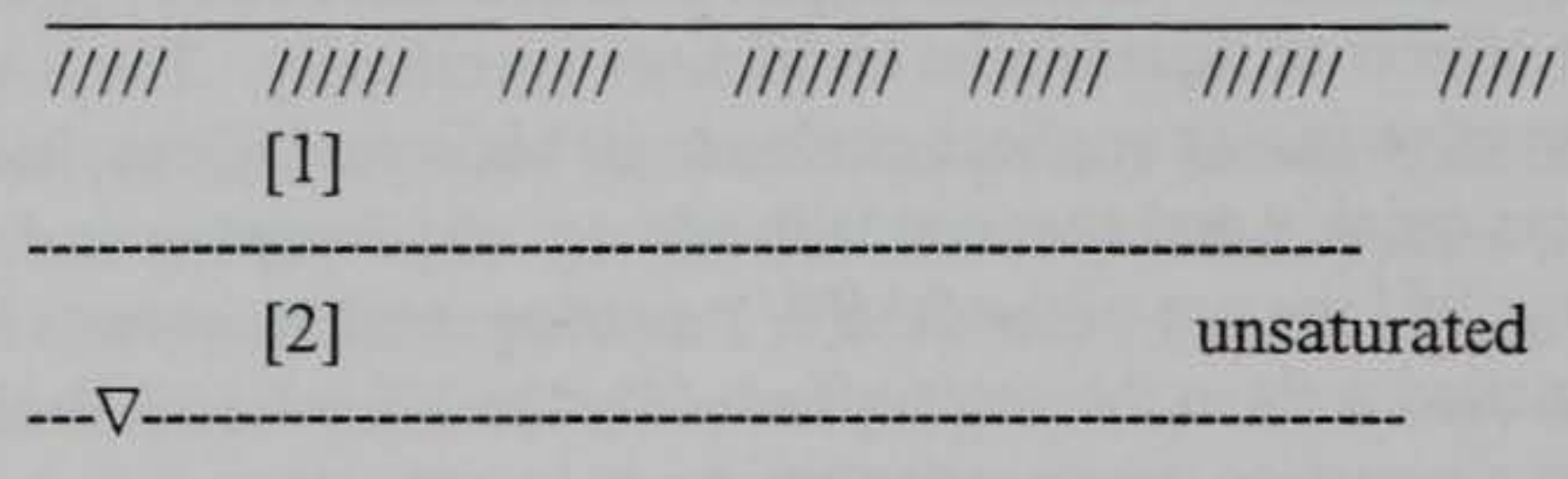

\begin{tabular}{llllll} 
& [3] & & & saturated \\
\hline " & & & & \\
\hline & " & " & "
\end{tabular}

In this diagram, the soils are assumed to be sandy or silty deposits of the types conventionally held to be susceptible to liquefaction. It is generally recognized that only saturated soils can liquefy, or, in an extreme sense, soils that could become saturated by migration of excess pore water pressures from adjacent soils. If the soils in layer three have, either in the laboratory or in the field, ever experienced liquefaction when subjected to a given earthquake loading (characterized by a peak acceleration, $\mathrm{a}_{\max }$, a fundamental period, $\mathrm{T}$, and a number of cycles, N), then the soil is considered potentially liquefiable in future events. If, on the other hand, the same soil has not liquefied during real events or in the laboratory when subjected to any set of earthquake motions, the soil is considered non-liquefiable.

Engineering properties to be considered in characterizing the liquefaction potential of a soil include, but may not be limited to: density (bulk or relative), shear or compression wave velocity, attenuation quality factors for shear or compression, and the in situ stress conditions in effect prior to the earthquake. The earthquake ground motions may be characterized by the parameters mentioned earlier, which are themselves functions of such parameters as magnitude, focal depth, epicentral distance, and geometric constraints such as the type of fault and the energy radiation pattern from the source. The earthquake characteristics are generally independent of the properties of the soil in layer three as idealized, and the soil properties in layer three are, in general, independent of the earthquake shaking at its onset. Of course, the effects of ground shaking on the response of the soil are strain dependent during shaking.

Dr. Butler reiterated the task for earthquake scientists concerned with liquefaction potential evaluation, namely: to characterize the liquefaction potential of soil layer three using techniques that determine properties of the layer, independent of the earthquake, then relate them to liquefaction potential by means of a plot or chart (based on substantial accumulation of data). It may be possible, for example, to develop a relationship between geophysical and geotechnical measurements and liquefaction potential. Shear wave velocity or peak acceleration may, for instance, be relatable to liquefaction potential using strength parameters such as may be interpreted from standard penetration test blowcounts (for which a large body of data exists). The evolution of in situ test procedures 
may allow for correlation of additional types of data with liquefaction potential. Dr. Butler listed a variety of seismic survey techniques for obtaining velocity data, including: crosshole or surface refraction surveys and their adaptation for tomographic interpretation, uphole or downhole seismic surveys, the SASW approach, and reflection seismic surveys. Electrical surveying techniques are also available to interrogate the subsurface, including electromagnetic measurements, resistivity, and ground penetrating radar, where applicable.

\section{Topic III: Field Test Sites}

Mr. Ballard led the concluding workshop session on selection of documented test sites for research on site characterization techniques, by stating the primary objectives of the session, namely: (1) to examine potential test sites for relevancy to development of geophysical techniques; (2) to estimate test site criteria; and (3) to select and prioritize sites in accordance with accepted criteria. He followed his summary of the objectives by introducing the session speakers.

\section{Organization and Operation of National Geotechnical Test Sites - Richard Woods}

Prof. Richard D. Woods, University of Michigan, presented the National Geotechnical Experimentation Sites (NGES), which he manages and which are intended to accommodate researchers conducting experiments on in situ investigation tools and procedures. The NGES consists of five primary sites that vary in their type and amount of instrumentation and background data and which are located on property belonging to: the University of Houston, the University of Massachusetts, Northwestern University, Texas A\&M University, and the Treasure Island Naval Station offshore from San Francisco, California. The National Science Foundation (NSF) and the Federal Highway Administration (FHWA) provide research funding in support of the five primary sites. The Texas A\&M and Treasure Island sites are categorized as Level I sites, and receive the greatest amount of supportive funds for site improvement and user access and activities, while the three remaining primary sites are funded at lesser amounts (designated Level II). Thirty-five additional NGES sites are included in the overall system database, but are not currently funded for instrumentation or maintenance. Summary descriptions of each of the five primary sites are given in the technical paper submitted by Prof. Woods to the workshop, which is provided in Appendix H.

Prof. Woods also listed several international sites for consideration as experimentation facilities, in the following countries: Armenia, Brazil, Canada, France, Italy, Japan, the Netherlands, and the United Kingdom. He mentioned that a catalog has been published on diskettes, with a user's manual. Interested persons should contact Prof. Woods for copies. An online access feature was under development, but was not ready at the time of the workshop. 


\section{Effect of Stress State and Soil Fabric on Seismic Wave Velocities Measured by Borehole Methods - Ken Stokoe}

Prof. Stokoe returned to present the subject topic in the session relating to test site selection, and presented research results from large-scale laboratory triaxial chamber tests on fabric and soil structure effects. His presentation concluded with crosshole test program that included a case study on comparisons of horizontally and vertically polarized shear waves from crosshole tests at the Treasure Island NGES facility. No technical paper was submitted to accompany this presentation; Prof. Stokoe's lecture graphics for this topic are provided in Appendix I.

\section{Success Dam - John Nickell}

Mr. John Nickell, US Army Engineer District, Sacramento (CESPK-ED-D) made an impromptu presentation on Success Dam, California, for consideration by attendees as an additional field test site. WES has assisted CESPK in an evaluation of seismic stability of Success Dam, where a substantial in situ investigation program has been conducted. Mr. Nickell described conditions and geology of the Success Dam site, as well as preliminary stability analysis results. The length of study areas involving the embankment of this dam ranges from 3000 $\mathrm{ft}$ to $4000 \mathrm{ft}$, depending on inclusion of auxiliary dikes around the reservoir. The main embankment is $140 \mathrm{ft}$ tall, and is constructed of compacted earth and rock fill. Recent alluvium deposits left in place beneath the shells of the dam range in thickness from about $11 \mathrm{ft}$ to $25 \mathrm{ft}$. Mr. Nickell described the suite of field and laboratory tests conducted to assess liquefaction potential of the dam and its foundation, and related plans for additional experiments to further refine site characterization. In presenting the features and test programs at Success Dam, Mr. Nickell offered access and support to research personnel for an experimentation site that involved an actual reservoir dam. Persons interested in additional details on the investigations sponsored by CESPK at Success Dam should contact Mr. Nickell at the address given in the list of attendees provided earlier. (Note: Success Dam was chosen as the first test site. Field investigations were conducted during the summer of 1996.)

\section{Test Sites Discussion - Robert Ballard}

Mr. Ballard presided over an open discussion of the relative merits of various test sites that may be available for site characterization field research, and invited the inclusion of additional sites that had not yet been discussed in the workshop. This discussion was directed to aid the principal investigators in selection of candidate test sites for experiments to commence in FY 96. Attendees were polled to secure their informed opinions on potential test sites discussed to this point, and to add any new candidate sites that might prove useful beyond those originally considered. Mr. Ballard circulated a blank table to attendees early in the workshop to solicit opinions on the pros, cons, and priority of each test site name 
submitted. The consensus results obtained during the closing session of the workshop are summarized in Table 1 .

\section{Epilogue}

In the course of time since these workshop proceedings were compiled, certain events worthy of note have occurred during the progression of this Work Unit. A chronology of those events follows:

1. A lecture / workshop was conducted at WES on the subject of seismic tomography and Biot theory. The featured lecturer was Professor Tokuo Yamamoto, University of Miami.

2. Dr. Richard Rechtien's report "In Situ Seismic Investigation of Liquefaction Potential of Soils" was published.

3. Applications of the Biot theory as it pertains to the objectives of this Work Unit were documented.

4. Field tests were planned and conducted at Success Dam, California. The borehole pattern was an equilateral triangle twenty-five feet long on each side. A single boring ninety feet deep was placed at each apex and ten foot deep borings were placed along each leg at 2.5 foot spacing. Thus, a total of thirty borings were used during testing. High quality data were collected in a fashion suitable for tomographic analysis. These data will be analyzed during FY 97.

5. Dr. Barbara Luke, University of Nevada, Las Vegas, was hired under the ARO summer faculty program to plan and assist with potential Spectral Analysis of Surface Waves (SASW) applications at future test sites. She worked at WES during the time June-August 1996.

6. The Work Unit was successfully defended during field review and the concept of "Non-Invasive Characterization of Upstream, Water-Covered Dam Embankments and Foundations" was proposed as either a new start or inclusion in the existing Work Unit. (The proposal was later included as a part of the existing Work Unit).

7. Lastly, the U.S.-Japan Workshop on Advanced Research on Earthquake Engineering for Dams was held at WES on 12-14 November 1996. A paper 
"Geophysical Methods for Site Characterization and Measurement of In Situ Properties" by Robert F. Ballard, Jr. was presented which is available separately and summarizes the features and progress of the Work Unit. 


\begin{tabular}{|c|c|c|c|}
\hline \multicolumn{4}{|c|}{$\begin{array}{l}\text { Table } 1 \\
\text { Potential Field Test Sites }\end{array}$} \\
\hline Site (Owner) & Pros & Cons & Priority \\
\hline $\begin{array}{l}\text { Treasure Island } \\
\text { (NGES) }\end{array}$ & $\begin{array}{l}\text { Well documented } \\
\text { E a } r \mathrm{th} \mathrm{quak} \text { a } \\
\text { emphasis }\end{array}$ & $\begin{array}{l}\text { Man-made loose } \\
\text { sand deposit } \\
\text { Bay mud } \\
\text { Small, salt water site }\end{array}$ & Low \\
\hline $\begin{array}{l}\text { University of } \\
\text { Houston } \\
\text { (NGES) }\end{array}$ & & $\begin{array}{l}\text { Clay } \\
\text { Too small }\end{array}$ & Low \\
\hline $\begin{array}{l}\text { Texas A\&M } \\
\text { (NGES) }\end{array}$ & & $\begin{array}{l}\text { Doesn't meet } \\
\text { requirements }\end{array}$ & Low \\
\hline $\begin{array}{l}\text { Northwestern } \\
\text { University } \\
\text { (NGES) }\end{array}$ & Loose sands & $\begin{array}{l}\text { Not good for long- } \\
\text { term study } \\
\text { Denser than } \\
\text { required }\end{array}$ & Low \\
\hline $\begin{array}{l}\text { Unity Dam } \\
\text { (USBR) }\end{array}$ & $\begin{array}{l}\text { Clean sand } \\
\text { Documentation } \\
\text { Liquefiable }\end{array}$ & Limited access & High \\
\hline $\begin{array}{l}\text { Conconullay Dam }{ }^{1} \\
\text { (USBR) }\end{array}$ & $\begin{array}{l}\text { Documentation } \\
\text { Few fines, clean } \\
\text { sand, } \\
\text { some gravels }\end{array}$ & $\begin{array}{l}\text { Time factor } \\
\text { Complex geology }\end{array}$ & $\begin{array}{l}\text { High } \\
\text { POC: Mike Stevens }\end{array}$ \\
\hline $\begin{array}{l}\text { Bradbury Dam } \\
\text { (USBR) }\end{array}$ & $\begin{array}{l}\text { Gravelly site } \\
\text { Instrumented for } \\
\text { strong motions } \\
(\mathrm{SMIP})^{3} \quad\end{array}$ & Partially de-watered & Med/Low \\
\hline $\begin{array}{c}\text { Jackson Lake Dam } \\
\text { (USBR) }\end{array}$ & & $\begin{array}{l}\text { Remediated } \\
\text { Limited access }\end{array}$ & Low \\
\hline $\begin{array}{l}\text { Success Dam }{ }^{4} \\
\text { (CESPK) }\end{array}$ & $\begin{array}{l}\text { Accessible } \\
\text { Sands and gravels } \\
\text { Documentation } \\
\text { Ongoing WES work } \\
\text { (possible additional } \\
\text { funding) }\end{array}$ & $\begin{array}{l}\text { Borehole placement } \\
\text { Affected by four } \\
\text { major faults } \\
\text { Cemented lenses }\end{array}$ & High/Med \\
\hline Wildlife & $\begin{array}{l}\text { Liquefiable } \\
\text { Earthquake likely to } \\
\text { occur } \\
\text { Other test run there }\end{array}$ & $\begin{array}{l}\text { Boreholes not } \\
\text { accessible } \\
\text { Difficult site access }\end{array}$ & High/Med \\
\hline
\end{tabular}

\footnotetext{
${ }^{1}$ Second choice of group

${ }^{2} \mathrm{Mr}$. Stevens was POC at the time of the workshop - he has since left the USBR

${ }^{3}$ SMIP - Corps of Engineers' Strong Motion Instrumentation Program, managed by Robert F. Ballard, Jr, CEWES-GG

${ }^{4}$ First choice of group
} 


\section{Appendix A - List of Attendees}

The following participants attended from outside WES and either presented technical lectures on workshop topics, or prepared and submitted technical papers for the proceedings report, or both (addresses given below were correct at the time of the workshop):

\begin{tabular}{|c|c|c|}
\hline Name & Organization & Address/Phone (fax) \\
\hline Dr. Ronald D. Andrus & $\begin{array}{l}\text { National Inst. for Standards and } \\
\text { Technology }\end{array}$ & $\begin{array}{l}\text { NIST } \\
\text { Bldg. 226, Rm B158 } \\
\text { Gaithersburg, MD } \\
20899 \\
301-975-6051 \text { (fax 301- } \\
869-6275 \text { ) }\end{array}$ \\
\hline Prof. W. D. Liam Finn & Univ. of British Columbia & $\begin{array}{l}\text { Dept. of Civil } \\
\text { Engineering } \\
\text { 2324 Main Mall } \\
\text { Vancouver, BC } \\
\text { CANADA V6T 1W5 } \\
\text { 604-822-4938 (fax 604- } \\
822-6901 \text { ) }\end{array}$ \\
\hline Prof. Steven Glaser & Colorado School of Mines & $\begin{array}{l}\text { Division of Engineering } \\
\text { Golden, CO } 80401 \\
303-236-4196 \text { (fax 303- } \\
273-3602)\end{array}$ \\
\hline Prof. Richard Rechtien & $\begin{array}{l}\text { Consultant, Univ. of Missouri- } \\
\text { Rolla }\end{array}$ & $\begin{array}{l}\text { Dept. of Geology and } \\
\text { Geophysics } \\
\text { Rolla, MO } 65401 \\
573-364-3886\end{array}$ \\
\hline
\end{tabular}




\begin{tabular}{|c|c|c|}
\hline Mr. Phil Sirles & U.S. Bureau of Reclamation & $\begin{array}{l}\text { D-2230 } \\
\text { PO Box } 25007 \\
\text { Bldg. 67, Denver Federal } \\
\text { Center } \\
\text { Denver, CO } 80225\end{array}$ \\
\hline Prof. Kenneth H. Stokoe II & University of Texas at Austin & $\begin{array}{l}\text { ECJ } 9.227 \\
\text { Austin, TX } 78712 \\
512-471-4929 \text { (fax 512- } \\
471-6548 \text { ) }\end{array}$ \\
\hline Prof. Richard Woods & University of Michigan & $\begin{array}{l}\text { Dept. of Civil } \\
\text { Engineering } \\
2360 \text { G. G. Brown Lab } \\
\text { Ann Arbor, MI 48109- } \\
2125 \\
313-764-4303 \text { (fax 313- } \\
764-4292 \text { ) }\end{array}$ \\
\hline
\end{tabular}

The following participants from outside WES attended lectures and discussions, but did not make formal presentations or prepare technical papers for the proceedings:

\begin{tabular}{||l|l|l||}
\hline \hline Name & Organization & Address/Phone (fax) \\
\hline \hline Mr. William E. Hancock & US Army Engineer District, & CENPS-EN-GT \\
& Seattle & PO Box 3755 \\
& & Seattle, WA 98124-2255 \\
& & 206-764-3711 (fax 206- \\
& & $764-6795)$ \\
\hline Dr. Gregory L. Hempen & US Army Engineer District, St. & CELMS-ED-GG \\
& Louis & 1222 Spruce Street \\
& & St. Louis, MO 63103- \\
& & 2833 \\
& & $314-331-8441$ (fax 314- \\
& & $331-8244)$ \\
\hline Mr. William Joyner & US Geological Survey & Mail Stop 977 \\
& & 345 Middlefield Road \\
& & Menlo Park, CA 94205 \\
& & 415-329-5640 (fax 415- \\
& & $329-5163$ ) \\
\hline
\end{tabular}




\begin{tabular}{||l|l|l||}
\hline Mr. Kenneth Klaus & US Army Engineer District, & CELMK-ED-GT \\
& Vicksburg & 4155 Clay Street \\
& & Vicksburg, MS 39180- \\
& & 3435 \\
& $601-631-7122$ (fax 601- \\
& $631-5627)$ \\
\hline Mr. John Nickell & US Army Engineer District, & CESPK-ED-D \\
& Sacramento & 1325 J. Street \\
& & Sacramento, CA 95814- \\
& & 2922 \\
& & $916-557-6614$ (fax (916- \\
& & $557-7846)$ \\
\hline
\end{tabular}

The following WES participants either presented lectures or attended discussions during the workshop:

\begin{tabular}{||l|l|l||}
\hline \hline Name & Organization & Address/Phone (fax) \\
\hline \hline Mr. Robert F. Ballard, Jr. & U.S. Army Engineer Waterways & CEWES-GG \\
(Principal Investigator) & Experiment Station & 3909 Halls Ferry Road \\
& & Vicksburg, MS 39180- \\
& & 6199 \\
& & $601-634-2201$ (fax - \\
& WES & $3153)$ \\
\hline Dr. Dwain K. Butler & & CEWES-GG \\
(Co-Principal Investigator) & & 3909 Halls Ferry Road \\
& & Vicksburg, MS 39180- \\
& & 6199 \\
& WES & $601-634-2127$ (fax - \\
& & $3453)$ \\
\hline Dr. Arley G. Franklin & & Chief, CEWES-GG \\
& & 3909 Halls Ferry Road \\
& & Vicksburg, MS 39180- \\
& & 6199 \\
& WES & $601-634-2658$ (fax - \\
& & $3453)$ \\
\hline Dr. Joseph P. Koester & & CEWES-GG-H \\
& & 3909 Halls Ferry Road \\
& & Vicksburg, MS 39180- \\
& & 6199 \\
\hline
\end{tabular}




\begin{tabular}{|c|c|c|}
\hline Mr. Richard H. Ledbetter & WES & $\begin{array}{l}\text { CEWES-GG-H } \\
3909 \text { Halls Ferry Road } \\
\text { Vicksburg, MS } 39180- \\
6199 \\
601-634-3380 \text { (fax - } \\
4894)\end{array}$ \\
\hline Dr. John Peters & WES & $\begin{array}{l}\text { CEWES-GS-GC } \\
3909 \text { Halls Ferry Road } \\
\text { Vicksburg, MS 39180- } \\
6199 \\
601-634-2590 \text { (fax - } \\
4656)\end{array}$ \\
\hline Mr. Ronald Wahl & WES & $\begin{array}{l}\text { CEWES-GS-GC } \\
3909 \text { Halls Ferry Road } \\
\text { Vicksburg, MS 39180- } \\
6199 \\
601-634-3632 \text { (fax - } \\
4656 \text { ) }\end{array}$ \\
\hline Mr. Donald E. Yule & WES & $\begin{array}{l}\text { CEWES-GG-H } \\
3909 \text { Halls Ferry Road } \\
\text { Vicksburg, MS 39180- } \\
6199 \\
601-634-2964 \text { (fax - } \\
3453 \text { ) }\end{array}$ \\
\hline
\end{tabular}




\section{Appendix B - Agenda}

\section{EARTHQUAKE ENGINEERING \\ SITE CHARACTERIZATION WORKSHOP}

27-28 June 1995

U.S. Army Engineer Waterways Experiment Station

Vicksburg, Mississippi

Agenda

Tuesday, 27 June

$0800 \quad$ Registration

0830-0835 Welcome to WES - William F. Marcuson III

0835-0840 The COE EQEN Program - Arley G. Franklin

0840-0845 Introduction and Purpose of the Workshop - Dwain K. Butler

Topic I: Geotechnical Indicators of Liquefaction Potential of In Situ Materials

0845-0900 Introduction to Topic I - Richard H. Ledbetter

0900-1000 W.D. Liam Finn: Fundamentals of Liquefaction

1000-1045 Liquefaction Discussion: Moderator - Richard Ledbetter

1045-1100 BREAK

1100-1115 Introduction of Agency Representatives and Brief Statements

Regarding Research Programs and/or Interests: USGS, USBR, NIST (Joyner,

Sirles, Andrus) 


\section{Topic Il: Geophysical Indicators of Liquefaction Potential}

1115-1130 Introduction to Topic II: Dwain Butler

1130-1200 Kenneth H. Stokoe, University of Texas: Investigations of Liquefiable Soils Using Shear Wave Velocity and Associated Correlations 1200-1315 LUNCH - Presentation by Joseph P. Koester: Field Liquefaction Observations Following the Kobe EQ

1315-1345 Philip C. Sirles, Bureau of Reclamation: Seismic Velocity, Attenuation, and Liquefaction

1345-1415 Steven Glaser, Colorado School of Mines: A Non-Destructive Method for Estimating Properties of Soil Subjected to Earthquake Strong Motion

1415-1445 Ronald D. Andrus, National Institute of Standards and Technology: Geophysical Applications to Lifeline Earthquake Engineering 1445-1500 BREAK

1500-1545 Richard D. Rechtien, Consultant: The Biot Model and Waveform Tomography

1545-1645 Geophysical Indicators Discussion: Moderator - Dwain K Butler 1830 Mix and Mingle Time Followed by Dinner and Special Guest - Park Inn, Mirror Room

Wednesday, 28 June

\section{Topic III: Field Test Sites}

0800-0815 Introduction to Topic III - Robert F. Ballard, Jr.

0815-0845 Richard D. Woods, University of Michigan: Organization and Operation of National Geotechnical Test Sites

0845-0915 Kenneth H. Stokoe, U. of Texas: Effect of Stress State and Soil

Fabric on Seismic Wave Velocities Measured by Borehole Methods

0915-0945 Philip C. Sirles, USBR: TBD

0945-1000 BREAK

1000-1115 Test Sites Discussion: Moderator - Robert F. Ballard, Jr.

1115-1200 Open Discussion: Moderator - Dwain K. Butler

$1200 \quad$ Adjourn

Workshop Proceedings Coordinator - Joseph P. Koester 
Appendix C - Proceedings Submissions by Prof. W. D. Liam Finn 


\title{
A BASIS FOR SELECTING INDICATORS OF LIQUEFACTION POTENTIAL
}

\author{
by \\ W.D. Liam Finn \\ Department of Civil Engineering, The University of British Columbia \\ Vancouver, British Columbia, Canada V6T 1Z4
}

for

EARTHQUAKE ENGINEERING AND SITE CHARACTERIZATION WORKSHOP

US ARMY ENGINEERS WATERWAYS EXPERIMENT STATION

VICKSBURG, MISSISSIPPI, USA

June 27-28, 1995 


\section{Introduction}

One of the more significant factors leading to ground failure during earthquakes is the liquefaction of loose- to medium-dense sands below the water table. Attention was focused on this problem for the first time as a result of the widespread ground failures during the 1964 earthquake in Niigata, Japan (Kawasumi 1968). Most of the damage in Niigata attributable directly to the earthquake was associated with liquefaction and such damage has been a significant factor in most major earthquakes since then. Some recent examples are the extensive damage caused by liquefaction in the Marina District in San Francisco during the Loma Prieta earthquake of 1989 (Seed et al. 1990) and the destruction of port facilities on Port and Rokko Islands in Osaka Bay off Kobe City, during the 1995 Hyogo-ken-Nanbu earthquake (CAEE 1995).

Figure 1 illustrates the response of granular soils to cyclic loading in triaxial tests. The test specimens were prepared to relative densities that covered the range of sand states from highly contractive to highly dilative under shearing deformation (Vaid and Chern 1985). All test specimens carry initial static shear

stresses, $\tau_{\mathrm{st}}$. This simulates the most common situation in earth structures and under foundations. Contractive stress-strain response is shown in Figure l(a). At some stage in the cyclic loading, strain softening occurs leading to a large drop in undrained strength which then remains constant over a large range in strain. Large deformations occur when $\tau_{\text {st }}$ is greater than the steady state strength $\tau_{\mathrm{ss}}$ (or residual strength, $\mathrm{S}_{\mathrm{ur}}$ ). Deformations may also be significant when $\tau_{\mathrm{st}}<\tau_{\mathrm{ss}}$, if $\tau_{\mathrm{st}}+\tau_{\mathrm{cy}}>\tau_{\mathrm{ss}}$, where $\tau_{\mathrm{cy}}$ is the cyclic shear stress. The phenomenon of large flow deformations occurring at constant undrained strength is termed liquefaction. 
At the other extreme, the sand is strongly dilative and deformation is the result of progressive stiffness degradation in the sand due to the buildup in porewater pressure with cycles of loading. This phenomenon is called cyclic mobility and is illustrated in Figure 1(b).

Between these two clearly defined states is a transitional region combining features of both contractive and dilative response. This type of behavior is characterized by a loss in undrained strength due to strain softening over a limited range followed by a regain of undrained strength. Further deformations result from cyclic mobility. This behavior is illustrated in Figure 1(c). The effective stress paths for these tests are shown in Figures 1(d) through 1(f). Note the pick up in shearing resistance $\left(\sigma^{\prime}{ }_{1}-\sigma_{3}^{\prime}\right) / 2$ with increasing strain in Figures $1(\mathrm{e})$ and $1(\mathrm{f})$. The strain histories of sands in these three different states are shown together in Figures $1(\mathrm{~g})$ through $1(\mathrm{I})$.

The instability of loose saturated sands and the residual strength after structural collapse may also be determined by static triaxial or simple shear tests in the laboratory. The stress-strain curve derived from a static triaxial test is shown in Figure 2. It has the same basic characteristics as the stress-strain curves in Figure 1.

In engineering practice the word liquefaction is usually associated with the development of high porewater pressures due to seismic loading irrespective of whether large deformations occur or not. Indeed the empirical procedures for assessing liquefaction potential are all based primarily on surface manifestations of high porewater pressure such as sand boils without consideration of whether the soil would behave in a contractive or dilative mode during shearing. However, the consequences of these high porewater pressures clearly depend on whether the soil is contractive or not, and there is great need for a reliable in-situ indicator of these conditions. 


\section{Objectives}

In this paper we will first explain the basic phenomenon of the development of porewater pressure under cyclic loading which is the fundamental cause of liquefaction and cyclic mobility. We will examine what variables control the potential for high porewater pressures and consider what measures of in-situ properties might identify this potential. Our primary interest here will be in the use of in-situ methods. In a companion paper entitled "Evaluation of Liquefaction Potential by In-Situ Methods" (Finn 1995), the state-of-the-art used in current engineering practice is described in considerable technical detail. In this paper, we will discuss the basic links between the various indicators of liquefaction potential and the soil parameters that control the development of seismic porewater pressures. This framework gives a better understanding of the indicators in current use and provides the basis for developing alternative concepts of how to evaluate liquefaction potential.

There are three basic requirements for evaluating liquefaction potential of a soil deposit during an earthquake:

a. Characterizing the intensity of the earthquake shaking of the soil.

$b$. Characterizing the in-situ state-of-the-soil.

c. Developing a criterion for liquefaction occurrence based on indicators of shaking intensity and the in-situ condition of the soil.

We will, first of all, characterize the intensity of shaking. 


\section{Characterizing Earthquake Shaking}

Seismic shear stresses play a major role in the development of liquefaction. Time histories of shear stresses generated by earthquakes are usually very nonuniform and cannot be used directly in empirical assessments of liquefaction. Seed (1983) suggested replacing the irregular time history by an equivalent number of uniform cycles and normalizing the uniform shear stress by dividing by the effective overburden stress. Seed proposed that this uniform cyclic shear stress ratio (CSR) be determined by:

$$
\operatorname{CSR}=\frac{\tau_{c}}{\sigma_{v o}^{\prime}}=0.65 \frac{\sigma_{v}}{\sigma_{v o}^{\prime}} \frac{a_{\max }}{g} r_{d}
$$

where

$$
\begin{aligned}
\tau_{\mathrm{c}} & =\text { equivalent average shear stress } \\
\sigma_{\mathrm{v}} & =\text { total overburden stress } \\
\sigma_{\mathrm{vo}}^{\prime} & =\text { effective overburden stress } \\
\mathrm{a}_{\max } & =\text { maximum surface acceleration in units of } \mathrm{g} \\
\mathrm{g} & =\text { acceleration due to gravity } \\
\mathrm{r}_{\mathrm{d}} & =\text { a reduction factor to account for soil flexibility and depth }
\end{aligned}
$$

In Japanese practice, the reduction factor $\mathrm{rd}$ is often approximated using the following expression, 


$$
r_{d}=(1-0.015 Z)
$$

where $Z=$ depth in meters.

Equation (1) defines an equivalent level of shaking only. However, the development of porewater pressure also depends on the number of cycles of CSR which are equivalent in their effects to the complex time history of shear stresses developed during the earthquake. The equivalent number of cycles depends on the duration of shaking, which in turn depends on the magnitude of the earthquake. Therefore, the intensity of shaking will be characterized by both the critical stress ratio, CSR, and by the magnitude, $\mathrm{M}$, of the earthquake. 


\section{Mechanism of Porewater Pressure Development}

Consider a small cube of saturated sand as shown in Figure 3(a). Assume that all drainage is prevented when the sample is sheared in direct simple shear. In one cycle of small shear strain, $\gamma$, an increment in porewater pressure, $\Delta u$, develops. Now consider a sample with exactly the same granular structure and density but of completely free-draining (Figure 3(b)). When subjected to one cycle of the same shear strain, it undergoes a vertical strain $\Delta \varepsilon_{\mathrm{vd}}$. Since at the beginning of the cycle, both samples had the same structure, they both have the potential to develop the same vertical strain increment $\Delta \varepsilon_{\mathrm{vd}}$.

Since the sample in Figure 3(a) did not change in volume, the potential compactive strain $\Delta \varepsilon_{\mathrm{vd}}$ must have been neutralized in some way. This can only be accomplished, if the sample rebounds the same amount, $\Delta \varepsilon_{\mathrm{vd}}$. For this to occur, the effective stresses between the grains must be reduced by the appropriate amount $\Delta \mathrm{p}$, such that $\Delta \mathrm{p} / \overline{\mathrm{E}}_{\mathrm{r}}=-\Delta \varepsilon$ where $\overline{\mathrm{E}}_{\mathrm{r}}$ is the effective constrained rebound modulus of the soil for simple shear conditions. The decrease in $\Delta \mathrm{p}$ is accomplished by an increase in the porewater pressure by an increment $\Delta \mathrm{u}=$ $-\Delta \mathrm{p}$. Therefore, the increment in porewater pressure is given by

$$
\Delta u=\bar{E}_{r} \Delta \varepsilon_{v d}
$$

This is the fundamental mechanism of porewater pressure development during earthquakes. There is very strong field evidence supporting this concept of how seismic porewater pressures that may lead to liquefaction are generated.

\section{Examples from Post-Earthquake Studies}


Water pumping out of the ground under the gradients from the porewater pressures generated during the 1983 Nihon-Kai-Chiba earthquake in Japan is shown in Figure 4. The speed with which these pressures can develop and their magnitude, sometimes results in an explosive ejection of the soil as shown by the huge crater in Figure 5. Sometimes the pressures are relieved in a more controlled fashion over a wide area giving the familiar sand volcano effects shown in Figure 6.

Settlement of the ground, similar to that occurring in Figure 3(b) is shown in Figure 7. The large flow deformations that can occur when very loose sand liquefies and the undrained shearing resistance drops to low values of residual strength, are exemplified by data from the 1995 Hyogoken-Nanbu earthquake in Kobe. Figure 8 shows the large lateral movements of a heavy sea wall caisson that occurred when the foundation soil and backfill liquefied. The large settlements are shown by the fleet of vans trapped in a water filled depression created when the sea wall moved outwards up to $3 \mathrm{~m}$ (Figure 9).

Large quantities of sand were ejected during liquefaction in Kobe at level sites such as the parking lot of the amusement park on Port Island shown in Figure 10. Widespread settlement occurred all over Port and Rokko Islands. Typical settlement is shown in Figure 11 by the movement of the ground relative to the pile foundation of the elevated railway on Port Island. These examples stress the key role played by compaction potential in causing liquefaction. 


\section{Potential Indicators of Liquefaction}

\section{Characterization of In-Situ State of Soil}

For a given intensity of earthquake shaking, liquefaction potential is controlled by the tendency for compaction and the capacity for drainage. The faster the soil can drain, the lower the potential for high porewater pressures and liquefaction to develop. The extent of potential natural drainage during an earthquake is difficult to evaluate in practice. Therefore a reliable indicator of the in-situ permeability would be a major improvement in practice. We will return to the drainage concept later. First, we will look at indicators of other insitu soil characteristics.

\section{Compaction Potential}

Cyclic shearing strain is recognized as the prime agent for generating the volume changes in saturated cohesionless soils which can lead to liquefaction. The small cyclic strains resulting from earthquake shaking prior to liquefaction generally result in the compaction of both loose and dense sands and hence in the generation of porewater pressures. For a given level of equivalent cyclic shear loading, the shear strain depends on the in-situ shear modulus, G. Therefore, for a given intensity of loading, the shear modulus could be a useful indicator of liquefaction potential. The shear modulus in-situ is best evaluated by directly measuring the in-situ shear wave velocity, $V_{s}\left(G=\rho V_{s}^{2}\right.$, where $\rho$ is the mass density). $V_{s}$ is measured using downhole or crosshole methods, or by 
using a seismic cone (Robertson et al. 1986). It may also be determined indirectly, by spectral analysis of surface waves (Nazafian and Stokoe 1984).

We are now in a position to characterize the earthquake shaking at a site in terms of earthquake magnitude, $M$, and cyclic stress ratio, $\tau_{c} / \sigma^{\prime}{ }_{v o}$, and the site condition in terms of shear wave velocity, $V_{s}$. Since $V_{s}$ is dependent on the mean normal effective stresses, we normalize all shear wave velocities to a standard pressure, $\mathrm{P}_{\mathrm{a}}$, of the 1 tsf $(100 \mathrm{kPa})$, giving,

$$
V_{s 1}=V_{s}\left(P_{a} / \sigma_{v o}^{\prime}\right)^{0.25}
$$

where $\sigma^{\prime}{ }_{v o}=$ effective overburden pressure in the same units as $\mathrm{P}_{\mathrm{a}}$.

Available field data is now plotted in terms of the state parameters, $\tau_{\mathrm{c}} / \sigma^{\prime}{ }_{\text {vo }}$ and, $\mathrm{V}_{\mathrm{s} 1}$, and a boundary curve drawn between liquefied and non-liquefied sites for various earthquakes as shown in Figure 12. Liquefaction potential assessment by the shear wave velocity does not appear to be very dependent on earthquake magnitude. This is surprising because porewater pressure development depends on the duration as well as the intensity of shaking and magnitude is a good indicator of duration. Although field data for a wide range of shear wave velocities and earthquake magnitudes is not yet available, shear wave velocity is being used in practice as an indicator of liquefaction for materials which are difficult to probe by other means such as gravelly or cobbly soils.

The liquefaction assessment chart in Figure 12 shows the essential requirements of any indicator of liquefaction potential; it must be capable of being plotted on a chart such as Figure 12 and it should be possible to refer all measurements to some basic reference state. Finally, there must be sufficient direct field data to develop a criterion based on the indicator unless there is a strong, well-defined correlation between the proposed indicator and another indicator which is itself supported by an extensive data base. 
Bierschwale and Stokoe (1984) describe some of the early procedures for using shear wave velocity to evaluate liquefaction potential. Robertson (1990) describes the more recent state-of-the-art.

The shear wave velocity is an indicator that is directly linked to the mechanism by which porewater pressure is developed in a soil by seismic loading. It is a direct measure of the shear modulus which controls the shear strains that will develop under the equivalent cyclic loading described by Equation 1, and hence, controls the development of the volumetric strains and porewater pressures.

This direct connection between an indicator and the cause of liquefaction is the exception rather than the rule. Other in-situ indicators used in practice measure the combined effects of a number of in-situ states such as density, stiffness, structure and fabric.

An important requirement for liquefaction is a very high degree of saturation. Otherwise, some compaction can be accommodated without significant porewater pressure development. It may be possible to assess the degree of saturation using $\mathrm{P}$-waves which travel at different velocities through the soil and water. A reliable indicator for this state is very needed.

\section{Density}

The shearing resistance of sand depends on the relative density, that is the relationship between the field density and the loosest and densest states of the material. Relative density is defined as,

$$
D_{r}=\left[\frac{\gamma_{d}-\gamma_{d(\min )}}{\gamma_{d(\max )}-\gamma_{d(\min )}}\right]\left[\frac{\gamma_{d(\max )}}{\gamma_{d}}\right]
$$

where $\gamma_{d}$ is the dry density. 
The evaluation of the loosest and densest states is controlled by ASTM Standards and is conducted on reconstituted samples of the soil. Determining the in-situ density is a difficult problem. In some critical cases in which expense was justified, frozen samples have been retrieved (Byrne et al. 1994). In other cases, in-situ densities have been determined by nuclear probe. This procedure was used in assessing the liquefaction potential of Dashihe Dam in China by Morgenstern and Finn (1994) and showed promise. There is a lot of laboratory data, chiefly from the late 1960 's and early 1970 's relating liquefaction potential of reconstituted sand samples from cyclic loading tests with relative density but there is no data base of field data that would lead directly to a criterion based on relative density. However, a knowledge of the in-situ relative density would be very useful to an experienced engineer in making judgements about liquefaction potential and its consequences.

\section{Electrical Resistivity, Ground Radar}

Any in-situ procedure that can assess the fabric and structure of a saturated deposit has the capacity to be an indicator of liquefaction potential. Fabric and structure are reflections of density, shearing stiffness, shearing resistance and porosity. Electrical techniques and ground radar may be useful tools for assessing fabric and structure and, hence, in indicating liquefaction. Soil fabric and structure are important for other reasons. To a major extent, they control permeability which controls ease of drainage and hence liquefaction potential. 


\section{Methods Used in Practice}

The methods used in current practice are discussed fully in the companion paper (Finn 1995) referred to earlier. They are listed here for convenience only. The cited paper should be consulted for details and references.

\section{SPT-N Method}

In engineering practice, the most wisely used indicator of liquefaction potential is the Standard Penetration Resistance $\mathrm{N}$ in blows/ft standardized to 1 tsf and 60 percent of the free fall energy of the hammer used to drive the penetration probe, $\left(\mathrm{N}_{1}\right)_{60}$. The largest direct data base on liquefied and nonliquefied sites is associated with $\left(\mathrm{N}_{1}\right)_{60}$.

\section{CPT: $\mathrm{q}_{\mathrm{c} 1}$ Method}

In recent years, the cone penetration test is being used more and more as an indicator of liquefaction because of the reliability and reproducibility of measurements of cone bearing, $q_{c}$, normalized to a reference pressure of 1 tsf, $q_{\mathrm{cl}}$. There is a good correlation between $\mathrm{N}$ and $\mathrm{q}_{\mathrm{c}}$ which allows the data base for $\left(\mathrm{N}_{\mathrm{I}}\right)_{60}$ to support $\mathrm{q}_{\mathrm{cl}}$ as an indicator of liquefaction potential in addition to the more limited field data directly connecting $\mathrm{q}_{\mathrm{cl}}$ and the occurrence of liquefaction.

\section{Becker Hammer Test}


This test is used to establish the penetration resistance $\left(N_{1}\right)_{60}$. of gravelly and cobbly soils which cannot be probed by the cone or the SPT sampler. A large diameter steel tube is driven by blows from a pile driver. These blows are calibrated for a given rig and hammer to $\left(\mathrm{N}_{1}\right)_{60}$ for sands by running Becker and SPT tests in sand, side by side. Liquefaction potential is then assessed using the liquefaction assessment chart based on $\left(\mathrm{N}_{1}\right)_{60}$.

\section{Shear Wave Velocity}

This method is being used increasingly in the same soils for which the Becker test was developed. In these soils, the shear wave velocity is derived from a spectral analysis of surface waves (SASW). This method requires no drill holes and no penetration testing. It has become a fast and more reliable test in recent years. 


\section{Geophysical Versus Geotechnical Indicators}

The geotechnical approach to assessing the in-situ state of a potentially liquefiable soil is very location specific. The state-of-the-soil is probed at distinct locations and a great many soundings are necessary in order to define even crudely the 3-D distribution of soil states. Furthermore, the methods require drill holes or the driving or pushing of probes. Geophysical methods provide data on a much larger scale and fill out the 3-D picture much better and more cheaply. For example, the details of soil layering can be defined globally by ground penetrating radar.

The geophysical methods such as ground radar and the spectral analysis of surface waves do not require drill holes or probes and theoretically they can function in any type of soil. This feature can make them very cost-effective. The role of ground radar and other geophysical (or electrical) measures of soil type or soil state in detecting liquefiable soils is worthy of research because of the potential savings in costs and perhaps an increase in reliability of estimating liquefaction. This research would be best conducted jointly by professionals from both groups. 


\section{Conclusions}

Any in-situ test that provides a measure of density, shear modulus, fabric and/or soil structure has the potential to be a useful indicator of liquefaction potential. However, to be a clear discriminant between liquefiable and nonliquefiable sites, it must be quantitatively linked to site performance in past earthquakes, either by direct measurement or through a reliable correlation with an indicator supported by such a data base. The engineering profession is strongly attached to the indicators now being used to assess liquefaction. One area where a new, reliable, simple indicator would be very welcome is gravely, cobbly soils. Existing methods are effective here but their implementation is not always easy, and interpretation is still occasionally controversial.

There is scope for the development for geophysical (and electrical) methods for the assessment of liquefaction potential. The attraction of such methods is that they usually do not require drill holes, are more global in their assessments and can be very cost-effective. Indications of potential methods were presented in the paper, but the main function of the paper was presentation of the fundamentals of liquefaction to provide a framework of understanding that would facilitate the development of new indicators for engineering practice. 


\section{Acknowledgments}

The work described in this paper was supported in part by the Natural Science and Engineering Council of Canada, and the U.S. Army Corps of Engineers, Waterways Experiment Station. 


\section{References}

Byrne, P. M., Imrie, A. S. and Morgenstern, N. R. "Results and implications of seismic response studies - Duncan Dam," Proceedings of the 46th Annual Canadian Geotechnical Conference, Saskatoon, Saskatchewan, Canada, pp. 271-281.

CAEE. (1995). "The Hyogo-ken-Nanbu (Kobe) earthquake of 17 January 1995," Preliminary Reconnaissance Report, Canadian Association for Earthquake Engineering, Vancouver.

Finn, W. D. Liam. (1995). "Evaluation of liquefaction potential by in-situ methods," Paper presented at Earthquake Engineering and Site Characterization Workshop, USACE, Waterways Experiment Station, Vicksburg, MS, USA, June 27-28.

Kawasumi, H. (Editor-in-Chief). (1968). "General Report on the Niigata Earthquake of 1964," Tokyo Electrical Engineering College Press.

Morgenstern, N. R. and Finn, W. D. Liam. "Final report on joint Sino-Canadian investigations on earthquake safety of Chinese tailings dams," to Central Research Institute of Building Construction, Beijing, P.R. China, by the Chief Investigator, December.

Nazarian, S. and Stokoe, K. II. (1984). "In-situ shear wave velocities from spectral analysis of surface waves," Proceedings, 8th World Conference on Earthquake Engineering, San Francisco, Vol. III, pp 31-38, July 21-28. 
Robertson, P. K., Campanella, R. G., Gillespie, D. and Rise, A. (1986).

"Seismic CPT to measure in-situ wave velocity," J. Geot. Eng. Div., ASCE.

Robertson, P. K. (1990). "Seismic cone penetration testing for evaluating liquefaction potential," Proceedings, Symp. on Recent Advances in Earthquake Design Using Laboratory and In-Situ Tests, ConeTec Investigations Ltd., Burnaby, BC, February 5.

Seed, H. B., Tokimatsu, K., Harder, L. F. and Chung, R. M. (1985). "Influence of SPT procedures in soil liquefaction resistance evaluations," Journal of Geotechnical Engineering, Vol. 111, No. 12, pp 1425-1445.

Seed, H. B. et al. (1990). "Preliminary report on the principal geotechnical aspects of the October 17, 1989 Loma Prieta earthquake," Report No. UCB/ EERC-90-05, University of California, Berkeley.

Vaid, Y. P. and Chern, J. C. (1985). "Cyclic and monotonic undrained response of saturated sands," ASCE National Convention, Session - Advances in the Art of Testing Soils Under Cyclic Loading, Detroit, pp. 120-147, October $21-25$. 


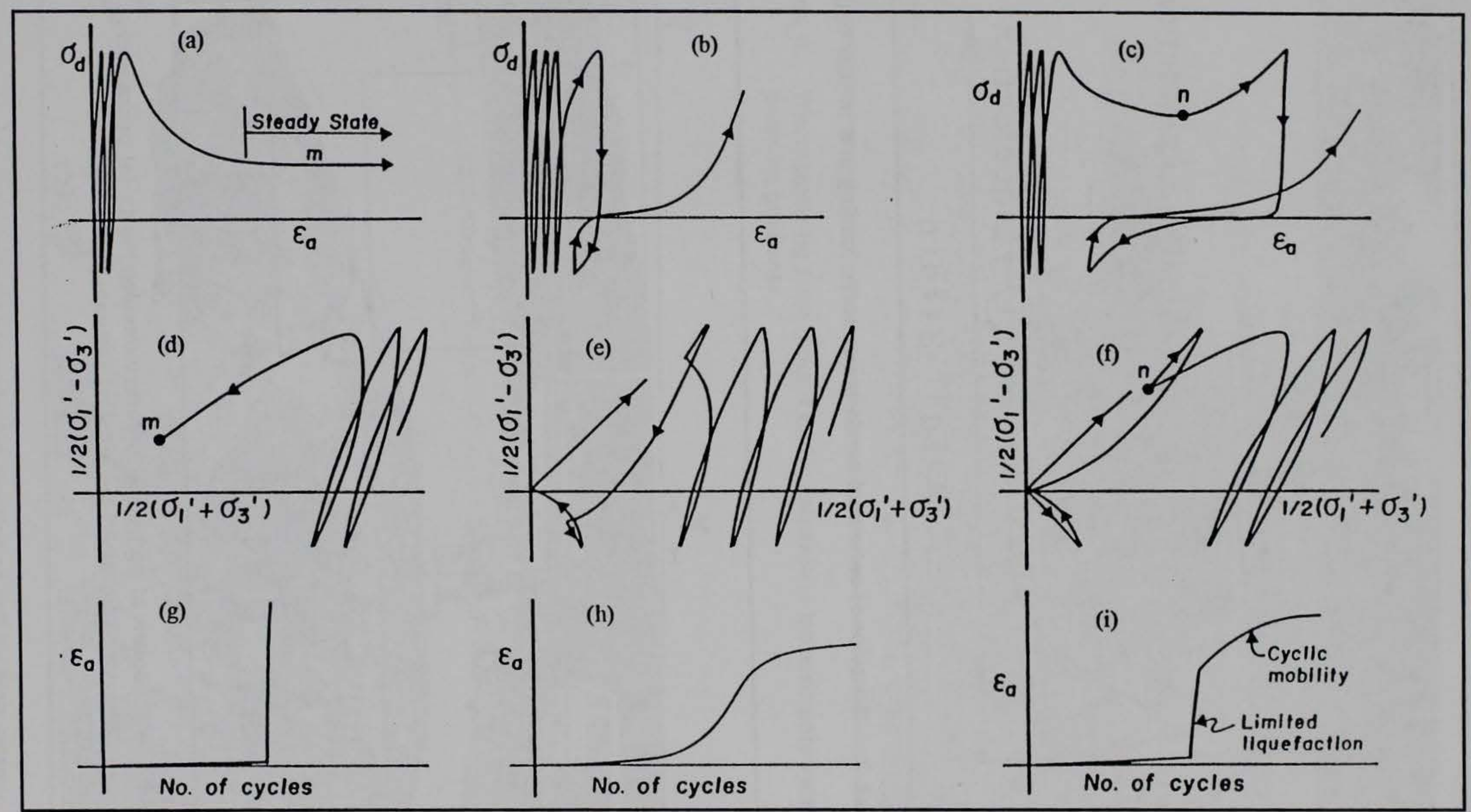

Figure 1. Definition of liquefaction, limited liquefaction, and cyclic mobility under cyclic loading (Vaid and Chern 1985) 


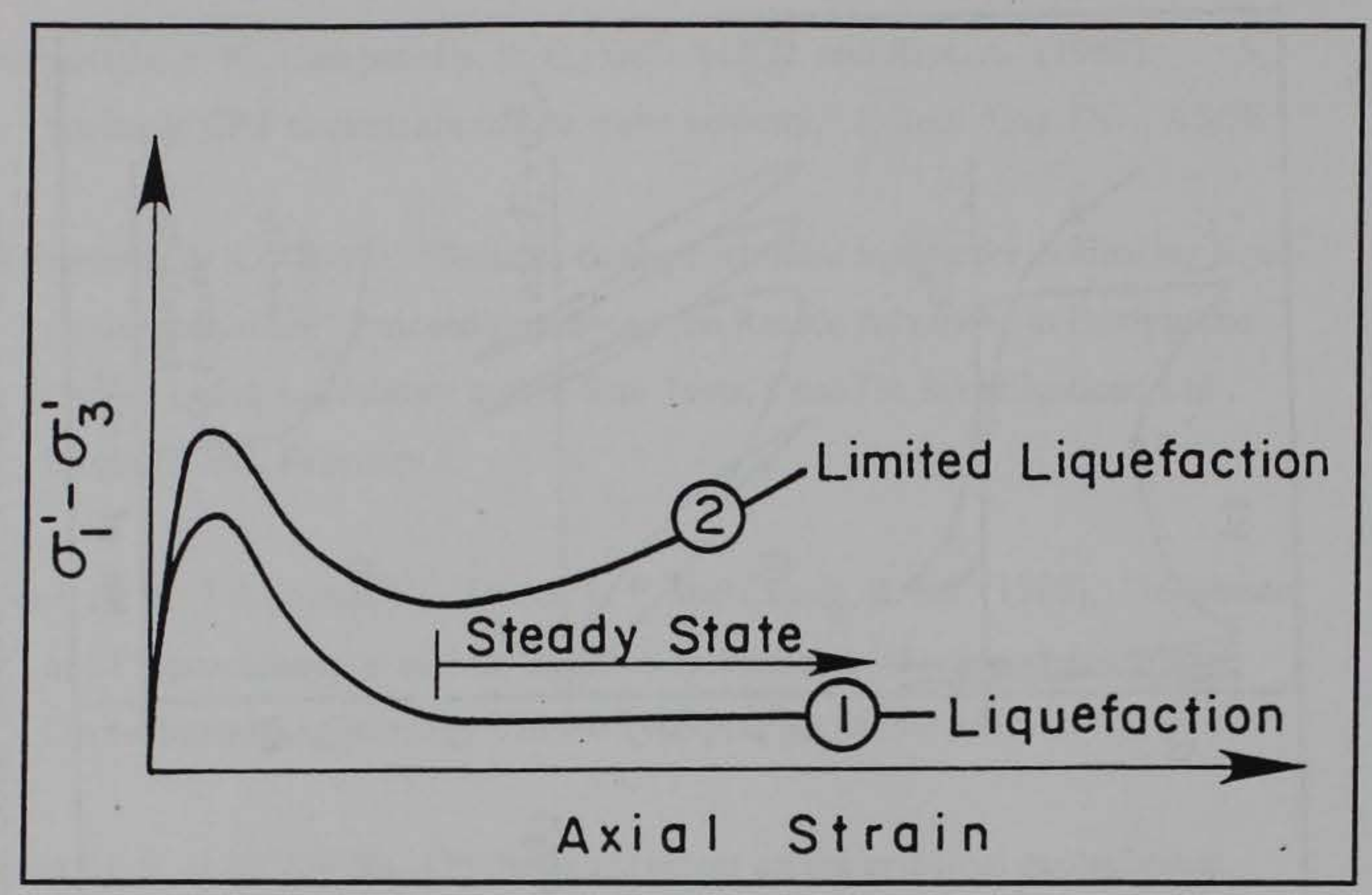

Figure 2. Behavior of saturated sands under static loading in a triaxial test

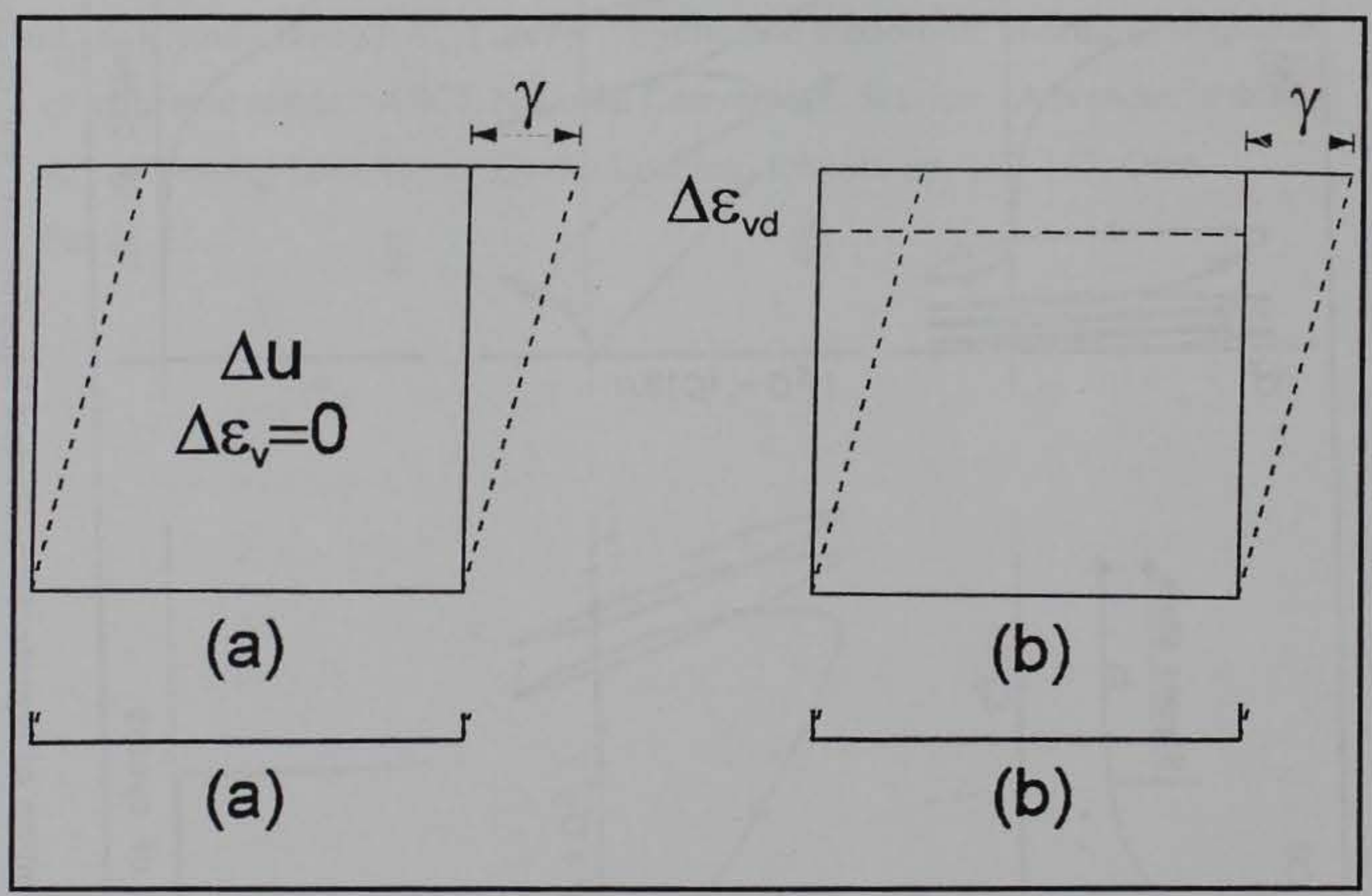

Figure 3. Mechanism of porewater pressure development: (a) undrained behavior, (b) drained behavior of saturated sand 


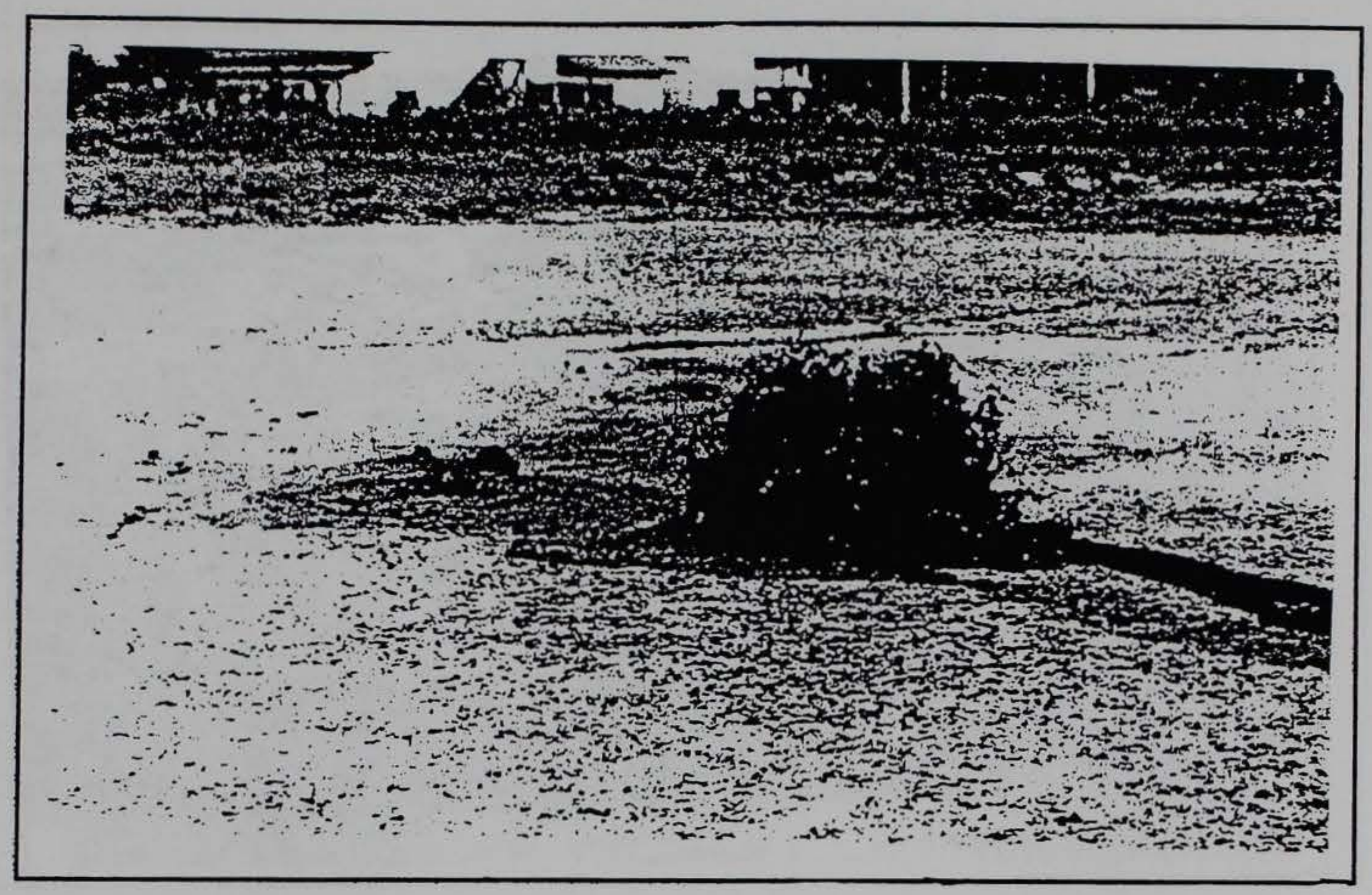

Figure 4. Water pumping from ground under seismically induced porewater pressure gradients

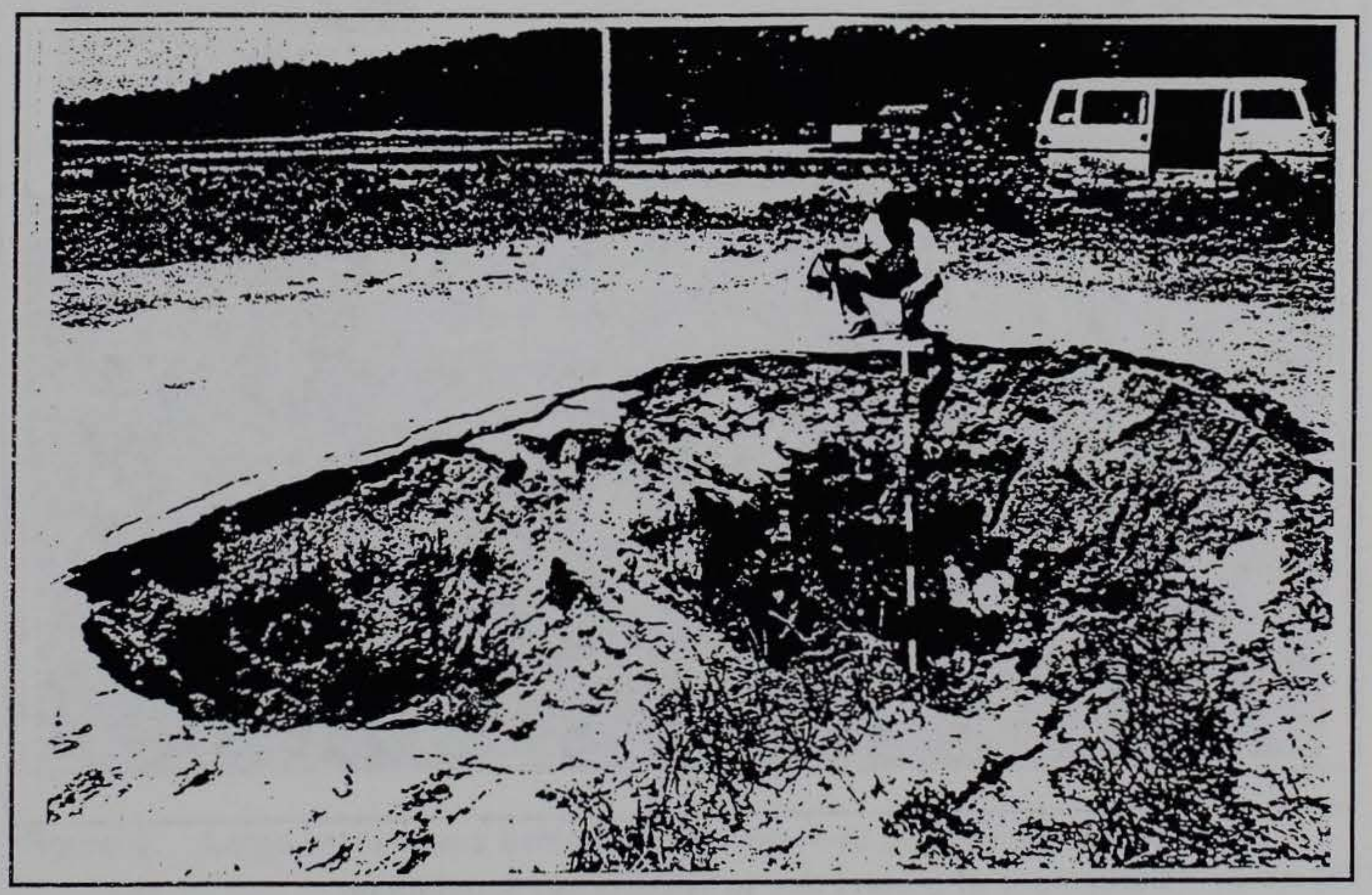

Figure 5. Huge crater caused by explosive ejection of soil by high seismic porewater pressures 


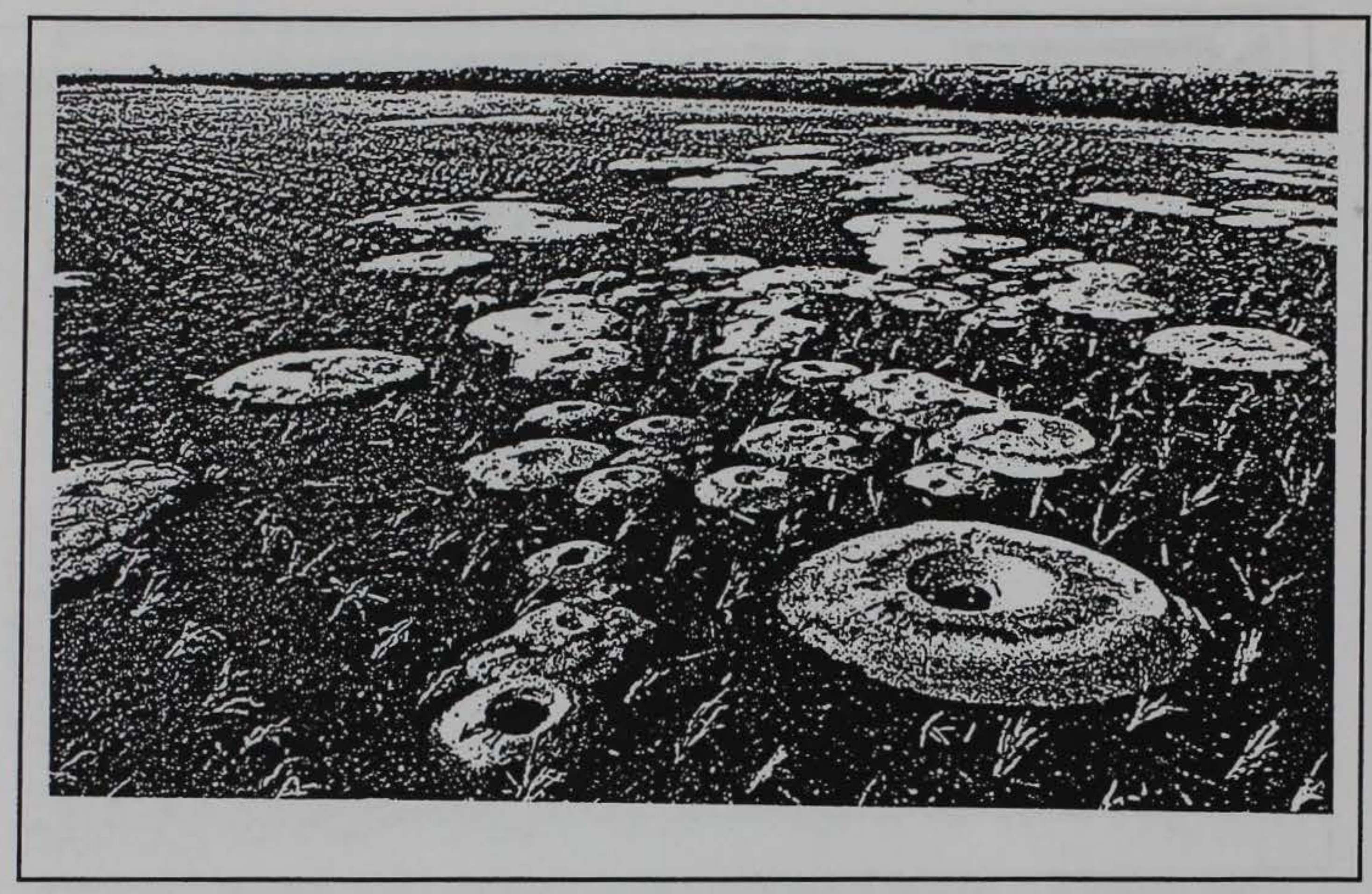

Figure 6 . Sand volcanoes caused by ejection of liquefied sand by seismic porewater pressures

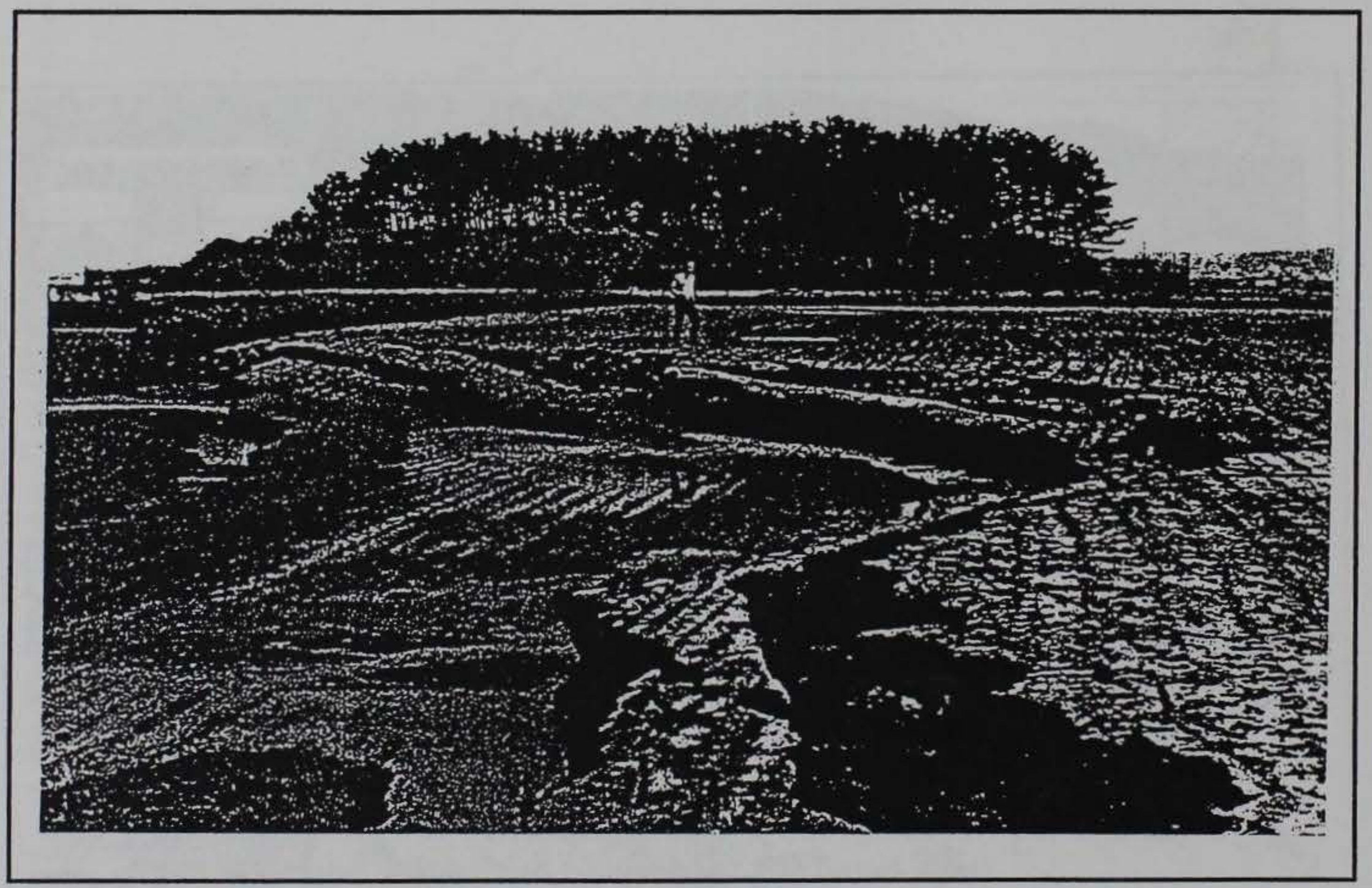

Figure 7. Settlement of ground due to widespread liquefaction 


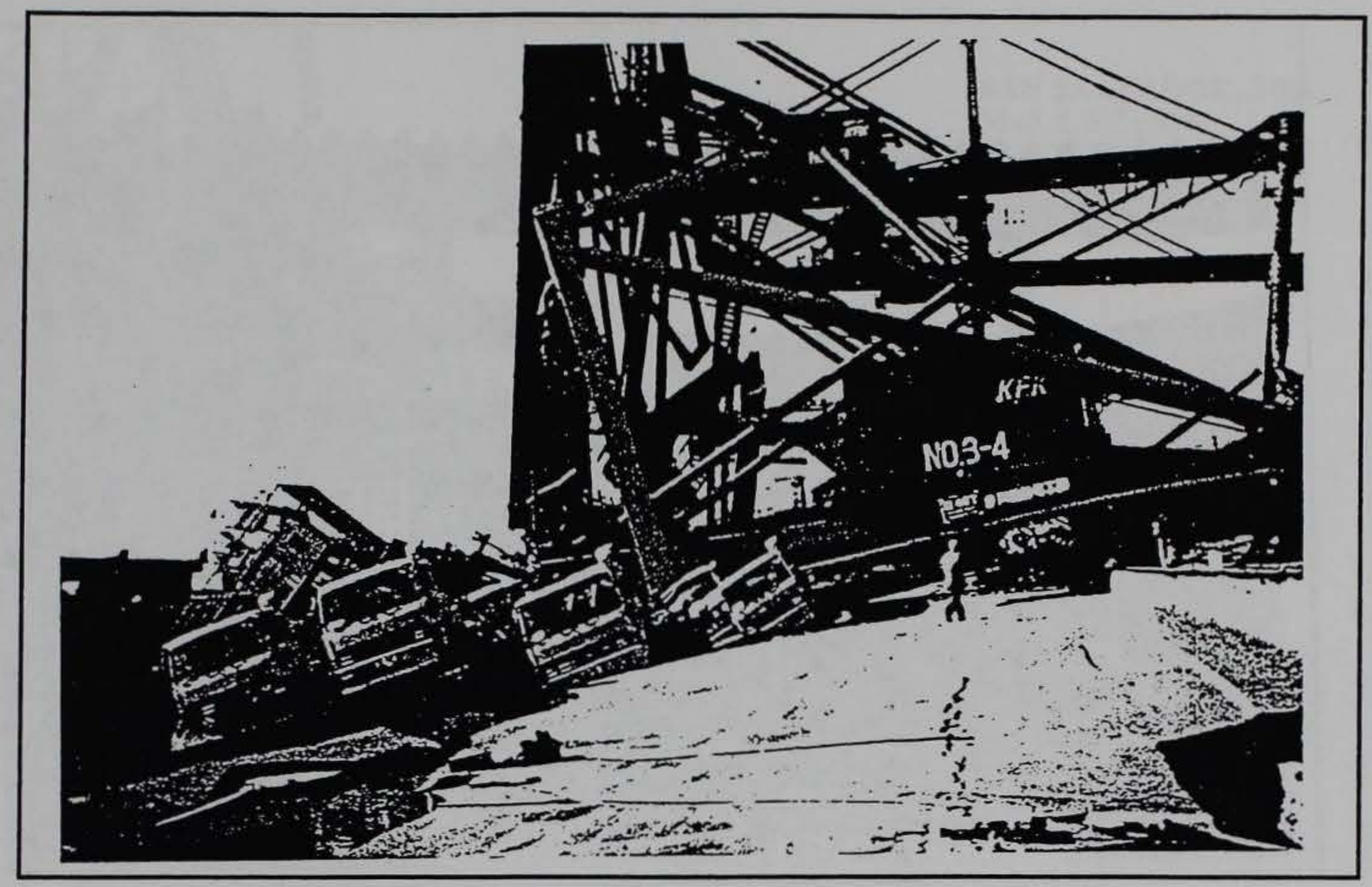

Figure 8. Large lateral movements of sea wall caisson due to liquefaction

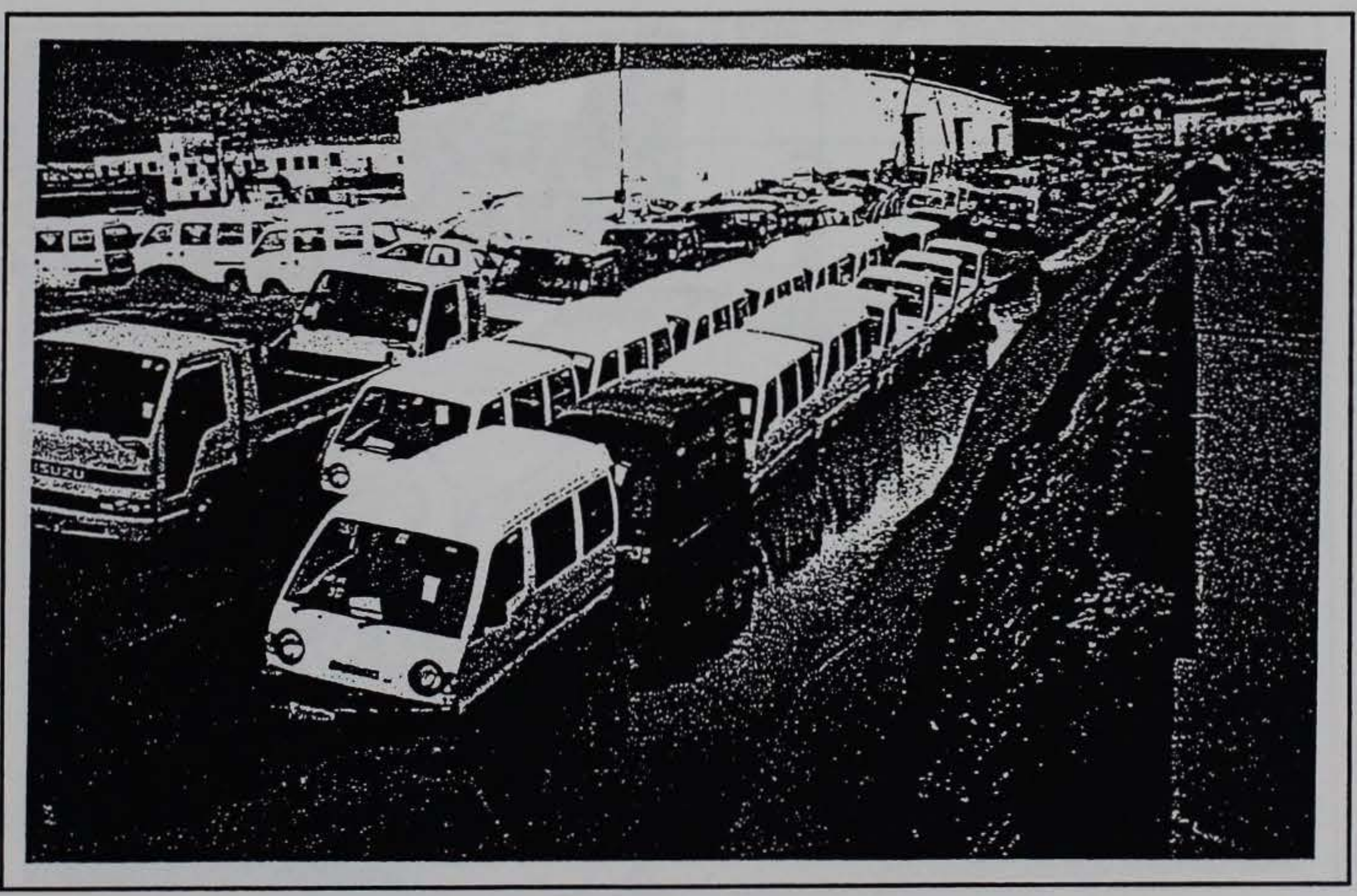

Figure 9. Large settlements behind moving sea wall due to liquefaction 


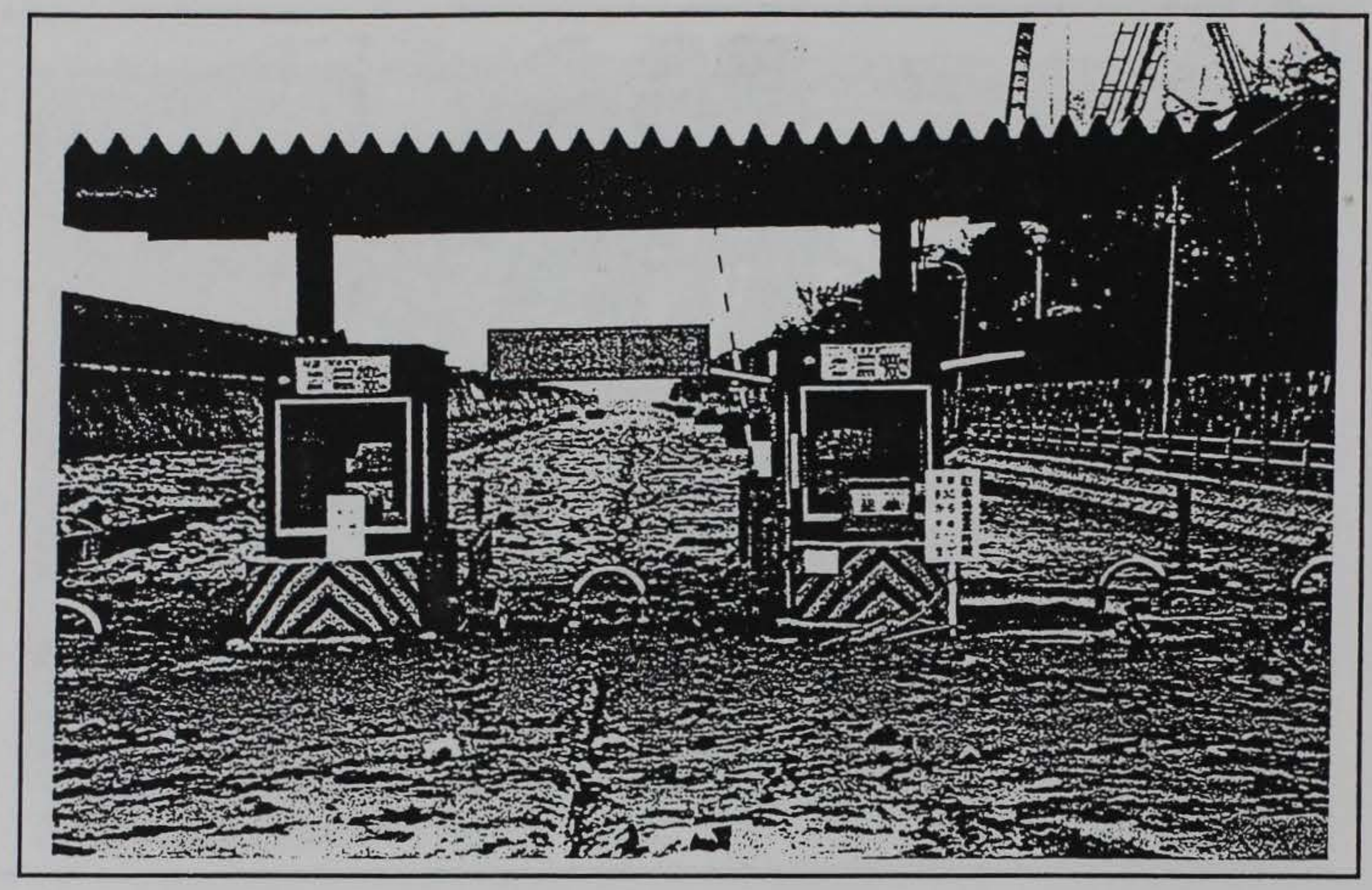

Figure 10. Widespread ejection of sand on Port Island due to liquefaction

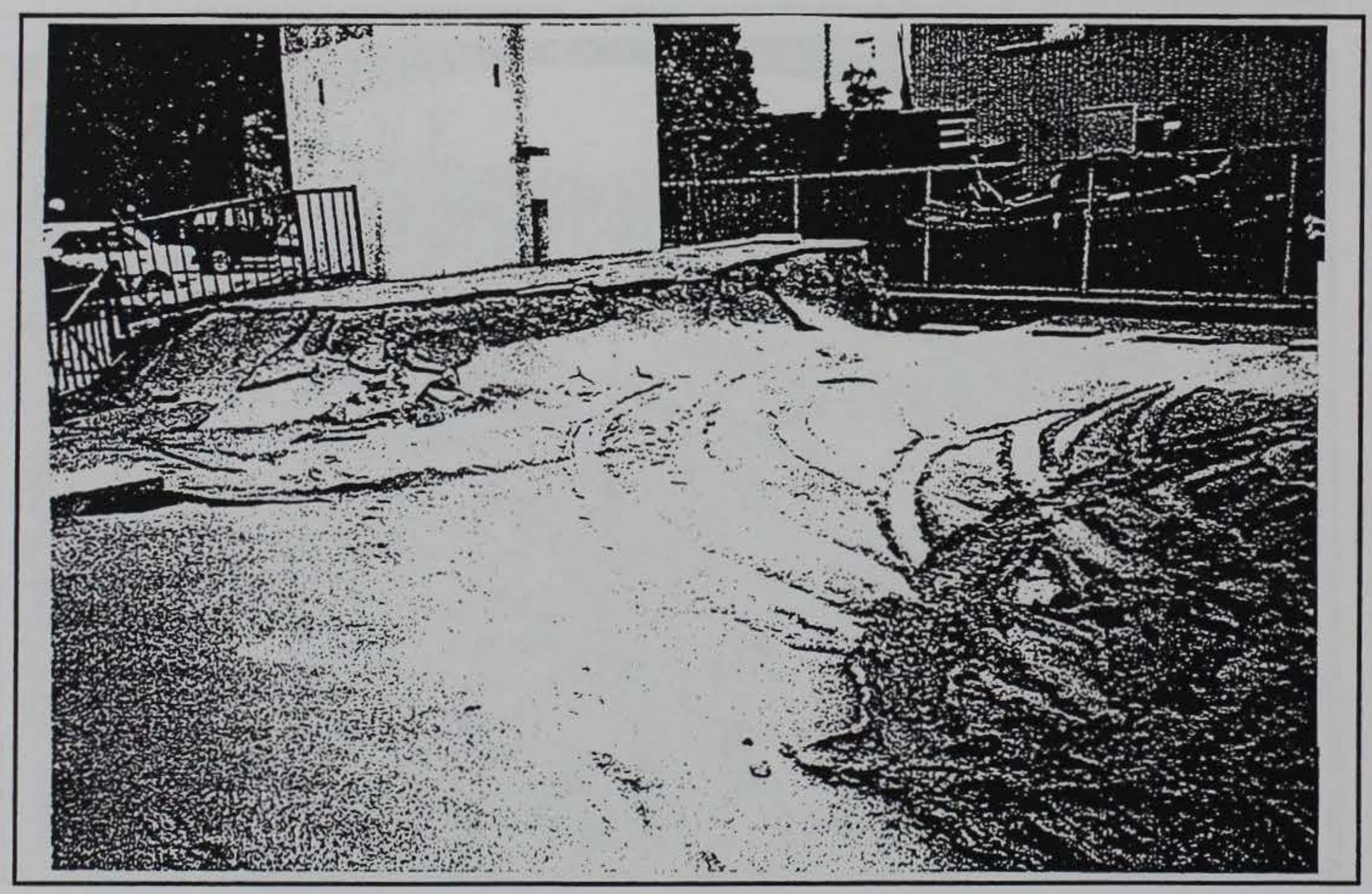

Figure 11. Typical settlement of level ground on Port Island due to liquefaction 


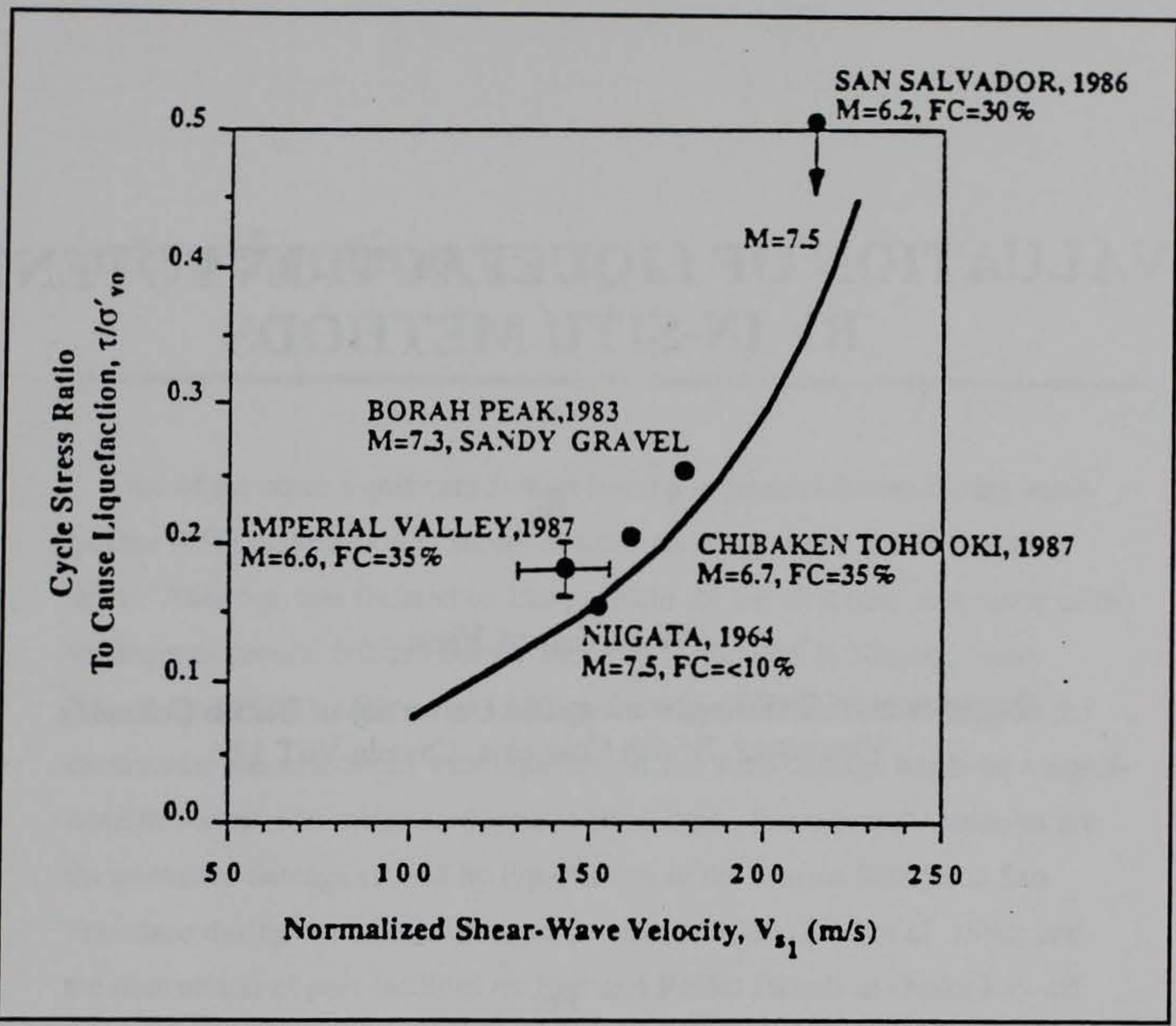

Figure 12. Liquefaction assessment chart based on normalized shear wave velocity, $\mathrm{V}_{\mathrm{sl}}$ (Robertson 1990) 


\title{
EVALUATION OF LIQUEFACTION POTENTIAL BY IN-SITU METHODS
}

\author{
By \\ W.D. Liam Finn \\ Department of Civil Engineering, The University of British Columbia \\ Vancouver, British Columbia, Canada V6T 1Z4
}

For

EARTHQUAKE ENGINEERING AND SITE CHARACTERIZATION WORKSHOP

US ARMY ENGINEERS WATERWAYS EXPERIMENT STATION

VICKSBURG, MISSISSIPPI, USA

June 27-28, 1995 


\section{Introduction}

One of the more significant factors leading to ground failure during earthquakes is the liquefaction of loose- to medium-dense sands below the water table. Attention was focused on this problem for the first time as a result of the widespread ground failures during the 1964 earthquake in Niigata, Japan (Kawasumi 1968). Most of the damage in Niigata attributable directly to the earthquake was associated with liquefaction and such damage has been a significant factor in most major earthquakes since then. Some recent examples are the extensive damage caused by liquefaction in the Marina District in San Francisco during the Loma Prieta earthquake of 1989 (Seed et al. 1990) and the destruction of port facilities on Port and Rokko Islands in Osaka Bay off Kobe City, during the 1995 Hyogo-ken-Nanbu earthquake.

The mechanics of liquefaction are now well understood and the potential for occurrence can be estimated with a reasonable degree of confidence. During shaking the sand tends to compact. The water in the pores cannot escape quickly enough, at least in the finer sands, to accommodate the compaction instantaneously. Therefore, stresses are thrown on the water which increase the porewater pressure and reduce the effective or intergranular stresses between the sand particles. Sand, a frictional material, depends on the effective stresses between the grains to mobilize shear strength and resistance to displacement.

The resistance to shearing strain or deformation is also reduced by increasing porewater pressure. The shear modulus $\mathrm{G}$ which controls the shearing strains is a function of the mean normal effective stress. Therefore, as the seismic porewater pressures increase the shear modulus decreases. In the 
extreme case, such as in Niigata, where nearly all shear strength and shear stiffness was lost at some sites, the sand behaved like a liquid, with disastrous consequences for structures.

Figure 1 illustrates the response of granular soils to cyclic loading in triaxial tests. The test specimens were prepared to relative densities that covered the range of sand states from highly contractive to highly dilative under shearing deformation (Vaid and Chern 1985). All test specimens carry initial static shear stresses, $\tau_{\mathrm{st}}$. This simulates the most common situation in earth structures and under foundations. Contractive stress-strain response is shown in Figure la. At some stage in the cyclic loading, strain softening occurs leading to a large drop in undrained strength which then remains constant at the undrained residual strength of the soil over a large range in strain.

Large deformations occur when $\tau_{\mathrm{st}}$ is greater than the steady state strength $\tau_{\mathrm{ss}}$ (or $S_{\mathrm{us}}$ ). Deformations may also be significant when $\tau_{\mathrm{st}}<\tau_{\mathrm{ss}}$ if $\tau_{\mathrm{st}}+\tau_{\mathrm{cy}}>$ $\tau_{\mathrm{ss}}$ where $\tau_{\mathrm{cy}}$ is the cyclic shear stress. The phenomenon of large deformations occurring at constant undrained strength is termed liquefaction.

At the other extreme the sand is strongly dilative and deformation is the result of progressive stiffness degradation in the sand due to the build up in porewater pressure with cycles of loading. This phenomenon is called cyclic mobility and is illustrated in Figure 1c.

Between these two clearly defined states is a transitional region combining features of both contractive and dilative response. This type of behavior is characterized by a loss in undrained strength due to strain softening over a limited range followed by a regain of undrained strength. Further deformations result from cyclic mobility. This behavior is illustrated in Figure lb. The deformation patterns of these sands are shown together in Figure 1(d).

A flow chart for assessment of the effects of various cyclic loading conditions is given in Figure 2. 
The magnitude of potential deformations at a liquefied site with contractive behavior depends on the extent to which the driving shear stresses exceed the residual strength. The residual strength therefore is a key parameter controlling the extent and cost of remedial measures to limit deformations to tolerable levels.

In engineering practice the word liquefaction is usually associated with the development of high porewater pressures due to seismic loading irrespective of whether large deformations occur or not. Indeed the empirical procedures for assessing liquefaction potential are all based primarily on surface manifestations of high porewater pressure such as sand boils without consideration of whether the soil would behave in a contractive or dilative mode during shearing.

In this paper, procedures will be presented for determining the potential for triggering liquefaction and for estimating residual strength. 


\section{Empirical Assessment of Liquefaction}

The potential for triggering liquefaction is evaluated using procedures based on the standard penetration test, cone tip penetration resistance and normal shear wave velocity. The procedures involves three steps:

a. Characterizing the dynamic effects of the earthquake.

b. Characterizing the in situ state of the soil.

c. Application of a criterion for the incidence of soil liquefaction.

\section{Characterizing the Earthquake}

Seismic shear stresses play a major role in the development of liquefaction. Time histories of shear stresses are usually very non-uniform and are difficult to apply in empirical methods. Seed (1983) suggested replacing the irregular time history by an equivalent number of uniform cycles and normalizing the shear stresses by dividing by the effective overburden stress. Seed proposed that this uniform cyclic shear stress ratio (CSR) be determined by:

$$
\operatorname{CSR}=\frac{\tau_{u}}{\sigma_{\Lambda>}^{\prime}}=0.65 \frac{\sigma_{\Lambda}}{\sigma_{\Lambda>}^{\prime}} \frac{a_{\jmath \underline{ }}}{g} r_{c}
$$


where

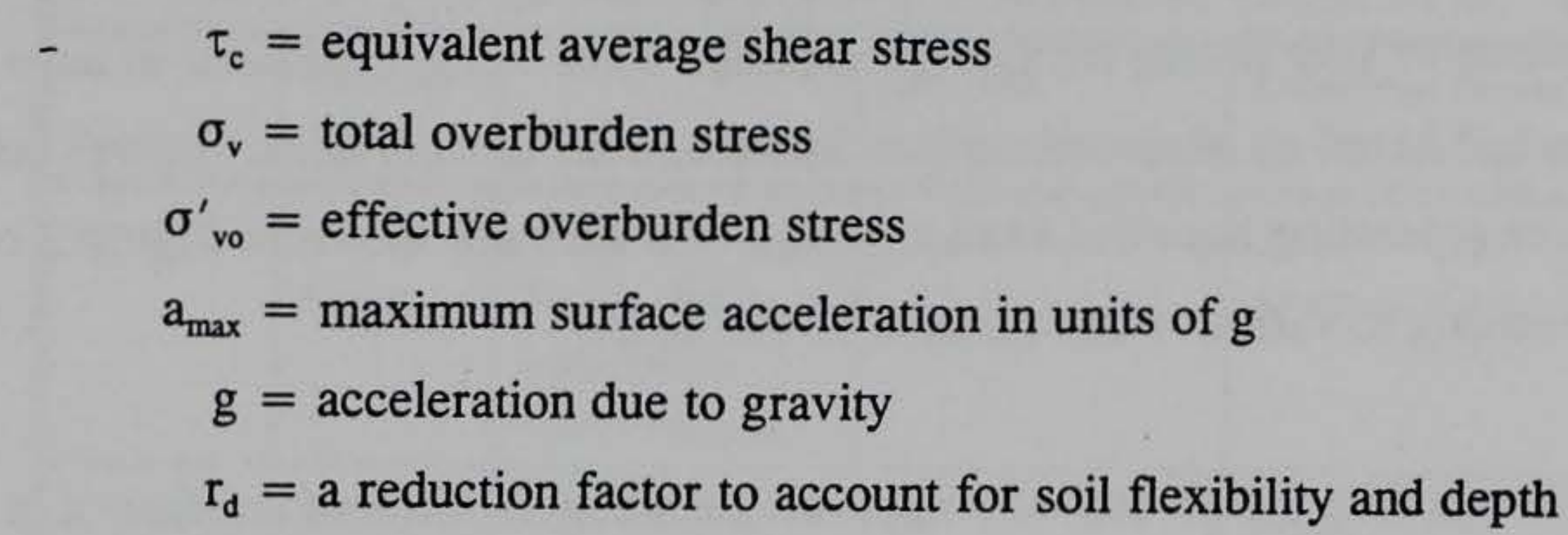

In Japanese practice the reduction factor $r_{d}$ is often approximated using the following expression:

$$
r_{c}=(1-0.015 Z)
$$

where $\mathrm{Z}=$ depth in meters.

\section{Characterizing the In Situ State of the Soil}

The in situ state of the soil can be characterized by in situ testing or by testing. undisturbed samples obtained from boreholes or test pits. Granular soils are extremely difficult to sample without disturbance. Hence, methods to characterize the soil in the ground rely heavily on in situ tests. The most widely used methods are the standard penetration test (SPT) and the cone penetration test with pore pressure measurement (CPTU).

\section{Standard Penetration Test (SPT)}

Seed and his colleagues (Seed 1979, Seed et al. 1983, and Seed et al. 1985) developed correlations between the SPT N-value and the cyclic stress ratio to 
cause liquefaction $\left(\mathrm{CSR}_{\text {cri }}\right)$ during earthquakes of magnitude $\mathrm{M}=7.5$. The correlations which are presented in Figure 3, were based on the observed response of sites during earthquake loading. Sites were considered to have liquefied based on observed surface features, such as sand boils. Lower bound curves separating liquefied from non-liquefied sites are shown in Figure 3 corresponding to various fines contents of the sands.

To compare the ground conditions at one site with those of another, it is necessary to standardize the measured penetration values to a standard driving energy and effective overburden pressure. Seed normalized the SPT to an energy level of 60 percent of the free-fall potential energy of the hammer and an effective overburden pressure of $100 \mathrm{kPa}$ (1 tsf). Hence, the correlations presented in Figure 3 show the normalized SPT N value, $\left(\mathrm{N}_{1}\right)_{60}$.

The correction for energy level may be made using the data in Table 1 or by direct measurement of the energy imparted to the rods.

The correction factors $\mathrm{C}_{\mathrm{N}}$ for overburden pressure may be determined using the curves in Figure 4 which allow for the effects of relative density or by using the equation (Liao and Whitman 1985),

$$
C,=1 / \sqrt{\sigma_{1}^{\prime}}
$$

where $\sigma^{\prime}{ }_{\text {vo }}$ is expressed in tons/per/sq ft.

The use of equation (3) which ignores any effects of relative density is becoming common. Judgment is required in limiting the maximum value of the correction factor. Generally the upper limit is taken as 2.0. 


\begin{tabular}{|c|c|c|c|c|}
\hline \multicolumn{5}{|c|}{$\begin{array}{l}\text { Table } 1 \\
\text { Summary of Energy Ratios for SPT Procedures (Seed et al. 1985) }\end{array}$} \\
\hline Country & \begin{tabular}{|l|} 
Hammer \\
Type \\
\end{tabular} & Hammer Release & $\begin{array}{l}\text { Est. Rod } \\
\text { Energy (percent) } \\
\end{array}$ & $\begin{array}{l}\text { Correction Factor for } \\
60 \text { percent Rod Energy } \\
\end{array}$ \\
\hline Japan' & $\begin{array}{l}\text { Donut } \\
\text { Donut }\end{array}$ & $\begin{array}{l}\text { Free-Fall } \\
\text { Rope \& Pulley } \\
\text { with Special } \\
\text { Throw Release }\end{array}$ & $\begin{array}{l}78 \\
67\end{array}$ & $\begin{array}{l}78 / 60=1.30 \\
67 / 60=1.12\end{array}$ \\
\hline U.s. & $\begin{array}{l}\text { Safety } \\
\text { Donut }^{2} \\
\end{array}$ & $\begin{array}{l}\text { Rope \& Pulley } \\
\text { Rope \& Pulley }\end{array}$ & $\begin{array}{l}60 \\
45 \\
\end{array}$ & $\begin{array}{l}60 / 60=1.00 \\
45 / 60=0.75\end{array}$ \\
\hline Argentina & Donut & Rope \& Pulley & 45 & $45 / 60=0.75$ \\
\hline China & $\begin{array}{l}\text { Donut } \\
\text { Donut }\end{array}$ & $\begin{array}{l}\text { Free-Fall }{ }^{3} \\
\text { Rope \& Pulley }\end{array}$ & $\begin{array}{l}60 \\
50\end{array}$ & $\begin{array}{l}60 / 60=1.00 \\
50 / 60=0.83\end{array}$ \\
\hline $\begin{array}{l}1 \text { Japanes } \\
\text { effects. } \\
2 \text { Prevale } \\
3 \text { Pilcon-t } \\
\end{array}$ & $\begin{array}{l}\text { PT resul } \\
\text { ethod in } \\
\text { hammer } \\
\end{array}$ & $\begin{array}{l}\text { ave additional co } \\
\text { United States t } \\
\text { velop and energ }\end{array}$ & $\begin{array}{l}\text { ctions for borehol } \\
\text { atio of about } 60 p \\
\end{array}$ & $\begin{array}{l}\text { meter and frequency } \\
\text { nt. }\end{array}$ \\
\hline
\end{tabular}

The correlations shown in Figure 3 are representative of earthquakes with a magnitude $M=7.5$. The critical correlations for earthquakes of other magnitudes may be established by multiplying the critical cyclic stress ratios by the magnitude dependent correction factors in Table 2 (Seed and Harder 1990).

\begin{tabular}{|c|c|c|}
\hline \multicolumn{3}{|c|}{$\begin{array}{l}\text { Table } 2 \\
\text { Correction Factors for Magnitude }\end{array}$} \\
\hline Earthquake Magnitude (M) & $\begin{array}{l}\text { No. of Representative Cycles } \\
\text { at } 0.65 \mathrm{~T}_{\mathrm{c}}\end{array}$ & $\begin{array}{l}\text { Magnitude or Duration } \\
\text { Correction Factor: } \mathrm{C}_{\mathrm{M}}\end{array}$ \\
\hline 8.5 & 26 & 0.89 \\
\hline 7.5 & 15 & 1.0 \\
\hline 6.75 & 10 & 1.13 \\
\hline 6.0 & $5-6$ & 1.32 \\
\hline 5.25 & $2-3$ & 1.5 \\
\hline
\end{tabular}

There are two important limitations associated with Figure 3. The field data correspond to level ground conditions with no initial static shear stresses on 
horizontal planes and to effective overburden pressures less than $150 \mathrm{kPa}$.

Seed (1983) outlined procedures for making corrections when these conditions are violated.

The first estimate of the liquefaction resistance of a soil element in a dam or slope is determined using the in situ $\left(\mathrm{N}_{1}\right)_{60}$ penetration resistance and the appropriate curve for critical conditions in Seed's liquefaction assessment chart.

This resistance must then be corrected for deviations from the standard conditions of the database underlying the chart. A typical element in a slope, for example, will carry a static shear stress $\tau_{\mathrm{st}}$ on the horizontal plane and therefore has an initial shear stress ratio $\tau_{\mathrm{st}} / \sigma^{\prime}{ }_{0}=\propto$. A correction factor $\mathrm{K}_{\alpha}$ is established for various values of $\propto$ by laboratory tests. As an illustration, the $\mathrm{K}_{\alpha}$ factor for Folsom gravels is shown in Figure 5 (Hynes et al. 1988). Note that, as is commonly assumed in practice, initial static shear increases liquefaction resistance substantially. However, this increase applies to resistance to cyclic mobility rather than to liquefaction, that is to non-contractive materials.

Vaid and Chern (1985) have shown for contractive materials that initial static shear decreases the resistance to cyclic loading. This suggests that for contractive soils, the cyclic strength should be reduced not increased for the effects of static shear. $\mathrm{K}_{\alpha}$ factors less than unity have been reported by Marcuson et al. (1990) and Seed and Harder (1990). Typical values of $K_{\alpha}$ may be found in Figure 6 for a range in relative densities.

For effective overburden pressures other than in the range $100-150 \mathrm{kPa}$, a correction factor $\mathrm{K}_{\mathrm{o}}$ is used. Values of $\mathrm{K}_{\mathrm{o}}$ for many soils are shown in Figure 7. Increasing confining pressure can lead to a substantial reduction in resistance to cyclic loading (Seed and Harder 1990). However, Vaid and Thomas (1994) have shown (Figure 8) that for some sands the reductions are much smaller than those given by the generalized average reduction curve in Figure 7 which is commonly used in practice. $\mathrm{K}_{\mathrm{o}}$ data derived from tests on sands from the foundations of Duncan Dam confirmed that the average curve in Figure 7 may be very conservative in some cases (Byrne et al. 1993). These 
findings suggest that for important projects, site specific values of $\mathrm{K}_{\mathrm{o}}$, and $\mathrm{K}_{\alpha}$ should be determined.

\section{Cone Penetration Test (CPI)}

Electric cone tip penetration resistance $\left(Q_{c}\right)$ has been measured at few sites as yet where the occurrence or nonoccurrence of liquefaction during actual earthquakes have been documented. Therefore the data base on cone penetration resistances at liquefied sites has been extended by converting the well documented correlation between liquefaction potential and standard penetration resistance to cone penetration resistance.

There has been a number of studies on the correlation between cone resistance and standard penetration resistance (Douglas et al. 1981, Robertson et al. 1983). Figure 9 indicates that the ratio of cone resistance to blowcount increases with increasing mean grain diameter (Robertson et al. 1983).

The liquefaction assessment chart in Figure 3 based on $\left(\mathrm{N}_{1}\right)_{60}$ can now be converted to a chart based on $Q_{c 1}$ as shown in Figure 10 , where $Q_{c 1}$ is the tip penetration resistance normalized to $100 \mathrm{kPa}$ ( $1 \mathrm{tsf}$ ) using either Figure 4 or Equation 3. Cyclic strength must be corrected for initial static shear stress $\left(\mathrm{K}_{\alpha}\right)$ and overburden pressure $\left(\mathrm{K}_{c}\right)$ in the same manner as $\left(\mathrm{N}_{1}\right)_{60}$.

\section{Fines Content}

Seed et al. (1985) reviewed sites that did and did not liquefy during earthquakes where the fines content was greater than 5 percent. They found that for the same penetration resistance the liquefaction resistance increased with increasing fines content (Figures 3 and 10). 
The field data in Figure 3 shows a strong dependency of liquefaction resistance on fines content. But, surprisingly, there appears to be considerable confusion about the effect of fines on liquefaction resistance. Part of the problem depends on the manner on which the comparison is made. In the case of the field data, for the same normalized penetration resistance $\left(\mathrm{N}_{1}\right)_{60}$ the liquefaction resistance increases with increasing fines content. What the soils being compared have in common is the $\left(\mathrm{N}_{1}\right)_{60}$ value. If the basis for comparison is changed the conclusion may well be different. For example, Troncoso (1990) compared the cyclic strength of tailings sands with different silt contents ranging from 0 to 30 percent at a constant void ratio. On this basis of comparison he found that cyclic strength decreased with increased silt content (Figure 11). Kuerbis and Vaid (1989) studied the effects of fines using samples deposited in a manner that replicated field deposition conditions. They found for the sand tested that up to 20 percent fines could be accommodated within the sand skeleton and that samples with the same sand skeleton void ratio had the same cyclic strength for fines content less than 20 percent.

The different methods for considering the effects of fines are summarized in Table 3.

\begin{tabular}{|l|l|}
\hline $\begin{array}{l}\text { Table } 3 \\
\text { Effects of Fines on Cyclic Strength }\end{array}$ \\
\hline \hline Criterion of Equivalency Clean and Silty Sand & Effect of Fines on Cyclic Strength \\
\hline \hline 1. Same $\left(\mathrm{N}_{1}\right)_{60}$ & Increase \\
\hline 2. Same void ratio & Decrease \\
\hline 3. Same void ratio in sand skeleton & $\begin{array}{l}\text { No change while fines content can be } \\
\text { accommodated in sand voids }\end{array}$ \\
\hline
\end{tabular}

Another way of looking at the field data is to note that the penetration resistance of silty sands is somewhat lower than for clean sands at the same cyclic strength. Corrections based on the curves in Figure 3, can be applied to the $\left(\mathrm{N}_{1}\right)_{60}$ values measured in silty sands and then the curve for clean sands may be 
used to determine cyclic strength for the corrected $\left(\mathrm{N}_{1}\right)_{60}$ value. Such corrections have been widely used.

Corrections to the normalized cone penetration resistance with fines $\left(\mathrm{Q}_{\mathrm{c} 1}\right)_{\mathrm{f}}$ can be established from Figure 10. These may be used to adjust cone penetration resistance data from test sites to cone penetration resistances of clean sands with similar liquefaction potential. The correction is given by

$$
Q_{u n}=\left(Q_{u}\right)_{s}+\Delta Q_{u n}
$$

where $\Delta \mathrm{Q}_{\mathrm{cl}}$ are given in Figure 12, from Robertson (1990).

It is possible to estimate the fines content (FC) directly from CPT and/or CPTU (CPT with porewater pressure measurements) data. Figure 13 presents the latest soil classification chart based on normalized CPT and CPTU data. Soils that fall in zone 6 are generally clean sands or silty sands with a small amount of fines. Soils that fall in zone 5 are silty sands and sandy silts that generally have fines contents greater than about 15 percent.

Based on data collected in the Richmond area of the Fraser Delta of British Columbia a correlation has been established by Finn et al. (1989) between fines content and the time for 50 percent dissipation $\left(\mathrm{T}_{50}\right)$ of the pore pressures developed during penetration (Figure 14). The results in Figure 14 suggest that for $T_{50}>50 \mathrm{sec}$ the fines content is greater than 40 percent. For $T_{50}$ between $10 \mathrm{sec}$ and $50 \mathrm{sec}$ the cone penetration process is partially drained and there is a poor correlation between $\mathrm{T}_{50}$ and fines content.

If the fines are plastic, criteria based on field data from Chinese earthquakes must be taken into account (Wang 1979) to determine if the soil will liquefy. 


\section{Liquefaction Potential of Plastic Fine-Grained Soils}

Liquefaction potential of plastic fine-grained soils are determined using the Chinese criteria developed by Wang (1979). These criteria are:

a. Percent finer than $0.005 \mathrm{~mm} \leq 15$ percent.

b. Liquid limit, $\mathrm{LL} \leq 35$ percent.

c. Natural water content $\geq 0.9 \mathrm{LL}$.

d. Liquidity index, $\mathrm{I}_{\mathrm{w}} \geq 0.75$.

Soils which satisfy all four criteria are judged vulnerable to liquefaction or significant strength loss. In addition, any fine grained soils for which the standard penetration resistance $\mathrm{N} \leq 4$ are considered to be vulnerable to liquefaction or to significant strength loss under cyclic loading whether or not they satisfy the Chinese criteria (Woodward Clyde Consultants 1989). The Chinese criteria are usually applied strictly with no account taken of uncertainties in the measurements of the parameters in the criteria.

In connection with investigations of the liquefaction potential of Sardis Dam in Mississippi (Finn et al. 1990b), Woodward Clyde Consultants (1989) suggested that allowances should be made for uncertainties in the measured values of the parameters in the criteria. Following a study of Wang's database, they 
recommended ignoring the liquidity index and malting the following changes in the measured soil properties before applying the criteria:

a. Decrease per cent fines by 15 percent.

$b$. Decrease LL by 5 percent.

c. Increase water content by 3 percent.

These changes increased significantly the extent of the soils vulnerable to liquefaction and strength loss so that almost the entire length of dam required remediation. Therefore, engineers of the Vicksburg District of the U.S. Army Corps of Engineers, who are responsible for the safety assessment and remediation of Sardis Dam, reviewed reports on the scatter in measured index properties in U.S. Corps of Engineers' laboratories over the last 30 years to determine the likely range of variations in test data. In addition they conducted tests on samples of standard soils of low to medium plasticity in their own laboratory to establish the scatter in their own data. These standard soils are used to check comparability of testing procedures and results between different Corps of Engineers, laboratories and private laboratories. As a result of these studies the following changes in measured properties were adopted before applying the Chinese criteria (again ignoring the liquidity index):

a. Decrease the fines content by 5 percent.

b. Decrease the liquid limit by 2 percent.

c. Increase the water content by 2 percent.

This change reduced the length requiring remediation to about $1220 \mathrm{~m}$ $(4000 \mathrm{ft})$.

The impact of the Chinese criteria on the extent of remediation necessary for stability appeared to be so critical that an investigation of Chinese proce- 
dures was undertaken by Koester (1990). The Chinese determine the liquid limit using a fall cone rather than the Casagrande device generally used in North America. Using a standard Chinese fall cone and following Chinese standard SD 128-007-84, Koester (1990) showed that the fall cone gives a liquid limit about 3 percent to 4 percent greater than the Casagrande device. He continued the study of the Chinese criteria for liquefaction and reported his final conclusions in Koester (1992).

On the basis of all the above studies the following changes in measured index properties were finally adopted to account for uncertainty before application of the Chinese criteria:

a. Decrease the fines content by 5 percent.

b. Increase the liquid limit by 1 percent.

c. Increase the water content by 2 percent.

These changes reduced the length requiring remediation to about $926 \mathrm{~m}$ $(3000 \mathrm{ft})$.

Clearly the Chinese criteria for evaluating the potential for liquefaction or significant strength loss in clayey soils, based on liquid limit, water content and percent fines $\leq 0.005 \mathrm{~mm}$, can have a major impact on the extent of remedial measures necessary to achieve stability in earth structures with potentially liquefiable fine grained materials.

Before applying the Chinese criteria the uncertainties in the measured soil properties should be taken into account in a reasonably conservative manner. This may be done by adjusting the measured water content, liquid limit, and the fines content before applying the criteria. The amount of these adjustments should be based preferably on the estimated variability in data appropriate for the laboratory conducting the tests. In the absence of such specific information, the adjustments noted above of increasing the liquid limit by 1 percent, 
the water content by 2 percent, and decreasing the fines content by 5 percent may be considered. These adjustments reflect conservative estimates of the variability to be expected from very experienced personnel operating under high standards of quality control. 


\section{Liquefaction Assessment from Shear Wave Velocity}

Empirical methods have been developed to evaluate liquefaction resistance directly from shear wave velocity (Bierschwale and Stokoe 1984). Over the past 15 years, significant advances have been made in measuring shear wave velocities in the field. Accurate and detailed profiles can be determined with conventional crosshole and downhole seismic methods (Stokoe and Hoar 1978, Woods 1978). Shear wave velocity, $V_{s}$ is influenced by many of the variables that influence liquefaction potential, such as, soil density, confinement, stress history and geologic age. Thus, $\mathrm{V}_{\mathrm{s}}$, has promise as a field index in evaluating liquefaction susceptibility. The most significant advance in recent years has been the development of the seismic cone penetration test (Robertson et al. 1986) which allows the measurement of seismic velocity in conjunction with penetration resistance.

The major advantage of using shear wave velocity as an index of liquefaction resistance is that it can be measured in soils that are hard to sample such as cohesionless silts and sands or hard to penetrate such as gravels.

\section{Direct Shear Wave Velocity Correlations}

The limiting shear wave velocities separating liquefied from non-liquefied sites for a given intensity and duration of shaking must be determined from field data. So far the data base is quite limited but it clearly shows that shear 
wave velocity may be a useful index of liquefaction potential. Data from sites in the Imperial Valley, California which liquefied during the 1979 Imperial Valley, 1981 Westmorland and 1987 Superstition Hills earthquakes suggest that the limiting shear wave velocity separating liquefiable from nonliquefiable sites is about $140 \mathrm{~m} / \mathrm{s}$ for earthquakes of local magnitude $\mathrm{M}_{\mathrm{L}}=6.5$ generating peak ground accelerations of about $0.17 \mathrm{~g}$ (Holzer et al. 1988, Youd and Wieczorak 1984).

Shear wave velocity is a function of void ratio and effective confining stress. Hence, for a sand of constant void ratio (constant density) the shear wave velocity will increase with increasing depth. Therefore, a correlation between $V_{s}$ and CSR to cause liquefaction should be based on normalized effective overburden stress, similar to the manner in which penetration resistance is normalized with depth. Shear wave velocity being proportional to the square root of the shear modulus is a function of the effective overburden stress to the power of 0.25 ,

$$
\left.V_{\theta}=f\left[\left(\sigma^{\prime}\right)^{\epsilon} \sqrt{\natural}\right\urcorner\right]
$$

Therefore, a normalized shear wave velocity can be established using the relationship

$$
V_{\theta l}=V_{\theta}\left(P / \sigma_{1}^{\prime}\right)^{\epsilon=1-}
$$

where

$$
\begin{aligned}
\mathrm{P}_{\mathrm{a}} & =\text { reference stress, typically } 100 \mathrm{kPa} \\
\sigma^{\prime}{ }_{\mathrm{vo}} & =\text { effective overburden stress in same units as } \mathrm{P}_{\mathrm{a}}
\end{aligned}
$$

The proposed correlation between normalized shear wave velocity and the critical cyclic stress ratio necessary to prevent liquefaction is shown in 
Figure 15 (Robertson 1990). The data base is still very small so it is still too soon to use the shear wave velocity criterion alone in practice. 


\section{Liquefaction Potential of Gravels by Becker Penetration Test (BPT)}

The presence of large gravel and cobble particles preclude the use of the SPT in the evaluation of liquefaction potential. Misleadingly high SPT blowcounts would be recorded as the 2 in sampler bounced off the large particles. A much larger and heavier penetration tool is required to penetrate gravels and provide a continuous record of penetration resistance. Harder and Seed (1986) developed the Becker Penetration Test (BPI) for this situation.

In the BPT a double-walled casing, generally 6.6 in. O.D. in the U.S., is driven into the ground with a diesel pile hammer (Figure 16). The casing can be driven with an open bit and reversed air circulation to obtain disturbed samples or with a plugged bit and driven as a solid penetrometer. The blows required for each foot of penetration are recorded and provide a record of penetration resistance for the entire profile. Two types of rigs are in use, the B-180 rig (also known as HAV-180) and the AP-1000 developed later in the 1970 's. Both rigs use the same model of diesel hammer, an ICE Model 180. Harder and Seed (1986) showed that the older B-180 rig was more efficient with the result that the blowcounts from AP-1000 rig were about 50 percent higher than those from the B-180 rig. Harder and Seed (1986) developed the BPT procedures using the AP-1000 so blowcounts obtained by the B-180 rig must be adjusted to equivalent AP-1000 blowcounts unless correlations are developed specifically for the B-180 rig. The adjustment factor is 1.5 . 
The first step in evaluating liquefaction potential using BPT blowcounts $\mathrm{N}_{\mathrm{b}}$ is to correct the blowcounts to standard combustion conditions, $\mathrm{N}_{\mathrm{bc}}$ using the procedures prescribed by Harder and Seed (1986). Then using a correlation developed by Harder and Seed (1986) and shown in Figure 17, the $\mathrm{N}_{b c}$ are converted to equivalent SPT $\mathrm{N}_{60}$. Finally, the SPT blowcounts are converted to $\left(\mathrm{N}_{1}\right)_{60}$ for use in the liquefaction assessment chart in Figure 3 or Figure 5.

The BPT procedure has been used to evaluate the liquefaction potential of foundation gravels in the Mormon Island Dam near Sacramento, California. An excellent description of the use of the BPT on this project may be found in Hynes et al. (1988).

The correlation between $\mathrm{N}_{\mathrm{bc}}$ and $\mathrm{N}_{60}$ is established by conducting both tests in the same sand profile. Is this correlation still valid when BPT tests are run in deposits of gravel and cobbles? Even in relatively fine-grained soils, the correlation between SPT and CPT has been found to be dependent on mean grain size as shown in Figure 9. A larger database on the liquefaction of gravels is needed to resolve this question.

As the use of the Becker penetration test spread, two major problems emerged. The Harder-Seed (1986) correlation appeared not to be as generally applicable as originally thought and the effects of casing friction on blowcounts at deep penetration became a major concern. Fundamental research on both of these questions have been conducted in British Columbia, Canada by Sy (1993a) using different Becker rigs and a variety of sites.

\section{Energy Standard for the Becker Penetration Test}

Sy (1993a) has instrumented Becker penetration tests to measure the energy transferred through (ENTHRU) the anvil and capblock to the Becker casing. He showed that the average transferred energy was about 30 percent of the rated energy of the hammer for the various types of rigs. Sy (1993a) proposed 
adopting this energy level as the standard for establishing the Becker blowcount/ft, $\mathrm{N}_{\mathrm{b} 30}$.

$$
N_{-\Sigma \epsilon}=N,(E N T H R U / 30)
$$

Using this standard, he has been able to show that, in the same deposit, the $\mathrm{HAV}-180$ and the AP-1000 rigs deliver the same $\mathrm{N}_{\mathrm{b} 30}$.

Blowcount data for HAV-180 and AP-1000 rigs are shown in Figure 18a from tests BPT-2 and BPT-5, respectively, at the same site. The corrected blowcounts based on the Harder-Seed correction procedure are shown in Figure $18 \mathrm{~b}$. Note that the blowcounts from the more energy efficient HAV-180 rig are less than the blowcounts from the AP-1000 rig even after the correction. However, when both sets of blowcount data are corrected to the same transferred energy level of 30 percent of the rated hammer energy, both sets of data plot together (Figure 18c).

\section{Effect of Friction on Becker Blowcount}

The friction between the Becker casing and the ground increases with depth of penetration. This friction is not present in the Standard Penetration Test. Clearly, it is not possible to maintain a stable correlation between BPT and SPT soundings. The original Harder-Seed (1986) correlation includes the effects of friction for depths up to $50 \mathrm{ft}$ only. One solution to the friction problem may be to use different correlations over different depth ranges.

Tests were conducted by Sy (1993a) at the site of a large development in Richmond, B.C., Canada, to determine the effects of casing friction on Becker blowcounts. The BPT was conducted in two ways. First the test was conducted in the standard way using an uncased hole. Then a BPT was conducted using modified procedures. The bottom of the casing was the standard size 
with a 6.6 in. O.D. over a length of $1 \mathrm{ft}$. Above this, the casing O.D. was 5.5 in. During penetration drilling mud was pumped into the casing, exited through holes near the bottom of the $5.5 \mathrm{in}$. O.D. casing and was forced upwards between the casing and the ground. This procedure ensured virtually friction free driving over the entire penetration depth. SPT tests were also conducted at the site. The results are shown in Figure 19a in which both BPT and SPT energy corrected blowcounts are plotted with depth. The comparison between the two BPT blowcounts are for the same level of transferred energy. Therefore, the different casing frictions are primarily responsible for the differences in penetration resistances. The effect of friction on the blowcounts is very substantial but difficult to see clearly because of the small blowcount scale. The result is much clearer in Figure $19 \mathrm{~b}$ where the BPT blowcounts are normalized by the SPT $\mathrm{N}_{60}$ values. Clearly the effect of friction is an order of magnitude and increases with depth.

Recently at the Terzaghi Dam in British Columbia, BC Hydro decided to use Becker blowcounts from cased holes, although the data were recognized to be conservative, rather than the data from the uncased holes which incorporated frictional effects that could not be evaluated at the time (Sy 1993b).

Sy (1993a) at the University of British Columbia has developed correlations between SPT $\mathrm{N}_{60}$ and BPT $\mathrm{N}_{\mathrm{b} 30}$ for various average friction forces on the casing. The friction was evaluated using CAPWAP analyses (Goble et al. 1980). Therefore, by using the energy correction approach, it is possible to take frictional effects into account directly in determining the in-situ $\mathrm{N}_{60}$ from $\mathrm{N}_{\mathrm{b} 30}$.

\section{Spectral Analysis of Surface Waves}

The Spectral Analysis of Surface Waves (SASW), has emerged as a potential alternative to the BPT for assessing the liquefaction potential of gravels, cobbles and rockfill. The distribution of shear wave velocity in the coarse materials required for use in Figure 15 is determined by analysis of surface 
waves only. Therefore, the method does not require a borehole. The method was pioneered by Nazarian and Stokoe (1984).

Recent developments in the method have reduced costs and accelerated the procedure so that it has become a viable tool for routine use in practice (Robertson et al. 1992). Since the method is not widely used yet, a brief explanation and some typical results will be given here.

In the SASW method, Rayleigh waves are generated in the soil by steady state harmonic excitation over a range of frequencies or by hammer impact on the ground surface. The propagation of these surface waves is measured by receivers as shown in Figure 20. The field dispersion curve which gives the relationship between phase velocity and wave length is then determined (Figure 21a).

The field dispersion curve is used to establish the shear wave velocity profile for the site. The process of going from dispersion curve to velocity profile is an inverse process and is basically nonlinear. An iterative forward process is commonly used. The dispersion curve for an assumed initial velocity profile (shear wave velocities and layer thicknesses over a half space) is determined and compared with the field curve. The initial profile is modified using some form of optimization until the theoretical dispersion curve agrees with the field curve within prescribed limits. Computed and measured dispersion curves are shown in Figure 21a, and the associated shear wave velocity is shown in Figure 21b.

The processing of the receiver data previously required the use of a spectral analyzer. The spectral decomposition is now based entirely on the personal computer using improved algorithms. This reduces the capital cost of equipment and gives a faster site evaluation.

The SASW method is fast. Tokimatsu et al. (1991) quote times of $30 \mathrm{~min}$ to $1 \mathrm{hr}$ to establish a profile to a depth of $50 \mathrm{~m}$. Robertson et al. (1992) quote times of $1 \mathrm{hr}$ to $2 \mathrm{hr}$ for a profile depth of $30 \mathrm{~m}$. The SASW has other 
advantages. It does not require a borehole. This reduces execution time and allows the method to be used at gravel and rockfill sites at which is difficult to conduct cross-hole methods or downhole methods and in which it is impossible to conduct seismic cone (SCPT) measurements. A disadvantage is the limited profile depth that can be explored with common convenient energy sources. 


\section{Acknowledgments}

The author's research on liquefaction at the University of British Columbia is funded by a grant from the National Science and Engineering Council of Canada under Grant No. 81498. 


\section{References}

Addo, K. O., and Robertson, P. K. (1992). "Shear-wave velocity measurement of soils using Rayleigh waves," Canadian Geotechnical Journal Vol. 29, No. 4, pp. 558-568.

Bierschwale, J. G., and Stokoe, K. H. (1984). “Analytical evaluation of liquefaction potential of sands subjected to the 1981 Westmorland earthquake," Geotechnical Engineering Report GR84-15, Civil Engineering Department, University of Texas, Austin.

Byrne, P. M., Imrie, A. S., and Morgenstern, N. R. "Results and implications of seismic response studies - Duncan Dam," Proceedings of the 46th Annual Canadian Geotechnical Conference, Saskatoon, Saskatchewan, Canada, pp. 271-281.

Douglas, B. J., Olsen, R. S., and Martin, G. R. (1981). "Liquefaction susceptibility from S-wave velocity," Pre-print 81-544, ASCE National Convention, St. Louis, Missouri, October, ASCE, New York.

Finn, W. D. Liam, Robertson, P. K., and Woeller, D. J. (1990). "Liquefaction studies in the Fraser Delta," Report to Energy Mines and Resources, Geological Survey of Canada, Ottawa.

Harder, L. F., and Seed, H. B. (1986). "Determination of penetration resistance for coarse-grained soils using the Becker hammer drill," Report 
No. UCB/EERC-86/06, Earthquake Engineering Research Centre, University of California at Berkeley.

Holzer, T. L., Youd, T. L., and Hanks, T. C. (1988). "Dynamics of liquefaction during the Superstition Hills earthquake $(M=6.5)$ of November 24, 1987," Poster Presentation ASCE Geotech. Eng. Div., Specialty Conf., Earthq. Eng. and Soil Dynamics II, Park City, UT.

Hynes-Griffin, M. E., Wahl, R. E., Donaghe, R. T. and Tsuchida, T. (1988). "Seismic stability evaluation of Folsom Dam and reservoir project," Report No. 4, Mormon Island Auxiliary Dam - Phase I, U.S. Army Corps of Engineers, Waterways Experiment Station, Vicksburg, MS.

Kawasumi, H. (Editor-in-Chief). (1968). "General report on the Niigata earthquake of 1964," Tokyo Electrical Engineering College Press.

Koester, J. P. (1990). Letter Report to Vicksburg District, U.S. Army Corps of Engineers.

Koester, J. P. (1992). "The influence of test procedure on correlation of Atterberg limits with liquefaction in fine-grained soils," Geotechnical Testing Journal, GTJODJ, Vol. 15, No. 4, pp. 352-361.

Kuerbis, R. H., and Vaid, Y. P. (1989). "Undrained behaviour of clean and silty sand," Proceedings, 12 Int. Conf. on Soil Mechanics and Foundation Engineering, Rio de Janeiro, Brazil.

Liao, S. C., and Whitman, R. V. "Overburden correction factors for SPT in sand," JGED, ASCE, Vol. 112, No. 3, pp. 373-377.

Marcuson, W. F., Hynes, M. E., and Franklin, A. G. (1992). "Seismic stability and permanent deformation analyses: the last twenty five years," Proceedings, ASCE Specialty Conference on Stability and Performance of Slopes and Embankments - II, Geotechnical Special Publication No. 31, 
Eds. R. B. Seed and R. W. Boulanger, ASCE, New York, Vol. I, pp 552-592.

Nazarlan S., and Stokoe, K. H. II. "In situ shear wave velocities from spectral analysis of surface waves," Proceedings, 8th World Conference on Earthquake Engineering, San Francisco, Vol. III, pp 31-38, July 21-28, 1984.

Newmark, N. M. 1965. "Effects of earthquakes on dams and embankments," 5th Rankine Lecture, Geotechnique 15, No. 2, pp 139-160.

Robertson, P. K. (1990). "Seismic Cone Penetration Testing for Evaluating Liquefaction Potential," Proceedings, Symp. on Recent Advances in Earthquake Design Using Laboratory and In-Situ Tests, ConeTec Investigations Ltd., Burnaby, BC.

Robertson, P. K., and Campanella, R. G. (1985). "Liquefaction potential of sands using the CPT," J. Geot. Eng., ASCE, Vol. 111, No. 3.

Robertson, P. K., Campanella, R. G., Gillespie, D., and Rice, A. (1986). "Seismic CPT to measure in-situ wave velocity," J. Geot. Eng. Div., ASCE.

Robertson, P. K., Campanella, R. G., and Wightman, A. (1983). "SPT-CPT Correlations," J. Geot. Eng. Div., ASCE, Vol. 109, GT11, pp. 14491459.

Robertson, P. K., Woeller, D. J., and Finn, W. D. Liam. (1992). “Seismic cone penetration test for evaluating liquefaction potential under cyclic loading," Canadian Geotechnical Journal, Vol. 29, No. 4, pp 686-695.

Seed, H. B., and De Alba, P. (1986). "Use of SPT and CPT tests for evaluating the liquefaction resistance of soils," Proceedings of the Specialty Conference on the Use of In-Situ Tests in Geotechnical Engineering, ASCE, Geotechnical Special Publication No. 6, Blacksburg, Virginia. 
Seed, H. B., and Idriss, I. M. (1971). " Simplified procedures for evaluating soil liquefaction potential," Journal of the Soft Mechanics and Foundations

- Division, ASCE, Vol. 97, No.SM9, pp 1249-1273.

Seed, H. B., Idriss, I. M., and Arango, I. "Evaluation of liquefaction potential using field performance data," Journal of the Geotechnical Engineering Division., ASCE, Vol. 109, GT3, pp. 458-482.

Seed, H. B. (1977). "Earthquake resistant design of earth dams," Pre-print No. 2902, ASCE Dallas Convention.

Seed, H. B. (1979). "Considerations in the earthquake-resistant design of earth and rockfill dams," Geotechnique, Vol. 29, No.3, pp 215-263.

Seed, H. B. (1981) "Earthquake resistant design of earth dams," Proceedings, International Conference on Recent Advances in Geotechnical Earthquake Engineering and Soil Dynamics, Vol. III, St. Louis, MO, pp 1157-1173.

Seed, H. B. (1983). "Earthquake resistant design of earth dams," Seismic Design of Embankments and Caverns, Proceedings of ASCE Symposium, Philadelphia, pp 41-64.

Seed, H. B., Tokimatsu, K., Harder, L. F., and Chung, R. M. (1985). "Influence of SPT procedures in soil liquefaction resistance evaluations," Journal of Geotechnical Engineering, Vol. 111, No. 12, pp 1425-1445.

Seed, H. B. (1987). "Design problems in soft liquefaction," Journal of Geotechnical Engineering, ASCE, Vol. 113, No. 7, pp 827-845.

Seed, R. B., and Harder, L. F. (1990). "SPT-based analysis of cyclic pore pressure generation and undrained residual strength," Proceedings, H. Bolton Seed Memorial Symposium, Editor, J. M. Duncan, University of California, Berkeley, California, Vol. 2, pp 351-376. 
Stokoe, K. H., and Hoar, R. J. (1978). "Variables affecting in-situ seismic measurements," Proceedings, ASCE Geotechnical Eng. Div., Specialty

- Conf. on Earthq. Eng. \& Soft Dynamics, Park City, Utah, Vol. 2, ASCE, New York, pp. 919-939.

Sy Alex. (1993a). "Energy measurement and correlation of the standard penetration test and the Becker penetration test," Ph.D. Thesis, Department of Civil Engineering, University of British Columbia.

Sy Alex. (1993b). Private communication.

Tokimatsu, K., Kuwayama S., Abe A., Nomura S., and Tamura S. (1991). "Considerations to damage patterns in the Marina district during the Loma Prieta earthquake based on Rayleigh wave investigation," Proceedings, 2nd International Conference on Recent Advances in Geotechnical Engineering and Soil Dynamics, St. Louis, Missouri, Vol. II, pp 1649-1654, March 11-15.

Tokimatsu, K., Kuwayama, S., and Tamura, S. (1991). "Liquefaction potential evaluation based on Rayleigh wave investigation and its comparison with field behaviour," Proceedings, 2nd International Conference on Recent Advances in Geotechnical Engineering and Soil Dynamics, St. Louis, Missouri, Vol. I, pp 357-364, March 11-15.

Troncoso, J. H. (1990). "Failure risks of abandoned tailings dams," Proc., International Symposium on Safety and Rehabilitation of Tailings Dams, ICOLD, Sydney, Australia, pp. 82-89.

Vaid, Y. P., and THOMAS, J. (1994). "Post-liquefaction behaviour of sand," Proceedings, 13th International Conference of Soil Mechanics and Foundation Engineering," New Delhi. 
Wang, W. (1979). "Some findings in soil liquefaction," Water Conservancy and Hydroelectric Power Scientific Research Institute, Beijing, Peoples

- Republic of China.

Woods, R. D. (1991). "Field and laboratory determination of soil properties at low and high strains," Proceedings, 2nd International Conference on Recent Advances in Geotechnical Earthquake Engineering and Soil Dynamics, St. Louis, Missouri, pp 1727-1741.

Woodward Clyde Consultants. (1989). Private communication.

Youd, T. L., and Wieczorak, G. F. (1984). "Liquefaction during the 1981 and previous earthquakes near Westmorland, California," Open File Report 84-680, U.S. Geological Survey, Menlo Park, California. 

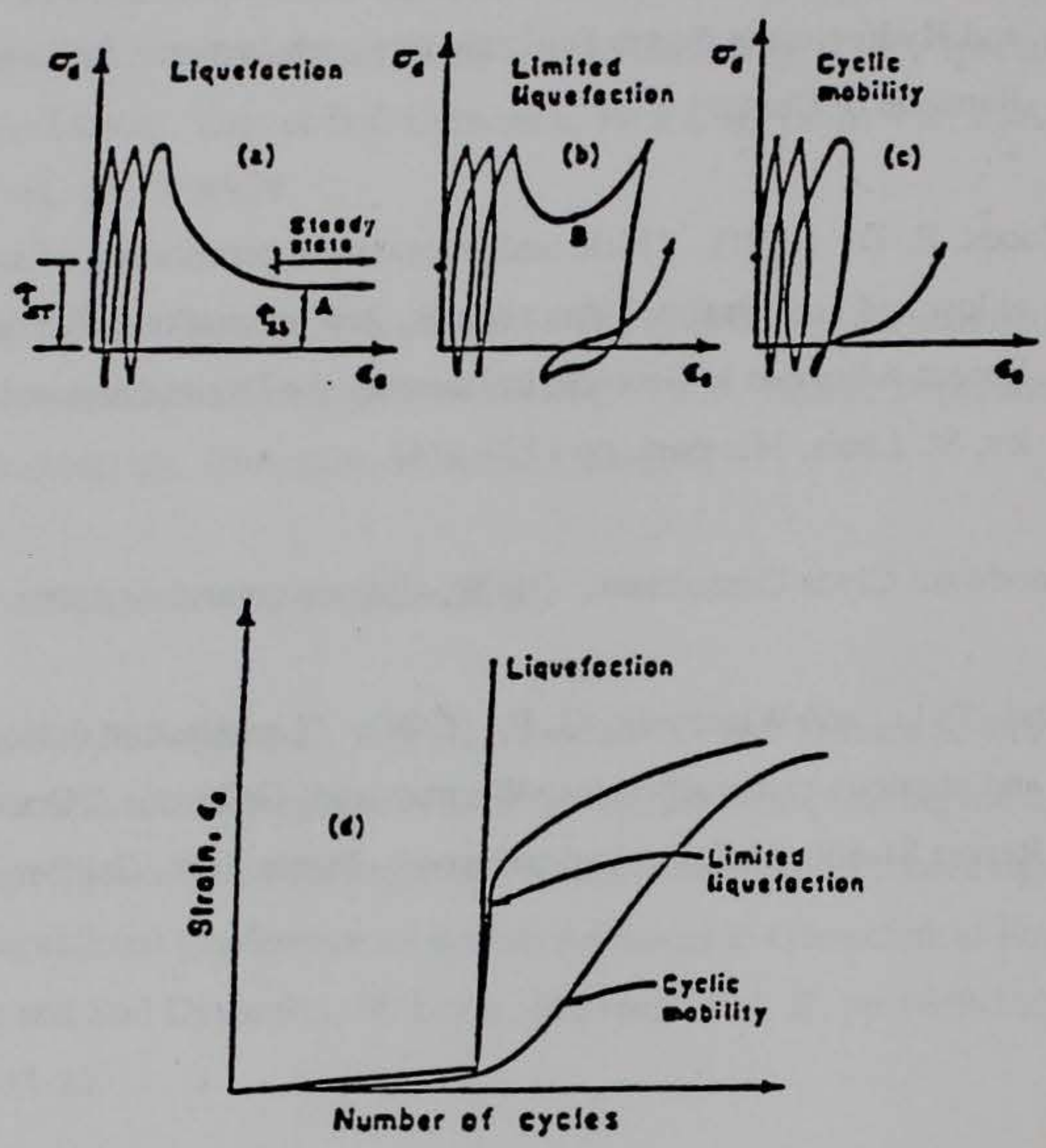

Figure 1. Definition of liquefaction, limited liquefaction and cyclic mobility under cyclic loading (Vaid and Chern 1985) 


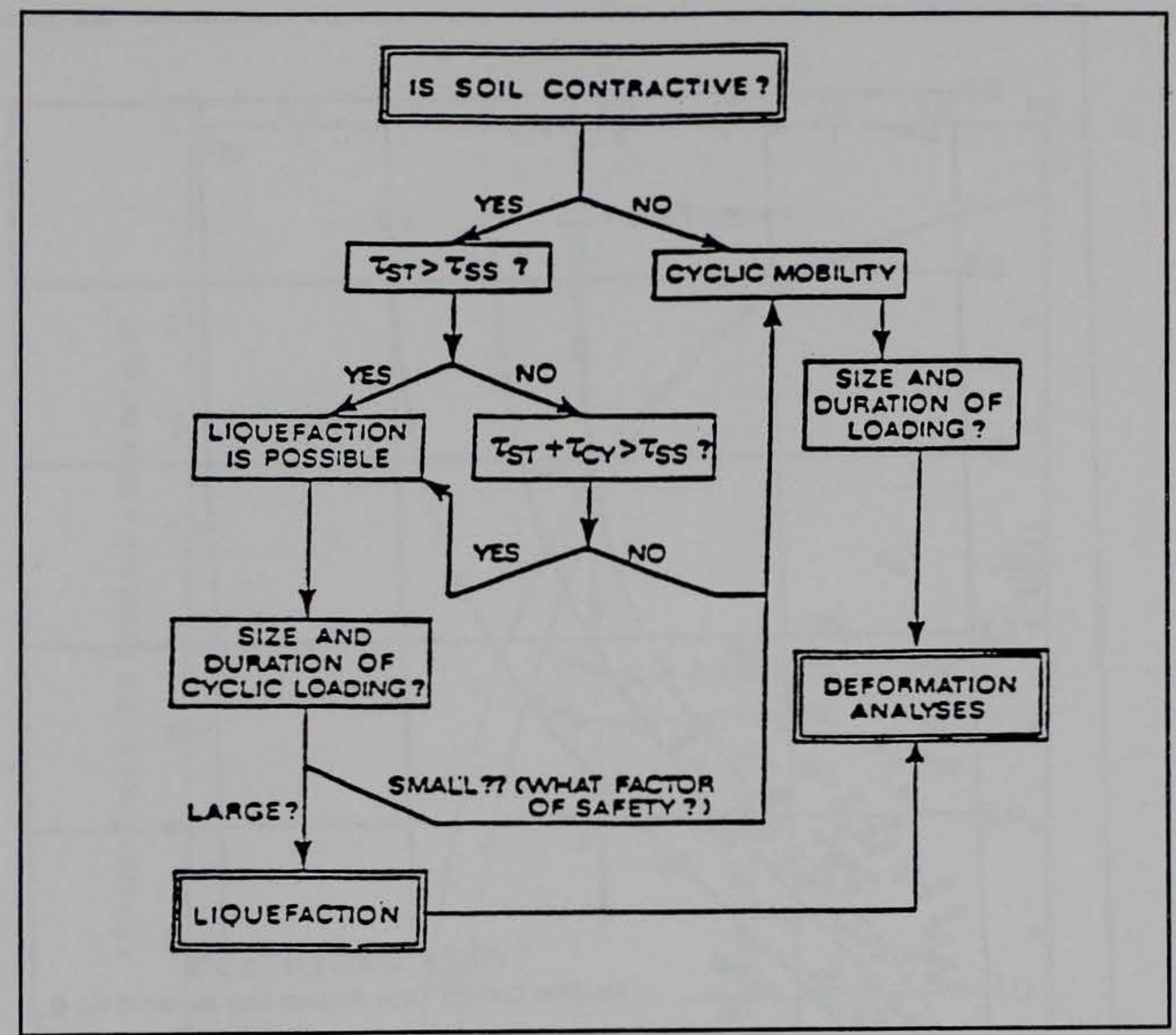

Figure 2. Flow chart for assessment of cyclic loading conditions (Robertson 1990) 


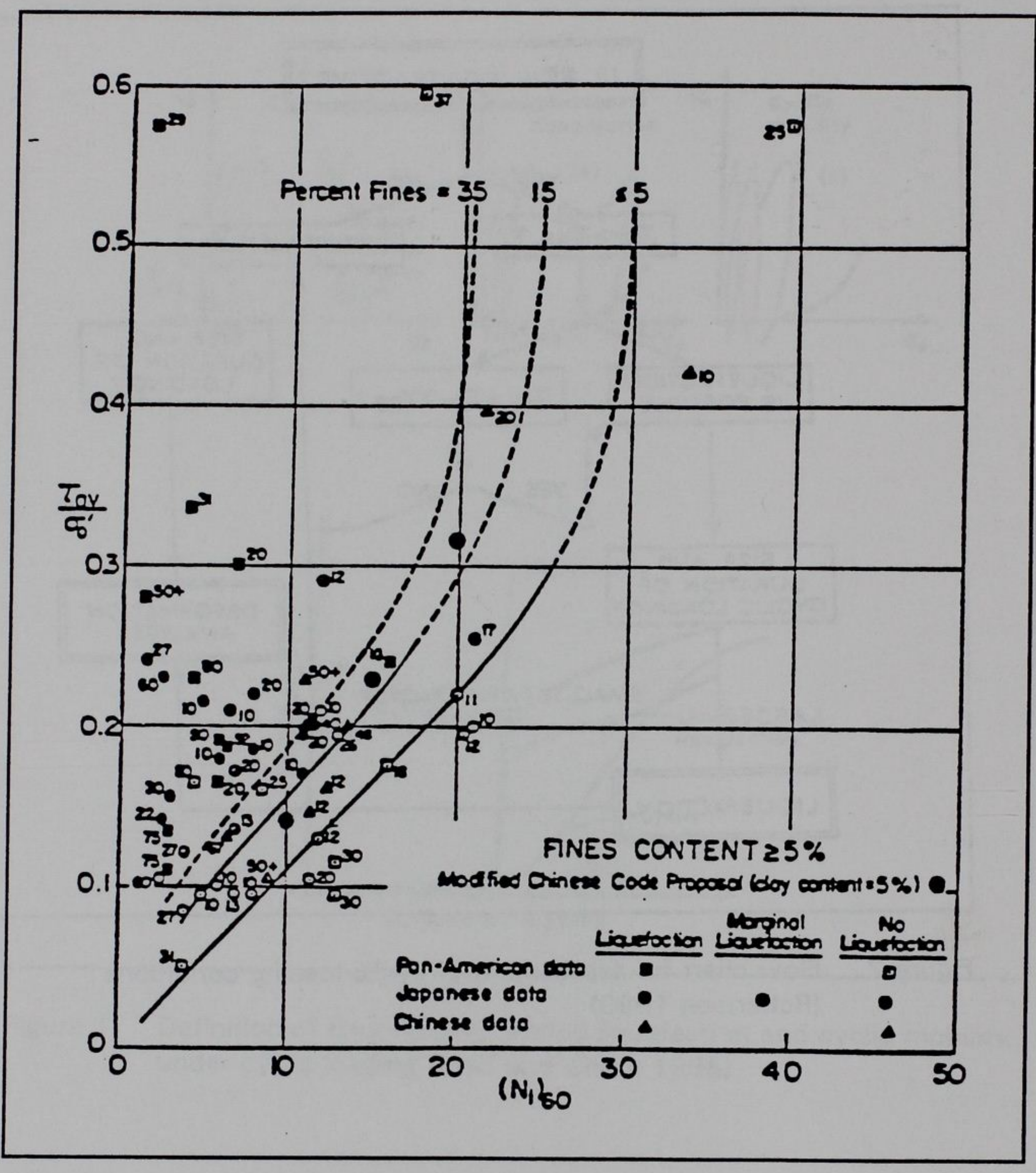

Figure 3. Relationship between stress ratio causing liquefaction and $\left(N_{1}\right)_{60}$ values for silty sand for $M=7.5$ (Seed et al. 1985) 


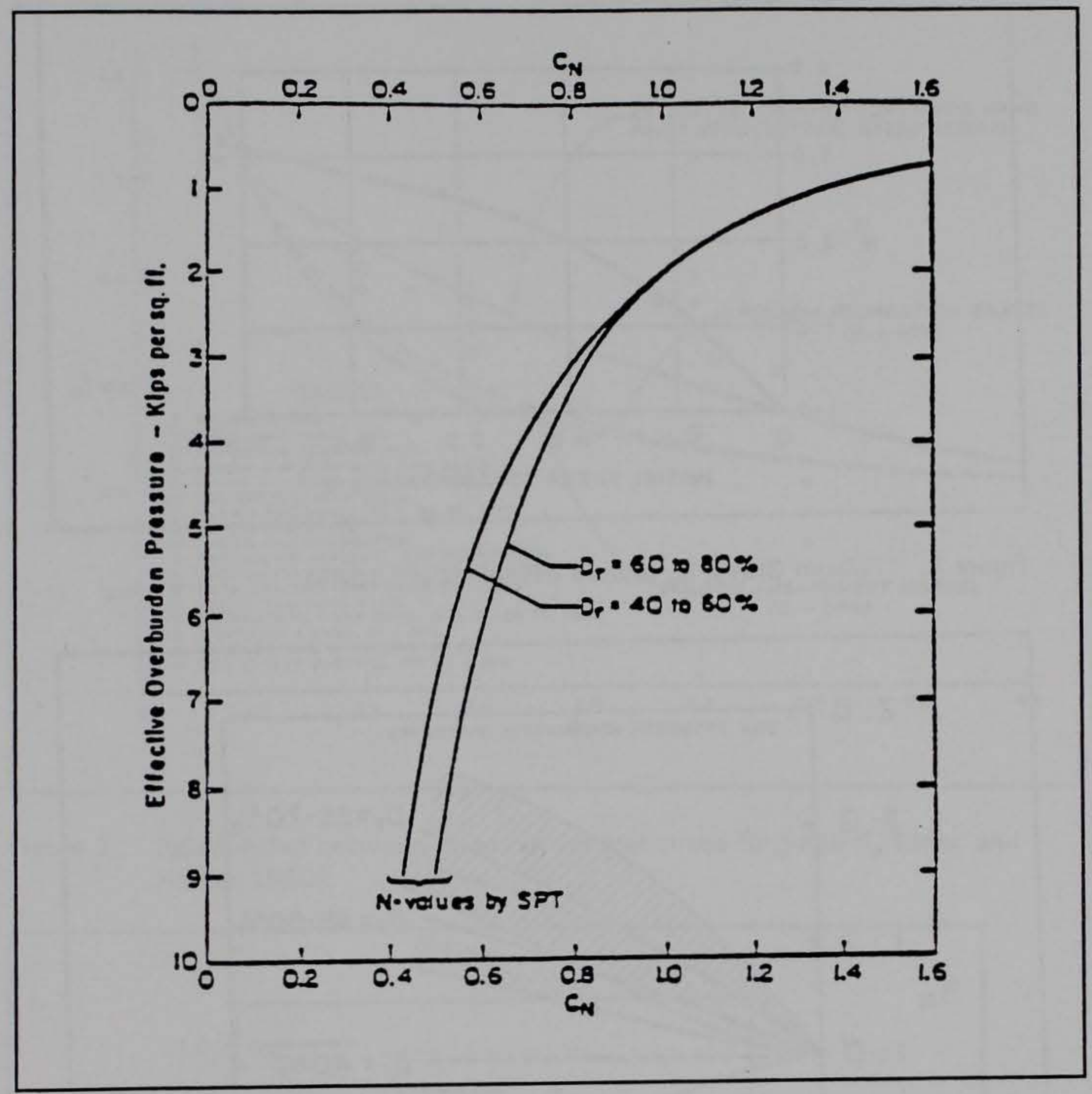

Figure.4. Charts for values of overburden correction factor $C_{N}$ (Seed 1983) 


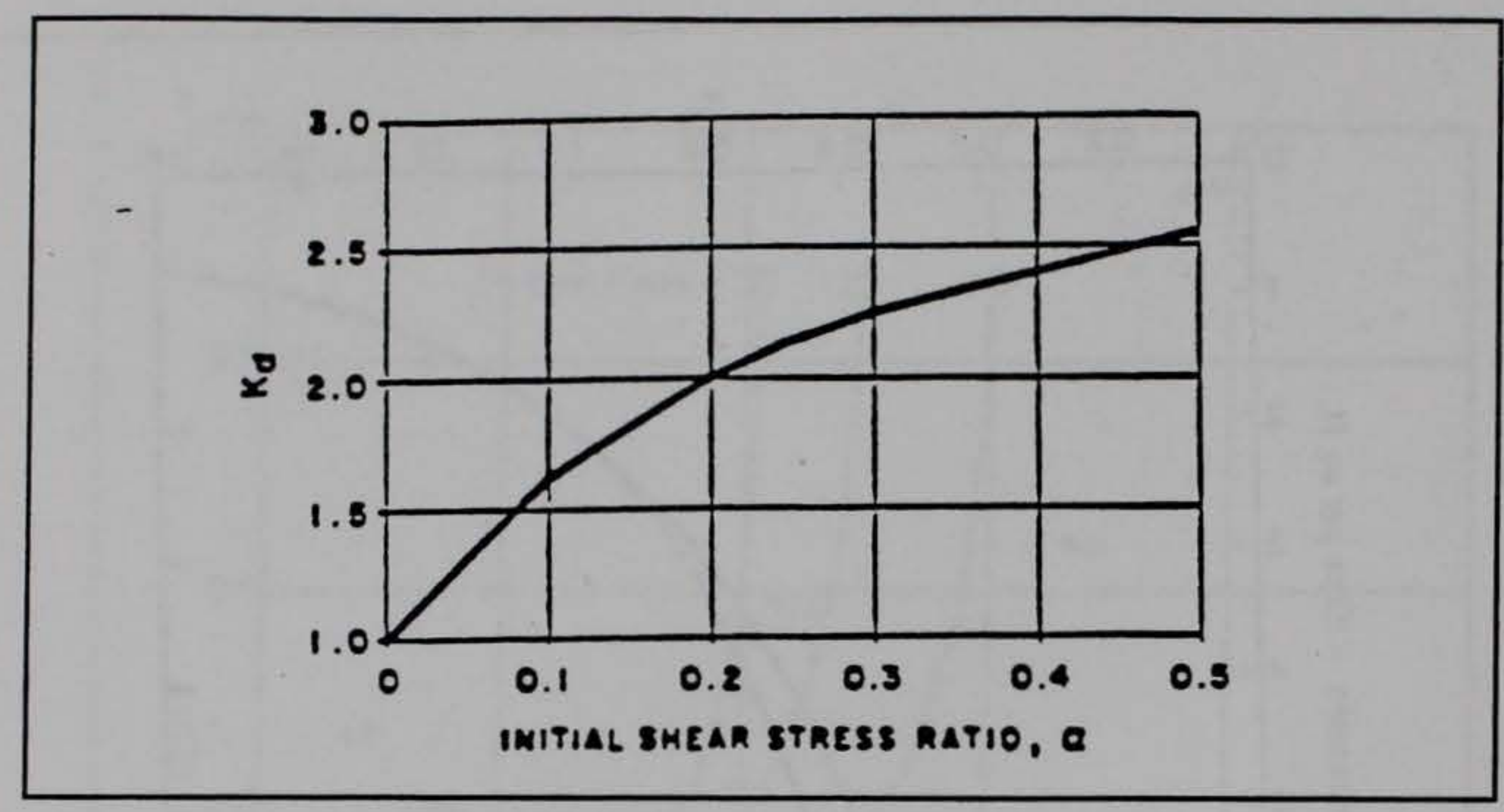

Figure 5. Folsom Gravel $K_{\alpha}$ factors (Hynes et al. 1988)

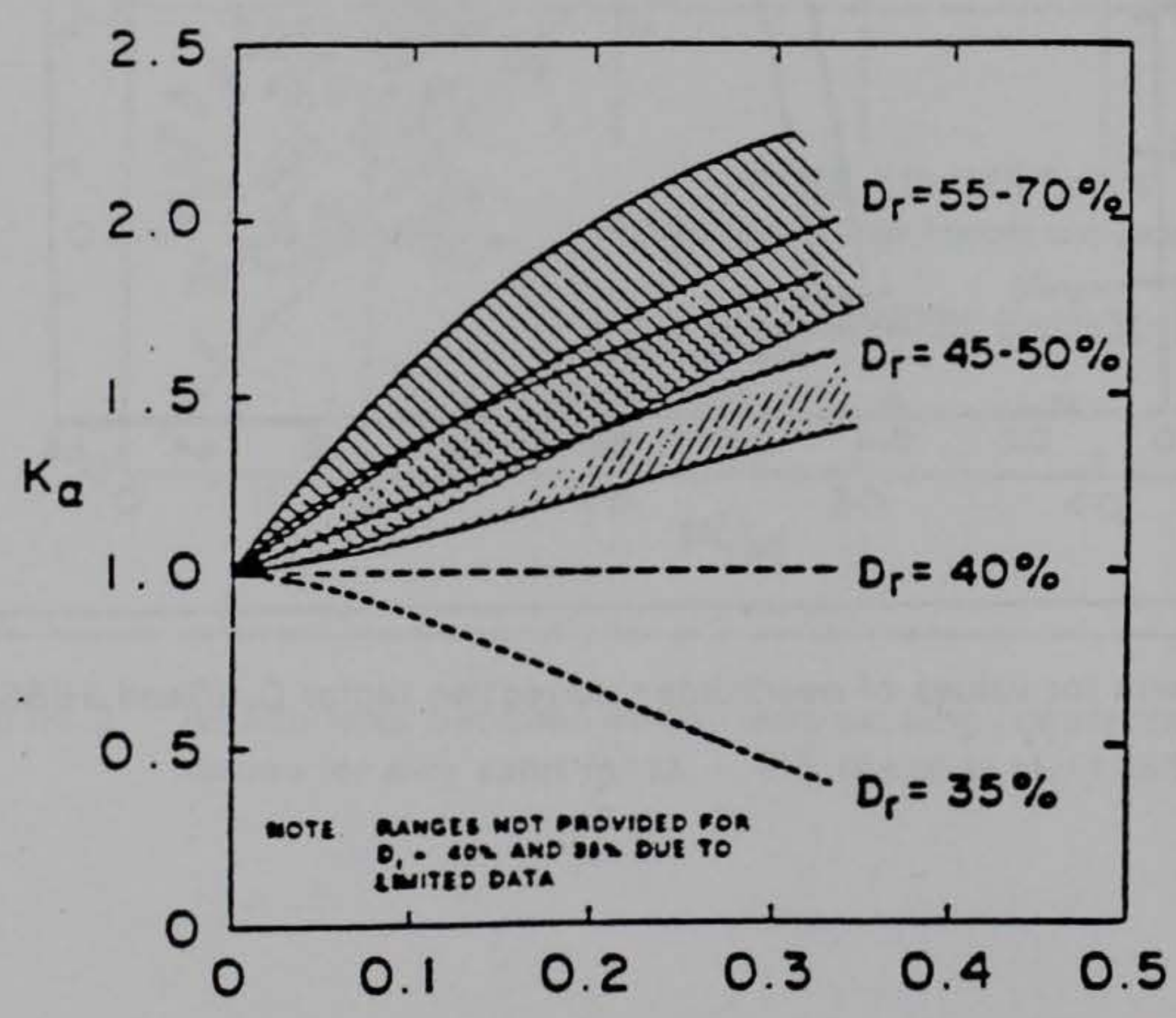

INITIAL STATIC STRESS RATIO, $Q=\tau_{o v} 1 \sigma_{0}^{\prime}$

Figure 6. Ranges in $K_{\alpha}$ factors (Seed and Harder 1990) 


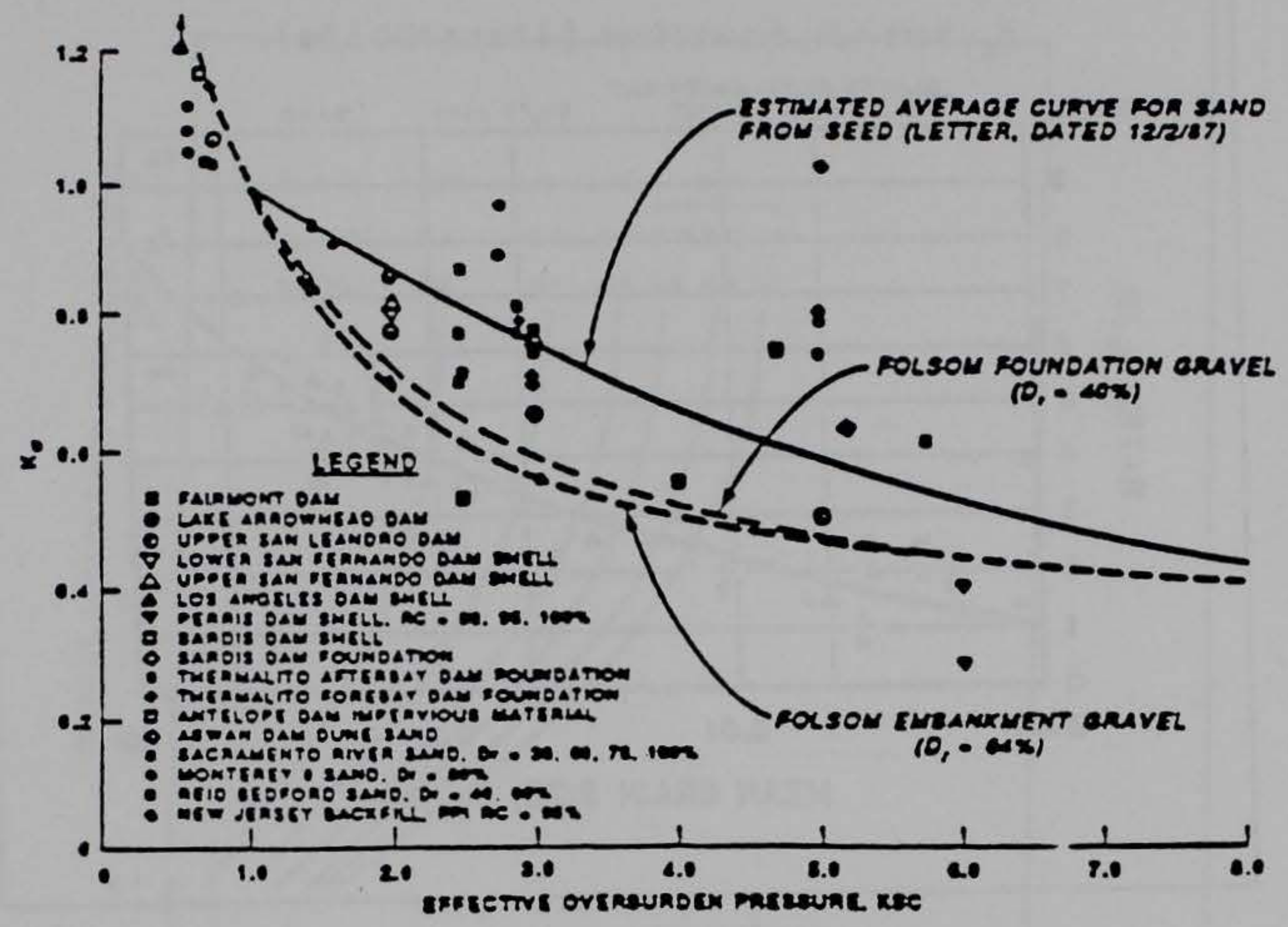

Figure 7. Relationship between effective vertical stress $\left(\sigma^{\prime}{ }_{0}\right)$ and $K_{\alpha}$ (Seed and Harder 1990)

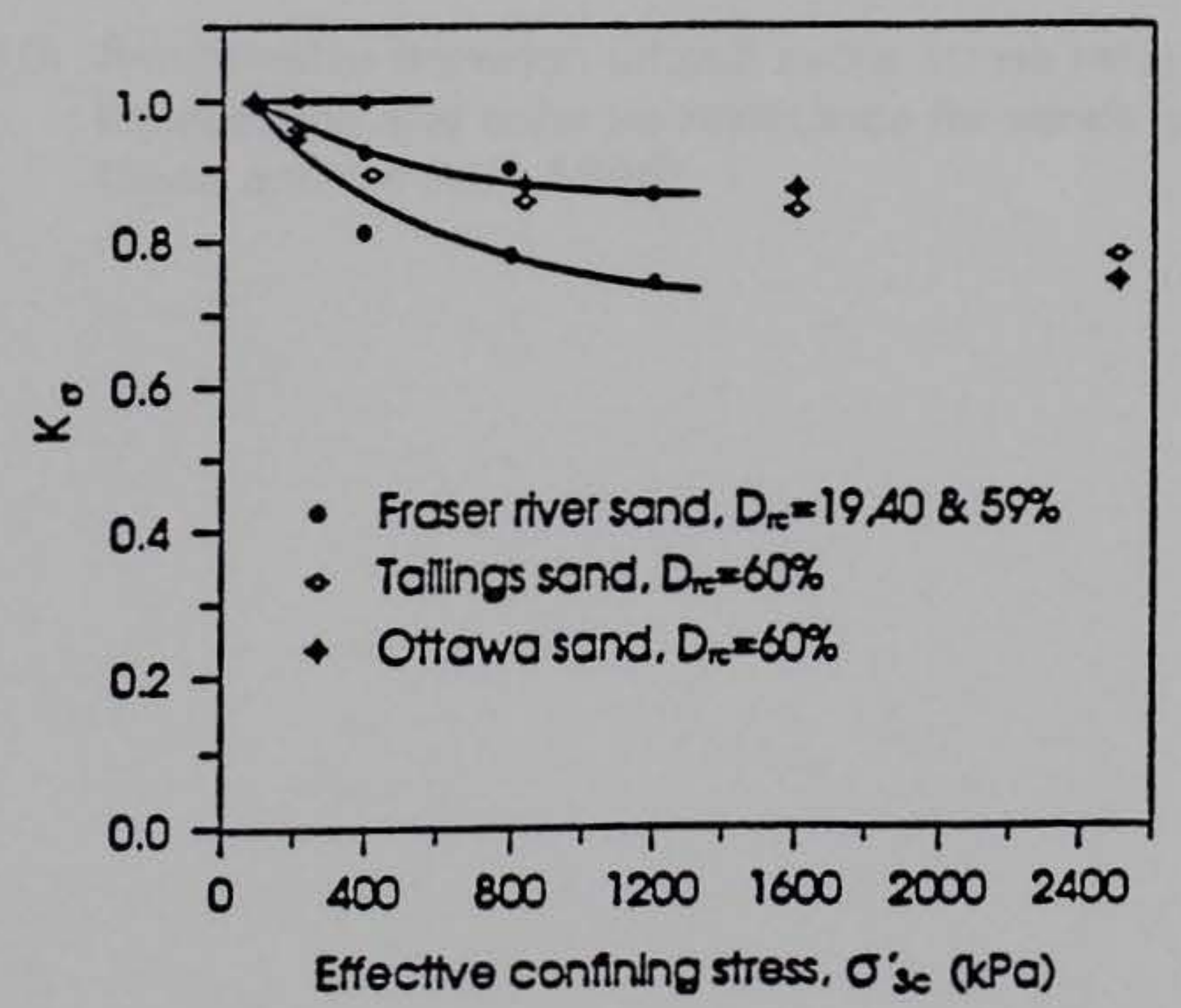

Figure 8. $K_{\circ}$ - Factors for clean sand as a function of relative density and sand type (Vaid and Thomas 1994) 


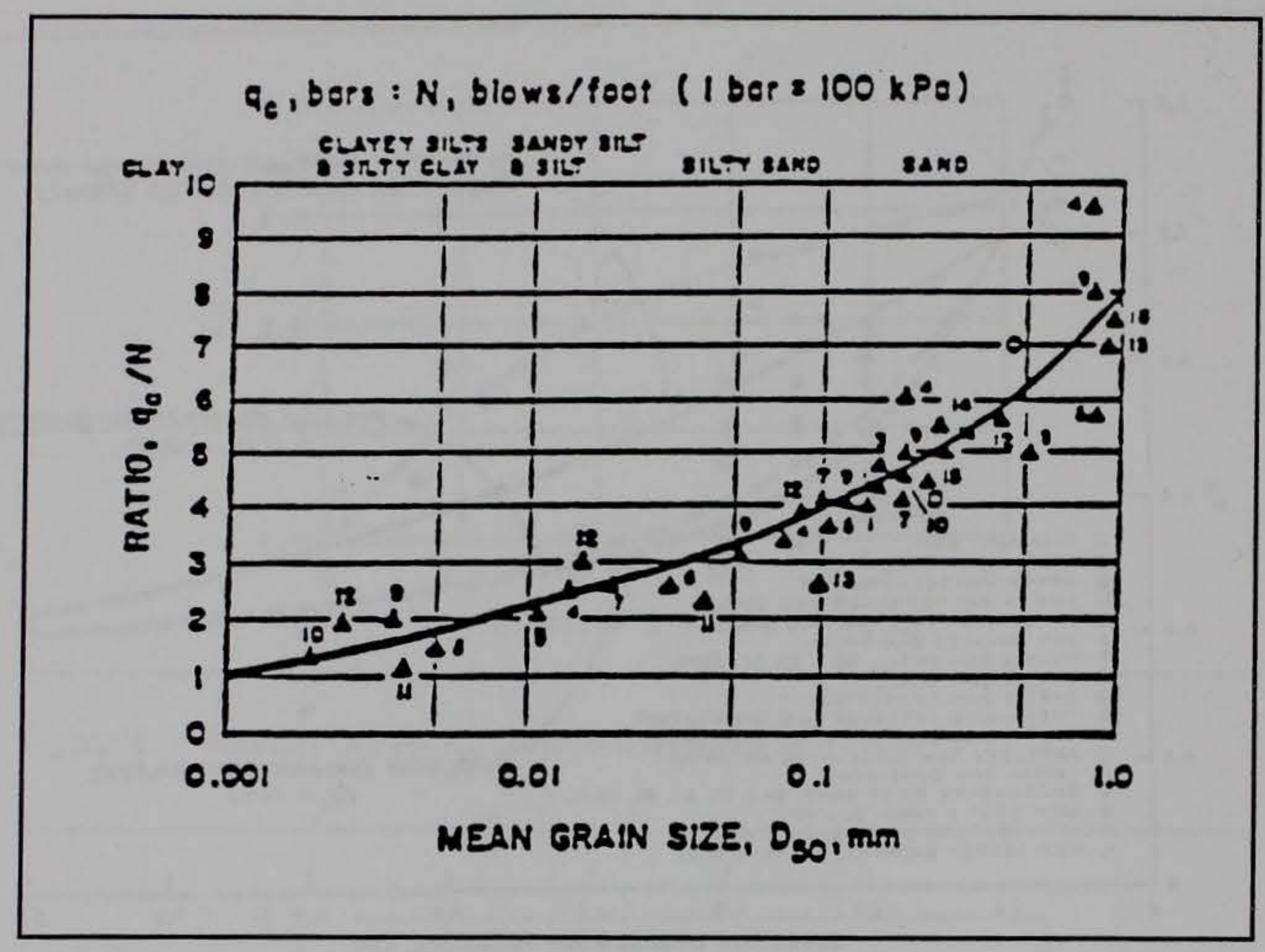

Figure 9. Relationship between $q_{c} / N_{S P T}$ and medium grain size $D_{50}$ numbers next to data points indicate various sources of data (Robertson et al. 1983) 


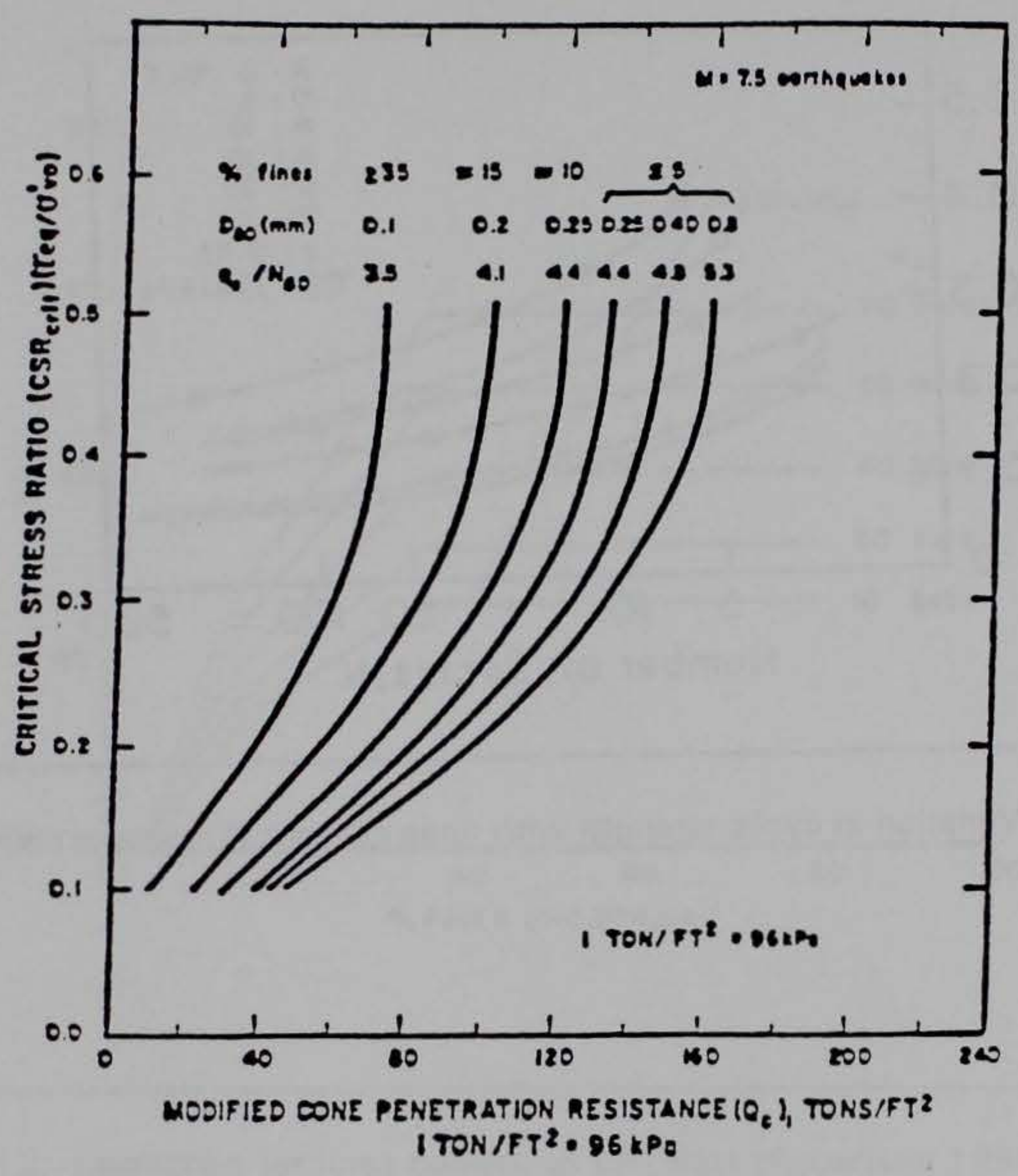

Figure 10. Relationship between critical cyclic stress ratio causing liquefaction and cone tip resistance for sands and silty sands (Seed and De Alba 1986) 


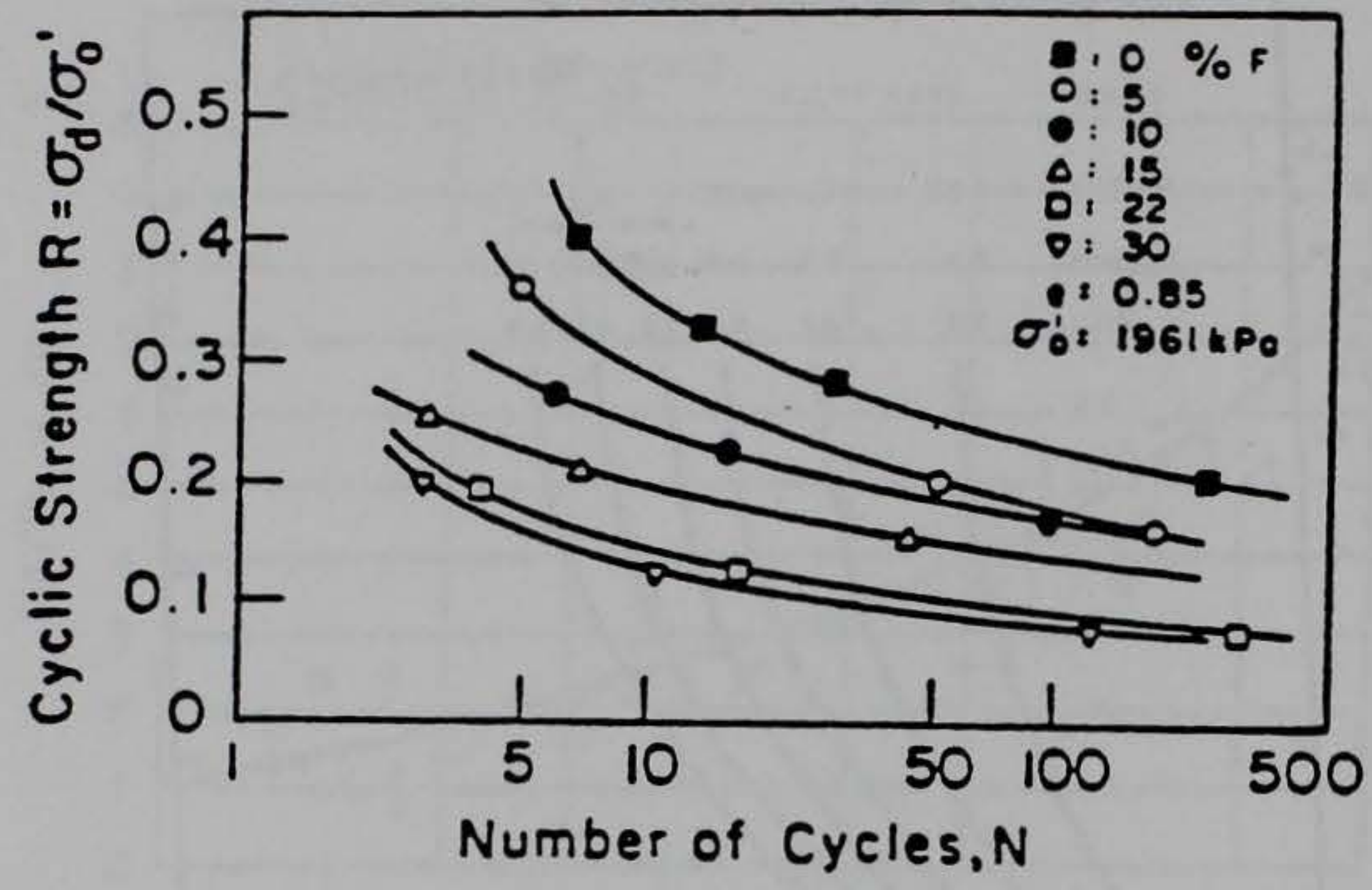

Figure 11. Variation in cyclic strength with fines content (Troncoso 1990) 


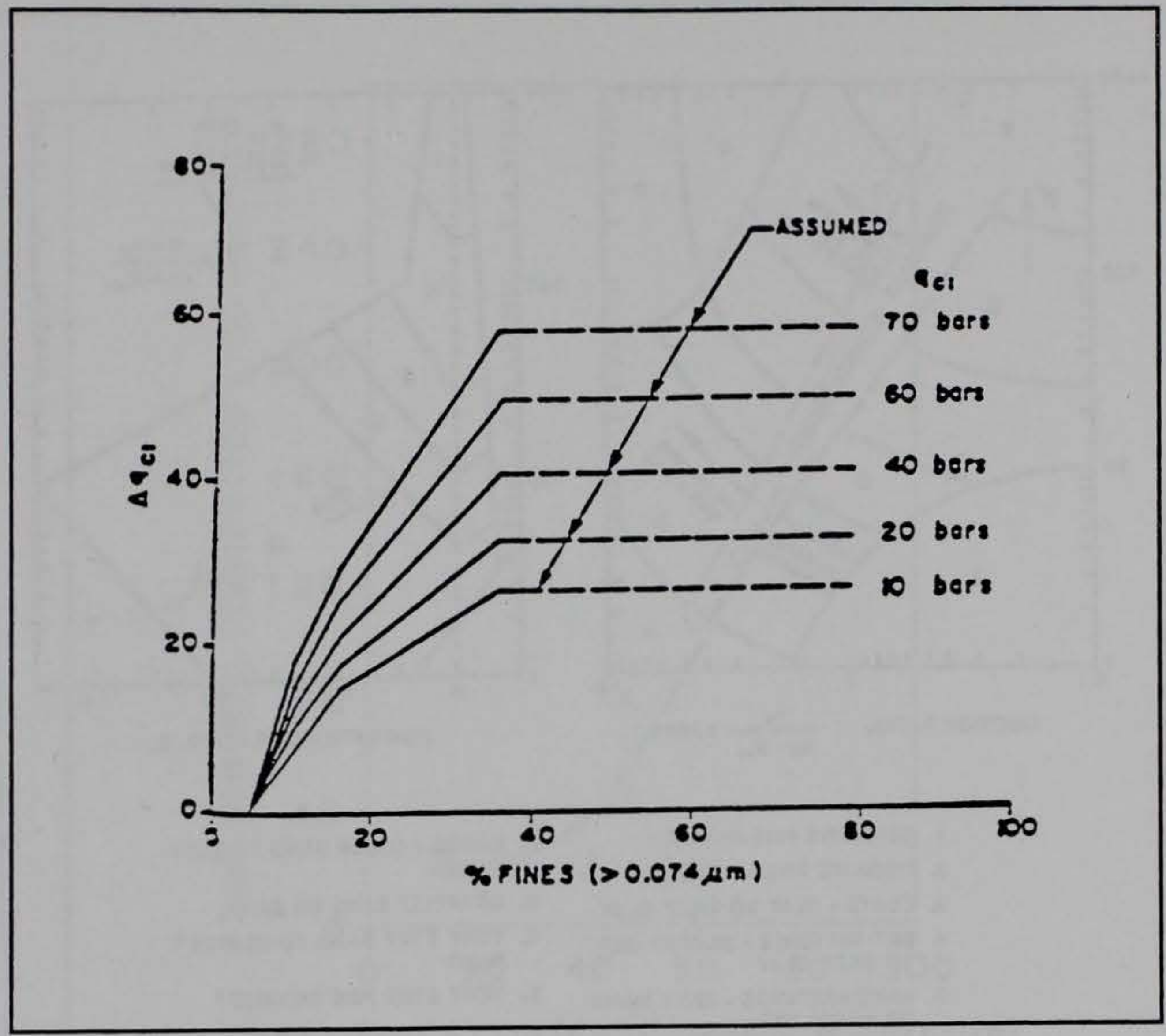

Figure 12. Correction for fines content to CPT data (Robertson 1990) 


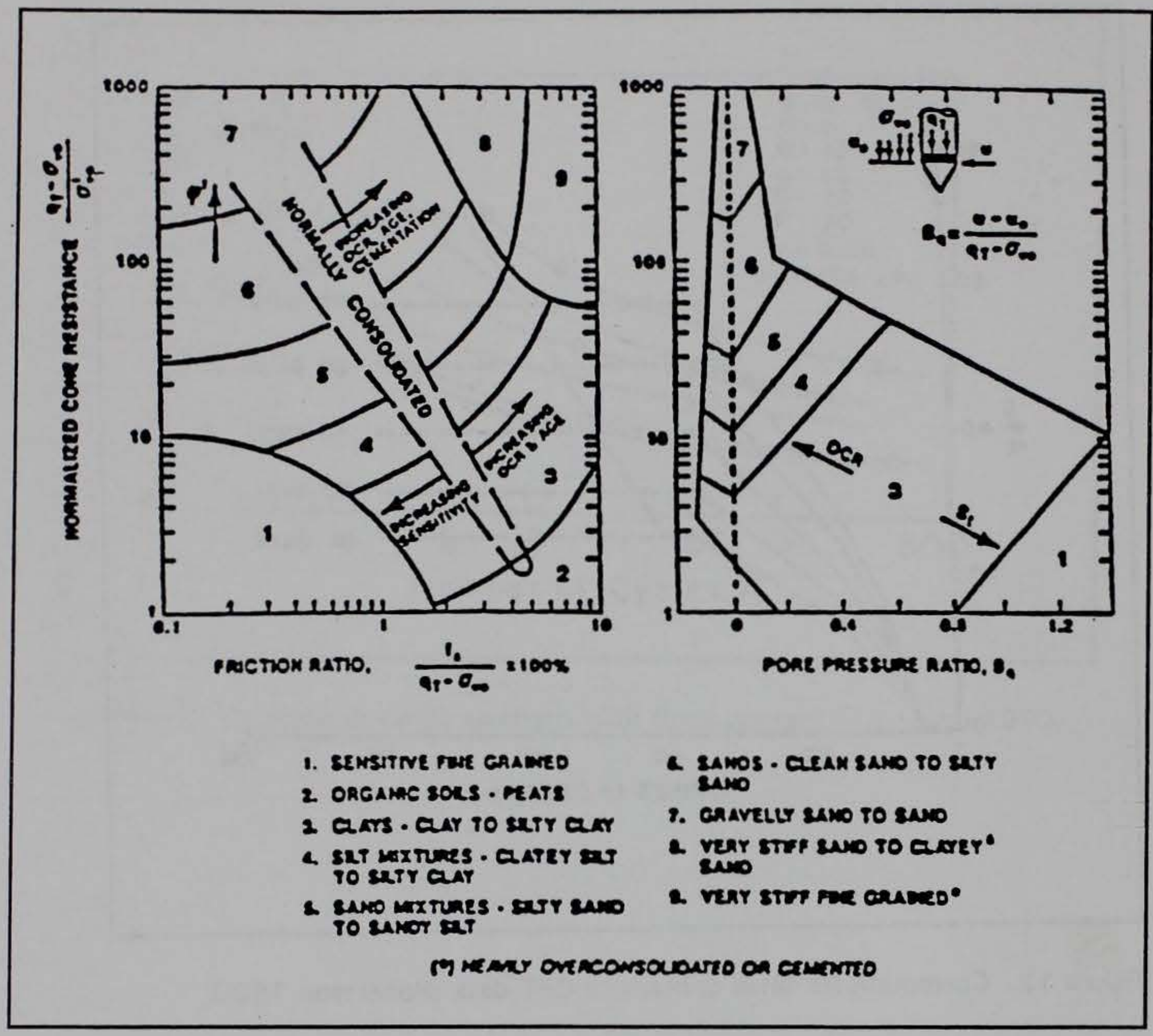

Figure 13. Proposed soil classification chart based on normalized CPT and CPTU data (Robertson 1990) 


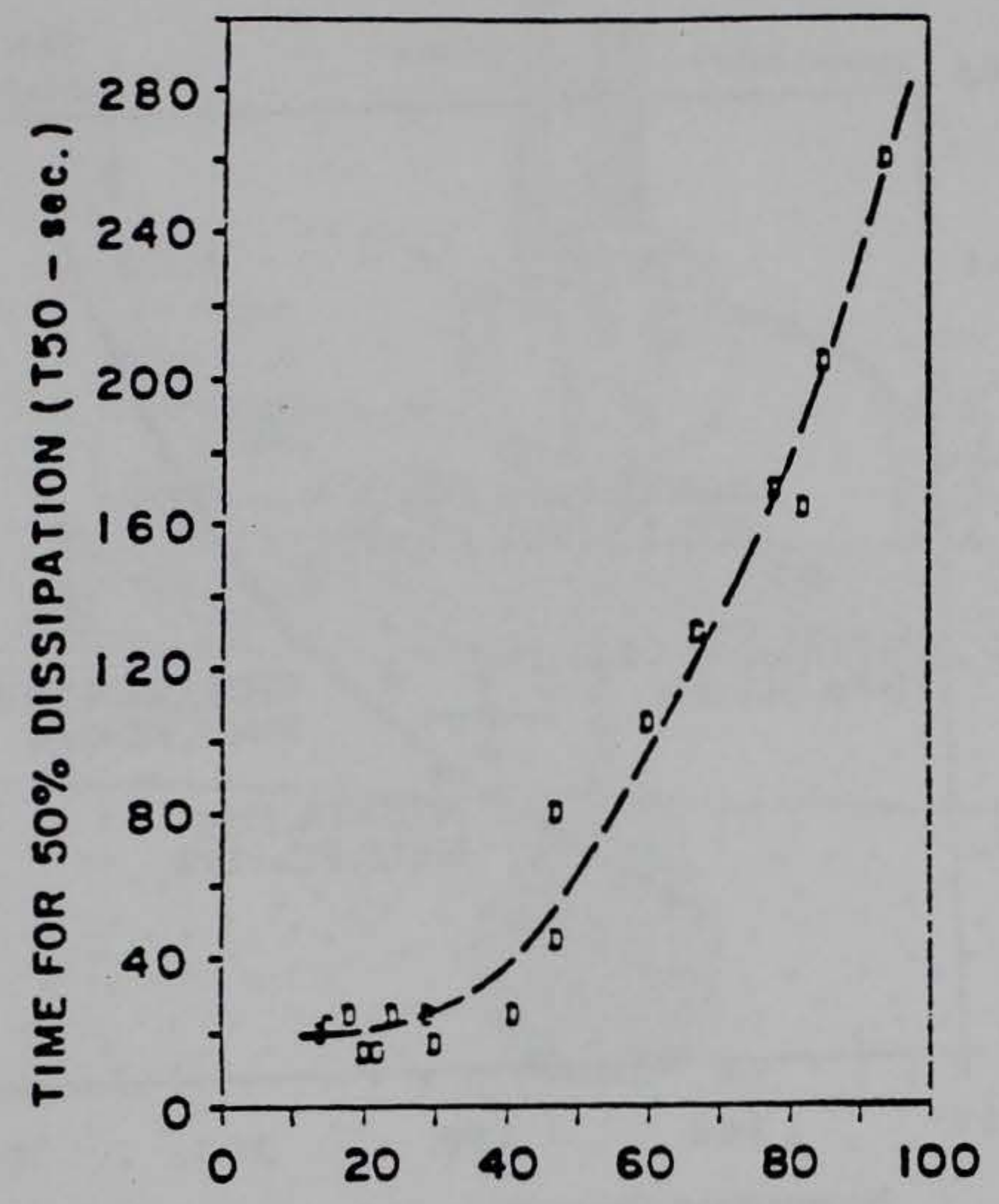

FINES CONTENT (\% possing * 200 seive)

Figure 14. Correlation between fines content and time for 50 percent dissipation from CPTU (Finn et al. 1989) 


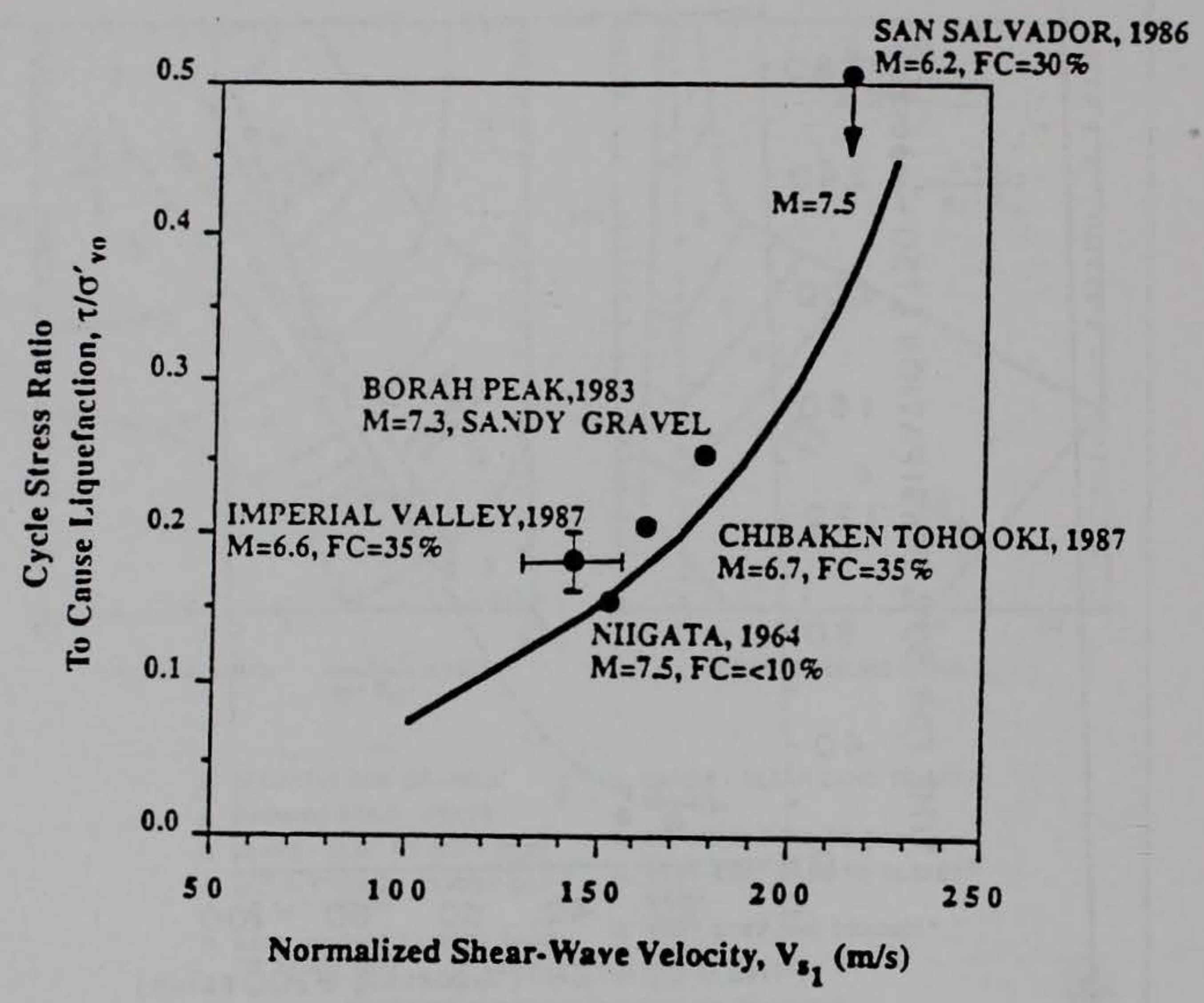

Figure 15. Proposed correlation between normalized shear wave velocity and cyclic stress ratio (CSR) to cause liquefaction (Robertson et al. 1992) 


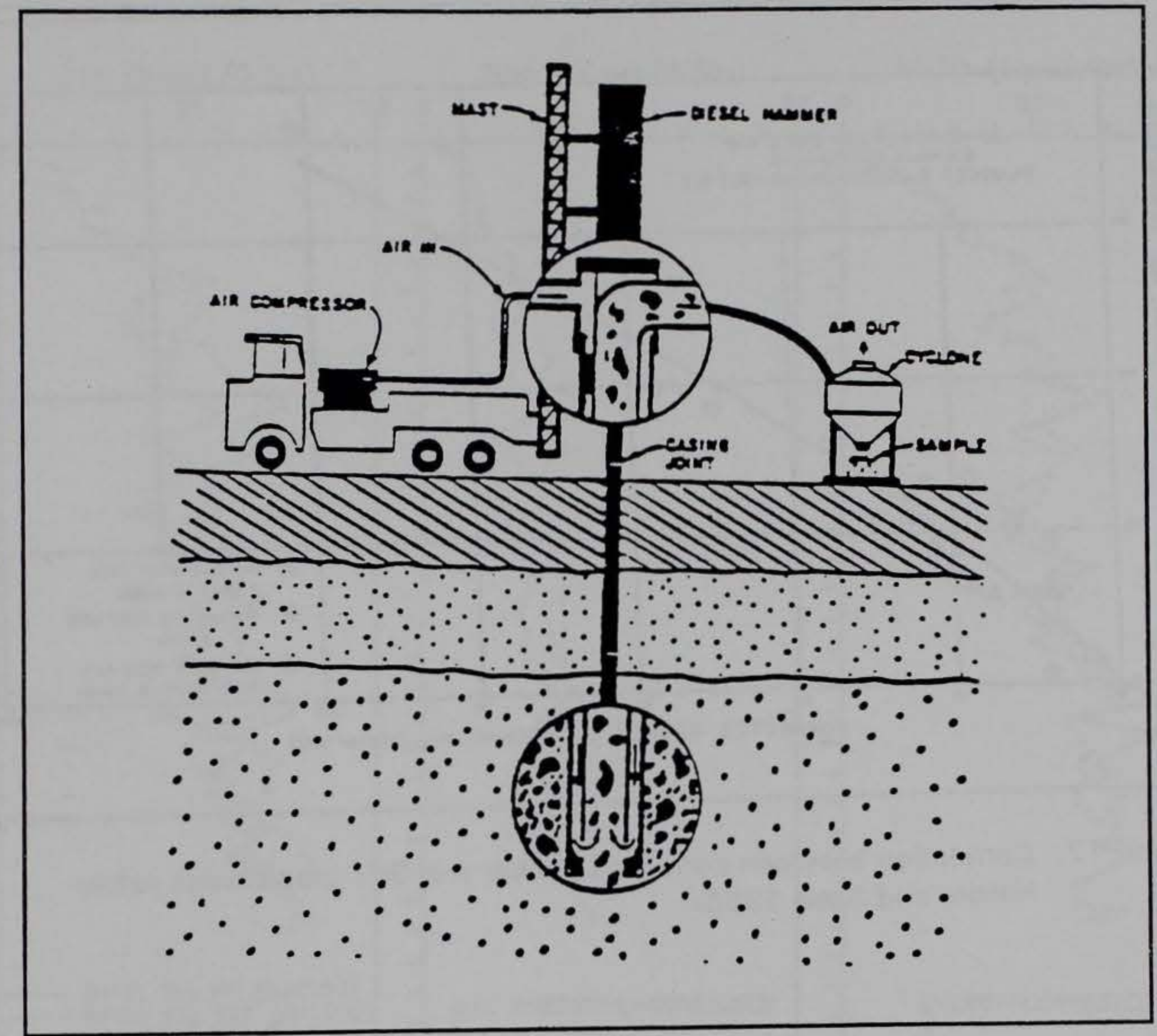

Figure 16. Becker penetration test (Harder and Seed 1986) 


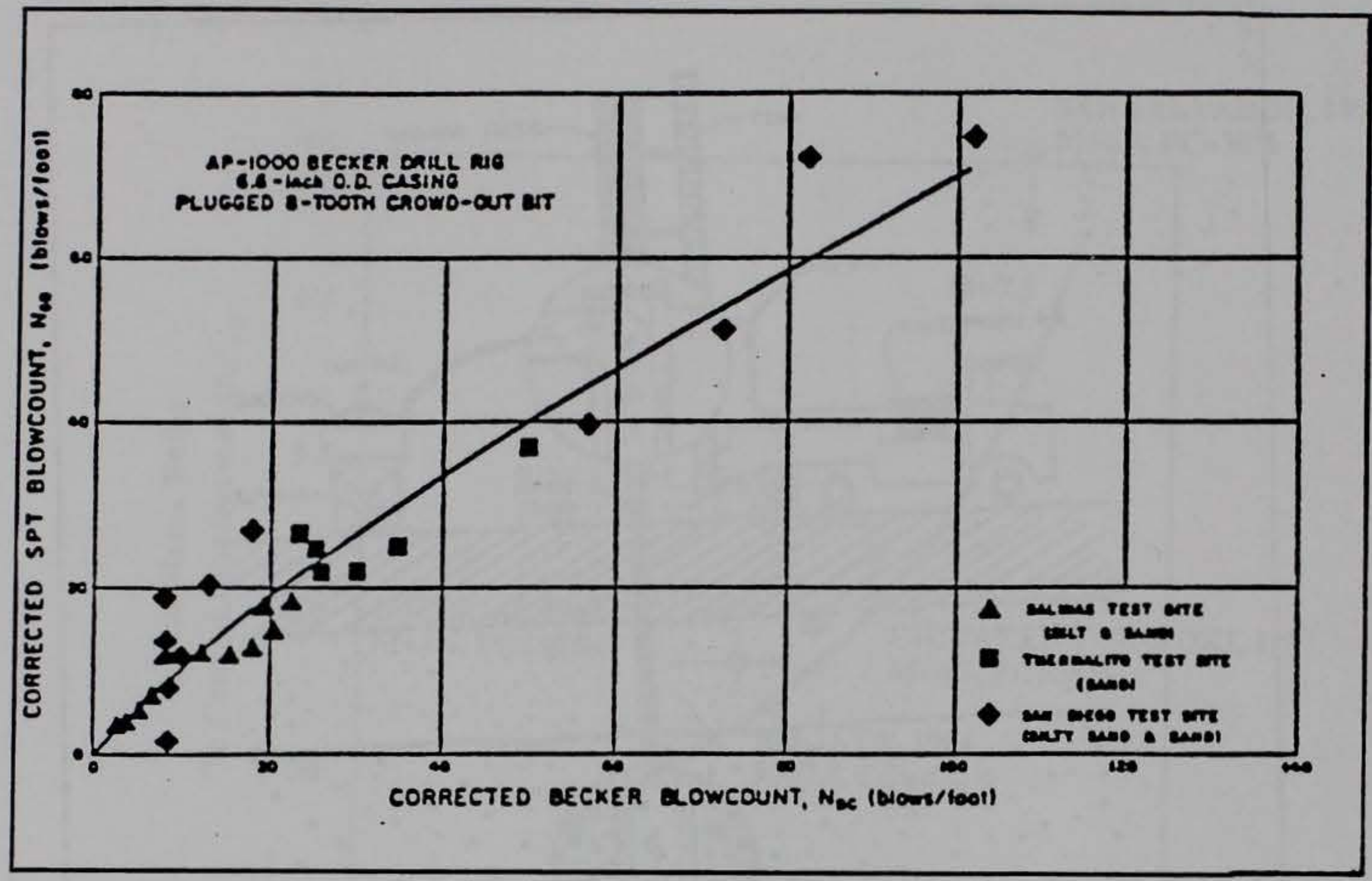

Figure 17. Correlation between corrected Becker and SPT blowcounts (after Harder and Seed 1986) 


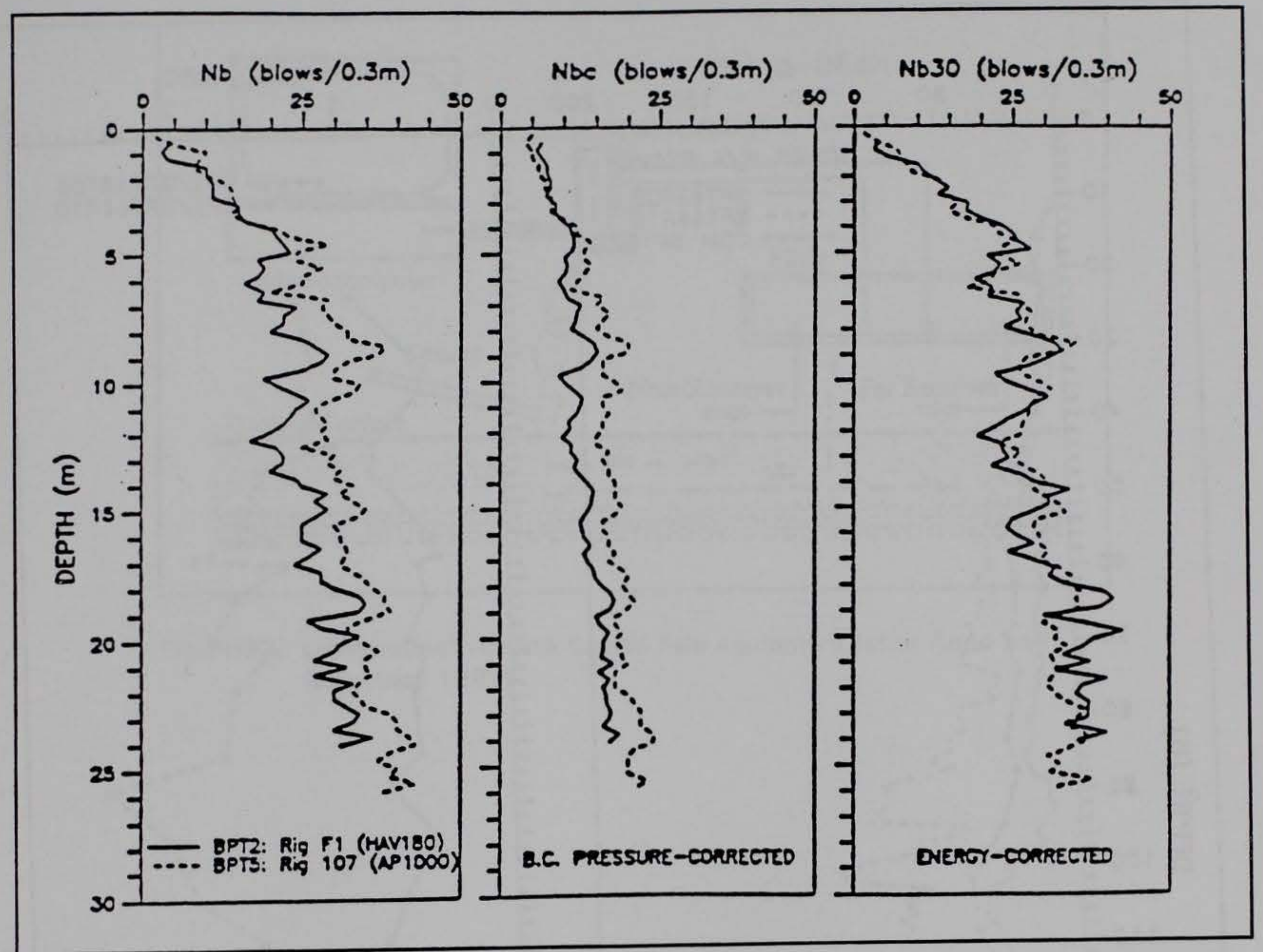

Figure 18. BPT-2 and BPT-5: measured and corrected blowcounts versus depth 


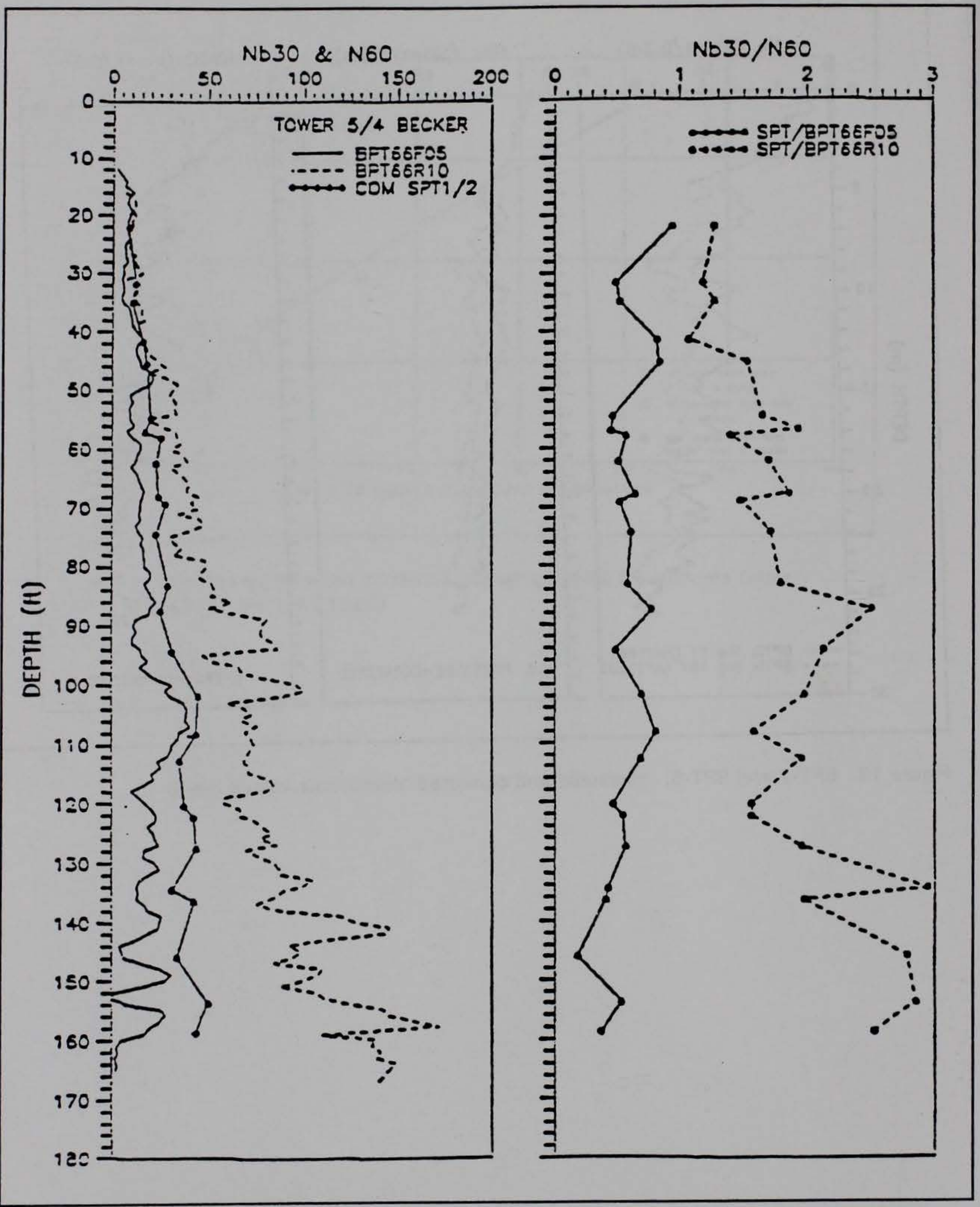

Figure 19. (a) Becker blowcounts $\mathrm{N}_{\mathrm{b} 30}$ for mudded hole (BPT-66 F05) and uncased hole (BPT-66 R10); and (b) effect of friction on normalized Becker blowcounts 


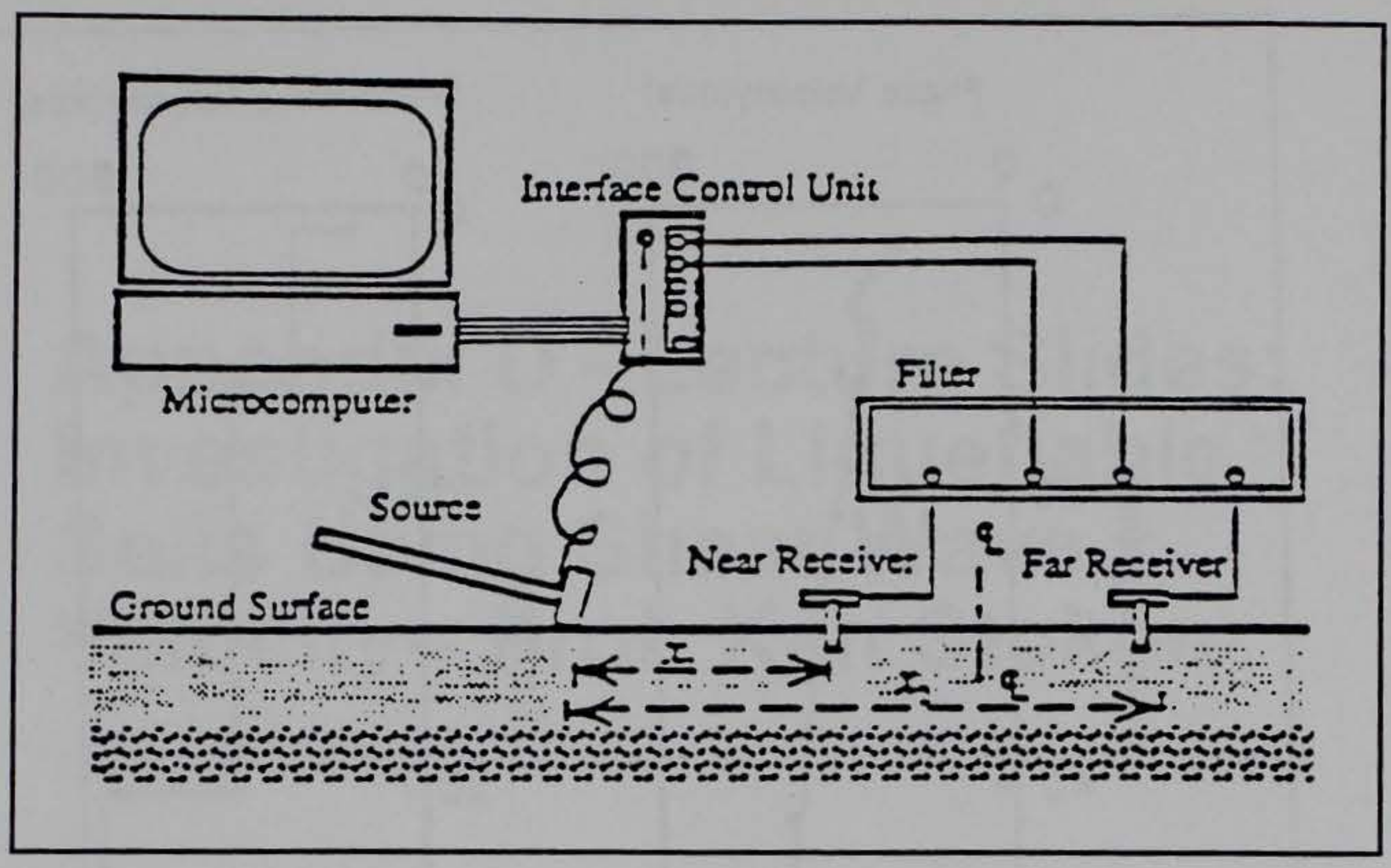

Figure 20. University of Alberta SASW field equipment (after Addo and Robertson 1992) 


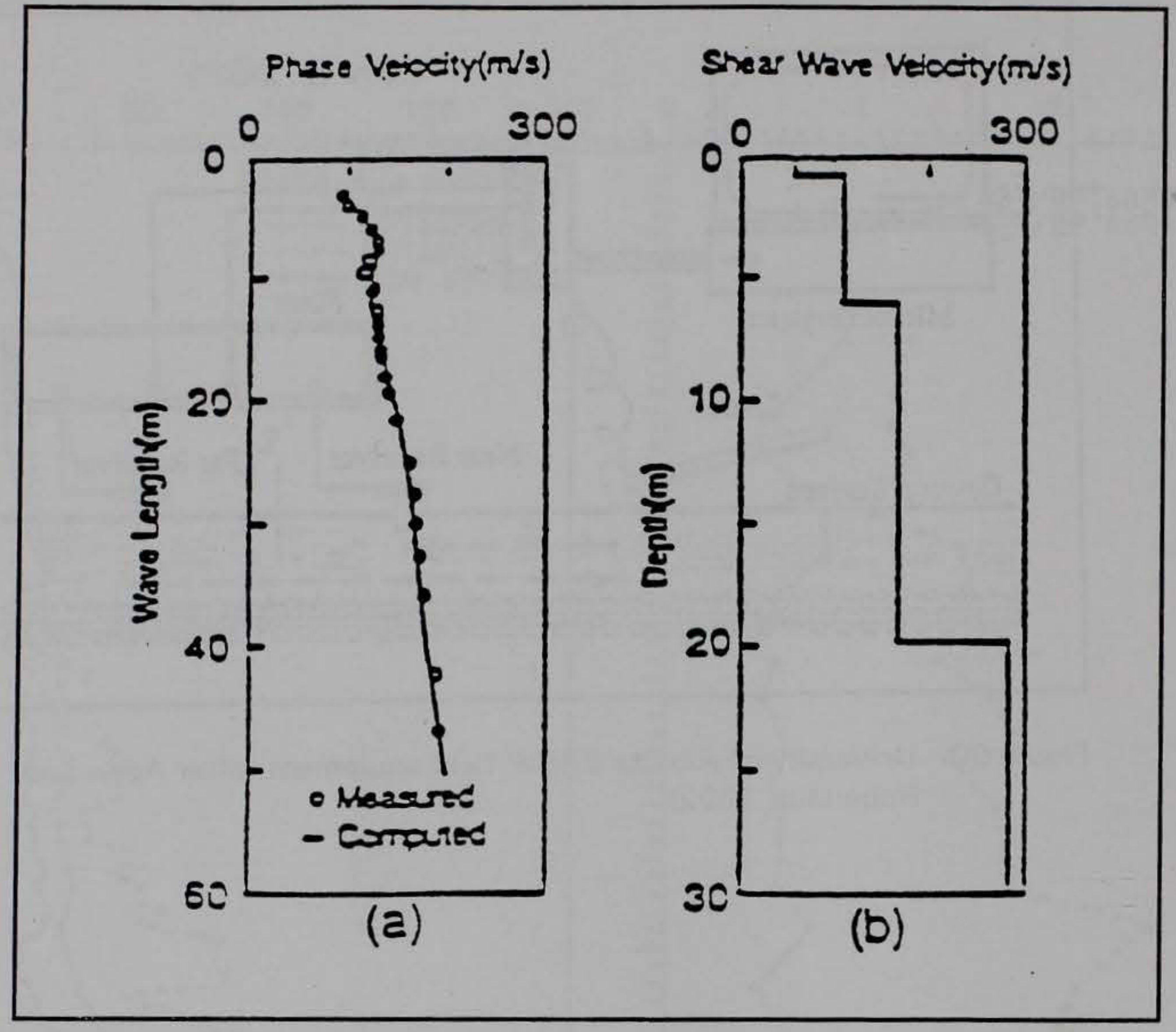

Figure 21. Measured and computed dispersion curves and resulting shear wave velocity (Tokimatsu et al. 1991) 


\section{Appendix D - Lecture Slides: Investigation of Liquefiable Soils Using Shear Wave Velocity - Prof. Ken Stokoe}




\section{Investigation of Liquefiable Soils Using Shear Wave Velocity}

by

Kenneth H. Stokoe, II Brunswick Abernathy Regents Professor University of Texas at Austin and

Ronald D. Andrus Research Civil Engineer National Institute of Standards and Technology 


\section{OUTLINE}

1. Discuss Field Seismic Tests

2. Present Typical Field Data

3. Present Analytical Studies

- Identify Important Parameters

- Investigate Typical Ranges

- Develop Assesment Charts

4. Compare Field Performance With

Liquefaction Assesment Charts

5. Qualitative Evaluation of In Situ Density

6. Summarize Findings and Experiences 


\section{BASIS OF WORK}

- Field, Laboratory and Analytical Studies

- Sites Composed of Gravelly, Sandy and Silty Soils

- All Sites Exhibited Surface Manifestations of Liquefaction

- All Liquefiable Deposits Have Been Shallow $(<12 \mathrm{~m})$ 


\section{FIELD INVESTIGATIONS:}

- SEISMIC TESTING

Crosshole, Downhole, SCPT and SASW

- PENETRATION TESTING

SPT, CPT and Becker

- SAMPLING

Intact (3-in. Shelby tube)

Disturbed (SPT split spoon to backhoe)

FIELD LOCATIONS:

- CALIFORNIA Imperial Valley and S.F. Bay Area

- IDAHO 


\section{Simplified Schematic of Crosshole Seismic Test}

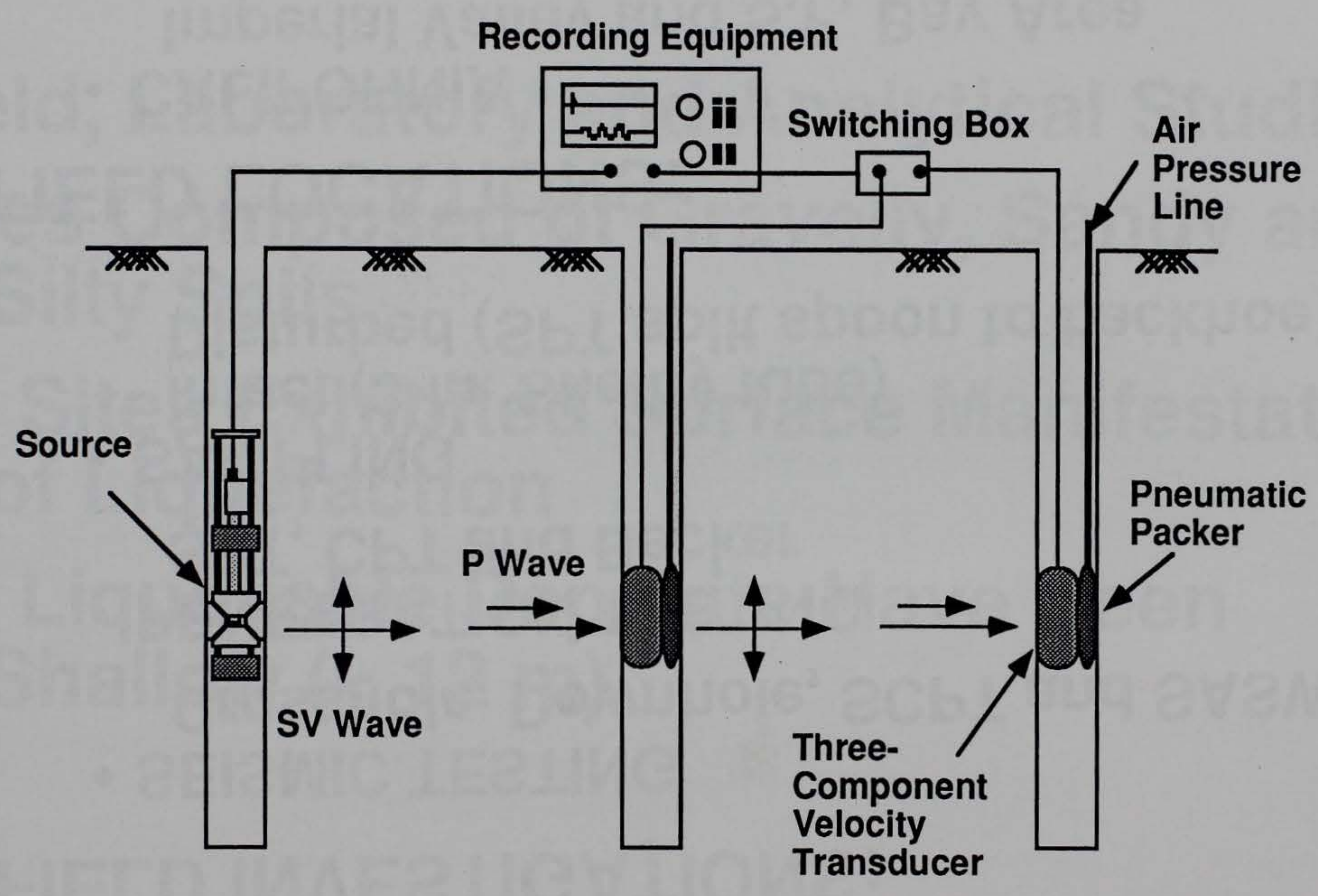




\section{Typical Crosshole Measurements}
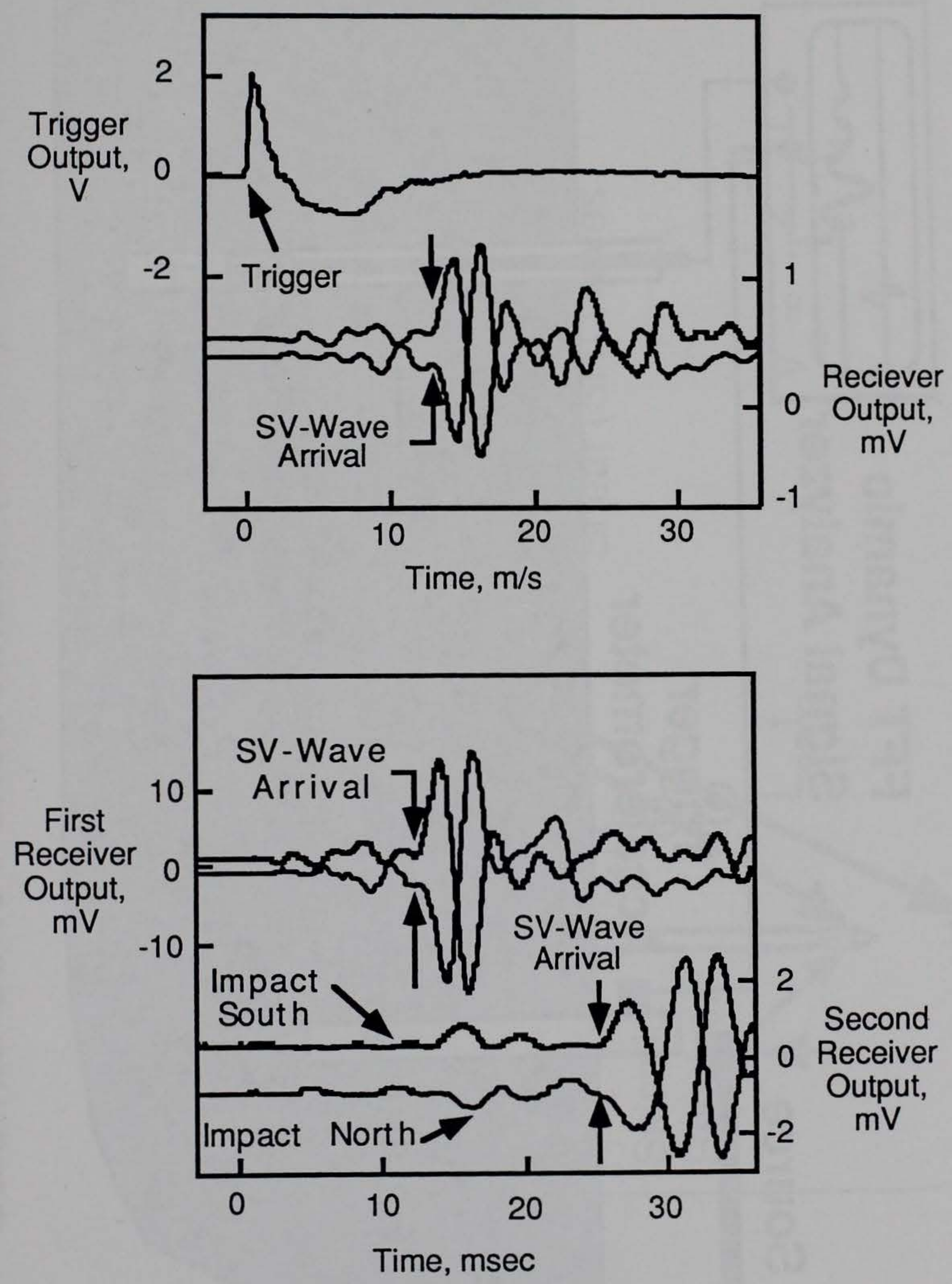


\section{Rapid-Deployment Crosshole System}

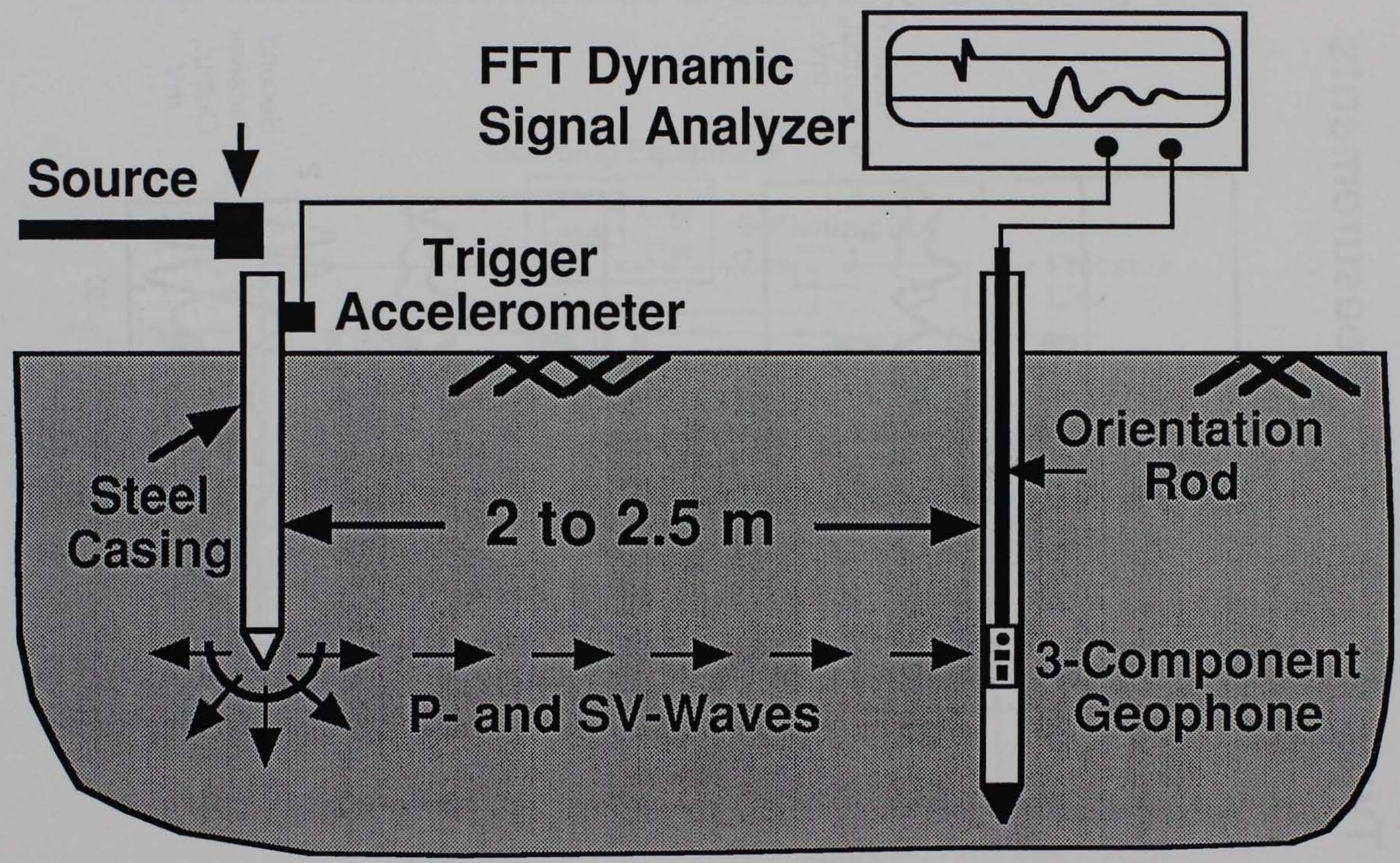




\section{Seismic Cone Penetrometer (SCPT)/Downhole Test}

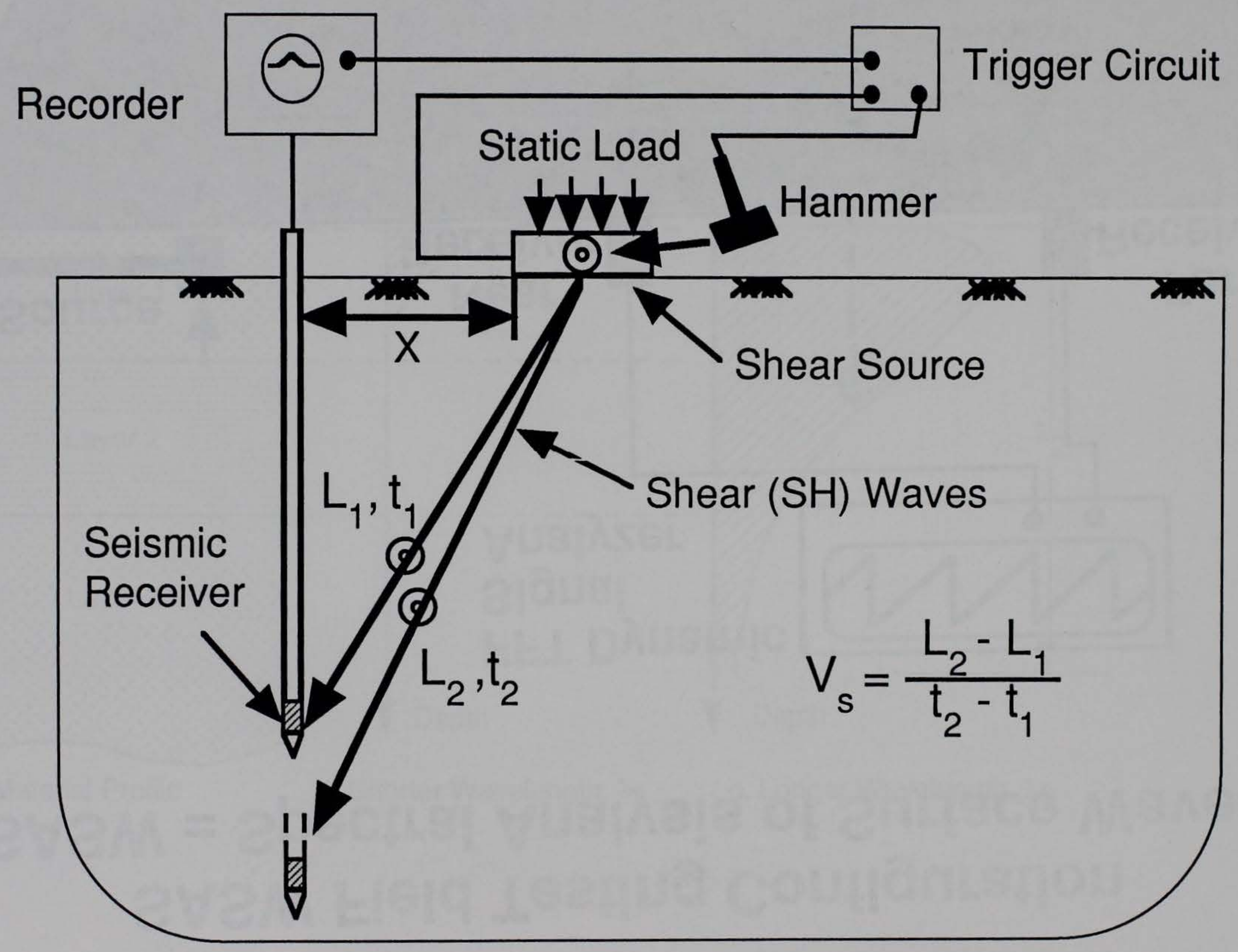




\section{SASW Field Testing Configuration (SASW = Spectral Analysis of Surface Waves)}

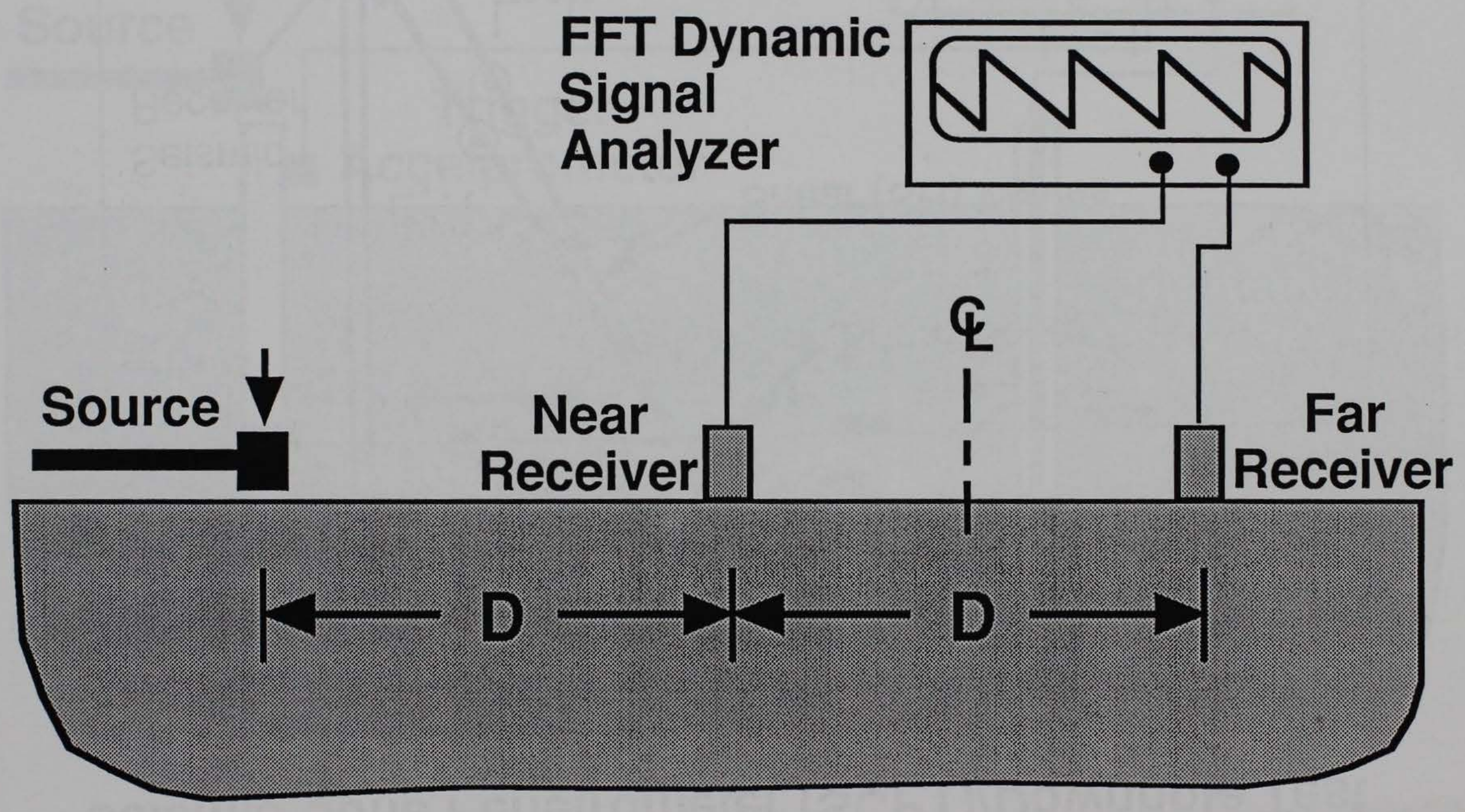




\section{Approximate Distribution of Vertical Particle Motion with Depth for Two Rayleigh Waves with Different Wavelengths}
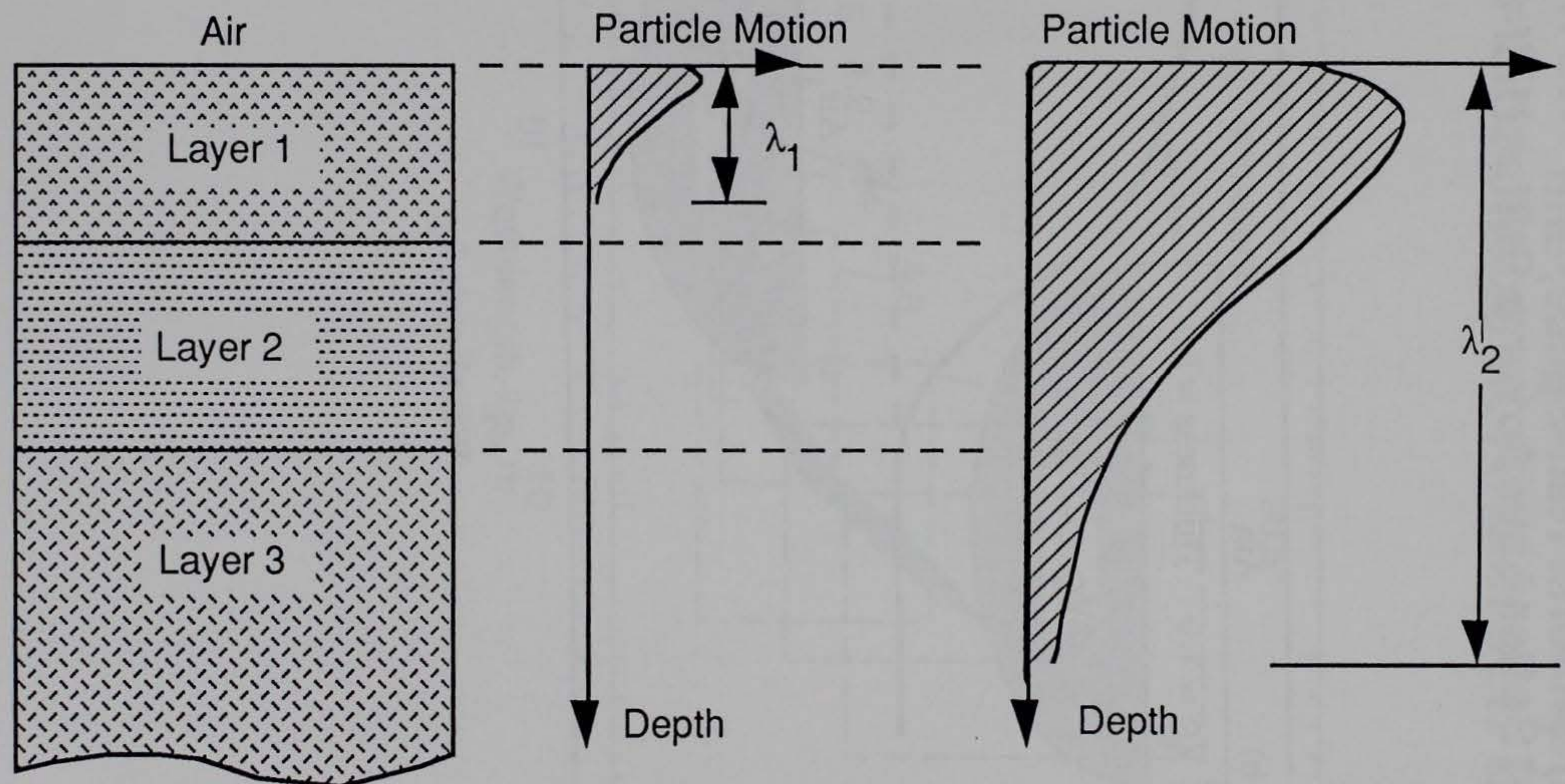

a. Material Profile

b. Shorter Wavelength, $\lambda_{1}$

c. Longer Wavelength, $\lambda_{2}$ 
Dispersion Curves for Plane Rayleigh Waves Propagating in:

(a) Uniform Half-Space, and

(b) Softer Layer over a Stiffer Half-Space

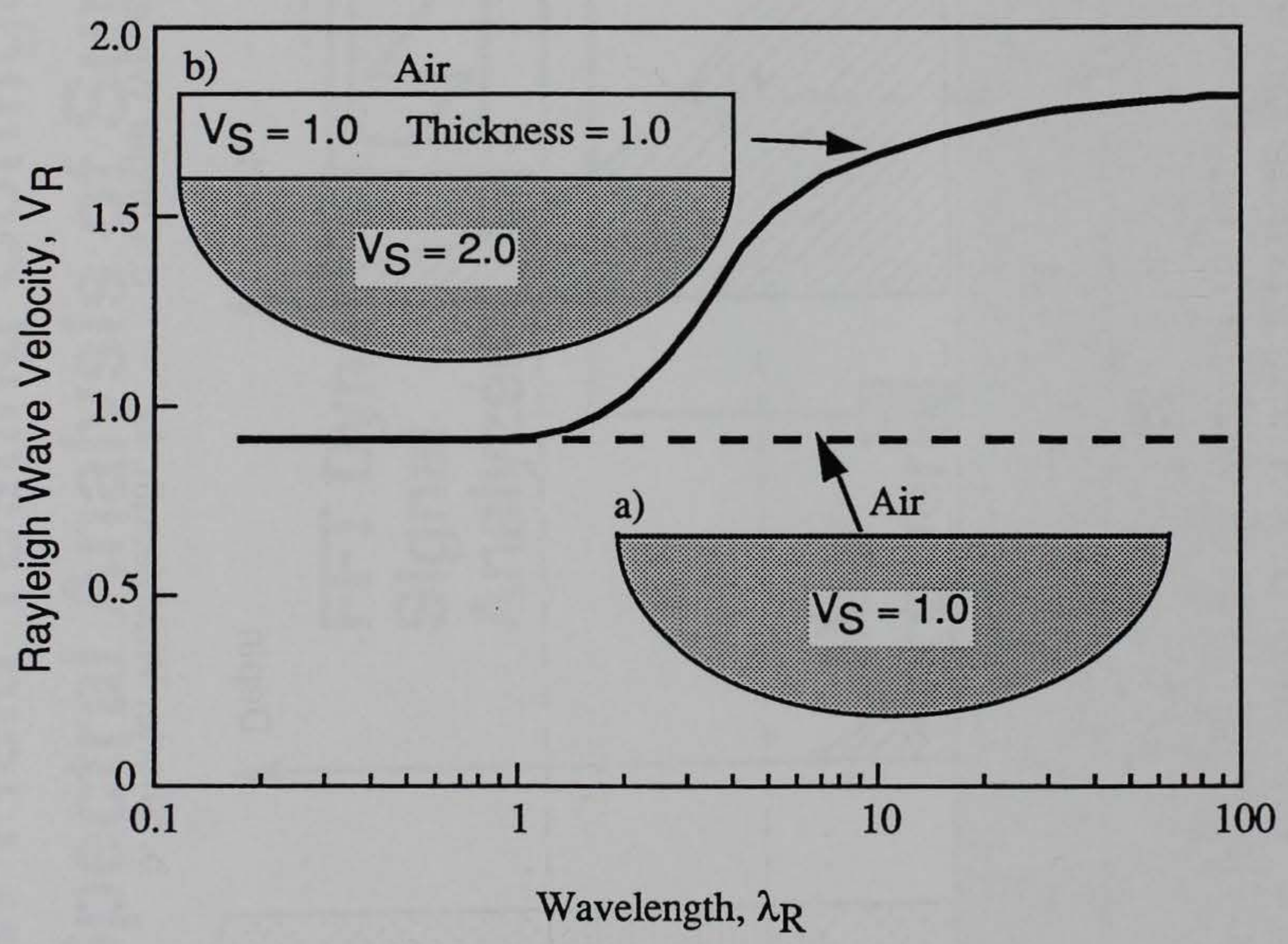




\section{Composite Experimental Dispersion Curve from Testing with Multiple Receiver Spacings at Andersen Bar}

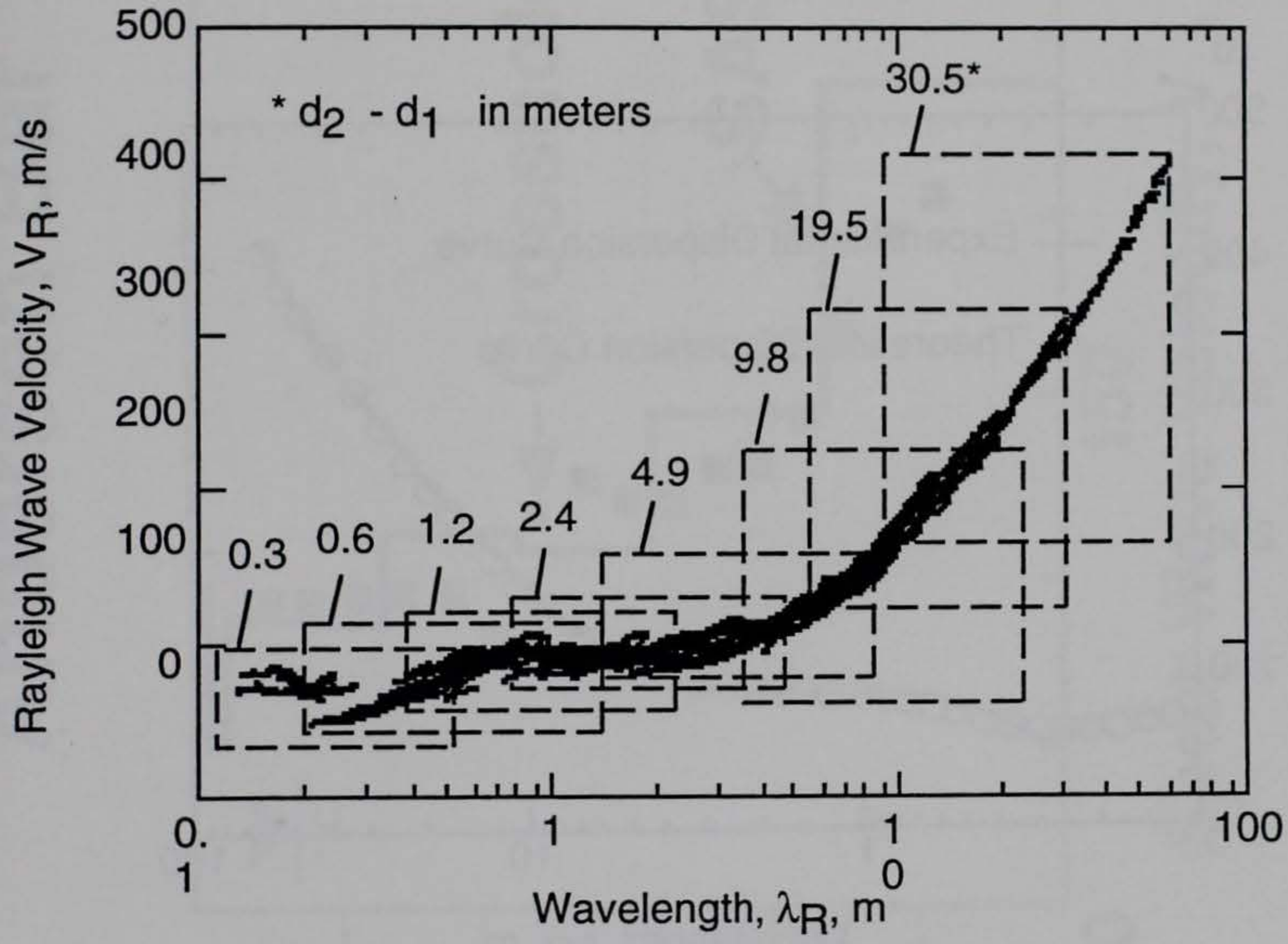




\section{Match Between Experimental and Theoretical Dispersion Curves at Andersen Bar}

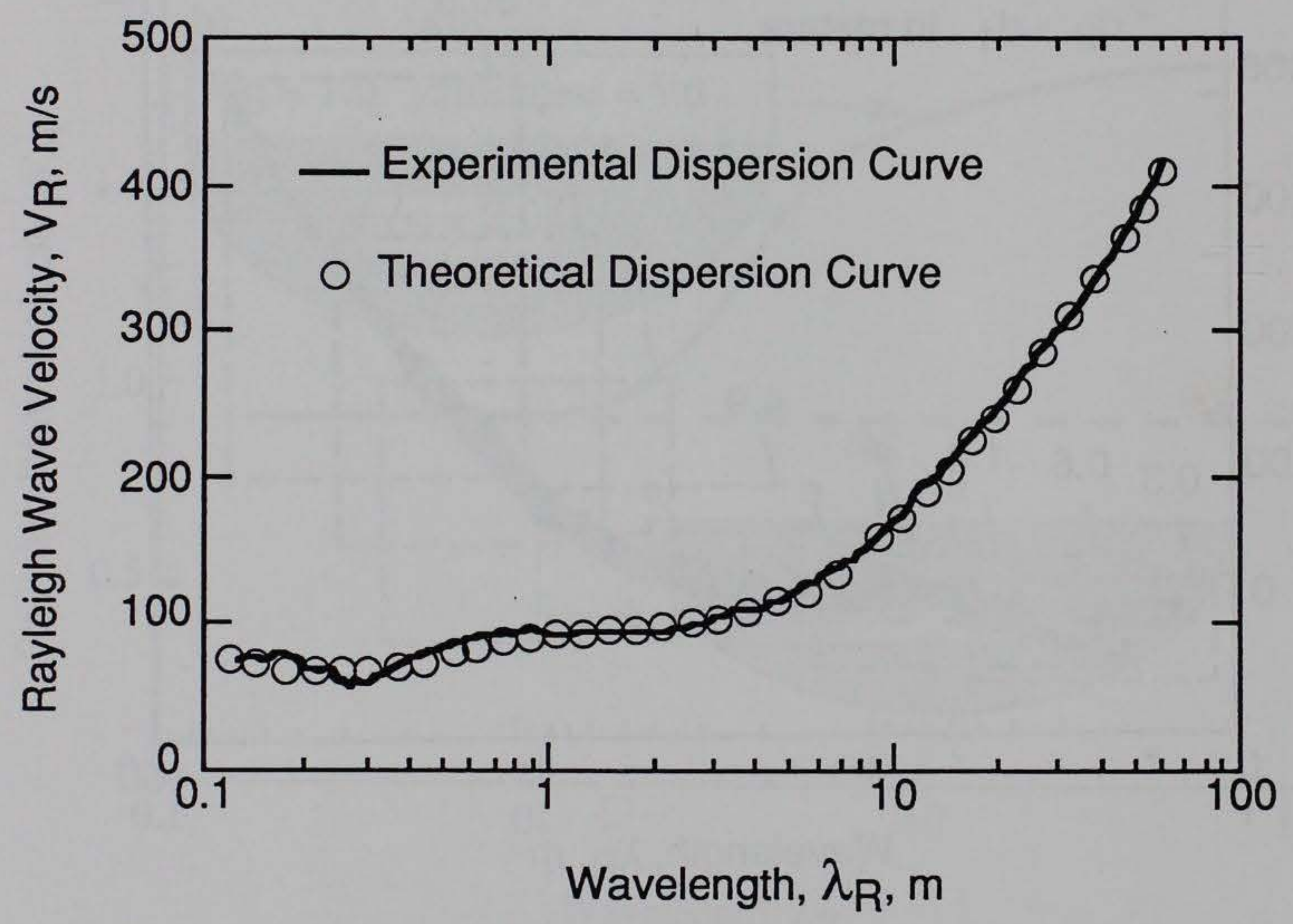




\section{Andersen Bar}

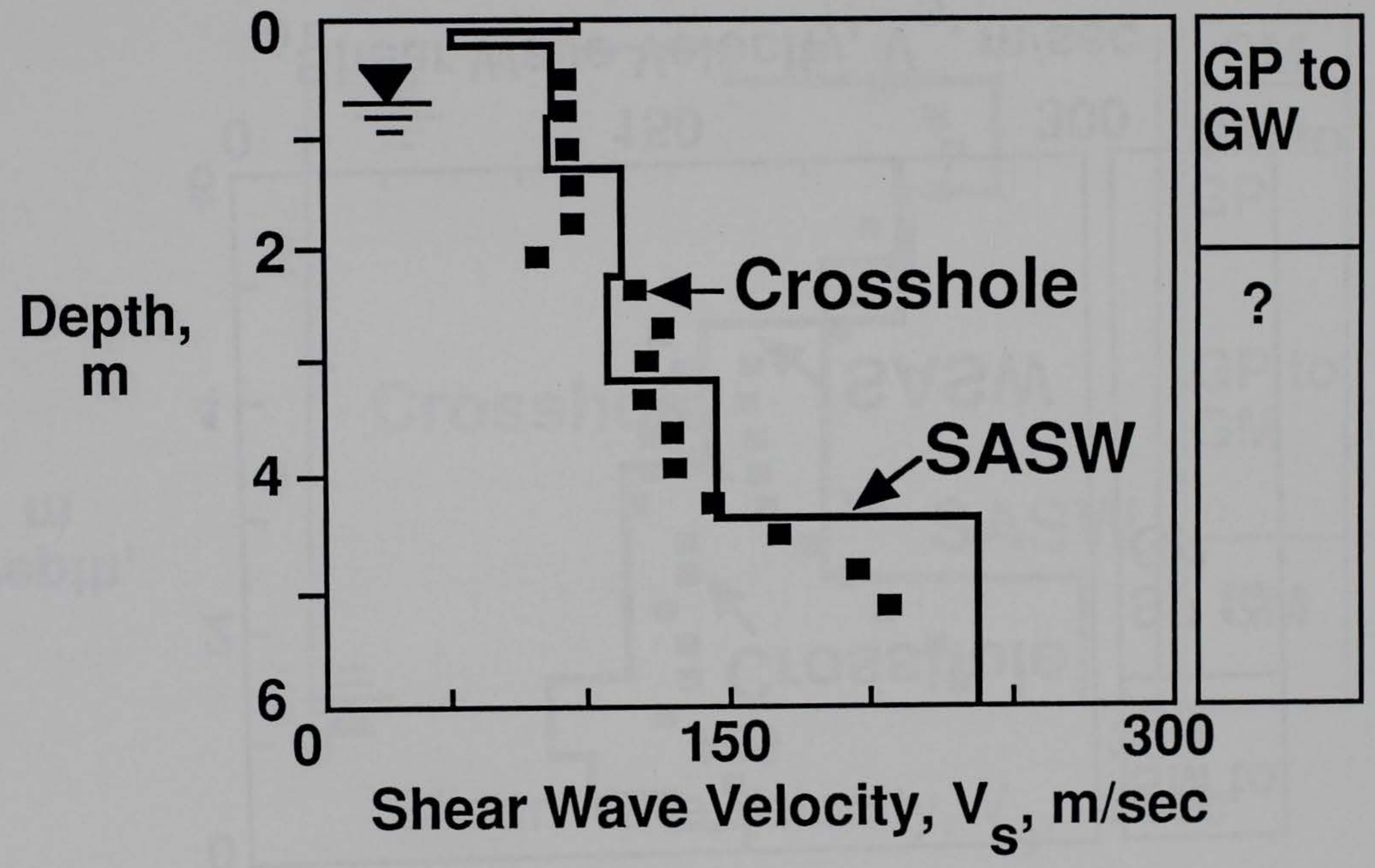




\section{Pence Ranch}

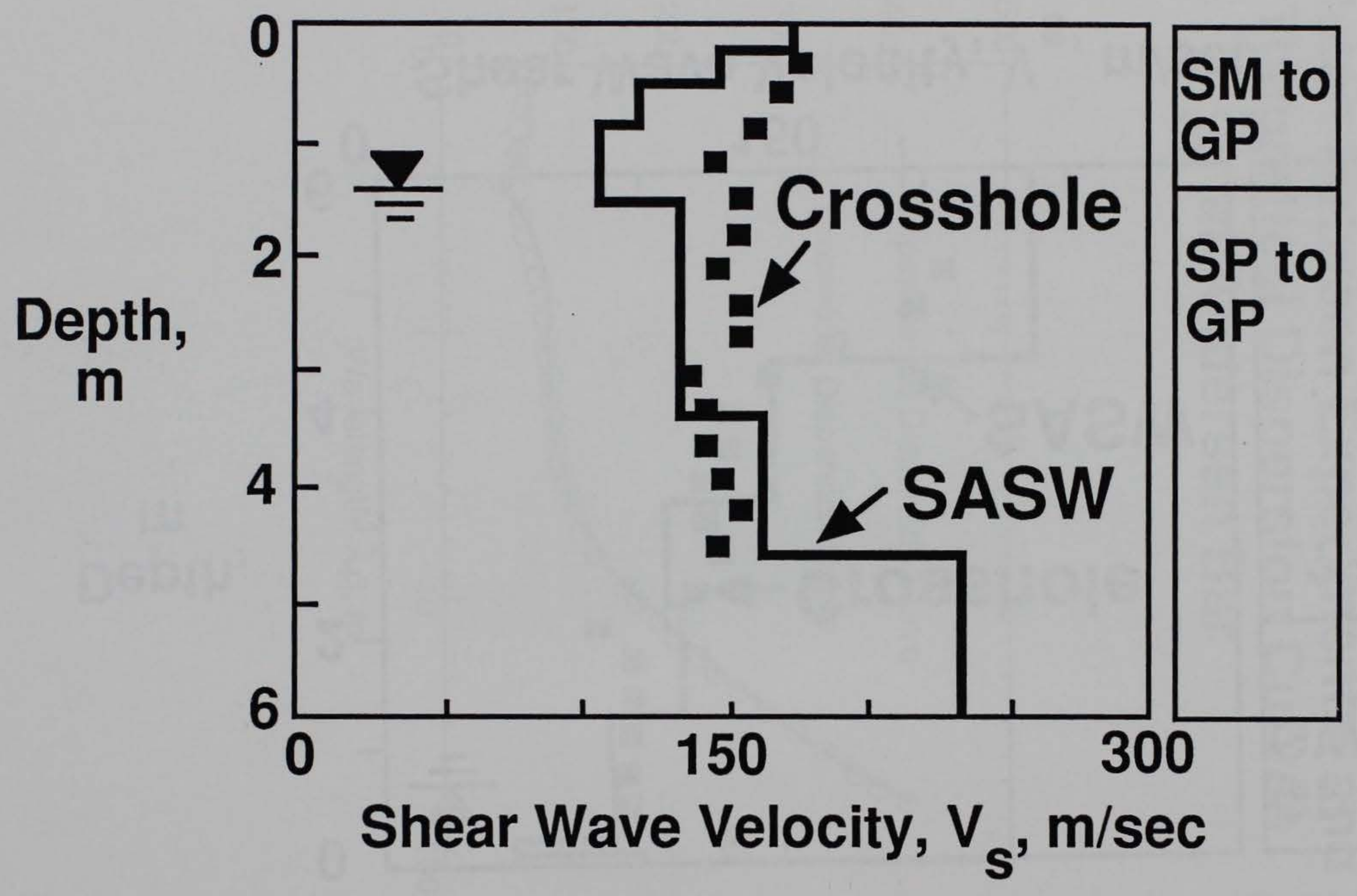




\section{Larter Ranch}

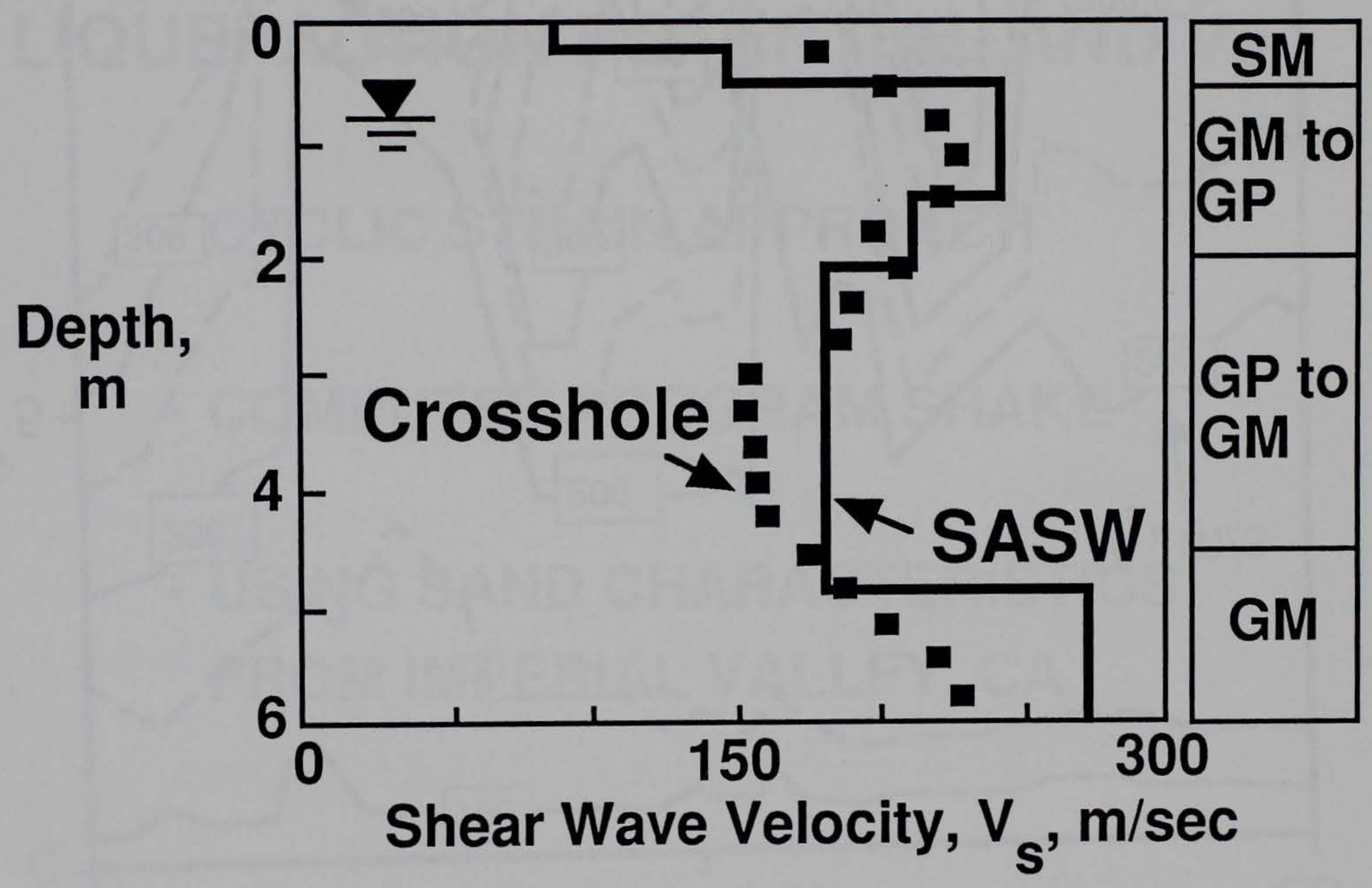


Gulf of Mexico: SASW Lateral Variability Study

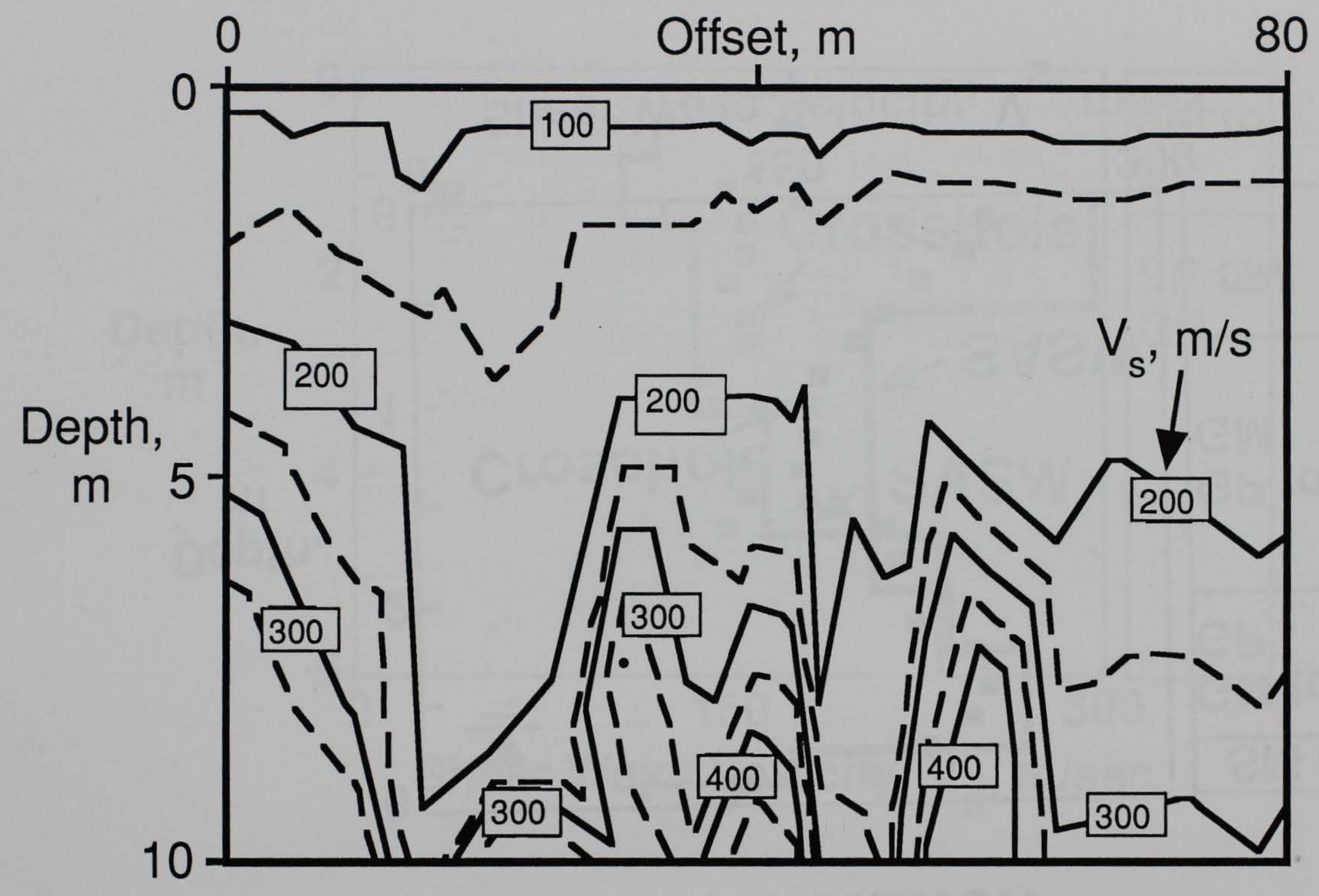




\section{PARAMETRIC STUDY RELATING LIQUEFACTION POTENTIAL AND Vs}

- CYCLIC STRAIN APPROACH

- COMPUTER PROGRAM SHAKE

- USING SAND CHARACTERISTICS FROM IMPERIAL VALLEY, CA 


\section{PARAMETERS VARIED}

SHEAR WAVE VELOCITY (VS) OF SAND

DEPTH AND THICKNESS OF SAND LAYER

CHARACTERISTICS OF GROUND MOTION

- peak acceleration, amax

- number of cycles, Nc

STRONG-MOTION RECORD

- Salton Sea (225 deg.) amax $=0.20 \mathrm{~g}$ (1981)

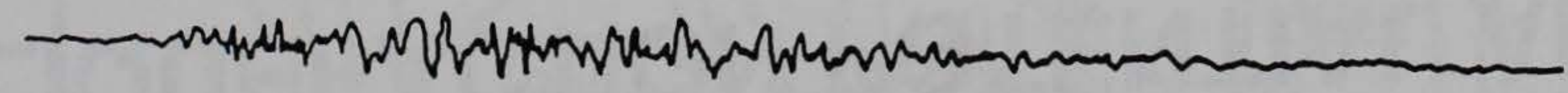

Time Scale (seconds)

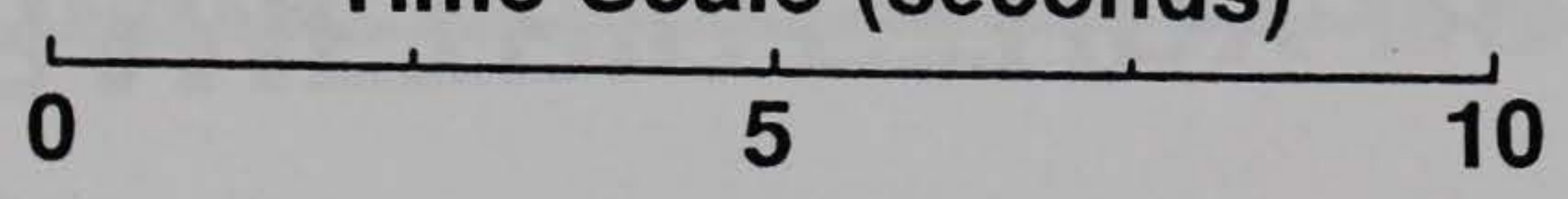




\section{Soil Profiles}

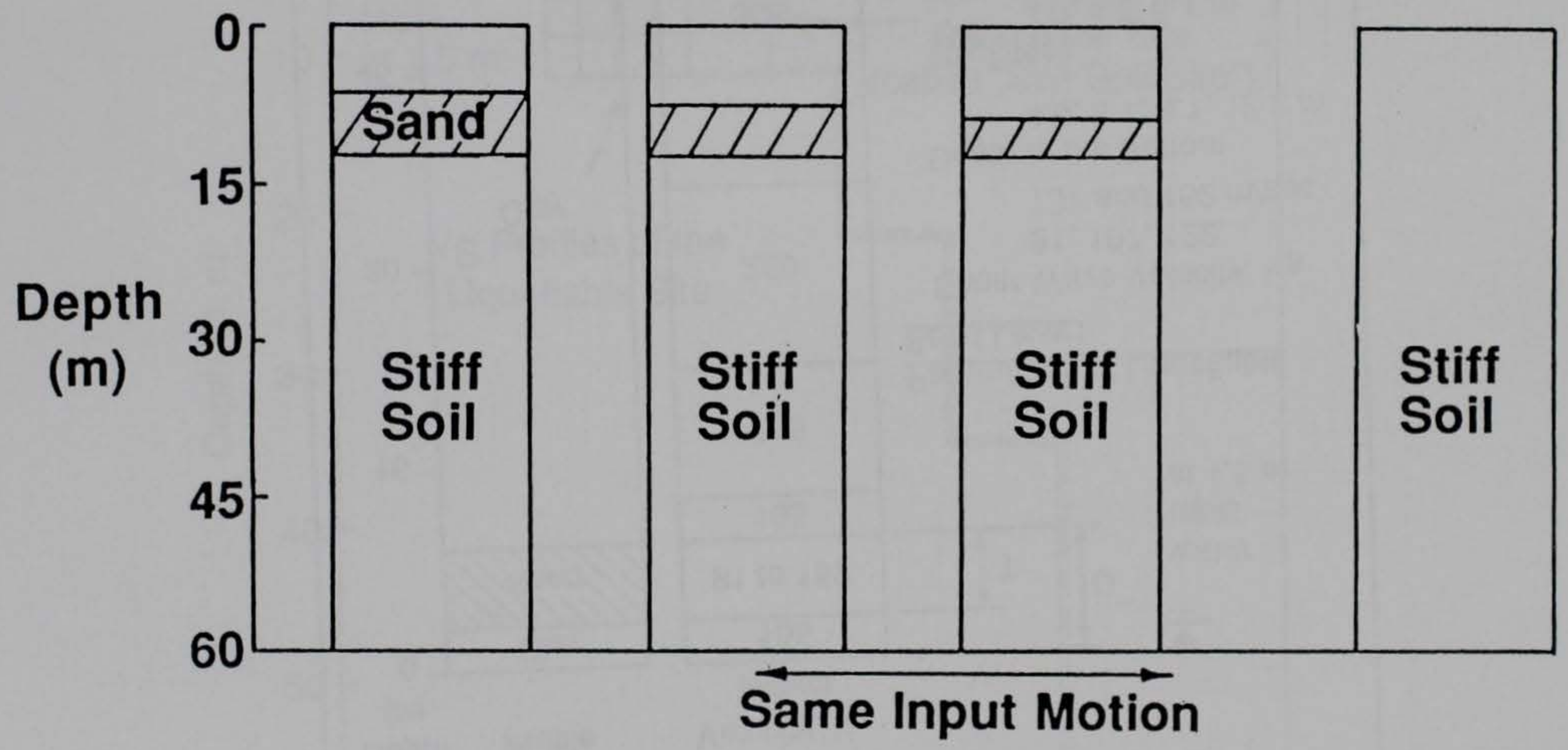




\section{Soil Profiles Used in Parametric Studies}

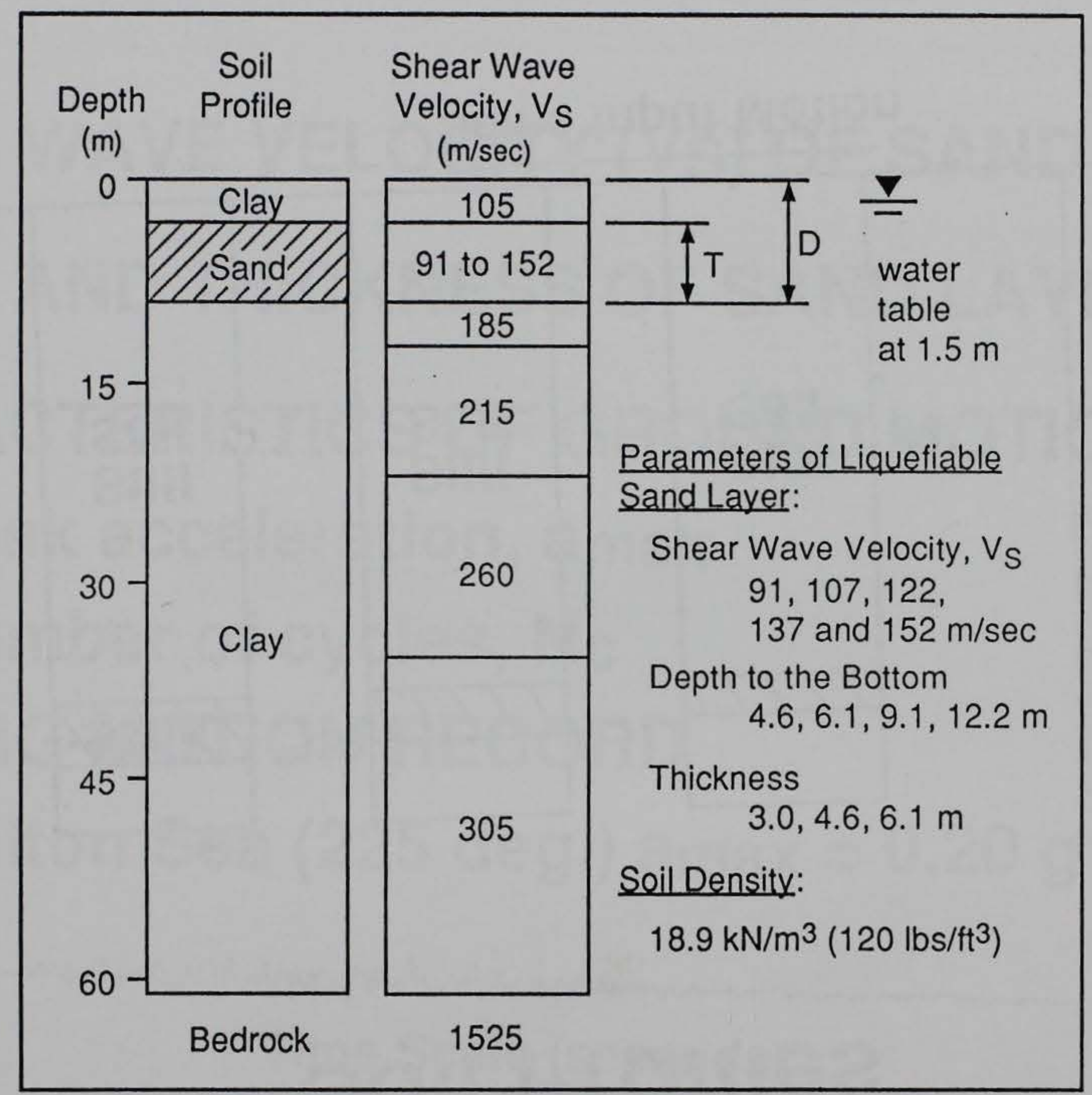




\section{Shear Wave Velocity Profiles Used in Parametric Studies}

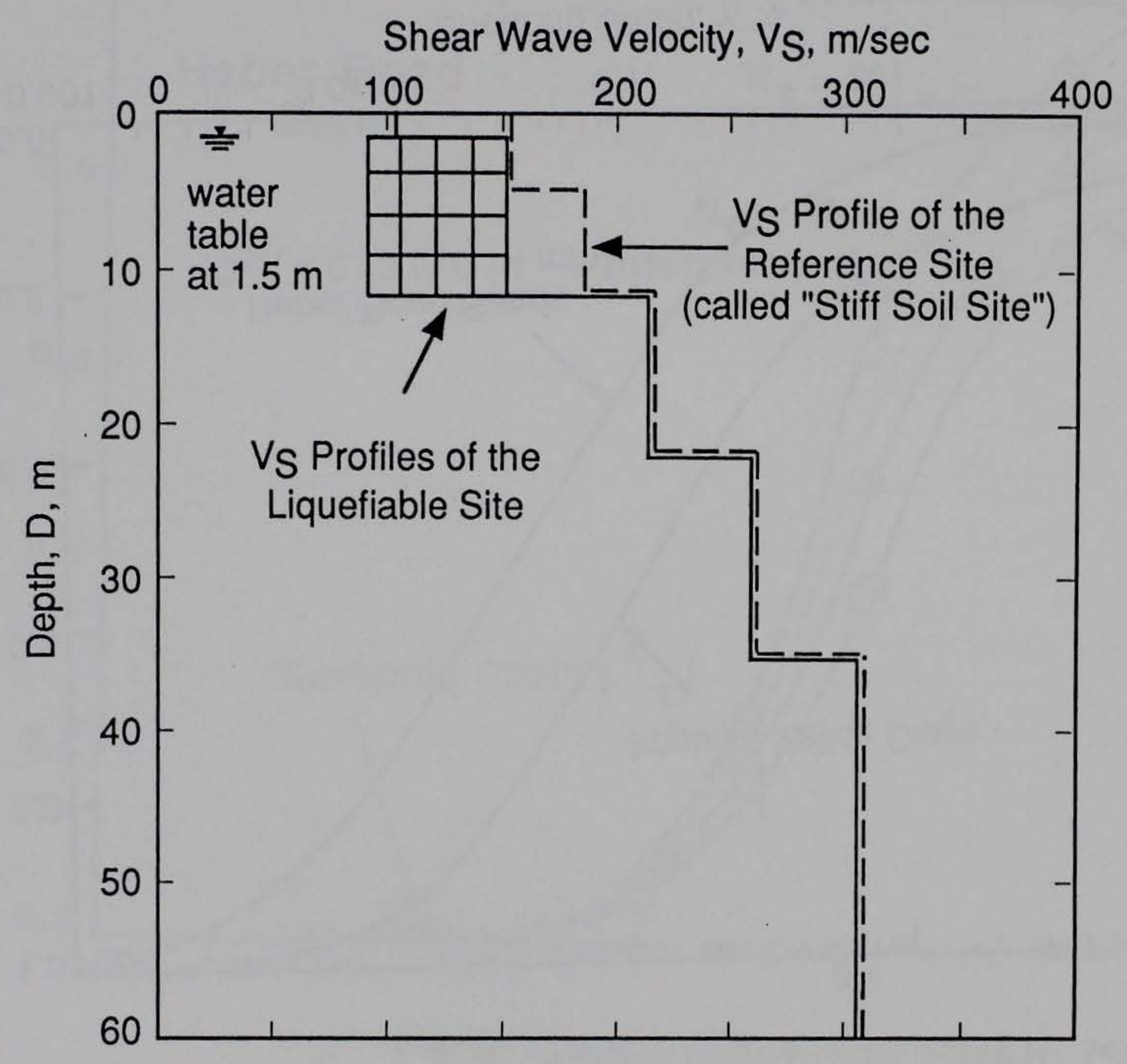




\section{Variation in Normalized Modulus with Strain for Imperial Valley Soils}

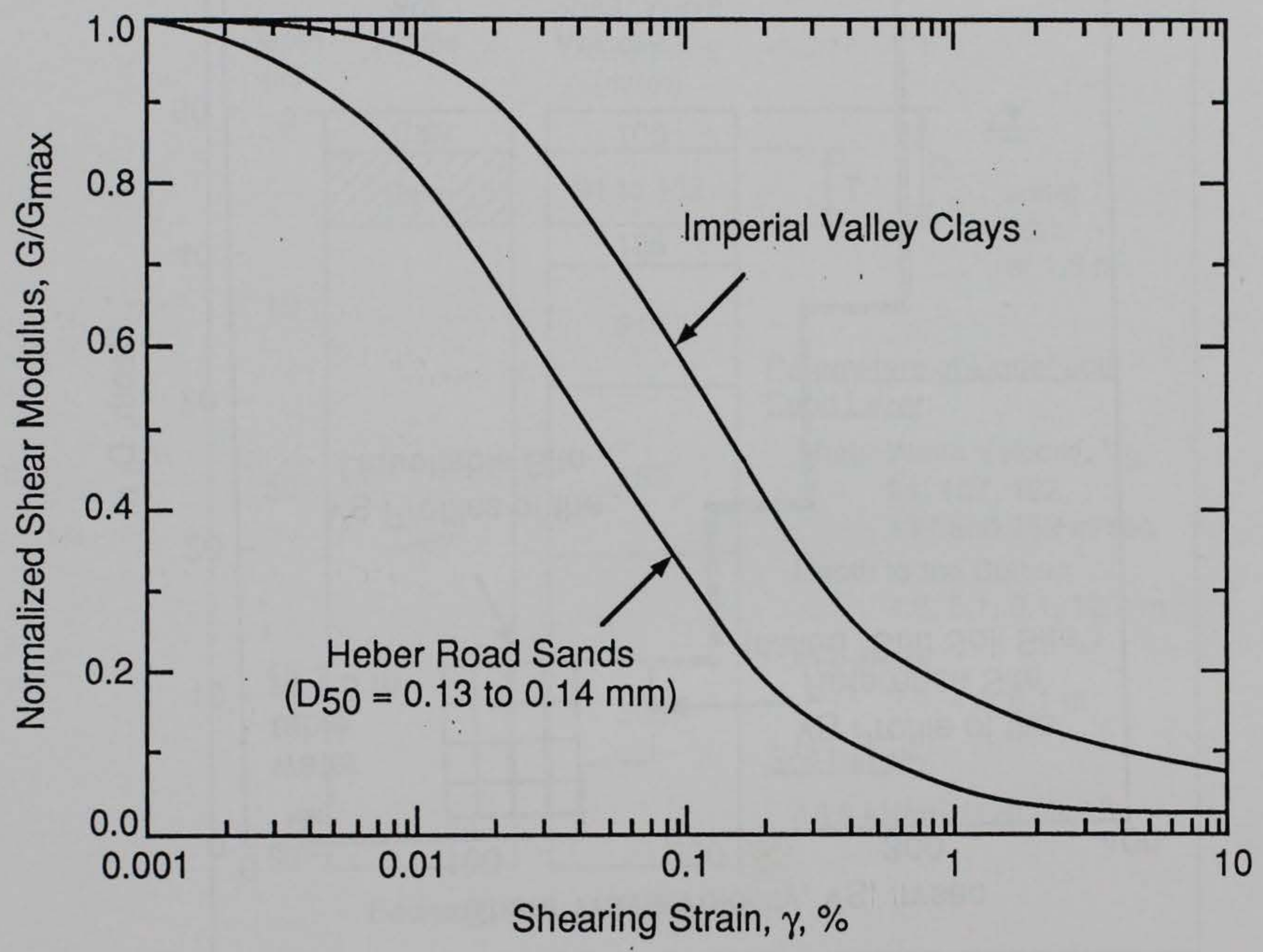




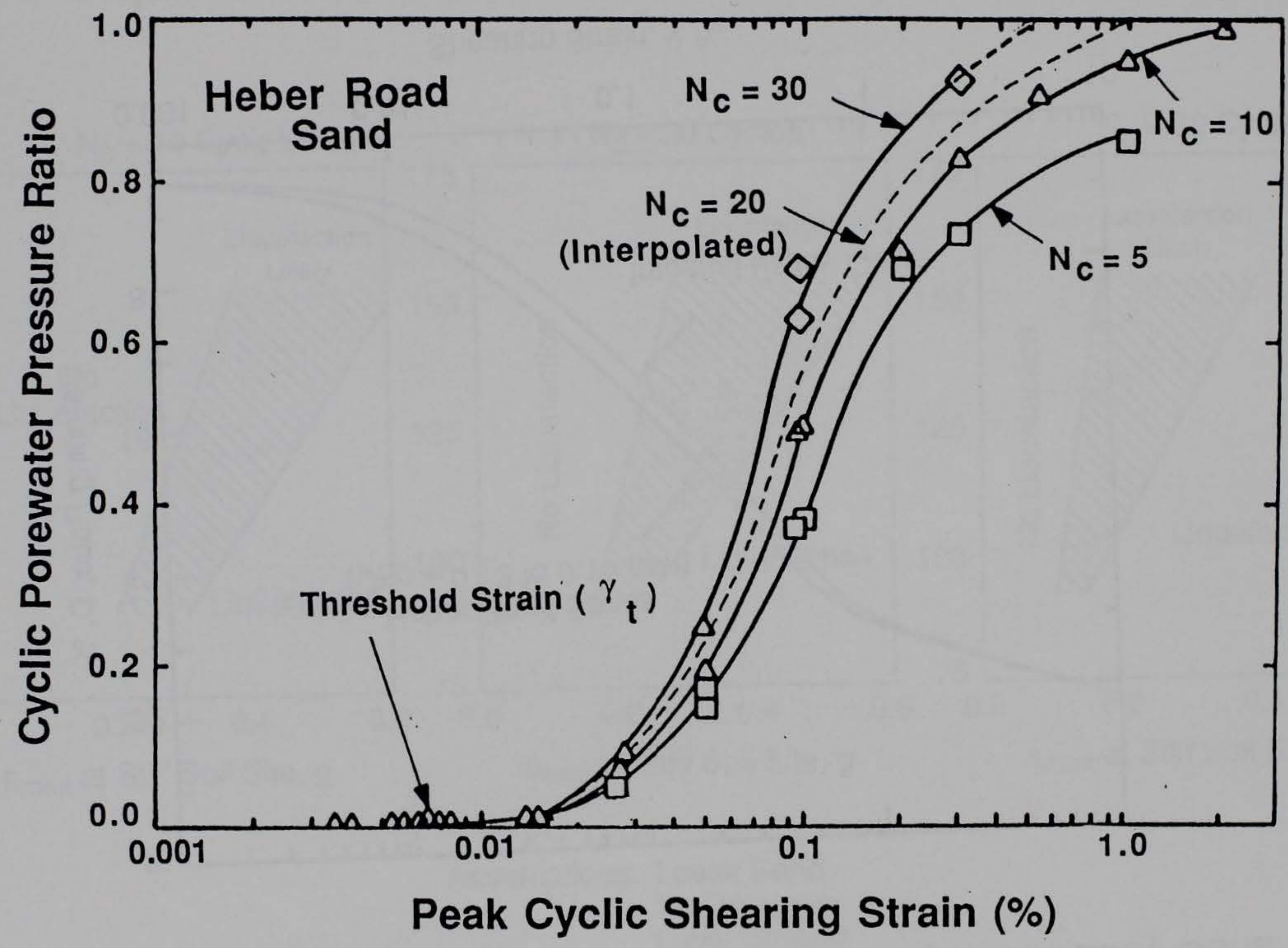


Variation in Material Damping with Strain for Imperial Valley Soils

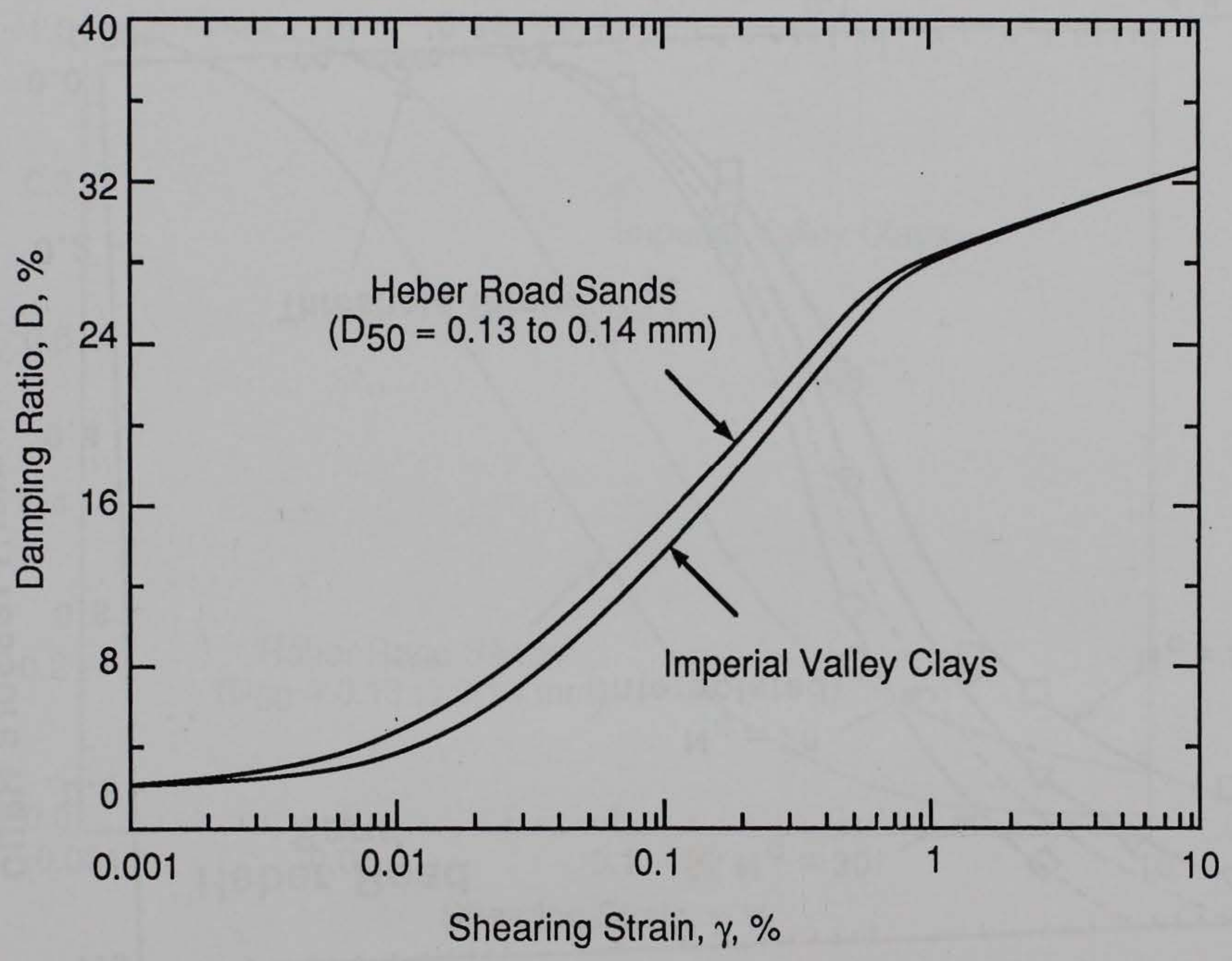




\section{Liquefaction Potential Charts Based on $\mathrm{V}_{\mathrm{S}}$}
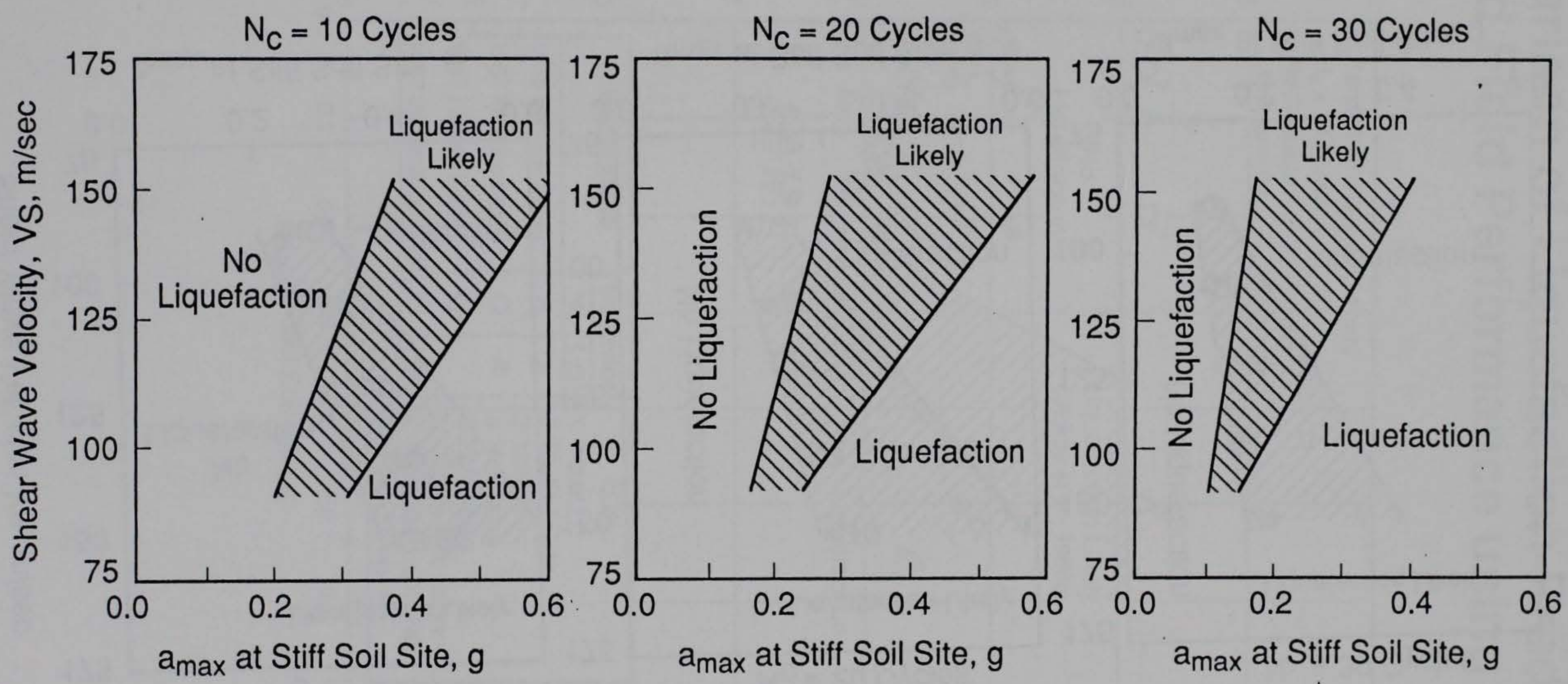

Assumptions: Loose Sand No Drainage Level Ground 


\section{Liquefaction Potential Charts Based on $\mathrm{V}_{\mathrm{S}}$}
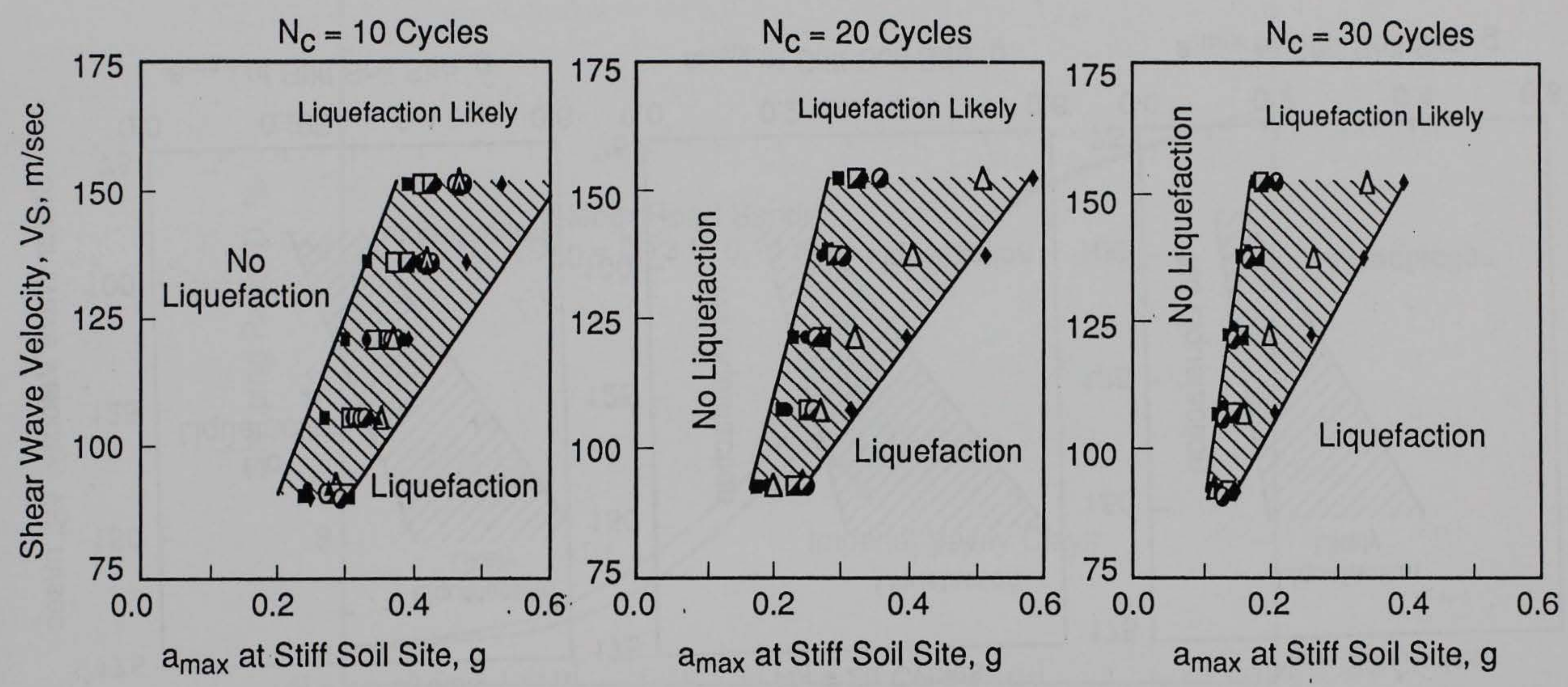

Assumptions: Loose Sand No Drainage Level Ground 


\section{Comparison of Liquefaction Predictions and Field Performance using $\mathrm{V}_{\mathbf{S}}$}

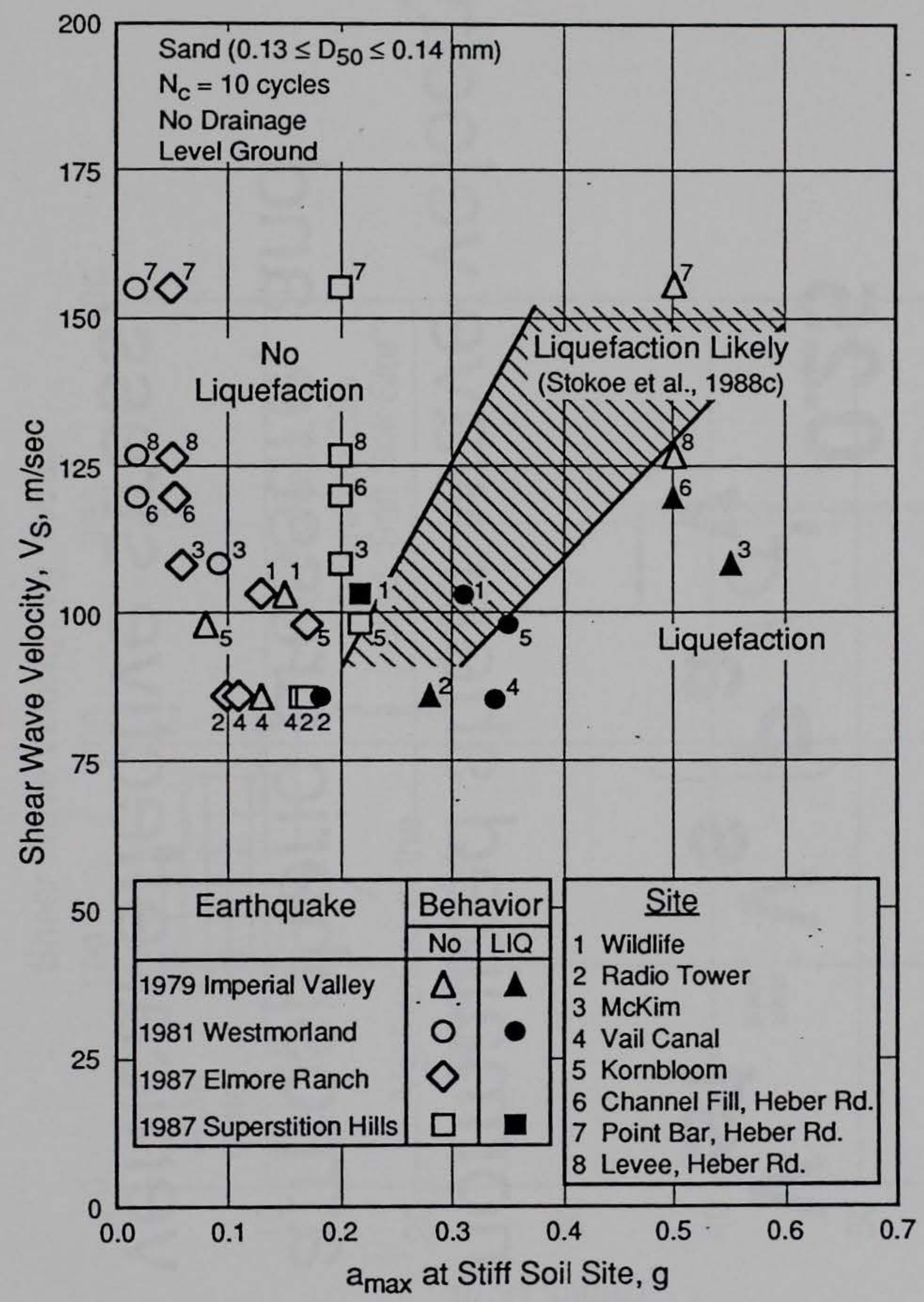




\section{Normalization of Shear Wave}

Velocity with Respect to

Effective Overburden Stress

$$
V_{s 1}=V_{s}\left(P_{a} / \sigma_{v}^{\prime}\right)^{0.25}
$$

where:

$V_{s 1}=$ normalized shear wave velocity,

$\mathrm{P}_{\mathrm{a}}=$ atmospheric pressure, and

$\sigma_{v}^{\prime}=$ vertical effective stress. 


\section{Shear Wave Velocity Profiles Used in Parametric Studies (Andrus, 1994)}

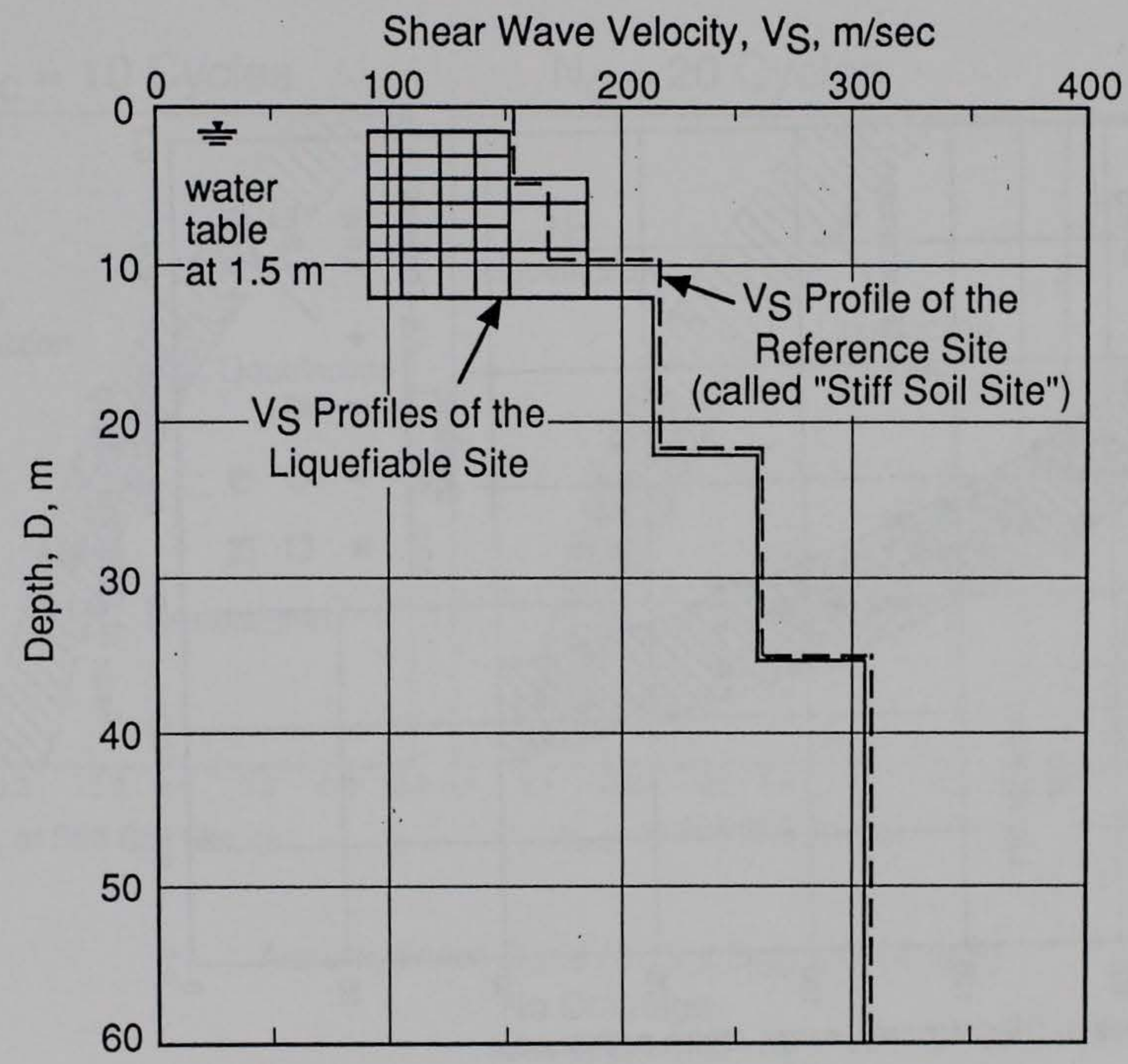




\section{Liquefaction Potential Chart Based on $\mathbf{V}_{\mathbf{S 1}}$}

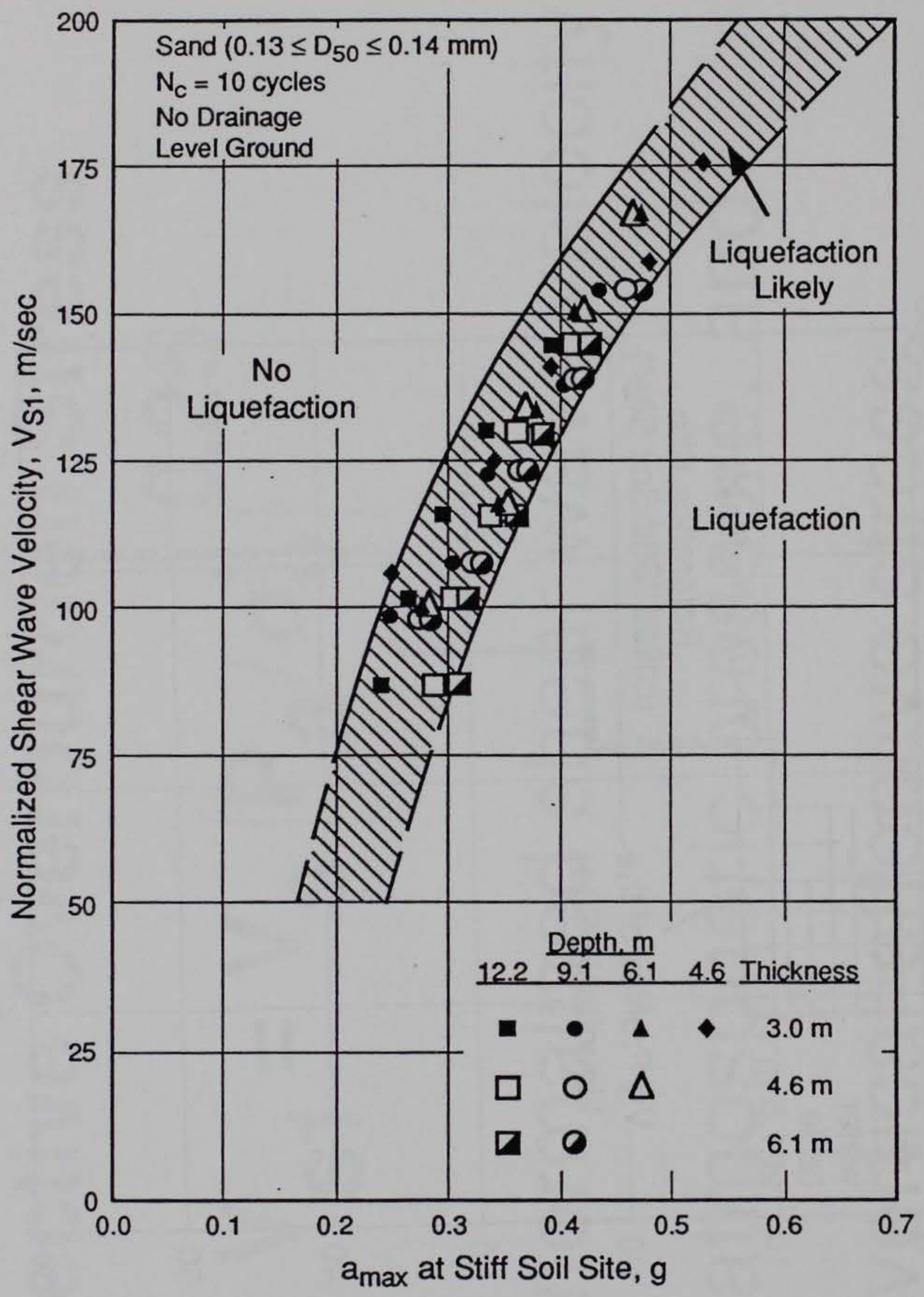




\section{Liquefaction Potential Charts Based on $\mathrm{V}_{\mathrm{S} 1}$ (Andrus, 1994)}
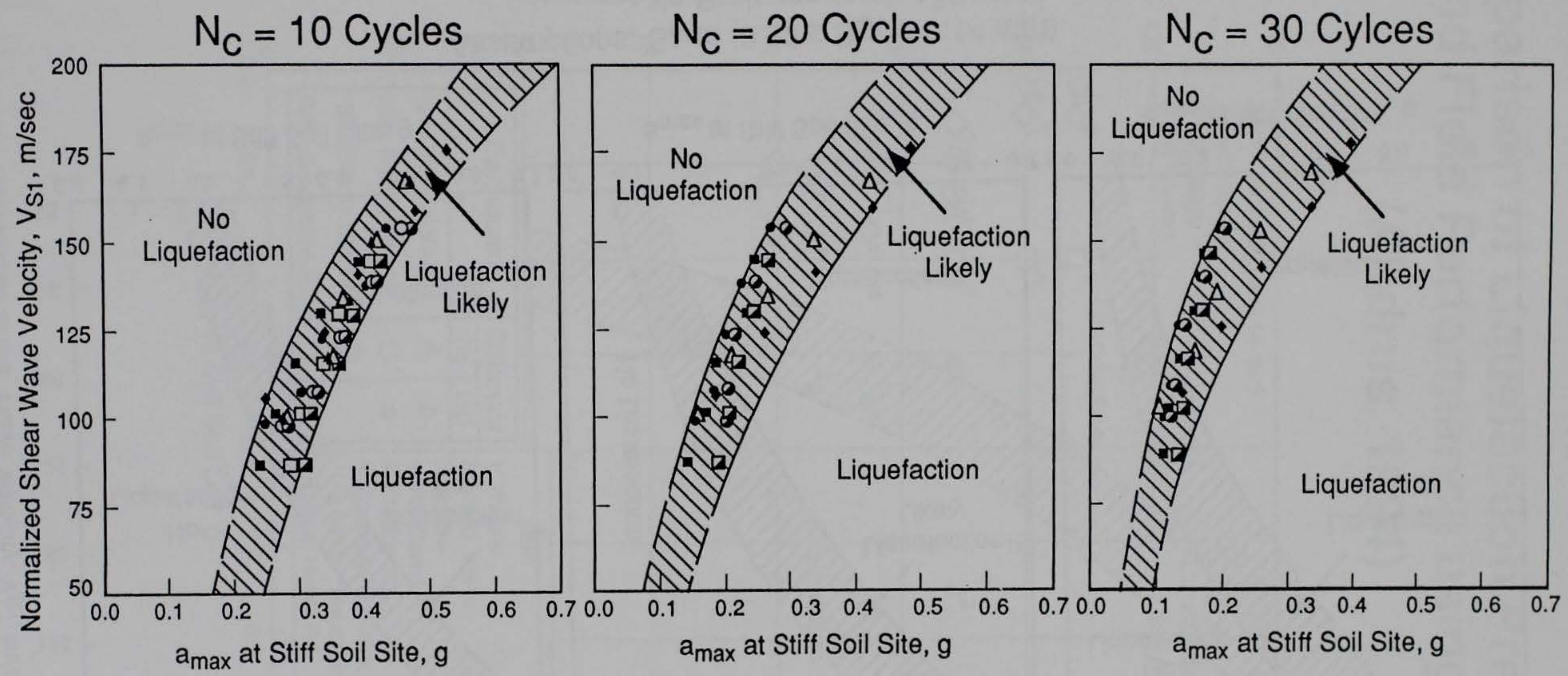

Assumptions: Sand $\left(0.13 \leq D_{50} \leq 0.14 \mathrm{~mm}\right)$

No Drainage

Level Ground 


\section{Liquefaction Potential Charts Based on $\mathrm{V}_{\mathrm{S} 1}$ (Andrus, 1994)}
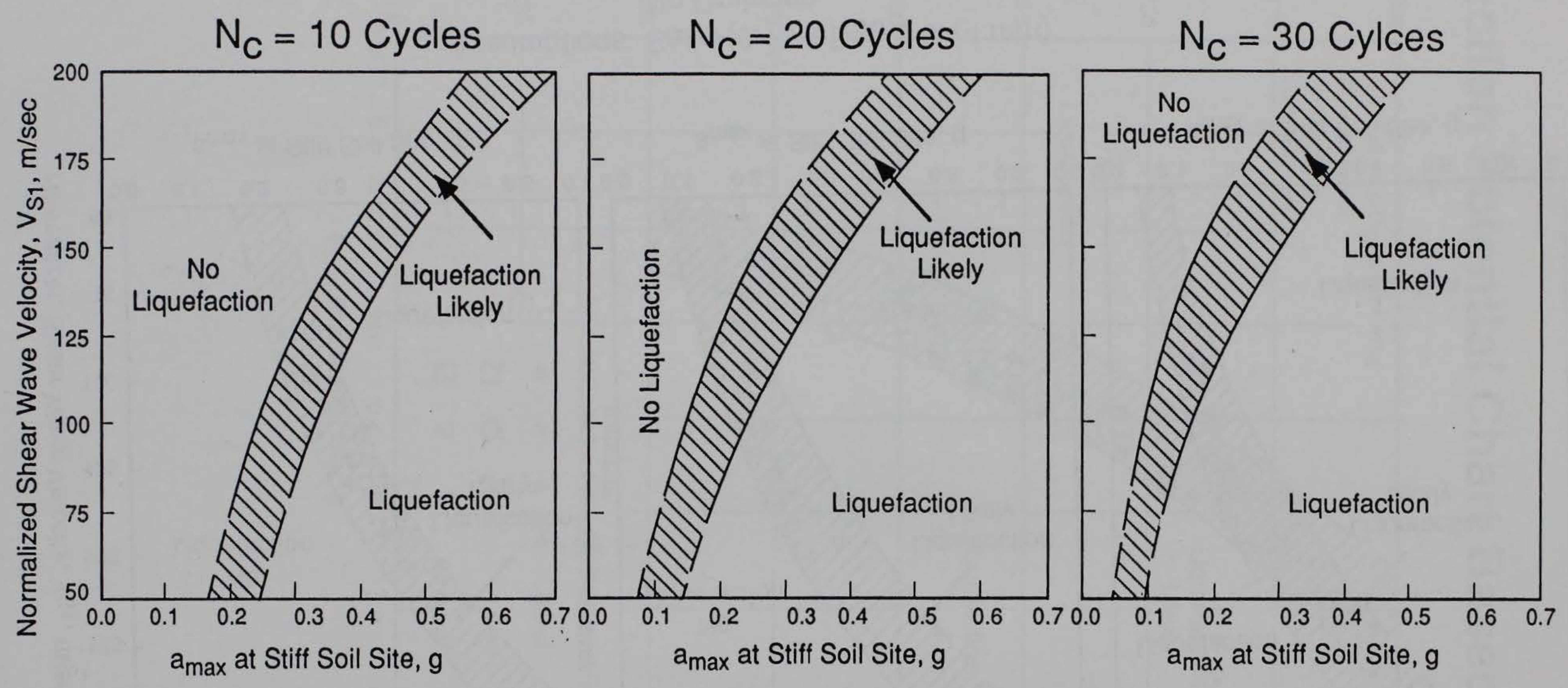

Assumptions: Sand $\left(0.13 \leq D_{50} \leq 0.14 \mathrm{~mm}\right)$

No Drainage

Level Ground 


\section{Comparison of Liquefaction Predictions and Field Performance using $\mathrm{V}_{\mathrm{S} 1}$ (Andrus, 1994)}

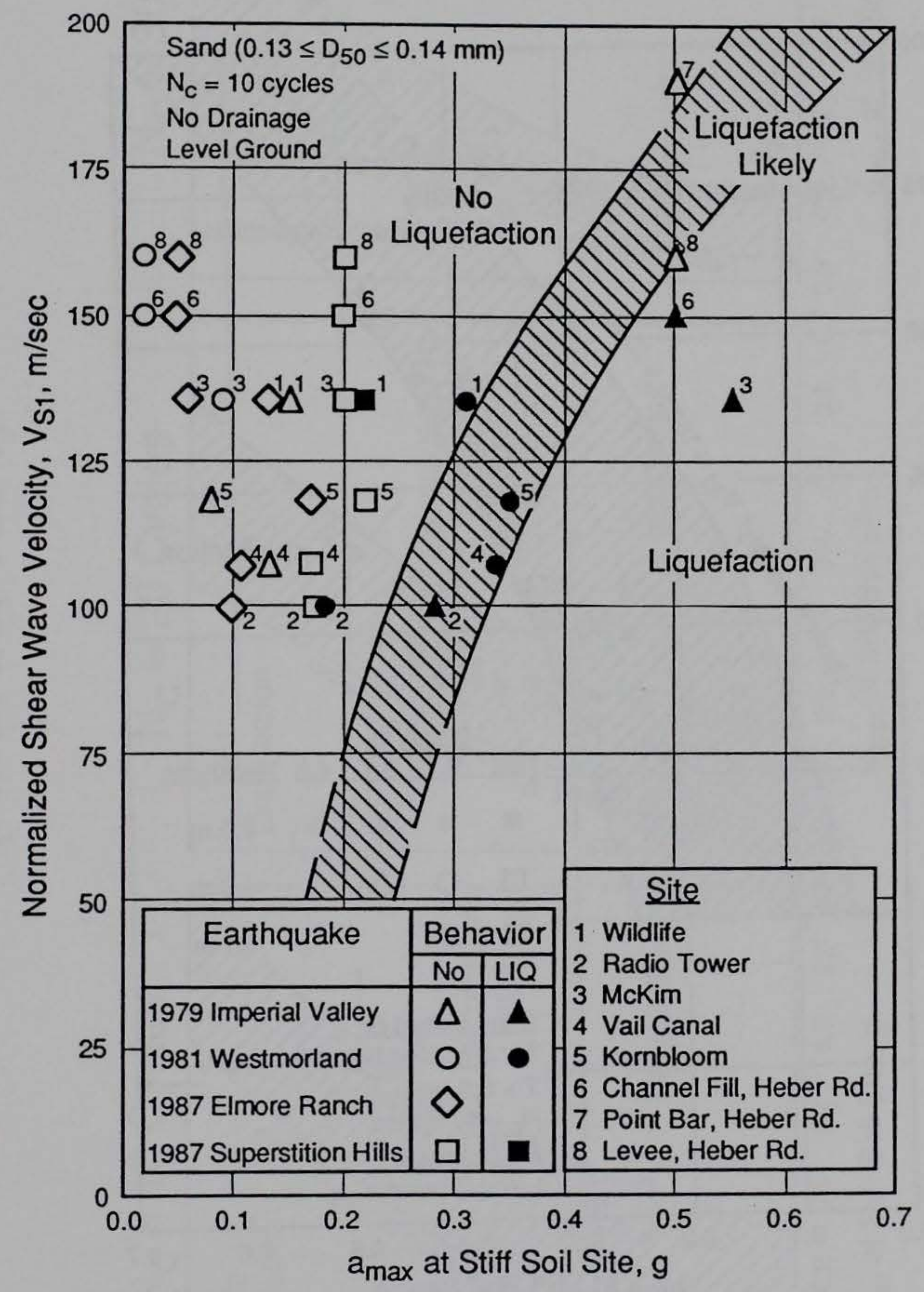




\section{Liquefaction Potential Chart Based on $V_{s 1}$ and $T>0.3 \mathrm{~m}$ (Andrus, 1994)}

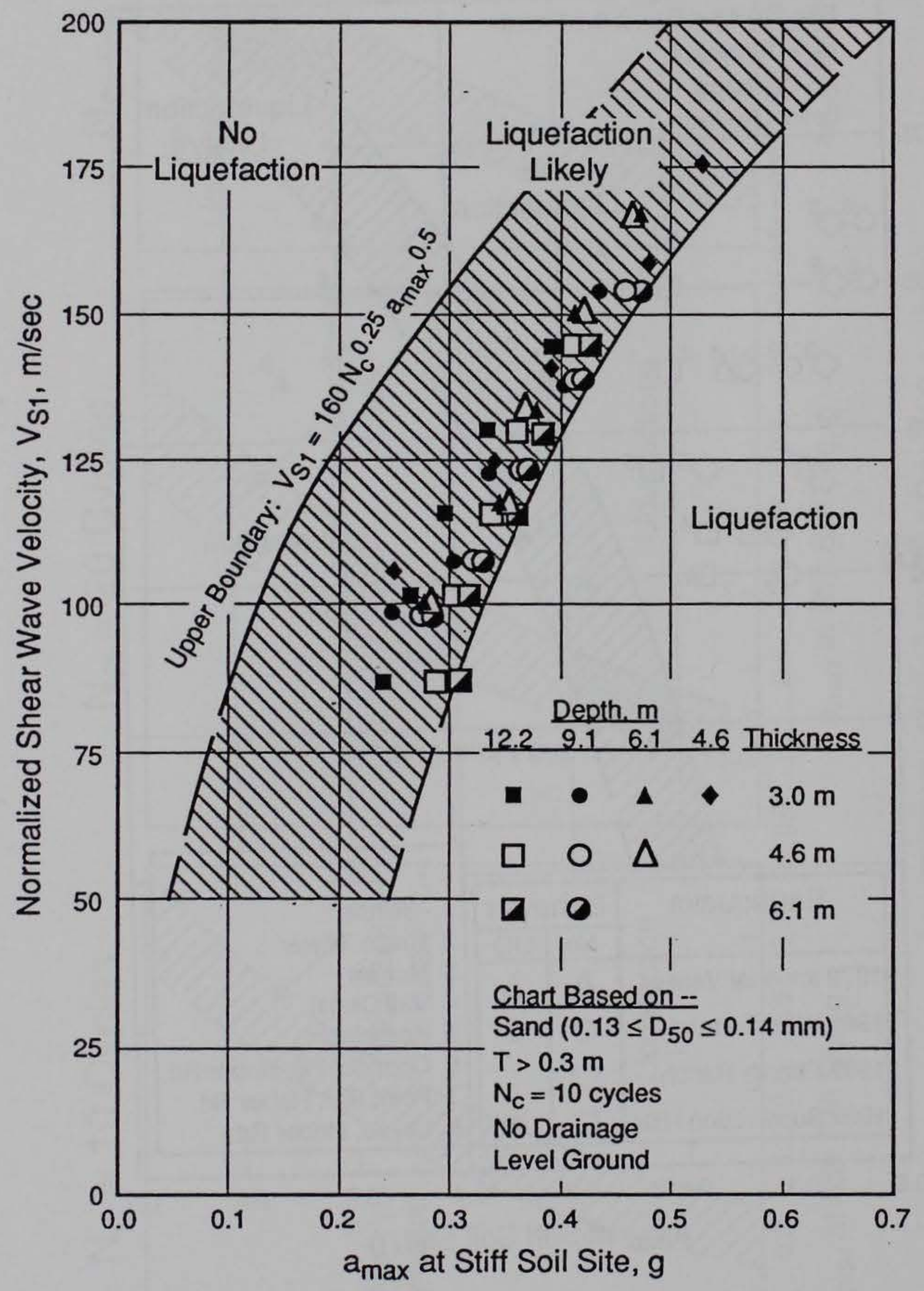




\section{Liquefaction Potential Charts Based on $\mathrm{V}_{\mathrm{S} 1}$ and $\mathrm{T}>0.3 \mathrm{~m}$ (Andrus, 1994)}
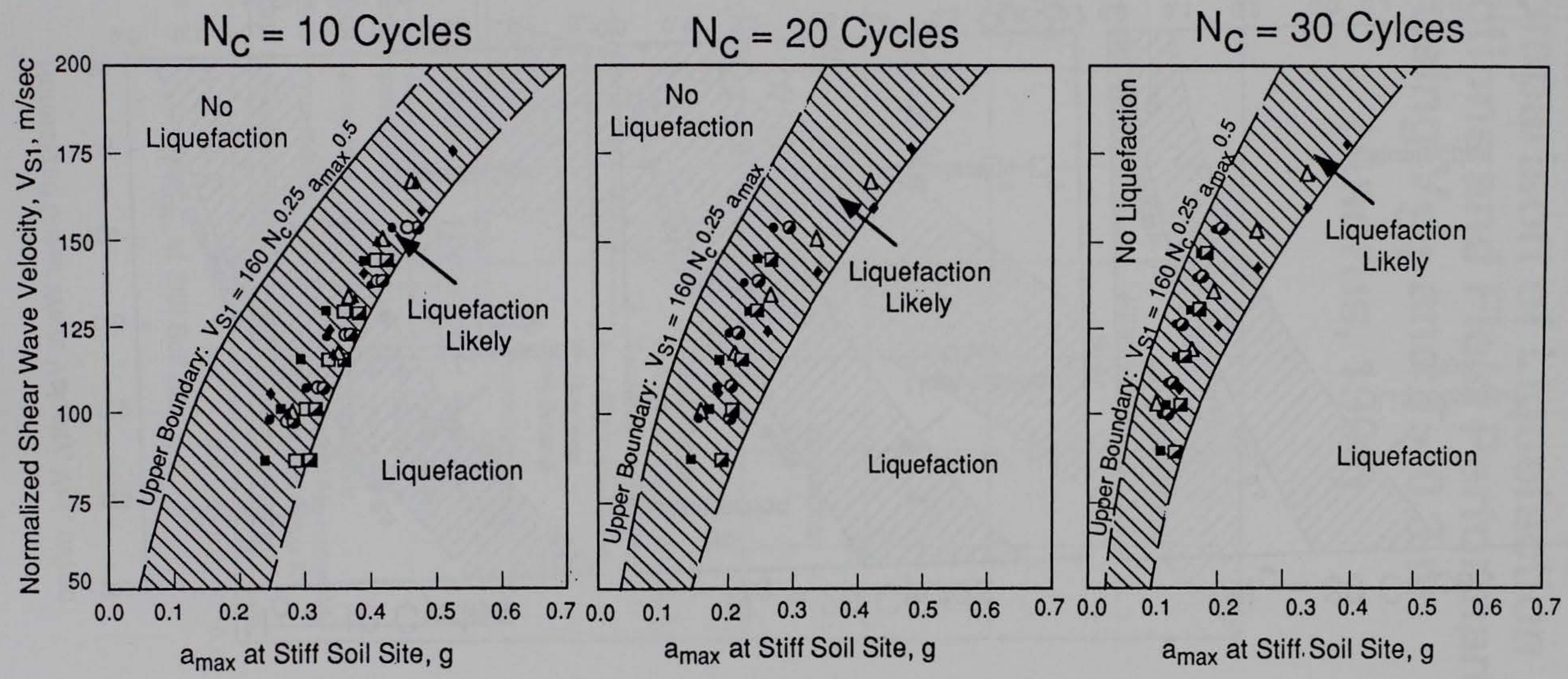

Assumptions: Sand $\left(0.13 \leq D_{50} \leq 0.14 \mathrm{~mm}\right)$

No Drainage

Level Ground 


\section{Liquefaction Potential Charts Based on $\mathrm{V}_{\mathrm{s} 1}$ and $\mathrm{T}>0.3 \mathrm{~m}$ (Andrus, 1994)}
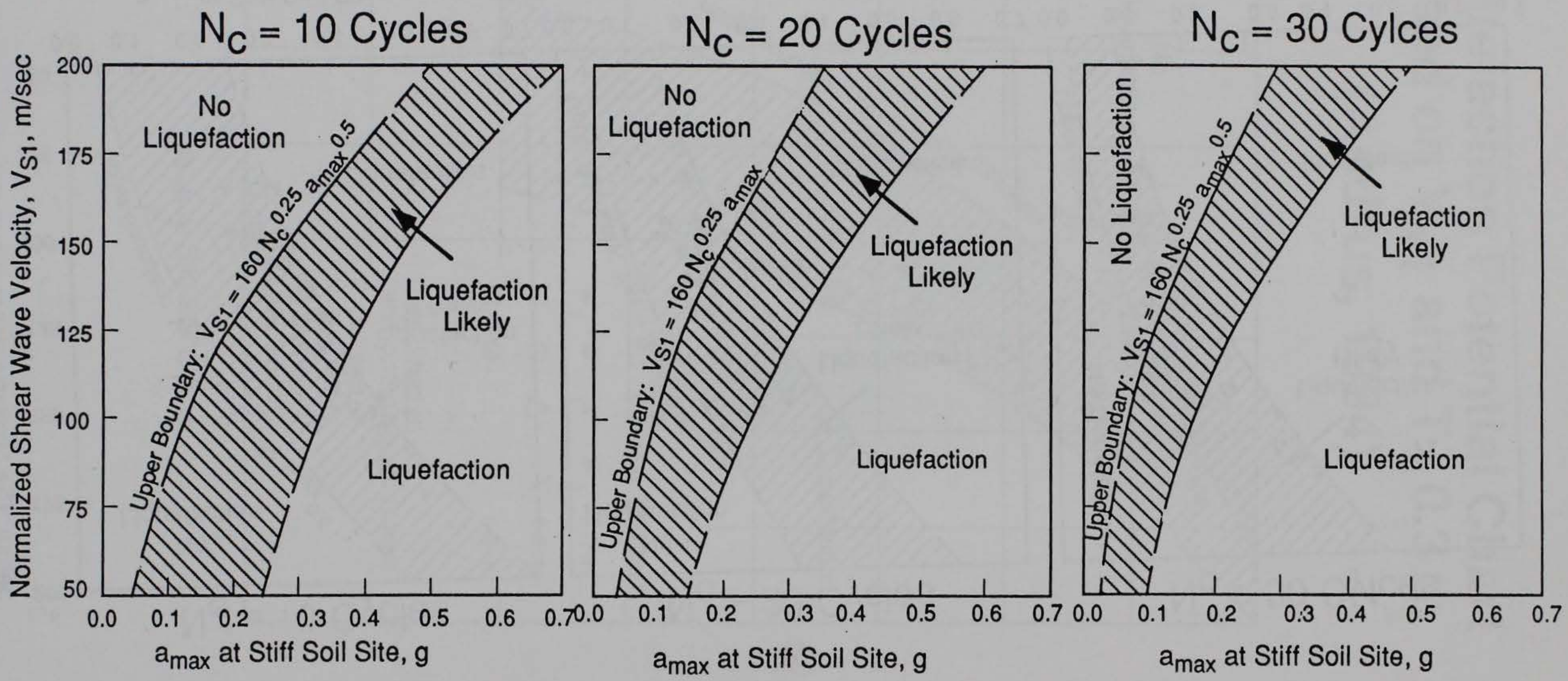

Assumptions: Sand $\left(0.13 \leq D_{50} \leq 0.14 \mathrm{~mm}\right)$ No Drainage Level Ground 


\section{Comparison of Liquefaction Predictions and Field Performance using $\mathrm{V}_{\mathrm{S} 1}$ and $\mathrm{T}>0.3 \mathrm{~m}$ (Andrus, 1994)}

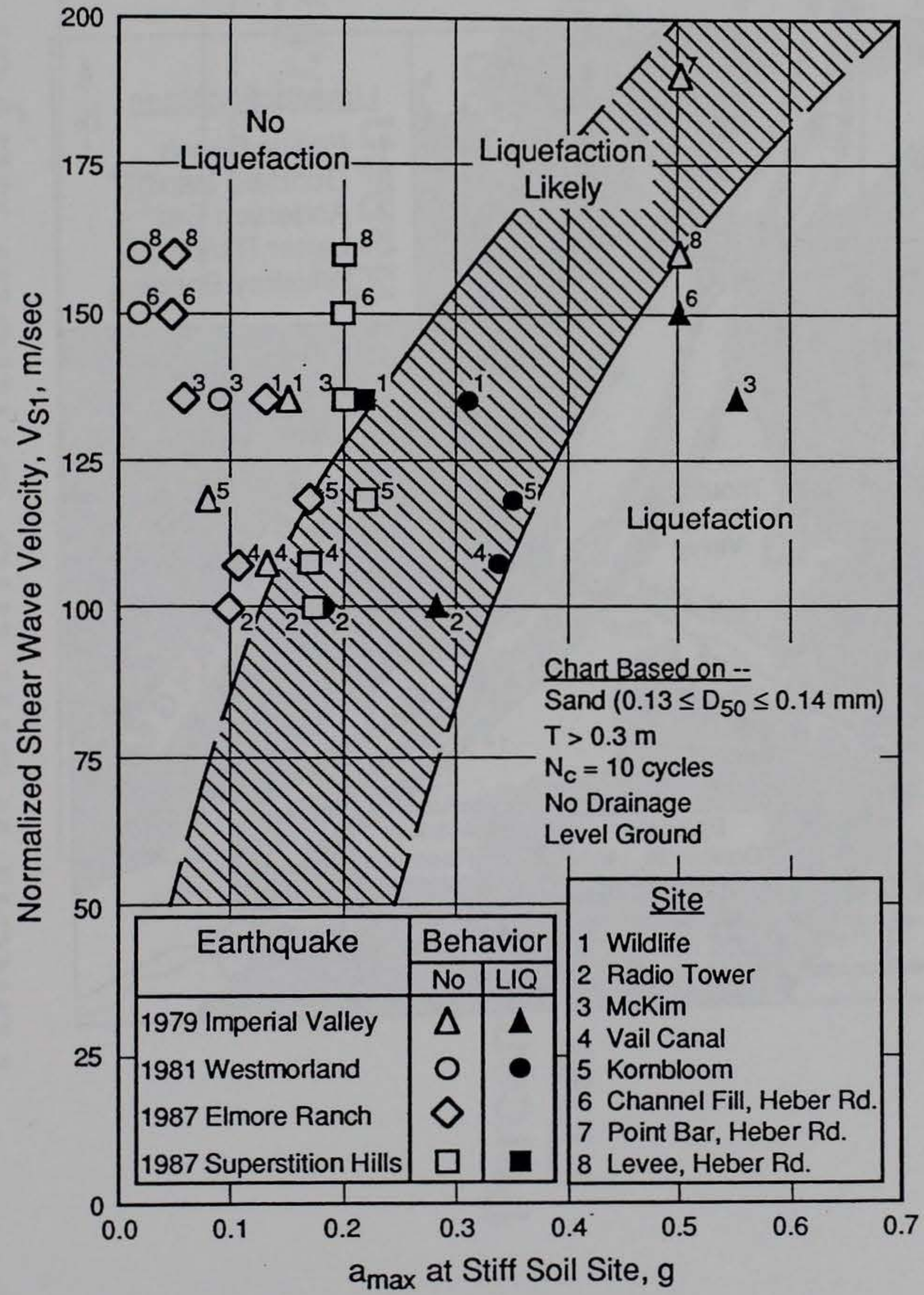




\section{Liquefaction Sites: Gravelly Soils}

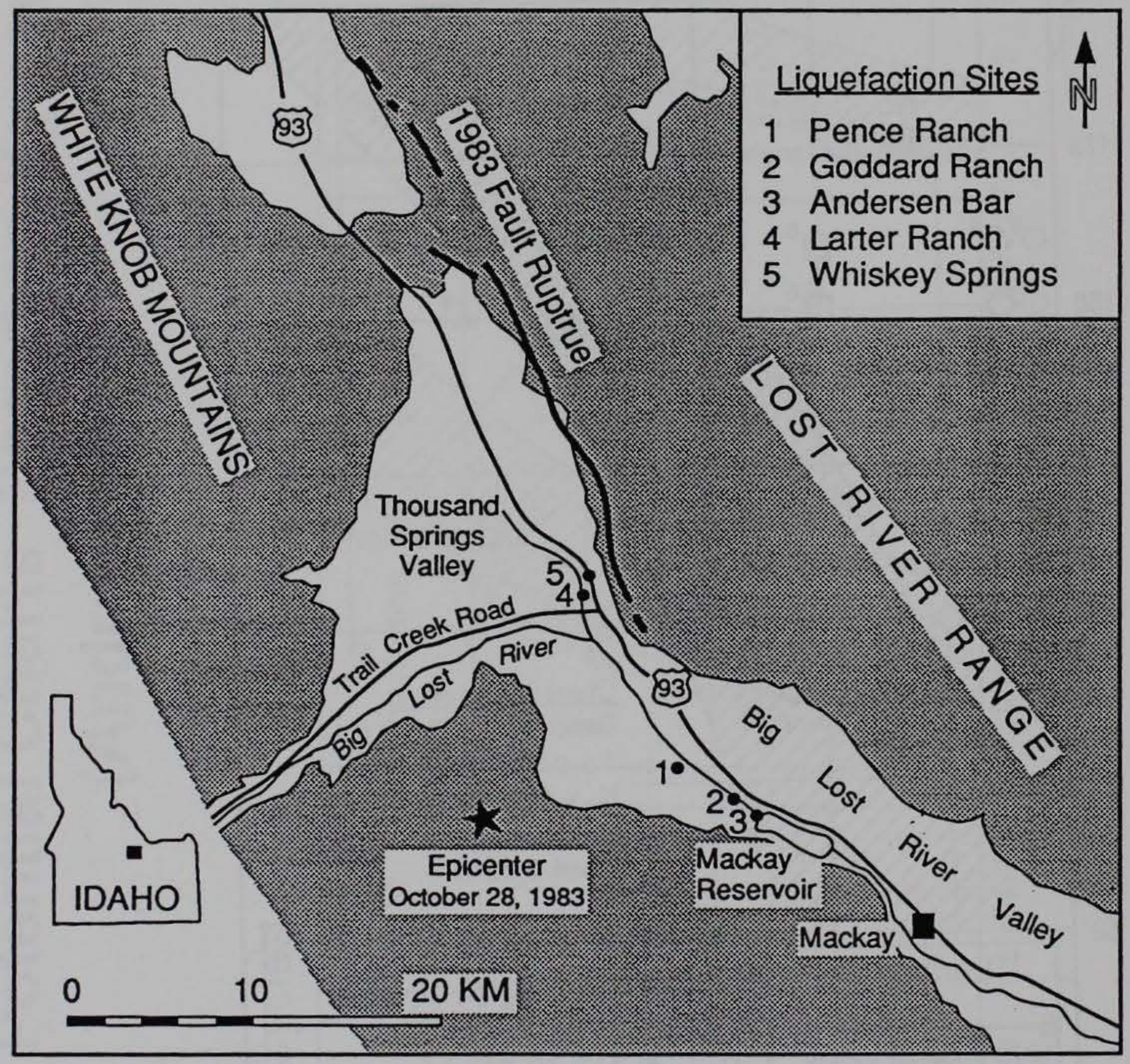


Grain-Size Distribution of Test-Pit Samples Taken from the Critical Layer (Idaho)

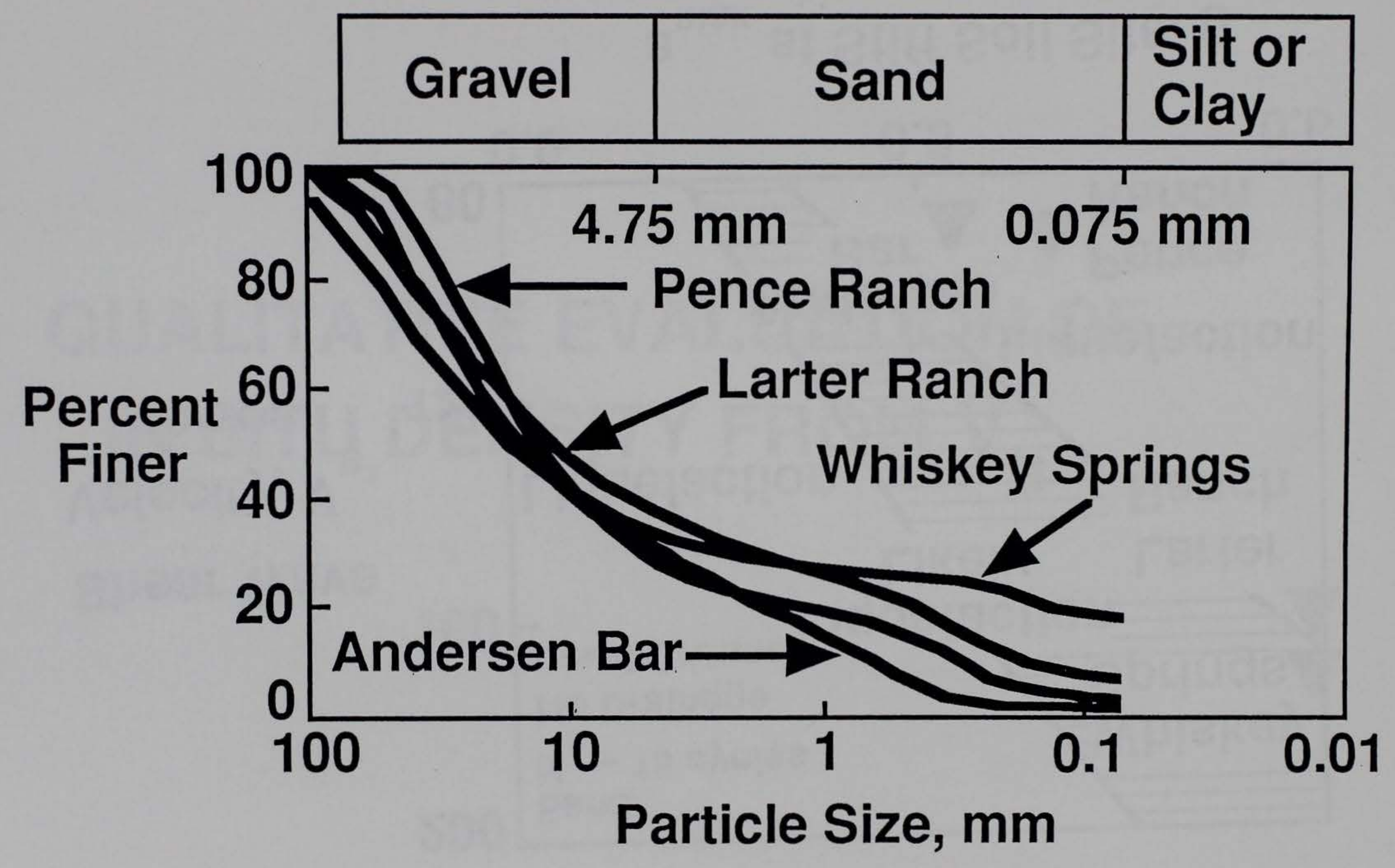




\section{Liquefaction Assessment Chart Based on Shear Wave Velocity}

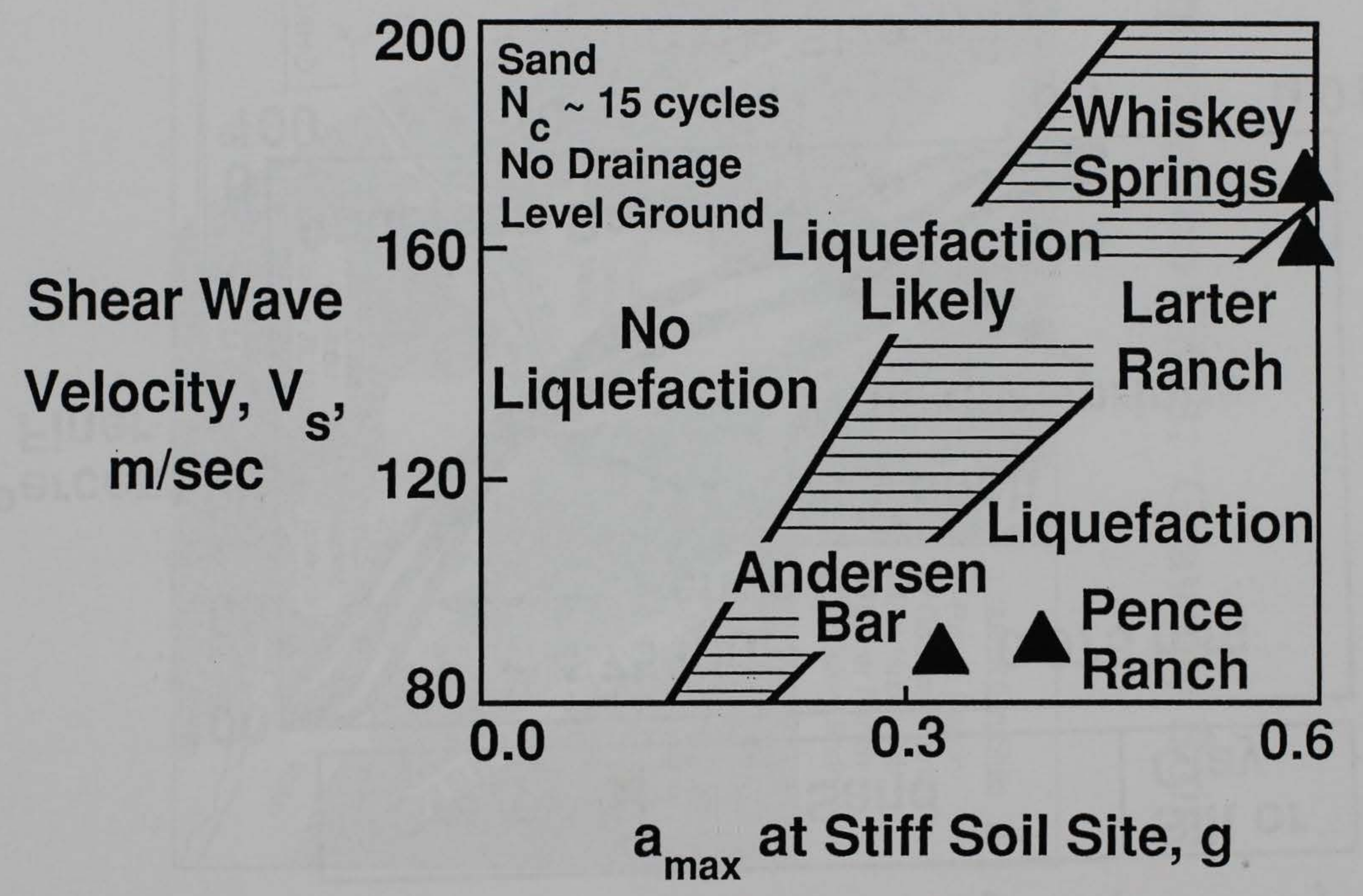




\section{QUALITATIVE EVALUATION OF IN SITU DENSITY FROM $V_{S}$}




\section{Relationship Between Low-}

Amplitude Shear Modulus, $\mathbf{G}_{\text {max }}$, and Mean Effective Stress, $\sigma_{m}^{\prime}$ (in psf)

$$
G_{\max }=1000 \mathrm{~K}_{2}\left(\sigma_{m}^{\prime}\right)^{0.5}
$$

where $\mathrm{K}_{2}=$ material parameter

$$
\text { (Seed et al., 1985). }
$$




\section{Relationship Between Low-}

Amplitude Shear Modulus, $G_{\text {max }}$, and

Shear Wave Velocity, $V_{s}$

$$
\mathbf{G}_{\max }=(\gamma / \mathbf{g}) \mathbf{v}_{\mathbf{s}}^{2}
$$

where $\gamma=$ total unit weight, and $\mathbf{g}=$ acceleration of gravity. 


\section{Recommended Values of $\mathrm{K}_{2}$}

\begin{tabular}{l|l|l} 
Quantitative & Sands & Gravels
\end{tabular} Density

Loose

Medium

Dense

\begin{tabular}{c|c}
25 & 40 \\
50 & 80 \\
75 & 120
\end{tabular}




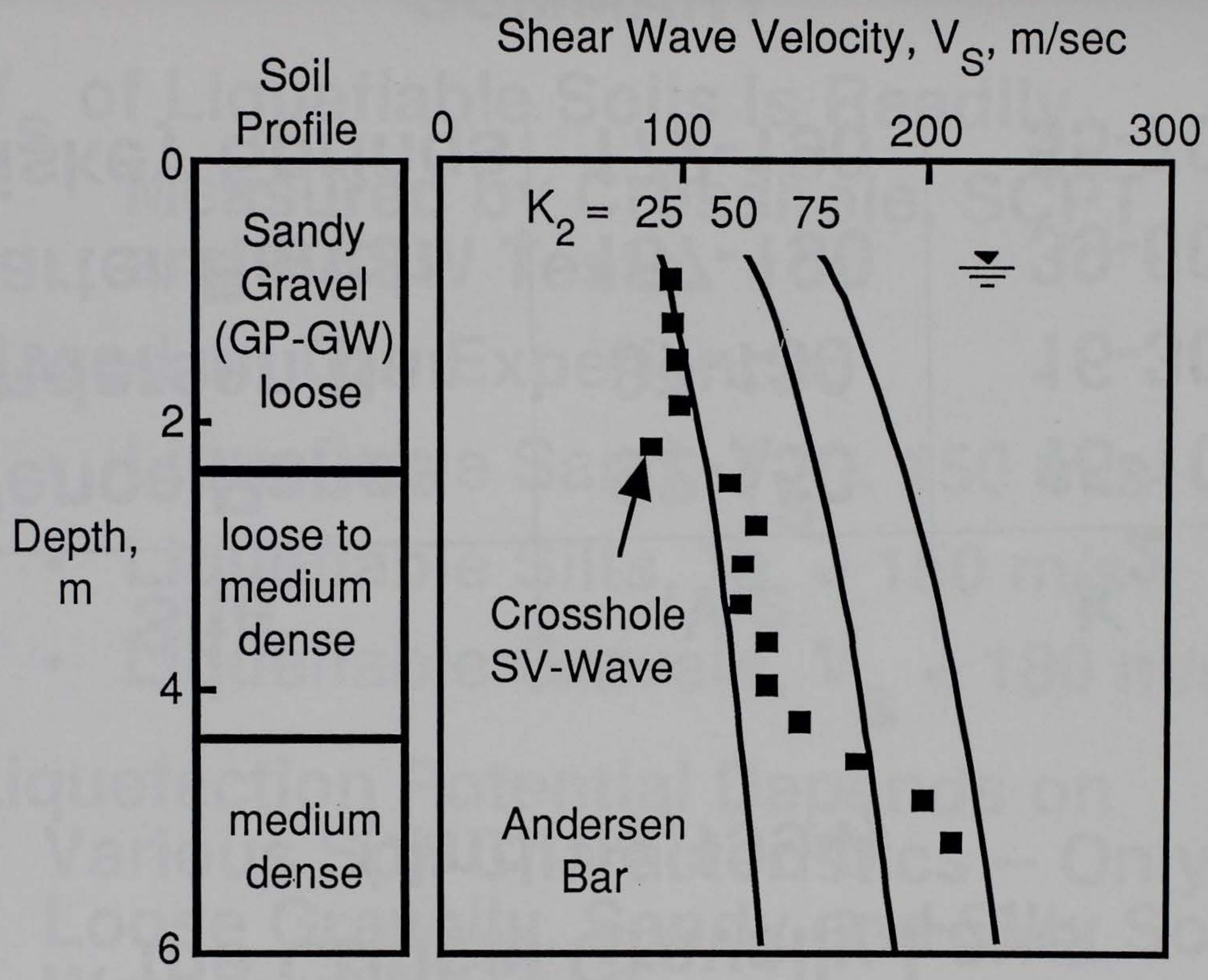




\section{Velocity Data and $\mathrm{K}_{2}$ Values from \\ the Critical Gravelly Layer (Andrus,1994)}

\begin{tabular}{c|c|c} 
Site & $\mathbf{V}_{\mathbf{s}}$ & $\mathrm{K}_{2}$ \\
\hline Pence Rance & $92-150$ & $15-10$ \\
Andersen Bar & $87-130$ & $16-30$ \\
Larter Ranch & $157-190$ & $39-60$ \\
Whiskey Springs & $172-190$ & $55-70$
\end{tabular}




\section{SUMMARY}

1. $V_{s}$ of Liquefiable Soils Is Readily Measured by Crosshole, SCPT and SASW Tests

2. Based on Our Experience:

- Liquefiable Sand, $V_{s}<150 \mathrm{~m} / \mathrm{s}$

- Liquefiable Silts, $V_{s}<150 \mathrm{~m} / \mathrm{s}$

- Liquefiable Gravels, $V_{s}<180 \mathrm{~m} / \mathrm{s}$

3. Liquefaction Potential Depends on

Various Soil Characteristics -- Only

Loose Gravelly, Sandy and Silty Soils

Were Investigated 
4. Liquefaction Potential Depends on the Site and Strong-Motion Characteristics:

- Layer Depth and Thickness

- Number of Cycles and $a_{\max }$

5. Liquefaction Assesment Based on $\mathrm{V}_{\mathrm{s}}$ Correlates Well With Field Performance

6. Liquefaction Assesment Based on V and $\mathrm{T}>0.3 \mathrm{~m}$ Also Correlates Well s1

7. Qualitative Evaluation of In Situ Density Also Performed With $\mathrm{V}_{\mathbf{s}}$ 
Appendix E - Lecture Slides and Article Submitted by Mr. Philip Sirles 


\section{GEOPHYSICS IN DAM \\ SAFETY INVESTIGATIONS}

\section{LIQUEFACTION INVESTIGATIONS:}

* PURPOSE AND OBJECTIVES

A. EMBANKMENT

- Old Embankments

- New Embankments

B. FOUNDATION

- Homogeneous Geologic Conditions

- Heterogeneous Geologic Conditions

- UnKnown Geologic Conditions

* FIELD METHODS USED FOR

IDENTIFICATION OF LIQUEFACTION POTENTIAL

A. SURFACE TECHNIQUES

- REFRACTION SURVEYS

- Reflection SURVeYs

- SASW SURVEYS

- Electrical Surveys

- Electromagnetic SuRveys

B. BOREHOLE TECHNIQUES

- Crosshole Seismic Surveys

- Downhole Seismic SuRvers

- Geophysical Borehole Logging 


\section{GEOPHYSICS $\ldots$}

I. LIQUEFACTION $---\rightarrow$

* PURPOSE

A. EMBANKMENT - DETERMINE SEISMIC STABILITY OF THE STRUCTURE. -

- Method of construction and equipment?

HydRaulic Fill/SLUiced CORE

HoMOgeneous CoMpacted Fill

ZONED EARTHFILL

- Physical Size?

Structural Height, Length, Crest Width, ApPuRtenant Features

B. FOUNDATION - DETERMINE SEISMIC STABILITY OF CRITICAL LAYERS WITHIN FOUNDATION SOIL DEPOSITS.

- Homogeneous Geologic Settings (Valley Dams)?

FLAT LYING, STRATIFIED, AND CONTINUOUS DEPOSITS TYPICALLY FINE-GRAINED MATERIALS (LOW ENERGY SYSTEMS)

- Heterogeneous Geologic Settings (Mountain-Dams)? UNCONFORMABLE, UNSTRATIFIED, AND DISCONTINUOUS DEPOSITS TYPICALLY COARSE-GRAINED MATERIALS (HIGH ENERGY SYSTEMS) POSSIBLY FINE- AND COARSE-GRAINED MATERIALS JUXTAPOSED *VERTICALLY AND LATERALLY HETEROGENEOUS

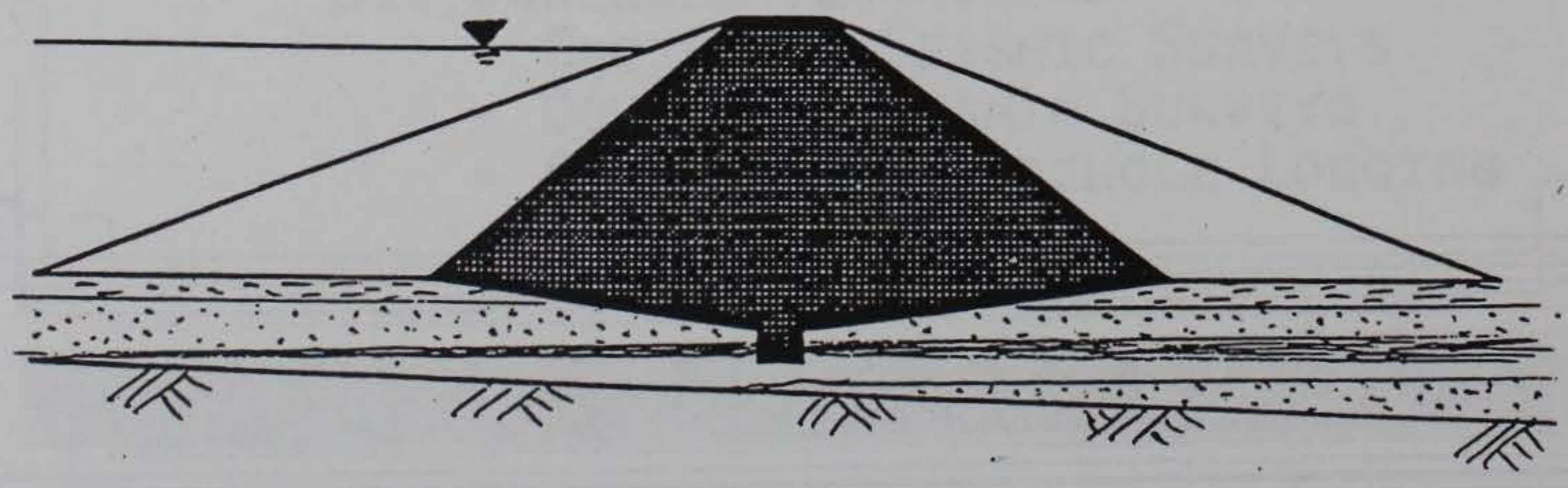




\section{GEOPHYSICS...}

I. LIQUEFACTION --.->

* OBJECTIVES :

A. EMBANKMENT - DETERMINE LATERAL AND VERTICAL SHEAR WAVE VELOCITY DISTRIBUTION:

- Maximum section (through cutoff)

- DownSTREam aREa OF CRITICAL faIluRe MIDSLOPE OF EMBANKMENT

- UPSTREAM AREA OF CRITICAL FAILURE - MIDSLOPE OF EMBANKMENT

- total coverage OR Selected locations (27,000' CREST LENGTH)

B. FOUNDATION - DETERMINE PRESENCE, DISTRIBUTION, AND CONTINUITY, OF LIQUEFIABLE MATERIALS:

- Directly beneath embankMENT CREst

- BENEATH UPSTREAM OR DOWNSTREAM SHELlS

- Along downstream or upstream toe

- Total coverage OR Selected locations

* AGREED UPON BY FET AND DESIGN ENGINEERS * - "NEEDS vS. WANTS" (\$) -

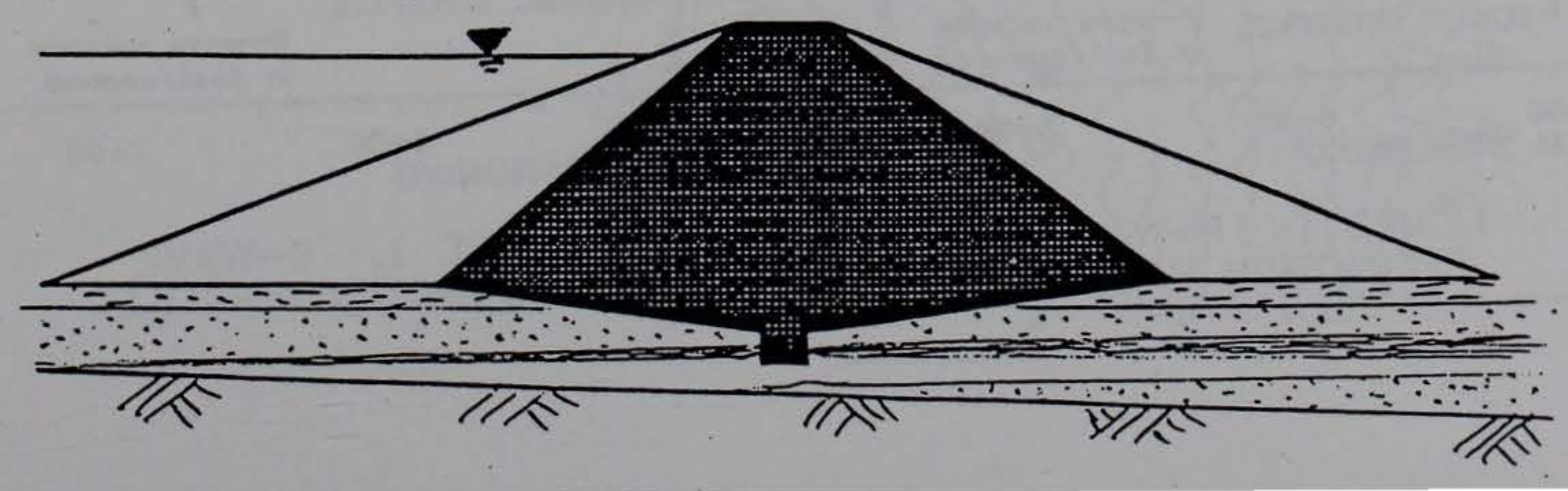


I. LIQUEFACTION $---\rightarrow$

GEOPHYSICS...

\section{* FIELD METHODS CURRENTLY USED:}

\section{A. SURFACE TECHNIQUES - MAXIMUM COVERAGE FOR MINIMUM COST:}

1. P- and S-WAVE REFraction: Determine lateral VELOCITY VARIATIONS, VELOCITY LAYERING, AND DEPTH TO SATURATED MATERIALS. OVERLAPPING AND CONTIGUOUS SPREADS WITH TIGHT GEOPHONE AND SHOT SPACING [1].

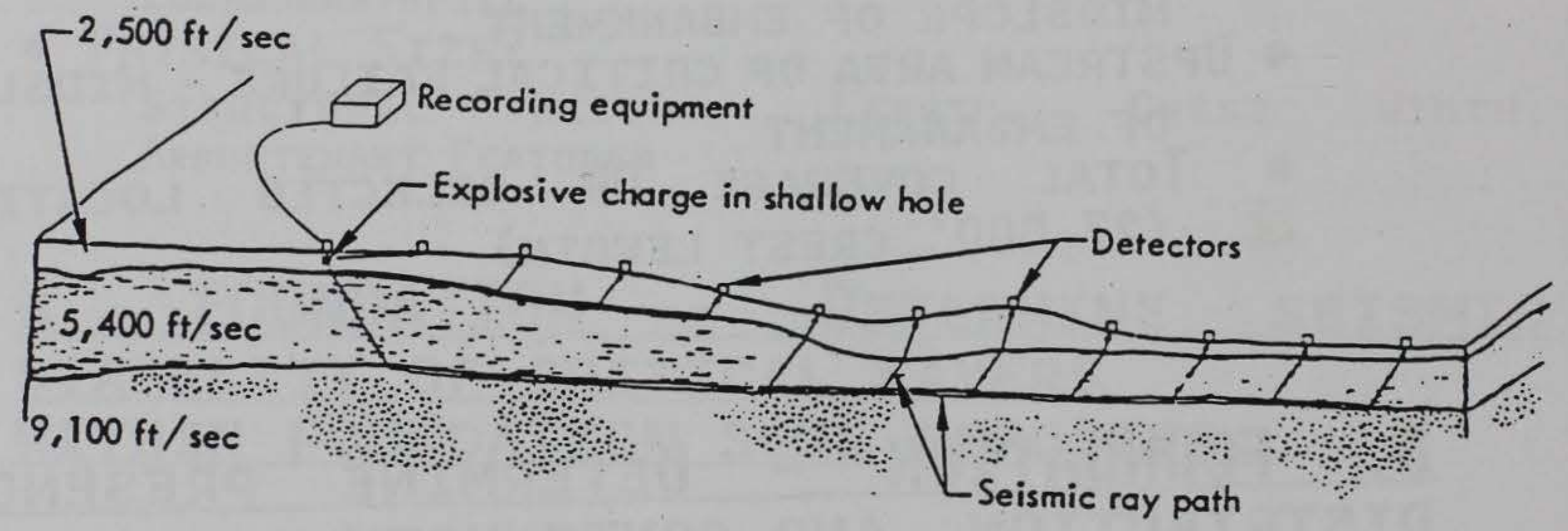

Schematic of seismic refraction survey.
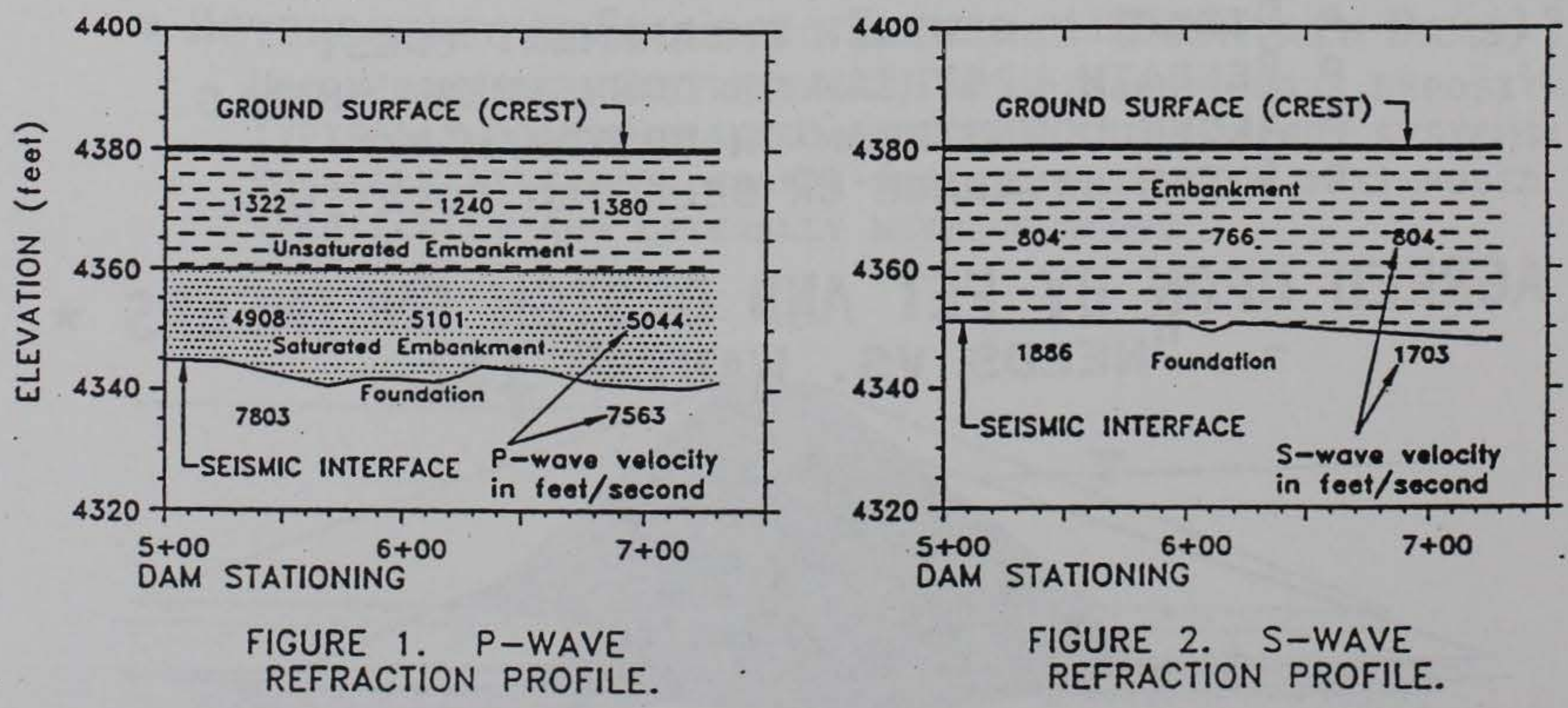

FIGURE 2. S-WAVE REFRACTION PROFILE. 
I. LIQUEFACTIONOPHYSI

\section{GEOPHYSICS...}

\section{* FIELD METHODS CURRENTLY USED:}

2. P-WAVE REFLECTION: DETERMINE LATERAL VARIABILITY AND CONTINUITY OF SUBSURFACE LAYERS; PARTICULARLY ALLUVIUM/BEDROCK INTERFACE OR DENSE LAYERS WITHIN ALLUVIAL DEPOSITS. COMMON OFFSET GATHERS (COG) ARE WELL SUITED FOR THIS PURPOSE, AS WELL AS DETECTION OF TRANSVERSE CRACKS IN EMBANKMENTS [2].

- Generally No Velocity INFORMation OR CROSS-SECtION OF SUBSURFACE PROPERTIES; THEREFORE, USED FOR "QUALITATIVE" INTERPRETATIONS.
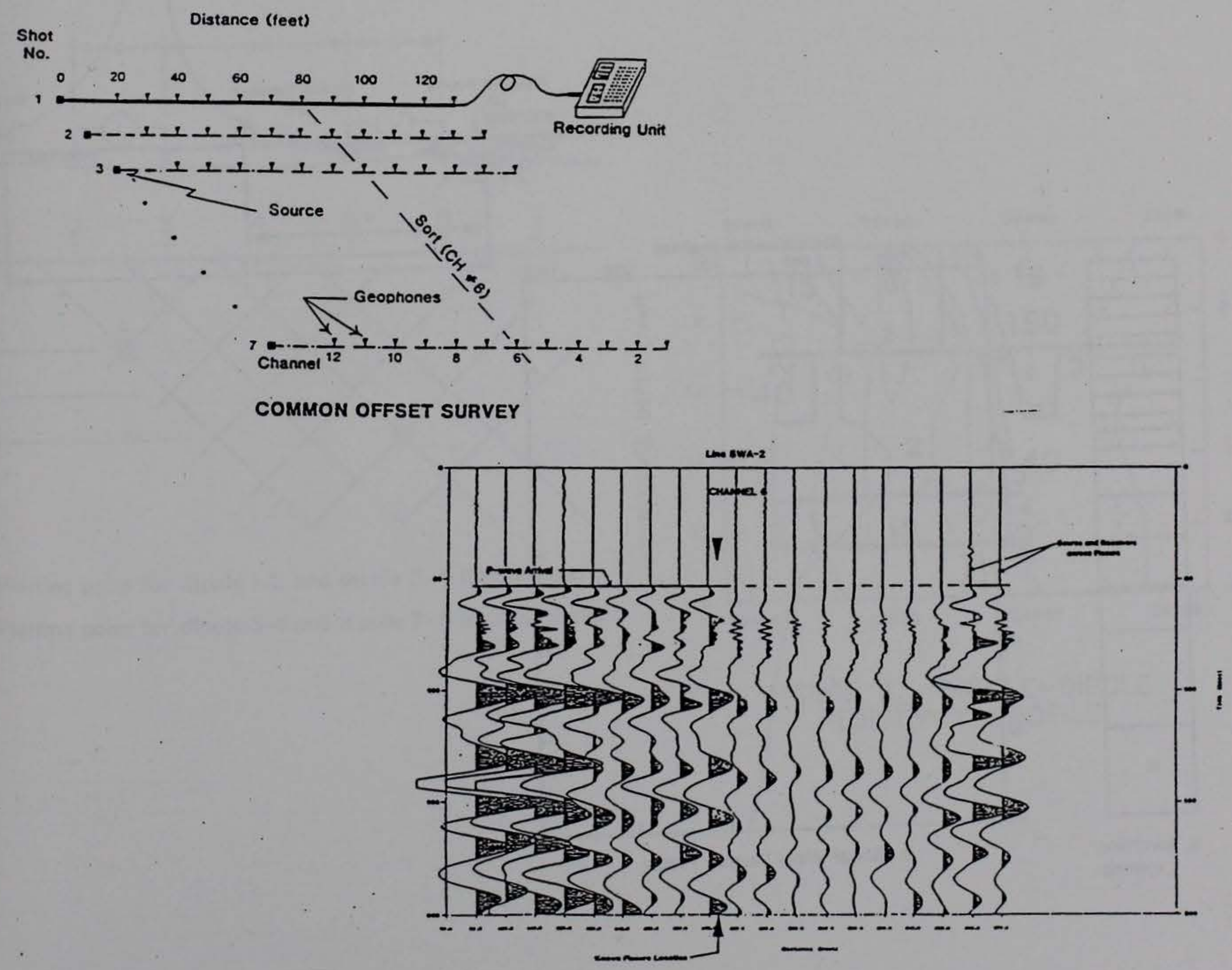


\section{GEOPHYSICS... \\ I. LIQUEFACTION ----> \\ * FIELD METHODS CURRENTLY USED:}

3. SPECTRAL ANALYSIS OF SURFACE WAVES (SASW): DETERMINe SURFACE-WAVE AND S-WAVE Velocity VARIATIONS WITH DEPTH. REQUIRES FREQUENCY SPECTRAL ANALYZERS AND INVERSE MODELING CAPABILITY [3]. SURVEYS ARE EXPANDED ABOUT A CENTER POINT YIELDING APPARENT (AVERAGE) VELOCITY INFORMATION BELOW THAT LOCATION.

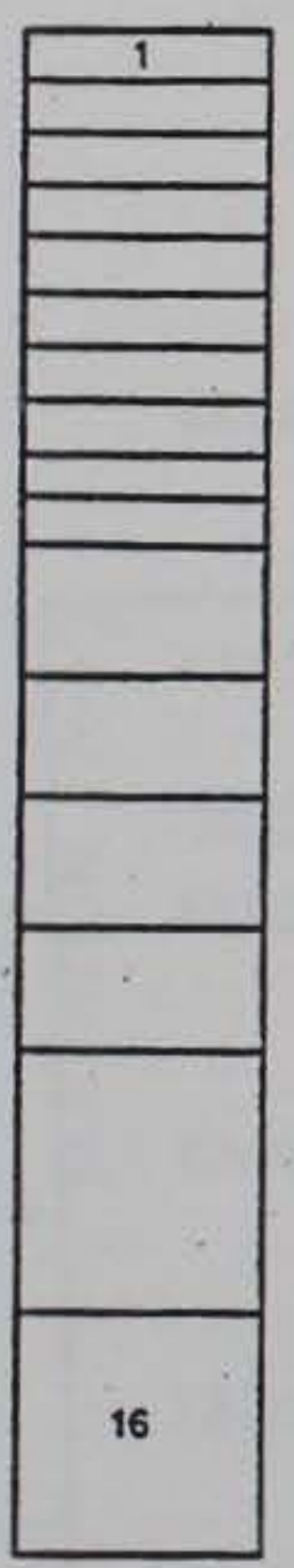

a. Inversion Layering

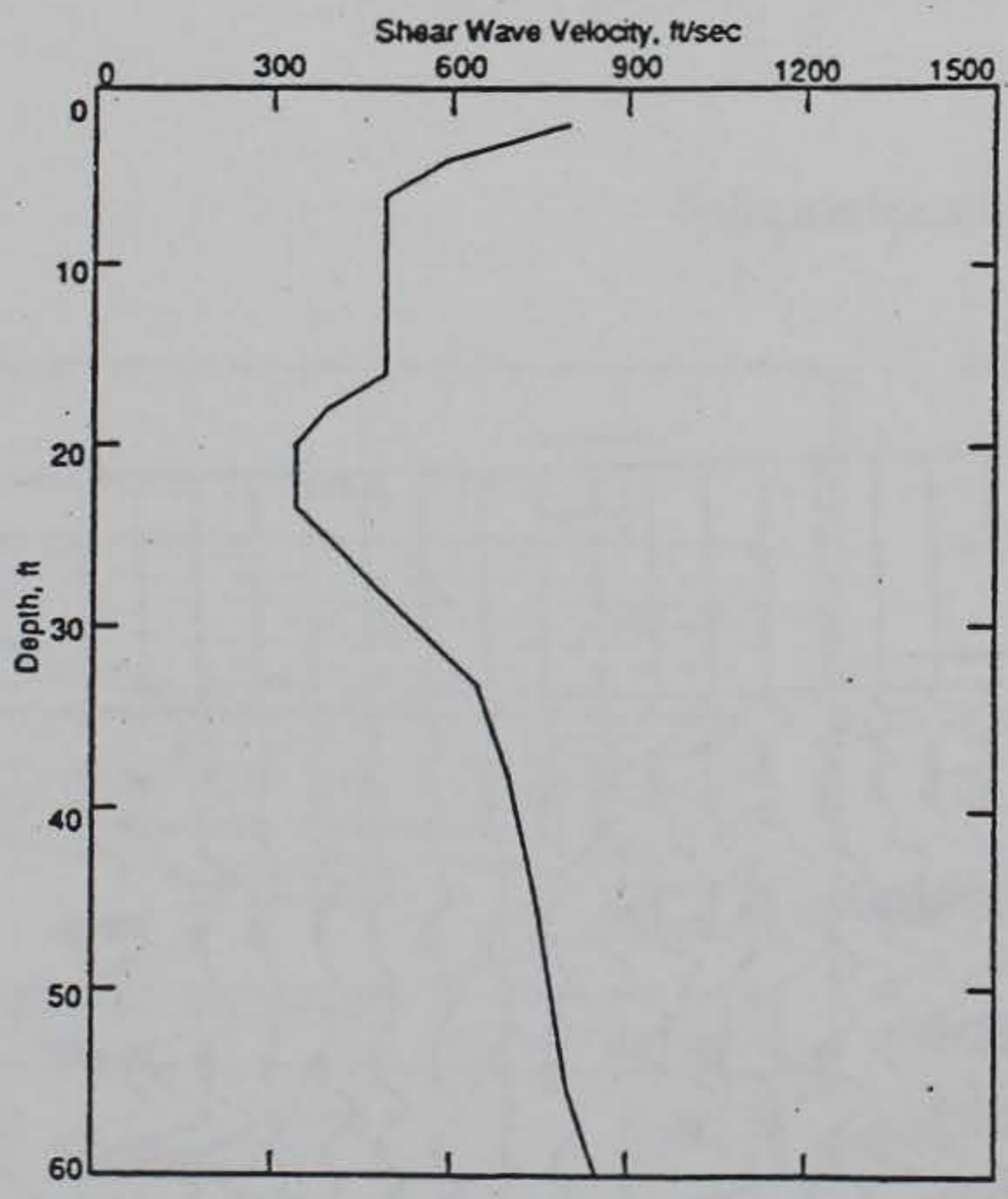

b. Shear Wave Velocity Profile

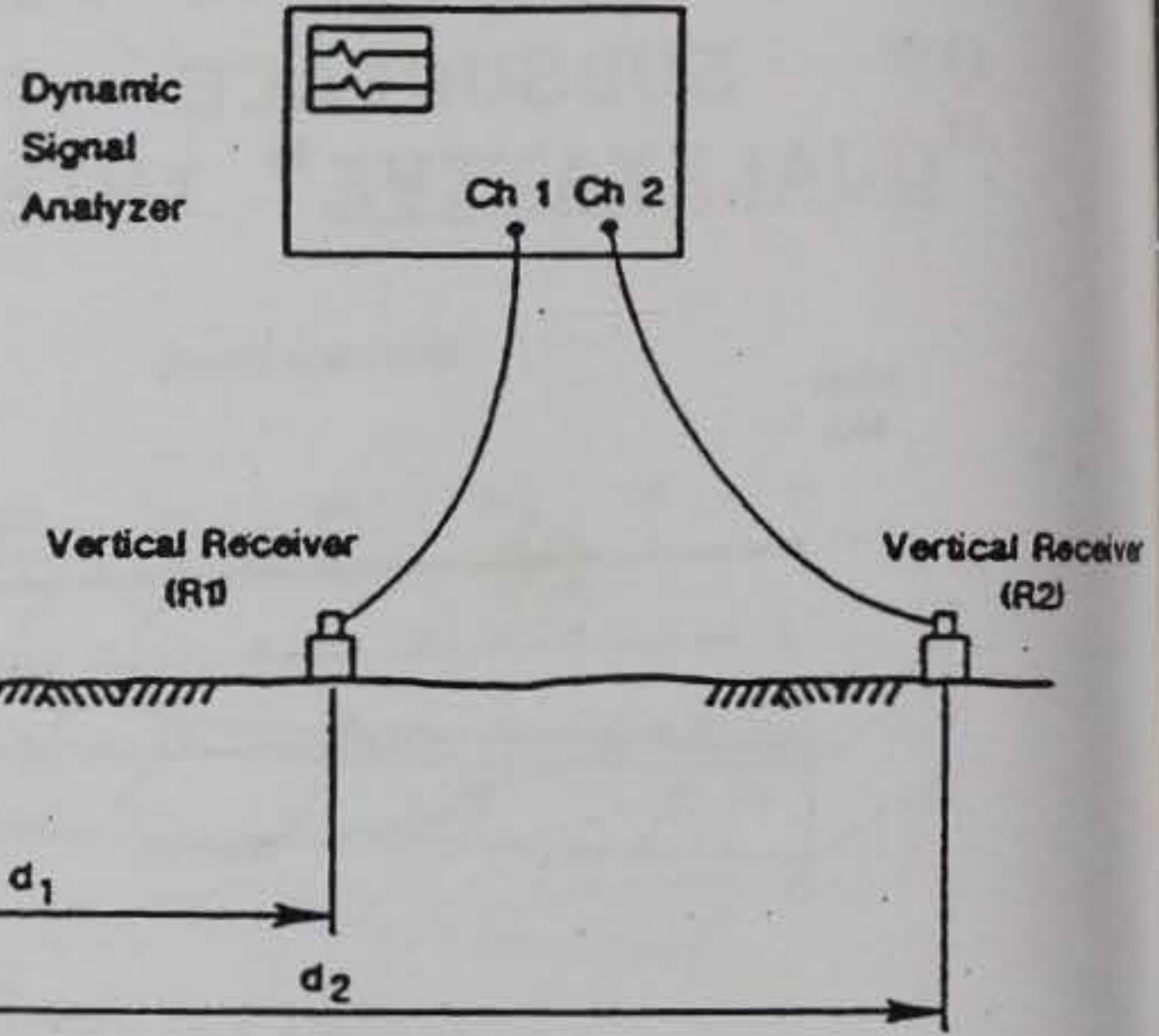


I. LIQUEFACTION --

GEOPHYSICS...

\section{* FIELD METHODS CURRENTLY USED:}

4B. ELECTRICAL SURVEYS: VerTiCAL Electrical SOUNding VES: GEOPHYSICAL TECHNIQUE REFERRED TO AS

"ELECTRICAL DRILLING" (ONE-DIMENSIONAL). USED TO IDENTIFY CHANGES IN MATERIAL PROPERTIES VERTICALLY. EXPANSION IS ABOUT A CENTER POINT AND DEPTH OF INVESTIGATION CAN BE 100 'S OF FEET. SEVERAL VES'S MAY BE PERFORMEd TO DEVELOP A CROSSSECTION FROM THE INDIVIDUAL EARTH MODELS [5] . Battery. Current meter

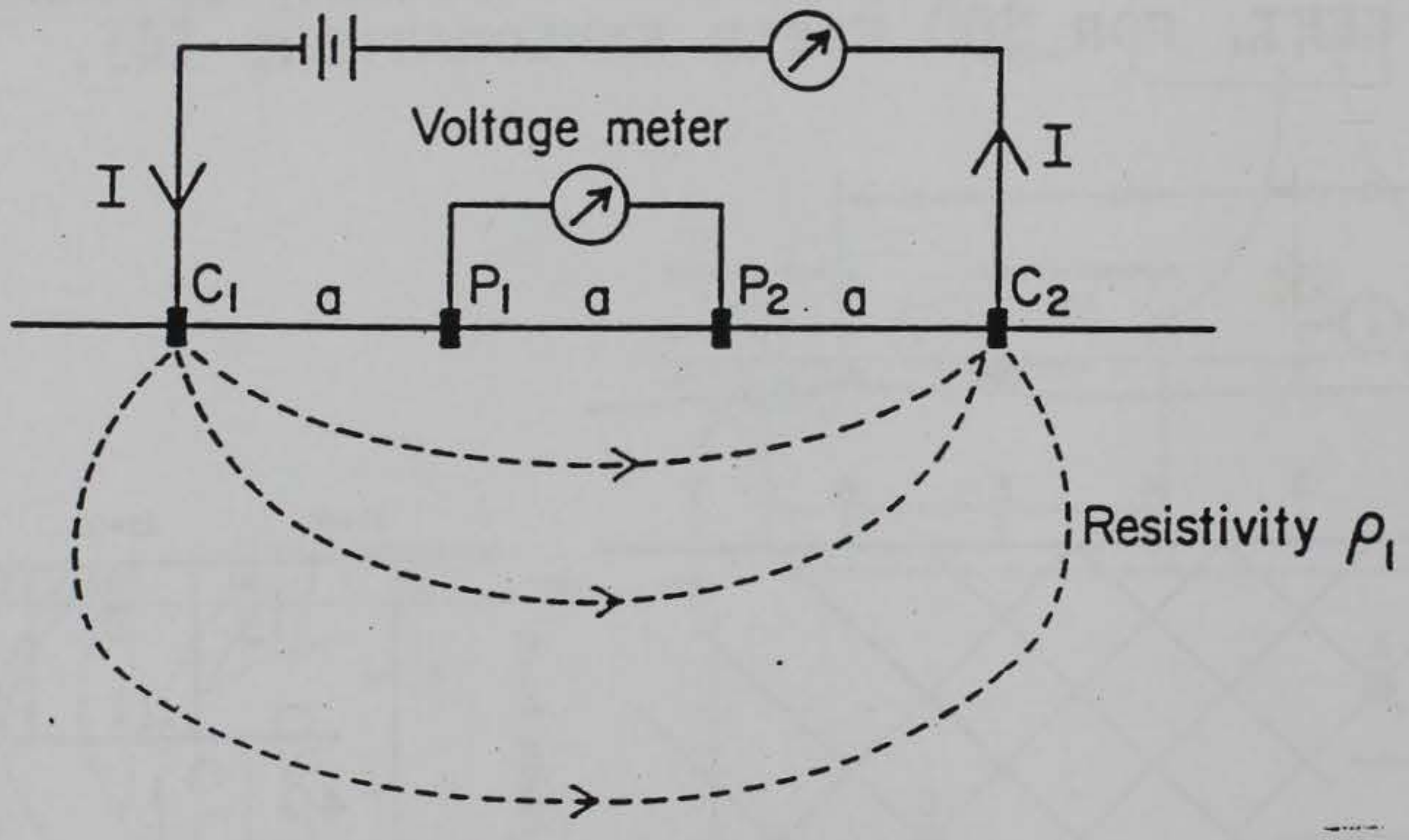

Current flow through earth
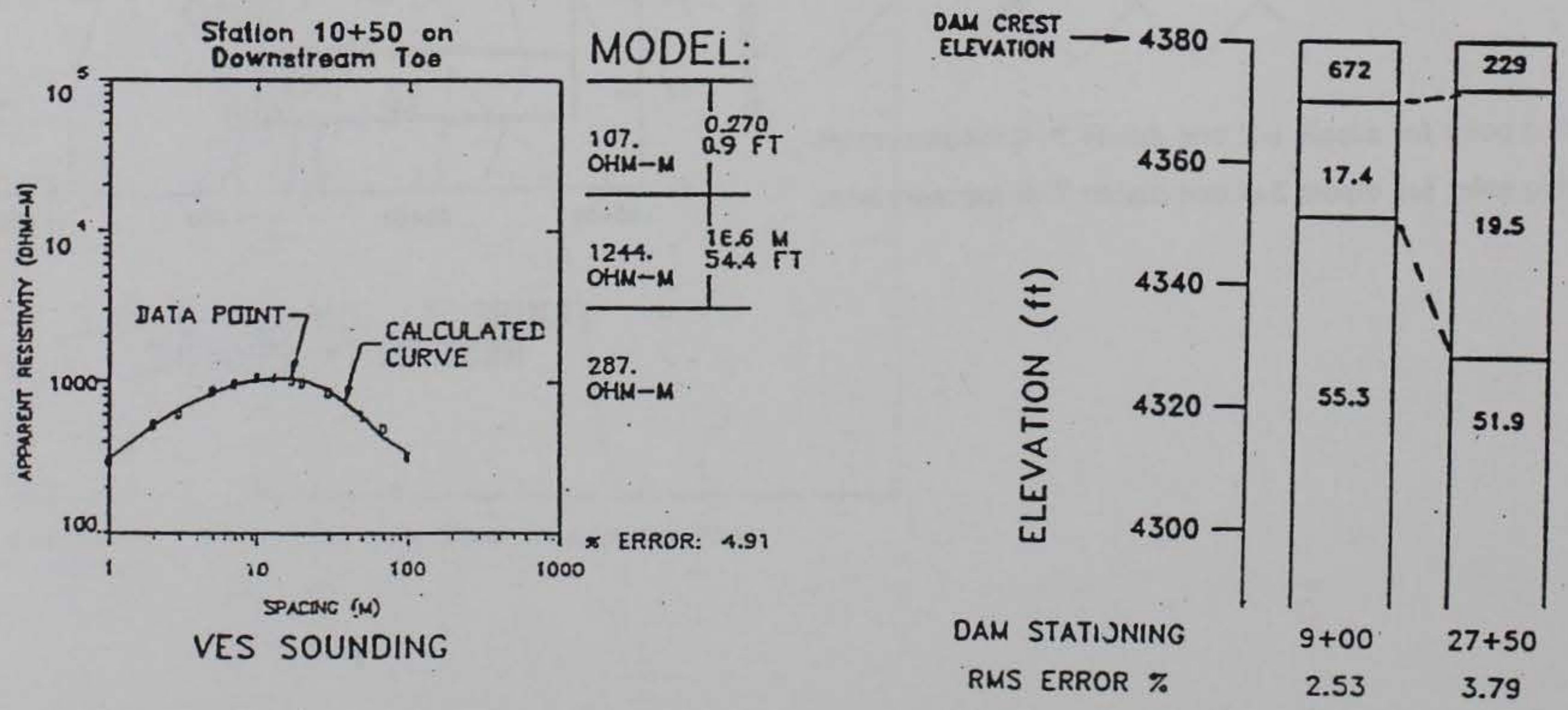
I. LIOUEFACTION GEOPHYSICS...

\section{* FIELD METHODS CURRENTLY USED:}

5. ELECTROMAGNETIC SURVEYS - EM PROFILING: VerY OUICK AND EFFICIENT METHOD FOR DEFINING SUBSURFACE MATERIAL CHANGES; PRIMARILY LATERALLY, BUT ALSO VERTICALLY. EQUIPMENT MEASURES CONDUCTIVITY OF MATERIAL FROM A "FOCUS" DEPTH, DEPENDENT UPON TRANSMITTER AND RECEIVER (COIL) SEPARATION AND ORIENTATION (VERTICAL OR HORIZONTAL DIPOLES). NEED TO BE CAUTIOUS OF BURIED FERROUS METAL OBJECTS (I.E., CONDUCTORS), AS WELL AS OVERHEAD OR NEARBY POWER LINES [6].

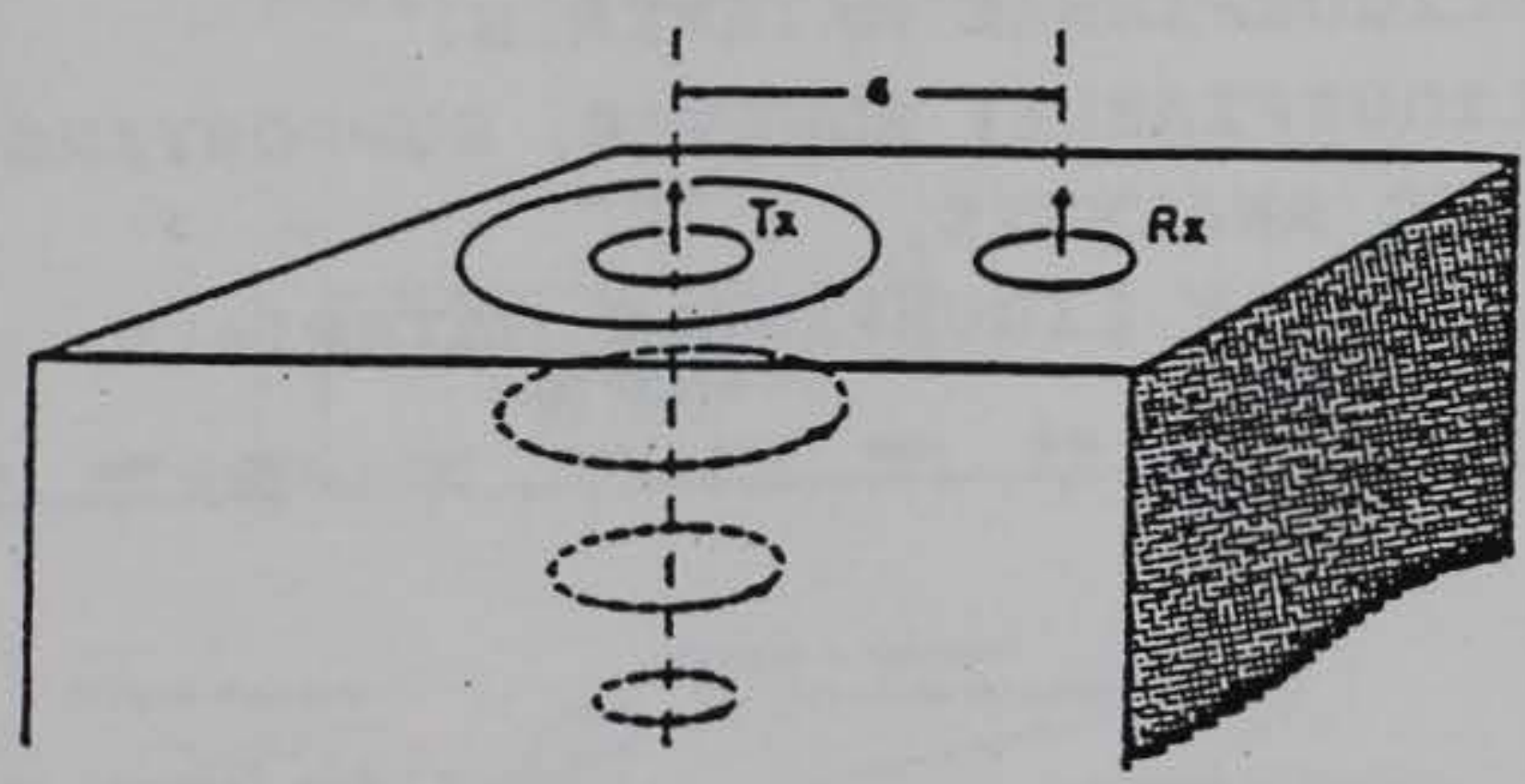

Induced current flow (homogenous halfspace)

Vertical dipole (VD) mode.

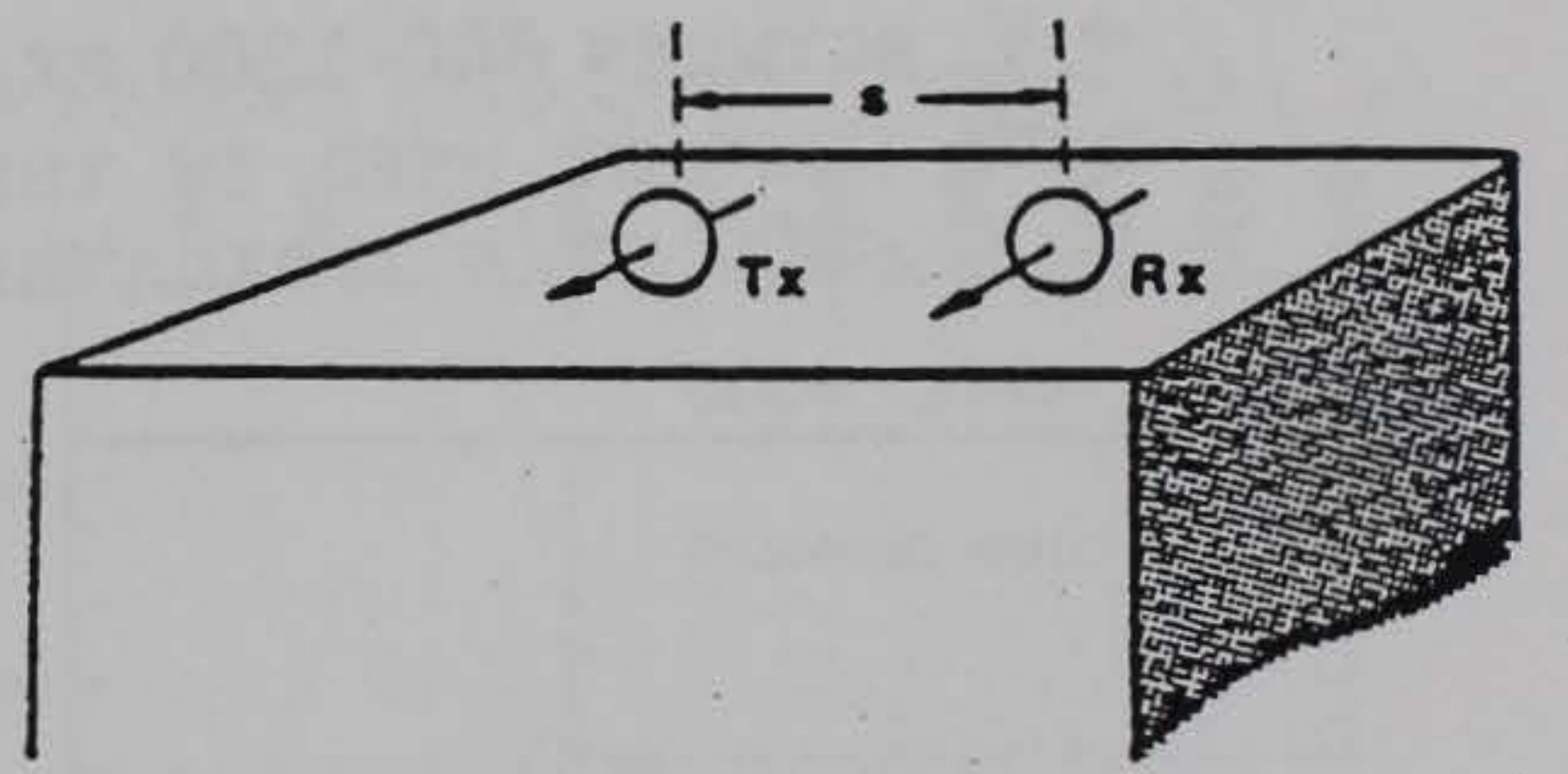

Horizontal dipole (HD) mode.

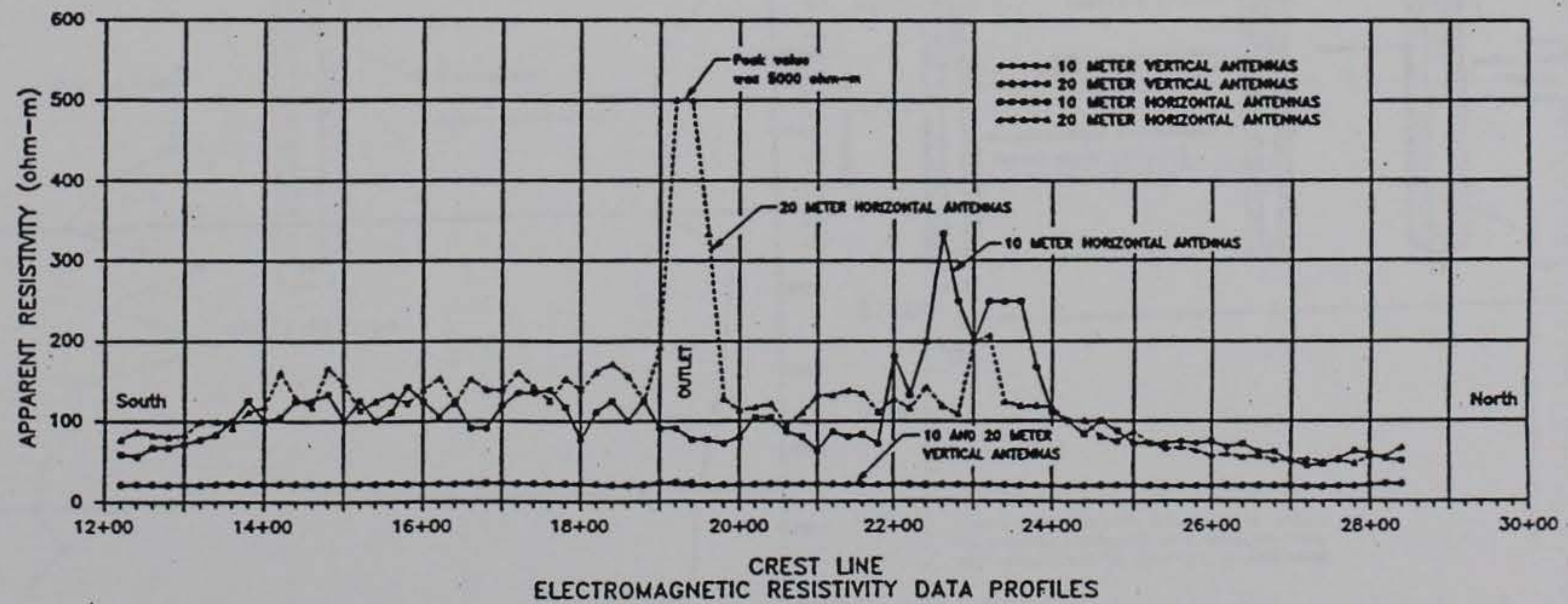


GEOPHYSICS...

I. LIQUEFACTION ---->

* FIELD METHODS CURRENTLY USED:

B. BOREHOLE TECHNIQUES - DRILLING REQUIRED TO PERFORM SURVEYS:

1. CROSSHOLE SEISMIC SURVEYS: PREFERRED METHOD FOR DETERMINING VERTICAL DISTRIBUTION OF P- AND S-WAVE velocities. An ASTM StANDARD EXISTS (D4428 M-84). THE DIAGNOSTIC GEOPHYSICAL TOOL USED BY RECLAMATION FOR EVALUATING LIQUEFACTION POTENTIAL OF SOILS: 1989 DESIGN STANDARDS INDICATE -

- $V_{s}>1200 \mathrm{FT} / \mathrm{s}$ INDICATES NONLIQUEFIABLE MATERIALS.

- $V_{\mathrm{s}}$ BETWEEN 800-1200 FT/S NONLIQUEFIABLE; HOWEVER, SUPPORTING DATA MUST BE USED IN THE DYNAMIC ANALYSIS.

- $V_{s}<800 \mathrm{Ft} / \mathrm{S}$ INDICATES POTENTIALLY LIQUeftable MATERTals.
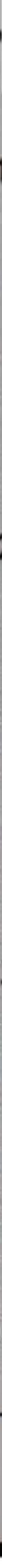
GEOPHYSICS...

\section{* FIELD METHODS CURRENTLY USED:}

\section{B. BOREHOLE TECHNIQUES}

2. DOWNHOLE SEISMIC TESTING: AlteRnATE, LesS - EXPENSIVE METHOD FOR DETERMINING VERTICAL Distribution OF P- aND S-WAVE Velocities. ONE DRILL HOLE REQUIRED, TYPICALLY SHALLOW ( $<70$ FT) SURVEYS WHERE VERTICAL VARIATION OF MATERIALS ENCOUNTERED IS MINIMAL. LESS RESOLUTION AND "AVERAGE OR APPARENT" VELOCITY PROFILES ARE OBTAINED (COMPARED TO CROSSHOLE DATA).
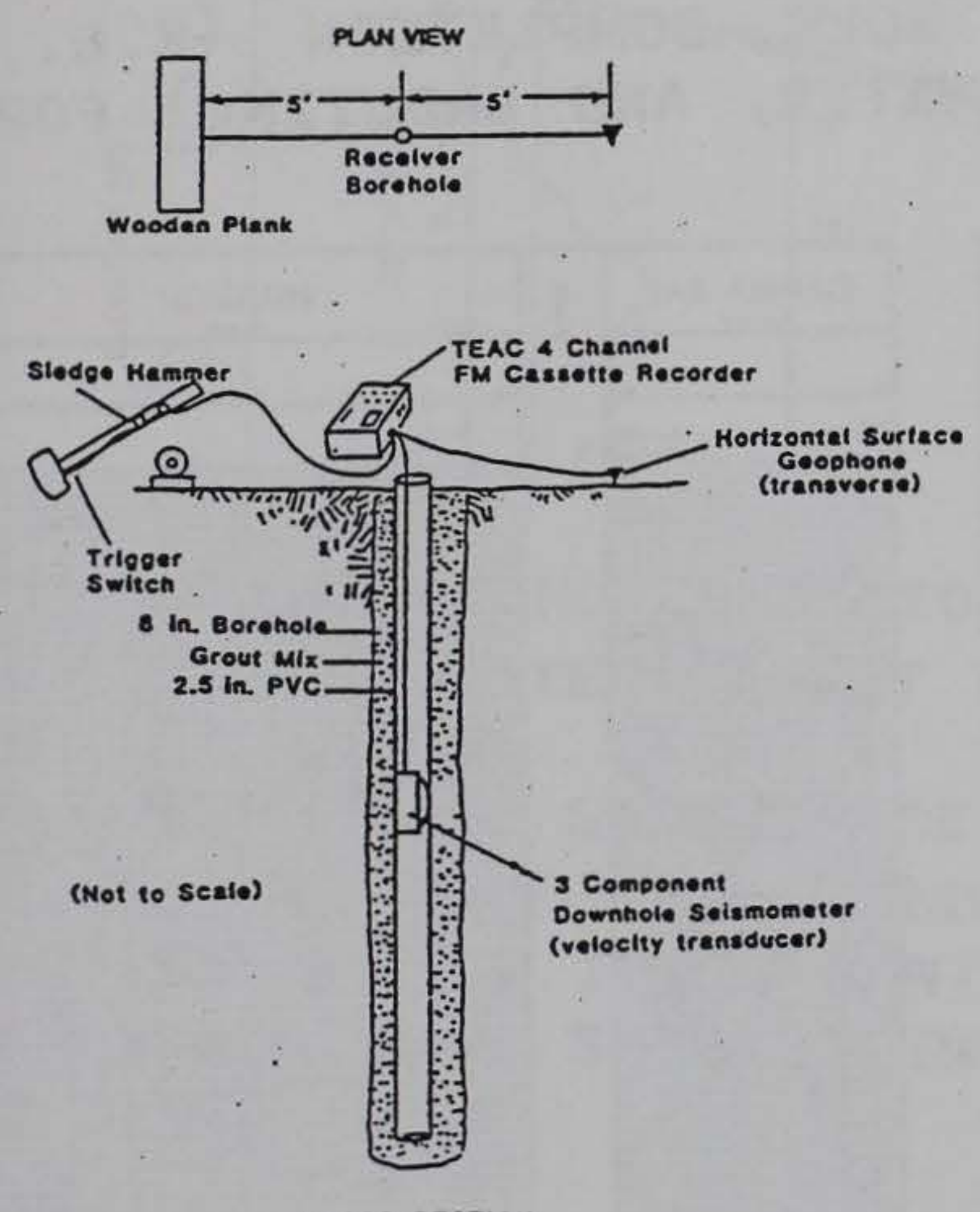

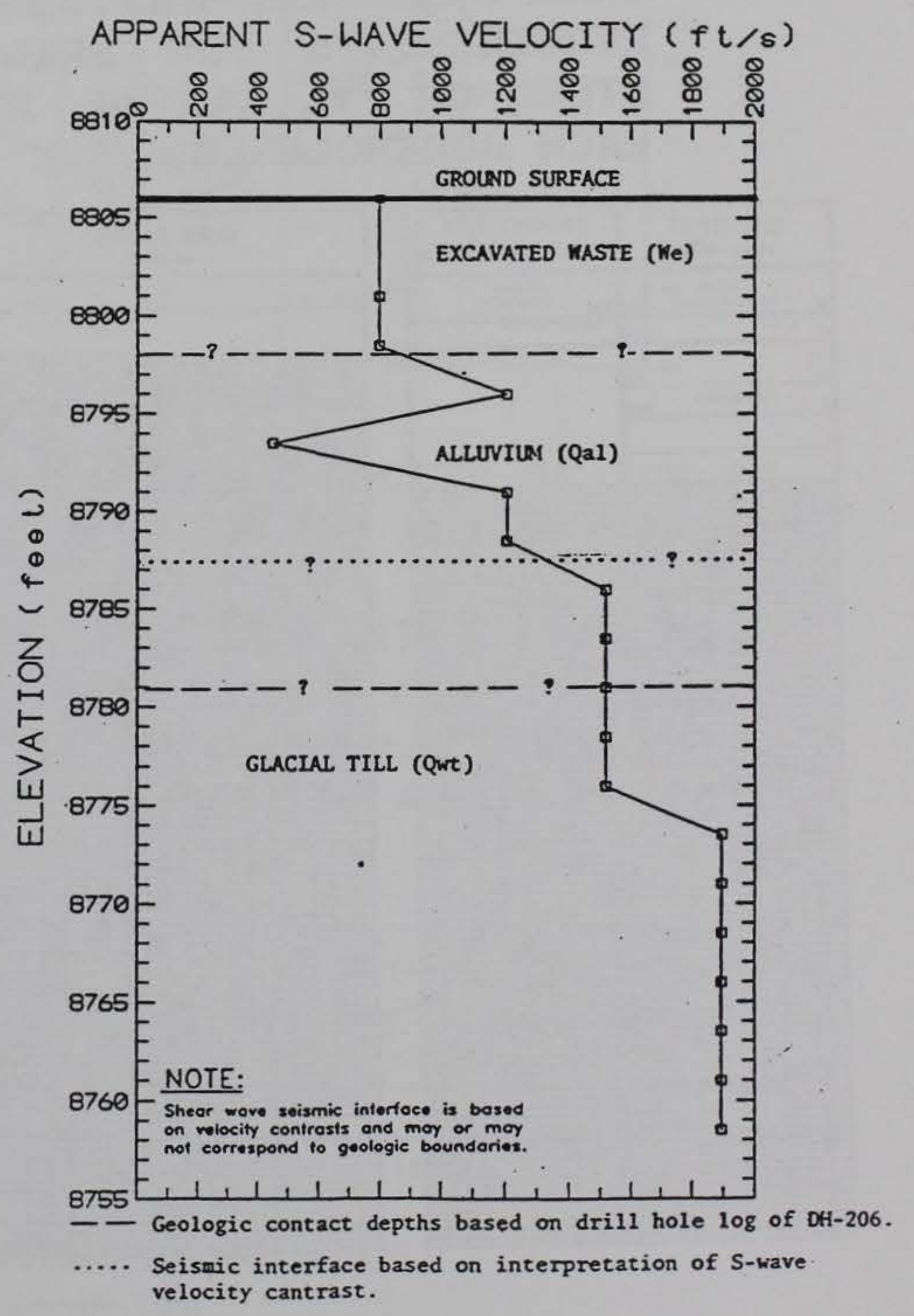


I. LIQUEFACTION ---->

GEOPHYSICS...

\section{* FIELD METHODS CURRENTLY USED:}

B. BOREHOLE TECHNIQUES

3. BOREHOLE GEOPHYSICAL LOGGING: TECHNIQUE INVOLVES LOGGING BOREHOLES WITH DIFFERENT GEOPHYSICAL PROBES THAT MEASURE DIFFERENT PHYSICAL PROPERTIES OF THE SURROUNDING MATERIALS. EACH LOG CAN BE INTERPRETED SEPARATELY, OR THE "SUITE" OF LOGS FROM AN INDIVIDUAL BORING CAN BE INTERPRETED THROUGH LOG ANALYSIS TO DETERMINE: POROSITY, MOISTURE CONTENT, RELATIVE FRACTIONS OF CLAY/SILTSAND/OVERSIZE, AND DENSITY. THERE ARE SPECIFIC REQUIREMENTS FOR DRILL HOLE COMPLETION (E.G., STEEL OR PVC CASING, DIAMETER, AND GROUTING) FOR EACH BOREHOLE LOG.
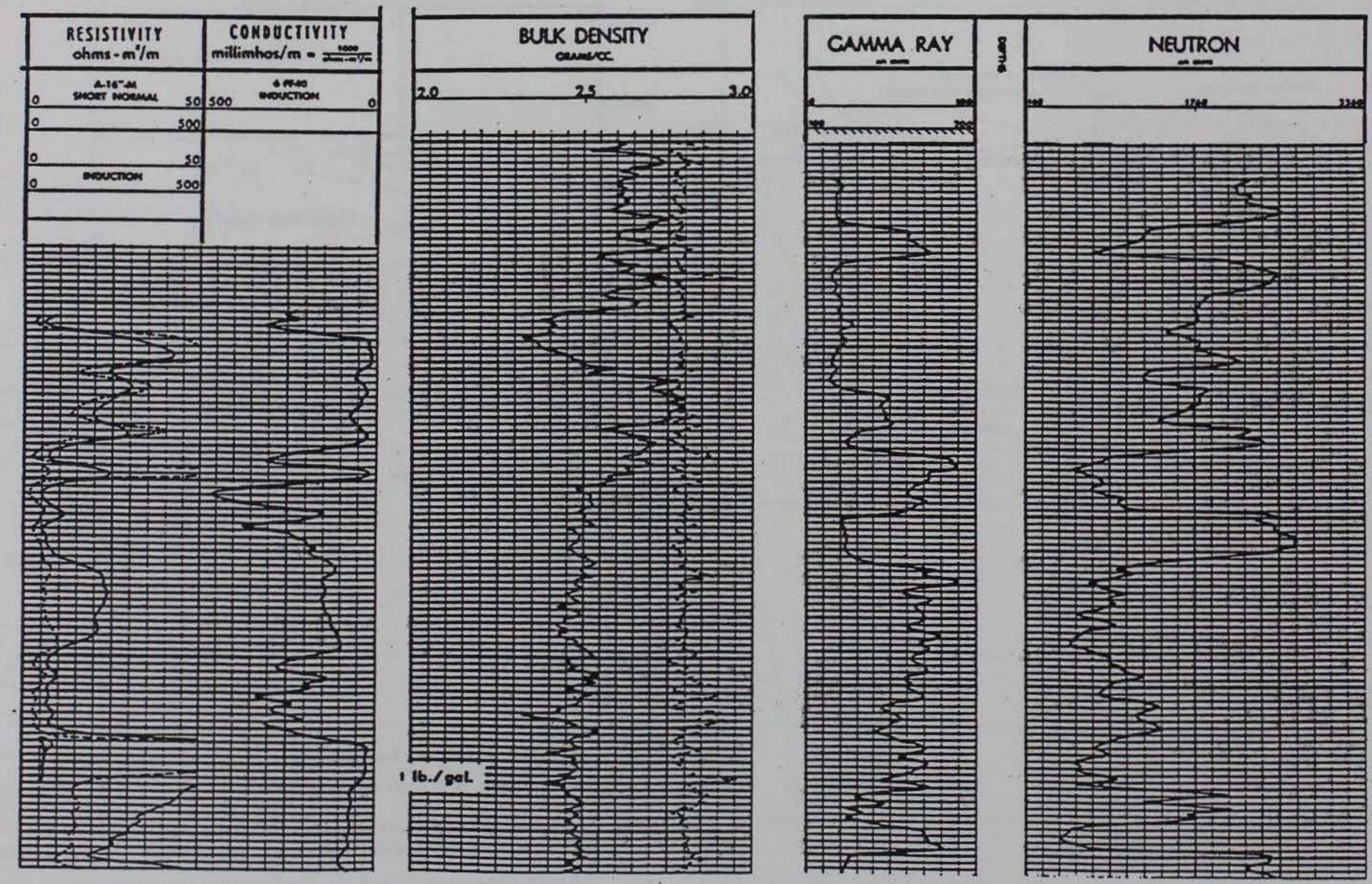
I. LIQUEFACTION GEOPHYSICS...

\section{* PITFALLS TO WATCH FOR WHEN ASSESSING LIQUEFACTION POTENTIAL UTILIZING GEOPHYSICAL METHODS :}

- "Refraction INTERPRETERS NIGHTMARE - hIDden LaYers (LOW VELOCITY LAYERS BENEATH HIGH VELOCITY LAYERS):

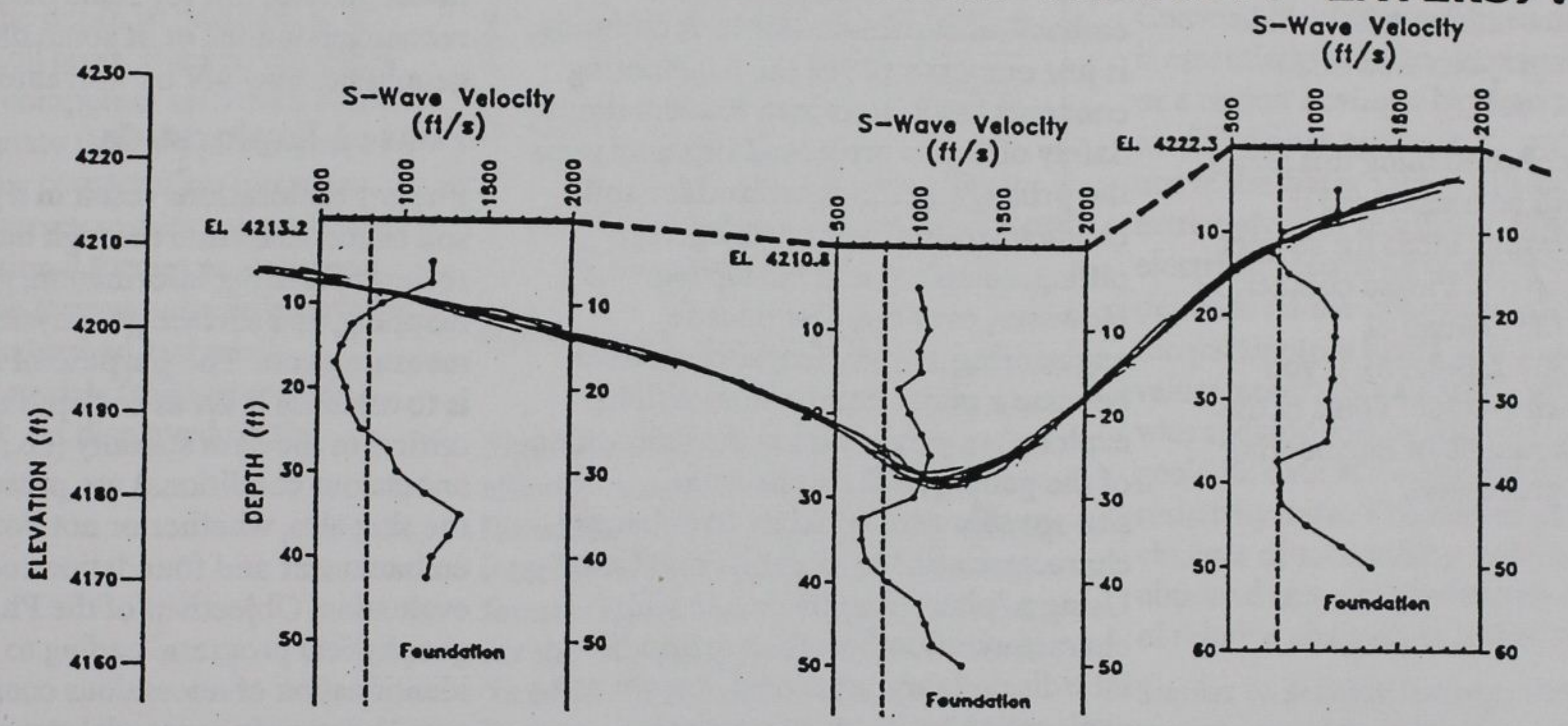

- Frozen gRound conditions (S-WAVe Velocity of ICE is $1100 \mathrm{FT} / \mathrm{S}$; WATER CANNOT TRANSMIT SHEAR, BUT ICE CAN!)

- Changes in subsurface material resistivities from HIGH- TO LOW-POOL CONDITION; PROBABLY RELATED TO INFLUX OF LOW IONIC CONTENT FRESH WATER. THEREFORE, CONSIDERED A SEEPAGE RELATED PROBLEM AND NOT SOIL RELATED.
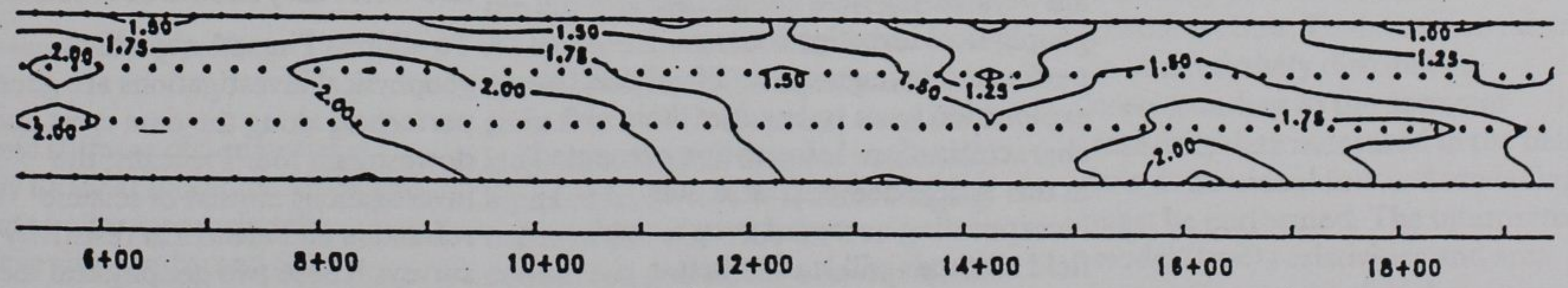

RESISTIVITY RATIO PSEUDOSECTION (HP/LP)

(Contour Inferral= 0.25) 


\section{"Tools of the Trade"}

\section{by Bob Dewey, Bureau of Reclamation representative, USCOLD Newsletter}

In at least this and the next two issues of the USCOLD Newsletter, the 1992

issues, you will find a series of articles featuring some very useful, unusual or otherwise special techniques available for the analysis and design of dams. The purpose of this series is to provide more exposure for tools of our trade that have proven to be highly valuable and are not well known or sometimes overlooked. In this issue we will focus on the use of geophysics for soil characterization, in particular its use for investigating the liquefaction susceptibility of embankment dams and their foundation materials. Future articles will include the use of petrographics and other state-of-the-art tools.

The possibility of continuing this series beyond 1992 will be considered if numerous interesting ideas for subject matter are suggested. Please contact Bob Dewey at the Bureau of Reclamation (303-236-4196), if you would like to write about "Tools of the Trade" which would be of engineering interest to our profession.
Tools of the Trade

\section{Geophysics for Soil Characterization at New and Existing Dams}

by Phil Sirles, Bureau of Reclamation

\section{Introduction}

With the profession's commitment to dam safety there has been

implementation of as many "tools of the trade" as necessary to characterize in situ soil conditions. Within the realm of site characterization, determining the liquefaction potential of an embankment dam and/or its foundation is just one example of the engineering concerns associated with Reclamation's Safety of Dams projects. For many years the primary methods utilized for soil characterization were drilling, test pitting, sampling and lab testing. However, over the past decade engineering geophysical surveys have become a major component of field exploration programs via the integration of the geophysical results with site-specific geologic data to enhance characterization of the soil conditions. Using a "phased" approach to soil characterization permits a group of interdisciplinary personnel, known as an exploration team, to interactively evaluate the extent and most efficient methods for the field exploration.

This article presents the current philosophy for using geophysical "tools" so that characterization of soil conditions, in particular, investigations for liquefaction assessment, may be completed as thoroughly and economically as possible. There should be no pretense that geophysical results are to be used as definitive or final answers during field explorations; geophysical investigations are performed to augment and facilitate thc exploration team to conduct their soil characterization. Information presented in this article demonstrates that incorporating accepted geophysical field methods will lead to better cvaluation of site soil conditions in a cost effective manner.

Typically three distinct phases are used for field explorations after the initial recommendations for conducting field explorations have been identified in a Safety Evaluation of Existing Dams (SEED) report. The exploration team convenes to discuss available information, site conditions, and review the recommendations identified in the SEED report. During this meeting the team agrees upon methods for evaluating the soil conditions, prepares a field program for Phase 1 investigations, and puts together a strategy for later phases of exploration. For most projects, geophysics will be conducted in the first phase of field investigations, but for some SEED recommendations or at some damsites geophysics may not be warranted.

\section{Phase 1 Exploration}

Phase 1 explorations result in a general soil characterization through literature review of existing information, geologic mapping, and surface geophysical measurements. The purpose of Phase 1 is to establish if areas or depth zones. critical to the dam stability (i.e., anomalous conditions) are present at the site; also, whether or not both the embankment and foundation require evaluation. Objectives of the Phase 1 geophysical program leading to identification of anomalous conditions are: 1) determine material strengths for the embankment and foundation; 2) identify the types of materials present; 3) evaluate the lateral continuity of the soil deposits; 4) estimate the depth to competent soils or rock; and 5) determine depth to the water table. If further field explorations are required, results from the Phase 1 geophysical surveys assist the exploration team's decisions regarding the most practical and effective methods of investigation and where they should be located.

To address Phase 1 objectives, geophysical investigations are generally performed along the dam crest and downstream toe. Typically, the investigations consist of seismic refraction and electrical resistivity surveys. These two geophysical methods are briefly described below. 


\section{Seismic Refraction Surveys}

Refraction surveys are performed to determine the velocities of subsurface layers and the lateral and vertical distribution or variations of the velocities. Refraction surveys are divided into two techniques: compressional- (P) and shear- (S) wave velocity measurements.

$\mathrm{P}$-wave velocities obtained in unconsolidated soils above the water table provide information about the material's in situ density and variability. Below the water table, the P-wave velocity is affected by the presence of pore water and saturation; because of this, $\mathrm{P}$-wave refraction surveying determines depth to the water table. Additionally, P-wave surveys are used to determine the depth to bedrock or a competent soil layer. P-wave velocities obtained in competent materials can be used to estimate their rippability and erodibility for construction purposes. Refraction survey results are presented in cross-sectional format as shown on Figure 1. The P-wave seismic interfaces between unsaturated materials, saturated materials (the water table), and bedrock are displayed on the profile.

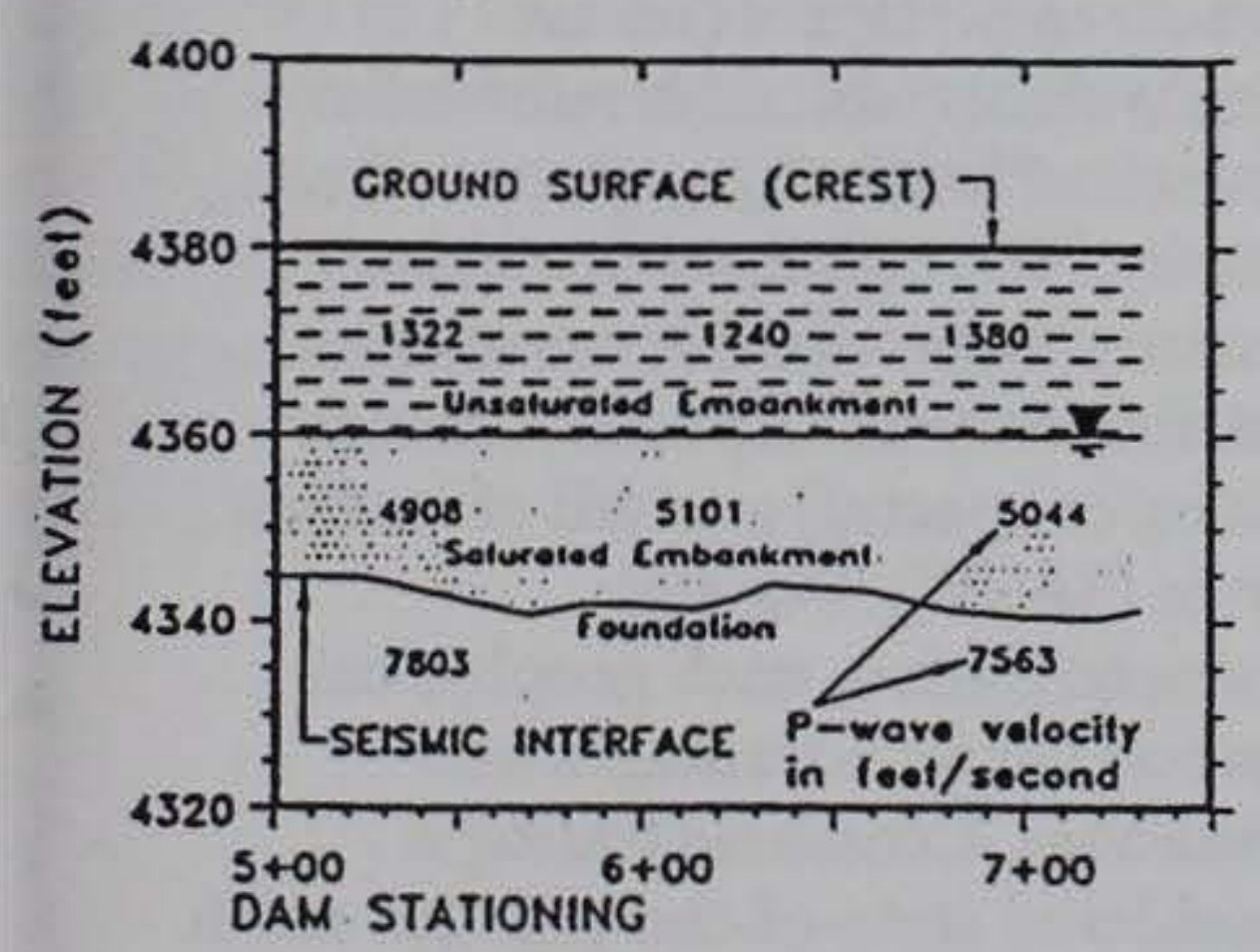

Figure 1. P-wave refraction profile.

The seismic stiffness of a material is defined by its shear modulus, which can be computed after measuring the material's in situ density and S-wave velocity. A material's S-wave velocity is not affected by the presence of pore water, hence, S-wave refraction surveys can determine the stiffness of the deposit above and below the water table. Dynamic analyses have shown that the S-wave velocities at soil sites are not as important as the vertical and lateral distribution of the velocity. Therefore, the purpose of performing $S$-wave refraction surveys is detection of the lateral and vertical variability of velocity for the embankment and its foundation. Figure 2 displays S-wave - data collected at the same location as

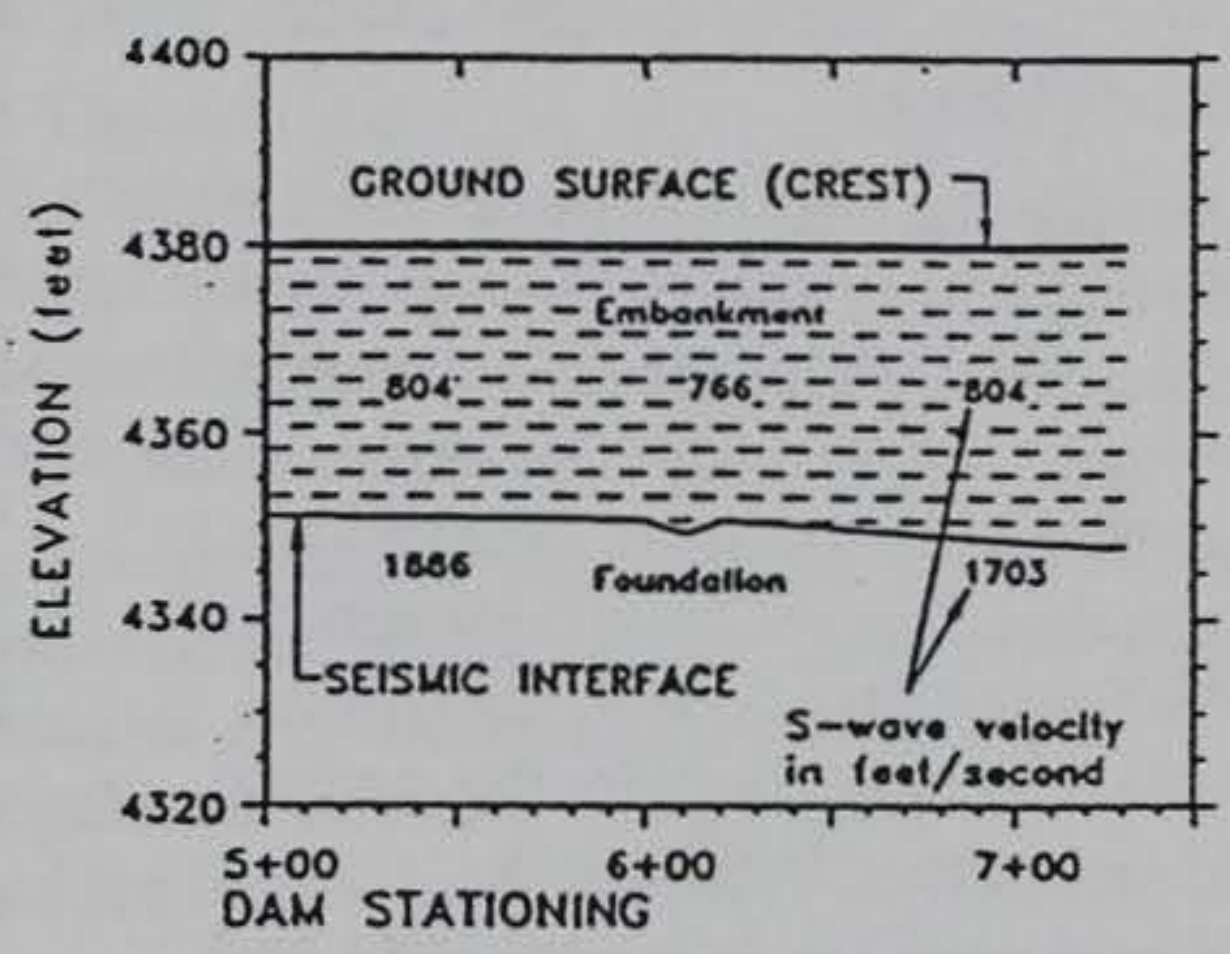

Figure 2. S-wave refraction profile.

Figure 1. Since the water table does not affect S- waves, the embankment/ foundation contact was the only seismic interface detected. The embankment/ foundation contact is slightly different for the two refraction profiles because "bedrock" is a weathered shale and $\mathrm{P}$-waves could not differentiate between residual soil and saturated embankment materials.

In general, refraction surveys have the limitation of sampling large volumes of the subsurface which produces an average velocity for each layer. The value in refraction surveying is the assessment of soil conditions over large areas. Also, determining the S-wave velocities (high- and low-velocity areas) permits a qualitative judgment about the liquefaction potential for the soils. At Reclamation, a conservative approach is used for liquefaction of soils: S-wave velocities less than $800 \mathrm{ft} / \mathrm{s}$ indicate materials that are potentially liquefiable; S-wave velocities ranging between 800 and $1200 \mathrm{ft} / \mathrm{s}$ are considered potentially non-liquefiable, but supporting evidence is required (c.g., gradation, SPT blow counts, percent saturation); and, if the S-wave velocities are greater than $1200 \mathrm{ft} / \mathrm{s}$ the materials are considered nonliquefiable.

\section{Electrical Resistivity Measurements}

The major factors controlling the electrical resistivity of earth materials are porosity, moisture content (degree of saturation), pore water conductivity, grain size, and clay content. A material's resistivity generally increases as any of these parameters decrease, except that resistivity generally decreases with decreasing average grain size. Because of surface conduction effects, the presence of even a small amount of clay in a soil deposit often results in a large decrease in the measured resistivities. Conversely, because the resistivity of air is essentially infinite, an air-filled void, or a region having a high percentage of air-filled pore space (e.g., porous media above the water table) will have extremely high resistivity. Since the electrical resistivity of a soil or rock depends on the combined effect of all of the parameters listed above, resistivity values generally cannot be correlated with specific soil or rock types until site geologic data are correlated with the resistivity data. The lateral and vertical changes of subsurface resistivities obtained at a site provide an indication of relative changes in soil or rock types.

Similar to seismic testing, electrical surveys are also divided into two methods: dipole-dipole resistivity profiling and vertical electric sounding (VES). Dipole-dipole profiling, sometimes referred to as "electrical trenching", provides resistivity information "focused" at depth along an entire survey line. For engineering projects the technique has a limited depth of investigation, generally about 40 feet. Dipole-dipole measurements provide a continuous apparent resistivity profile called a pseudosection. To determine the true in-situ resistivity distribution corresponding to the apparent resistivity data measured in the field, two-dimensional forward modelling must be performed. The interpreted model (true) resistivities and area boundaries are displayed superimposed 
on the pseudosection contours. The modeled true resistivities are presented in cross-sectional format (Figure 3 ).

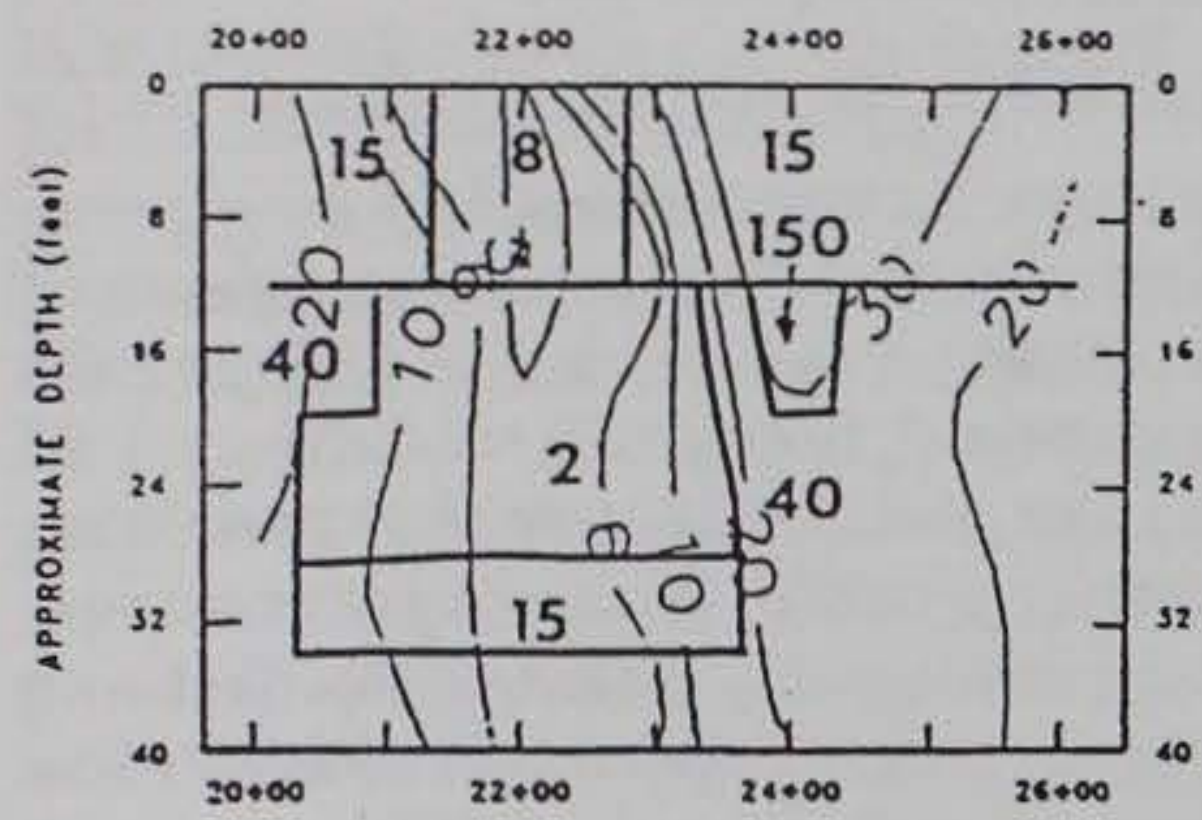

Figure 3. Dipole-Dipole resistivity profile.

The data presented in Figure 3 were collected over laterally heterogeneous glacial deposits where coarse- and fine-grained materials (high- and lowresistivities, respectively) are juxtaposed due to the depositional environment. The high resistivity areas indicate outwash channels, whereas the low resistivities are indicative of point-bar deposits.

VES measurements, sometimes referred to as "electric drilling", provide a one-dimensional earth model of the resistivity layering beneath a single measurement station. Generally, more vertical resolution of the subsurface layering and greater depth of investigation are obtained from VES data. Computed resistivity models

$\begin{array}{ccc}\text { DAM STATIONING } & 9+00 & 27+50 \\ \text { RMS ERROR } \% & 2.53 & 3.79\end{array}$

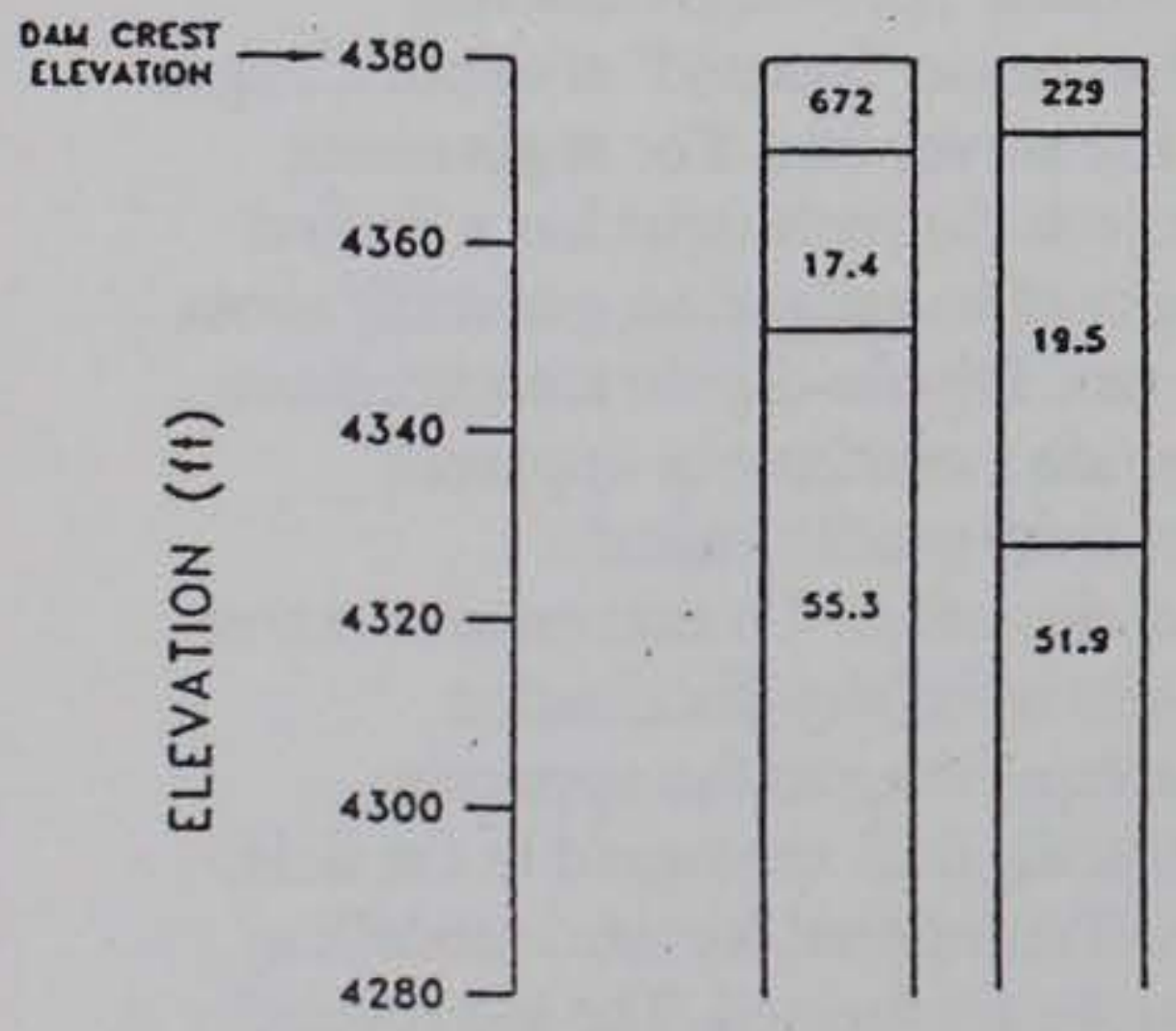

Figure 4. Vertical electric soundings. represent interpretation of the field data through an inversion proccdure. The earth models are typically plotted in "stick $\log$ " fashion, since the resistivity data represent the layering beneath an array center point. Figure 4 shows two VES earth models obtained on an embankment crest, one collected at the same location as the $\mathrm{P}$ - and $\mathrm{S}$-wave seismic data. The high resistivity surface layer represents unsaturated shell (Zone 2) materials, while the low resistivity middle layer represents fine-grained core (Zone 1) materials, and the deepest layer of moderate resistivity represents the foundation bedrock (shale).

Incorporating both the Phase 1 seismic and electrical results permits general characterization of material strengths and types, respectively. The exploration team then meets to discuss the Phase 1 results and decides what is required to verify (ground truth) the geophysical results, and also discusses the optimal field techniques for Phase 2

explorations. Drill holes, test pits, and material sampling can be located and performed in the anomalous areas as determined by the Phase 1 geophysics.

\section{Phase 2 Exploration}

Phase 2 field explorations rarely involve additional geophysical surveys; rather, drilling, sampling, and in situ and laboratory testing are performed. The types of field investigations used during Phase 2 may be highly varied (e.g., Standard, Becker, or cone penetration testing). The phased approach anticipates using correlations between the Phase 1 geophysical and Phase 2 geological data.

Physically measuring and testing the Phase 2 material samples results in properties which can be correlated with the geophysical information. This correlation permits "calibration" of the Phase 1 results on a site-specific basis. That is, by combining the geophysical and physical sets of data, the determination of lateral continuity of material properties between drill holes can be made.

Material properties obtained in the field during Phase 2 must be considered as investigations are progressing, such that the exploration team has flexibility for revising the original concept of the Phase 2 program. If the correlation between Phase 1 and 2 data is poor then additional exploration, Phase 3 , may be warranted. An example encountered frequently during Phase 2 is: the Phase 1 refraction S-wave measurements show high velocities (>1200 fps) for the near surface materials and they increase with depth, indicating non-liquefiable soil deposits; but, during drilling the SPT blow counts are moderately high to high for the upper soil layers, then they decrease with depth to very low values indicating the presence of potentially liquefiable layers at depth. This situation does not imply the geophysics is incorrect, rather, the subsurface drilling information has confirmed that a low-strength layer was undetected by refraction surveying and Phase 3 explorations are required.

\section{Phase 3 Exploration}

When representative geological data are obtained during Phase 2 and correlations with the Phase 1 geophysical data are satisfactory, Phase 3 field explorations may not be required. If the data obtained during Phases 1 and 2 are not sufficient to characterize the soil conditions at the site, supplemental information involving additional geological and geophysical testing must be acquired. For the example previously discussed, where low-strength soils are present beneath high-strength layers (which geophysically would be referred to as a "ghost" or "hidden" layer), one of two geophysical techniques is used to measure the in situ S-wave velocity distribution with depth: crosshole testing or spectral analysis of surface waves (SASW). For soil characterization, each geophysical method has its advantages and limitations. Crosshole testing is considered state-of-the-practice and is used more frequently, however, since crosshole testing requires drill holes there are circumstances where time constraints, site logistics, or the project budget does not permit installation of borings and SASW testing is acceptable. 
40 percent increase in S-wave velocity after compaction, with an effective depth of treatment to about 30 feet.

\section{Summary}

Implementing a phased approach to geotechnical exploration programs for soil characterization permits the exploration team to acquire the maximum amount of site information with the most effective methods. Typically, three phases of field exploration will sufficiently characterize the soils by evaluating both the lateral and vertical distribution of material properties. Assigning an interdisciplinary team of individuals to supervise all phases of the exploration program enables each team member to bring specialized testing methods to the project in order to address the engineering concerns of the site. Geophysical surveys, as presented in this article, should be used during the first phase of exploration to obtain an overall site assessment. Phase 1 geophysical results are presented to the exploration team in order to assist in planning the Phase 2 investigations. Specified field testing can be located and performed in areas or depth zones as defined during Phase 1 which are potentially critical to the dam safety. If soil conditions at the site are not sufficiently characterized after Phase 2 exploration, or the correlation between Phase 1 and 2 data is poor, additional geological and geophysical data should be acquired in Phase 3. This type of approach to field investigations makes use of state-of-the-art geophysical "tools of the trade" and requires cooperation among geologists, geophysicists, and engineers to utilize them as effectively as possible. $\not$

\section{IDB Loan to Nicaragua}

The Inter-American Development Bank has approved a $\$ 19$ million loan to help Nicaragua rehabilitate its national electric power system to meet current demand and allow for future expansion. The program will be carried out by the Nicaraguan Power Authority and consist of four components:

1. The rehabilitation of the spillways of the Asturias and Apanas dams and other civil works of the

Asturias-Centroamerica-Carlos Fonseca hydroelectric complex.

2. The rehabilitation and upgrading of 37.5 kilometers of transmission lines and substation equipment with a total of 385 megavoltamperes of transformer capacity.

3. The procurement of meters, service connections, metering equipment, vehicles and related equipment to regularize service to illegal users, reduce losses, build feeder lines to lowincome areas of Managua and improve INE's maintenance capacity.

4. The contracting of the consulting services required to strengthen the environmental, financial and planning procedures of INE.

The total cost of the program is estimated at $\$ 36.5$ million. It will be co-financed by the Central American Bank for Economic Integration with a $\$ 9.8$ million loan that includes $\$ 8.9$ million from the Mexican government, and by the Nordic Development Fund with a $\$ 3$ million loan. ${ }^{\circ}$

\section{Election (continued)}

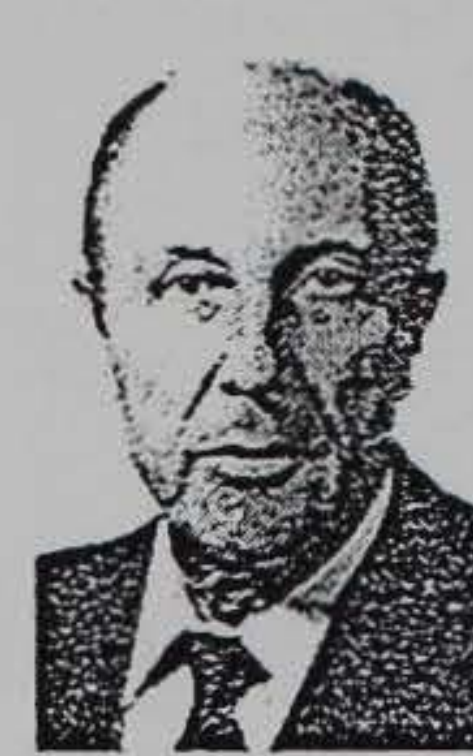

John J. Cassidy
John J. Cassidy is Engineering Manager, Hydraulics/Hydrology for Bechtel Corporation in San Francisco. He received B.S. and M.S. Degrees in Civil Engineering from Montana State University and a Ph.D. in Hydraulics from the University of Iowa. He has 37 years of experience in hydraulic design and analysis and hydrology. In his present position, he is responsible for development of inflow design flood hydrographs, flood routing calculations, conceptual designs for spillways and outlet works, analyses to determine cavitation potential, head losses in water passages, and transient pressure in penstock and tunnel systems. $\mathrm{He}$ is a Member of USCOLD and the American Society of Civil Engineers. He has served as Chairman of the ASCE National Water Policy Committee and member of the ASCE Task Force on Dam Safety. He has served USCOLD as a member of the Committee on Hydraulics for Dams and is currently the Chairman of the ICOLD Committee on Hydraulics. He was actively involved with the 16 th ICOLD Congress, having served on the Steering Committee as a member of the Public Relations Committee, as Chairman of the Finance Committee, and as ICOLD Secretary to Question 63. He will be the General Reporter on Reservoir and Spillway Operation at the ICOLD International Symposium on Dams and Extreme Floods to be held in Granada in 1992.

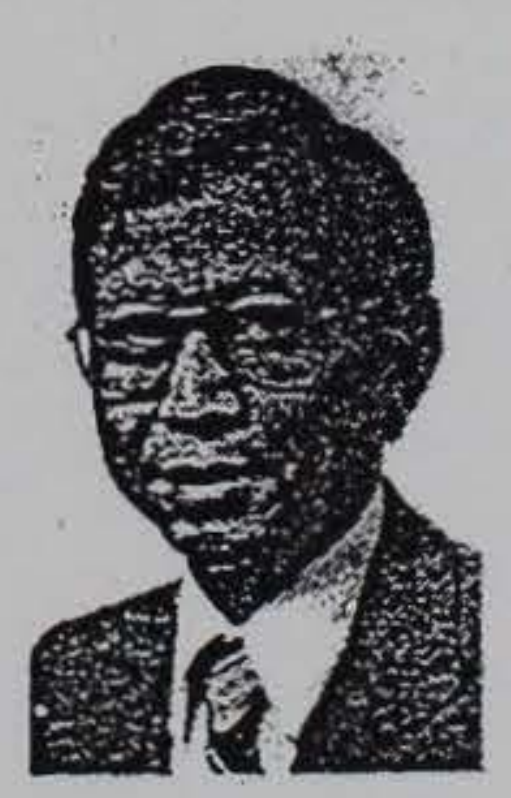

Catalino B. Cecilio

Catalino B. Cecilio is Senior Civil Engineer in charge of the hydrologic engineering group in the Hydro Engineering and Construction Department for Pacific Gas and Electric Company in San Francisco. He holds a B.S. degree in Civil

Engineering. His job responsibilities 


\section{Appendix F - Proceedings Submissions by Prof. Steven Glaser}


A Non-Destructive Method of Estimating Properties of Soil Subjected to Earthquake Strong Motion

\author{
by \\ Steven Glaser \\ Geomechanics Research Center \\ Division of Engineering \\ Colorado School of Mines \\ Golden, CO 80401
}




\section{Abstract}

This paper introduces parametric modeling, commonly known as system identification, to estimating dynamic soil properties. These methods are optimized for short and non-stationary signals. The Wildlife Site, CA, subjected to two large earthquakes (Elmore Ranch and Superstition Hills) on November 24, 1987 , was used in an example analysis since the associated data is the only publicly available record of buried and surface motions. During the second, larger, earthquake (Superstition Hills earthquake) the site soils liquefied. The pseudo-stiffness of the soil system between the two accelerometers is defined in order to present the changes of system behavior through time in a convenient form. The pseudo-stiffness decreased with rising pore pressure and correlated with the evolution of the pore pressure and shaking history. Both stationary and recursive parametric modeling methods are applied to the unique input-output data set from the two earthquakes. The results show weakening of the soils system as pore pressure increases, with estimates of natural frequency, damping ratio, and participation factor given. 


\section{Introduction}

An important goal for the geotechnical engineer is the ability to estimate soil properties without intruding into the soil mass. For the engineer interested in seismic behavior of soils, the dynamic properties of the soil are of interest, particularly large-strain properties. The archetypal large strain field excitation is earthquake strong motion. Ideally, both soil motions into the soil layer of interest and soil motion on the surface above the layer are recorded. Given this known input propagating upward from depth, and the output at the top of the soil column, the behavior of the soil can be modeled by inverse theory. If a suitable model is chosen to represent the system of interest, the estimated model parameters will correspond to important mechanical parameters of the system, such as damping, natural frequency, and stiffness. This estimation of parameters is commonly known as system identification (SI).

The traditional method of geotechnical analysis of dynamic soil motions is through the Fourier transform. However, serious problems arise when this method is applied to short data streams, and to signals changing through time non-stationary signals. This study was undertaken to show the effectiveness of a different type of model, a parametric model commonly used in automatic control and geophysics, which avoids many of the limitations inherent with calculating the system transfer function by Fourier techniques. An important aspect of particular parametric models is the theoretical link between the estimated system parameters and the mechanical parameters of a lumped-mass oscillator. The parametric model allows estimates of system dynamic properties to be to be made if an input-output data set is available. 
This paper applies both stationary and time-varying parametric models to the input-output data sets recorded during the two (Elmore Ranch and Superstition Hills) 1987 earthquakes at the Wildlife Site in the Imperial Valley, California. Since the inverse problem (identifying a system by working from recorded data) is non-unique, it is necessary to understand the mechanistic behavior of the system being modeled in order to facilitate selection of the correct model and solution. To this end detailed geotechnical, geological, and seismological analyses of the Wildlife site and earthquake events are presented. To gain clearer understanding of the relation between force, displacement, pore water pressure, and material stiffness, a new method of combining complex timedependant variables - the pseudo-stiffness - is introduced.

This paper will start by introducing and explaining parametric modeling in the context of SI. The Wildlife site will then be introduced and physical properties examined. The geotechnical behavior of the site during strong shaking will be examined, in particular the relation between strong shaking, pore pressure, and soil stiffness. Finally, the SI techniques will be applied to the Wildlife site data and system parameters estimated. 


\section{System Identification}

\section{Parametric Modeling}

The goal of system identification is to model a system in a manner that provides needed mechanical information about that system. The most common techniques have evolved from electrical and mechanical engineering, and involve solving the inverse problem for the system transfer function. Each method has limitations; in the words of G. E. P. Box, "All models are incorrect, but some are more useful than others."

The process of inversion allows the estimation of the system response function (filter) if the input and output signals are known. A simple model for characterizing a system is as a parametric relationship between system input and output. Such a model, referred to as an autoregressive-moving average (ARMA) model, is based on discrete time series analysis:

$$
y_{t}=a_{1} y_{t-1}+a_{2} y_{t-2}+\ldots+b_{0} x_{t}+b_{1} x_{t-1}+\ldots \equiv\left(\sum_{j=0}^{n b} b_{j} x_{t-j}+\sum_{k=1}^{n a} a_{k} y_{t-k}\right)
$$

where $y_{j}$ is the actual output data sequence, $x_{j}$, is the input sequence (assume white noise for simple spectral estimation), $n a$ and $n b$ are the AR and MA orders, respectively, and the subscript is the time step counter. The output is seen as a combination of the input history acted upon by the " $b$ " coefficients plus the past outputs acted upon by the " $a$ " coefficients. The input series, involving the " $b$ " coefficients, is a causal moving average (MA) process (convolutional). The series involving weighted past output values (" $a$ " 
coefficients) is a noncausal autoregressive (AR) process. The lengths of the AR and MA processes (model order) must be explicitly chosen so that the model best represents the process.

Applying the shifting theorem to Equation 1 yields the Fourier transform (Bracewell 1978)

$$
Y_{\omega}\left(1+a_{1} e^{i \omega}+a_{2} e^{2 i \omega}+\ldots\right)=X_{\omega}\left(b_{0}+b_{1} e^{i \omega}+b_{2} e^{2 i \omega}+\ldots\right)
$$

where $i$ is $\sqrt{-1}$ and $\omega$ is circular frequency. Applying the Z-transform (Bracewell 1978), where $z^{k}=e^{k i \omega}$, and rearranging, yields the frequency domain transfer function $\mathrm{H}_{\omega}$

$$
H_{\omega}=\frac{Y_{\omega}}{X_{\omega}}=\frac{b_{0}+b_{1} z^{1}+b_{2} z^{2}+\ldots}{1-a_{1} z^{1}-a_{2} z^{2}+\ldots}
$$

The ARMA model is very powerful in that it can easily model sharp drops, sharp peaks, and smooth spectral behavior. It is also the most parsimonious estimator (Robinson 1982), describing a complex process with very few parameters calculated from a small length of data. Parametric modeling avoids many of the difficulties inherent in the traditional Fourier methods, discussions of which can be found in many books and journals (e.g., Glaser 1993; Johansson 1993; Pandit 1991). Extensions of this model, e.g., ARMAX, ARX, BoxJenkins, allow input, system, and output noise to be expressly modeled (Ljung 1987). In particular, the ARX model includes the effect of uncertainties and noise as a white noise term.

The ARMA model has special significance since it can be derived directly from the differential equation of motion for an $\mathrm{N}$-degree-of-freedom (DOF) system, with the damping ratio and resonant frequency as the model parameters (e.g., Gersch and Luo 1970). A $2 n-2 n$ ARMA model is therefore a valid model 
for a layered soil system, or soil-structure interaction problem. The damping ratio and resonant frequency of the $N$-degree-of-freedom oscillators are contained in the $2 n$ AR parameters. Phase relations are preserved in the MA parameters. The modal frequencies $\xi_{\mathrm{j}}$, percent of critical damping $\left(\omega_{\mathrm{j}}\right.$, (Ghanem et al. 1991) and power participation factor $\mathrm{p}_{\mathrm{j}}$ (Pandit 1991; Safak 1988) are calculated from the system poles and residues found from partial-fraction expansion of Equation 2. The modal parameters are defined as

$$
\begin{aligned}
& \omega_{j}=\frac{\sqrt{\lambda_{j}^{2}+\delta_{j}^{2}}}{\Delta t} \\
& \xi_{j}=\frac{\delta_{j}}{\sqrt{\lambda_{j}^{2}+\delta_{j}^{2}}} \\
& p_{j}=-r_{j} \operatorname{conj}\left(z_{j}\right)-z_{j} \operatorname{conj}\left(r_{j}\right)
\end{aligned}
$$

where $\lambda=\operatorname{Arg}\left(\mathrm{z}_{\mathrm{j}}\right), \mathrm{d}_{\mathrm{j}}=-(0.5) \ln \left|\mathrm{z}_{\mathrm{j}}\right|^{2}, \mathrm{z}_{\mathrm{j}}$ is the pole for mode $j, r_{\mathrm{j}}$ is the residue for mode $j$, and $\Delta \mathrm{t}$ is the digitization rate.

Traditional methods of system estimation, both parametric and nonparametric, are strictly valid only for stationary data. A stationary signal is one whose statistics do not change with time. The commonly invoked, loose definition of stationarity requires that the variance of the signal be constant over any and all time windows. Inherent in a stationary transformation is the averaging of the signal components over the sampling duration. The difficulty with non-stationary signals is that these energies are changing during this period. If the frequencies present are changing over this time window, the resulting estimation, regardless of method used, will be a smeared average as if all the frequencies with energy were active without change throughout the period. 
The field of adaptive filtering was developed to model non-stationary processes. As the statistics of the signal change through time, the filter "adapts" to the changing variance with new parameter values that reflect the structure of the system at that point. The predicted value for the next time step can be compared with the actual value, and the difference will give a measure of how well the filter is doing its job (Ljung 1987).

A popular direct adaptive filter, or process model, is the Kalman filter (Kalman 1960). Sorenson (1970) points out that the Kalman approach is a direct descendant of Gauss's least squares mapping, except now neither the signal nor the noise model is stationary. The extended Kalman model (Ljung, 1979) constantly updates the estimates of the dynamic process by examining the error between actual and estimated values for the previous time step. The dynamics can be due to a changing input or noise process, or it can be due to the system itself changing. The effect is a linearization between single time steps, but if the system is changing slowly compared to the time step used, the linearization is "invisible" and the non-linear behavior is well modeled.

\section{Analysis Methods Applied to the Soil System}

For the problem at hand, estimating the soil parameters during the Superstition Hills earthquake at the Wildlife site, both the system input and output are known. Analysis of the records was undertaken using the standard routines contained in the MATLAB System Identification Toolbox (MathWorks 1991). The data were initially analyzed to determine if they could be modeled as stationary segments. A recursive segmentation scheme, which attempted to break the data into segments with a chosen maximum variance (Ljung 1987), did not work well since it was not possible to determine the "correct" variance a priori. Instead, a more direct method was used the output simulated by the calculated system had to accurately model the actual measured output. 
The input-output data record was broken into segments based on a mechanistic understanding of the seismic event (discussed in following sections). Initially is was assumed that the various segments were basically stationary. If the stationary model could not accurately and parsimoniously simulate the segment output, a non-stationary recursive model was used. In addition, the appropriateness of the model was checked by insuring 99 percent confidence in both the whiteness of the residual autocorrelation function and the cross-correlation function between the input and output residuals (Bohlin 1987). A final verification on model suitability was made by examining the ability of the parameters to model independent input-output data from the $90^{\circ}$ Superstition Hills and the complete Elmore Ranch time histories.

The stationary algorithm uses a least squares estimation for the ARX model. It is necessary to estimate the number of parameters to be calculated, which is essentially estimating the degree of freedom of the soil system. There is no obvious answer to the degrees of freedom of the system, so several verification techniques were employed to insure that a proper model order was estimated. Model order was increased in $2 n-2 n$ steps corresponding to an additional degree of freedom each. The simulated output of the model was then compared with the actual output for congruence, and the fewest parameters needed to accurately characterize the system was chosen as the system model order. Examination of the pole and zero plot insured that excessive, overlapping parameters were not included (Ljung 1987). If the segments proved non-stationary, they were analyzed using a recursive Kalman filter technique that expressly accounts for non-stationarity (Ljung 1987). 


\section{The Wildlife Site in the Imperial Valley}

\section{Introduction and Geography}

Two large earthquakes, the Elmore Ranch and Superstition Hills, occurred on November 24,1987 . The shaking was strong enough to induce liquefaction at the Wildlife site, which suffered more than $2 \mathrm{~m}$ of lateral spread towards the Alamo river, and sand boils occurred over at least 33 hectares (Holzer et al. 1989). Accelerograms from buried and surface transducers, as well as pore pressure time histories, were captured for both the Elmore Ranch and Superstition Hills earthquakes (Brady et al. 1989). This is the only full input-output data set known to exist for a site experiencing liquefaction, and the only set of records complete enough to allow an unambiguous system identification analysis.

The U.S. Geological Survey (USGS) chose to install an instrumentation array at the Wildlife site for two major reasons: it liquefied during the 1981 Westmoreland earthquake (shear magnitude, $M_{S}, 6.0$ ), and its location in a very seismically active area. The Wildlife site is located in the western Imperial Valley, $13 \mathrm{~km}$ north of Brawley, Imperial County, California, as shown in Figure 1. The Imperial Valley is one of the most seismically active regions of the United States (Hudnut and Sieh 1989). The Wildlife site is located in the Imperial Wildlife Management Area, on an incised flood plain of the Alamo river (Bennett et al. 1984) approximately $32 \mathrm{~km}$ east of the epicenter of the Superstition Hills earthquake. The deposits consist of various flood plain, fluvial, and lacustrine materials with 7 distinct units in the first $26 \mathrm{~m}$. The top three 
units were investigated thoroughly since they were believed to be the seat of any liquefaction (Holzer et al. 1989).

Besides surface and buried $(8 \mathrm{~m})$ accelerometers, an array of pore pressure transducers was installed at various depths at the site, making it one of four piezometric arrays in the U.S. (Holzer et al. 1989; Brady et al. 1989). The plan view of the array is shown at the top of Figure 2, while the bottom of Figure 2 presents the physical relation of the piezometers to the soil units. Two piezometers were installed in subunit $\mathrm{B} 1$, three in $\mathrm{B} 2$, and one in the dense clayey silt of Unit D.

\section{Geotechnical Description}

The pertinent geotechnical properties of the first $13 \mathrm{~m}$ of soil at the Wildlife are shown in Figure 3. The water table, controlled by the near-by Alamo river, was approximately $1.2 \mathrm{~m}$ below the surface when the Superstition Hills earthquakes struck. Unit $\mathrm{A}$ is a very soft sandy to clayey silt, which grades into the silty clay at the bottom of Unit B below. The upper meter of Unit B, B1, is a very loose, poorly graded, silty sand which phases towards the denser silty sand of subunit B2. In general, the materials in Unit B grade from coarsest at the bottom $(7 \mathrm{~m})$ to the finest at the top. Brady et al. (1989) note that a wood fragment recovered from a depth of $6 \mathrm{~m}$ was estimated to be about 230 years old by Carbon- 14 analysis. Unit $\mathrm{C}$ ranges from a medium-to-stiff clayey silt to a very stiff silty clay. Unit $D$ is a dense, well-graded silt, cemented towards the top of the unit.

The USGS undertook a thorough site investigation at the time the instrumentation array was installed (Bennett et al. 1984), and other researchers performed geophysical investigations to determine the in situ shear-wave velocity (Bierschwale 1984; Nazarian and Stokoe 1984). Bierschwale reported a crosshole S-wave velocity of about $100 \mathrm{~m} / \mathrm{s}$ for subunit $\mathrm{Bl}$, while Nazarian and Stokoe report a spectral-analysis-of-surface-waves S-wave velocity of about $85 \mathrm{~m} / \mathrm{s}$. Both standard penetration tests and cone penetration tests, as well as the soil description, indicated that subunit B1 would be the most likely to liquefy in 
the event of strong dynamic excitation. Piezometer P5 and P2 were installed in this subunit.

\section{Geology}

The Imperial Valley is a structural depression caused by the active spreading of the Gulf of California (Magistrale et al. 1989). The flanks of the Valley are the original continental crystalline plutonic and metamorphic rocks, about $2 \mathrm{~km}$ deep on the west side, while the middle of the central Valley is comprised of metamorphosed sedimentary rocks buried beneath $5 \mathrm{~km}$ of sediments (Magistrale et al. 1989).

The surface sediments in the areas of interest are Holocene lacustrine silty sand and claystone, interbedded with alluvial deposits, below which are slightly consolidated Pleistocene silty and clayey lake deposits with sand and gravelly units (Sharp et al. 1989; Bennett et al. 1984). The impedance contrasts (i.e., stiffness ratio) of the geology are such that the vertical motions due to a local earthquake are primary-waves (P-waves), while the horizontal motions are manifestations of the passage of shear-waves (S-waves) (Wald et al. 1990). This assertion is borne out by the phase shift that occurred between the buried and surface horizontal motion records and by the lack of shift in the vertical records.

The Superstition Hills fault is a northwest-trending fault that can be seen as a continuation of the San Andreas and San Jacinto fault zones (Figure 1). The region, from the west end of the Imperial Valley to the Brawley seismic zone, is marked by short, northeast-trending faults, believed to correspond to step-backs in the crystalline basement, perpendicular to the main faults.

\section{Seismology}


On the evening of November 23, 1987, an earthquake occurred along the previously unknown Elmore Ranch fault, with a Shear Magnitude $\left(\mathrm{M}_{\mathrm{S}}\right)$ of 6.2 and a hypocentral depth of about $11 \mathrm{~km}$ (Magistrale et al. 1989). The fault was a north-east trending, left-lateral displacement made up of a multitude of small displacements or fault zones. The fault zone appears to have followed along a basement step-back and continued to the Brawley seismic zone. The maximum measured surface horizontal displacement was $125 \mathrm{~mm}$, which occurred during the event itself. There has been no measured movement along the zone for over 2 years after initial displacement in 1987 (Sharp et al. 1989).

Twelve hours after the Elmore Ranch earthquake, a larger, long-duration earthquake struck on the Superstition Hills fault. This $6.6 \mathrm{M}_{\mathrm{S}}$ seismic event was caused by a northwestward-striking right lateral displacement coincident with previous earthquakes in 1968 and 1979 (Magistrale 1989). The two 1987 earthquakes Elmore Ranch and Superstition Hills, are associated with a welldefined conjugate fault system (Hudnut et al. 1989). The left-lateral motion relieved normal stress on the existent major northwest-striking fault system, allowing the shear stress from the Pacific plate to be relieved. Both faults appear to be geometrically constrained by the interface between the crystalline basement rocks to the West and the metamorphic rocks to the East (Sharp et al. 1989).

The Superstition earthquake was a complicated event characterized by an extended period of strong motion (Wald et al. 1990). Figure 4 shows the acceleration time history in the north-south direction, recorded at a depth of $8 \mathrm{~m}$. There appear to be arrivals of energy at approximately 3 and 9 seconds following arrival of the initial S-wave. Thorough and independent study of the strong motion and teleseismic records by several researchers indicates the overall earthquake event was made up of three distinct subevents that had to have occurred over an extended area (Hwang et al. 1990; Wald et al. 1990; Frankel and Wennerberg 1989). The physical location of these subevents is given in Figure 5 in both the map and plan view. While all three studies reached essentially the same general conclusions, the study by Wald et al. was the most exhaustive and their quantitative results will be used in this paper. 
Wald et al. (1990) calculated the arrival times relative to initial energy arrival, seismic magnitude, and horizontal extent of the three subevents, which are presented in Table 1 . While the $\mathrm{M}_{\mathrm{S}}$ of the three subevents are very similar, the energy released by subevent 3 , characterized by the seismic moment, is almost 3 times larger than the combined energy release of the first two subevents. The source durations of the first two subevents were short (less than $2 \mathrm{~s}$ for subevent 2), while it was estimated that subevent 3 required about $7.5 \mathrm{~s}$ for the displacement to propagate the $18 \mathrm{~km}$ (Wald et al. 1990). The calculated arrival times of the three subevents are shown in Figure 4, exactly matching the visually perceived arrival of packets of energy. While the propagation velocity of each subevent was greater or equal to the S-wave velocity, the very slow rupture velocity for the entire earthquake implies an overall rupture mechanism reminiscent of progressive failure (Frankel and Wennerberg 1989).

\section{Pore Pressure History}

Analysis of pore pressure histories recorded during the Elmore Ranch and Superstition Hills earthquakes yield additional understanding of the mechanistic behavior of the Wildlife site. Complete pore pressure records were made during both temblors at five different depths (Brady et al. 1989). Records show that an increase in pore water pressure was measured during both the Elmore Ranch and Superstition Hills earthquakes. The Superstition Hills records have been of greater interest, since for this excitation the pore pressures increased enough to cause liquefaction. This was proven by the appearance of sand boils at the Wildlife site after the Superstition Hills temblor (Holzer et al. 1989).

This paper will focus on the pore water pressure history of piezometer P5, which was buried at a depth of $2.9 \mathrm{~m}$, the top of soil layer B1. This transducer is being singled out for several reasons: it most clearly indicated that the excess pore pressure exceeded the total overburden pressure; it was located at the top of the layer expected by the experts at the USGS to liquefy during the Superstition Hills shaking and therefore (by some theories) would be at the point of initial 
liquefaction (Scott 1987; Florin and Ivanov 1962); and it is believed that P5 is the transducer in the array most likely to have performed correctly (Hushmand et al. 1992, 1991).

Figure 6 compares the surface north-south acceleration (Figure 3; Brady et al. 1989 ) with the pore pressure ratio $r_{u}$ (ratio of excess pore pressure $u$ to initial effective overburden stress $\bar{\sigma}_{v}$ ) history for piezometer P5, Superstition Hills earthquake. The pore pressure history is addressed here to enhance mechanistic understanding of the recorded strong motion signals and thus simplify and strengthen later interpretation. There is some controversy whether the pore pressure transducers at the site were operating properly (Hushmand et al. 1992, 1991), however, it was decided to utilize the must uncontroversial information available.

The initial segment of the P5 curve (Figure 6) is a sharp "spike" believed to be due to the powering up of electronics upon triggering. This spike is present in the records of all 5 piezometers from both the Elmore Ranch and Superstition Hills earthquakes. At time $t_{o}$ (subscript $=$ time from first arrival in seconds) the initial S-wave energy from the first subevent arrived, and a very slight increase in pore pressure was recorded by P5. At approximately time $t_{3.1}$ energy from subevent 2 excited the accelerometer, and the pore pressure started to increase at a steady rate. Finally, at time $t_{9.8}$ strong shaking was triggered by the arrival of subevent 3 , and the pore pressure ratio at P5 increased at a rapid rate to a maximum greater than 1.2. After $t_{9.8}$ the rate of increase of ru was relatively constant for the duration of source motion $(\approx 7.5 \mathrm{~s}$ ), until it reached 0.6 (a level often considered as functional liquefaction). The rate of pore pressure increase slowed until approximately time $t_{23}$, at which time $r_{u}$ was approaching 1 and the rate of increase reaches equilibrium.

\section{The Pseudo-Stiffness}

As the pore pressure ratio increases, the effective stress acting among the sand grains decreases, and the shear modulus (G) decreases. Since it was 
impossible to accurately measure stress and strain inside the soil body, the ratio of applied force to displacement (stiffness) is used to characterize material behavior. A simple model for the soil system, which allows calculation of a dynamic pseudo-stiffness for the liquefying soil layer between the two accelerometers, was chosen for several reasons. The soil profile of the Wildlife site above layer B1 is relatively uniform and the particle motion due to $\mathrm{S}$-waves is geologically restrained to the horizontal. In addition, the pore pressure history indicated location P5, at the top of layer B1, was the point of initial liquefaction (expected from Scott 1986; Florin and Ivanov 1961). Once the pore pressure in layer B1 begins to rise, the sand in this layer is very soft in comparison to the rest of the system. Therefore, the motion of the surface accelerometer relative to the buried accelerometer essentially reflects the behavior of the soil above layer B1 (i.e., layer A). Prior to softening, the stiffness will be dominated by the weakest soil between the two geophones, which is within the top $3.5 \mathrm{~m}$.

The here-proposed pseudo-stiffness is calculated by the following algorithm.

a. All horizontal motions from the surface () accelerometers are accounted for by taking the Euclidean norm of the north-south and east-west surface acceleration records: $a_{h s}=\sqrt{a_{s,(N-S)}^{2}+a_{s .(E-W)}^{2}}$.

b. All horizontal motions from the buried $(b)$ accelerometers are accounted for by taking the Euclidean norm of the north-south and east-west buried acceleration records: $a_{h b}=\sqrt{a_{b,(N-S)}^{2}+a_{b,(E-W)}^{2}}$.

c. The relative acceleration of the surface to buried transducer is determined from the step-by-step difference between the surface and buried horizontal accelerations: $a_{r e l_{(i)}}=a_{s, h_{(n)}}-a_{b, h_{i}}$.

d. The relative accelerations are converted into forces per unit volume by multiplying the differential accelerations acting at the top and bottom of the layer of interest by the soil unit mass, which should change relatively little during the softening process (e.g., Udwadia 1985): $F_{i}=a_{\text {rel }_{()}} \cdot \gamma$. 
e. The running total of the amount of force is computed for the system during each time step: $\operatorname{sum}(t)=\operatorname{sum}(t-l)+[$ force $(t)$-force $(t-1)]-$ yielding the cumulative horizontal unit force.

f. Steps 1, 2, 3, and 5 are applied to the displacement records to yield the cumulative horizontal displacement.

g. The ratio of the resulting cumulative horizontal unitforce to displacement are two independent variables that combine to give a pseudo-stiffness.

The use of a single transducer to provide acceleration and displacement measurements is not problematic since the derived displacement (Brady et al. 1989) is generally assumed to be identical to what would be recorded by an independent displacement transducer placed next to the accelerometer. The calculations do not distinguish between active (external, inertial) and restorative (internal, stiffness) forces acting on the soil.

The pseudo-stiffness behavior due to the Superstition Hills earthquake is shown in Figure 7. Each point on the curve is associated with a particular time step of the earthquake history. Some important times associated with changes in the earthquake source mechanism, motion record, and pore pressure history are highlighted. The pseudo-stiffness due to the Elmore Ranch earthquake was also calculated, and is shown in comparison in Figure 7. The pore pressure rise during the Elmore Ranch shaking was not large enough to force the sand out of elastic behavior, and the system exhibited the same stiffness up to that pore pressure ( $3.1 \mathrm{kPa}$, associated with an identical pseudo-force) $12 \mathrm{hr}$ later when it was excited by the Superstition Hills temblor.

The interrelation between Superstition Hills strong motion, pseudo-stiffness, and pore pressure ratio is shown in Figure 8. Layer B1 had an initial pseudostiffness of $3.2 \mathrm{MPA} / \mathrm{m}$, disturbed slightly by increasing pore pressure due to arrival of energy from subevent 2 . With the arrival of subevent 3 at time $t_{9.8}$ the pore pressure rapidly increases, and the pseudo-stiffness shows the soil dramatically weakening. The pseudo-stiffness decreased for approximately the 
duration of the subevent 3 motion, becoming a constant $0.07 \mathrm{MPA} / \mathrm{m}$ at approximately time $t_{25}$, coincident with $r_{u}=1$.

The pseudo-stiffness is a convenient representation of the system behavior, combining load, time, and displacement information in a simple curve. The pseudo-stiffness shows that the soil indeed did soften in relation to pore pressure buildup. In addition, the increases in pore pressure and decreases in stiffness occurred when additional energies arrived from subevents 2 and 3 . The understanding of the physical behavior of the Wildlife site gained in these sections will allow recognition of reasonable estimates in the following analysis. 


\section{System Identification of the Wildlife Site}

The input-output data record was initially broken into segments based on the mechanistic understanding discussed in previous sections. Segment 1 (see Figure 6) is the segment from the start of the time history to the arrival of subevent 2 at approximately $t_{2.8} \sec (171$ data points). Segment 2 runs from the arrival of subevent 2 to the arrival of subevent 3 at approximately $t_{8.8} \mathrm{sec}$ (150 data points). The segment corresponding to the shaking due to subevent 3 is assumed to be very non-stationary due to the nature of the signal and the rapid rise of pore pressure, and was not individually analyzed. Segment 3 encompassed the coda of the signal, after the shaking stopped at approximately $t_{17}$ seconds, to the end of the record at $93 \mathrm{sec}$ (1,870 data points).

The first two segments, corresponding to the beginning of the record up to the arrival of subevent 3 , can be accurately modeled by a stationary ARX model. Segment 1 is represented as a 3-Degree-of-Freedom (DOF) system, with a root mean square (RMS) error between simulated and actual velocity of 0.26 . Segment 2 proved to be representable as a 3-DOF system, with an RMS error between simulated and actual velocity of 1.1. A comparison of the spectral estimates of the first two segments is shown in Figure 9, along with the estimates of modal parameters. Table 2 presents a summary of the ARX-calculated modal parameters, where it is seen that the natural frequency diminished slightly after the arrival of subevent 2 , an indication of system softening. This is to be expected since the pore pressure begins to increase during this time segment.

The change in the soil system was so slight during the initial $8.8 \mathrm{~s}$ of excitation, that it proved possible to model the combined segment accurately with one 
4-DOF ARX model (RMS error $=0.59$ ), with the characteristics of the second subevent overwhelming the lower energy first arrival. The suitability of this model is verified by comparing the actual surface velocities from the Elmore Ranch $360^{\circ}$ horizontal record with the simulated output for the Elmore Ranch data. The pseudo-stiffness and pore pressure rise from Elmore Ranch was identical to that of the Superstition Hills segment, indicating that the physical behavior of the soil was the same for this degree of pore pressure increase. The congruity between simulation and real-life is shown in Figure 10. The signals are virtually identical, with an estimation RMS error of only 0.72 . The identified model performed equally well on all the other records available for this site.

In order to illustrate the time-varying behavior of the soil (due to the timevarying pore pressure) the initial $20 \mathrm{~s}$ of the Superstition Hills record was analyzed with a recursive technique employing a Kalman filter model with 3-DOF. The calculated model was able to simulate the actual surface velocity history with an RMS error of 1.27 . The spectral time history of the top $8 \mathrm{~m}$ of the Wildlife site for the initial $20 \mathrm{~s}$ of shaking is shown in Figure 11. In this figure the smoothed spectral time history is shown. The softening, indicated by the downward shift in natural frequencies and increase in damping corresponds with the initial increase in pore water pressure to about $3.1 \mathrm{kPa}$. This behavior also corresponds with decreasing pseudo-stiffness as illustrated in Figure 8. The smoothed recursive estimate of the relevant soil parameters is given in the top portion of Table 3. On the whole, the recursive estimates for important times in the seismic history compare well with the stationary ARX estimates from Table 2.

The system behavior during the subevent 3 strong shaking is obviously nonstationary and nonlinear due to the rapid build-up of pore water pressure and irregular shaking. The point at which a stationary model could no longer model the system behavior corresponds to the time when the pore pressure ratio reached approximately 0.6 , at $\mathrm{t}_{16.5}$. The spectral estimates from a Kalman filter model showed that the natural frequency diminished and damping ratio increased as the effective stress in soil layer B decreased. 
Initial visual inspection of the final segment, corresponding to the inertial soil motion after the end of source energy, indicated that the input-output signal had a regular oscillatory pattern and would therefore be easy to model as a low-order ARX system. However, this segment proved to be quite non-stationary due to the constant increase in phase shift between buried and surface signals, and the soil could not be accurately modeled as a time invariant system. This section lent itself well to rigorous statistical segmentation by defining segments such that the squared error between model-predicted and actual values were less than 0. 1. Application of a 3-DOF Kalman filter captures the essence of the soil response (RMS error $=0.76$ ), with the spectral time history shown in Figure 12. As indicated by the time dependent values for $\xi_{j}, \omega_{j}, p_{j}$ summarized at the bottom of Table 3, the soil system is slowly changing (weakening) as the pore water pressure comes to equilibrium. The energy transmitted through the system is also much smaller once the pore ratio approached 1 . The increase in damping as the sand changes to a viscous fluid is responsible for dissipating a large part of the energy at this point.

\section{Discussion}

The parametric models used in this study are powerful tools for the qualitative and quantitative estimation of in situ soil properties. The recursive methods allow the behavior of the soil system to be monitored throughout the excitation process and liquefaction, as shown in Figures 11 and 12. These two figures (Figure 11, two initial segments; Figure 12, coda) show the changing characteristics of the soil system through time by plotting the spectral density evolution through time. This unique insight into the liquefaction process elucidates the reaction of the soil system to incoming energies, and eventual softening due to the rise in pore water pressure. Confidence in the estimated models is increased by comparison with independent data from the E-W direction, and the Elmore Ranch temblor. The estimates all converged on the values reported.

A question must be raised about the meaning of the damping values calculated in this study. A major problem is that the damping is being modeled as 
viscous damping, which is known to be a poor model but the most amenable to calculation and the one most commonly used (Pandit 1991). Even with a perfect technique, the damping values estimated by the model will not truly represent what is physically occurring in the soil. The values calculated, reasonable compared to other modal studies (e.g., Iemura et al. 1990) and many laboratory studies (Vucetic and Dobry 1991), are better seen as "effective" damping coefficients which capture all forms of frequency-dependent mechanical losses, rather than an 'intrinsic' material property.

The damping estimates are often very sensitive to subtle changes in the modeling of the system, while the natural frequency estimates are more robust (Gersch 1974). This is especially true for recursive estimates which have very different damping values changing rapidly. In this case a limited number of data points enter directly into the calculation and variance is inversely proportional to the square root of the number of data points.

The physical interpretation of the instantaneous mechanical values is also not immediately clear. The ARMA parameters recursively calculated at any given time define the filter needed to transform that time step of input data into the next output value. The mechanical characteristics are mathematically extracted from the filter based on a limiting set of assumptions, and an "instantaneous frequency" or damping has no physical meaning. The ARX estimates are made with more input data points than the Kalman estimates, but the Kalman assumptions better model the changing system. There is no obvious choice between the ARX or Kalman model parameter estimates for the first two segments (-4 to $8.8 \mathrm{~s})$. A fundamental problem remains-at this point the geotechnical engineer does not really know what the "correct" answer should be! 


\section{Conclusions}

The Wildlife Site, CA was subjected to two large earthquakes on November 24, 1987. During the second, larger, earthquake (Superstition Hills) the site liquefied. The data collected are the only available records of buried and surface motions publicly available. In addition, pore water pressure records were recorded at several depths during the temblor.

The Elmore Ranch and Superstition Hills Earthquakes were analyzed from a seismological viewpoint to gain understanding of the site behavior. It is shown that the Superstition Hills earthquake was actually three distinct subevents. The strong motion and pore water pressure records were examined, and showed excellent correlation with the subevents. A significant rise in pore pressure that resulted in liquefaction of layer B occurred at the onset of subevent 3 .

This paper introduces the concept of pseudo-stiffness, integrating the change of system stiffness in time into a convenient form. The pseudo-stiffness decreased with rising pore pressure, and correlated very well with the evolution of the pore pressure and shaking history. At present the pseudo-stiffness is a qualitative tool, but work with other records should allow its quantitative use.

Both stationary and recursive parametric modeling methods are applied to the unique input-output data set from the two temblors. These unique results show weakening of the soils system as pore pressure increased, with the recursive estimates being summarized in Table 3 . While there are some important questions to be raised about the damping estimates, reasonable estimates were presented. Further work using system identification to estimate in situ soil properties is warranted. 


\section{Bibliography}

Bennett, M. J., McLaughlin, P. V., Sarmiento, J. S., and Youd, T. L. (1984). Geotechnical investigation of liquefaction sites, Imperial Valley, California, Open File Report 84-252, p. 103, Menlo Park, CA: United States Geological Survey.

Bierschwale, J. G. (1984). Analytical evaluation of liquefaction potential of sands subjected to the 1981 Westmoreland earthquake, University of Texas geotechnical engineering report GR-8415, p. 231, Austin TX: University of Texas Geotechnical Engineering Center.

Bohlin, T. (1987). Model validation, Encyclopedia of systems and control (Singh, M.), Oxford: Pergamon Press.

Bracewell, R. N. (1978). The Fourier transform and its applications, p. 443, NYC: McGraw-Hill.

Brady, A. G., Mork, P. N., Seekins, L. C., and Switzer, L. C. (1989). Processed strong-motion records from the Imperial Wildlife liquefaction array, Imperial County, California, recorded during the Superstition Hills earthquakes, November 24, 1987, Open File Report 97-87, p. 115, Menlo Park, CA: United States Geological Survey.

Florin, V. A., and Ivanov, P. L. (1961). Liquefaction of saturated sandy soils, Proceedings 5th international conference on soil mechanics and foundation engineering $I$, 107-111, Paris: Dunod. 
Frankel, A., and Wennerberg, L. (1989). Rupture Process of the MS 6.6 Superstition Hills, California, earthquake determined from strong-motion recordings: application of tomographic source inversion, Bulletin of the Seismological Society of America, 79(2), 515-541.

Gersch, W. (1974). On the achievable accuracy of structural system parameter estimates, Journal of sound and vibration, 34(1), 63-79.

Gersch, W., and Luo, S. (1972). Discrete time series synthesis of randomly excited structural system response, Journal of the acoustic society of America, 51(1), 402-408.

Ghanem, R. G., Gavin, H., and Shinozuka, M. (1991). Experimental Verification of a number of structural system identification algorithms, p. 302, Technical Report NCEER-91-0024, Buffalo: National Center for Earthquake Engineering Research.

Glaser, S. (1993). Estimating soil parameters important for lifeline siting using system identification techniques, NISTIR 5145, p. 91, Gaithersburg, MD:NIST.

Holzer, T. L., Youd, T. L., and Bennett, M. J. (1989). In situ measurement of pore pressure build-up during liquefaction, N. J. Raufaste, Proceedings of the 20 th joint panel meeting of the U.S.-Japan cooperative program in wind and seismic effects, 24 Gaithersburg, MD, (NIST SP 760) 118-130.

Hudnut, K. W., and Sieh, K. E. (1989). Behavior of the Superstition Hills fault during the past 330 years, Bulletin of the Seismological Society of America 79(2), 309-329.

Hushmand, B., Scott, R. F., and Crouse, C. B. (1992). In-place calibration of USGS pore pressure transducers at Wildlife Liquefaction Site, California, USA, Proceedings of the Tenth World Conference on Earthquake Engineering. 3 Madrid, 1263-1268, Rotterdam: Balkema. 
Hushmand, B., Scott, R. F., and Crouse, C. B. (1991). In-situ calibration of USGS piezometer installations, Recent advances in instrumentation, data acquisition and testing in soil dynamics, G.S.P. 29, Orlando, FL, 49-69, ASCE: New York.

Hwang, L. J., Magistrale, H., and Kanamori, H. (1990). Teleseismic source parameters and rupture characteristics of the 24 November 1987, Superstition Hills earthquake, Bulletin of the Seismological Society of America, 80(1), 43-56.

Iemura, H., Yamada, Y., Izuno, K., Iwasaki, Y., and Ohno, S. (1990). Phaseadjusted control of structures with identification of random earthquake ground motion, Proceedings, U.S. national workshop on structural control research, Los Angeles, (Ed. Housner and Masri), 116-124.

Johansson, R. (1993). System identification and modeling, p. 512, Englewood Cliffs, NJ: Prentice Hall.

Kalman, R. E. (1960). A new approach to linear filtering and prediction problems, Transactions of the ASME, journal of basic engineering, (3), 35-45.

Ljung, L. (1987). System identification: theory for the user, Englewood Cliffs, NJ: Prentice-Hall.

Ljung, L. (1979). Asymptotic behavior of the extended Kalman filter as a parameter estimator for linear systems, IEEE transactions on automatic control, $A C-24(1)$, 36-50.

Magistrale, H., Jones, L., and Kanamori, H. (1989). The Superstition Hills, California earthquakes of 24 November 1987, Bulletin of the Seismological Society of America, 79(2), 239-251.

MathWorks. (1991). System identification toolbox, (Ljung, L. J.), Natick, MA: The MathWorks. 
Nazarian, S., and Stokoe II, K. H. (1984). In situ shear wave velocities from spectral analysis of surface waves, Proceedings, eighth world conference on earthquake engineering, III San Francisco, CA, 31-38, Englewood Cliffs: Prentice-Hall.

Pandit, S. M. (1991). Modal and spectrum analysis: data dependent systems in state space, p. 415, New York: Wiley.

Robinson, E. A. (1982). A historical perspective of spectrum estimation, Proceedings of the IEEE, 70(9), 885-907.

Safak, E. (1988). Analysis of recordings in structural engineering: adaptive filtering, prediction, and control, (Open-File Report 88-647), Menlo Park, CA: U.S. Geological Survey.

Scott, R. F. (1986). Solidification and consolidation of a liquefied sand column, Soils and foundations, 26(4), 23-31.

Sharp, R. V., Budding, K. E., Boatwright, J., Ader, M. J., Bonilla, M. G., Clark, M. M., Fumal, T. E., Harms, K. K., Lienkaemper, J. J., Morton, D. M., O’Neill, B. J., Ostergren, C. L., Ponti, D. J., Rymer, M. J., Saxton, J. L., and Sims, J. D. (1989). Surface faulting along the Superstition Hills fault zone and nearby faults associated with the earthquakes of 24 November, 1987, Bulletin of the Seismological Society of America, 79(2), 252-281.

Sorenson, H. W. (1970). Least-squares estimation: from Gauss to Kalman, IEEE spectrum, 7(7), 63-68.

Udwadia, F. E. (1985). Some uniqueness results related to soil and building structural identification, SIAM journal of applied mathematics, 45(4), 674-685.

Vucetic, M., and Dobry, R. (1991). Effect of soil plasticity on cyclic response, Journal of Geotechnical Engineering, 117(GT2), 89-107. 
Wald, D. J., Helmberger, D. V., and Hartzell, S. H. (1990). Rupture process of the 1987 Superstition Hills earthquake from the inversion of strong-motion data, Bulletin of the Seismological Society of America, 80(5), 1079-1098. 


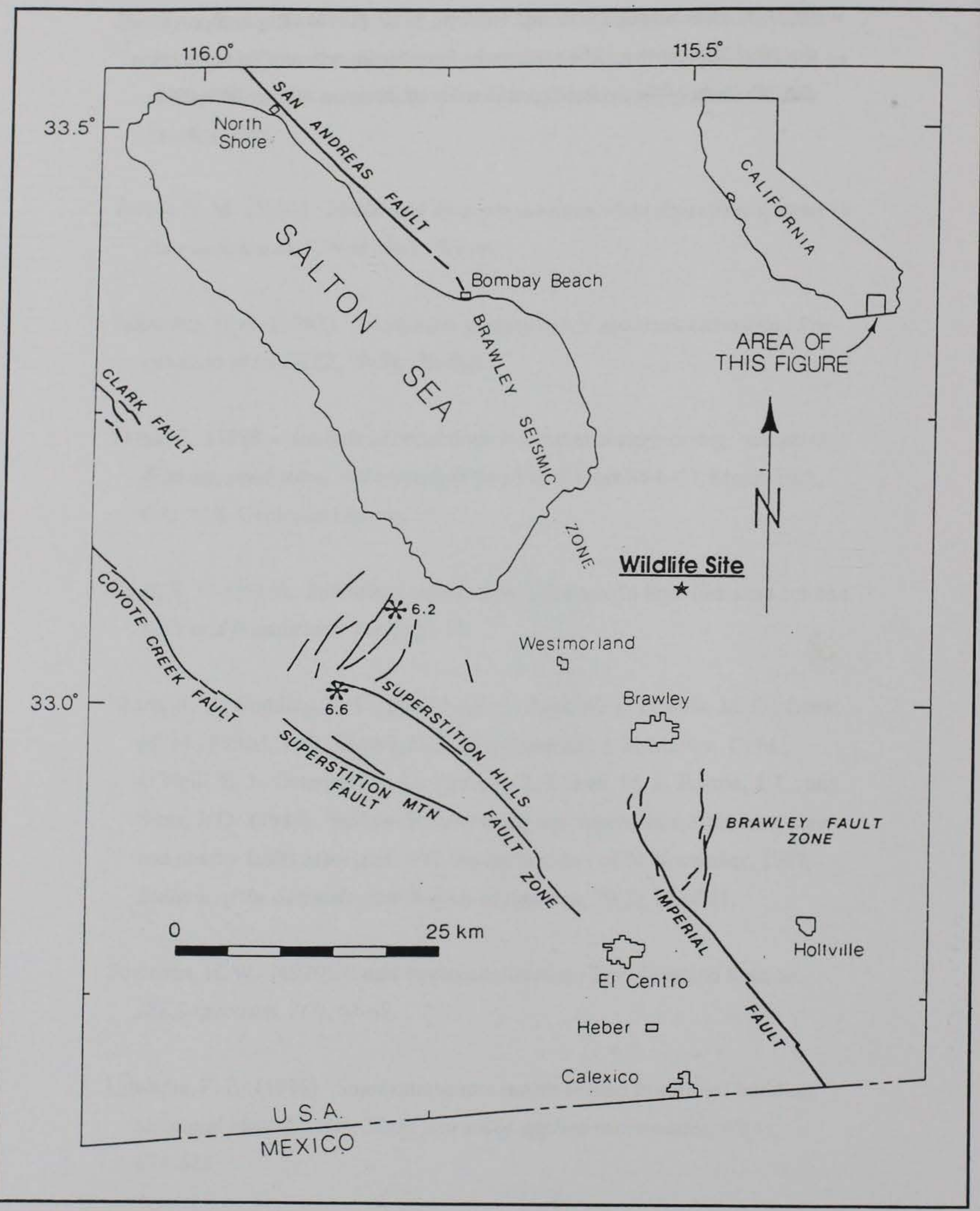

Figure 1. Location of the Wildlife Site, Imperial Valley, California, with the locations -of the Elmore Ranch $\left(M_{s} 6.2\right)$ and Superstition Hills $\left(M_{s} 6.6\right)$ earthquakes indicated by * (Sharp et al. 1989) 


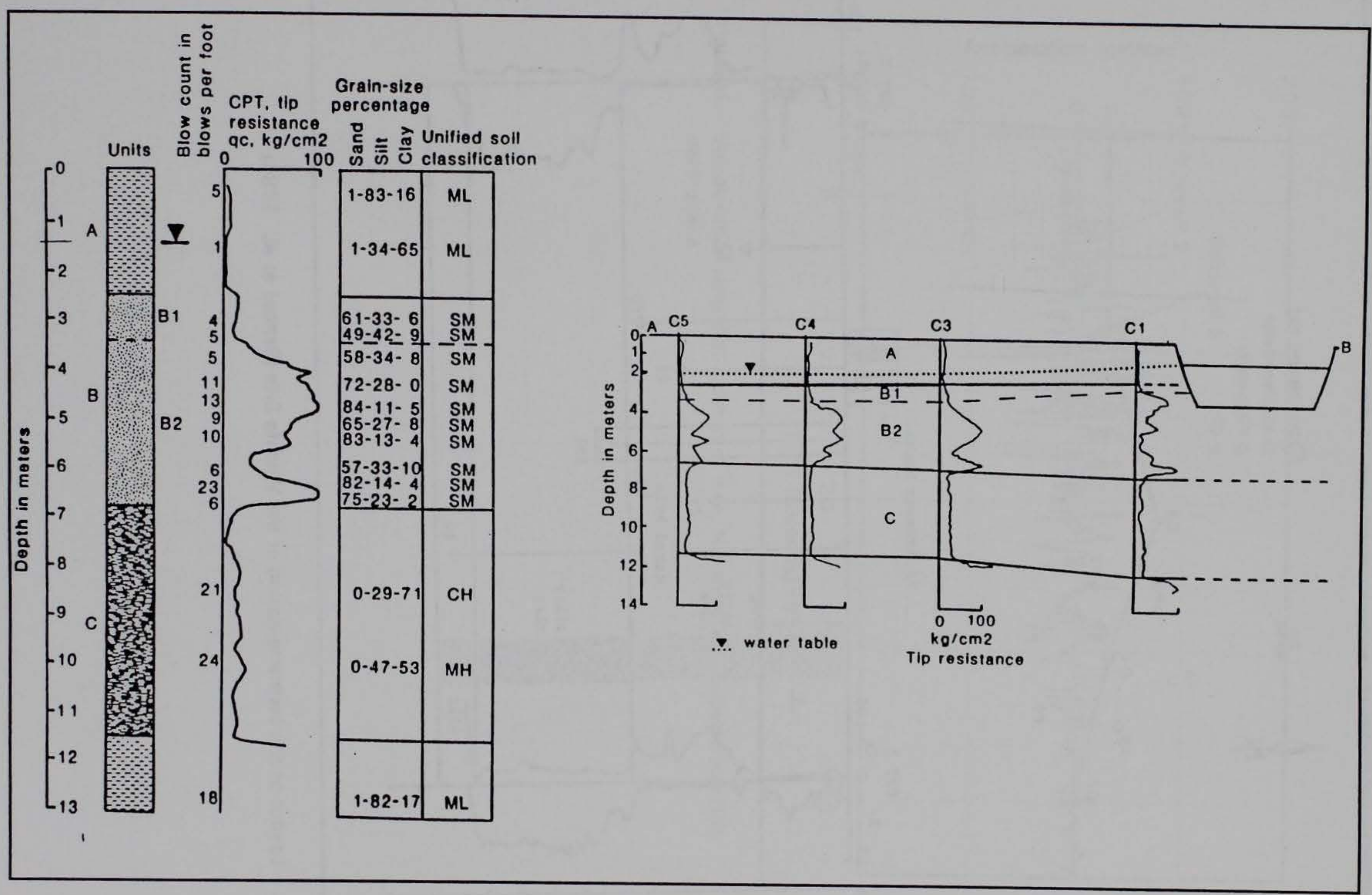

Figure 2. Summary of the geotechnical properties of the Wildlife Site (Bennet et al. 1984) 


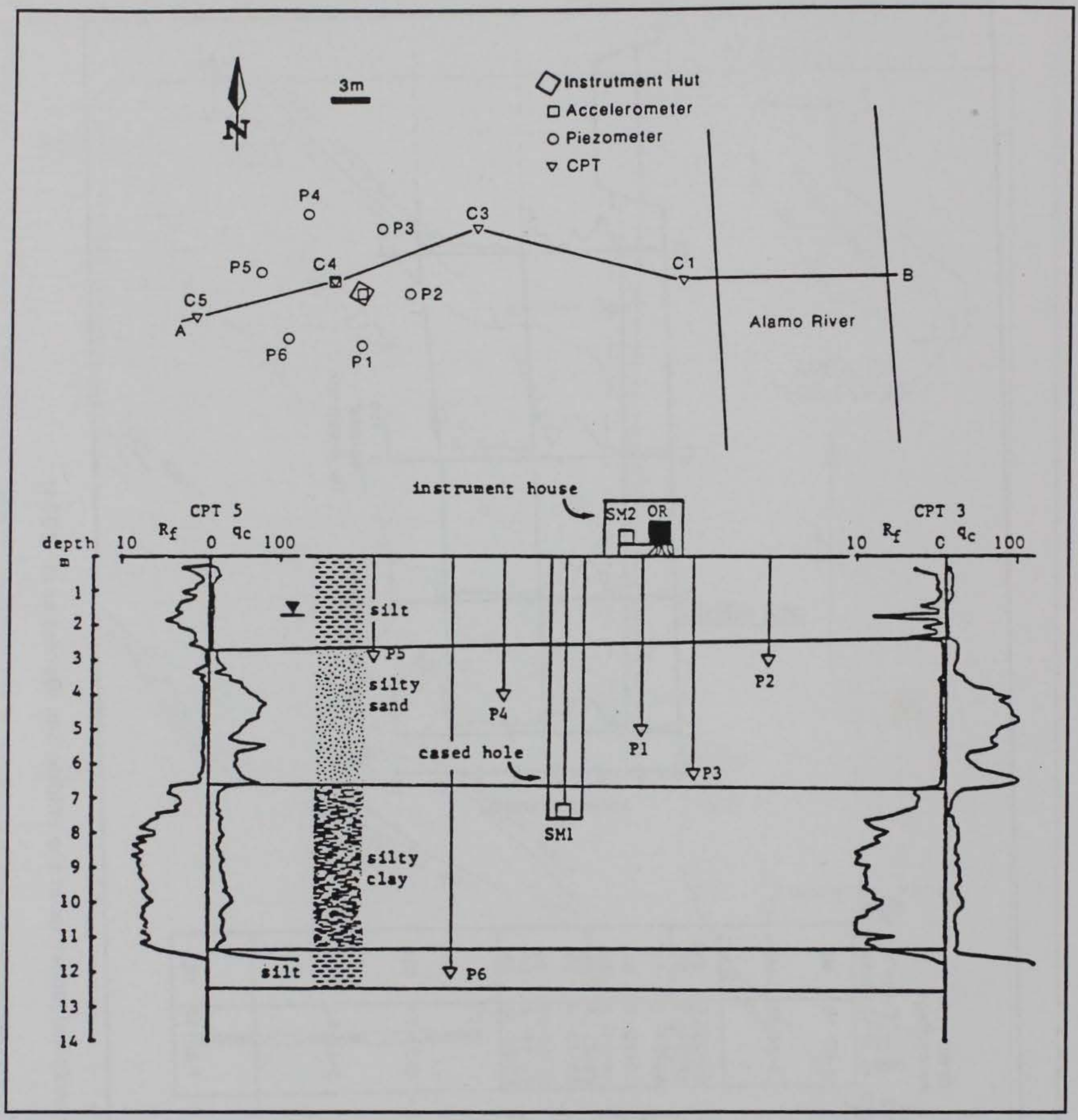

Figure 3. Layout of the instrumentation at the Wildlife Site (Bennet et al. 1984) 


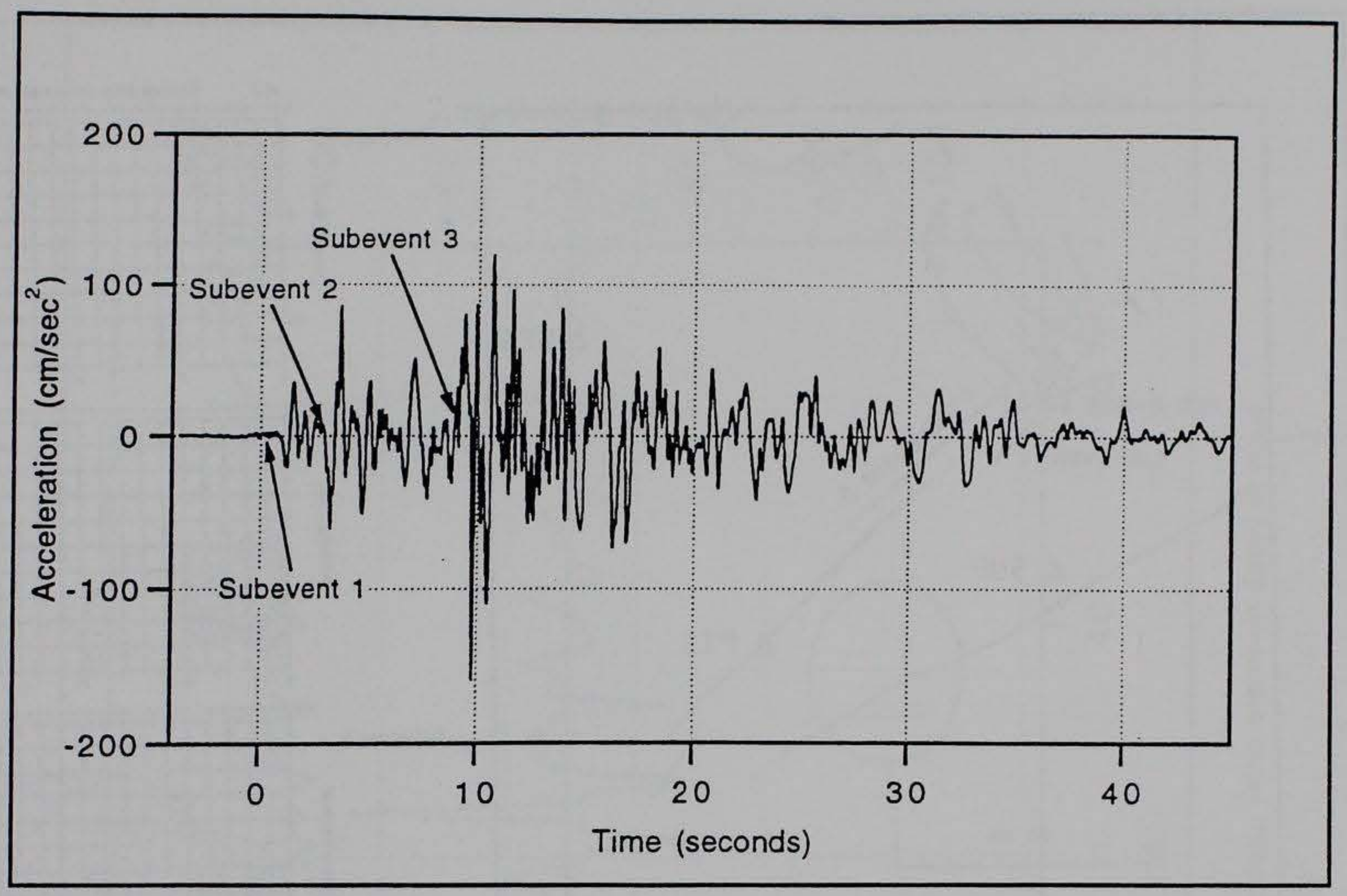

Figure 4. Acceleration record at a depth of $8 \mathrm{~m}, \mathrm{~N}-\mathrm{S}$ direction, Superstition Hills earthquake 


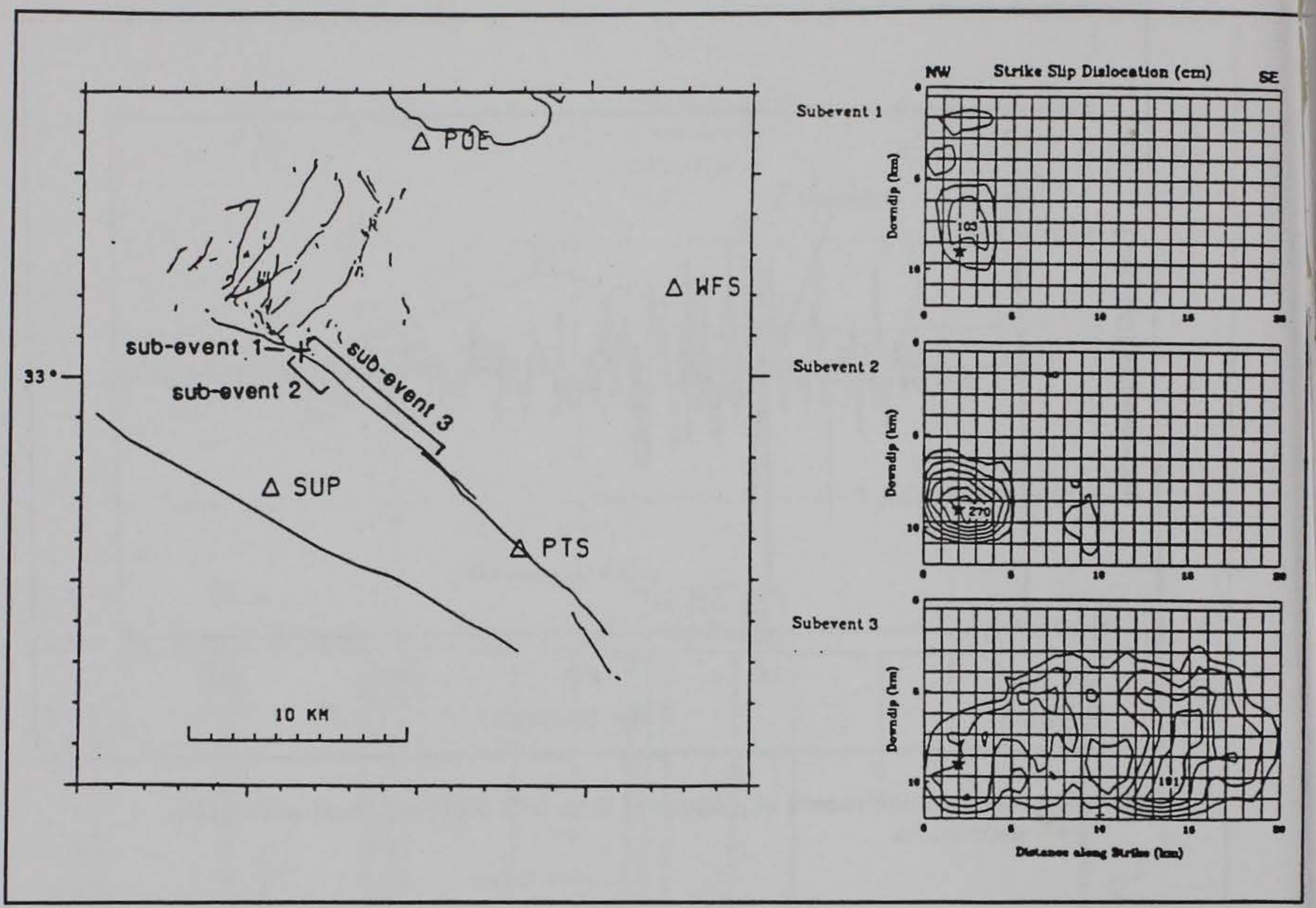

Figure 5. Location and extent of the 3 Superstition Hills subevents (Wald et al. 1990) 


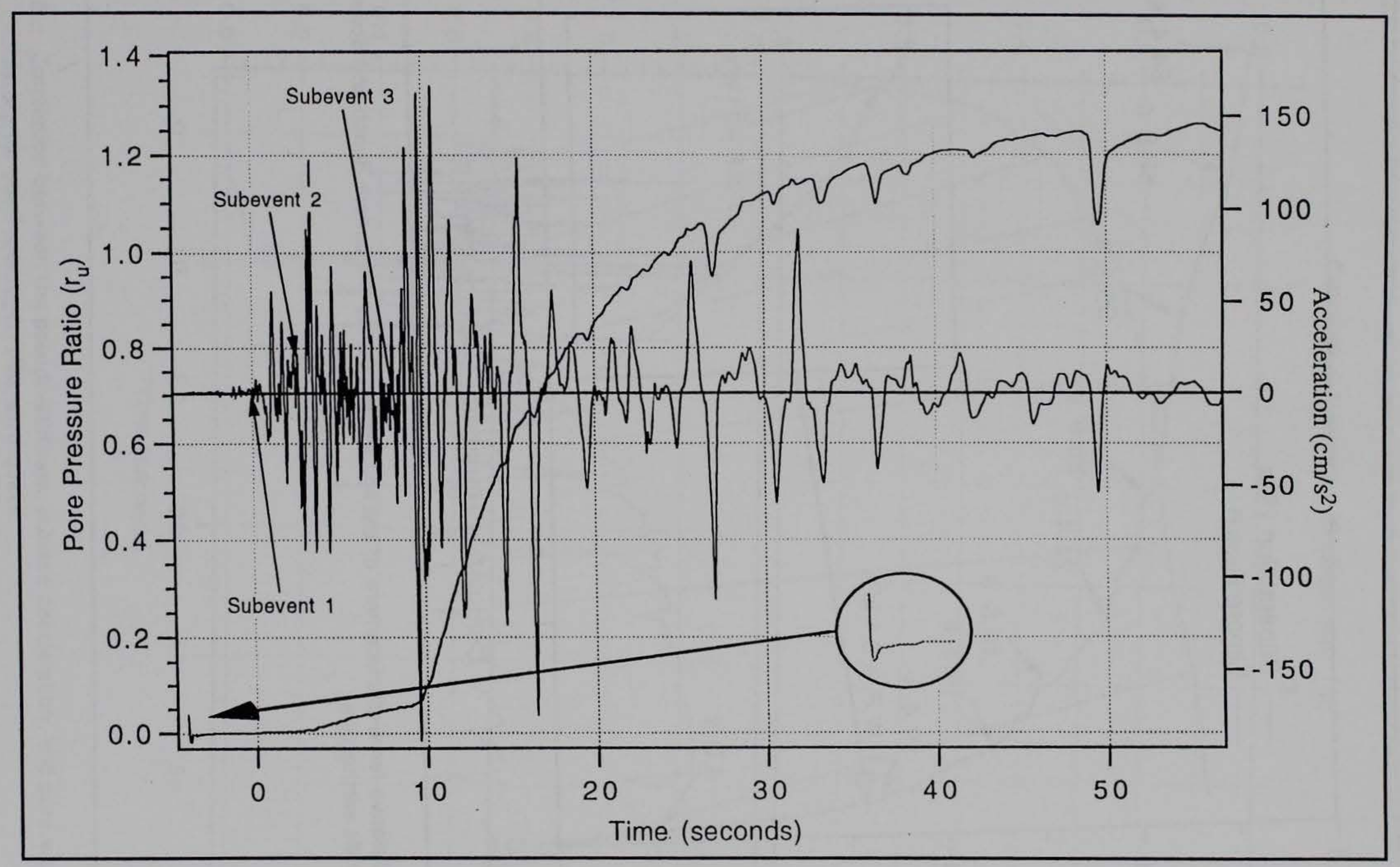

Figure 6. Pore pressure ratio history compared to top N-S acceleration. Note warm-up detail in inset 


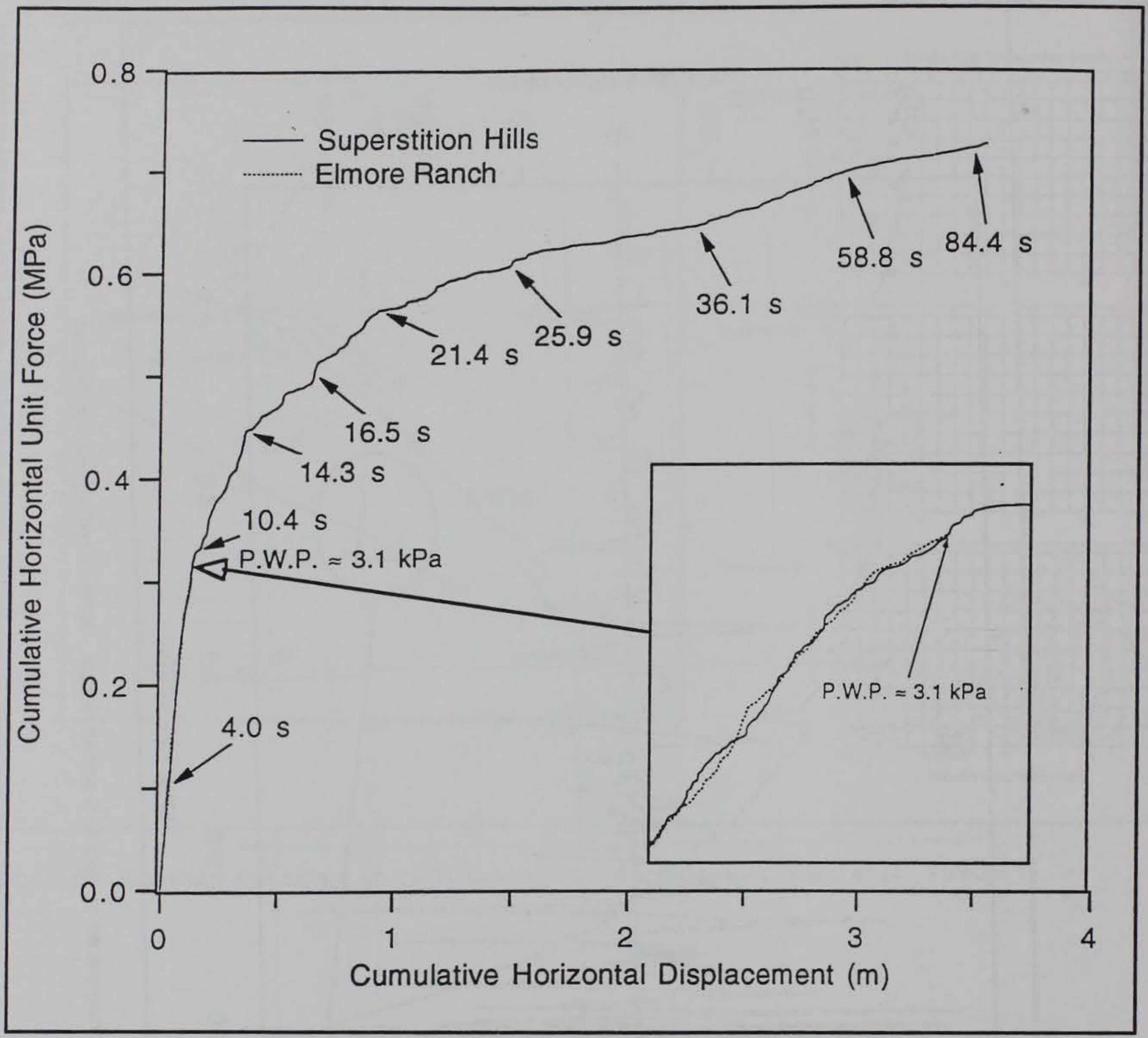

Figure 7. Relative force-displacement of the soil system during the Elmore.Ranch and Superstition Hills earthquake 


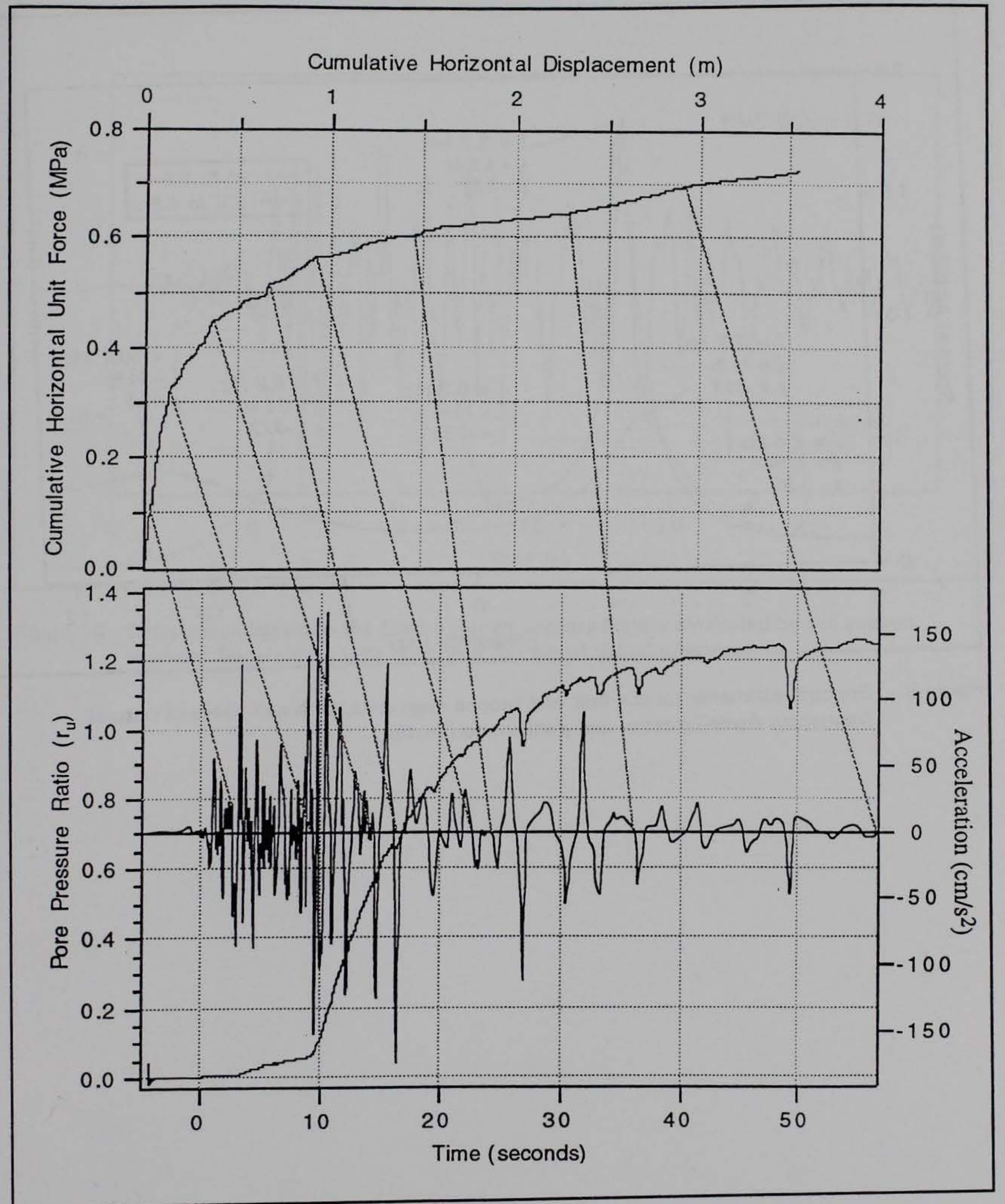

Figure 8. Correlation between the pseudo-stiffness, surface acceleration, and pore water pressure history for the Superstition Hills earthquake 


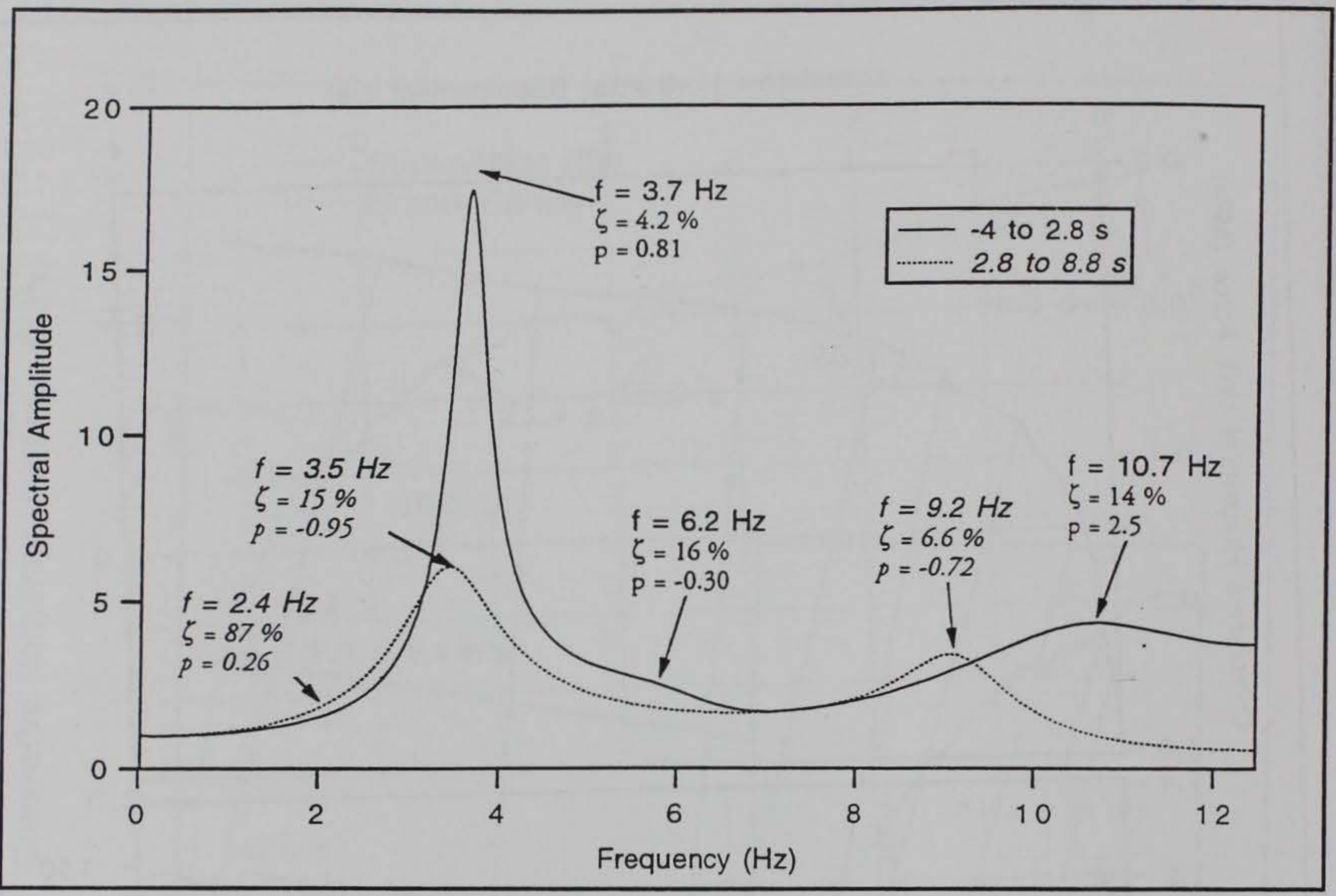

Figure 9. Spectral estimates for the first and second segments, with estimates of natural frequency, damping ratio, and participation factor 


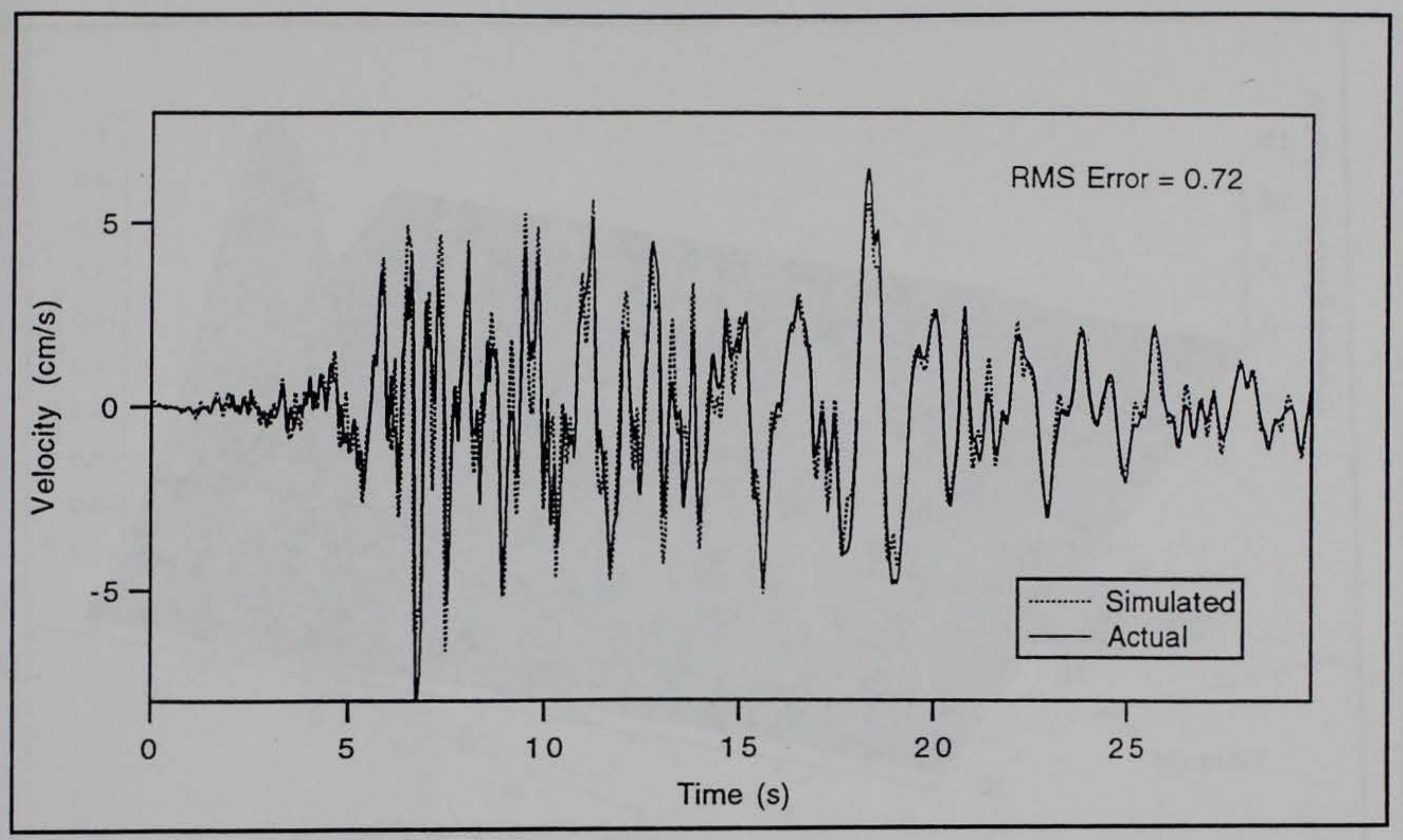

Figure 10. Comparison between the Elmore Ranch velocity history simulated by the second segment Superstition Hills filter, and the actual velocity history 


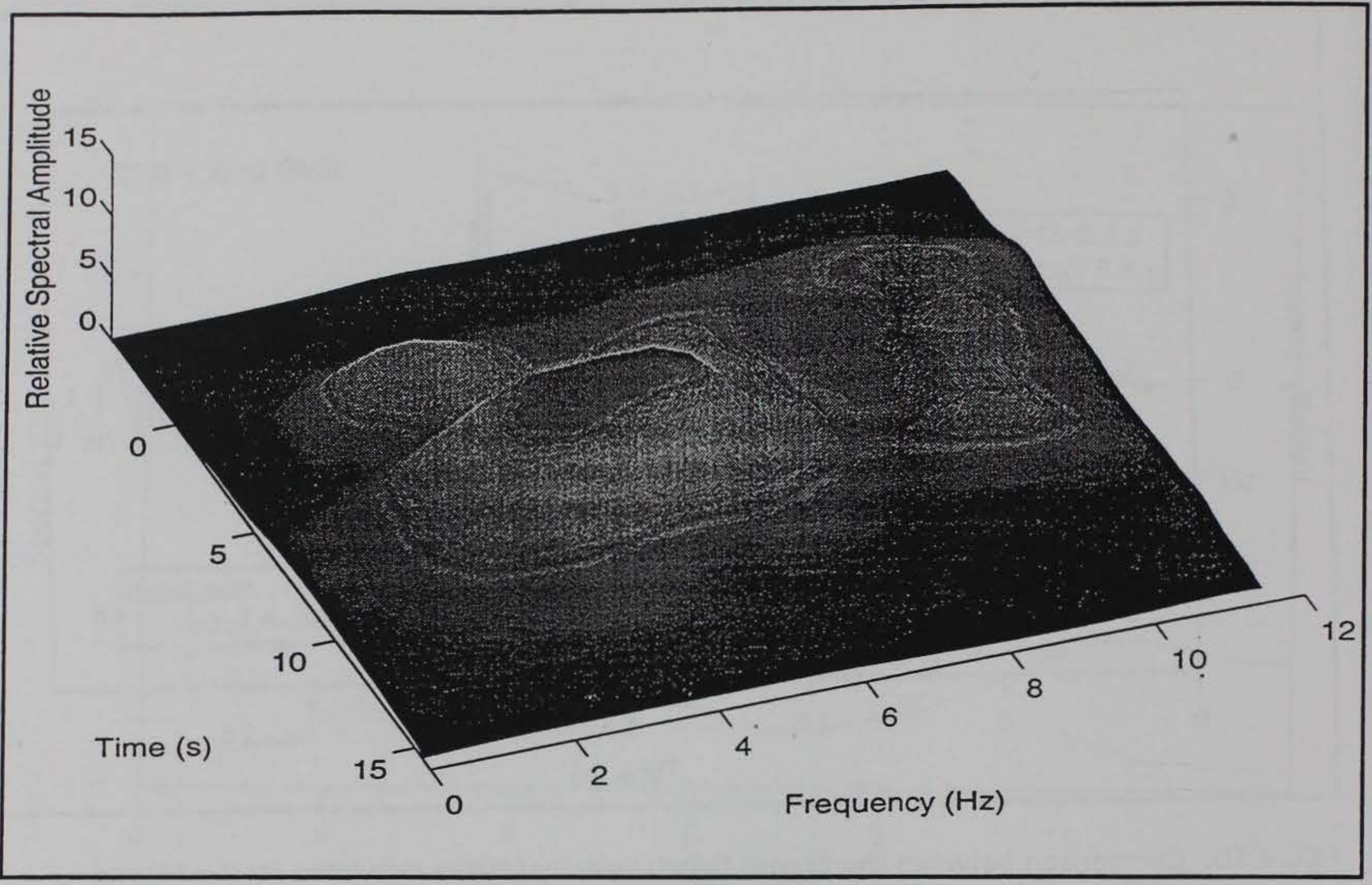

Figure 11. Soil system evolutionary time history for the initial $20 \mathrm{~s}$ of the Superstition Hills earthquake. The changing system is shown in spectral representation 


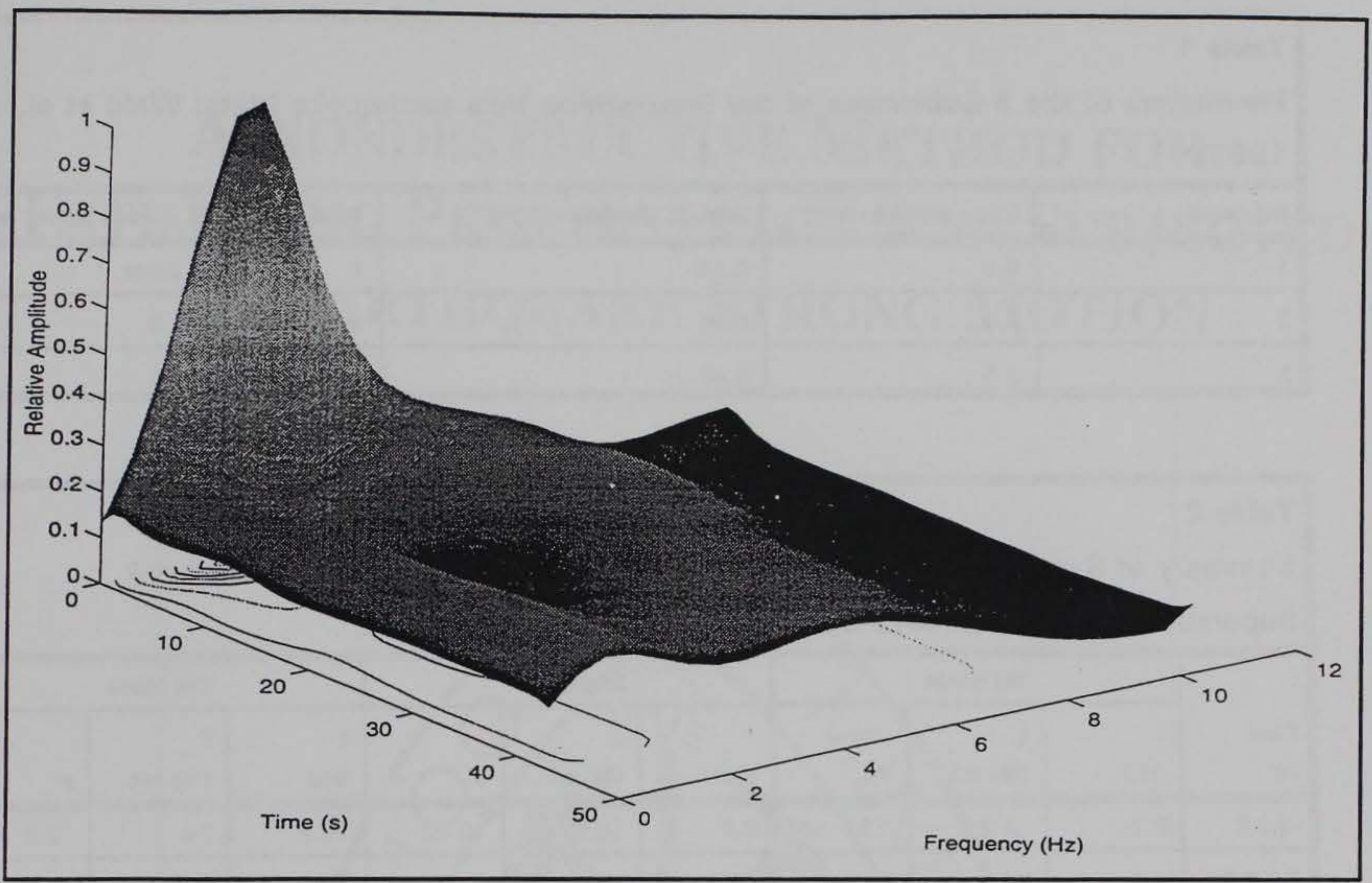

Figure 12. Soil system evolutionary time history for the coda of the Superstition Hills earthquake. The changing system is shown in spectral representation 


\begin{tabular}{|c|c|c|c|c|}
\hline \multicolumn{5}{|c|}{$\begin{array}{l}\text { Table } 1 \\
\text { Parameters of the } 3 \text { Subevents of the Superstition Hills earthquake (data: Wald et al. } \\
\text { 1990) }\end{array}$} \\
\hline Subevent & Shear Magnitude $M_{3}$ & Seismic Moment $\left(\times 10^{25}\right)$ & Delay (s) & Source Extent (km) \\
\hline 1 & 5.6 & 0.44 & 1 & point \\
\hline 2 & 6.0 & 0.91 & 3.1 & 2 \\
\hline 3 & 6.4 & 3.46 & 9.6 & 18 \\
\hline
\end{tabular}

\section{Table 2}

Summary of System Parameters Estimated for the First Two Subevents of the Superstition Hills Earthquake Using the ARX (Stationary) Model

\begin{tabular}{|c|c|c|c|c|c|c|c|c|c|}
\hline \multirow[b]{2}{*}{$\begin{array}{l}\text { Time } \\
\text { (s) }\end{array}$} & \multicolumn{3}{|c|}{ 1st Mode } & \multicolumn{3}{|c|}{ 2nd Mode } & \multicolumn{3}{|c|}{ 3rd Mode } \\
\hline & $\begin{array}{l}f \\
(\mathrm{~Hz})\end{array}$ & $\begin{array}{l}\zeta \\
(\%) \text { crit. }\end{array}$ & p & $\begin{array}{l}f \\
(\mathrm{~Hz}) \\
\end{array}$ & $\begin{array}{l}\zeta \\
\text { (\%) crit. }\end{array}$ & $\mathbf{p}$ & $\begin{array}{l}f \\
(\mathrm{~Hz}) \\
\end{array}$ & $\begin{array}{l}\zeta \\
\text { (\%) crit. }\end{array}$ & $\mathbf{p}$ \\
\hline$-4: 2.8$ & 3.7 & 4.2 & 0.81 & 6.2 & 16 & -0.30 & 10.7 & 14 & 2.5 \\
\hline 2.8:8.8 & 2.4 & 87 & 0.26 & 3.5 & 15 & -0.95 & 9.2 & 6.6 & -0.72 \\
\hline
\end{tabular}

\section{Table 3}

Summary of Recursively-Estimated System Parameters Evolving Through Time During the Superstition Hills Earthquake

\begin{tabular}{|c|c|c|c|c|c|c|c|c|c|}
\hline \multirow[b]{2}{*}{$\begin{array}{l}\text { Time } \\
\text { (s) }\end{array}$} & \multicolumn{3}{|c|}{ 1st Mode } & \multicolumn{3}{|c|}{ 2nd Mode } & \multicolumn{3}{|c|}{ 3rd Mode } \\
\hline & $\begin{array}{l}f \\
(\mathrm{~Hz})\end{array}$ & $\begin{array}{l}\zeta \\
(\%) \text { crit. }\end{array}$ & $\mathbf{p}$ & $\begin{array}{l}f \\
(\mathrm{~Hz})\end{array}$ & $\begin{array}{l}\zeta \\
\text { (\%) crit. }\end{array}$ & p & $\begin{array}{l}f \\
(\mathrm{~Hz})\end{array}$ & $\begin{array}{l}\zeta \\
\text { (\%) crit. }\end{array}$ & p \\
\hline-1 & 4.7 & 10 & 0.33 & - & - & - & 8.6 & 6 & 0.11 \\
\hline 2.4 & 3.9 & 7 & 0.17 & -- & -- & -- & 9.4 & 5 & -0.10 \\
\hline 5.6 & 3.5 & 90 & -0.05 & 4.3 & 8 & 0.16 & 9.4 & 7 & 0.16 \\
\hline 8.6 & 2.4 & 87 & 0.26 & 3.5 & 15 & 0.95 & 9.2 & 7 & -0.72 \\
\hline 26 & 0.8 & 5 & 0.19 & 5.3 & 22 & 0.26 & 10.1 & 9 & 0.43 \\
\hline 32 & 0.42 & 27 & 0.13 & 5.3 & 27 & 0.24 & 10.1 & 13 & 0.31 \\
\hline 37 & 0.35 & 34 & 0.10 & 5.3 & 28 & 0.24 & 10.1 & 14 & 0.30 \\
\hline 56 & 0.35 & 20 & -0.02 & 5.8 & 44 & -0.20 & 10.0 & 23 & 0.22 \\
\hline 72 & 0.21 & 45 & 0.08 & 7.1 & 66 & 0.50 & 9.8 & $31^{-}$ & 0.41 \\
\hline
\end{tabular}




\section{A NONDESTRUCTIVE METHOD FOR Estimating Properties of SoIL SubJected TO EARTHQUAKE STRONG MOTION}

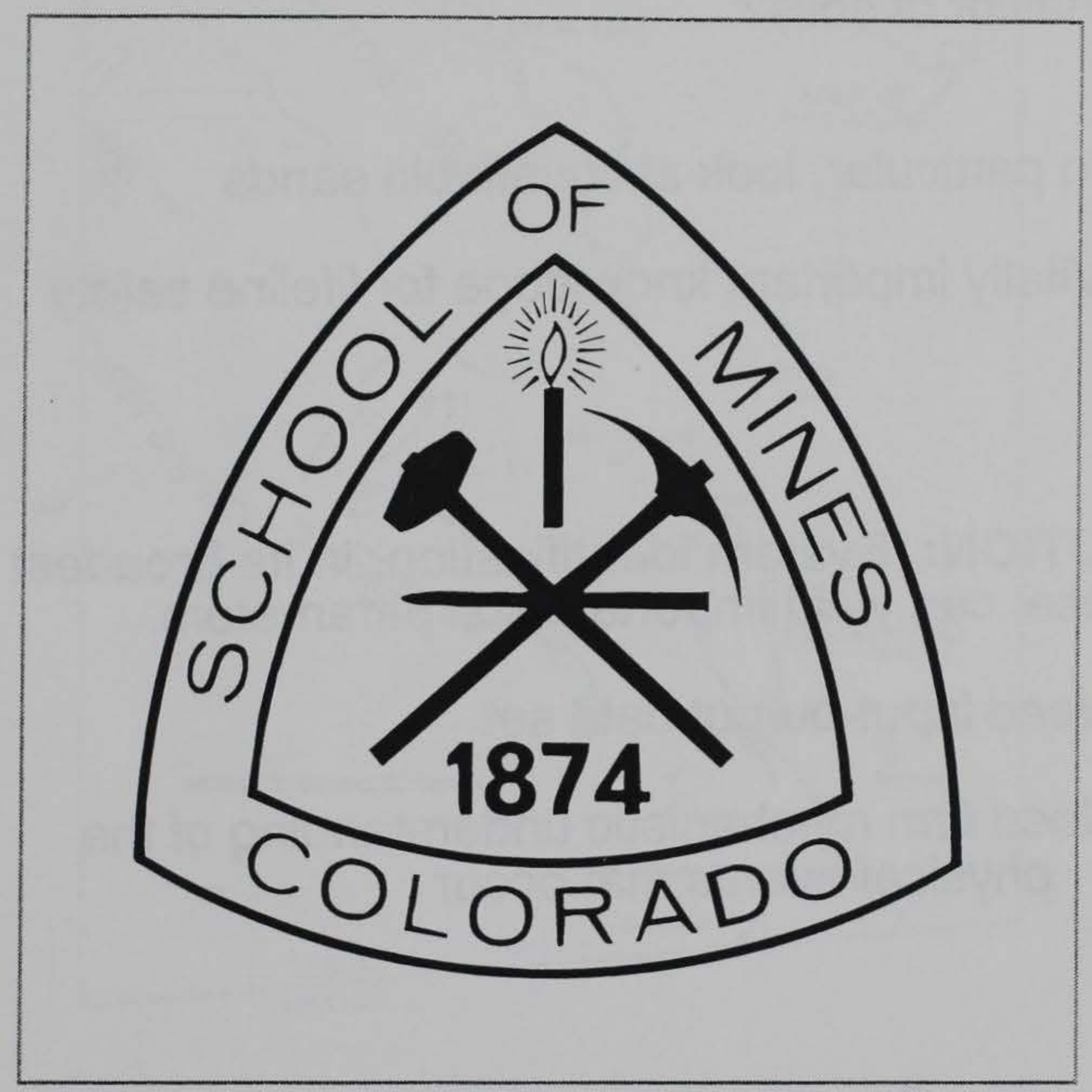

WATERWAYS EXPERIMENT STATION, EARTHQUAKE ENGINEERING SITE CHARACTERIZATION WORKSHOP, JUNE 27, 1995

Steven Glaser, Division of Engineering, Colorado School of Mines 
PROBLEM: Can we use earthquake strong motion records to gain understanding of the non-linear behavior of soils?

- In particular, look at liquefiable sands

- Vitally important knowledge for lifeline safety

SOLUTION: System identification, in its broadest sense, can yield important soil parameters.

- Need input-output data set

- Need firm mechanistic understanding of the physical events that occur

\section{$\therefore$ Study the Wildlife Site}




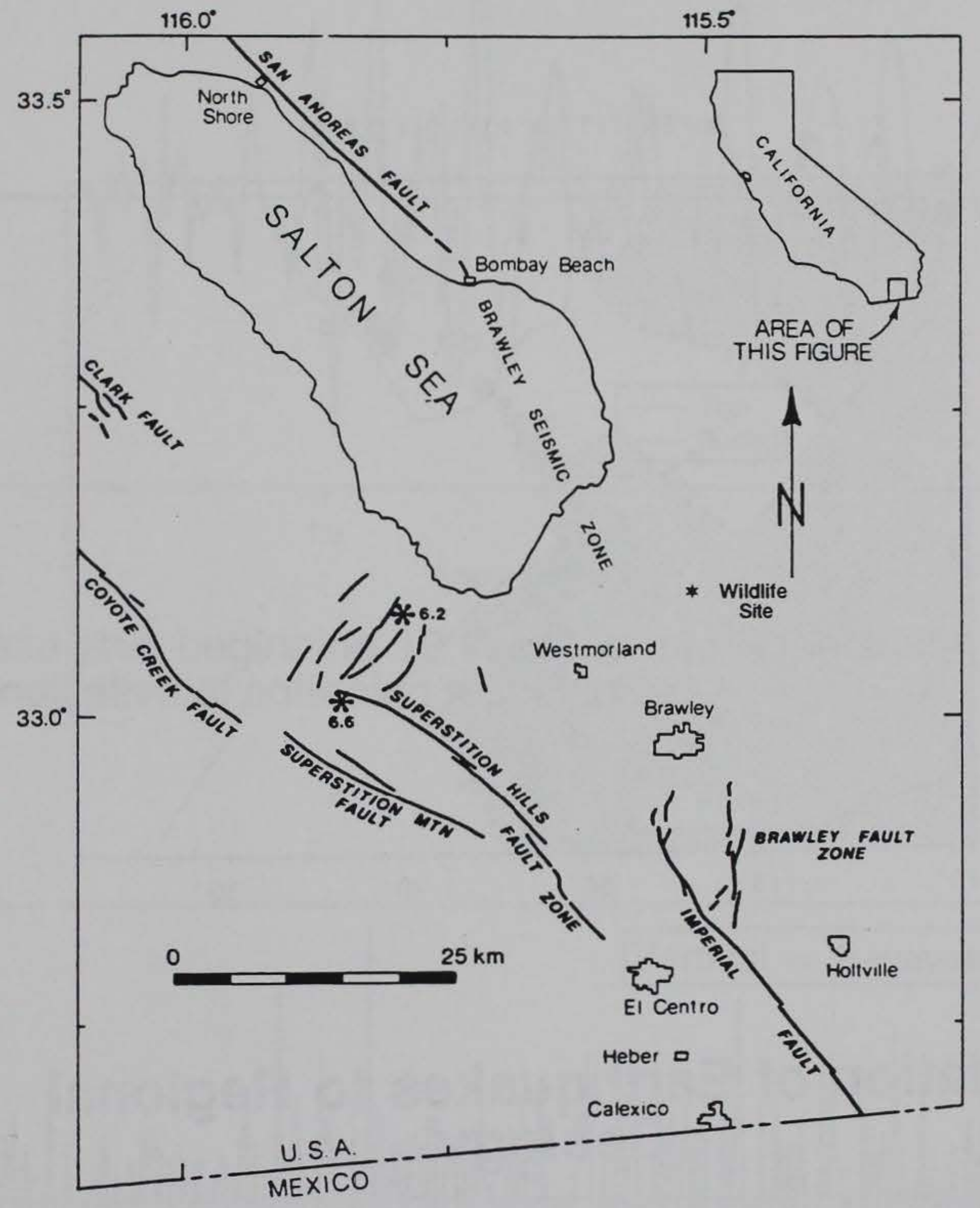

\section{The Wildlife Site in the Imperial Valley, CA}

- Area is extremely seismically active

- Site liquefied during the 1981 M 5.5 Westmoreland earthquake 


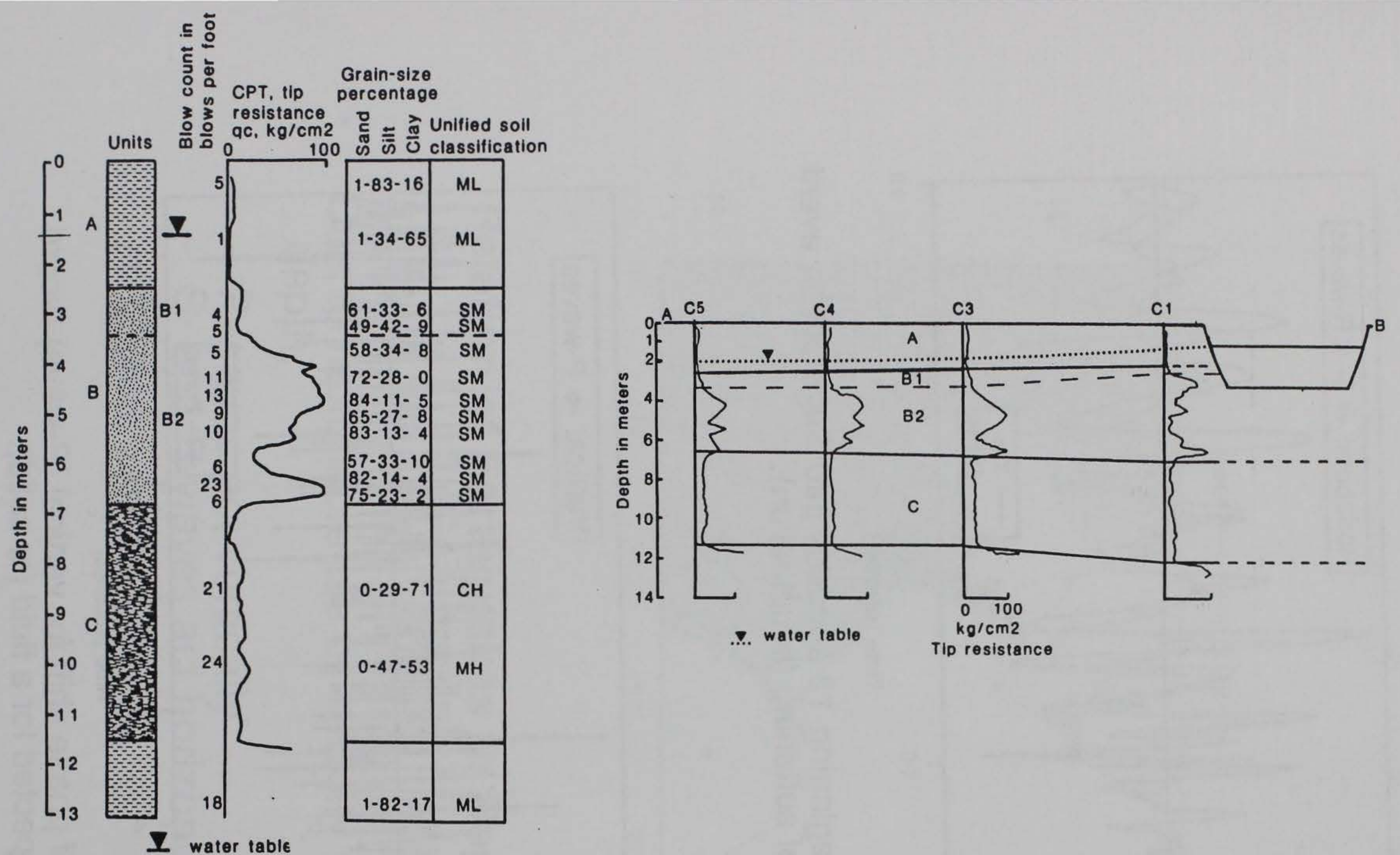

Geotechnical Properties of The Wildlife Site

- Layer B1 is the most susceptible to liquefaction

- Layer $\mathrm{C}$ is weak, but cohesive

- Pore pressure ratio $\left(r_{u}=\frac{u}{\sigma_{v}}\right)$ greater than 1 only for P5 \& P2 

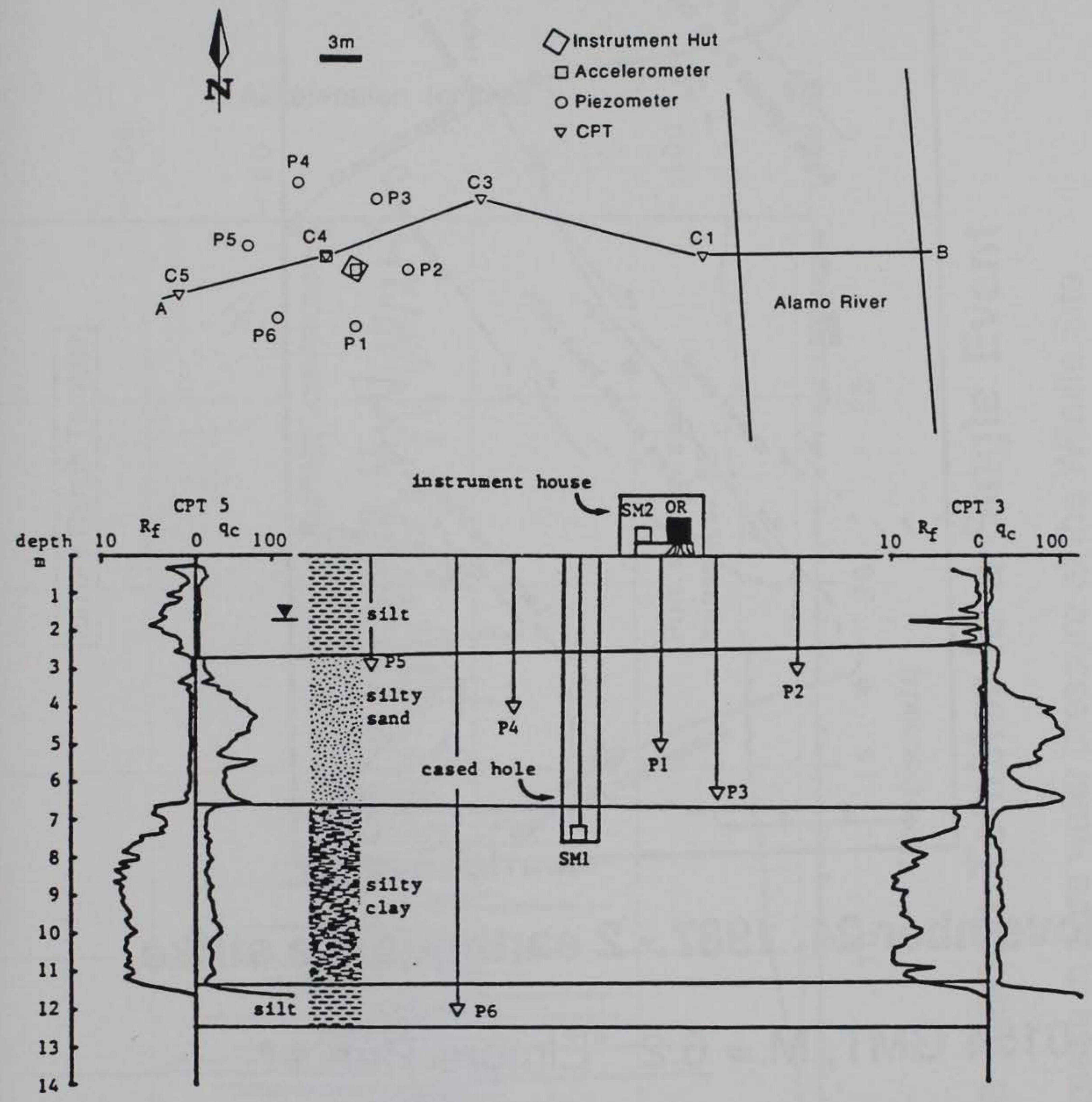

\section{Instrumentation and Layout of The Wildlife Site}

- The only site in the U.S. having experienced strong motion and equipped with buried and surface accelerometers, and piezometers 


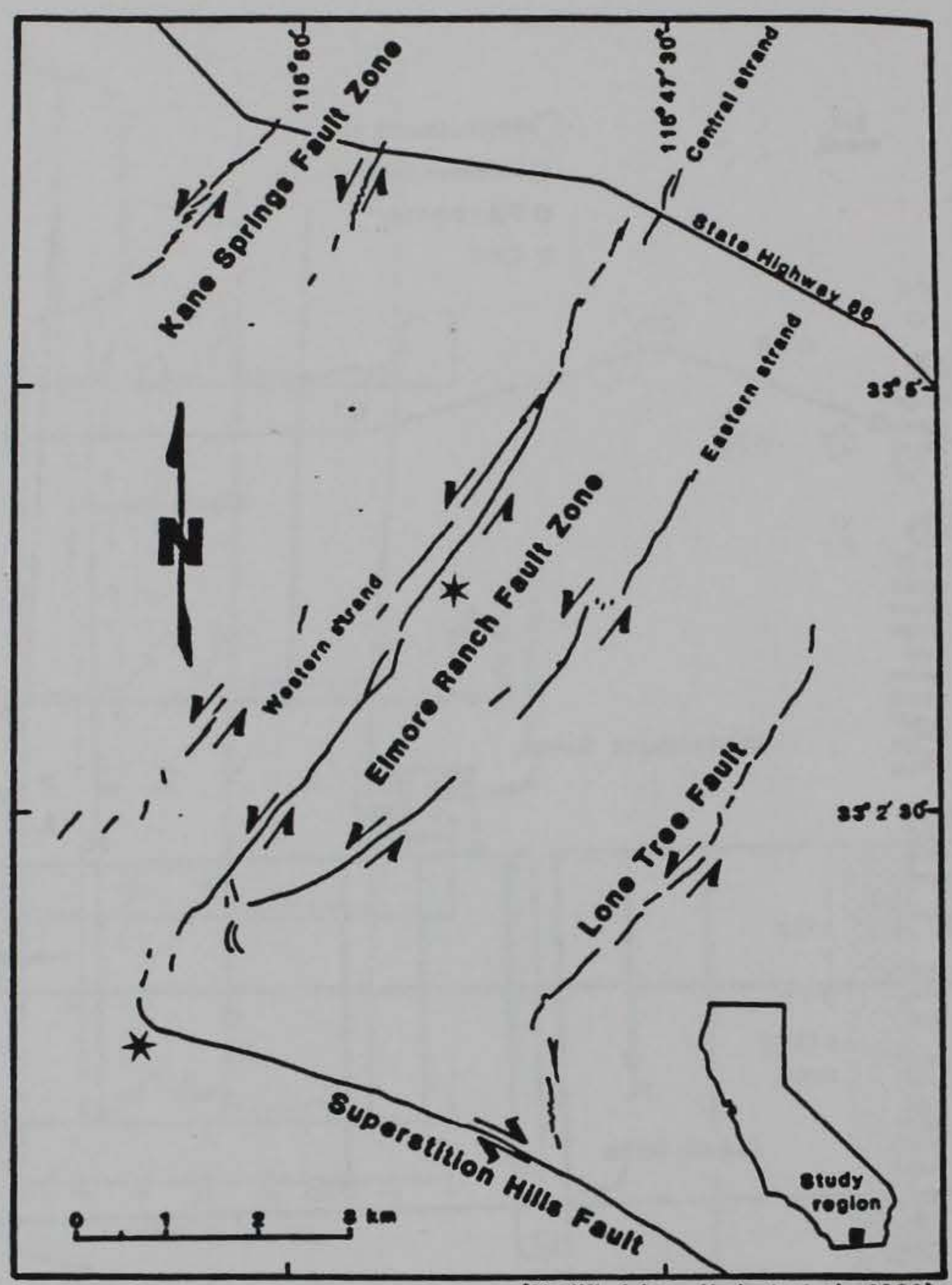

(Modiliod from Hudnut 21 21. 1089)

\section{November 24, 1987 - 2 earthquakes strike}

- 0154 GMT, M = 6.2 "Elmore Ranch"

- 1315 GMT, M = 6.6 "Superstition Hills"

- The temblors occurred on conjugate faults 


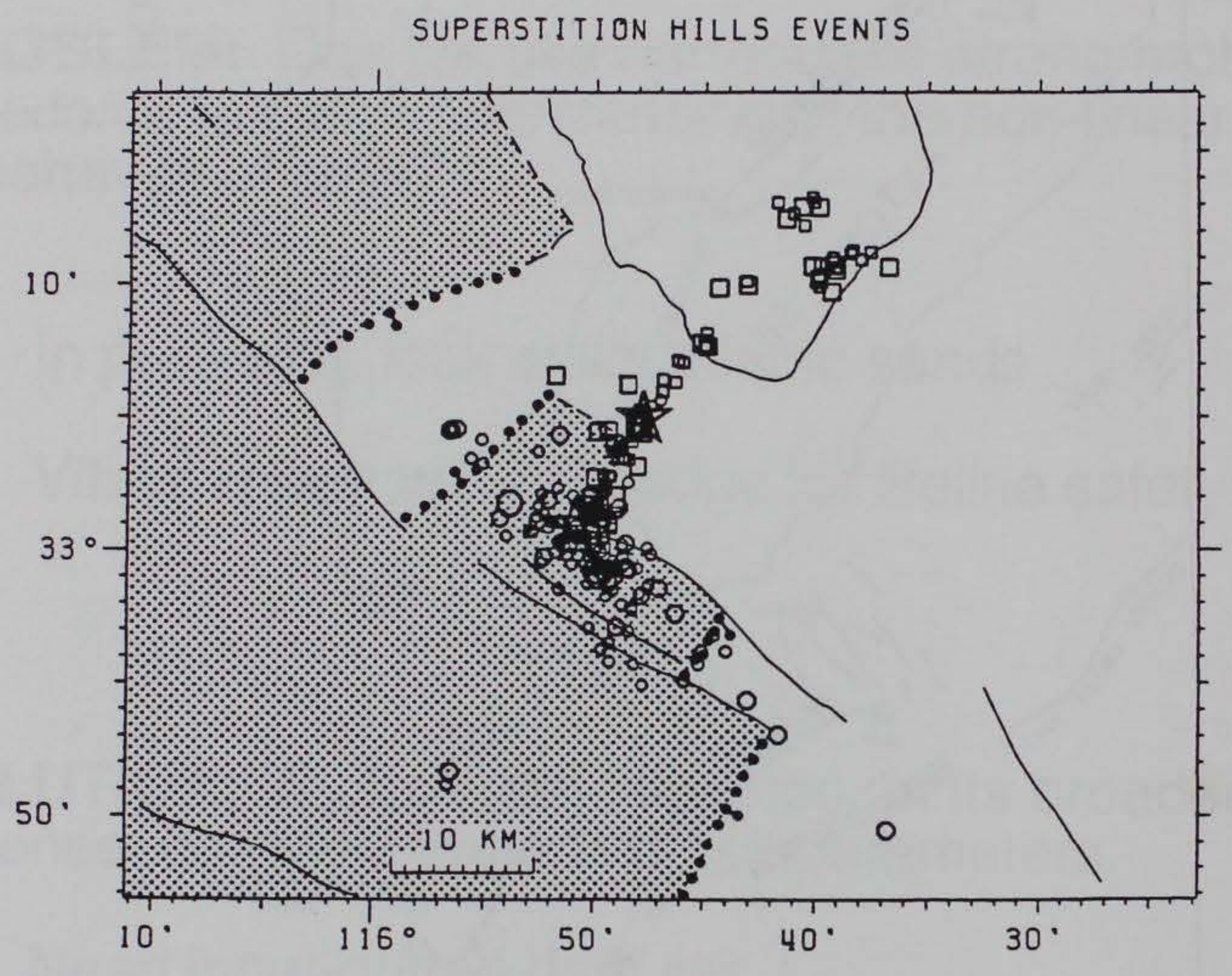

\section{Relation of Earthquakes to Regional Geology}

- Due to rapid increase of velocity with depth,

- P-waves act vertically

- S- and R-waves act horizontally 


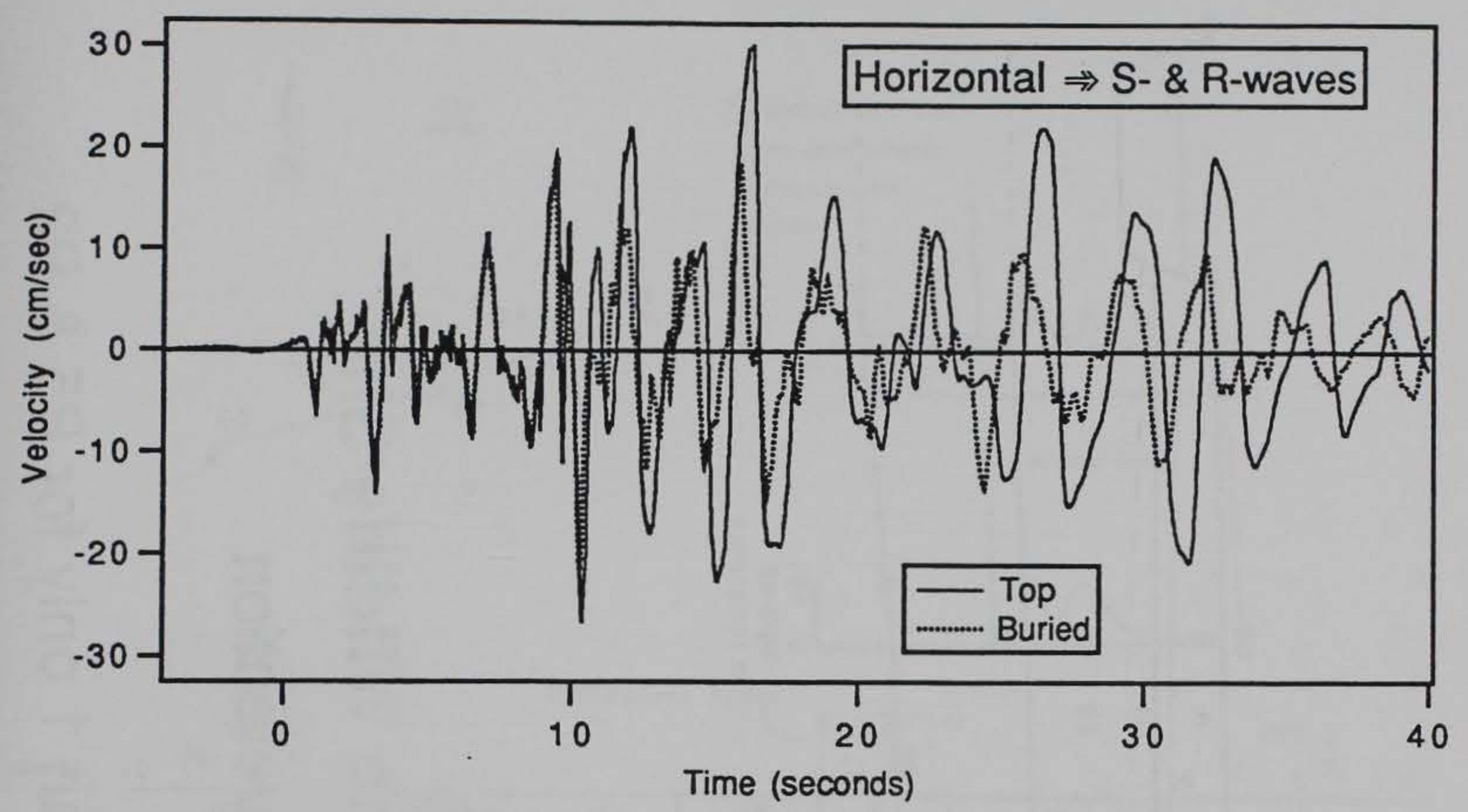

- Phase shift beginning 12 seconds into Superstition event is indicative of softening (liquefaction).

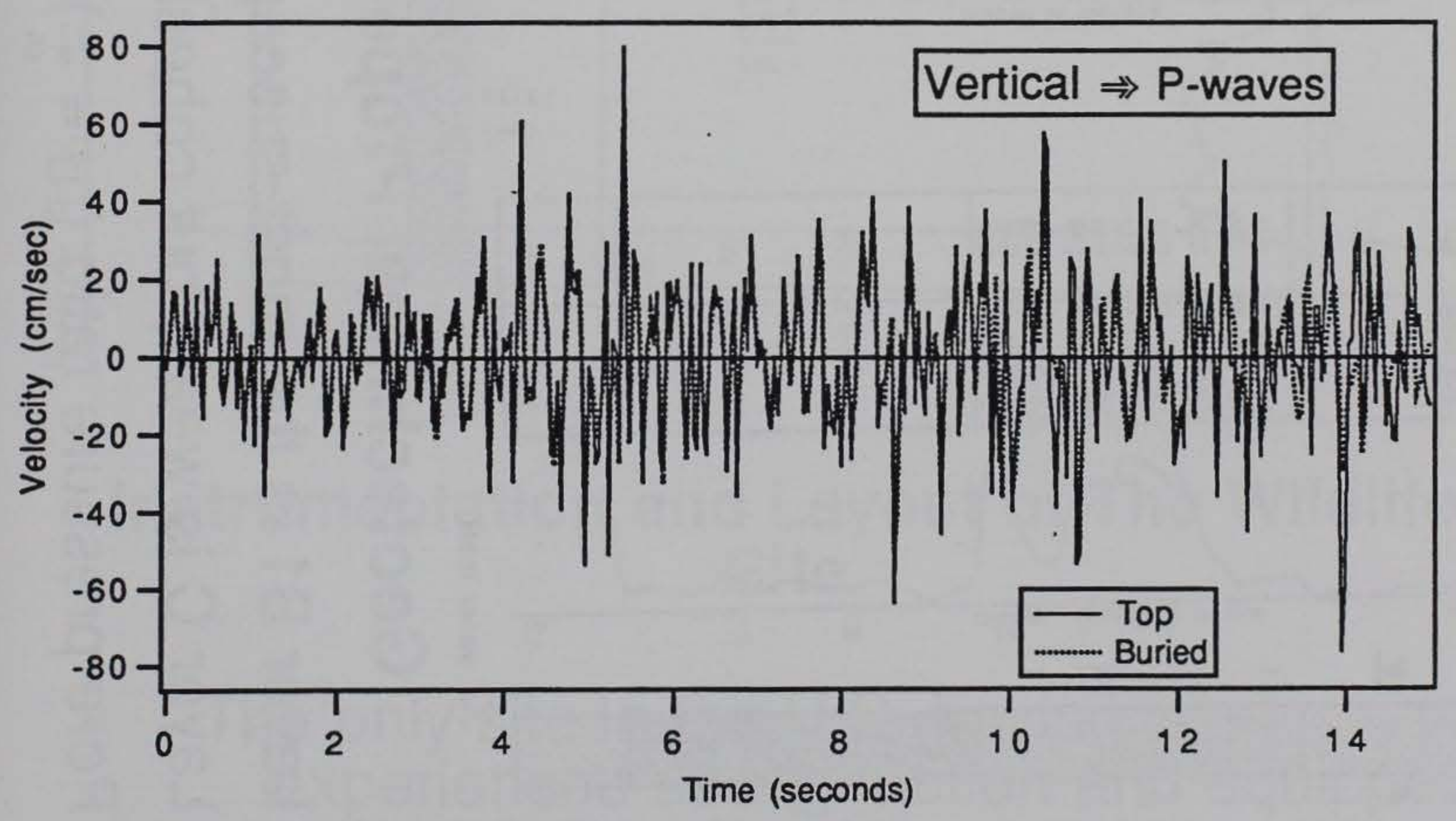

- Lack of phase shift for vertical (P-wave) record is expected for a fluid (or solid).

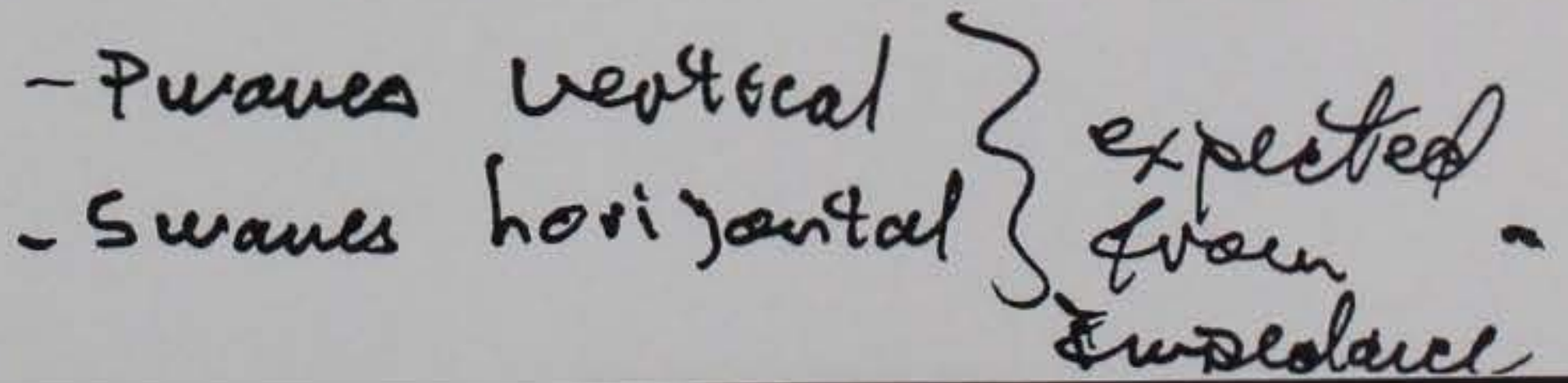




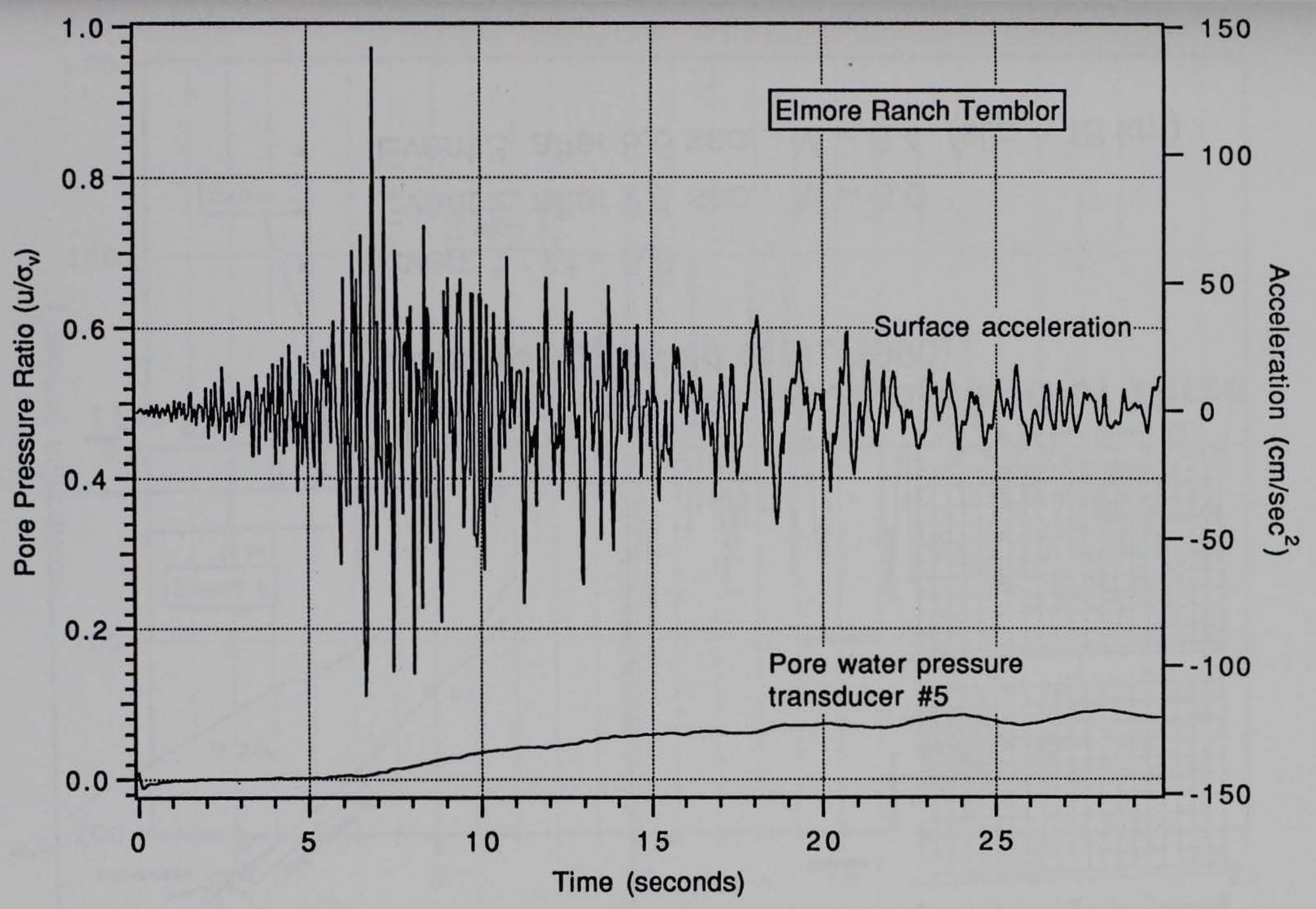

The Elmore Ranch Temblor is a Single Event

- Some increase in pore water pressure at the Wildlife Site

- No attendant liquefaction at the Wildlife Site 

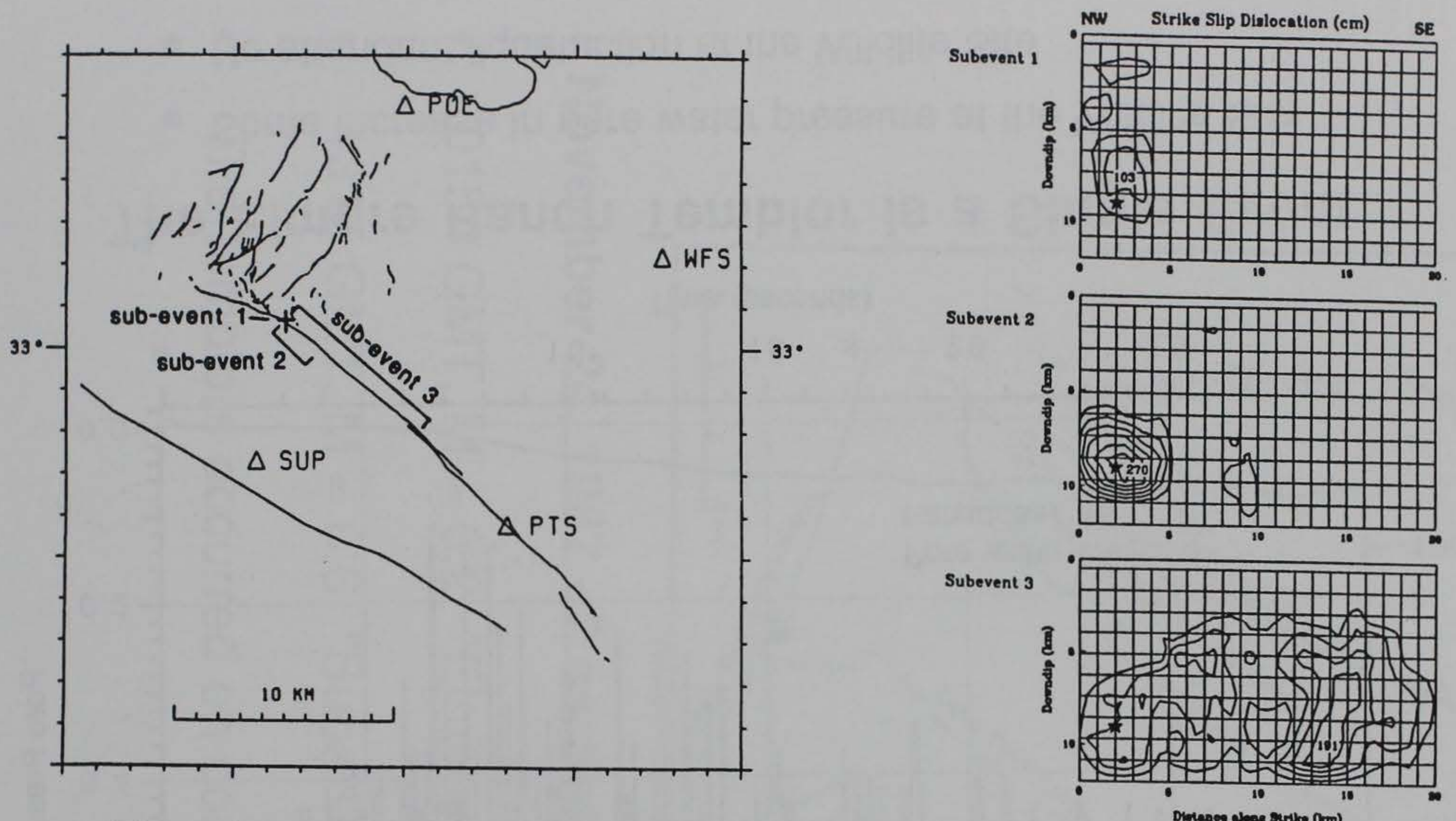

The Superstition Hills Temblor is Comprised of Three Subevents (Wald et al., 1990)

- $\quad$ Event 1, $M=5.6$

- $\quad$ Event 2, after $2.1 \mathrm{sec} ., M=6.0$

- Event 3, after $8.6 \mathrm{sec}$., $M=6.4(\mathrm{slip} \approx 18 \mathrm{~km})$ 


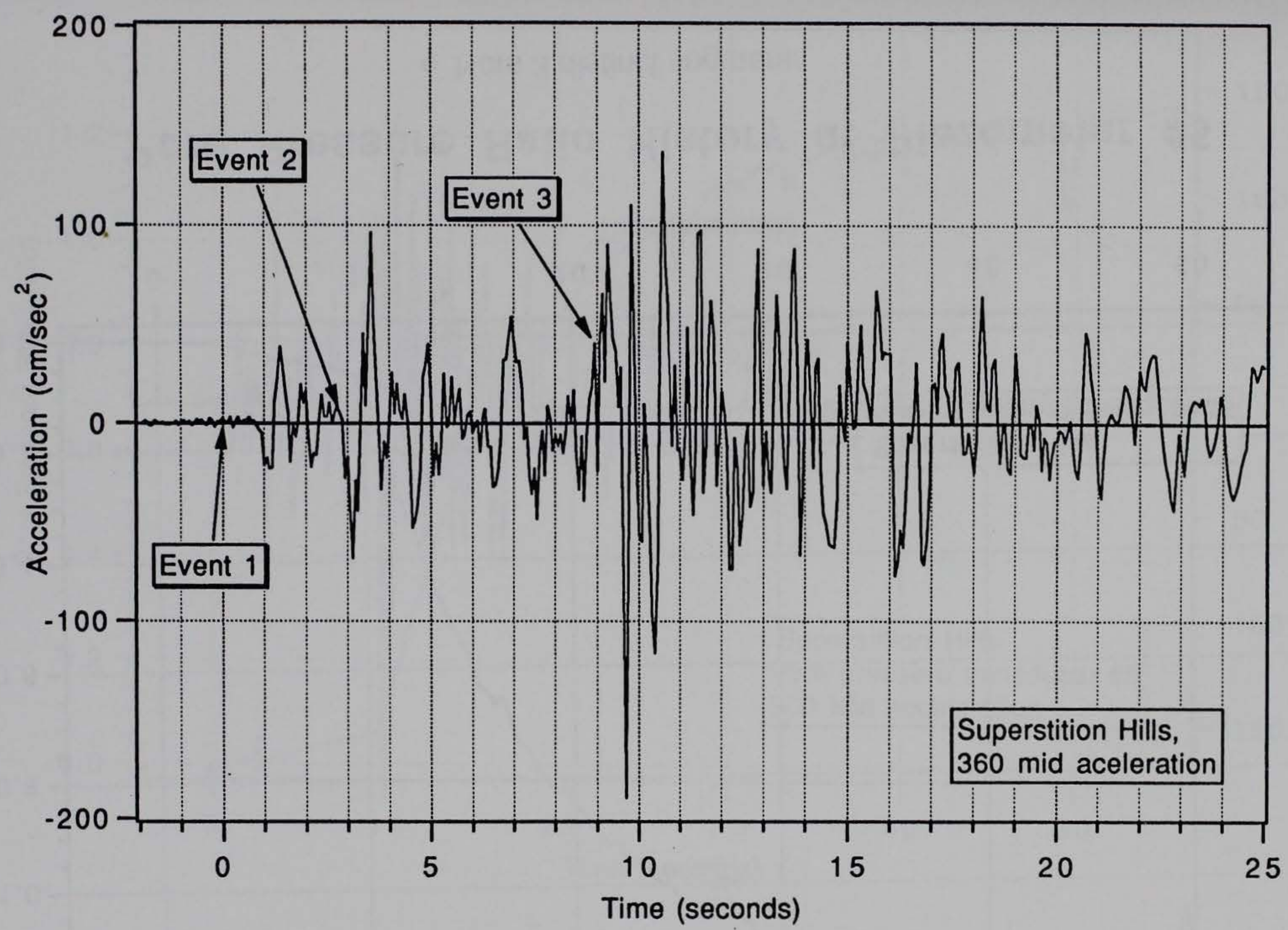

Buried Acceleration Record of the Superstition Hills Earthquake

- Obvious arrivals of the subevents

- 7.5 second duration of event 3 apparent from record 


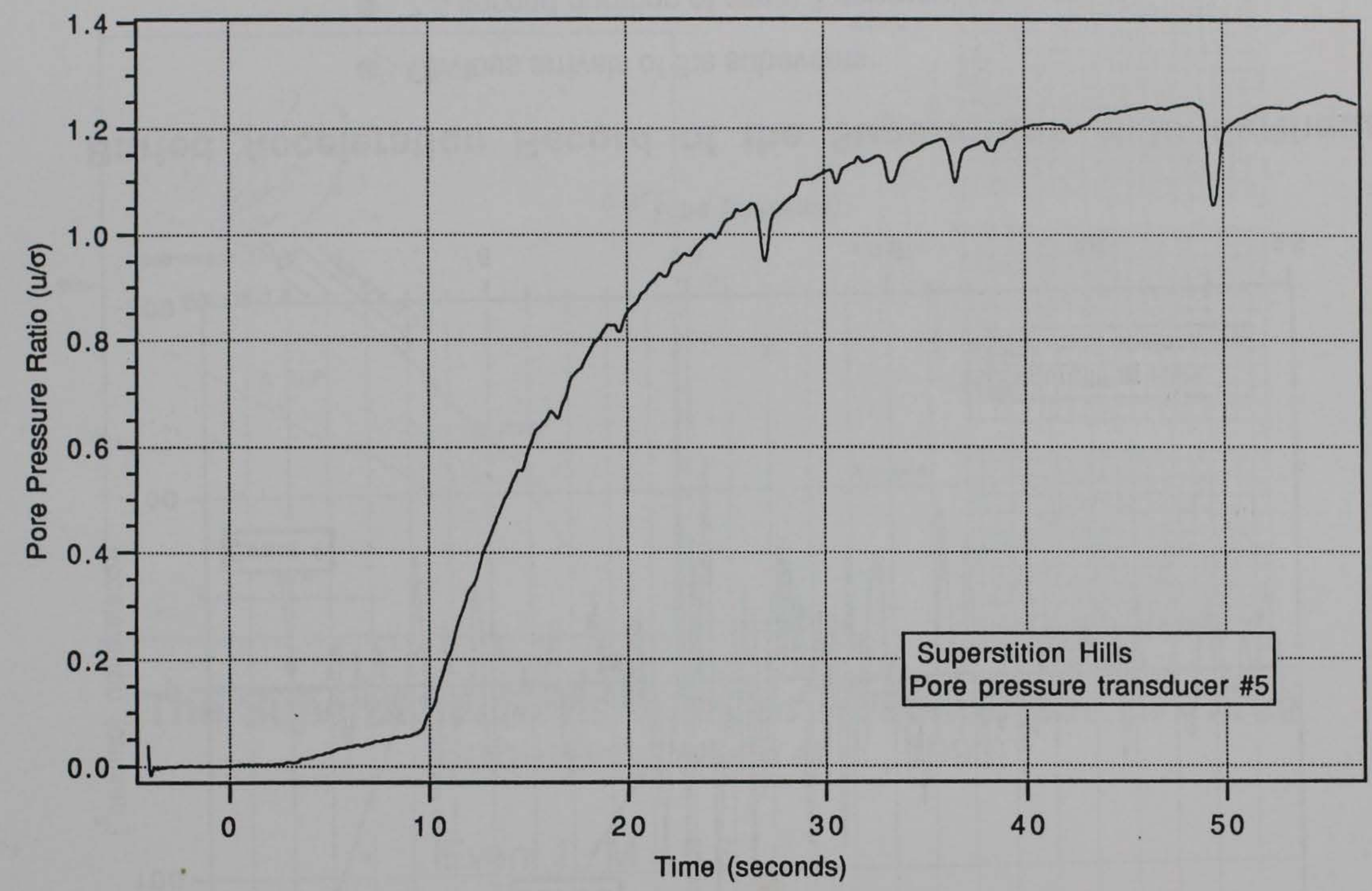

Pore Pressure Ratio History at Piezometer \#5

- Note 3 distinct segments

11 


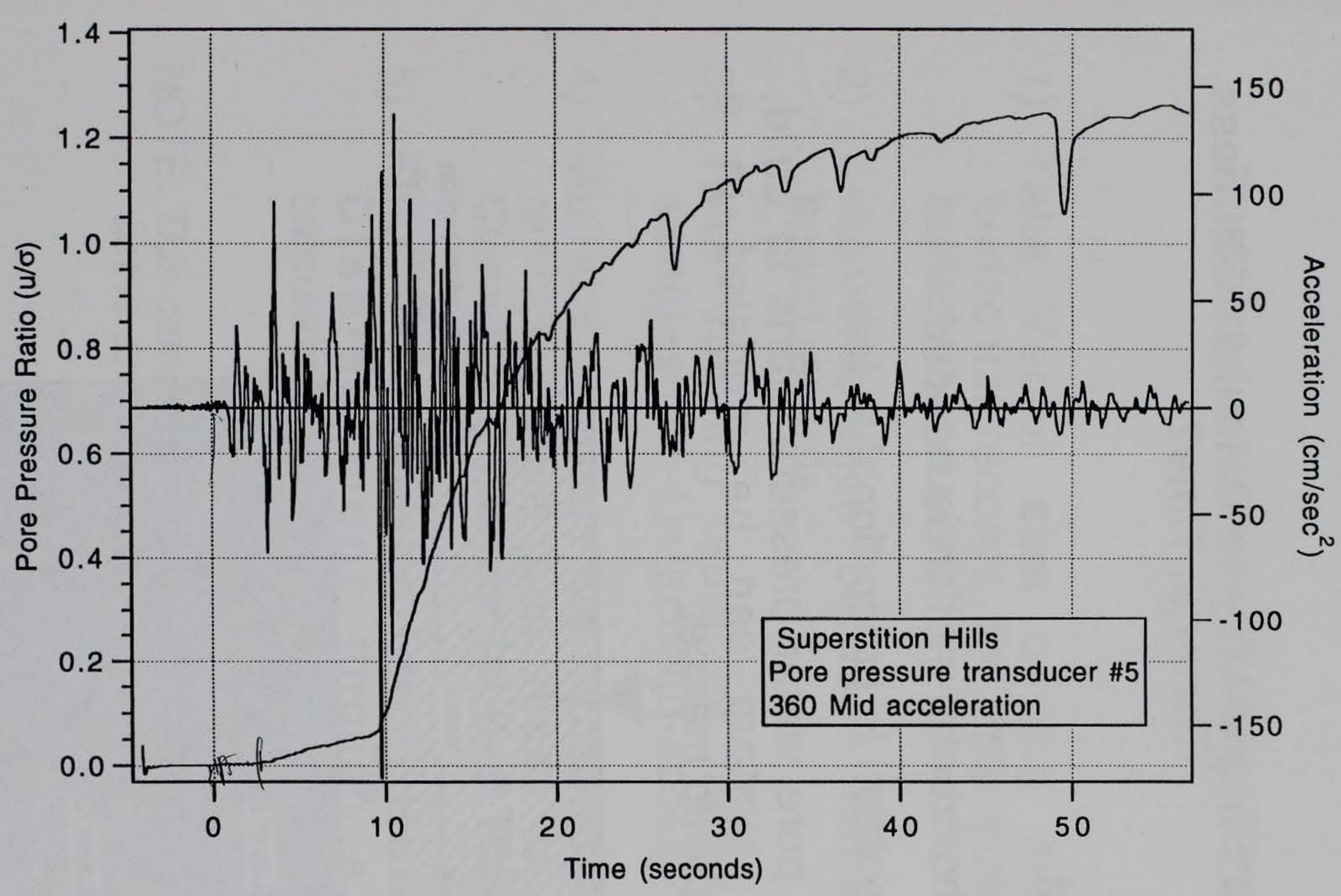

Acceleration Vs Pore Pressure \#5

- Three subevents are obvious in the seismic and pore pressure records

- Change in pore pressure relates directly to soil motion 


\section{Formation Stiffness is a Very Important Parameter}

\section{Is there a Simple Way to Calculate Stiffness Through Time?}

Note That -

- Only horizontal motion is needed

- Acceleration is proportional to force

- Once pore water pressure starts to build, the system can be modeled in a simplified manner

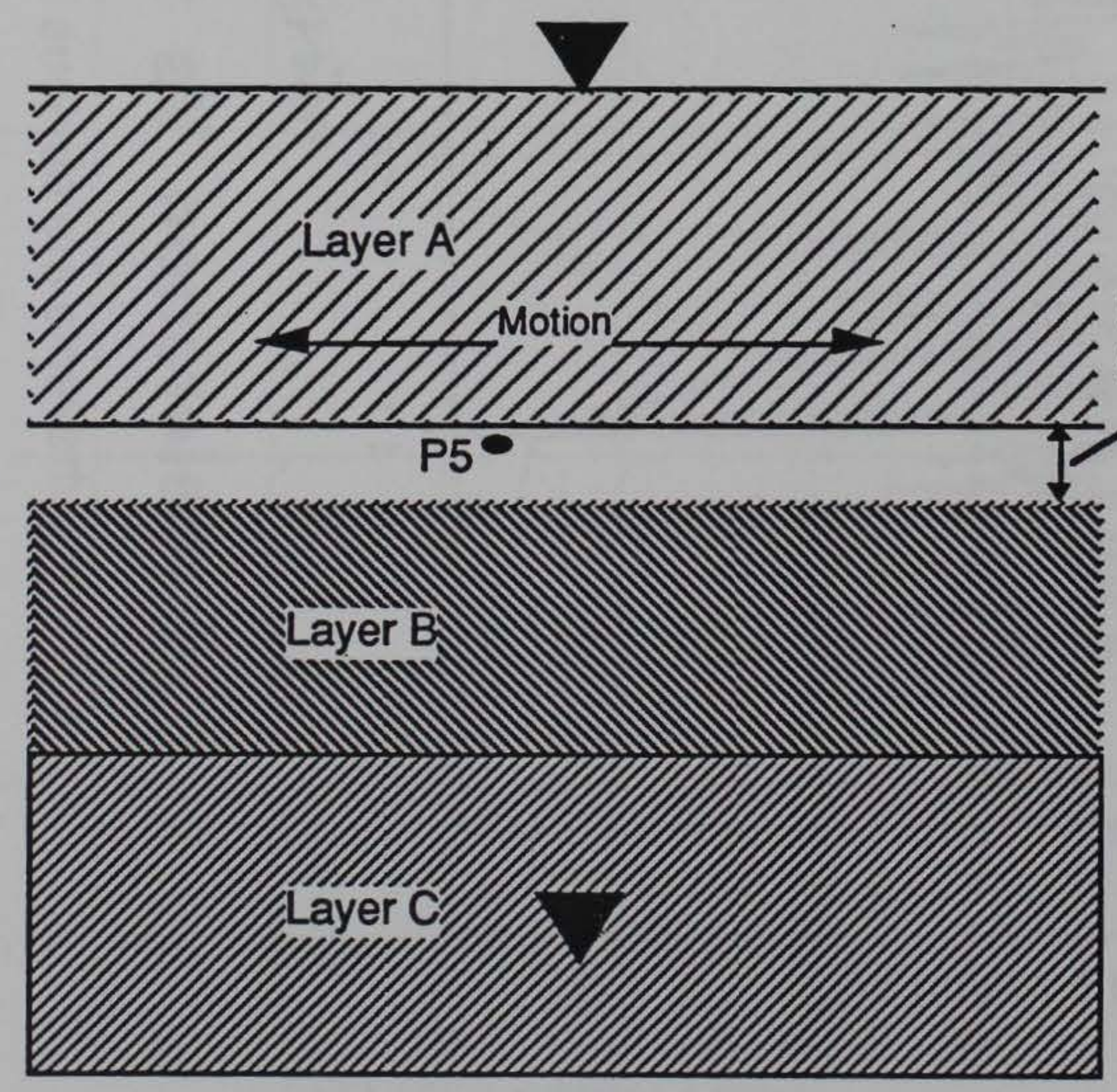




\section{Postulate a Pseudo-Stiffness Curve}

1) Take Vector sum of the orthogonal horizontal records, for both surface and buried transducers.

2) Take difference between surface and buried records.

3) Take running sum of acceleration$\operatorname{sum}(i)=\operatorname{sum}(i-1)+(\operatorname{accel}(i)-\operatorname{accel}(i-1))$

4) Multiply cumulative acceleration by representative unit mass to yield Cumulative Horizontal Unit Force.

5) Find the Cumulative Horizontal Displacement through a similar calculation.

NOTE: This calculation does not distinguish between active and restorative force. 


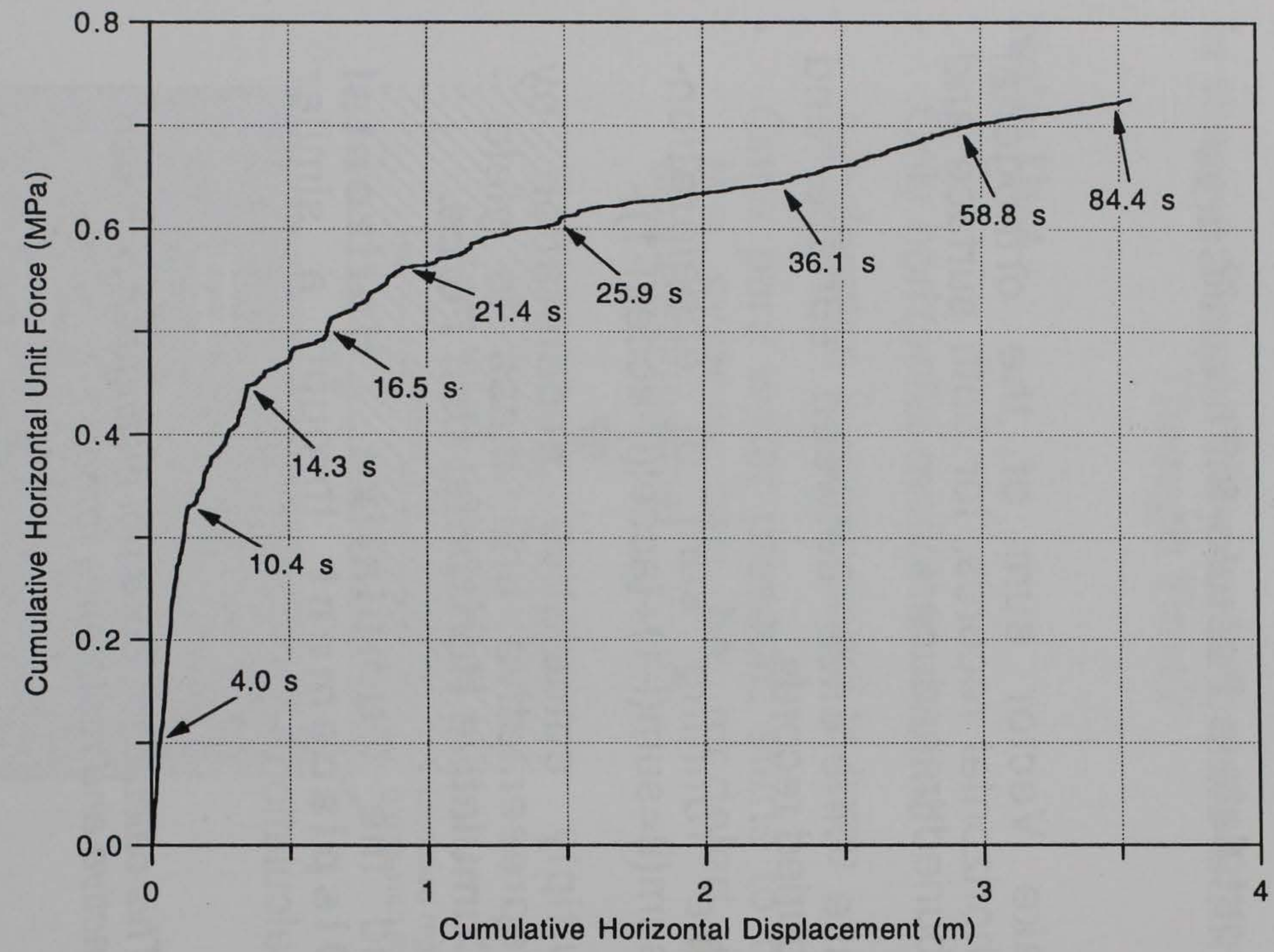

Pseudo-Force Displacement Curve for Superstition Hills

- For relative motions

- Time relation shown on curve 


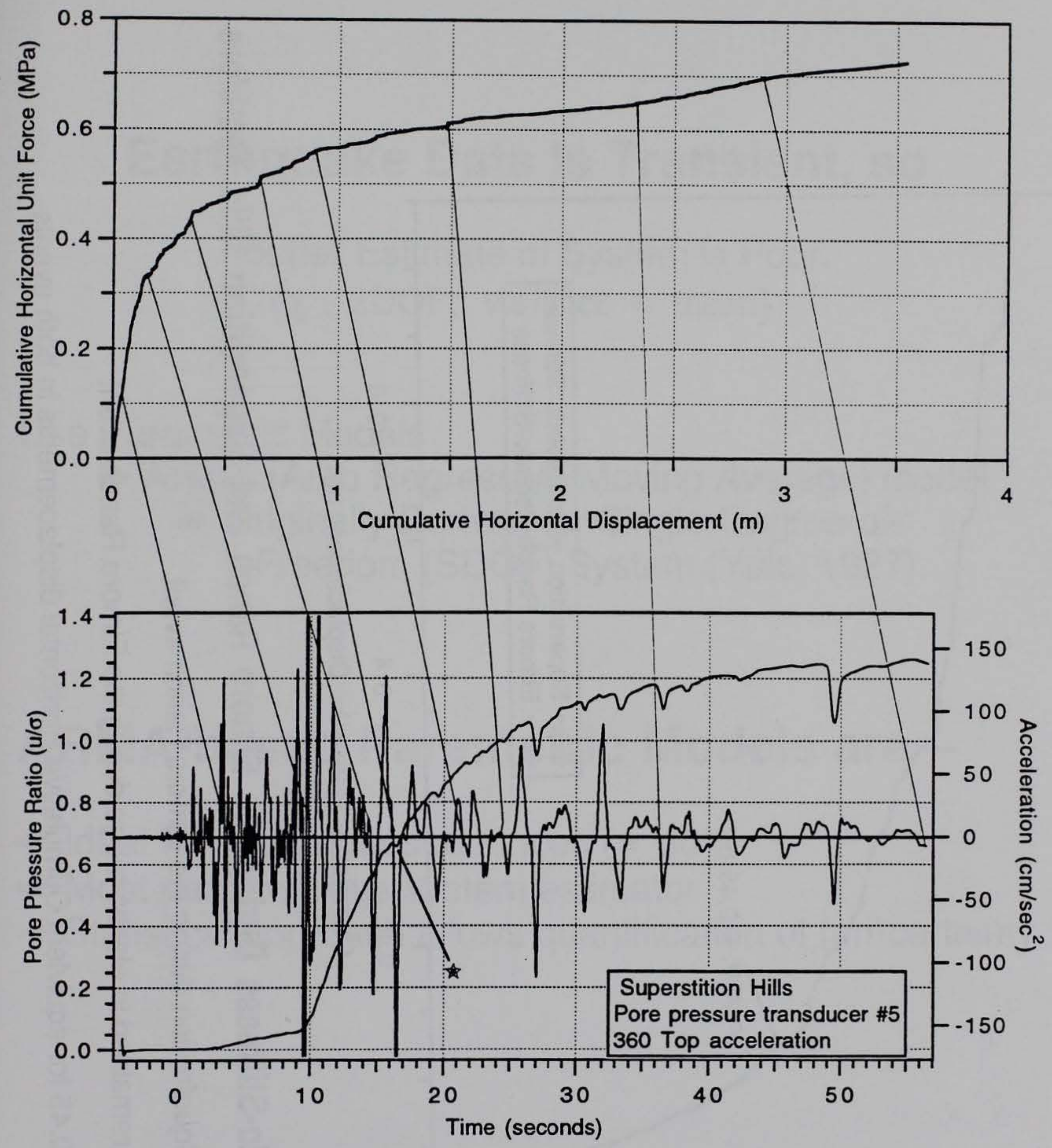

\section{Top Acceleration Compared to Pseudo-Stiffness}

- At the rate of pore pressure buildup starts to decrease, $r_{u}>0.6$

- Material starts to seriously weaken

- End of source events (event 3) 


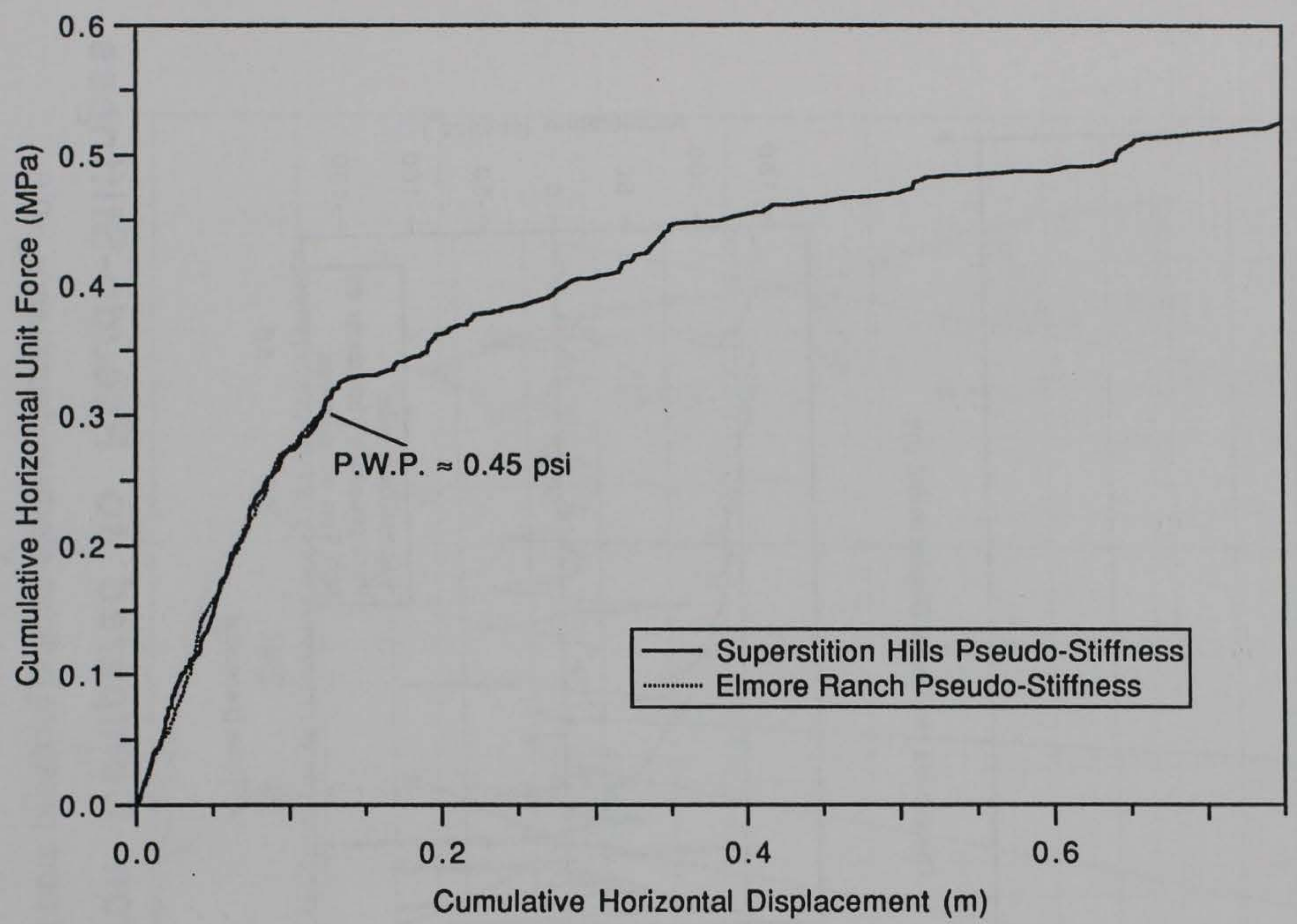

Comparison of Pseudo-Stiffness During the Elmore Ranch and Superstition Hills Temblors

- No liquefaction during the Elmore Ranch event

- Soil remained in elastic range during the Elmore Ranch event

- $\mathrm{r}_{\mathrm{u}} \approx 0.45$ for equivlent Cumulative Horizontal displacements in both events 


\section{Earthquake Data is Transient, so}

Fourier Estimate of System is Poor.

$\left(\chi^{2}, 2 \mathrm{DOF}\right.$, variance $\approx$ mean $)$

Use Parametric Models

ARMA (Auto Regressive-Moving Average) model

- Originally Derived for Single-Degree-of-

Freedom (SDOF) System (Yule, 1927).

\section{ARMA-based Parametric Models are -}

Ideal for short data sequences $(\approx 50)$

Most parsimonious system estimator

Statistical approach allows quantification of (un)certainty 


\section{Model System as Linear Filter}

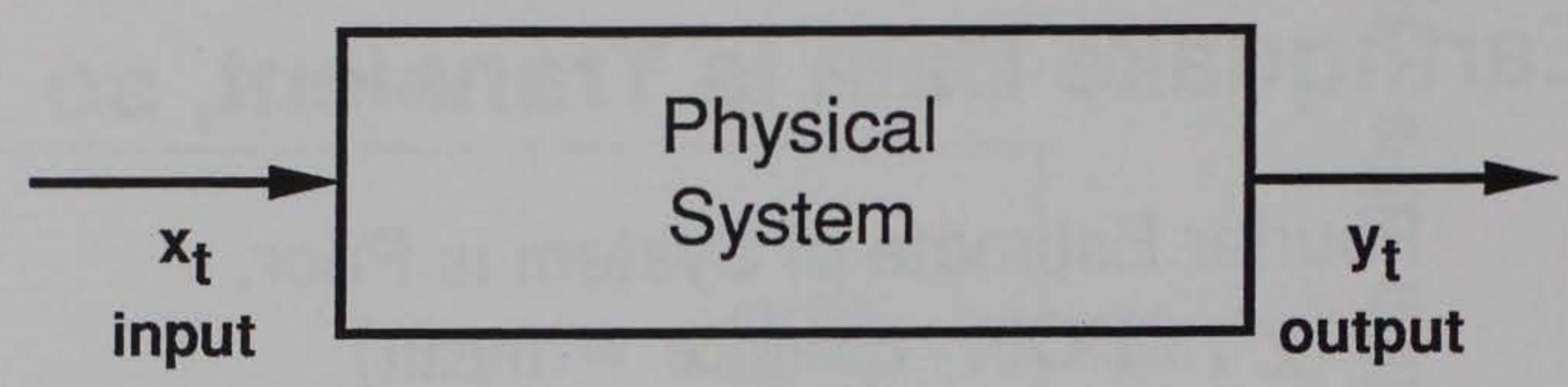

$$
y_{t}=b_{0} x_{t}+b_{1} x_{t-1}+\cdots+a_{1} y_{t-1}+a_{2} y_{t-2}+\cdots
$$

$y=$ actual system output sequence

$\mathrm{X}=$ actual system input sequence

$\mathrm{t}=$ time-step counter

Which can be rewritten as -

$$
y_{t}=\sum_{j=0}^{n b} b_{j} x_{(t-j)}+\sum_{k=1}^{n a} a_{k} y_{(t-k)}
$$

$\mathrm{na}=\mathrm{AR}$ order

$\mathrm{nb}=\mathrm{MA}$ order

Applying the shifting theorem and Z-Transform Yields

$$
H_{\omega}=\frac{Y_{\omega}}{X_{\omega}}=\frac{b_{0}+b_{1} z^{1}+b_{2} z^{2}+\cdots}{1-a_{1} z^{1}-a_{2} z^{2}-\cdots}
$$

- The Frequency Domain Transfer Function of the System of Interest 


\section{Output is a Combination of :}

input history acted on by "b" coefficients

past outputs acted on by "a" coefficients

$A R=$ noncausal process; parameters contain resonant frequency and damping ratio.

MA = causal, convolutional process; parameters contain the phase relations.

$\therefore \quad$ N-DOF System Modeled as 2n-2n ARMA

Solve For ARMA Coefficients by Various LeastSquare Based-Schemes 


\section{Earthquake Data is Non-stationary!}

Transient, non-repetitive signal.

Excitation statistics (mean \& variance) change through time.

System statistics change through time.

Neither parametric nor Fourier methods are proper for non-stationary signals.

\section{Solutions?}

- Cut data into pseudo-stationary pieces (too short for reliable Fourier estimates). Use Berg parametric algorithm.

- Use recursive (e.g. Extended Kalman filter) techniques. Characterize the evolution of the dynamic system directly. 


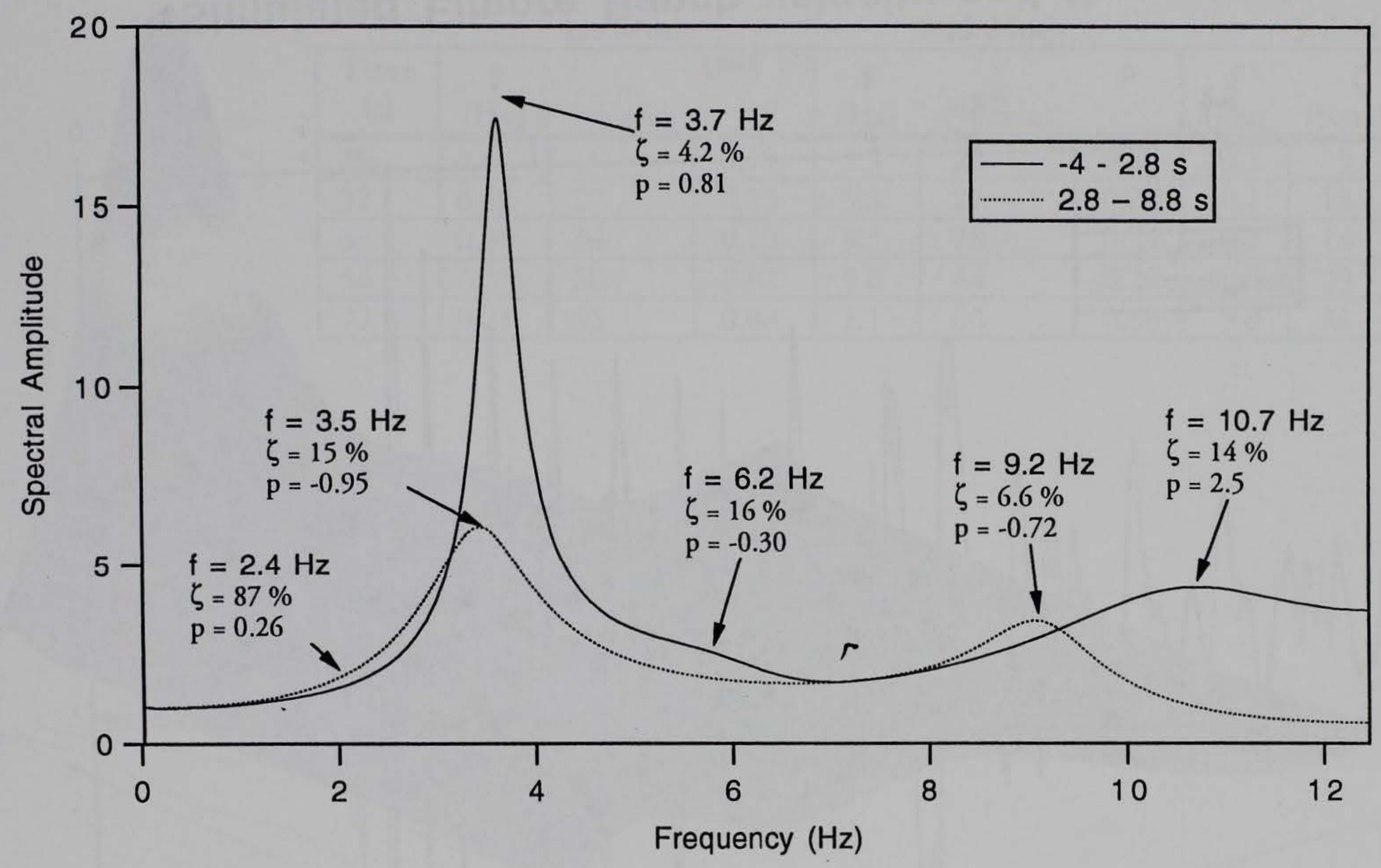

Spectral Estimates for the First and Second Segments

- The natural frequency shifts lower as pore pressure builds 


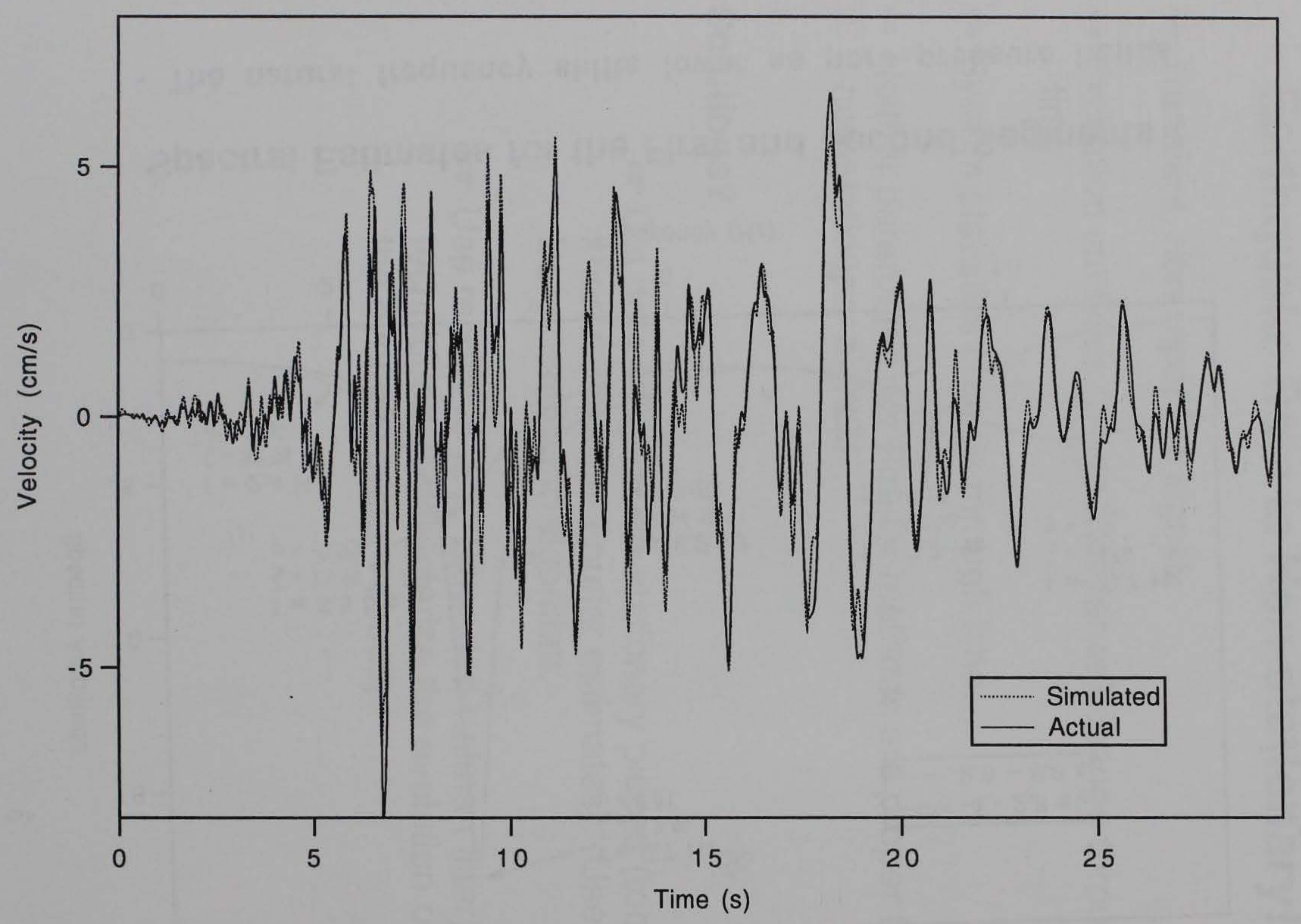

Simulated Elmore Ranch velocity and the actual.

- Filter derived from Superstition Hills data. 


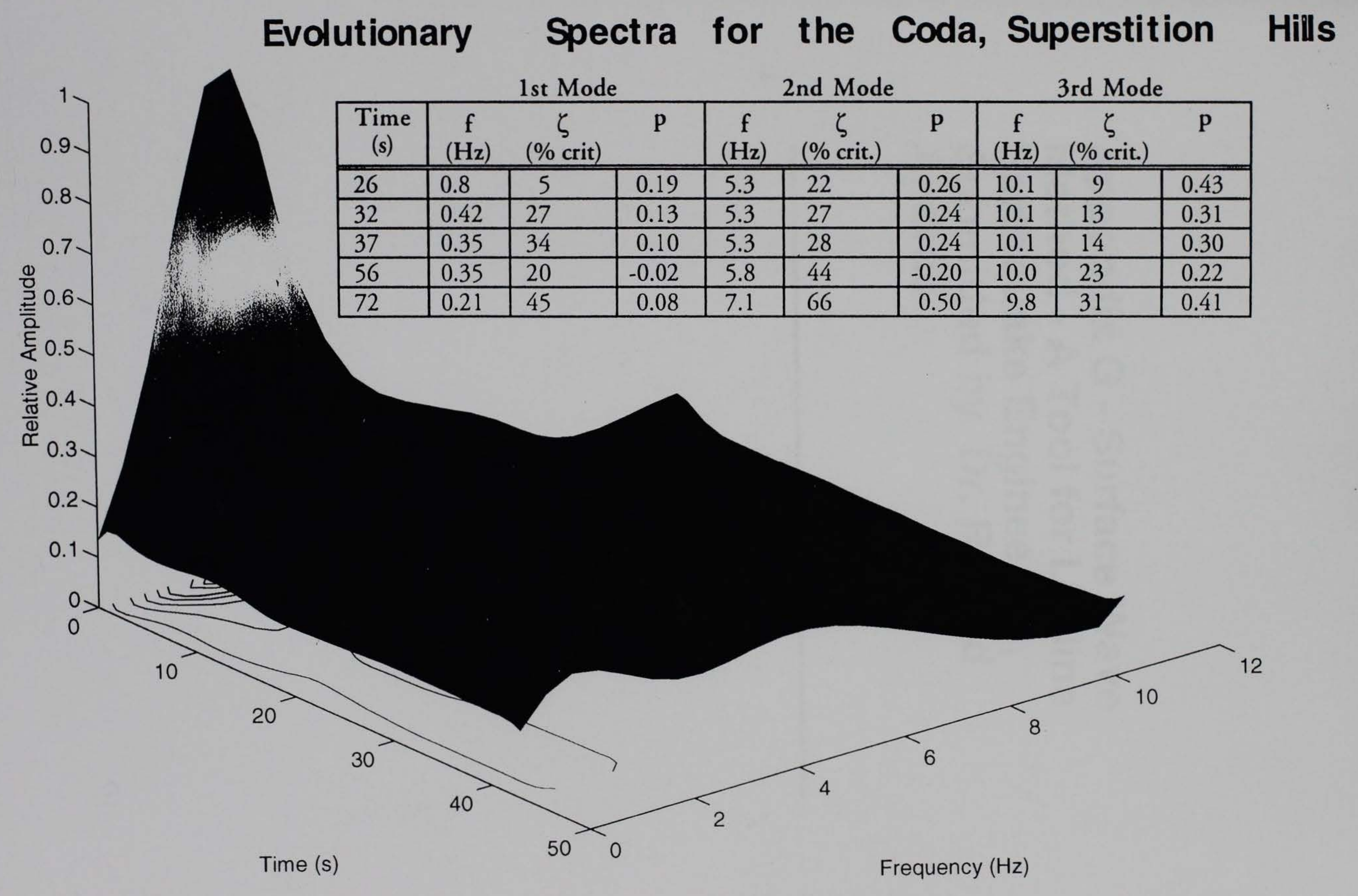




\section{Appendix G - Surface Wave Method - A Tool for Lifeline Earthquake Engineering, Submitted by Dr. Ronald Andrus}




\title{
Surface Wave Method - A Tool for
}

Lifeline Earthquake Engineering

\author{
by
}

Ronald D. Andrus

Structures Division Building and Fire Research Laboratory

National Institute of Standards and Technology Gaithersburg, MD 20899 


\section{Introduction}

Liquefaction of granular soils is one of the major causes of lifeline damage in past earthquakes. Screening techniques based on geology, hydrology, and soil conditions can identify areas along the lifeline corridor requiring more rigorous analyses. These areas can extend for several kilometers, however. The Spectral-Analysis-of-Surface-Waves (SASW) method has great potential for rapid determination of the layer thickness and small-strain shear wave velocity, $\mathrm{V}_{\mathrm{s}}$, of soil deposits. The SASW method is nonintrusive and nondestructive. It is based on the principal that surface seismic waves of high frequency propagate only in near-surface layers, and surface waves of low frequency propagate at different velocities if stiffness varies with depth. Thus, different portions of the soil profile can be tested by using surface waves over a wide range of frequencies. The general SASW test configuration of source, receivers, and recording equipment is shown in Figure 1. Liquefaction potential and $\mathrm{V}_{\mathrm{S}}$ of granular soils are influenced by many of the same factors (e.g., density, confinement, and geologic age). This paper evaluates the ability of the SASW method to delineate liquefiable soil using data from two sites (Goddard Ranch and Larter Ranch) where liquefaction occurred during the 1983 Borah Peak, Idaho, earthquake and the liquefaction assessment procedure by Stokoe et al. (1988b). Application of the SASW method to lifelines is discussed. 


\section{Examples of Correlating $\mathrm{V}_{\mathrm{s}}$ and Liquefaction Potential}

Stokoe et al. (1988b) applied the strain approach by Dobry and his colleagues (1982) in an analytical study of the liquefaction potential of sandy soils in the Imperial Valley, California, to generate liquefaction assessment charts based on measured $\mathrm{V}_{\mathrm{S}}$ and maximum horizontal ground surface acceleration, $\mathrm{a}_{\max }$, for stiff soil (nonliquefiable clay) site at the candidate-site location. The chart for 15 cycles of shaking, the approximate number of cycles of the Borah Peak earthquake $\left(M_{S}=7.3\right)$, at a level ground site with the liquefiable sand in the upper $12 \mathrm{~m}$ is shown in Figure 2. Liquefaction is predicted to occur right of the shaded region. Within the shaded region, liquefaction would likely occur depending on thickness and depth of the liquefiable layer. Liquefaction is predicted not to occur left of the shaded region because the sand is too dense to liquefy. During the Borah Peak earthquake, the estimated values of $\mathrm{a}_{\max }$ at Goddard Ranch and Larter Ranch are $0.34 \mathrm{~g}$ and $0.6 \mathrm{~g}$, respectively. As illustrated in Figure 2, liquefaction is predicted at Goddard Ranch in sediments with $\mathrm{V}_{\mathrm{s}} \leq 110 \mathrm{~m} / \mathrm{s}$ and liquefaction likely in sediments with $110 \mathrm{~m} / \mathrm{s}<\mathrm{V}_{\mathrm{s}} s$ $170 \mathrm{~m} / \mathrm{s}$. Similarly, liquefaction is predicted at Larter Ranch in sediments with $\mathrm{V}_{\mathrm{s}} \leq 165 \mathrm{~m} / \mathrm{s}$ and liquefaction likely in sediments with $165 \mathrm{~m} / \mathrm{s}<\mathrm{V}_{\mathrm{s}} \leq$ $280 \mathrm{~m} / \mathrm{s}$.

At Goddard Ranch, liquefaction occurred as evidenced by numerous sand boils in the low-lying areas (Youd et al. 1985). Shown in Figure 3 are sediment layers beneath the gravelly side bar investigated. Also shown are several penetration profiles determined by the Cone Penetration Test (CPT) and the Standard Penetration Test (SPT). Liquefaction most likely occurred in 
Unit C1, a loose (low penetration resistance) sandy gravel with less than a few percent fines (Andrus 1994). Unit C2, a loose to medium dense sandy gravel, using penetration resistance is predicted to be liquefiable to marginally liquefiable material. Unit B is a sandy silt with clay, and is nonliquefiable. Three $\mathrm{V}_{\mathrm{S}}$ profiles determined by the SASW method are shown in Figure 4. Profile SA-85 was determined in an earlier study (Stokoe et al. 1988a) before penetration and borehole data were available. Profiles SA-2 and SA-3 were determined assuming the layering observed in penetration profiles. Regions of liquefaction and liquefaction likely have been shaded in Figure 4 using values of $\mathrm{V}_{\mathrm{S}}$, and are in good agreement with the assessment based on penetration resistance. Soil type is needed to correctly assess no liquefaction for Unit B.

At Larter Ranch, liquefaction caused the steeply sloping (about 34 percent) distal end of an alluvial fan to move laterally downslope about $1 \mathrm{~m}$. Numerous sand boils erupted along the toe of the fan. Shown in Figure 5 are sediment layers beneath the slide. Also shown are penetration profiles determined by the CPT, SPT, and Becker Penetration Test (BPT). Liquefaction most likely occurred in Unit C, a loose to medium dense sandy gravel with about 7 percent fines (Andrus 1994). Beneath the zone of fissures, Unit C is predicted marginally liquefiable since it exhibits higher penetration resistances. Three $\mathrm{V}_{\mathrm{S}}$ profiles determined by the SASW method are shown in Figure 6. These profiles were determined in an earlier study (Stokoe et al. 1988a) before penetration and borehole data were available. Regions of liquefaction and liquefaction likely have been shaded in Figure 6 using $V_{S}$, and are in good agreement with the assessment based on penetration resistance.

These findings illustrate the ability of the SASW method to delineate liquefiable materials in granular deposits. Soil type is needed to correctly predict behavior in deposits with layers of soft clay. 


\section{Application of the SASW Method to Lifelines}

The SASW method consists of making field measurements of surface wave velocity at various frequencies and determining $V_{S}$ profile through a process called inversion. Several different source and receiver spacings are required to measure over a wide range of frequencies due to attenuation and near-field effects. Although it is preferable to conduct the test with receivers spaced about a common midpoint (see Figure 1) and source locations reversed, the common source test configuration shown in Figure $7 \mathrm{a}$ is more appropriate for automation. Hiltunen and Woods (1990) demonstrated that the sacrifice in quality is small with the common source configuration. Recent work by Nazarian et al. (1994) has shown that inversion can be automated, reducing the time for testing and determining $\mathrm{V}_{S}$ profile at a site like the one shown in Figure $7 \mathrm{a}$ to about $30 \mathrm{~min}$. For alignments of moderate length, test arrays could be effectively overlapped, as shown in Figure $7 \mathrm{~b}$, to produce profiles at discrete intervals of $4 x$. Since most liquefiable soil layers lie within the upper $10 \mathrm{~m}$ of soil deposits, a typical value of $\mathrm{x}$ would be $2 \mathrm{~m}$ for profiling depths of $0.5 \mathrm{~m}$ to $10 \mathrm{~m}$. Moving source-receiver systems are under development at the University of Texas at Austin (Stokoe 1995) for generating continuous $\mathrm{V}_{\mathrm{S}}$ profiles rather than profiles at discrete locations. Based on these developments, the SASW method appears well suited for rapid profiling along lifelines. 


\section{Acknowledgments}

Much of the information presented in this paper was compiled while the author was a graduate student at the University of Texas at Austin. The guidance of Professor Stokoe is gratefully acknowledge. Field work was funded by the U.S. Geological Survey. Special thanks to James Bay, Mark Fuhriman, Dong-Soo Kim, Byungsik Lee, Young-Jin Mok, Glenn Rix, Ignacio SanchezSalinero, and Jiun-Chyuan Sheu who assisted with the field investigations over the three different times investigations were performed. The review comments of Riley Chung and Professor Stokoe are sincerely appreciated. 


\section{References}

Andrus, R. D., Stokoe, K. H., II, Bay, J. A., and Youd, T. L. (1992). "In situ $\mathrm{V}_{\mathrm{s}}$ of gravelly soils which liquefied," Proceedings, Tenth World Conference on Earthquake Engineering, held in Madrid, Spain, on 19-24 July, Balkema, Rotterdam, pp. 1447-1452.

Andrus, R. D. (1994). "In situ characterization of gravelly soils that liquefied in the 1983 Borah Peak earthquake," Ph.D. Dissertation, University of Texas at Austin, $533 \mathrm{p}$.

Dobry, R., Ladd, R. S., Yokel, F. Y., Chung, R. M., and Powell, D. (1982). "Prediction of pore water pressure buildup and liquefaction of sands during earthquakes by the cyclic strain method," NBS Building Science Series 138 , U.S. Department of Commerce, National Bureau of Standards, $152 \mathrm{p}$.

Hiltunen, D. R., and Woods, R. D. (1990). "Influence of source and receiver geometry on the testing of pavements by the surface wave method," a paper prepared for presentation at the 69th Annual Meeting of the Transportation Research Board, Washington, D.C., January.

Nazarian, S., Yuan, D., and Baker, M. R. (1994). "Automation of spectral analysis of surface waves method," Dynamic Geotechnical Testing 11, ASTM STP 1213, R. J. Ebelhar, V. P. Dmevich and B. L. Kutter, Eds., American Society for Testing and Materials, Philadelphia, pp. 88-100.

Stokoe, K. H., II. (1995). Personal communication. 
Stokoe, K. H., II, Andrus, R. D., Rix, G. J., Sanchez-Salinero, I., Sheu, J. C., and Mok, Y. J. (1988a). "Field investigation of gravelly soils which did and did not liquefy during the 1983 Borah Peak, Idaho, earthquake," Geotechnical Engineering Center Report GR 87-1, University of Texas at Austin, 206 p.

Stokoe, K. H., II, Roesset, J. M., Bierschwale, J. G., and Aouad, M. (1988b). "Liquefaction potential of sands from shear wave velocity," Proceedings, Ninth World Conference on Earthquake Engineering, held in Tokyo, Japan, Vol. III, pp. 213-218.

Youd, T. L., Harp, E. L., Keefer, D. K., and Wilson, R. C. (1985). "The Borah Peak, Idaho earthquake of October 28, 1983-liquefaction," Earthquake Spectra, Vol. 2, No. 4, pp. 71-89. 


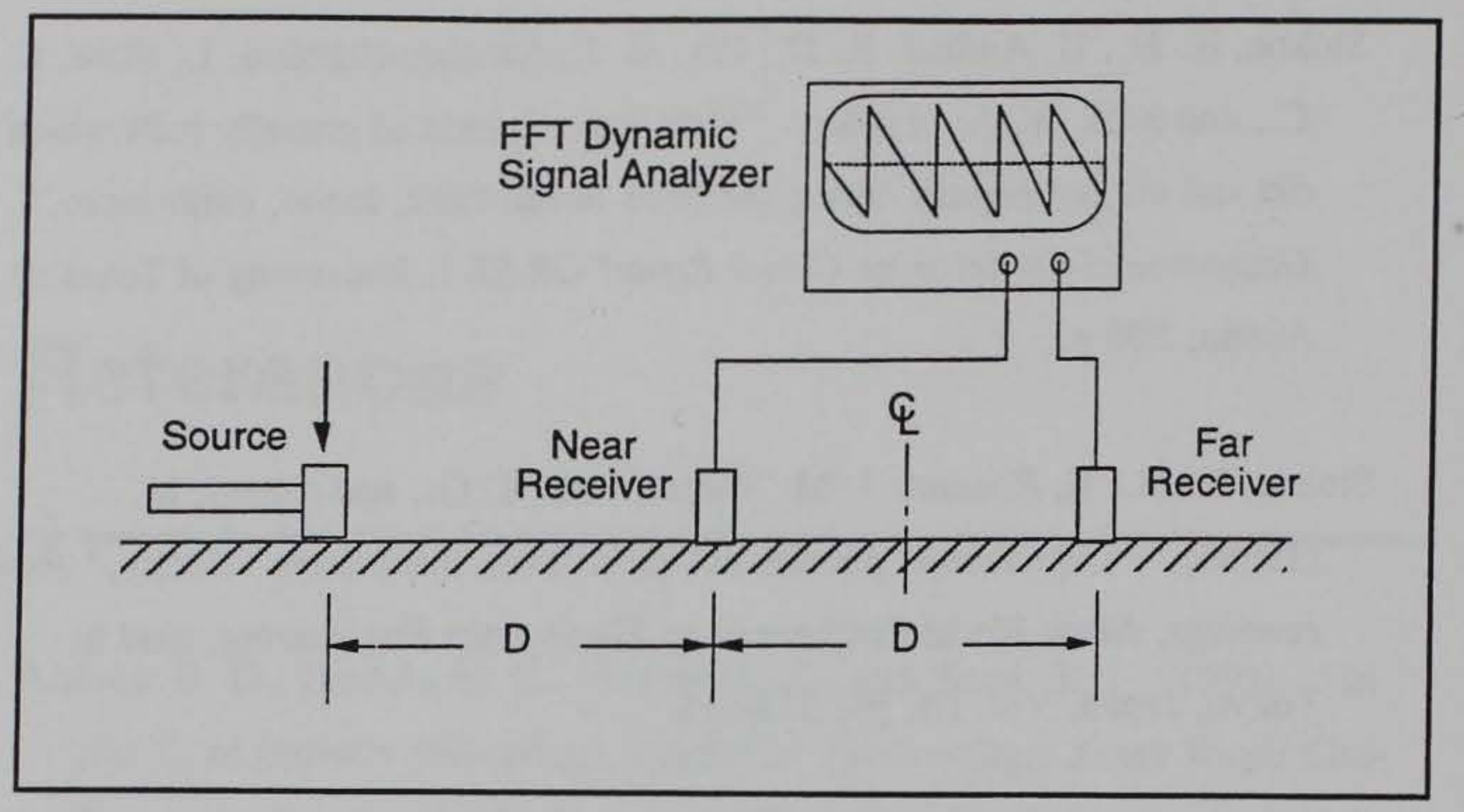

Figure 1. General SASW field testing configuration 


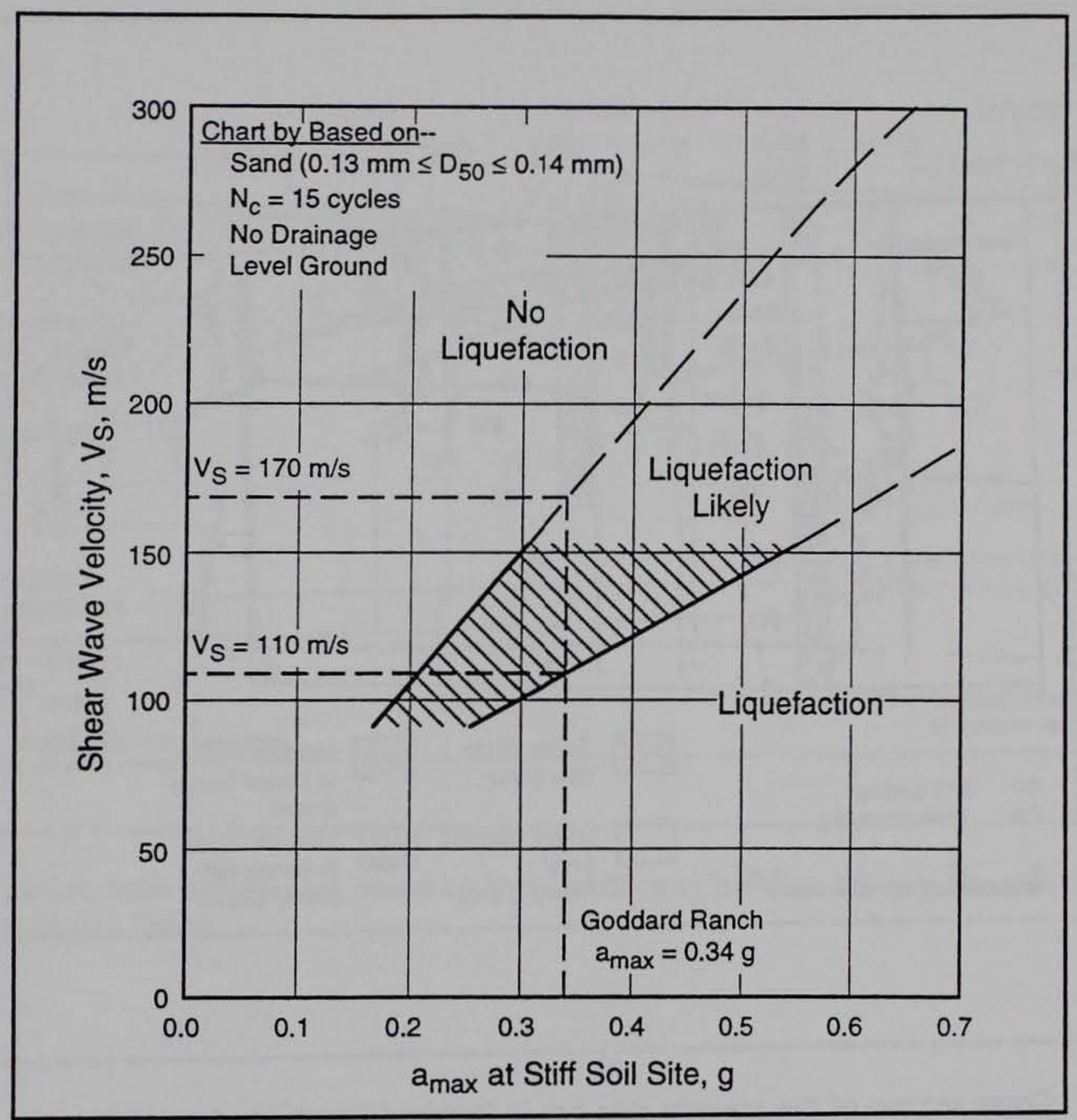

Figure 2. Liquefaction assessment chart by Stokoe et al. (1998b) based on $\mathrm{V}_{\mathrm{S}}$ and peak horizontal ground surface acceleration, $\mathrm{a}_{\max }$ at stiff soil site for 15 cycles of shaking, $N_{c}$ 


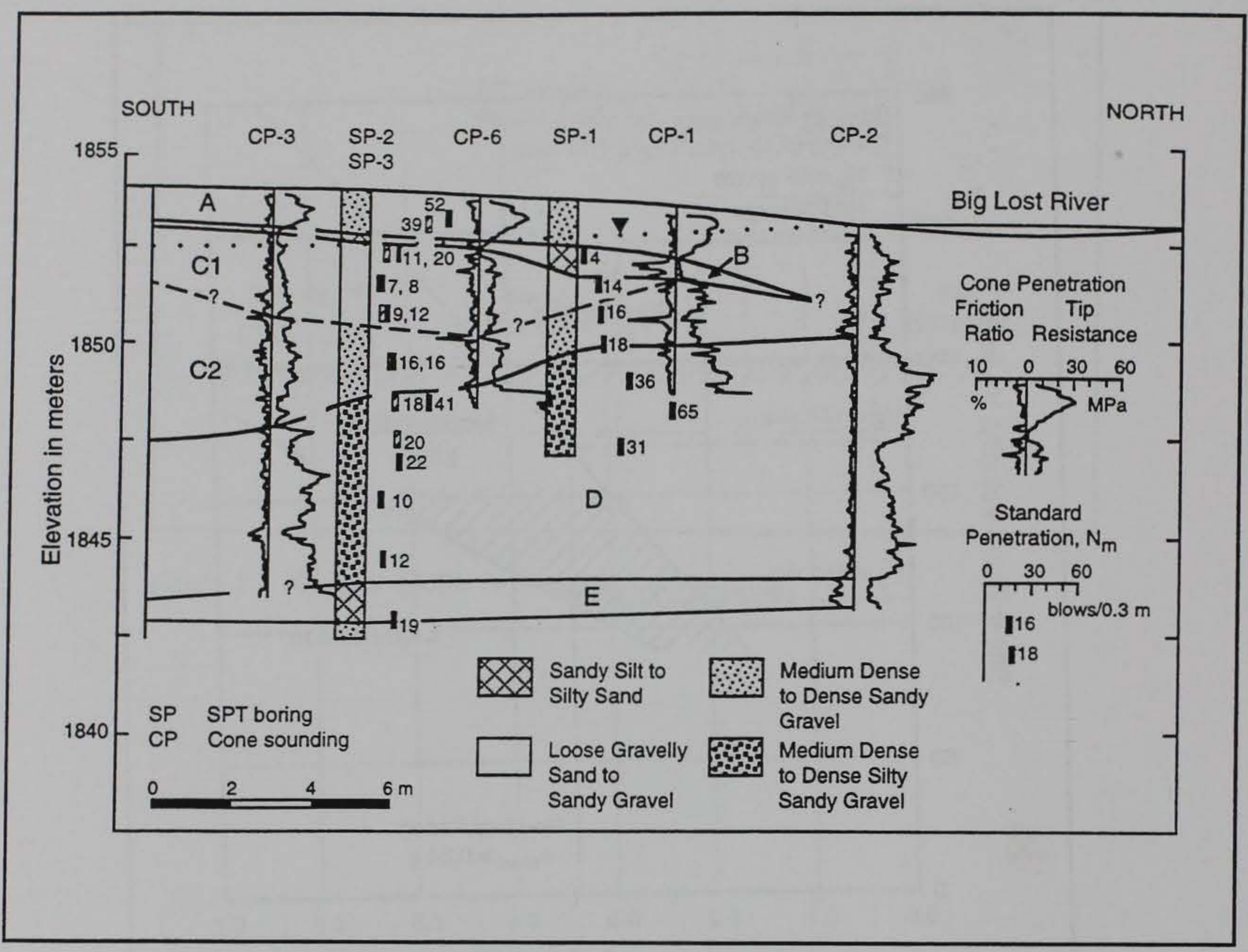

Figure 3. Cross section of the gravelly side bar at Goddard Ranch (Andrus 1994) 


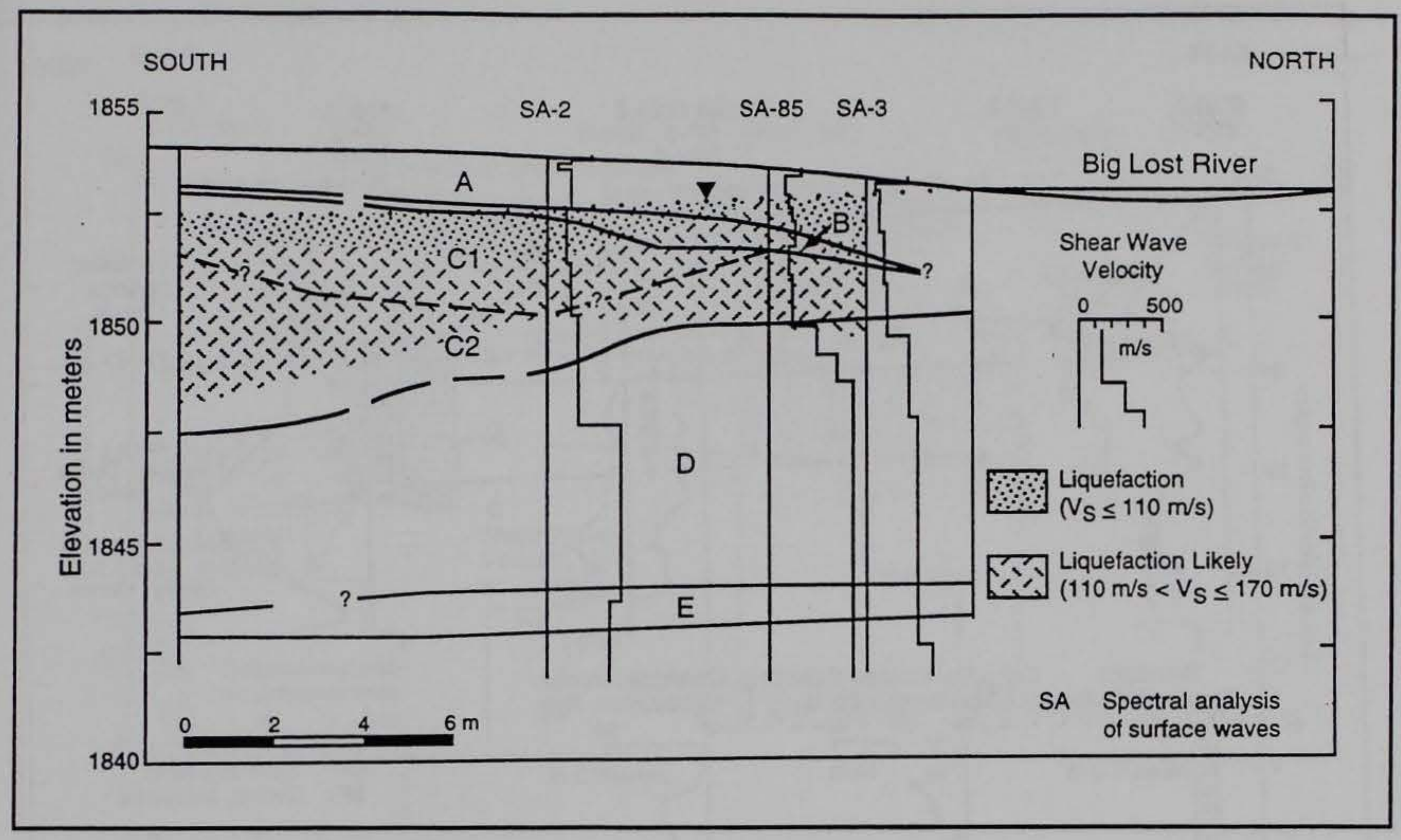

Figure 4. Liquefaction assessment based on $\mathrm{V}_{\mathrm{S}}$ of sediments beneath the gravelly side bar at Goddard Ranch 


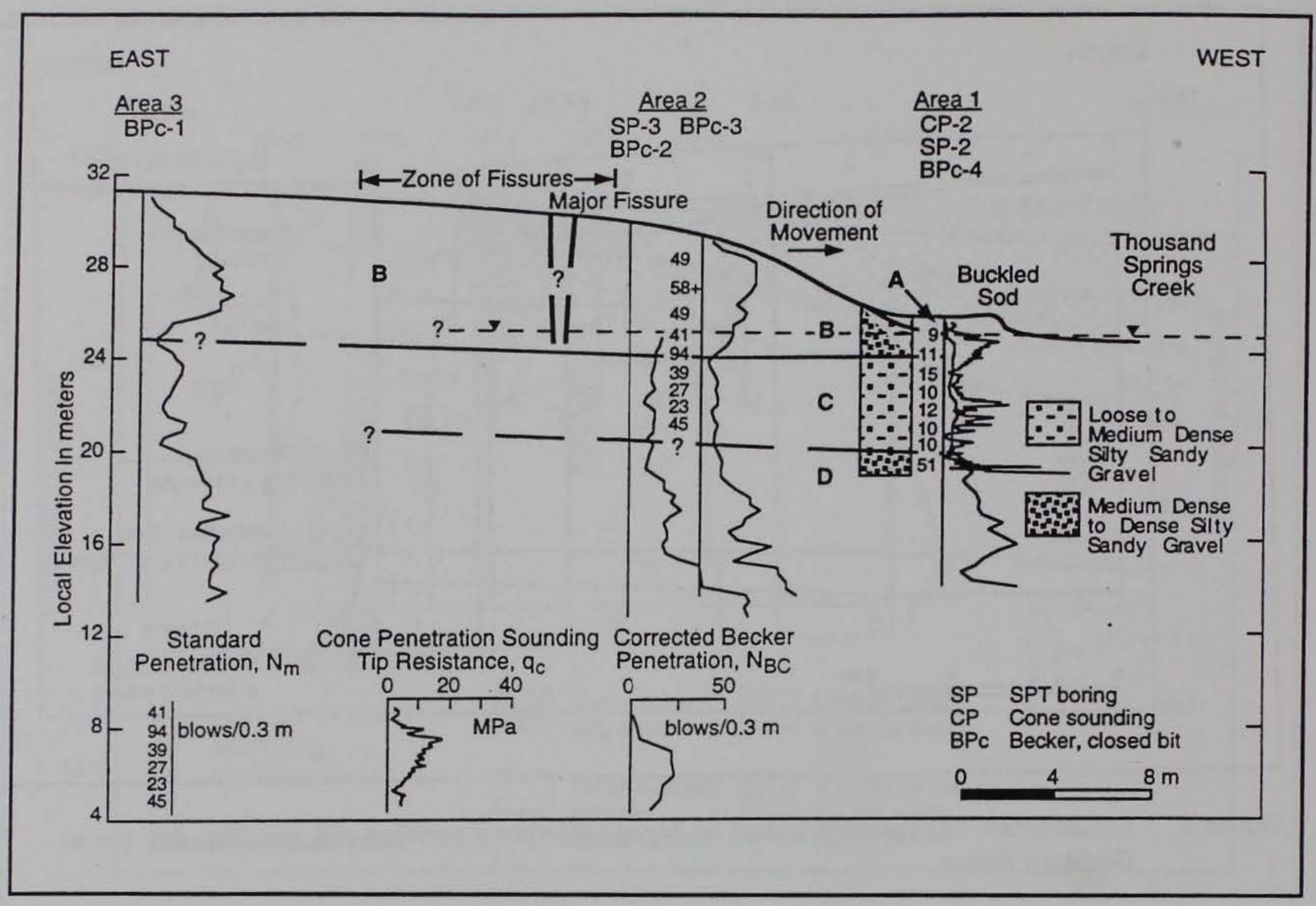

Figure 5. Cross section of the lateral spread at Larter Ranch (Andrus 1994) 


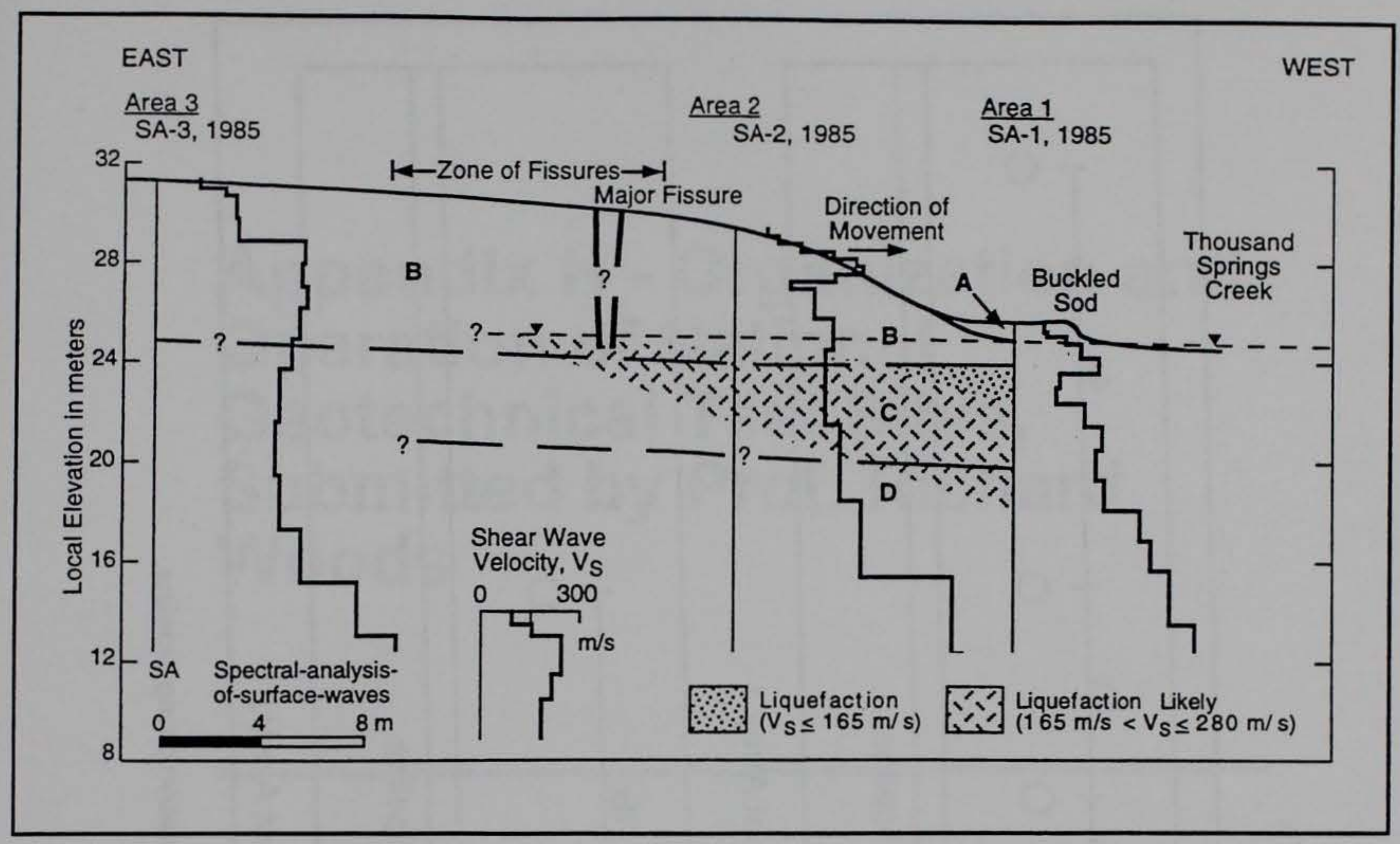

Figure 6. Liquefaction assessment based on $\mathrm{V}_{\mathrm{S}}$ of sediments beneath the lateral spread at Larter Ranch 


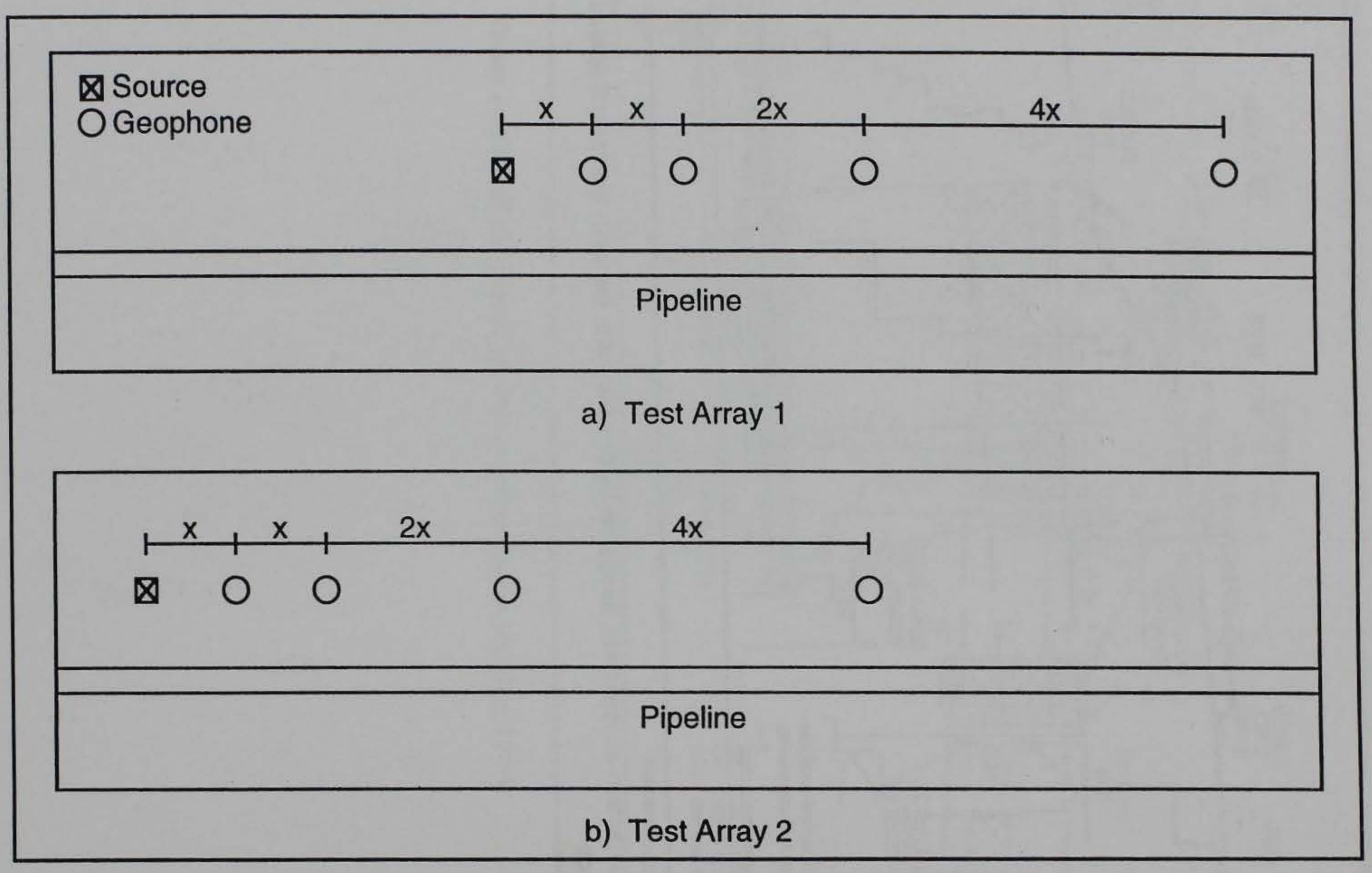

Figure 7. SASW testing with common source configuration along pipeline 


\section{Appendix $\mathrm{H}$ - Organization and Operation of National Geotechnical Test Sites, Submitted by Prof. Richard Woods}




\section{National Geotechnical Experimentation Sites}

by

Richard D. Woods

Department of Civil Engineering

University of Michigan

Ann Arbor MI 


\section{Introduction}

Anyone who has experienced the process of site preparation and site characterization for field experiments shares the knowledge that a substantial amount of time and resources must be devoted to this phase of research. Often the cost of site characterization exceeds the cost of other operations associated with the research. For these reasons alone there is strong justification for development of experimentation sites which have been thoroughly characterized and which have been made user-friendly with on-site utilities including; electricity, water, telephone and field office facility. It is also widely recognized that full-scale model or prototype tests are extremely valuable in geotechnical engineering, and well characterized, large field sites are necessary for these tests.

For the above reasons, it became evident during the past decade to many geotechnical engineers that easy access by investigators to well-characterized field sites would be of enormous benefit. These sites could be used to evaluate new techniques of soil improvement, new methods of soil testing, new methods of foundation and earth structure construction, as well as other activities not yet defined. Completely documented field sites with a public database containing results of previous tests and site characteristics could also provide appropriate locations for the installation of permanent instrumentation for measurement of site response during earthquakes and other mass movement phenomena where appropriate.

Sites like this exist in other countries like Canada, Brazil, United Kingdom, France, Italy, Japan, and Norway, and have promoted cooperation and exchange of information between public agencies, universities and private 
sector groups across international boundaries in a cost effective way. Three examples are presented to give a flavor of the sites in other countries.

In Canada, two experimentation sites have been created to study the characterization of sand for dynamic and static liquefaction potential. One site is at the Syncrude location in Alberta and the other is in the Frazier River Delta in British Columbia. Specifically, experiments are underway to: (1) evaluate high quality undisturbed sampling techniques like ground freezing, (2) calibrate and verify in-situ tests particularly with respect to influence of high overburden pressures, and (3) study triggering mechanisms for both static and dynamic liquefaction. These experiments are expected to lead to the improvement of design of embankments including tailings dams subject to earthquake shaking.

In Brazil, an experimentation site was created in 1989 at the Polytechnical School of the University of Sao Paulo in cooperation with the Brazilian Association of Foundation Engineering. Experimentation at the sites has been principally on load capacity of drilled pier foundations. Extensive laboratory tests have also been performed on samples recovered from this site. In addition to the pile load tests, experiments have been conducted on full-scale high pressure injected columns, diaphragm walls and high capacity earth anchors.

In the United Kingdom there are several sites but we highlight only the one at Bothkennar, Scotland. This is a deep soft clay site and was created as a result of a need recognized in the UK in the 1980's by the Science and Engineering Research Council (SERC) for a well characterized field site. The Council purchased the Bothkennar Site in 1987 to ensure permanent access and promote broad usage of the site. Experimentation progressed at an impressive rate at Bothkennar and a seminar was organized by SERC in 1992 to re-focus and plan future developments at the site. In addition a special issue of GEOTECHNIQUE in June 1992 detailed the geologic and geotechnical characteristics of the site. Some of the work reported in that article and performed since then includes: full-scale negative skin friction tests on a pile group, installation of and load tests on flight augered piles, full scale embankment studies, and geosynthetic reinforcement of several types of earth structures. Most work has 
been performed by UK researchers, but international collaboration has also played an important role. 


\section{Creation of National Geotechnical Experimentation Sites}

Two workshops in 1988 and 1991 identified and quantified the need for a system of multiple-user geotechnical experimentation sites in the United States (Benoit and de Alba 1988 and 1991). As a result of these workshops, the National Geotechnical Experimentation Sites (NGES) system was established in November 1992 and now is in full operation.

The first workshop, “Designated Sites for Geotechnical Experimentation in the United States," (Benoit and de Alba 1988) was held in September 1988 at the University of New Hampshire to explore the need for and potential interest in Geotechnical Experimentation Sites. Conclusions generated by this workshop included the following:

a. There is a strong need for a network of designated geotechnical experimentation sites.

b. There are numerous individually operated sites which are not coordinated.

c. The USA lags behind many other countries in developing multi-user sites.

d. A system of sites could increase cooperation among geotechnical researchers and lead to more cost-effective use of research funds. 
$e$. Sites are necessary to quickly and thoroughly evaluate emerging technology.

f. Sites could be used to enhance engineering education.

An initial list of sites was created by Benoit and de Alba and with it the interest in an identified site system grew. From this list it was determined that a sub-set of candidate sites for a nationwide system could be selected and to accomplish this a second workshop, "Selection and Management of National Geotechnical Experimentation Sites," (Benoit and de Alba 1991) was sponsored by NSF and FHWA in October 1991 in Orlando, FL.

The National Geotechnical Experimentation Sites system (NGES system) grew out of the 1991 Orlando Workshop. The workshop established the organizational framework for the system and recommended a set of sites to be designated for improvement. It also set into motion the preparation of a funding proposal to NSF and FHWA which would support the framework organization, initiate improvements at some selected sites, and establish a system database.

The resulting system consists of five sites which receive funding for site improvements, database creation and up-dating, and site management; and 35 sites which are included in the system and are described in the NGES Cata$\log$ (Benoit and de Alba 1993) but which currently receive no funding.

The NGES sites are overseen by a self-sustaining Management Board of eight members who direct the activities of the System Manager, currently, R. D. Woods (University of Michigan). The principal investigators for the NSF/FHWA NGES Umbrella Project are Professors J. Benoit and P. A. de Alba of the University of New Hampshire. The data base management and site subcontract management is the responsibility of the principal investigators.

The current cataloged 40 NGES sites were selected from a group of about eighty sites, each of which was presented by a sponsor. Three categories of ${ }^{-}$ sites were established for the system: Level I sites receive the highest level of 
funding for site improvements and user-friendly activities, Level II sites receive some funding, and Level III sites are listed in the NGES Catalog and are included in the data base but do not receive any NSF/FHWA funds at this time.

Funding provided to the Level I and Level II NGES sites up to now has been used to establish and keep up-to-date the databases, bring the sites up to a high level of geotechnical characterization, to make the sites user-friendly, and to provide continuity of management with the attendant preservation of all valuable data. All NGES sites are available to any interested and qualified individual, entity, or university. NGES site users are expected to provide their own funding for specific experiments and/or tests through traditional funding sources or self funding in the case of industrial users. NGES Sites are not in a position to provide funding for research at their sites by outside users.

In the future, site managers may have to make a charge for site usage to provide for maintenance and further upgrading. This charge, if any, will be nominal for all users. Potential NGES site users are encouraged to contact the Site Manager early in the planning for any use of that site. 


\section{Description of Sites}

The Level I sites are: Treasure Island Naval Station, San Francisco, California and Texas A \& M University, Riverside Campus, College Station, TX. The Level II sites are: University of Houston, Houston, TX; Northwestern University, Evanston, IL; and University of Massachusetts, Amherst, MA. . The Level III sites are distributed over the entire continental United States.

The Treasure Island Site is located in San Francisco Bay and is currently operated by the U.S. Navy. Treasure Island an artificial island formed by hydraulic filling on a shoal adjacent to Yerba Buena Island. The hydraulic fill varies across the island, but it is basically loose, fine to medium, silty sand, with occasional clayey zones. Because of the likelihood of an earthquake in the near future and because of the loose character of the soils, Treasure Island is a unique site for studying the potential for liquefaction of soil due to earthquake excitation. Figure 1 shows a sand boil on Treasure Island, indicative of liquefaction of the loose sand under the surface, which occurred during the Loma Prieta Earthquake in 1989.

The Texas A\&M University Site actually consists of two sub-sites, one predominantly clay and one predominantly sand. Both are located on the Riverside Campus of TAMU in College Station, TX. These sites have been set aside for geotechnical testing since the late 1970's. Many organizations both within and outside of the TAMU system have used this site.

Previous studies at the clay sub-site started with tests on horizontally loaded drilled shafts by the Texas Highway Department in the late 1970's. Other shallow and deep foundation studies and in situ testing studies have been performed 
in the intervening years. Two substantial full-scale soil-structure experiments have been performed at the sand sub-site. The first consisted of a $70 \mathrm{~m}$ long by $5 \mathrm{~m}$ high embankment passing over a full-size, instrumented culvert. The second consisted of an instrumented, $60 \mathrm{~m}$ long and $8 \mathrm{~m}$ high tied-back, ground-anchored, wall, which can be seen in the background in Figure 2.

This sub-site was also the location of the SPREAD FOOTING PREDICTION SYMPOSIUM, 1994, sponsored by the Federal Highway Administration and held in conjunction with the ASCE Geotechnical Engineering Division Specialty Conference on the prediction of Vertical and Horizontal Deformations for Foundations and Embankments over sand. Considerable new characterization data were collected for this settlement event in the area shown in Figure 2. The Prediction Symposium is described in detail in Briaud and Gibbens (1994).

Previous characterization of the University of Houston Site, a deep, stiff clay site has been extensive and consists of many borings from which samples have been retrieved and subjected to various laboratory tests. This was the site of the full-scale, nine (9) pile group load test sponsored by FHWA and performed by Prof. Michael O'Neill.

Extensive site characterization of the Northwestern University Site, a lakefill, loose sand site, was performed in preparation for the 1989 ASCE Geotechnical Congress, at which a pile load prediction event was held. Four test piles and nine anchor piles were installed for this prediction event, Figure 3.

The deep, varved clay deposits at the University of Massachusetts Site generally are in the age range of $10,000-8,000$ years old. A considerable body of field and laboratory testing data from a variety of tools is available.

Thus, through NGES, a resource is available to geotechnical engineers for testing new ideas for earthworks construction, in situ measurement of earth parameters, and long term measurement of ground behavior. The NGES sites 
are available to all interested users, government, university and private sector. The well-characterized NGES sites should encourage a variety of field experiments which should lead to better, safer and more economical earth structures.

Any interested engineer is encouraged to obtain a floppy disk version of the NGES Database and/or a Catalog of NGES Sites from Prof. Jean Benoit, University of New Hampshire. 


\section{Acknowledgments}

The National Science Foundation, Directorate for Engineering; Geomechanical, Geotechnical and Geo-Environmental Systems Program, and the Federal Highway Administration, Office of Engineering and Highway Operations Research, Materials Division have provided the funds to initiate the National Geotechnical Experimentation Sites. The cooperation of these agencies in jointly funding these sites represents a welcome development in the funding of geotechnical research. This is greatly appreciated by the geotechnical community. 


\section{References}

Benoit, J., and de Alba, P. (Editors). (1988). Designated sites for geotechnical experimentation in the United States, proceedings of the workshop at the University of New Hampshire, September 1988, report to the National Science Foundation, $165 \mathrm{p}$.

Benoit, J. and de Alba, P. (Editors). (1991). Selection and management of the national geotechnical experimentation sites, proceedings of the workshop at Orlando, Florida, October 1991, Report to the National Science Foundation and the Federal Highway Administration, 103 p.

Benoit, J., and de Alba, P. (1993). Catalog of national geotechnical experimentation sites, Report to National Science Foundation and Federal Highway Administration, April, 247 p.

Briaud, J. L., and Gibbens, R. M. (1994) (Editors). Predicted and measured behavior of five spread footings on sand, Geotechnical Special Publication No. 41, ASCE, June, 255 pp. 


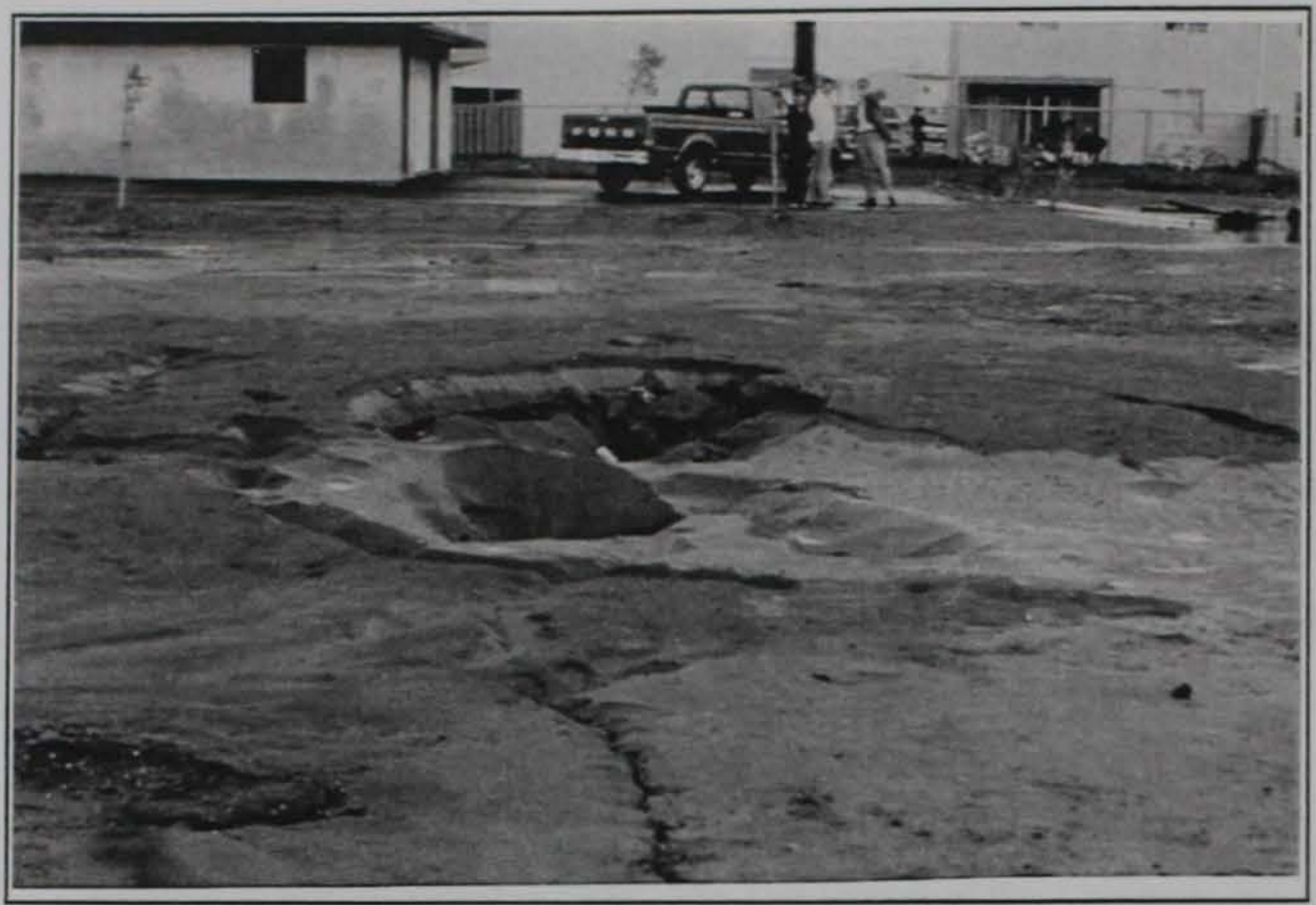

Figure 1. Liquefaction sand bolls on Treasure Island caused by Loma Prieta earthquake, 1989

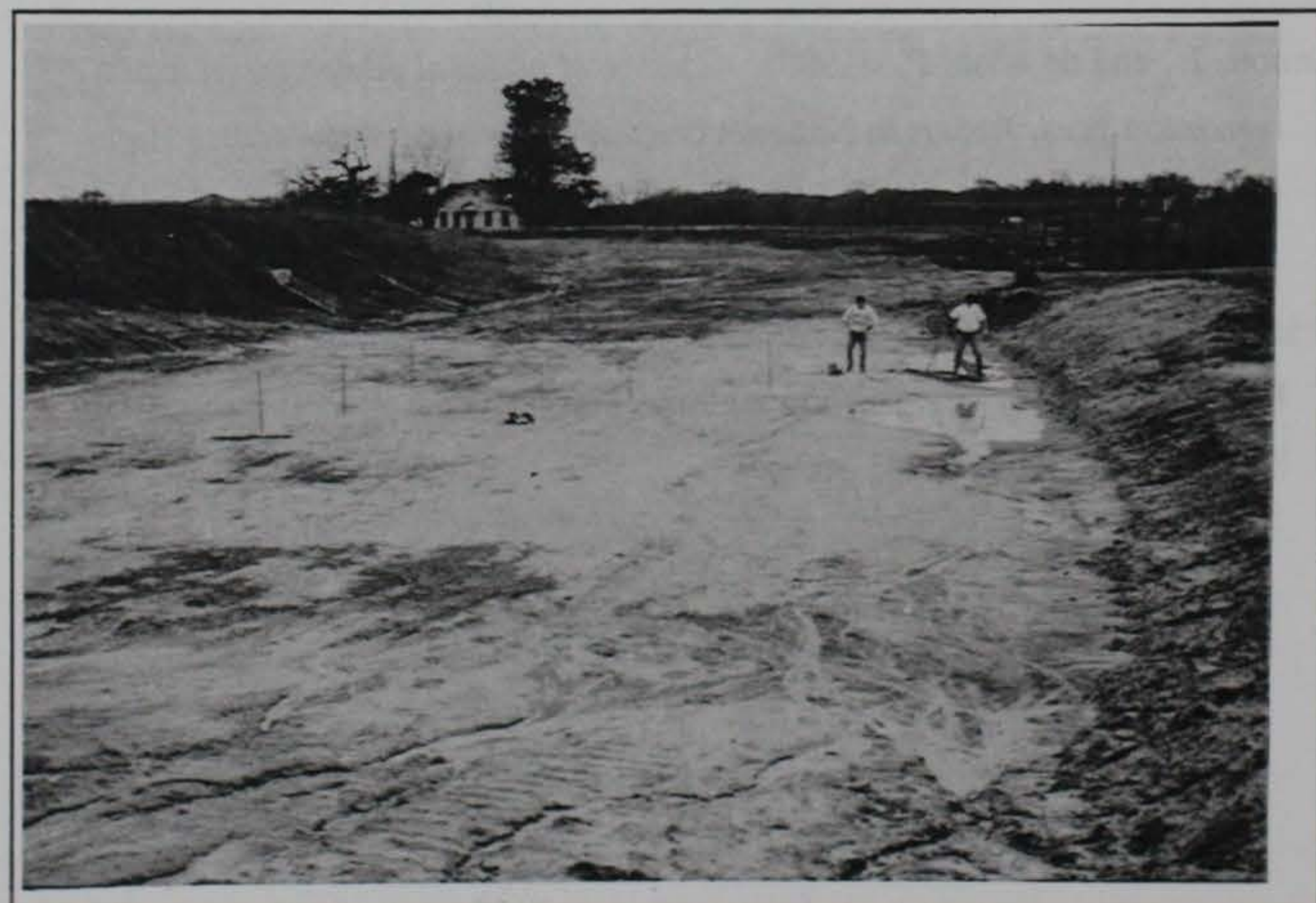

Figure 2. Site of spread footing settlement prediction experıment and full-scale tied-back wall at TAMU sand sub-site 


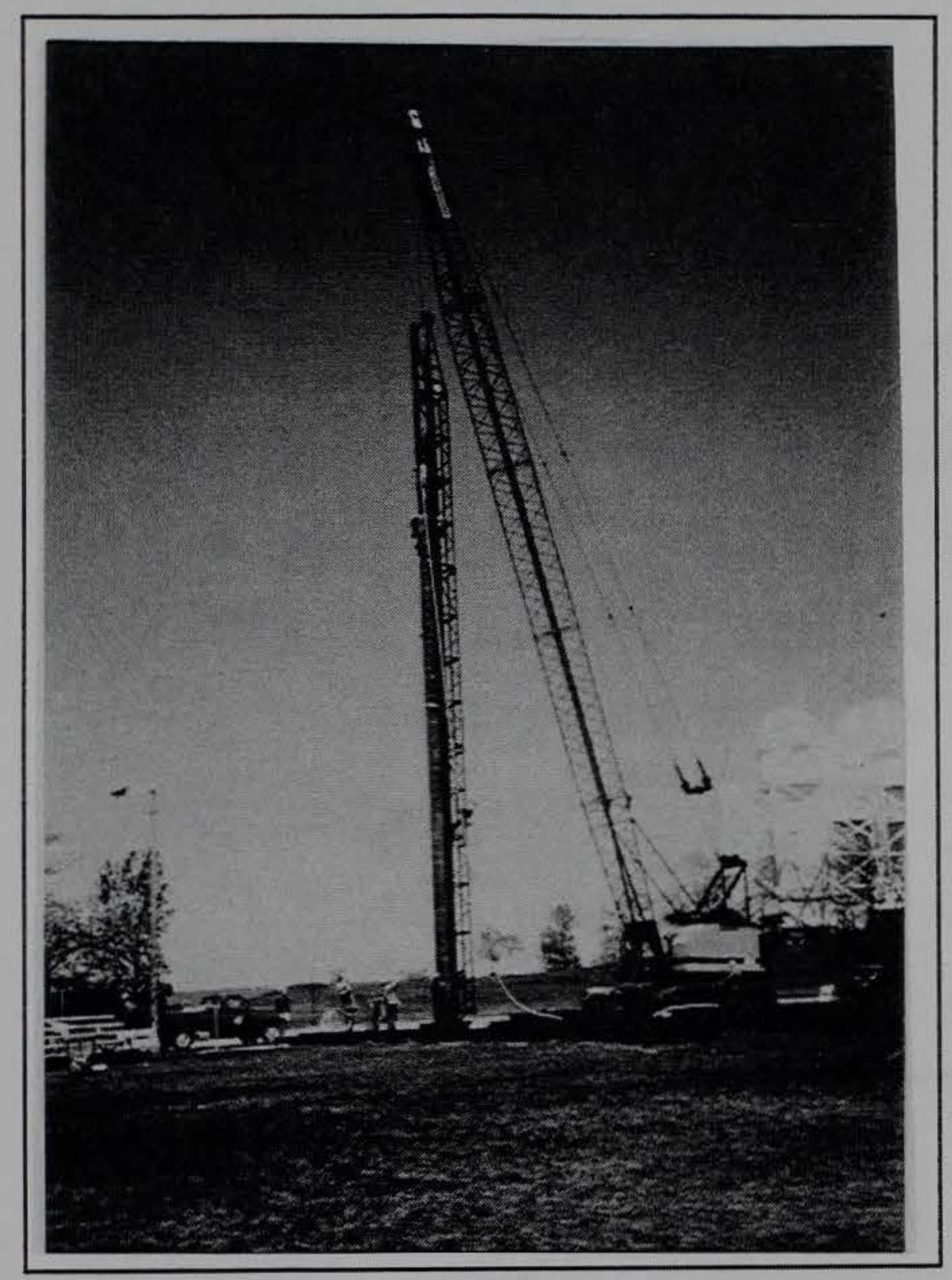

Figure 3. Site of driven pile capacity prediction experiment at Northwestern University site 
Appendix I - Lecture Slides: Effect of Stress State and Soil Fabric on Seismic Wave Velocities Measured by Borehole Methods - Prof. Ken Stokoe 


\section{Effects of Stress State and Soil Fabric on Body Wave Velocities Measured by Borehole Methods}

by

Kenneth H. Stokoe, II

Brunswick Abernathy Regents Professor

University of Texas at Austin

and

James N.-K. Lee

Research Civil Engineer

University of Texas at Austin 


\section{Simplified Sketch of Experimental Set-Up for Seismic Wave Testing in the LSTC}

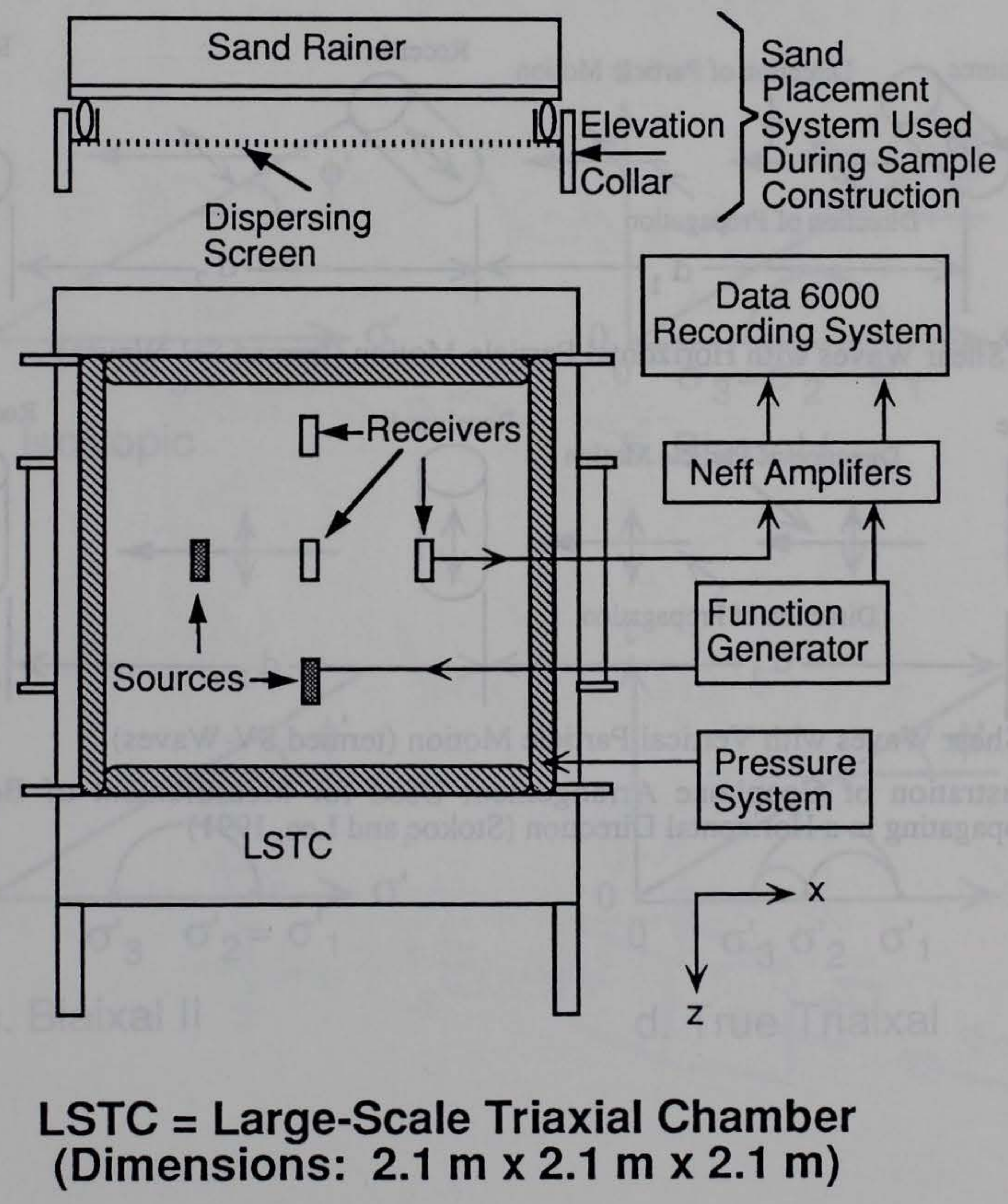




\section{Illustration of Stress State Used to Confine Dry Remolded Sand in the Large-Scale Triaxial Chamber (LSTC)}

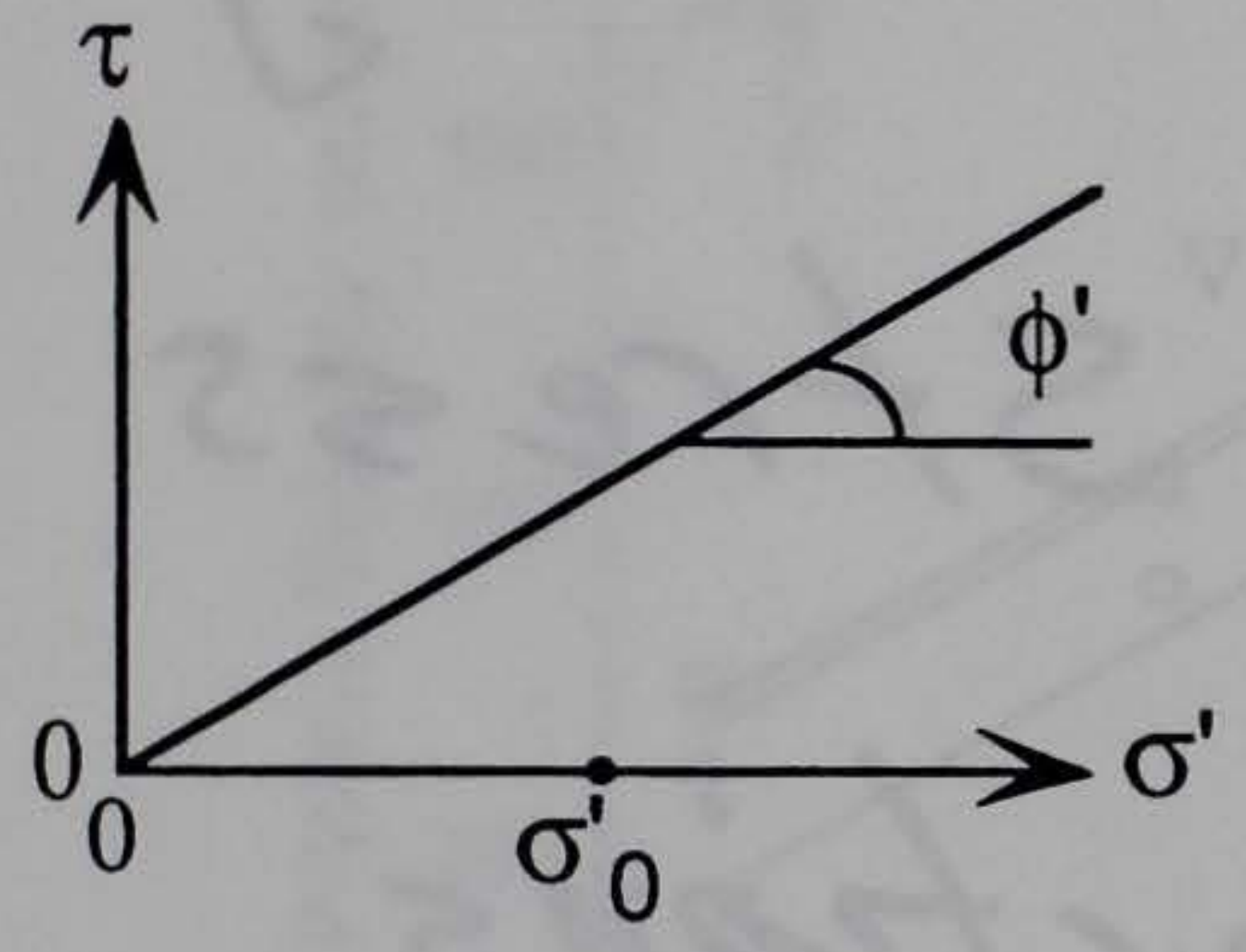

a. Isotropic

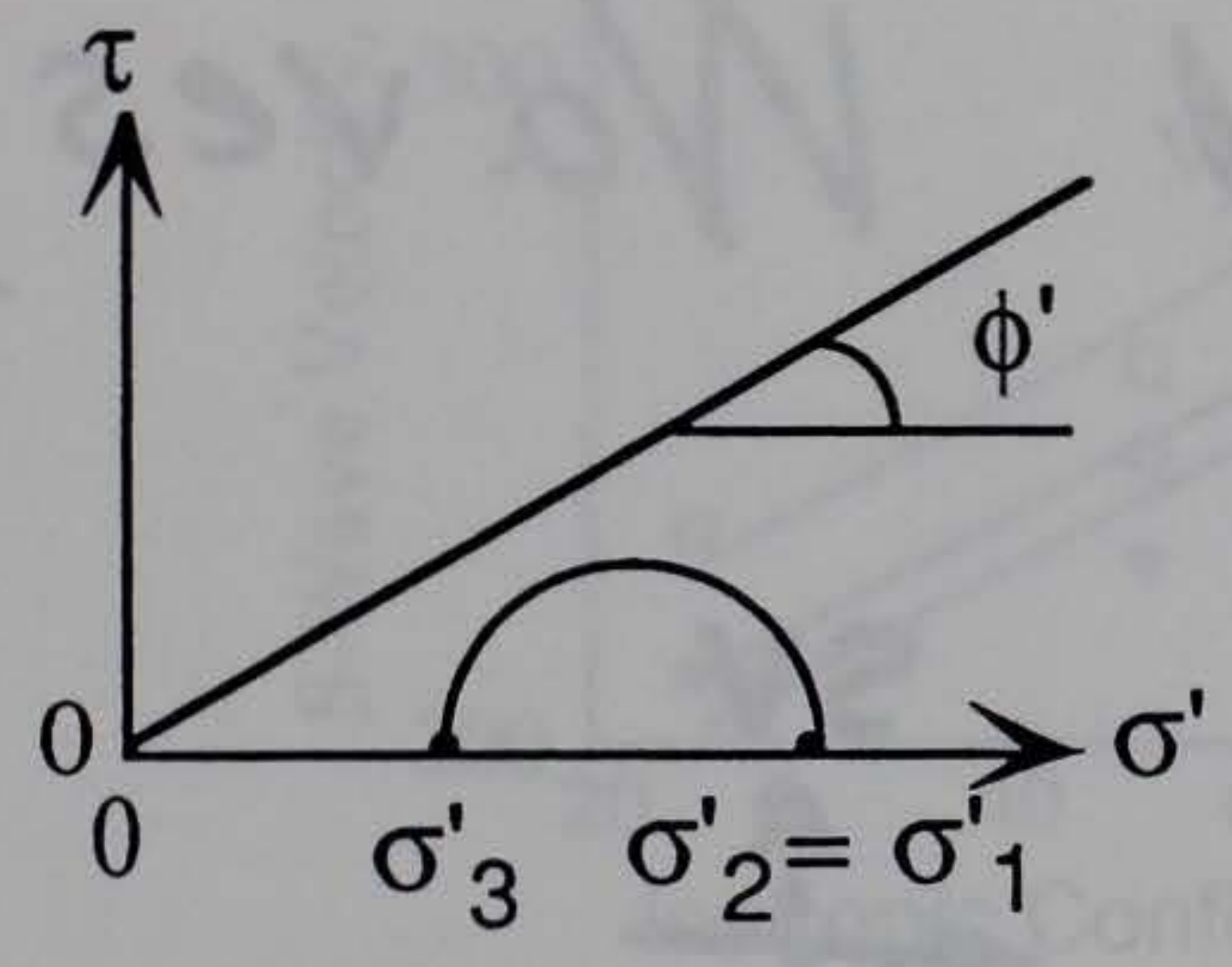

c. Biaixal II

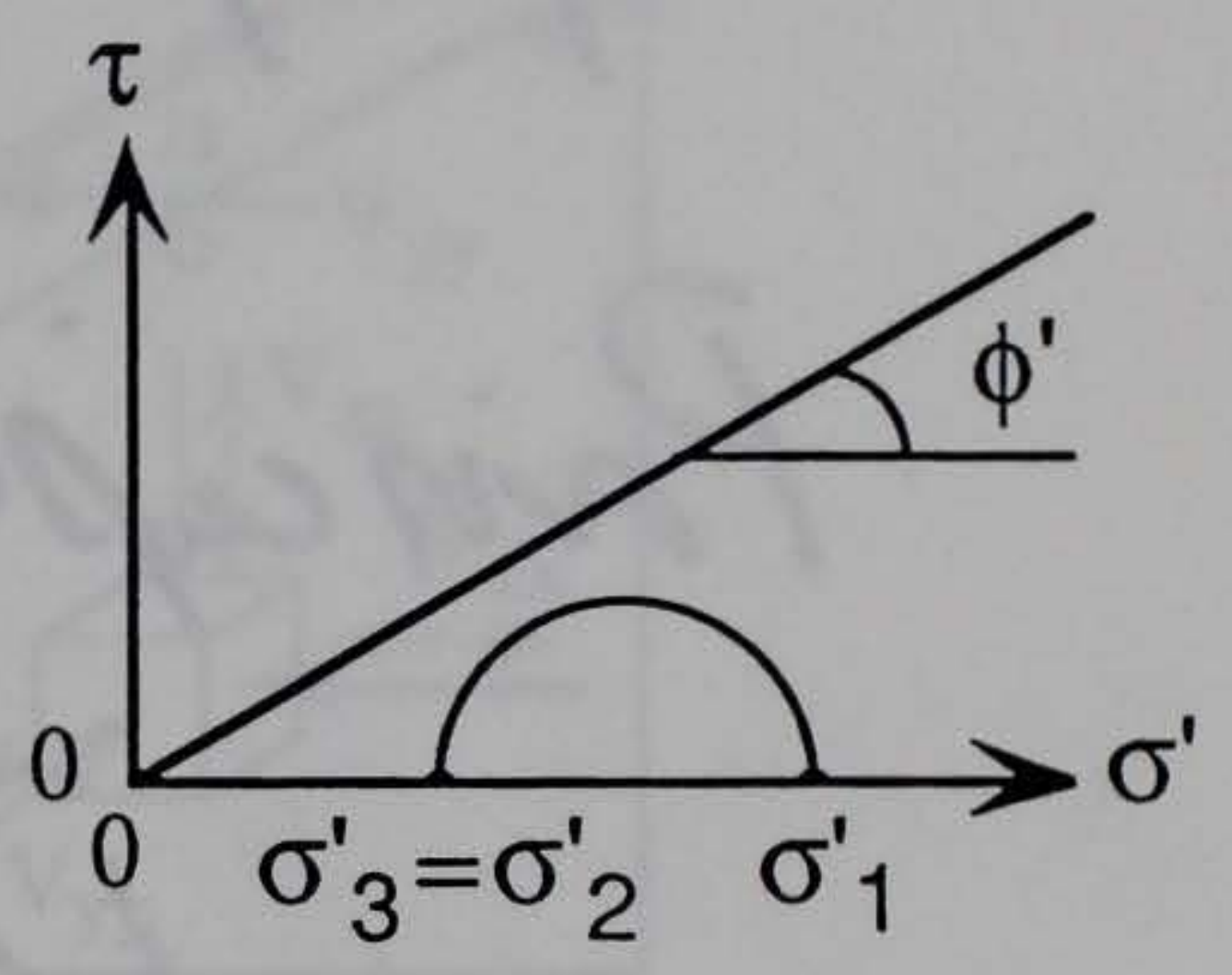

b. Biaxial I

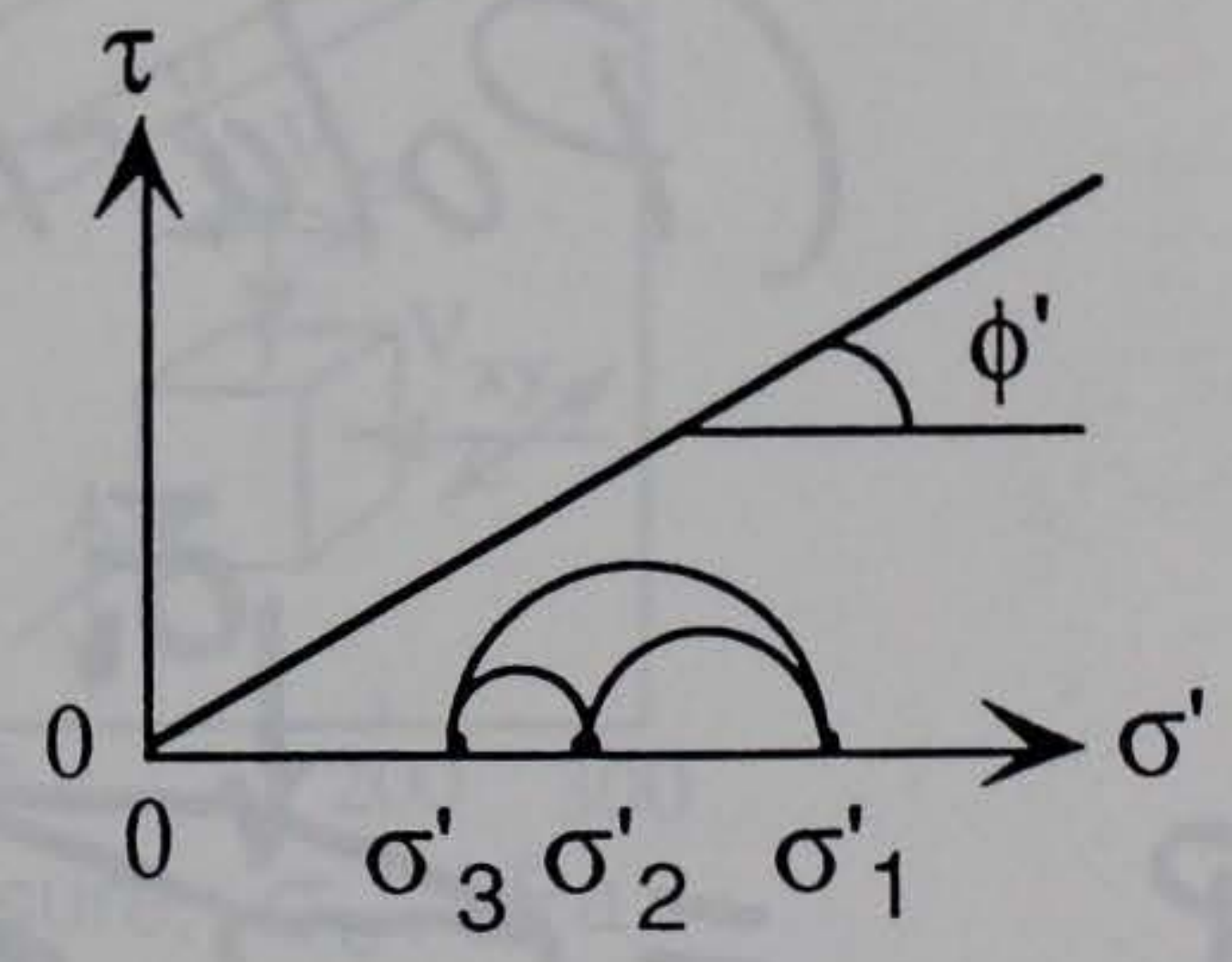

d. True Triaixal 
$P$ and 5 Waves Propagating Along Principal Stress Directions (Polarized Waves)

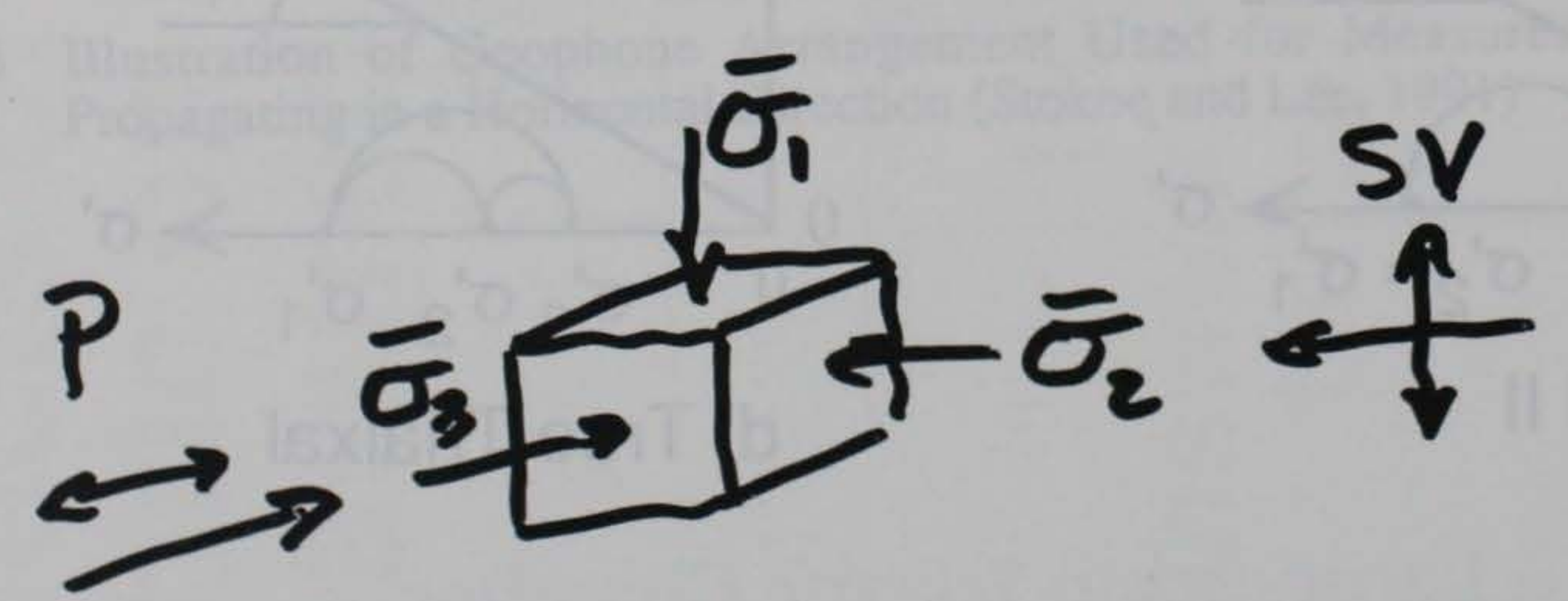




\section{Variation in P- and S-Wave Velocities along the Three Principle Stress Directions under Isotropic Loading}
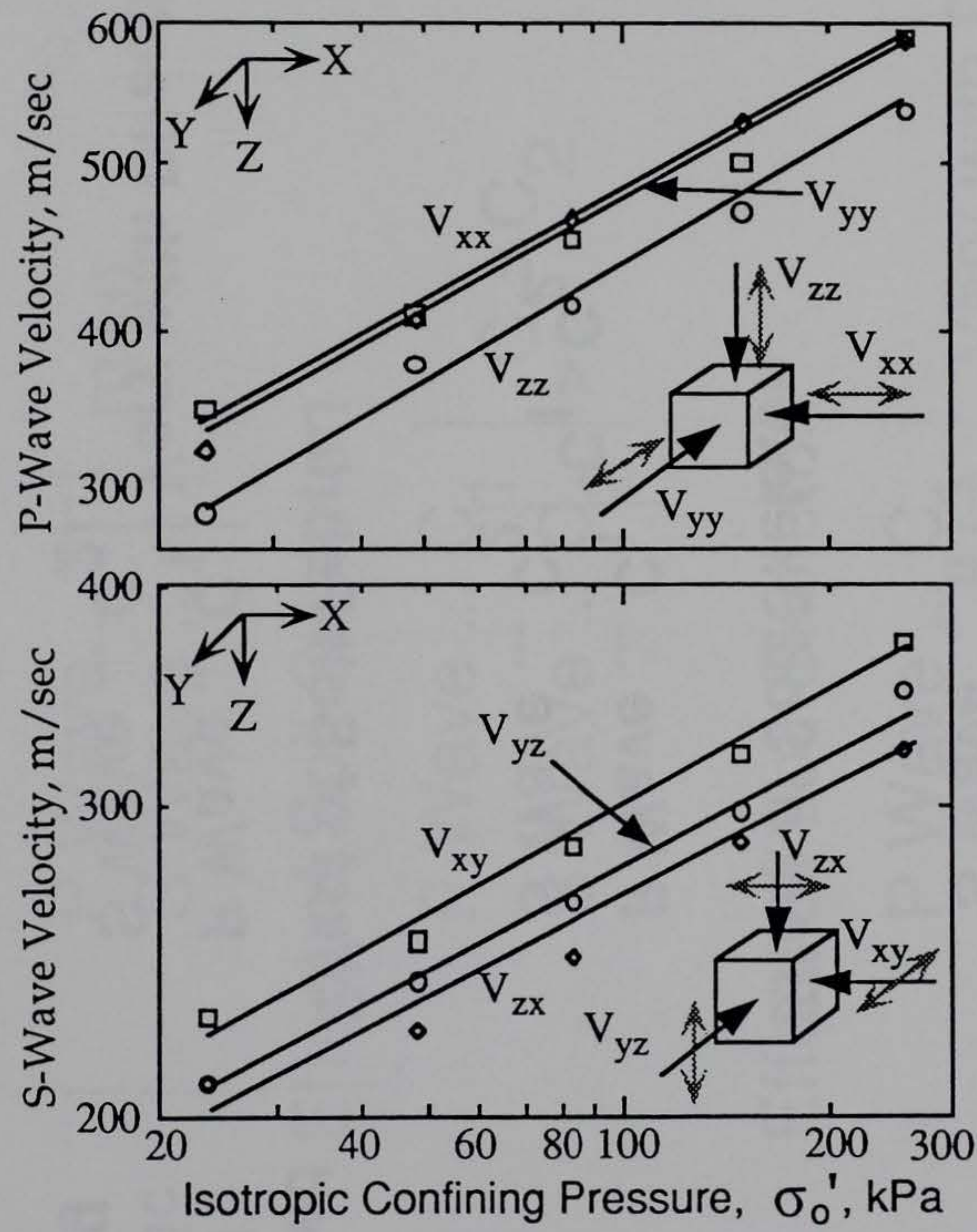
Effect of Stress State

$$
\left.\begin{array}{lll}
\text { P Wave ... } & m \\
\text { S Wave ... } & n
\end{array}\right\} m=n
$$

Effect of Soil Skeleton

$$
\left.\begin{array}{l}
P \text { Wave ... } C_{1} \\
\text { S Wave ... } C_{2}
\end{array}\right\} C_{1}>C_{2}
$$
Evaluated
Effect of Soil Fabric
Using
Isotropic
Loading
$\left.\begin{array}{l}P \text { Wave .... } C_{1} \\ \text { S Wave ... } C_{2}\end{array}\right\}$ Vary with Direction 


\section{Effect of Stress State}

$$
\left.\begin{array}{l}
\mathrm{P} \text { Wave ... } \mathrm{m} \\
\mathrm{S} \text { Wave ... }
\end{array}\right\} \mathrm{m}=\mathrm{n}
$$

Effect of Soil Skeleton

$$
\left.\begin{array}{l}
P \text { Wave } \ldots . . \\
\text { S Wave } . . . \\
C_{2}
\end{array}\right\} C_{1}>C_{2}
$$

Effect of Soil Skeleton

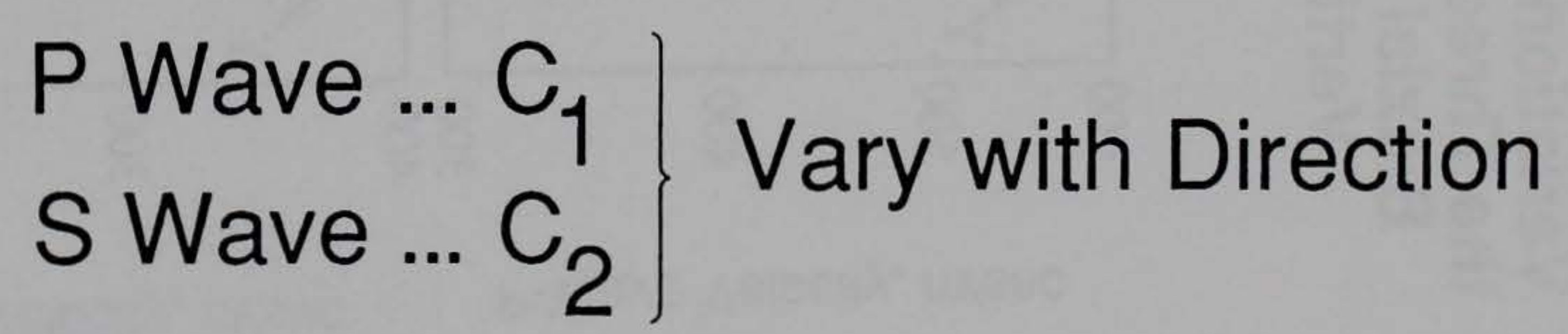


Variation in P-and S-Wave Velocities along the Three Principle Stress Directions under Biaxial Loading (Biaxial I) with Only the Vertical Effective Stress Changing

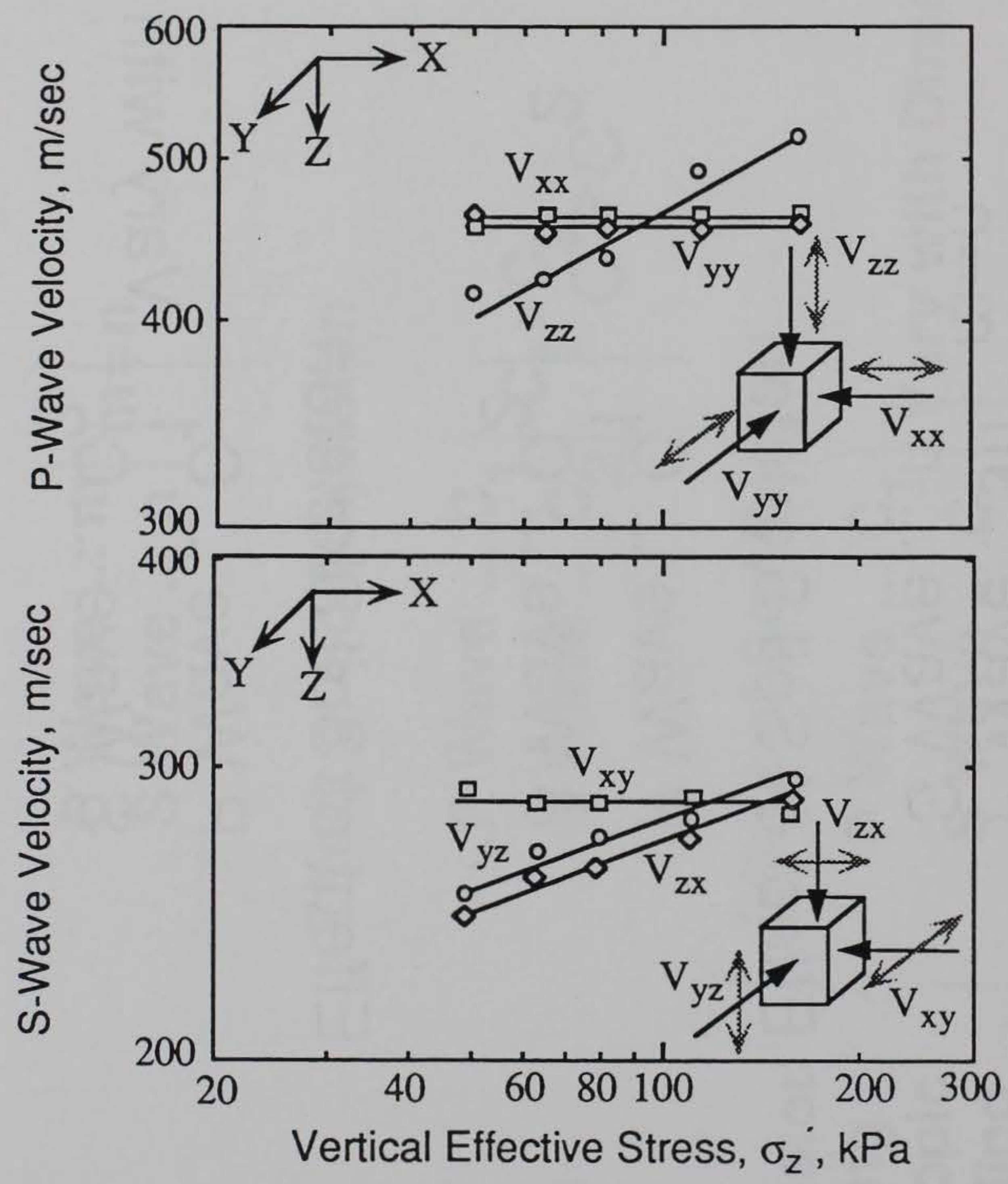




$$
\mathrm{V}_{\mathrm{p}}=\mathrm{C}_{1} \sigma_{\mathrm{a}}^{\prime} \mathrm{ma}
$$

where

$$
\begin{aligned}
\sigma_{\mathrm{a}}^{\prime}= & \text { effective principal stress in the direction of } \\
& \text { wave propagation, } \\
\mathrm{C}_{1}= & \text { material constant in compression and } \\
\mathrm{ma}= & \text { slope of the log } \mathrm{V}_{\mathrm{p}}-\log \sigma_{\mathrm{a}}^{\prime} \text { relationship. }
\end{aligned}
$$

Note: $\mathrm{ma}=\mathrm{m}$. 


$$
v_{s}=C_{2} \sigma_{a}^{\prime n a} \sigma_{b}^{\prime n b}
$$

where

$$
\begin{aligned}
\sigma_{\mathrm{a}}^{\prime}= & \text { effective principal stress in the direction of } \\
& \text { wave propagation, } \\
\sigma_{\mathrm{b}}^{\prime}= & \text { effective principal stress in the direction of } \\
& \text { particle motion, } \\
\mathrm{C}_{2}= & \text { material constant in shear, } \\
\mathrm{na}= & \text { slope of the } \log \mathrm{V}_{\mathrm{s}}-\log \sigma_{\mathrm{a}}^{\prime} \text { relationship and } \\
\mathrm{nb}= & \text { slope of the } \log \mathrm{V}_{\mathrm{s}}-\log \sigma_{\mathrm{b}}^{\prime} \text { relationship. }
\end{aligned}
$$

Note: $n a \cong n b \cong n / 2$. 


\section{Variation in P- and S-Wave Velocities along the Three Principle Stress Directions under Isotropic Loading}

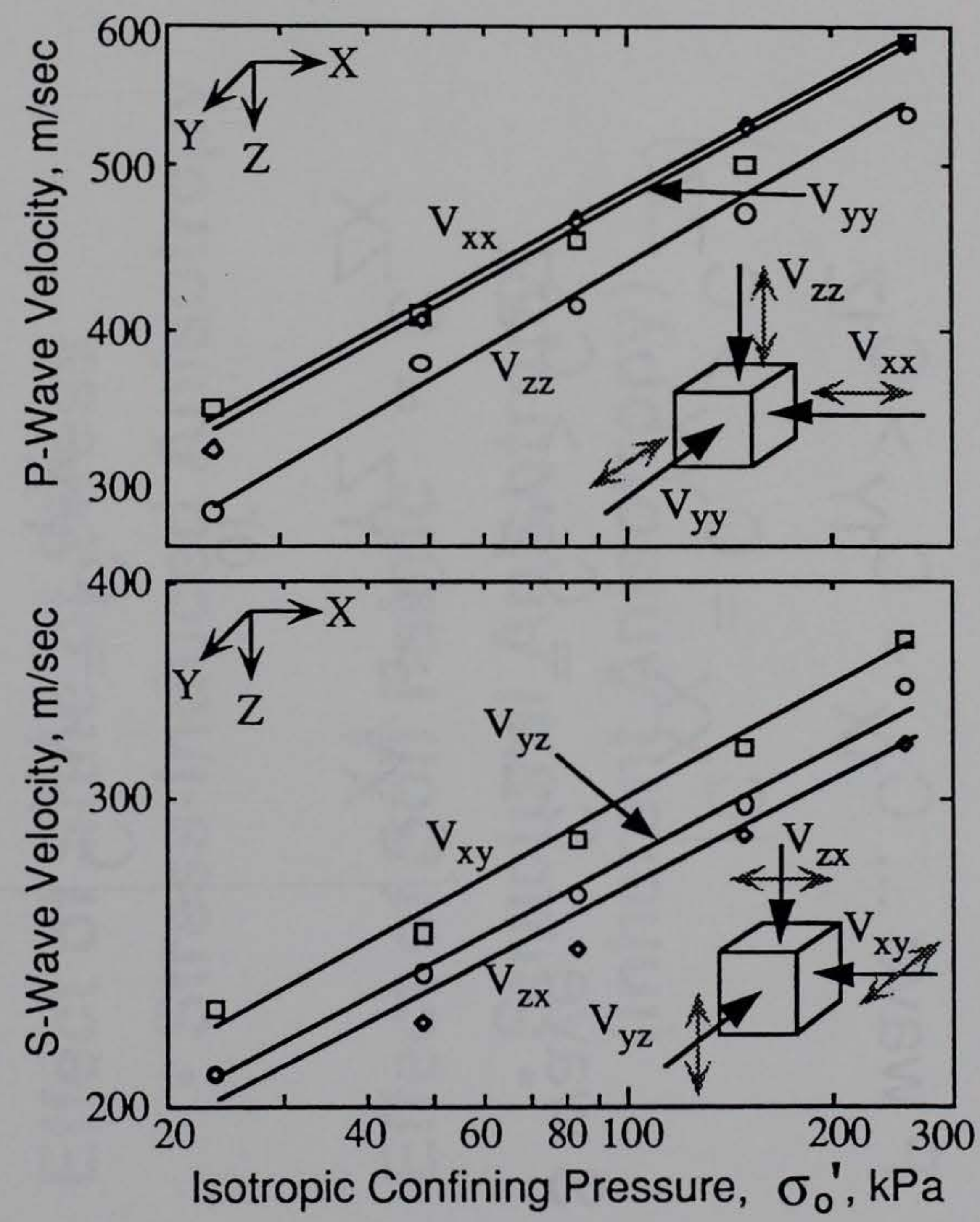




\section{Effect of Soil Fabric}

(Determined under Isotropic Loading)

P wave ... $C_{1 X}=C_{1 Y}>C_{1 Z}$

$$
\left(c_{X X}=C_{Y Y}>C_{Z Z}\right)
$$

S wave ... $C_{2 X}=C_{2 Y}>C_{2 Z}$

$$
\left(\begin{array}{c}
c_{X Y}>c_{Y Z}=c_{Z X} \\
\text { or } \\
c_{X Y}=c_{Y X} \\
c_{X Z}=c_{Y Z}=c_{Z X}=c_{Z Y}
\end{array}\right)
$$




\title{
Effect of State of Stress \\ - Stress-Induced Anisotropy
}

Effect of Soil Fabric

- Structural Anisotropy

\author{
(Inherent Anisotropy)
}


$P$ and 5 Waves Propagating At Oblique Angles to the Principal Stress Directions 


\section{Directions, Planes, and Stress States Associated with P-WaveVelocities Measurements}

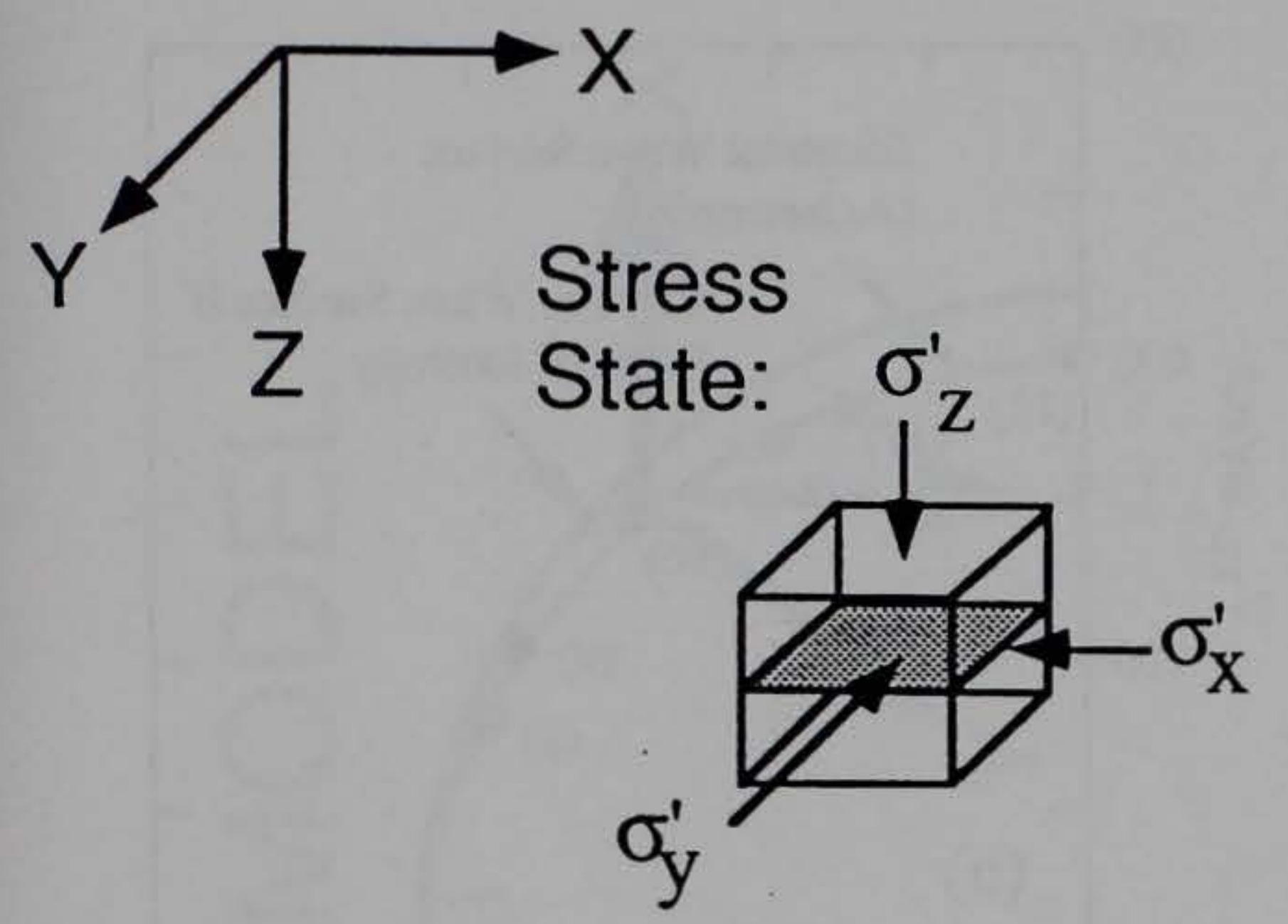

Measurement

Paths:

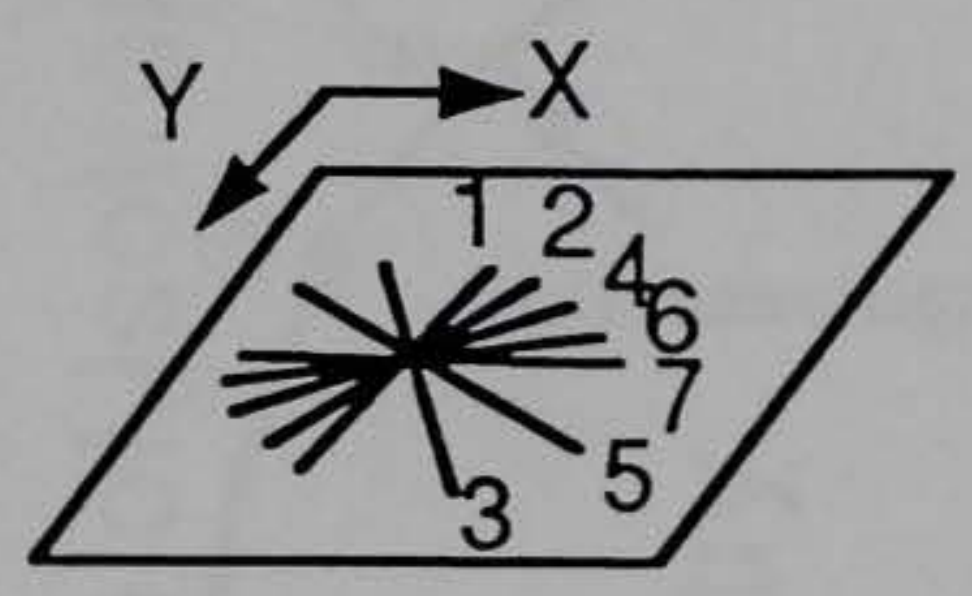

a. Measurements in the Horizontal Plane

Stress

State:

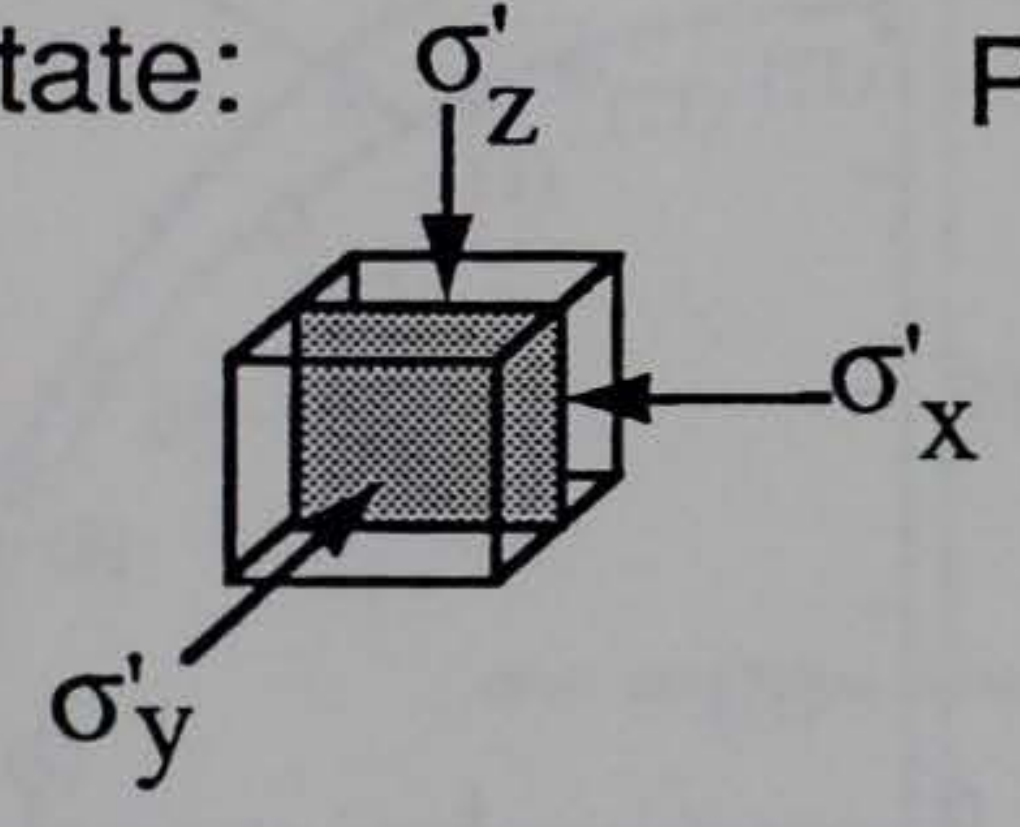

Measurement

Paths:

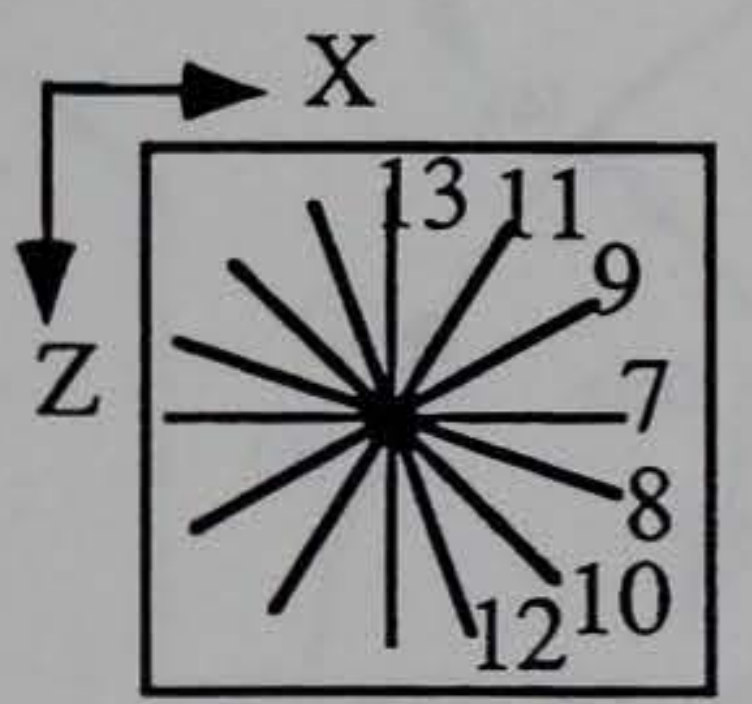

b. Measurements in the Vertical Plane

Figs. $a$ and $b$,Figs. $c$ and $d$ Figs. e and $f$

$$
\begin{array}{c|c|c}
\hline \sigma_{x}^{\prime}=83 \mathrm{kPa} & \sigma_{x}^{\prime}=83 \mathrm{kPa} & \sigma_{x}^{\prime}=48 \mathrm{kPa} \\
\sigma_{y}^{\prime}=83 \mathrm{kPa} & \sigma_{y}^{\prime}=83 \mathrm{kPa} & \sigma_{y}^{\prime}=48 \mathrm{kPa} \\
\sigma_{z}^{\prime}=83 \mathrm{kPa} & \sigma_{z}^{\prime}=48 \mathrm{kPa} & \sigma_{z}^{\prime}=83 \mathrm{kPa}
\end{array}
$$

c. Stress States Associated with Each Measurement 


\section{Variation in P-Wave Velocities with Propagation Direction for Measurements in the Horizontal and Vertical Planes under Isotropic and Biaxial Loadings}
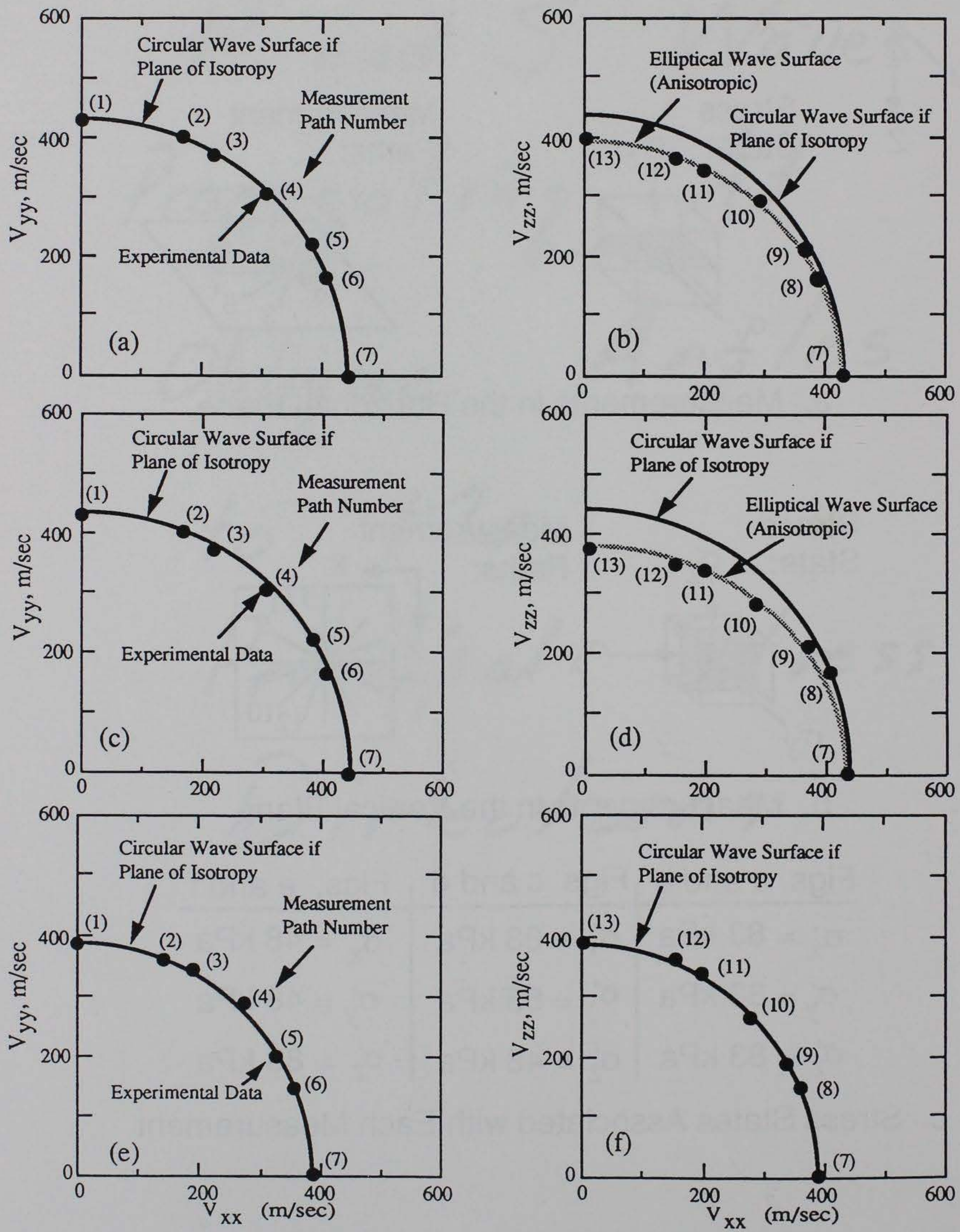


\section{CROSS - ANISOTROPIC MODEL}
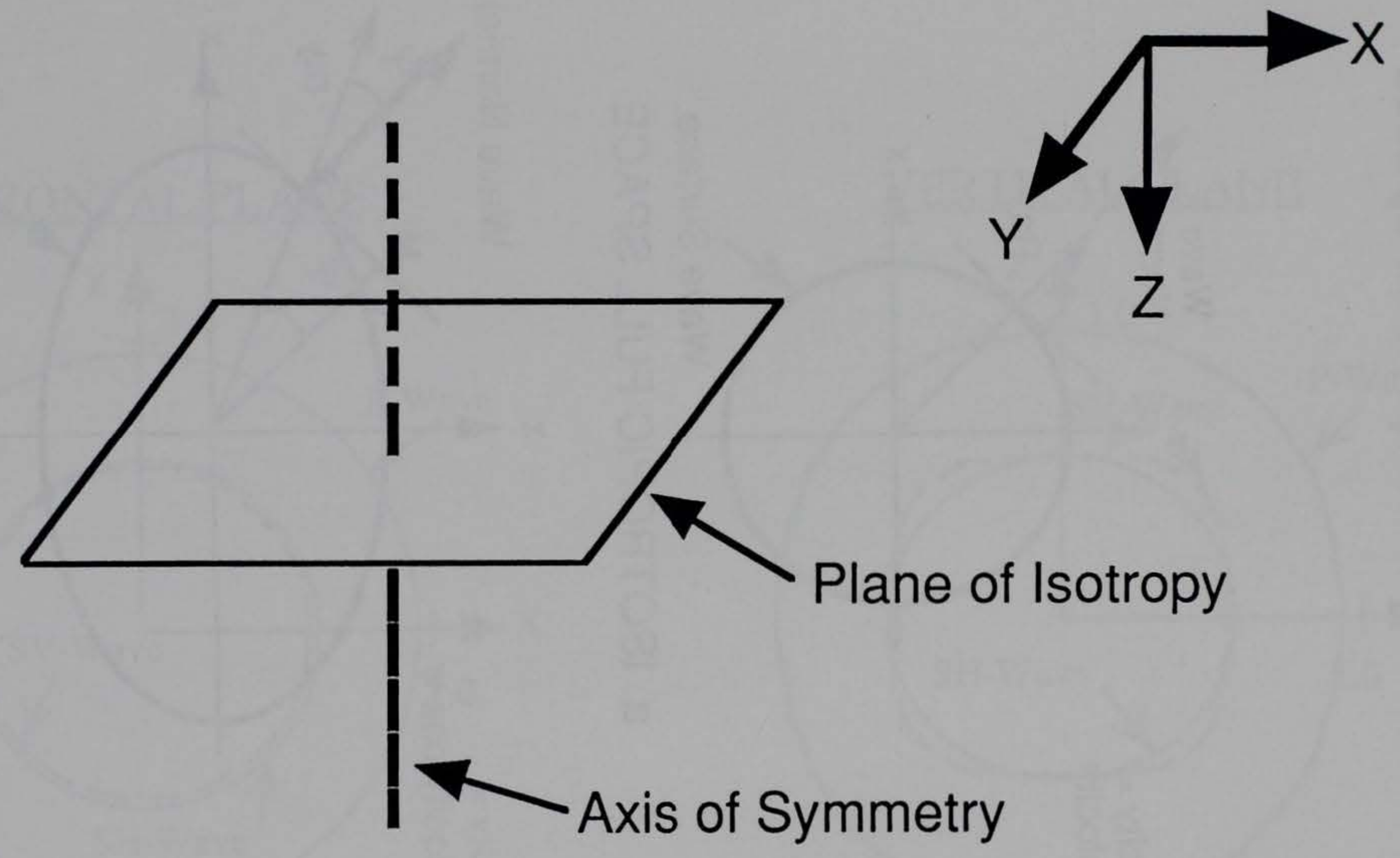


\section{Directions of Ray and Wave Normal on the Wave Surface from a Point Source in Isotropic and Anisotropic Full Spaces}

Ray Velocity = Phase Velocity

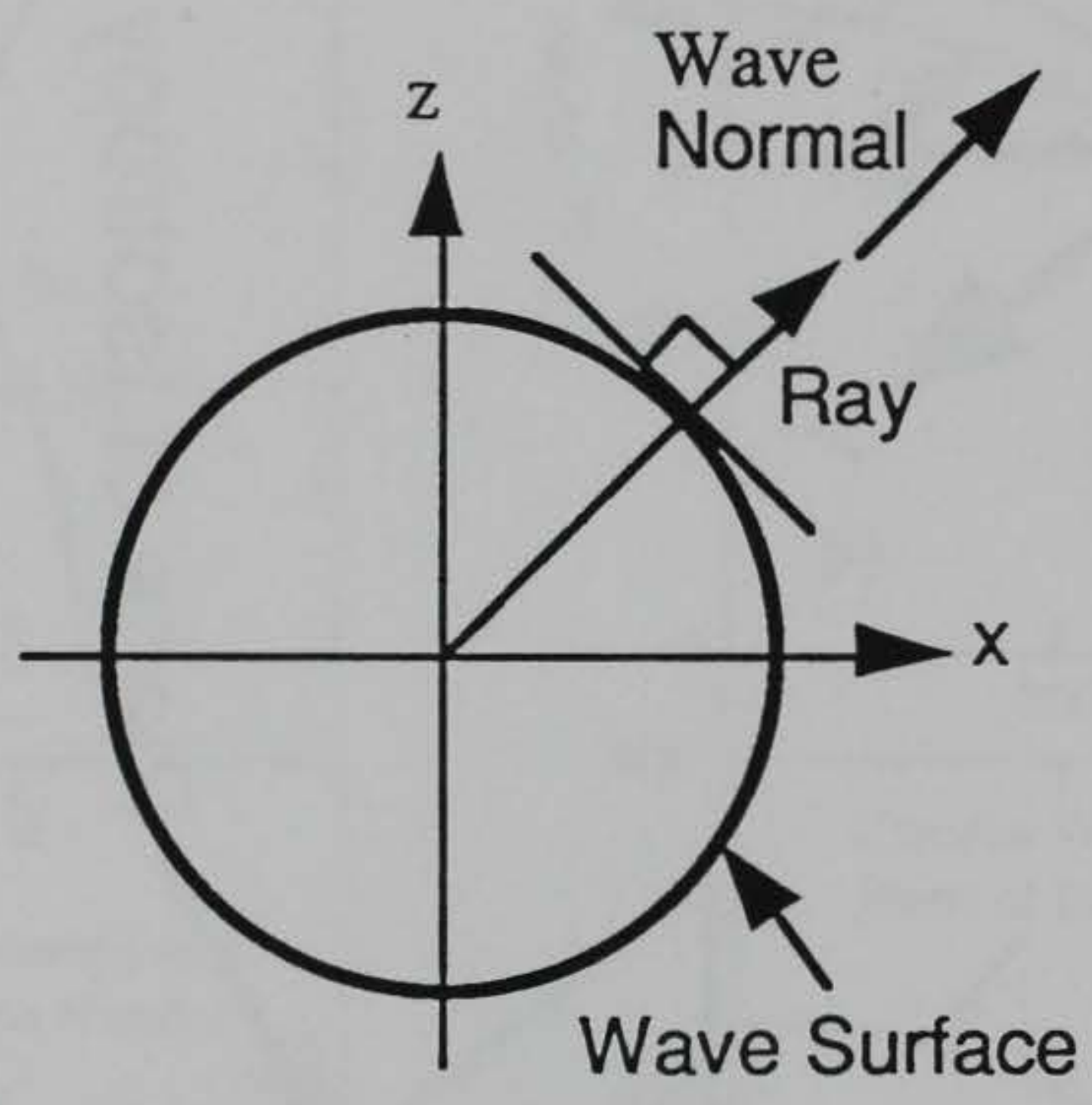

a. ISOTROPIC FULL SPACE

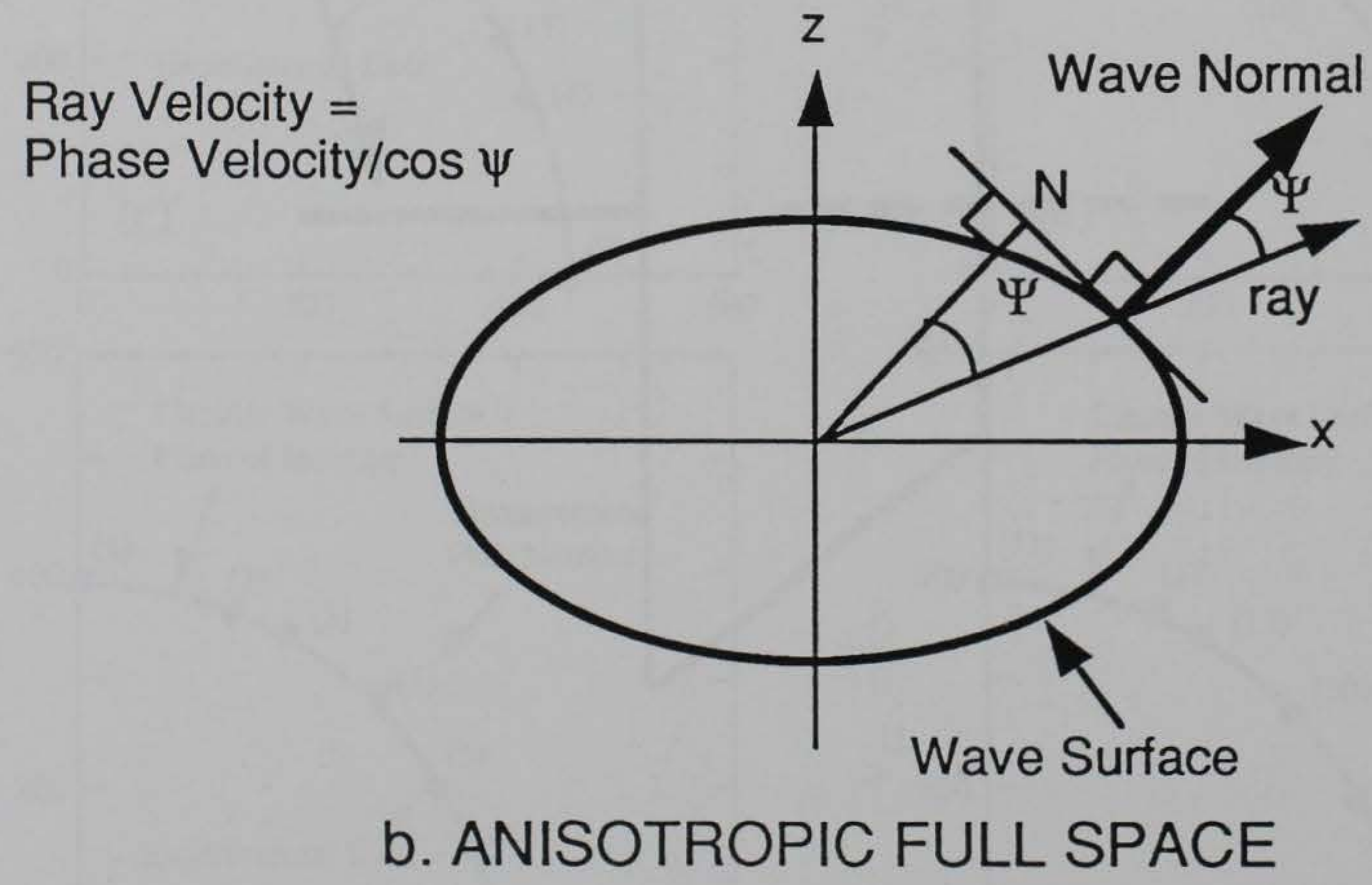




\section{Normally Consolidated, $\mathrm{K}_{0}{ }^{\prime}=\mathbf{0 . 5}$ \\ $\left(C_{x x} / C_{z z}=1.10\right)$}

HORIZONTAL PLANE

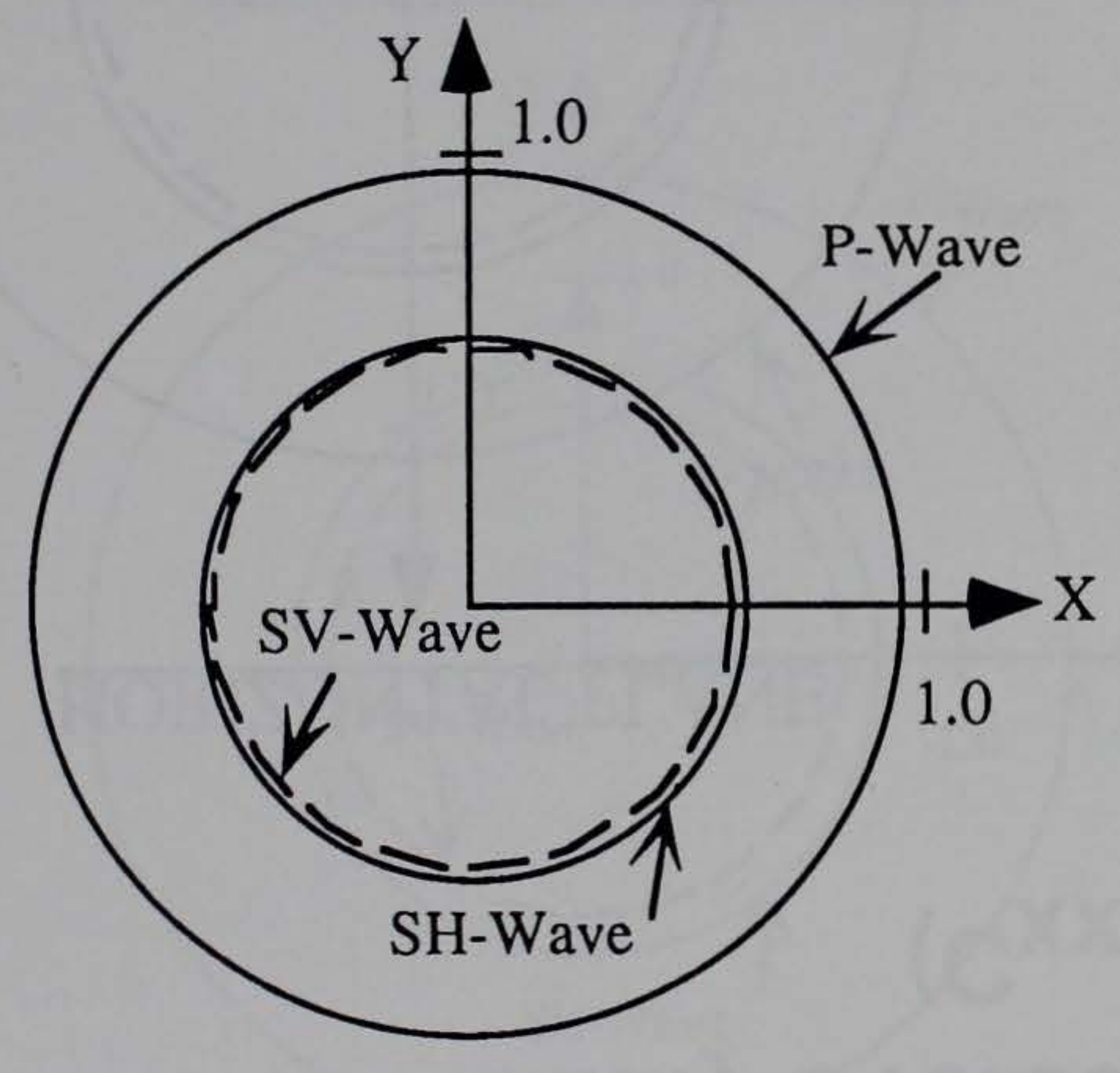

VERTICAL PLANE

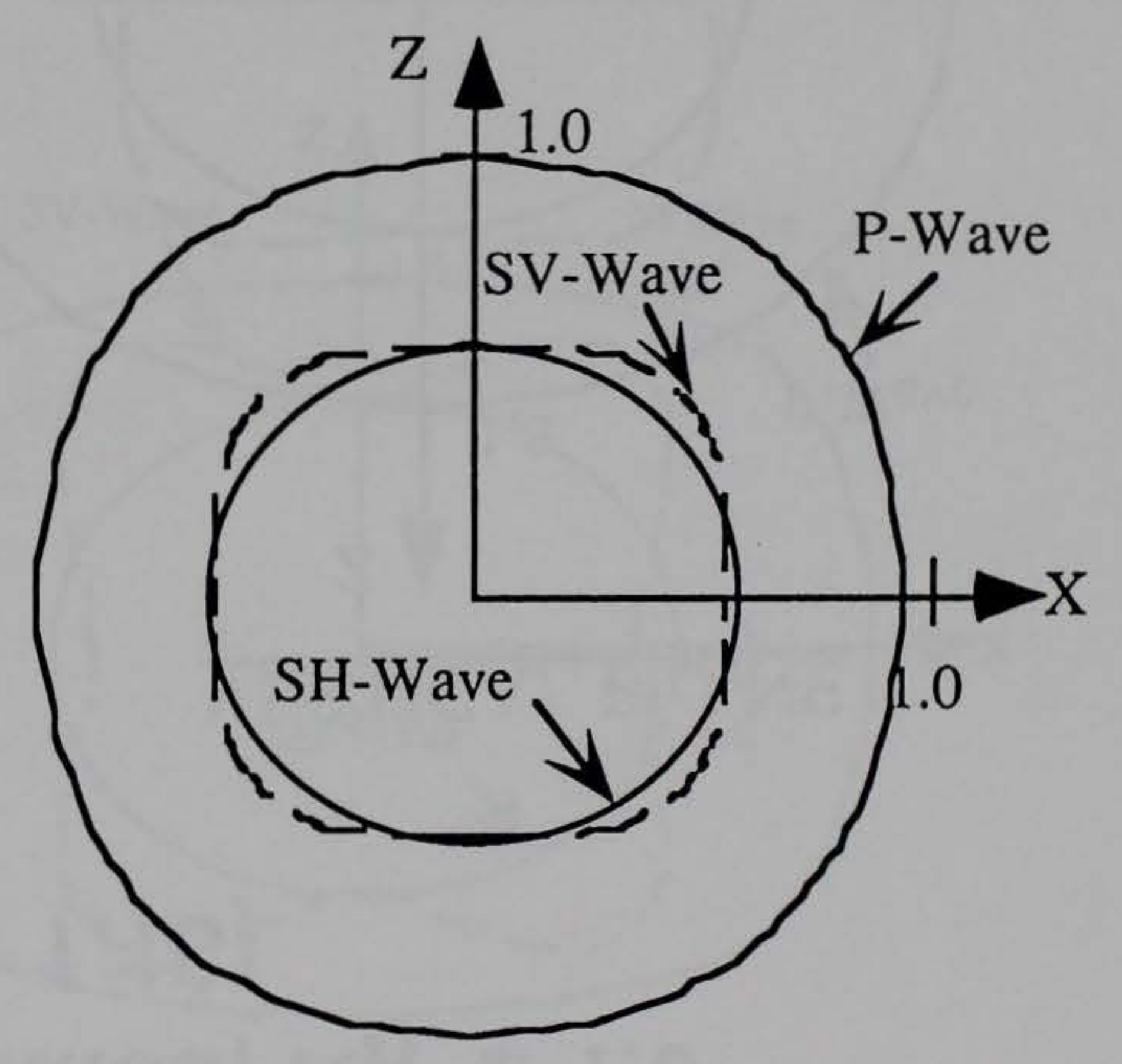




\section{Mildly Overconsolidated, $\mathrm{K}_{0}{ }^{\prime}=1.0$ $\left(C_{x x} / C_{z z}=1.10\right)$}

HORIZONTAL PLANE

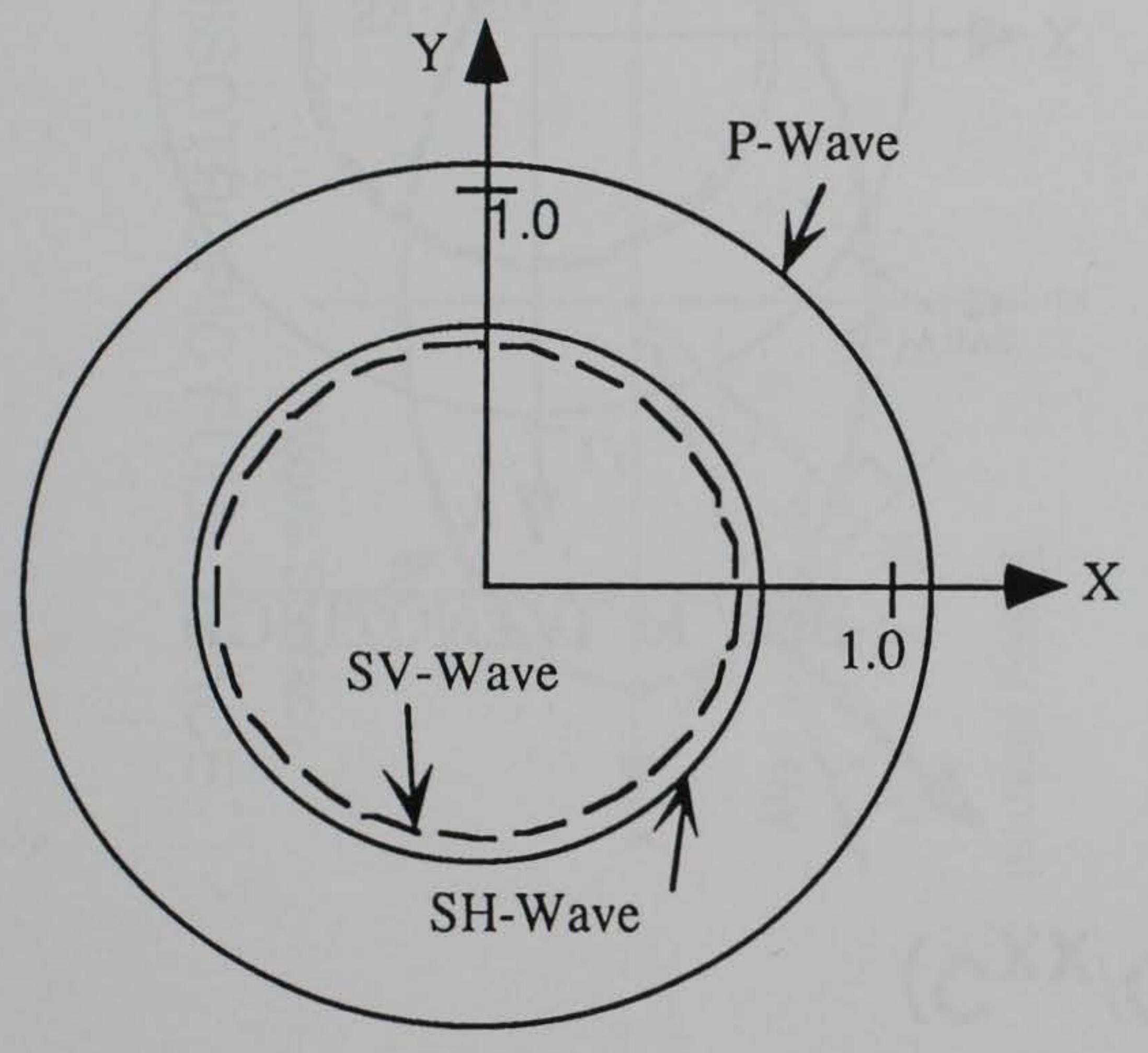

VERTICAL PLANE

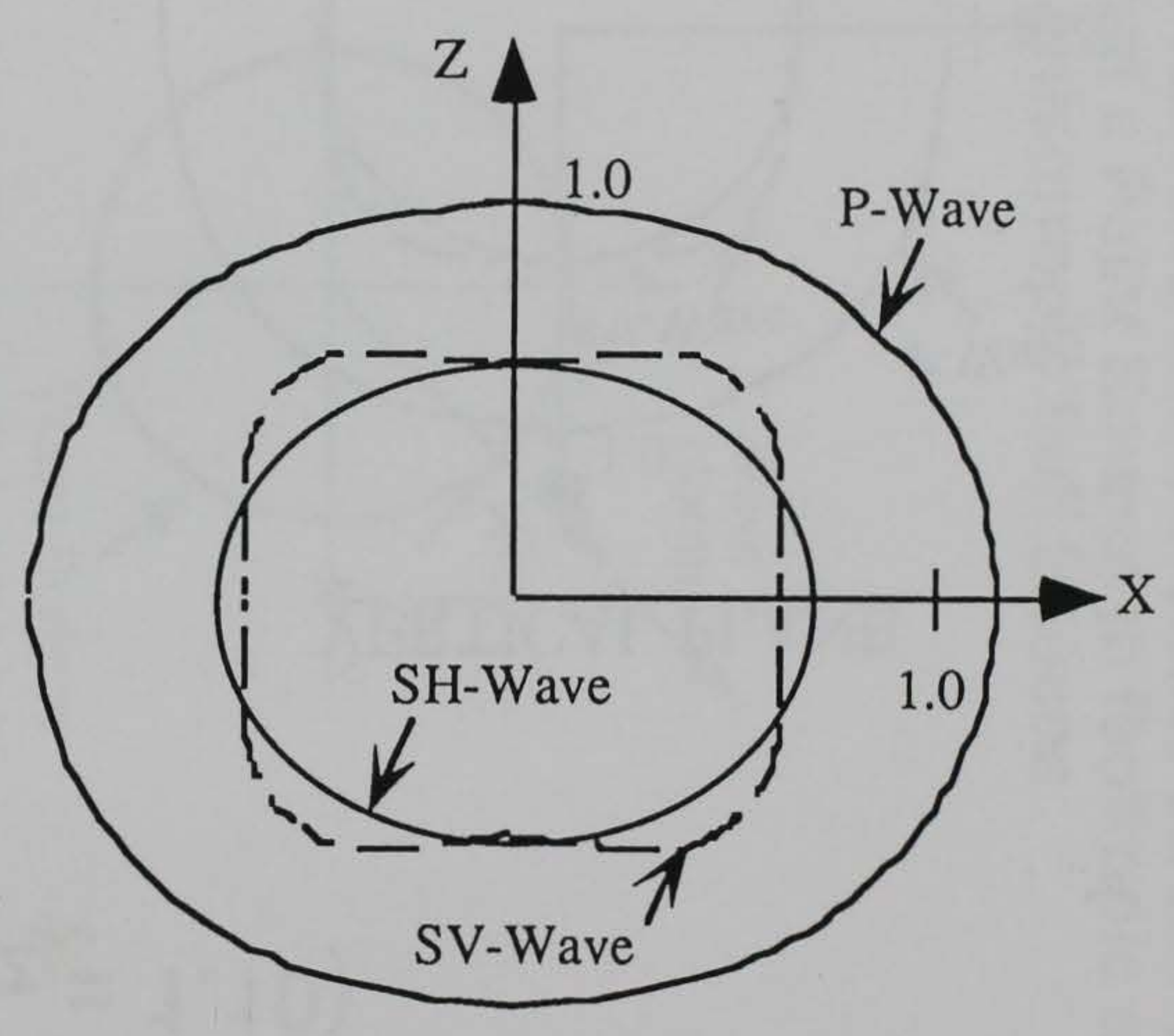




\section{Heavily Overconsolidated, $\mathrm{K}_{\mathrm{O}}{ }^{\prime}=\mathbf{2 . 0}$ $\left(C_{x x} / C_{z z}=1.10\right)$}

\section{HORIZONTAL PLANE}

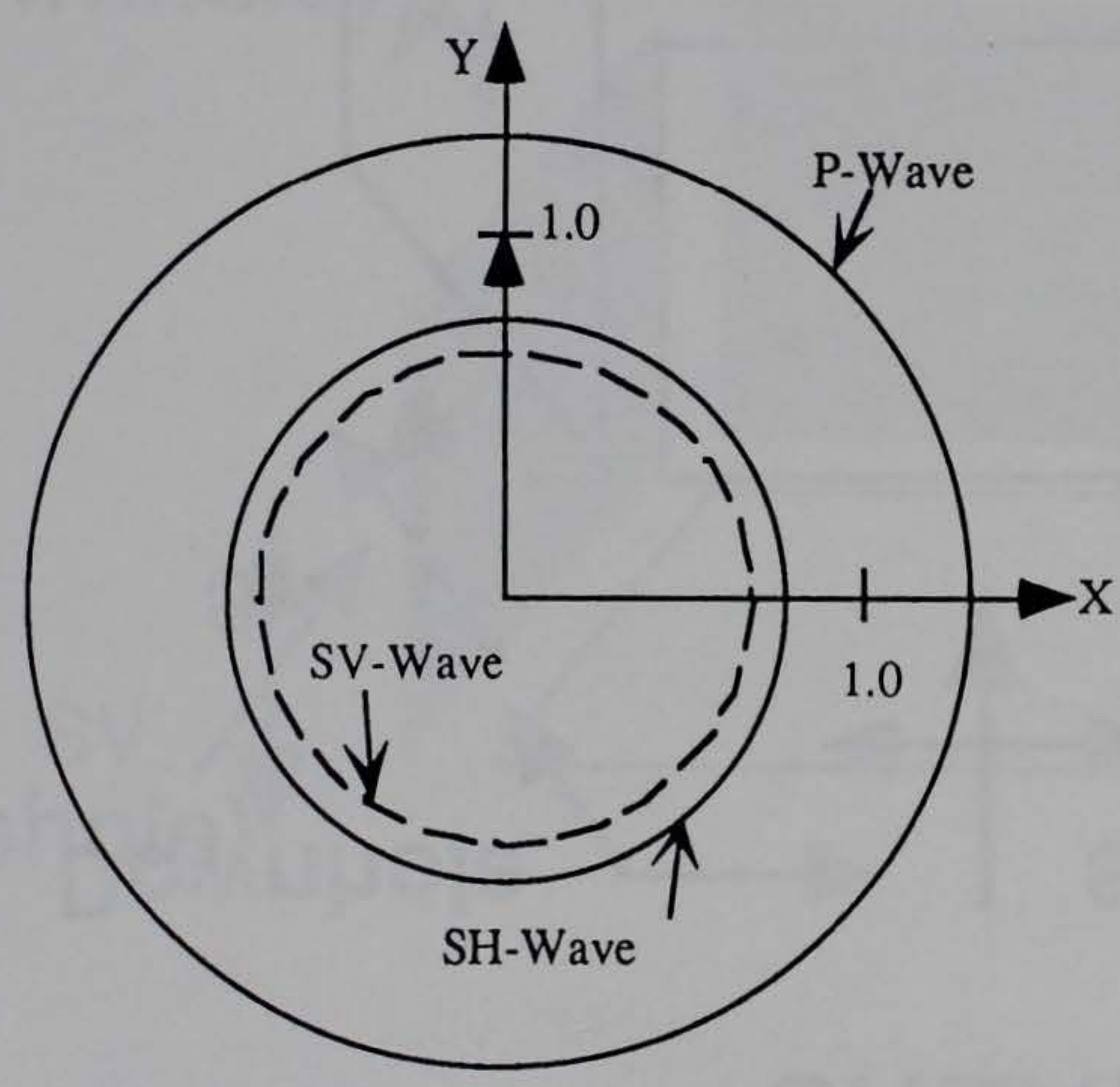

VERTICAL PLANE

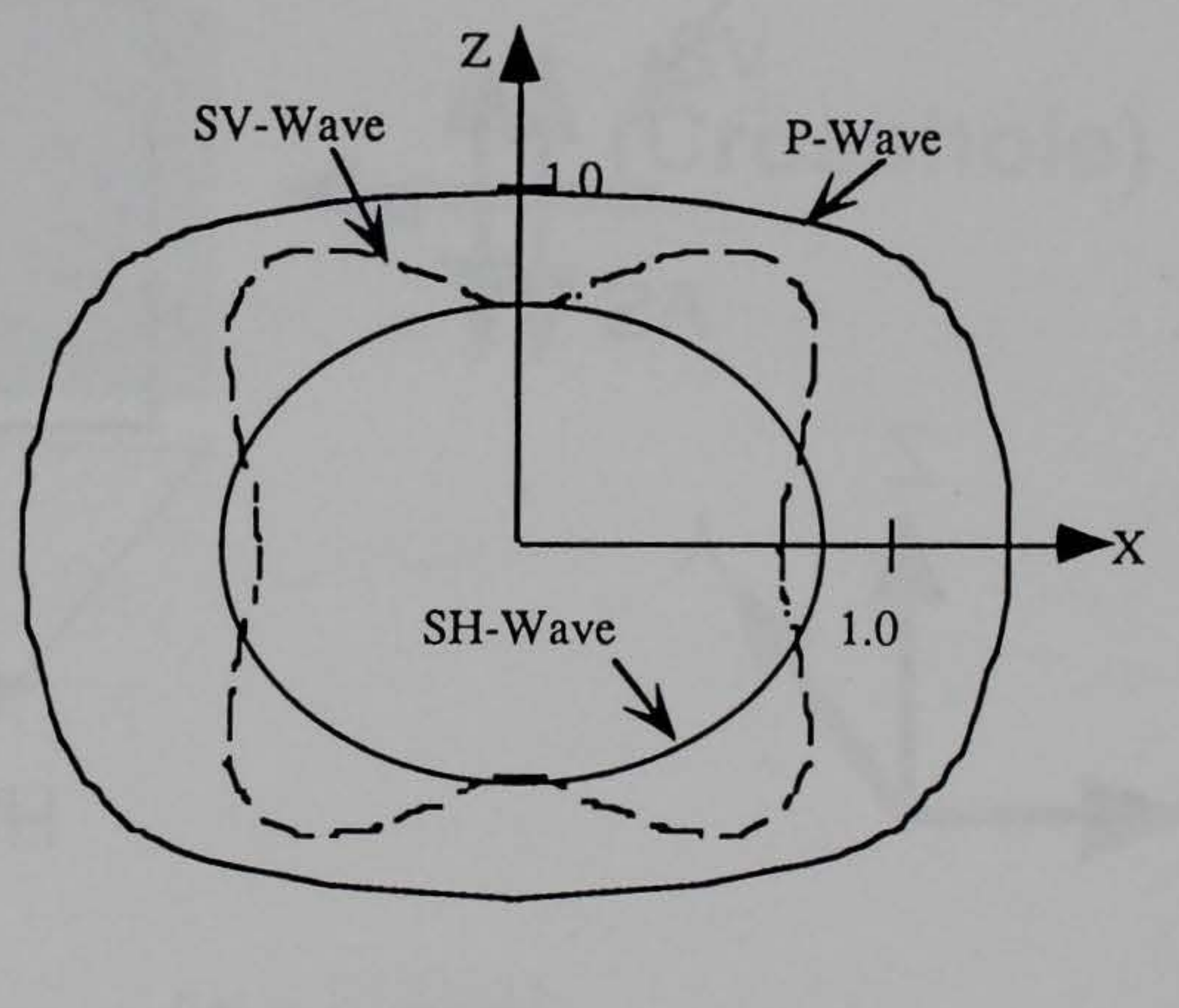




\section{SHEAR WAVES}

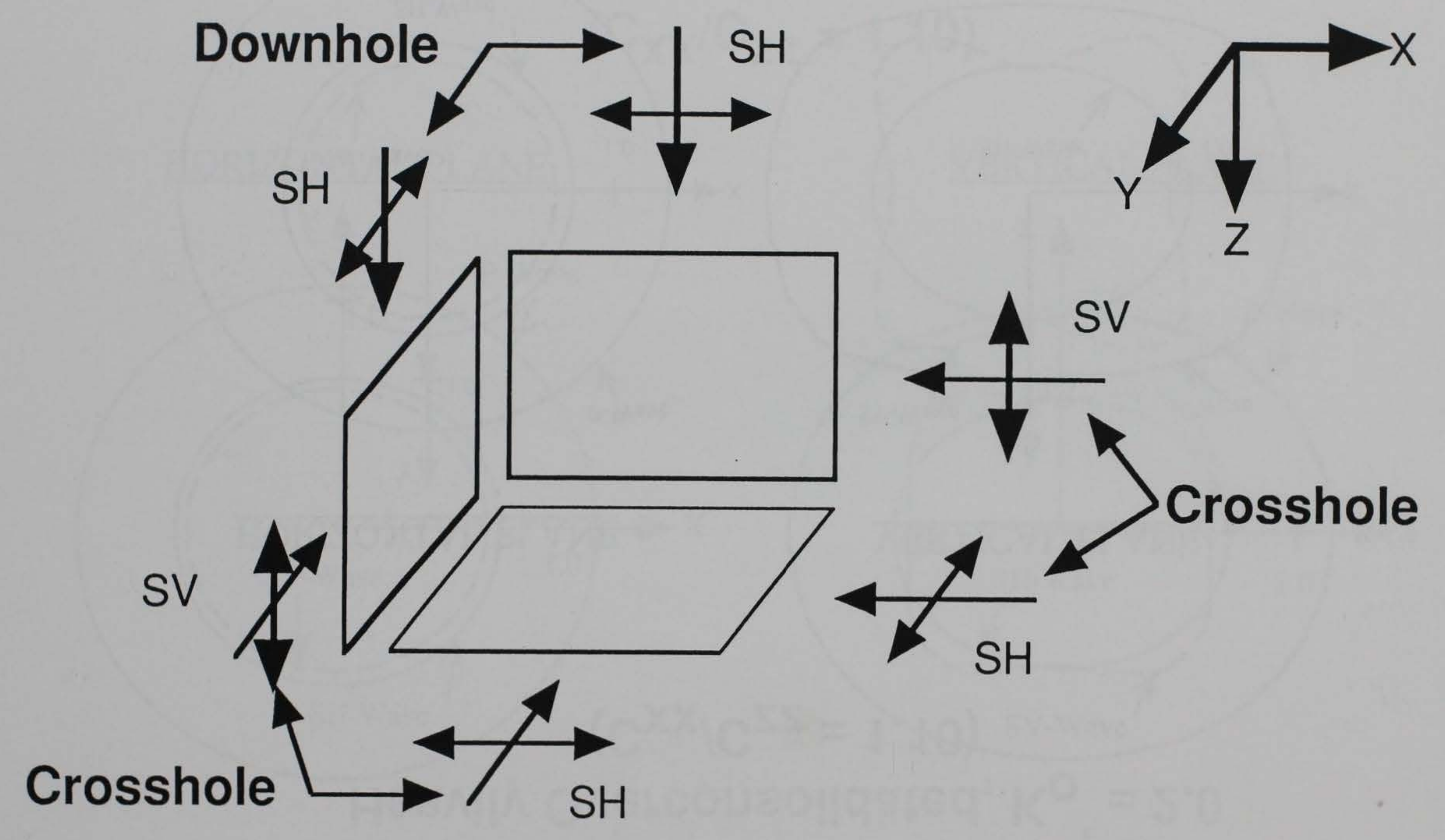




\section{EQUIVALENT SHEAR WAVES}

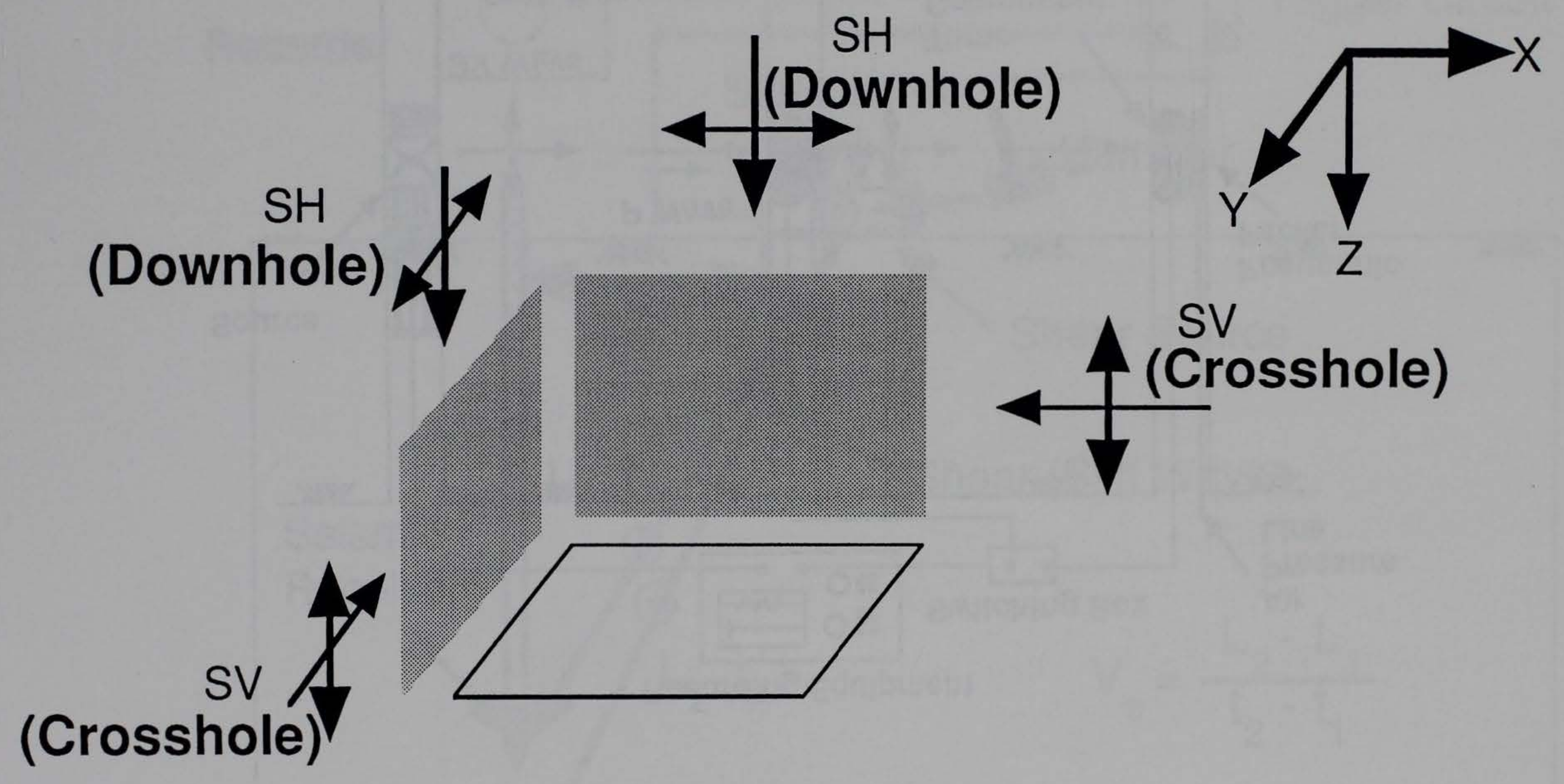




\section{Simplified Schematic of Crosshole Seismic Test}

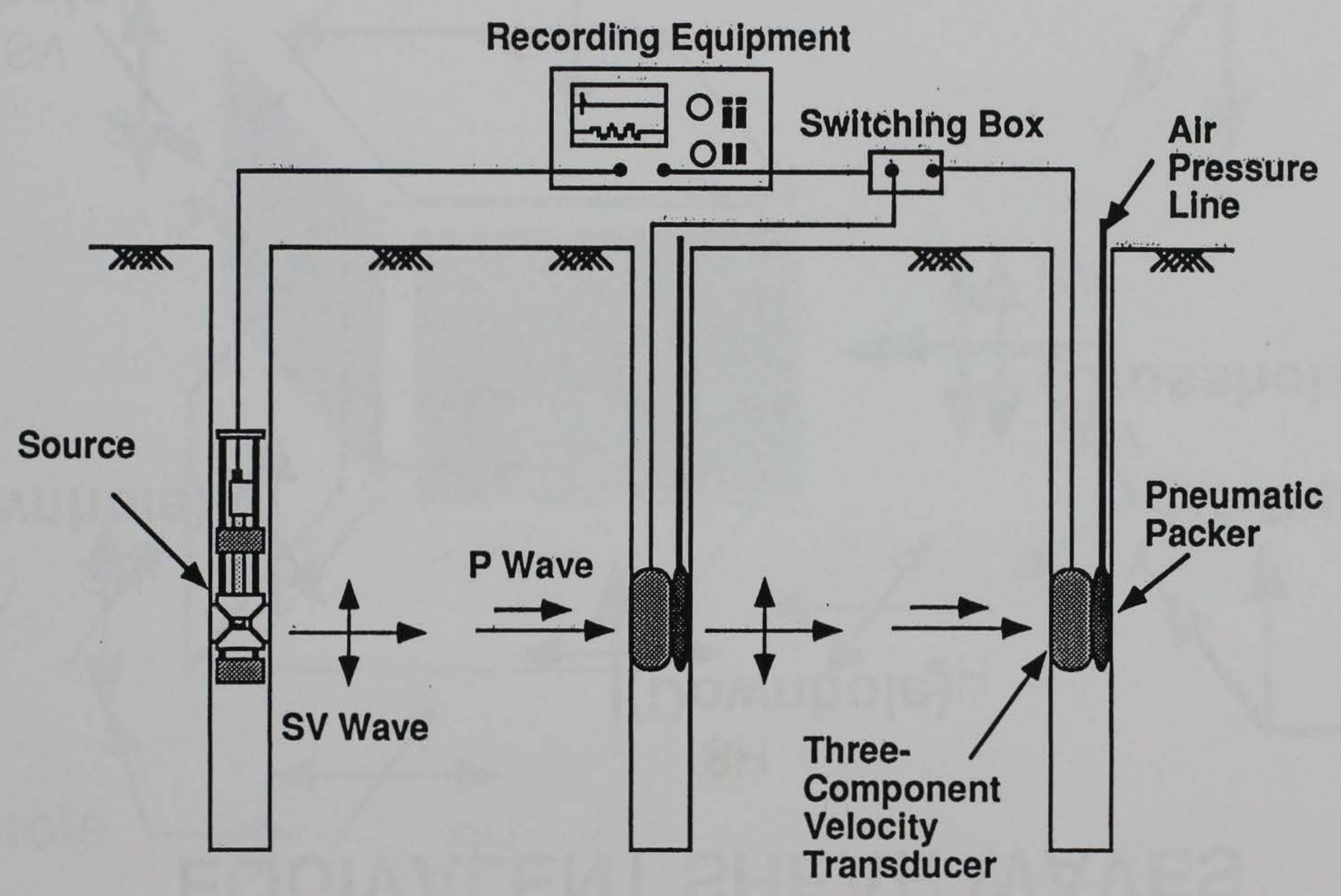


Seismic Cone Penetrometer (SCPF)/Downhøle Test

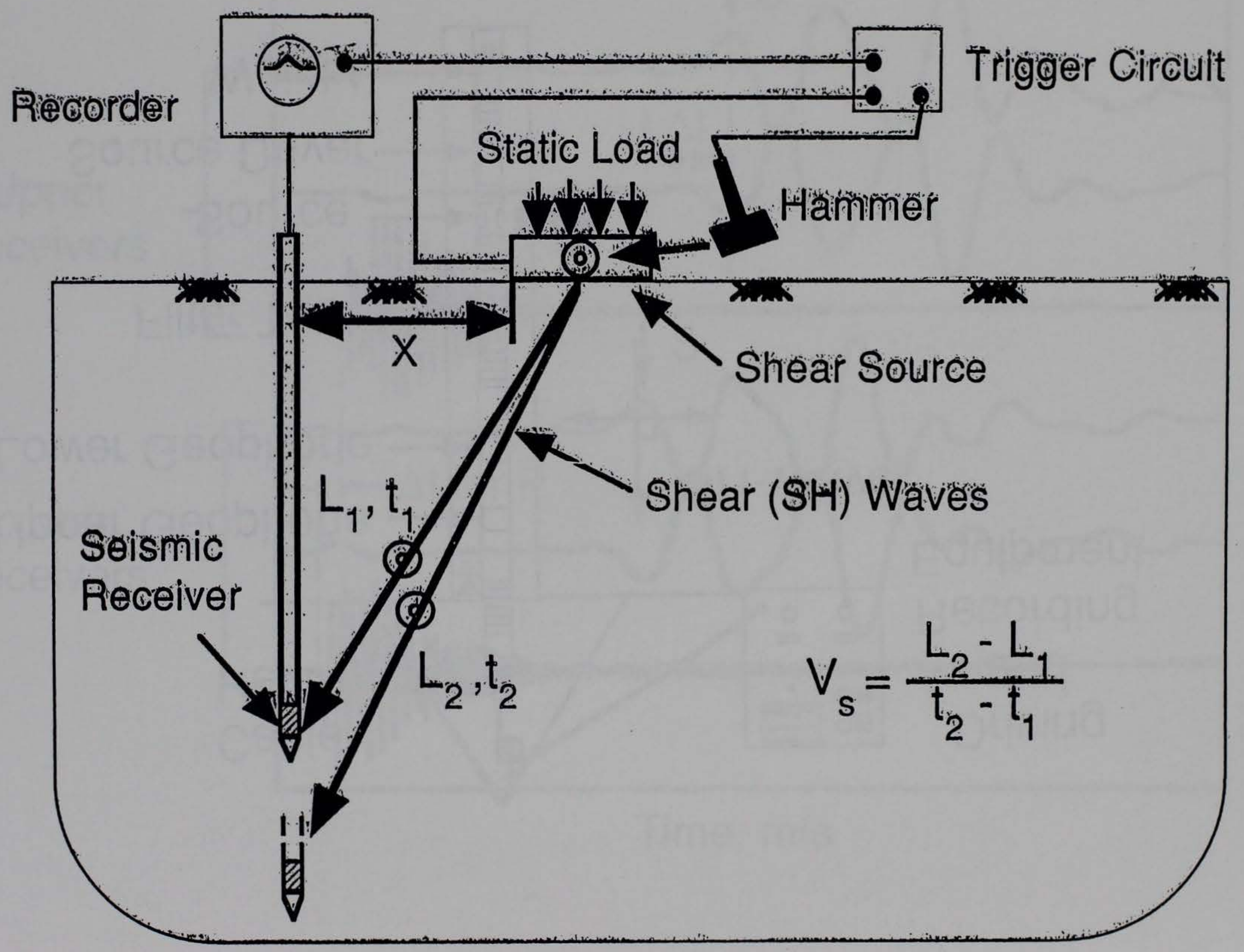




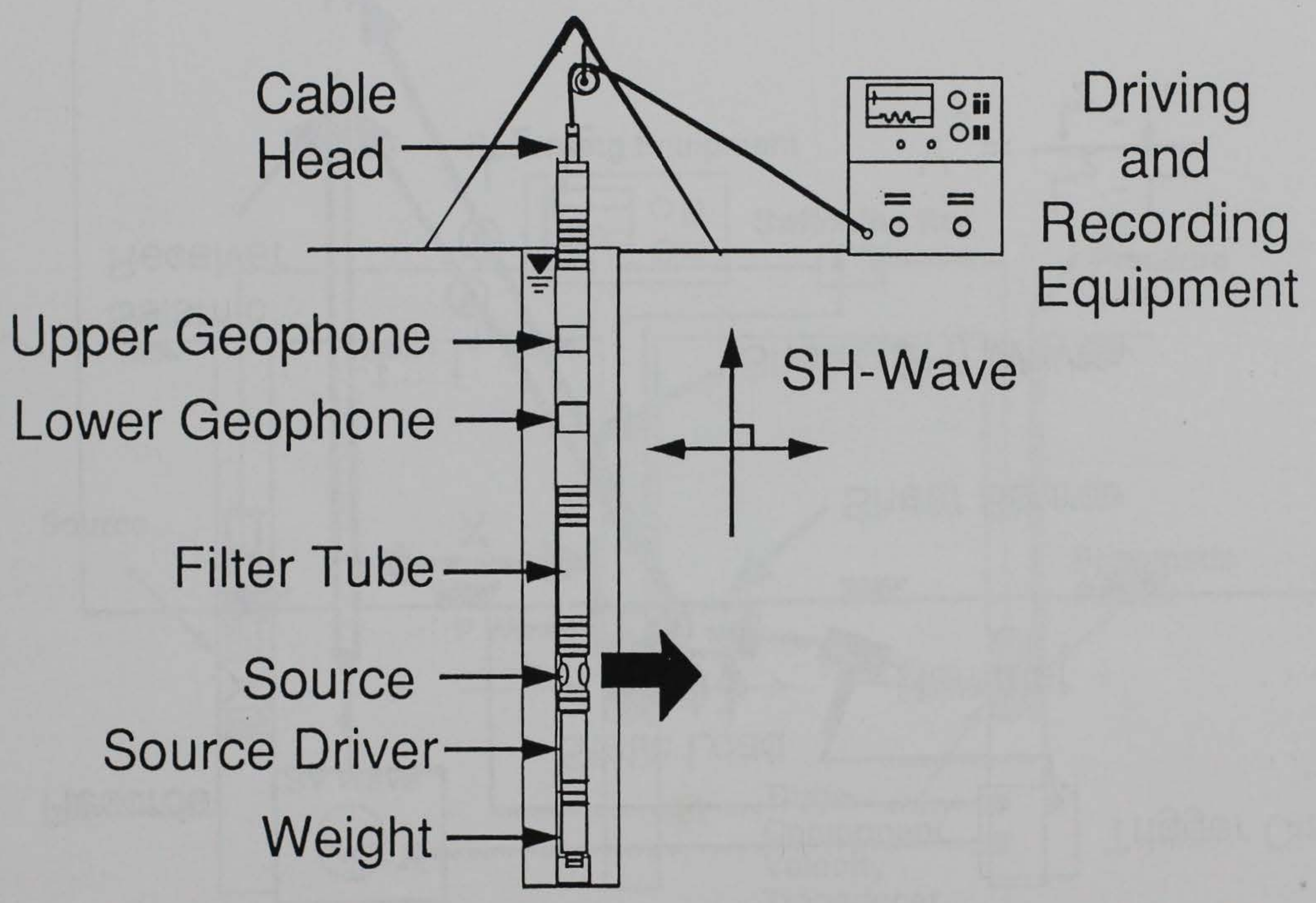




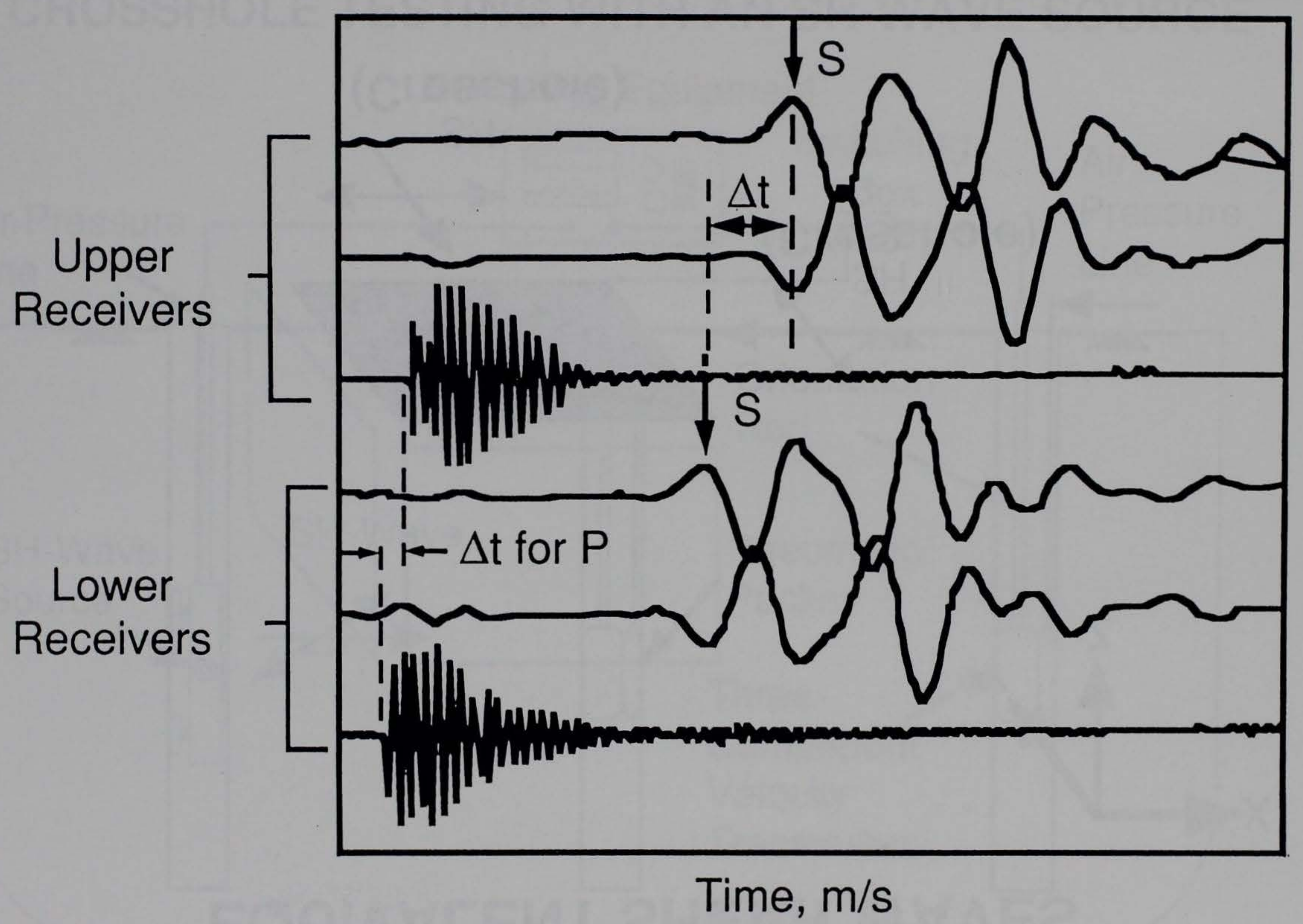




\section{EQUIVALENT SHEAR WAVES}

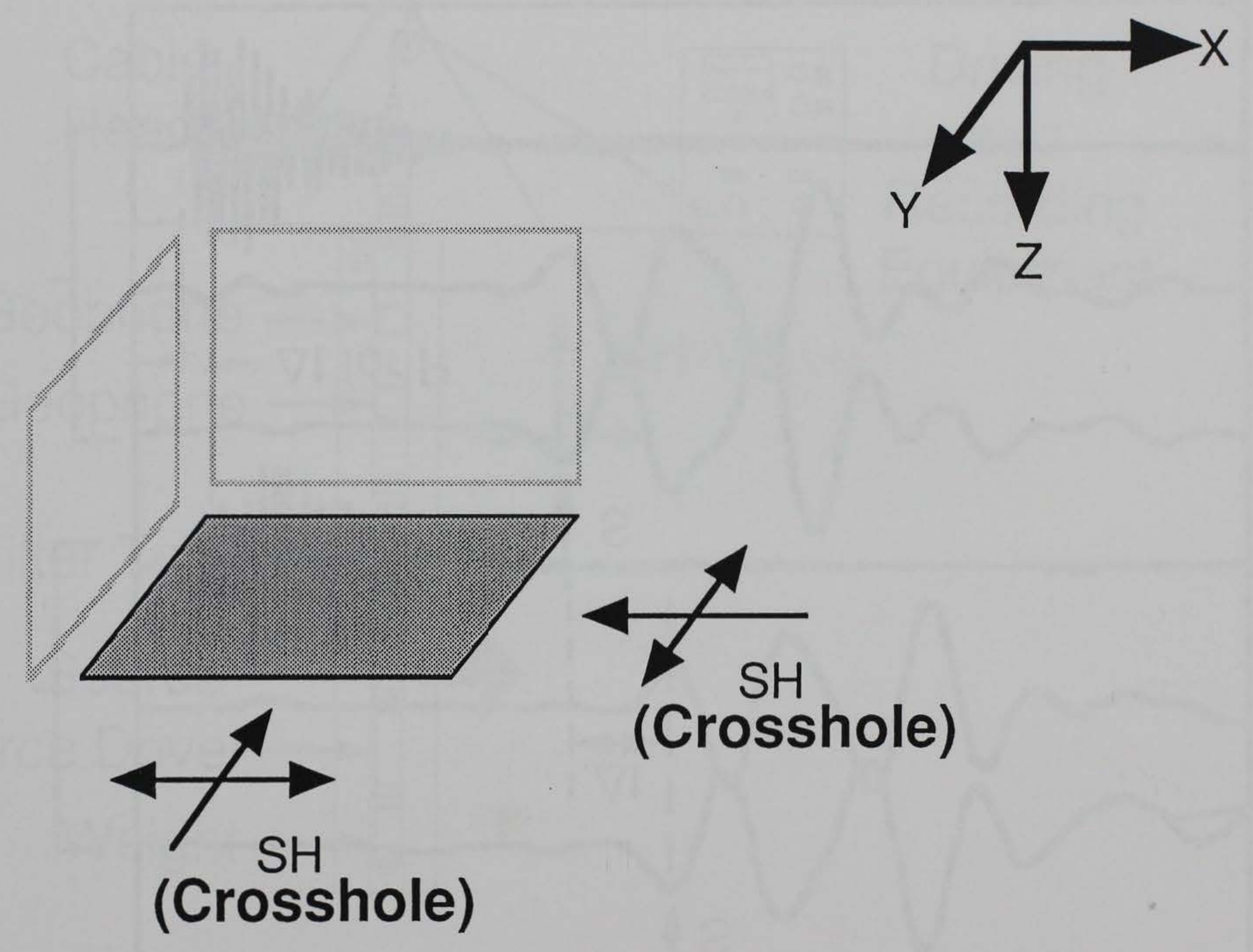




\section{CROSSHOLE TESTING WITH AN SH-WAVE SOURCE}

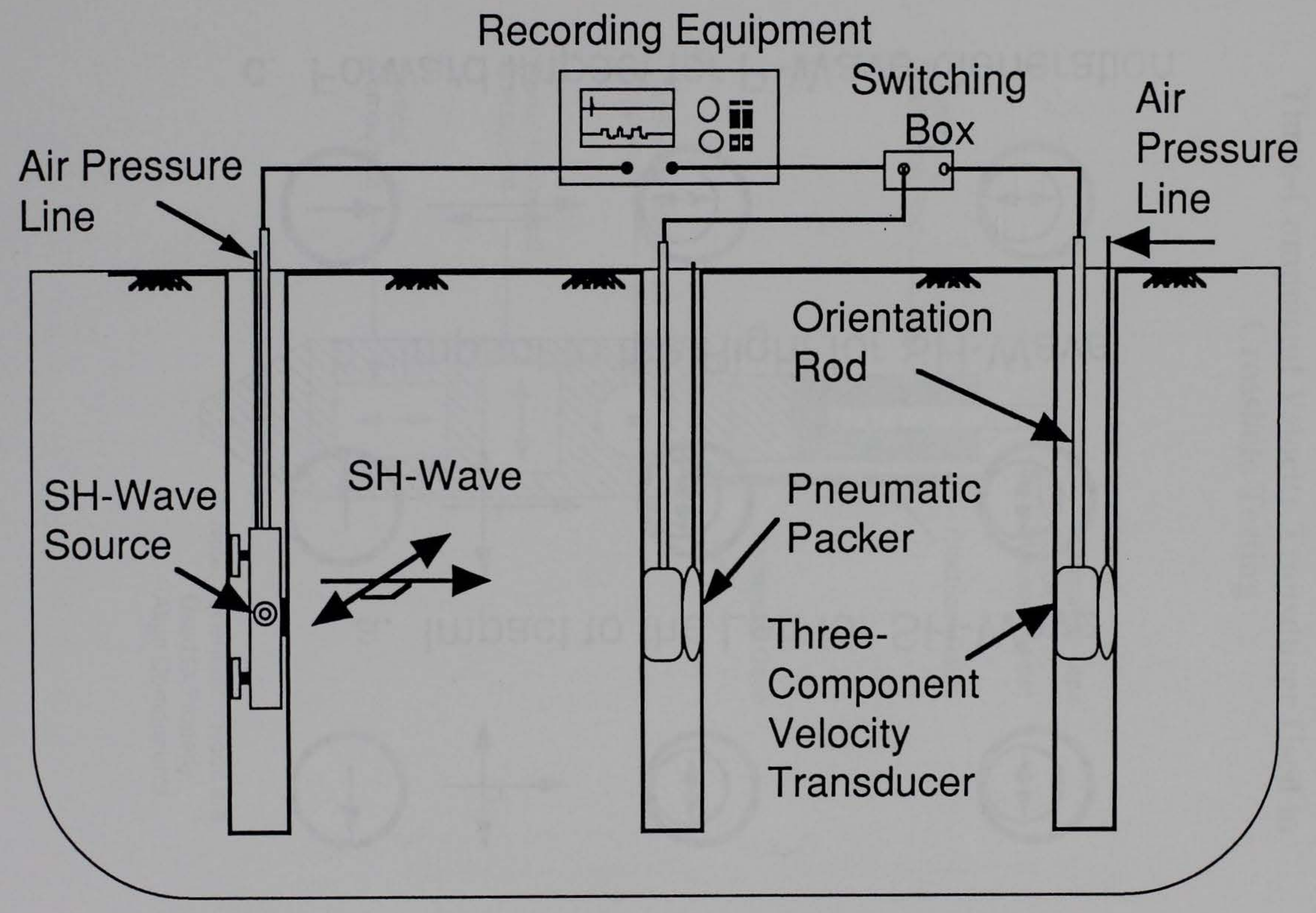


(1) $\div$ - (1) (1)

a. Impact to the Left for SH-Wave

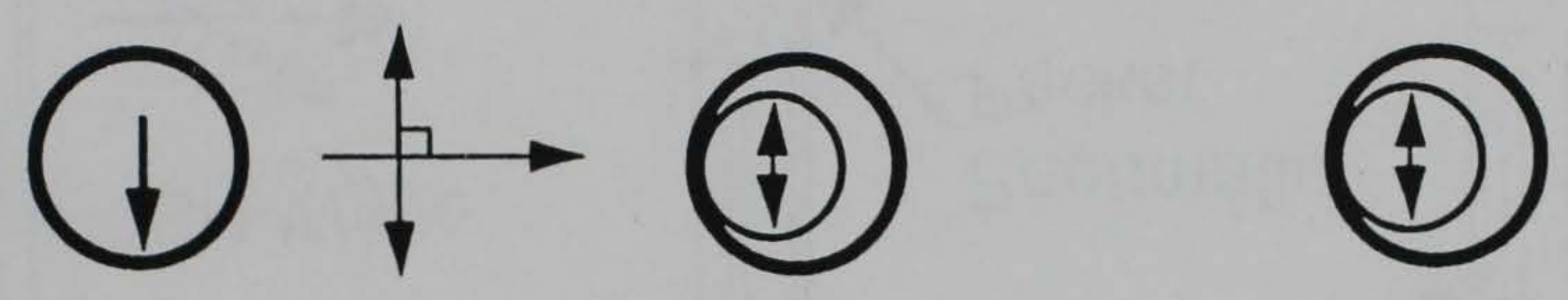

b. Impact to the Right for SH-Wave
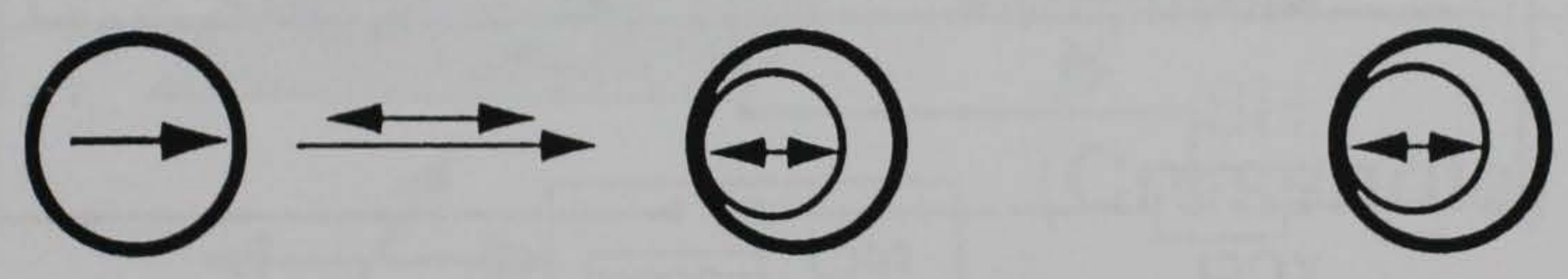

c. Forward Impact for P-Wave Generation 


\section{Three-Component Velocity Transducer Used in Crosshole Testing}

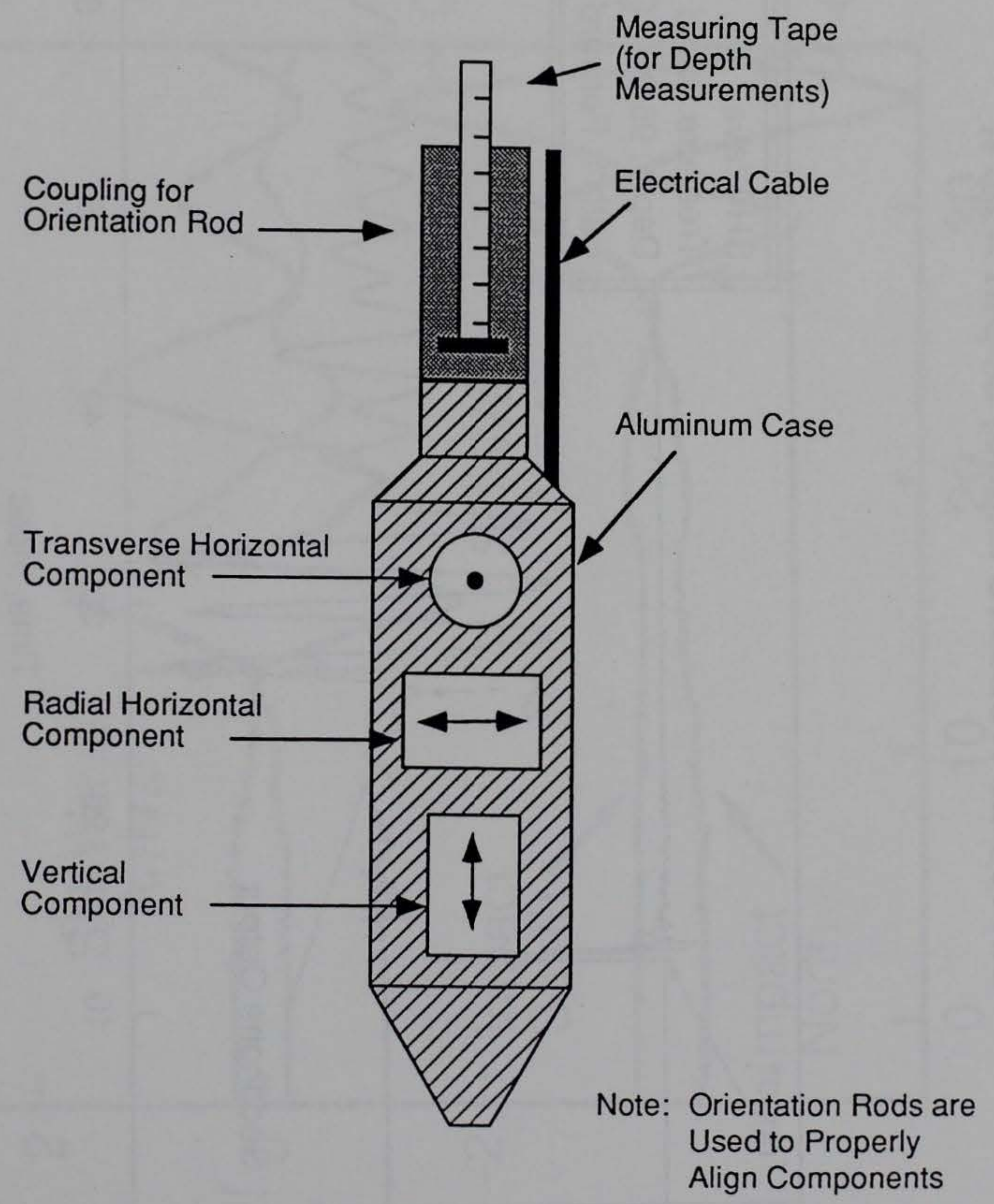


SH-Wave Generated Using the Horizontal Solenoid Source at Treasure Island, Depth $=96 \mathrm{ft}$

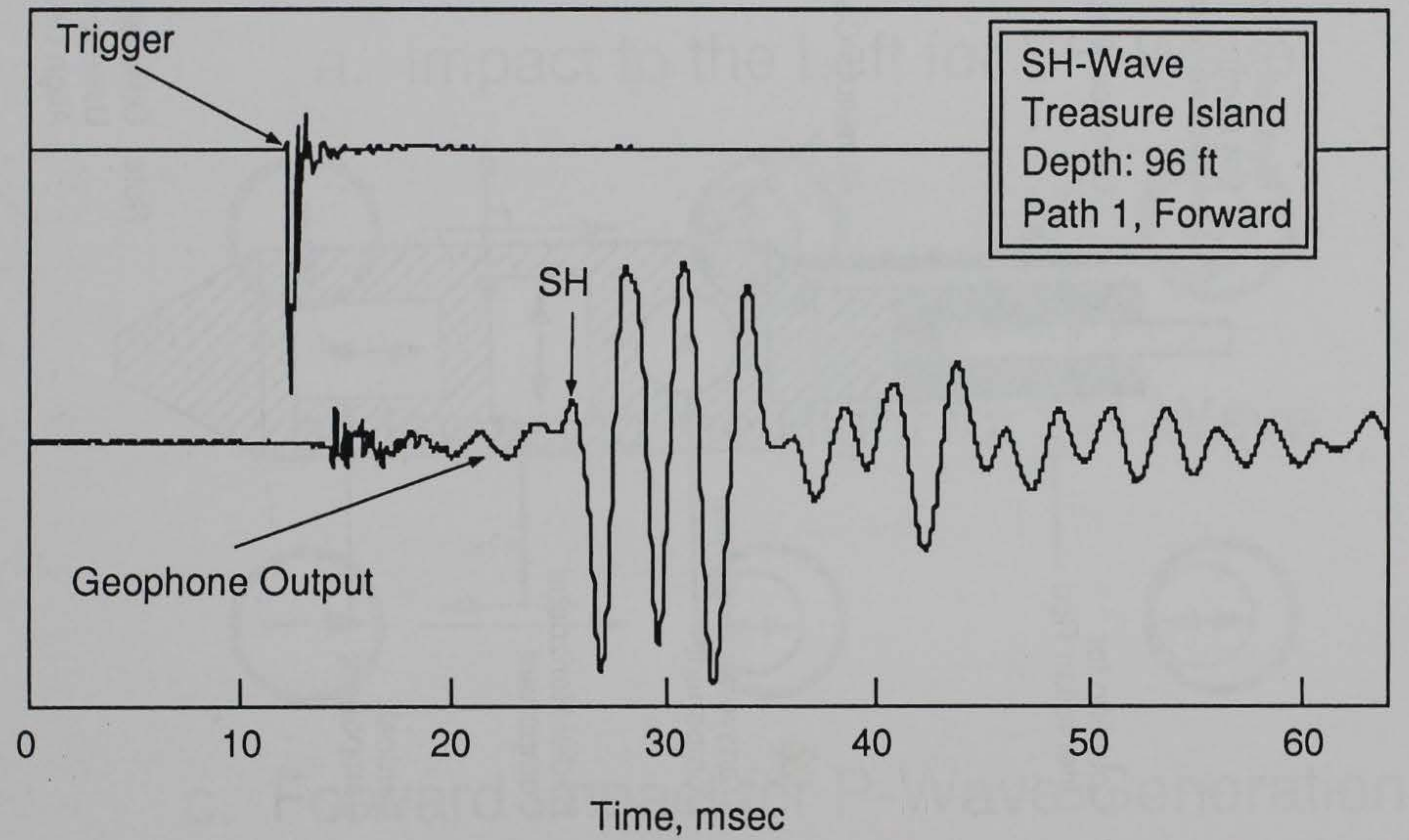




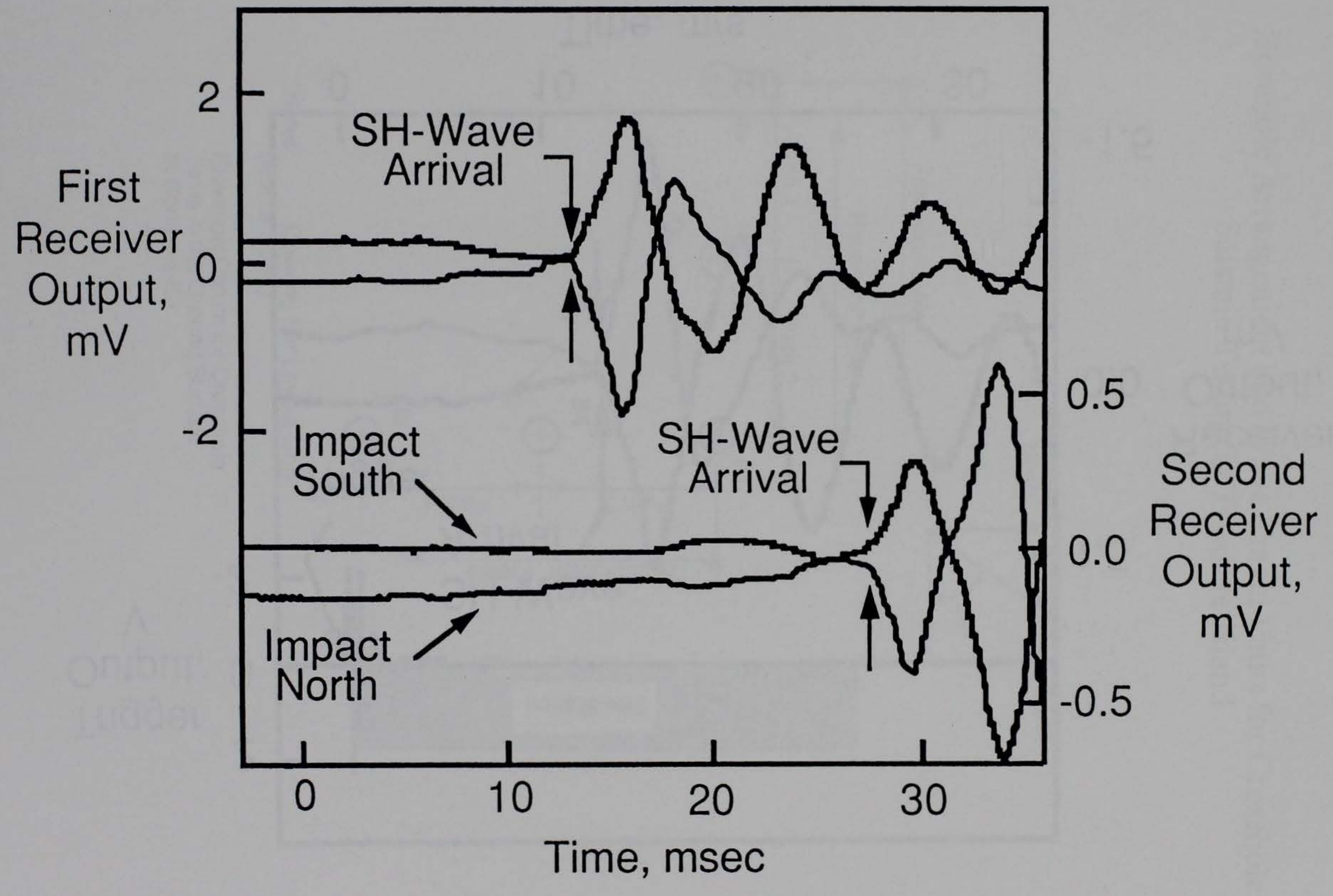




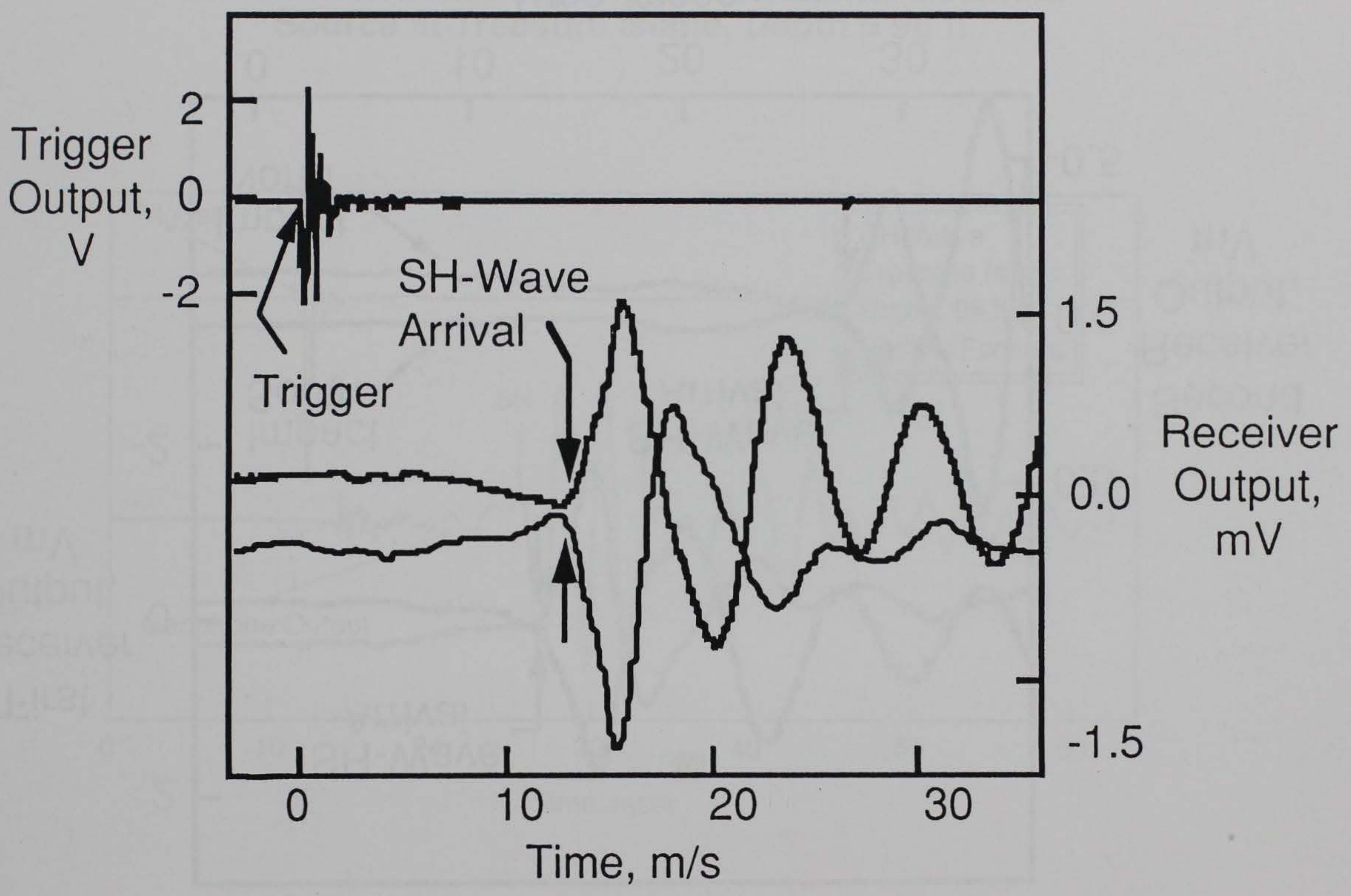




\section{Borehole Arrangement and Wave Travel Paths for Crosshole Seismic Testing at Treasure Island}

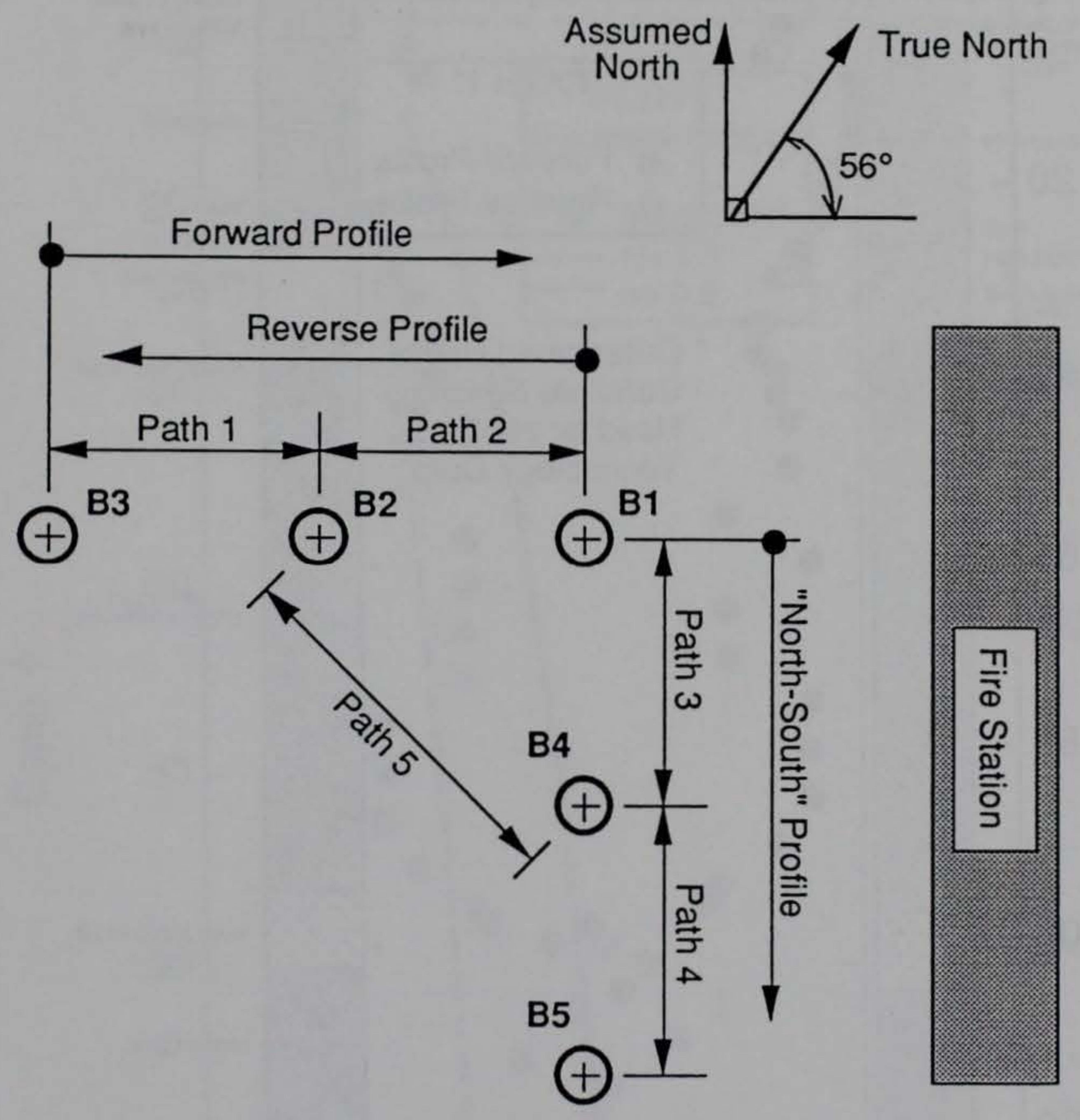

*Notes: Drawing For Layout Only (Not to Scale)

Elevation Datum for Crosshole Tests is the Ground Surface at Borehole B3 


\section{Comparison of Shear (SV) Wave Velocities Measured in the Forward and Reverse Directions Along Path 1 at Treasure Island}

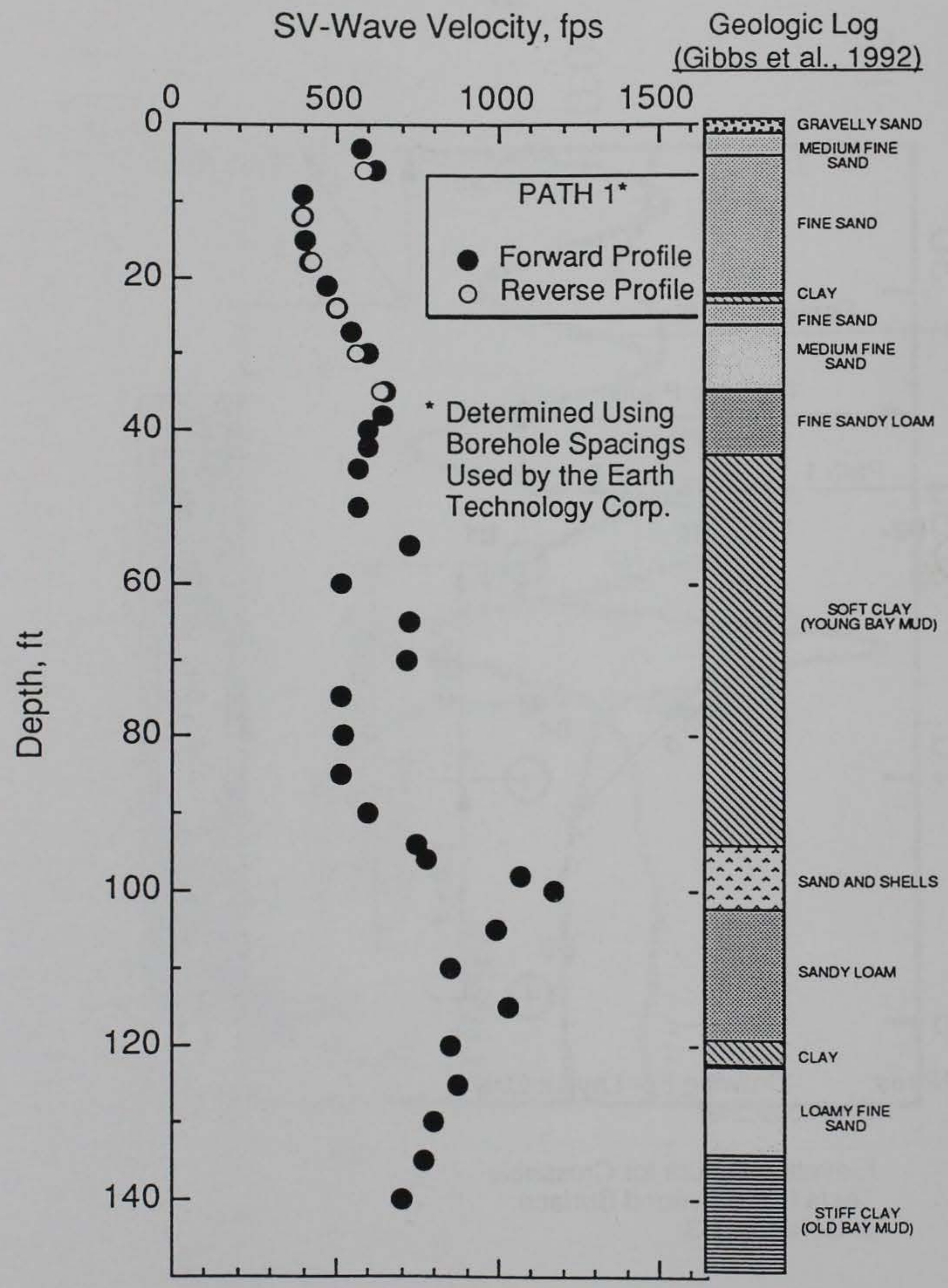




\section{Comparison of Shear (SV) Wave Velocities Measured Along}

Path 1 at Treasure Island with Theoretical S-Wave Velocities Predicted by Hardin and Drnevich (1972) for a NormallyConsolidated Soil with Void Ratios (e) of 0.5 and 1.0

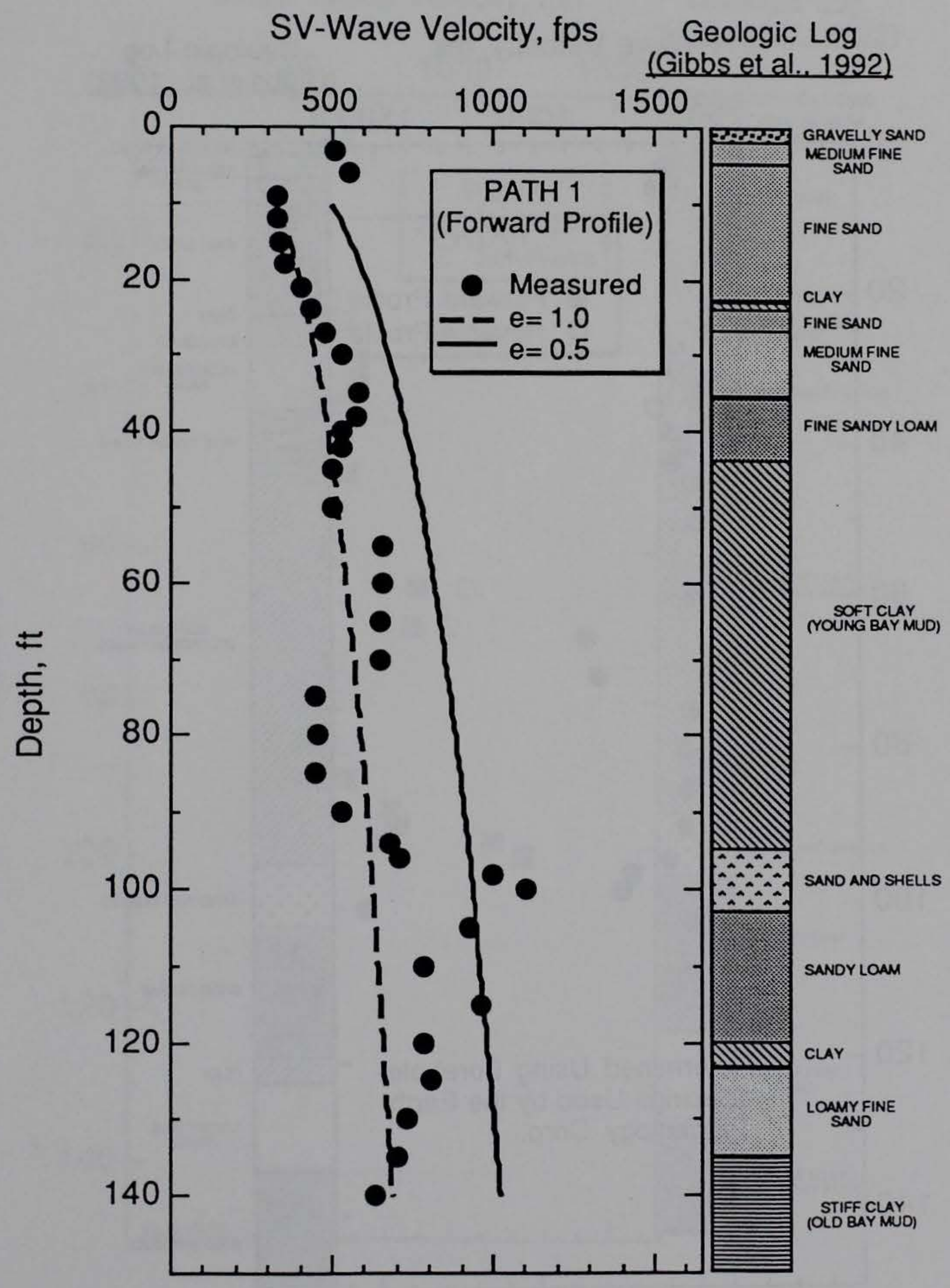




\section{Comparison of Shear (SH) Wave Velocities Measured in the Forward and Reverse Directions Along Path 1 at Treasure Island}

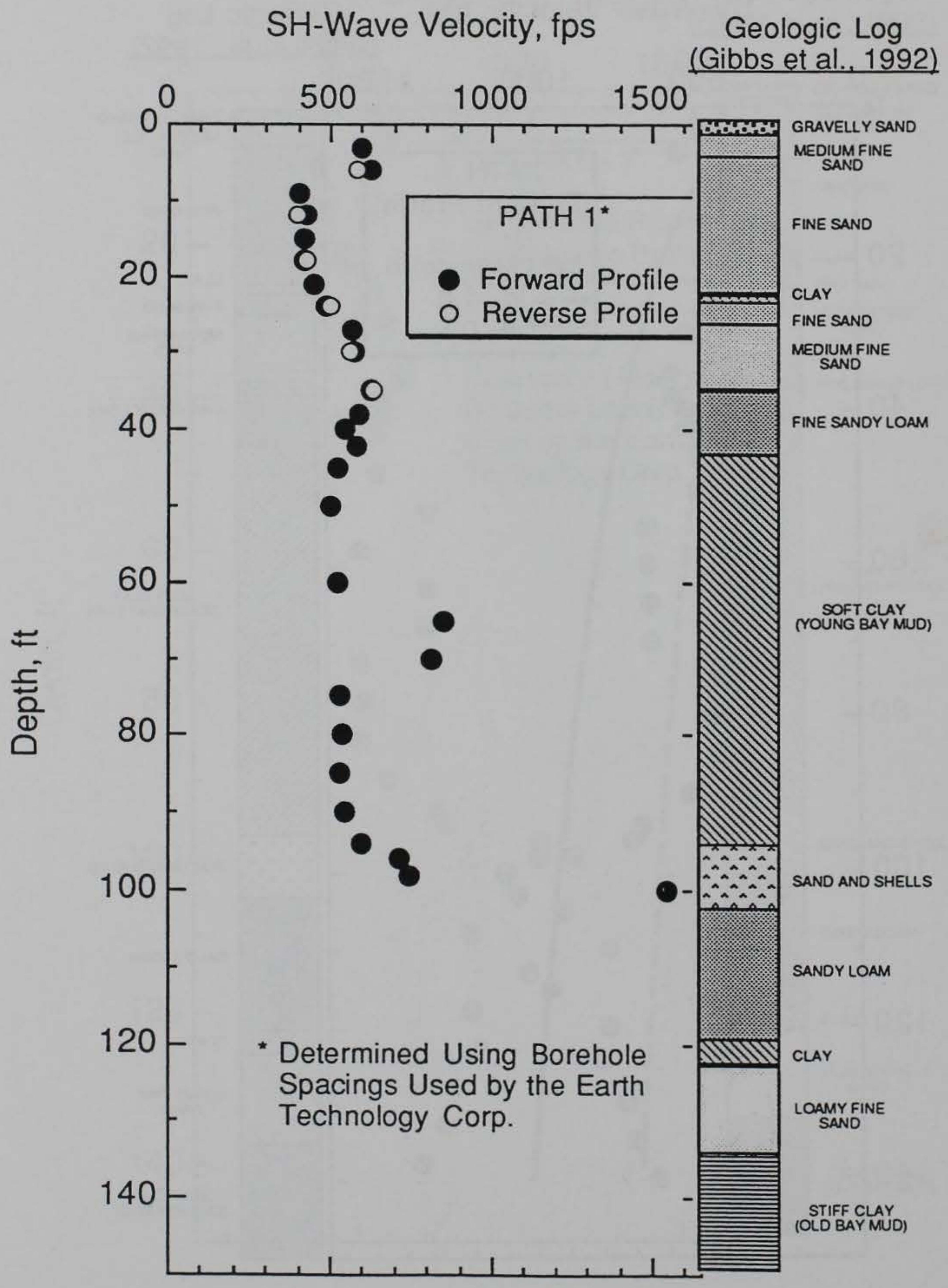




\section{Comparison of SV- and SH-Wave Velocities Along Path 1 at Treasure Island (Forward Direction Only)}

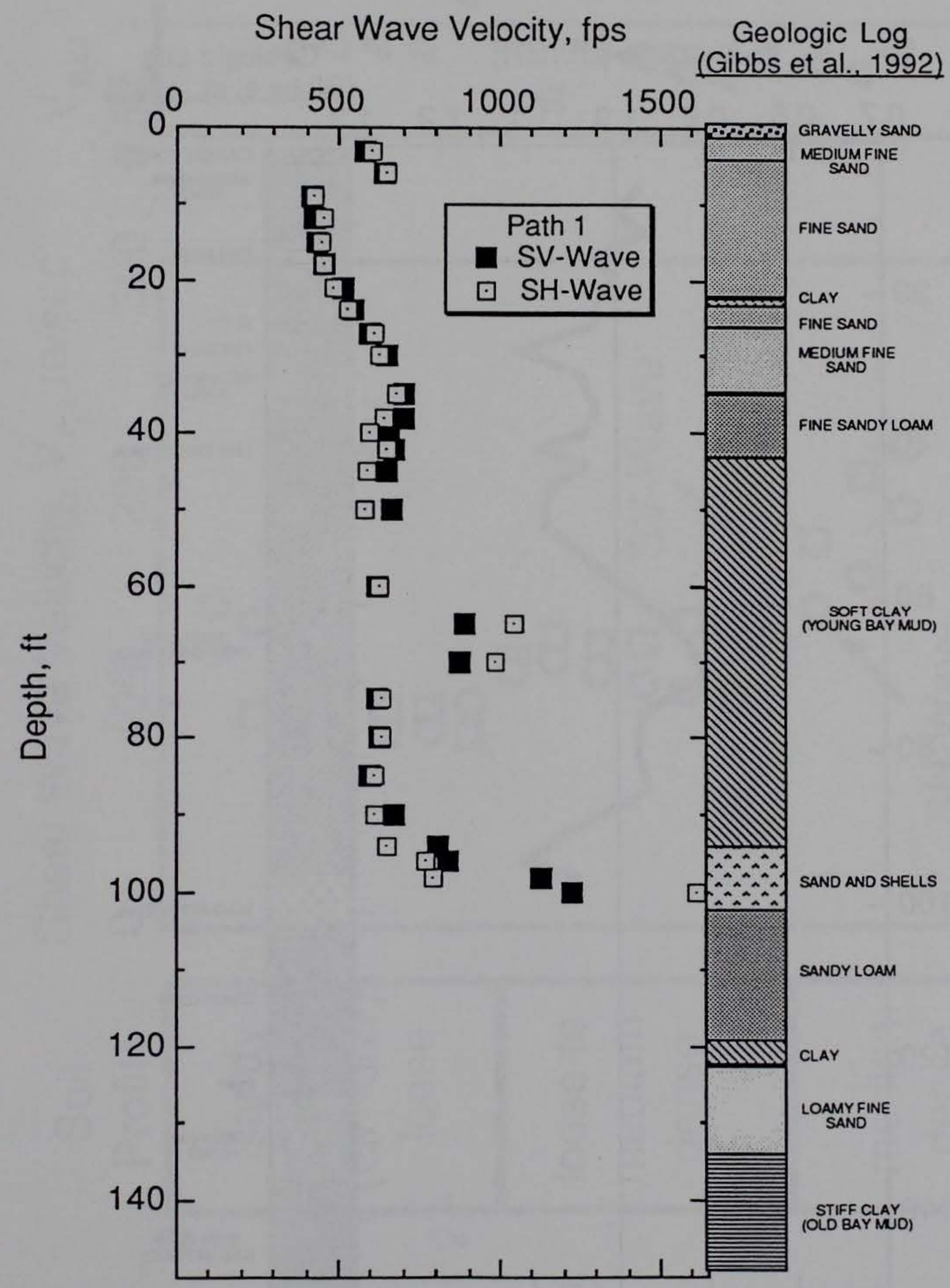




\section{Average Shear Wave Velocity Ratio (SV/SH) Along Paths 1, 2 and 3 at Treasure Island}

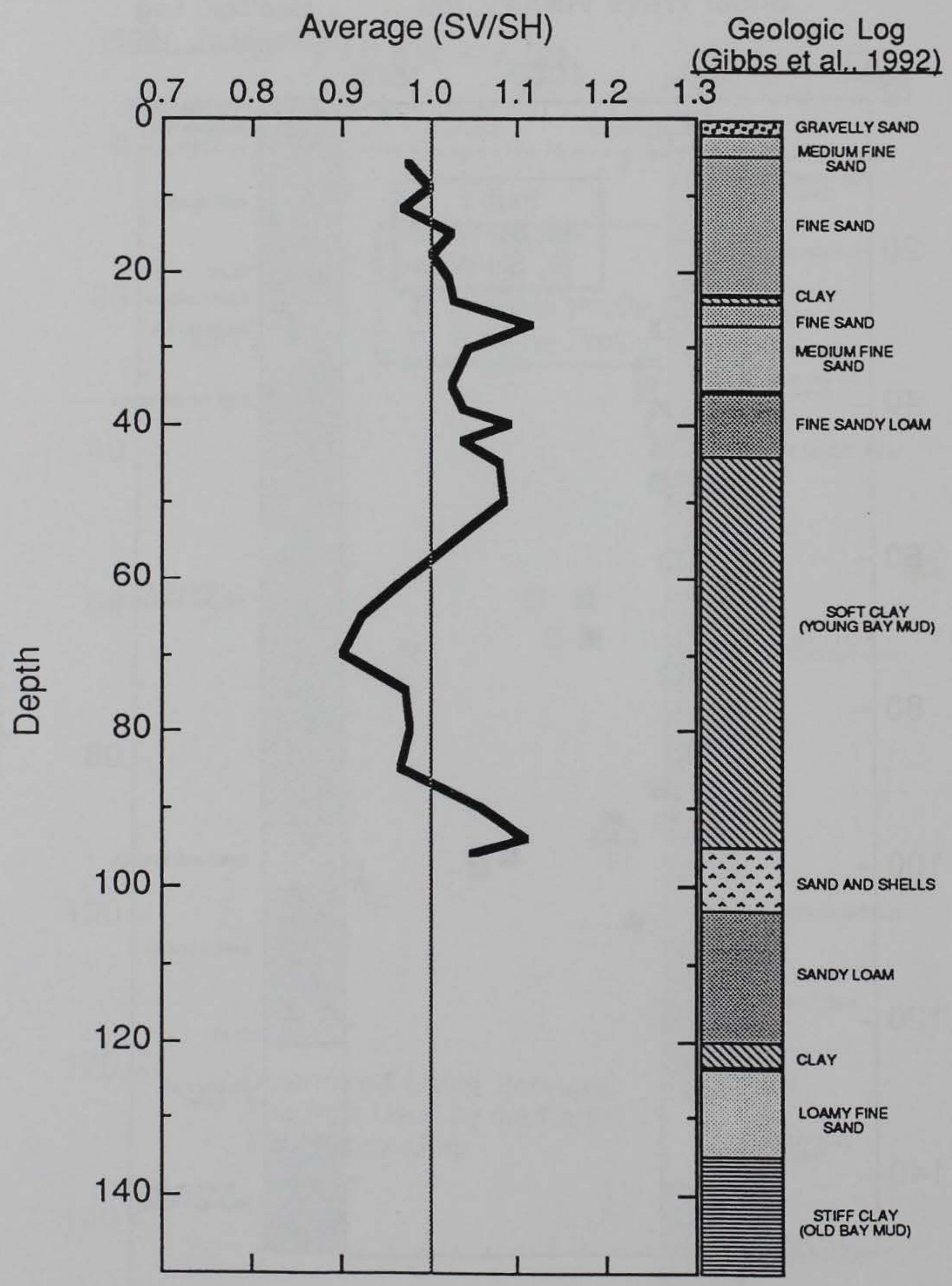




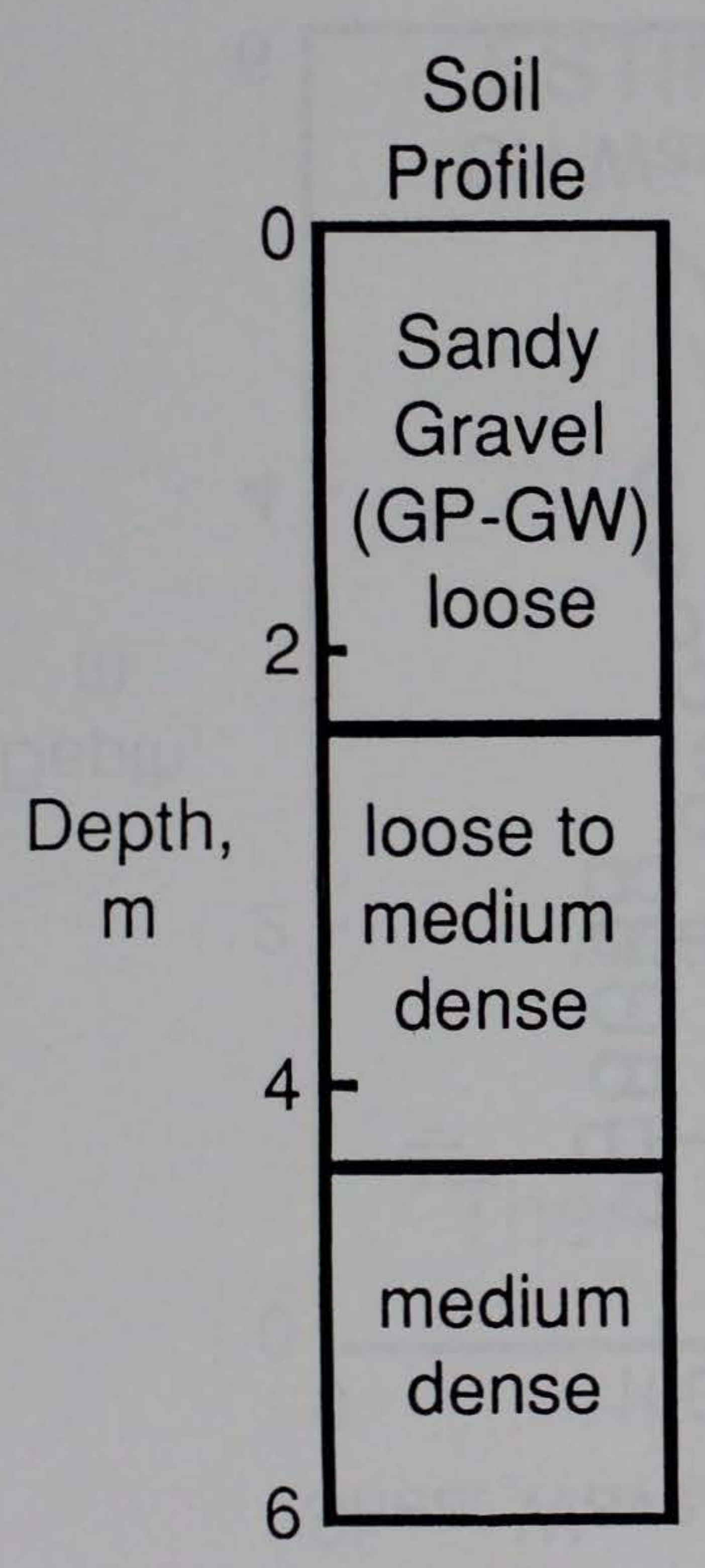

Shear Wave Velocity, $\mathrm{V}_{\mathrm{S}}, \mathrm{m} / \mathrm{sec}$
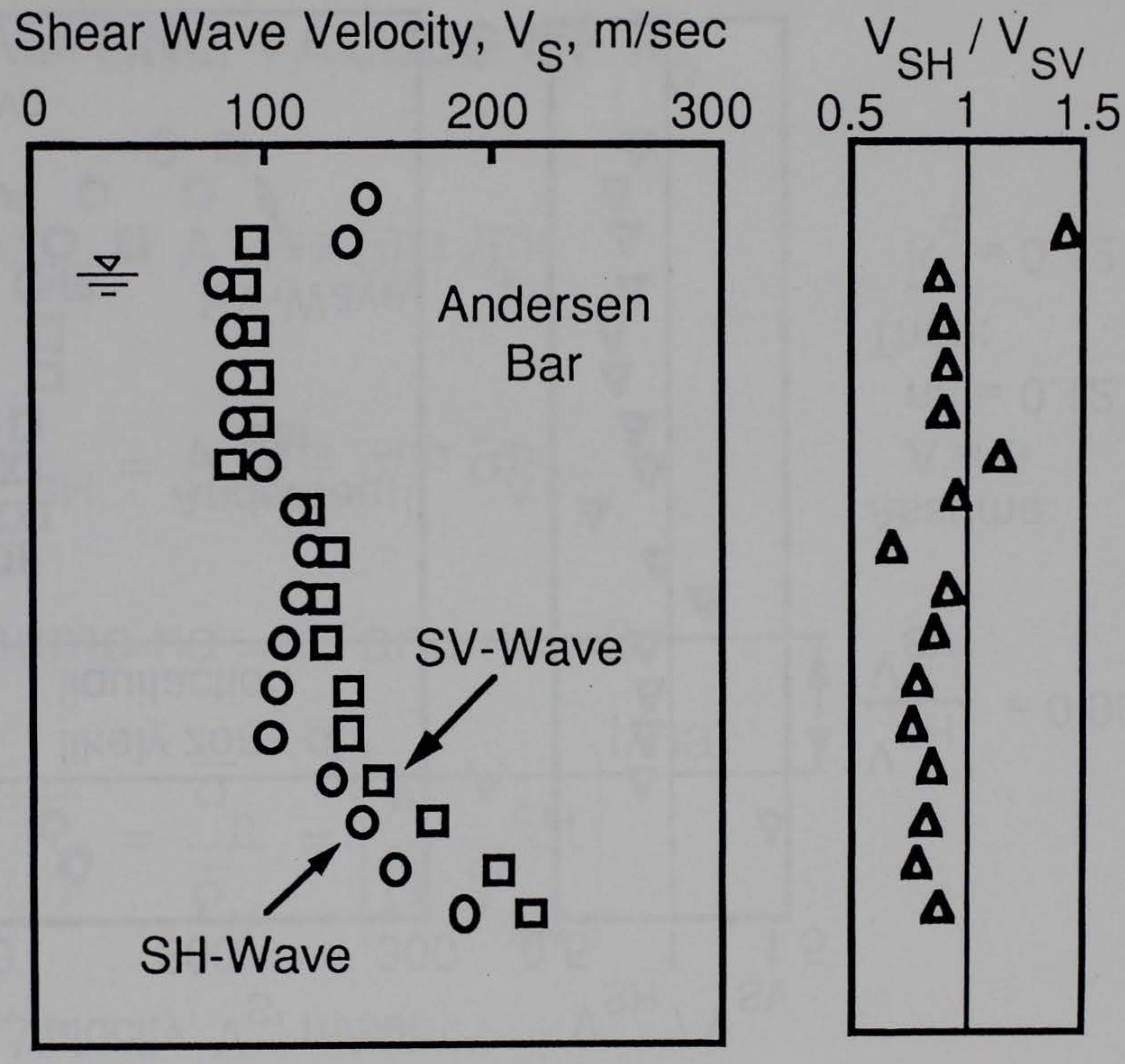
Shear Wave Velocity, $\mathrm{V}_{\mathrm{S}}, \mathrm{m} / \mathrm{sec}$

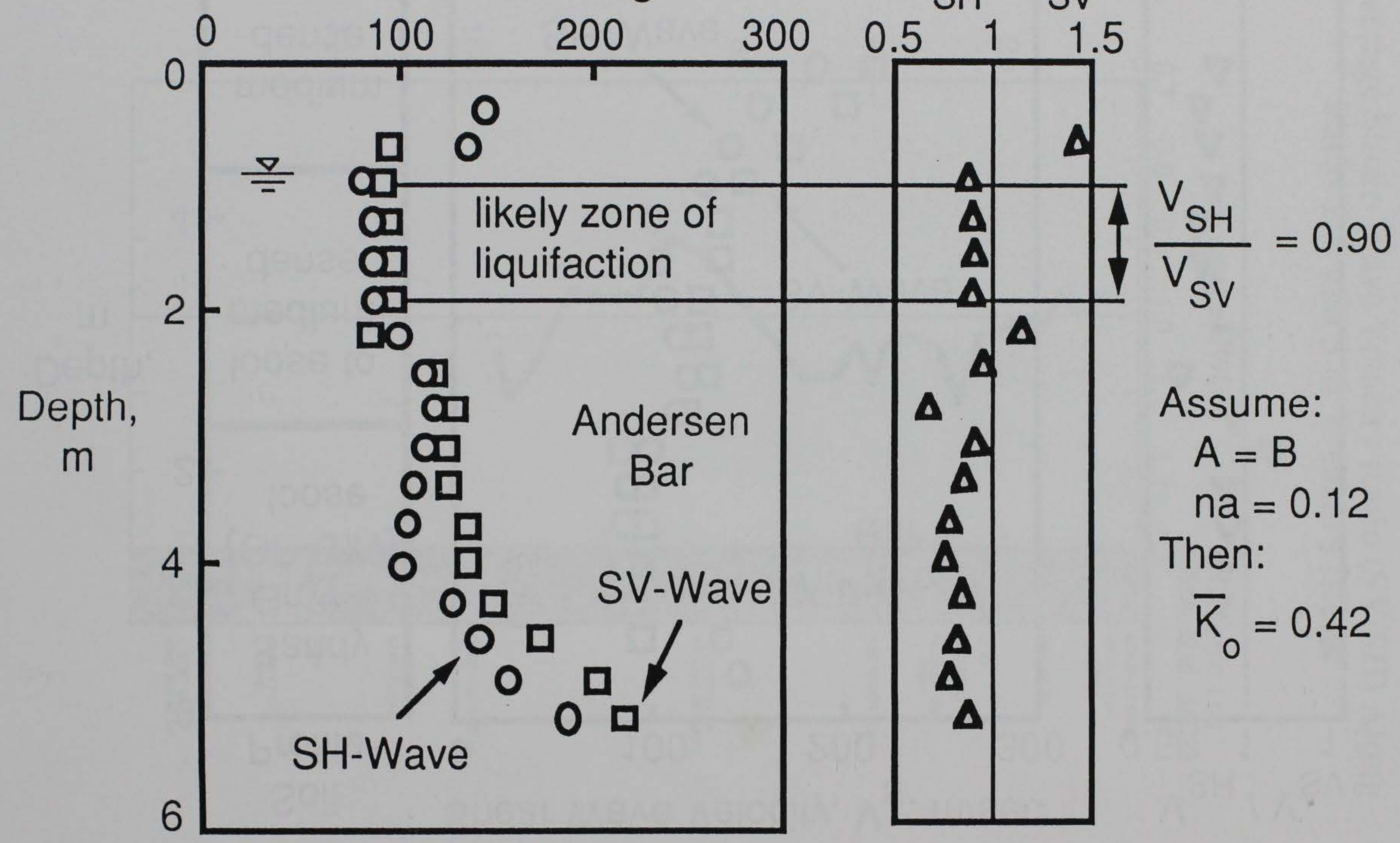




\section{ESTIMATING VALUES OF $\overline{\mathrm{K}}_{\mathrm{o}}$}

$$
\begin{aligned}
& V_{S V}=A \bar{\sigma}_{h}^{n a} \bar{\sigma}_{V}^{n b} \bar{\sigma}_{h}^{n c} \\
& V_{S H}=A \bar{\sigma}_{h}^{n a} \bar{\sigma}_{h}^{n b} \bar{\sigma}_{V}^{n c}
\end{aligned}
$$

Assume $\mathrm{na}=\mathrm{nb}$ and $\mathrm{nc}=0$

Then: $\bar{K}_{0}=\frac{\bar{\sigma}_{h}}{\bar{\sigma}_{V}}=\left(\frac{A}{B} \frac{V_{S H}}{V_{S V}}\right)^{1 / n a}$ 


\section{CONCLUSIONS}

1. Body Wave Velocities Can Be Used To Evaluate Material Anisotropy

2. Measurements Should Be Performed In

The Far Field

3. For Body Waves Propagating Along Principal Stress Directions:

- $\mathrm{V}_{\mathrm{p}}$ is influenced by $\sigma_{\mathrm{a}}^{\prime}$

- $\mathbf{V}_{\mathbf{s}}$ is influenced by $\sigma_{\mathrm{a}}^{\prime}$ and $\sigma_{\mathrm{b}}^{\prime}$

4. A Cross-Anisotropic Material Requires 5 Elastic

Constants:

- $M_{H}$ and $M_{V}$

- $\mathrm{G}_{\mathrm{HH}}$ and $\mathrm{G}_{\mathrm{HV}}$

- 5th Constant 


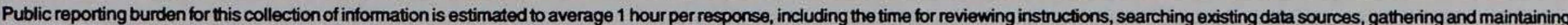

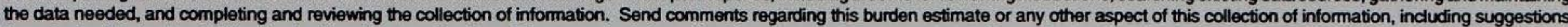

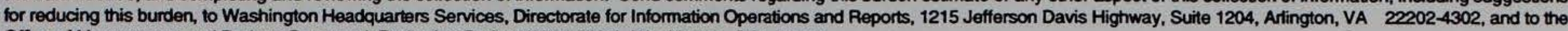
Office of Management and Budget, Paperwork Reduction Project (0704-0188), Washington, DC 20503.
1. AGENCY USE ONLY (Leave blank)
2. REPORT DATE
September 1997
3. REPORT TYPE AND DATES COVERED
Final report

\section{TITLE AND SUBTTTLE}

Earthquake Engineering Site Characterization -

Proceedings of Research Needs Workshop

6. AUTHOR(S)

Joseph P. Koester, Tina L. Holmes

\section{PERforming ORGANIZATION NAME(S) AND ADDRESS(ES)}

U.S. Army Engineer Waterways Experiment Station

3909 Halls Ferry Road, Vicksburg, MS 39180-6199
5. FUNDING NUMBERS

EQEN Work Unit 33014
8. PERFORMING ORGANIZATION REPORT NUMBER

Miscellaneous Paper GL-97-13

\section{SPONSORINGMONITORING AGENCY NAME(S) AND ADDRESS(ES)}

Headquarters, U.S. Army Corps of Engineers

Earthquake Engineering Research Program

Washington, DC 20314-1000
10. SPONSORING/MONITORING AGENCY REPORT NUMBER

\section{SUPPLEMENTARY NOTES}

Available from National Technical Information Service, 5285 Port Royal Road, Springfield, VA 22161.

\section{2a. DISTRIBUTIONAVAILABILITY STATEMENT}

12b. DISTRIBUTION CODE

Approved for public release; distribution is unlimited.

\section{ABSTRACT (Maximum 200 words)}

The Earthquake Engineering Site Characterization - Research Needs Workshop was held at the U.S. Army Engineer Waterways Experiment Station (WES) 27 and 28 June 1995 to bring together technical specialists from WES, Corps of Engineers Districts, the U.S. Bureau of Reclamation (USBR), and academia to solicit input for development of improved geophysical techniques for earthquake engineering site characterization. The ultimate goal of the work unit is to develop tools to assist Corps of Engineers agencies responsible for safe, cost-effective design of reservoir dams and other critical water resource and navigation facilities in their determination of accurate engineering site condition parameters. The focus of the work unit is on in situ technologies. Objectives for the workshop and subsequent research in the sponsoring work unit included: (1) consensus of attendees on the definition and causes of liquefaction during earthquakes; (2) selection of desirable characteristics of a test site for evaluation of geophysical techniques; and (3) determination of criteria for test site credibility. This report summarizes presentations and discussions that took place during the workshop. Hard copies of presentation materials and available papers are provided in appendices.

14. SUBJECT TERMS

Engineering properties of soils

Geophysics

In situ tests

Liquefaction potential

17. SECURITY CLASSIFICATION OF REPORT

UNCLASSIFIED
National Geotechnical Test Sites

Seismic velocity

Spectral analysis of surface waves (SASW)

Waveform tomography
18. SECURITY CLASSIFICATION 19. SECURITY CLASSIFICATION OF THIS PAGE

UNCLASSIFIED OF ABSTRACT
15. NUMBER OF PAGES 320

16. PRICE CODE

20. LIMITATION OF ABSTRACT 